\title{
MY LTFE
}

AMONG THE WILD BIRDS

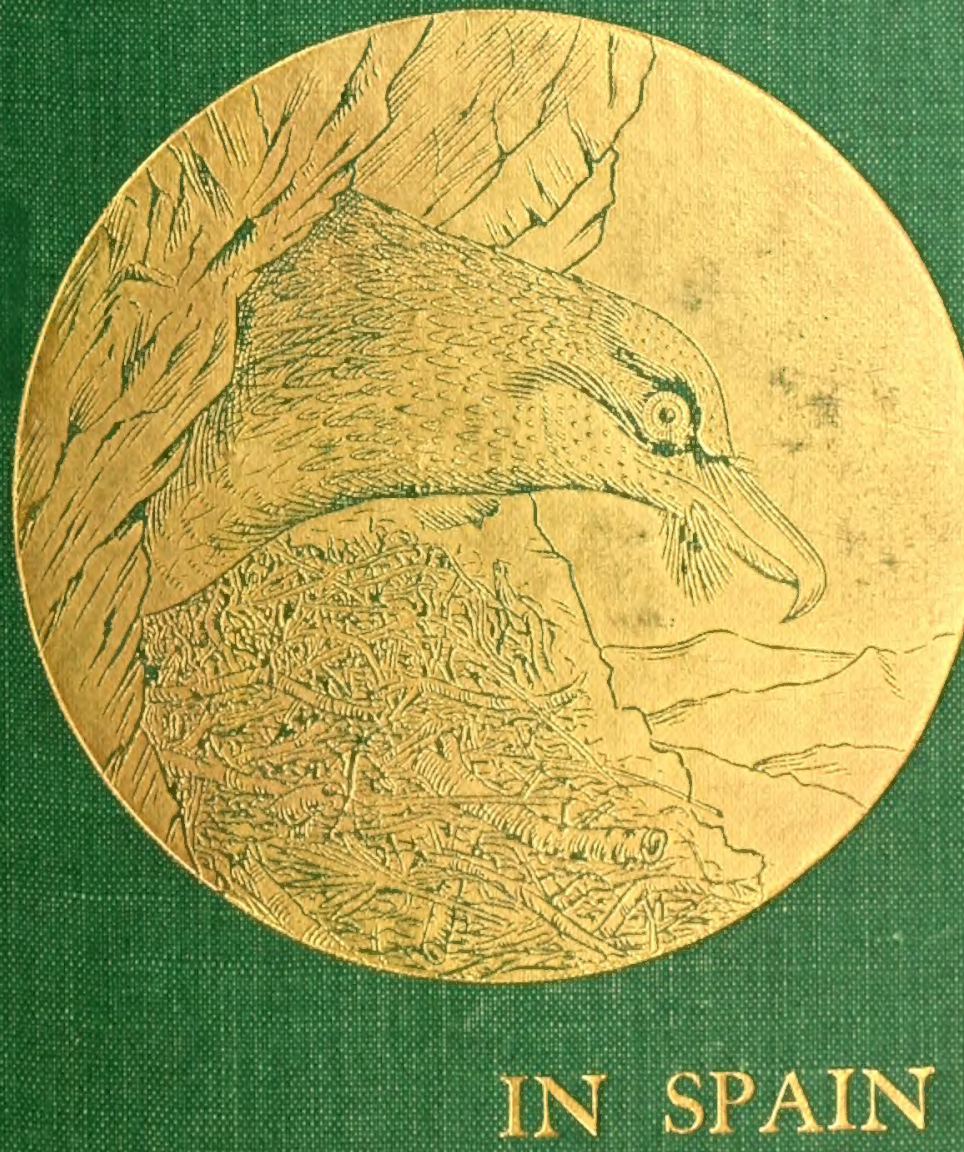

WILOUGHBY VERNER 






MY LIFE AMONG THE WILD BIRDS IN SPAIN 



\section{DEDICATEI)}

BI GRACIOUS PERMISSION

[0

1) (ำ

QUEEN VICTORIA-EUGENIE

$$
\text { OF SPAIN }
$$

BI HER MOST HUMBLE ANI)

OBEDIFNT SERVANI

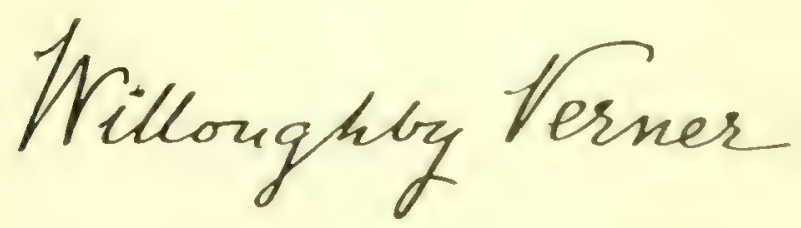



. 



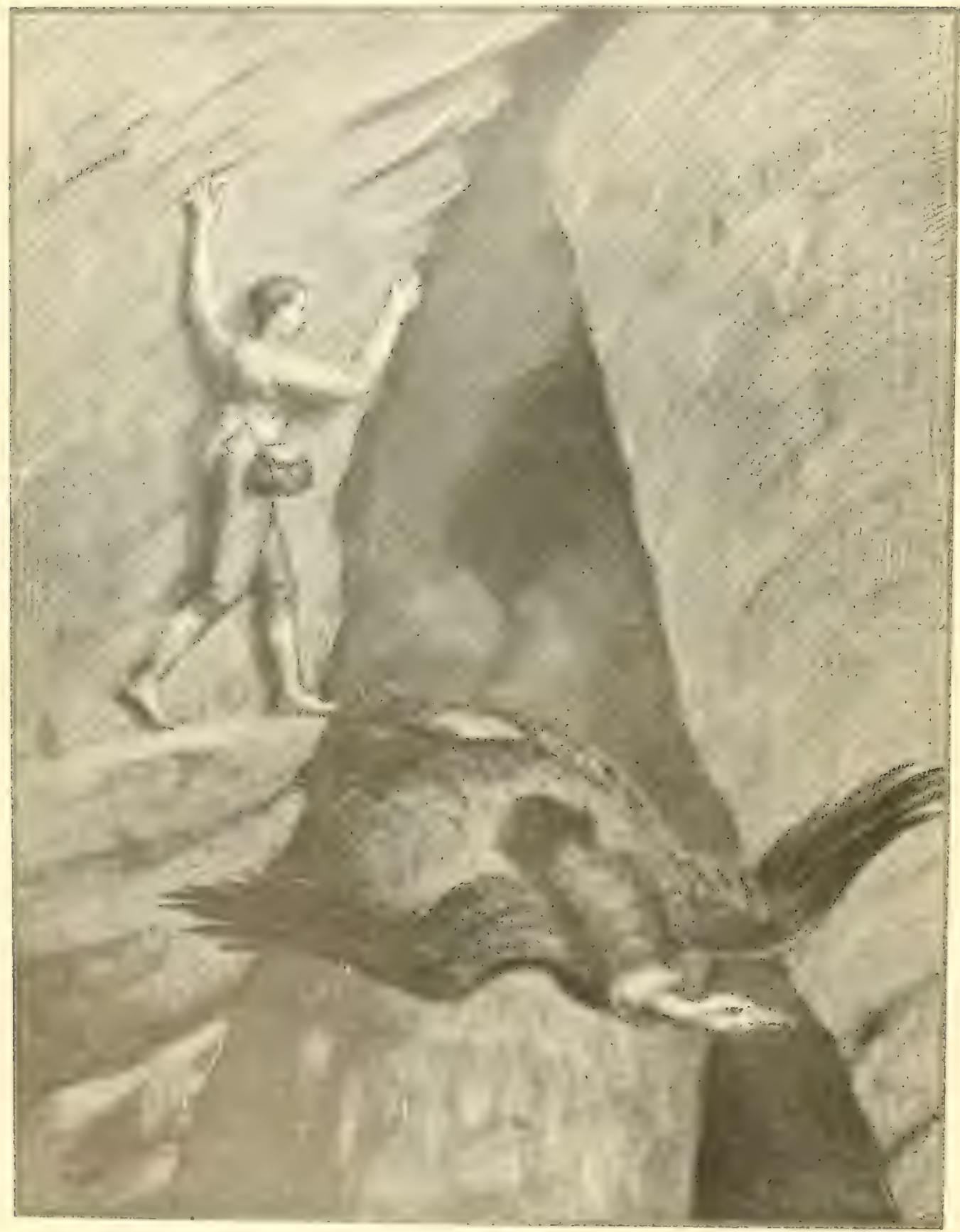

IXTERING NEST OF" GRIFFON VULTURE. 


\section{MY LIFE}

AMONG THE WILD BIRDS IN SPAIN

\section{AIMIII: $\mathrm{BY}$ \\ COLONEL WILLOUGHBY VERNER \\ (Lase Rifle Brigade)}

Author of

"Sketches in the Soudan," "The Military Life of H.R.H. George, Duke of Cambridge."

LonDon

JOHN BALE, SONS \& DANIELSSON, LTD.

OXFORI HOUSR:

83-91, GREAT TITCHFIELD STREET, OXFORI) STREET, W 


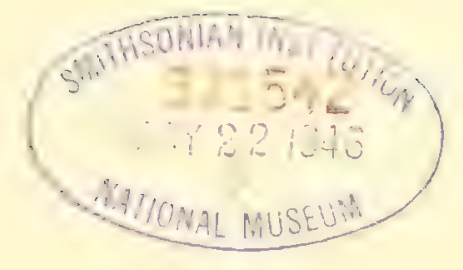


598.2946

$\sqrt{53}$

My thanks are due to the Editor of the Saturday Reritai for permission to reproduce portions of certain Chapters in this book which have appeared in that Rerieci'. 

I'RELACI:

I nave been in the habit of keeping a journal of natural history since I was fourteen years of age; jottings and notes on

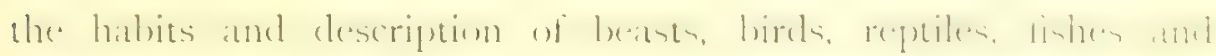
innects, bue especially birds. And I arly tome w illustrating my journals by sketches in pen and ink and water-colours. As far

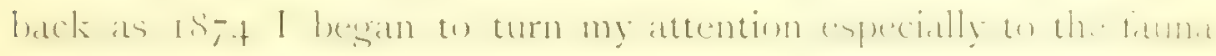

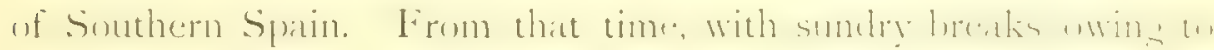
my military and othere duties, I have lived mush in then reagen and durine the last few years have renglarly wintered there. I realia more than ever that it is only by living amongst them that any

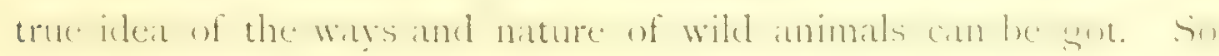
it has secemed to me: werth while to publish this account of my life in the wilds of Andalucia.

Willoughim VerNek.

Hartford Bridge,

Winchfield,

December, 1908. 



\section{CONTENTS.}

PREFACE $\ldots$

Contents...

List of: In.fustrations

\section{1.-Getting Ready.}

Chapter I.-The Study of Wild Birds

II.-Travel and Egutpmext

.. III.-Sretching and Photography

. IV.-On Clmming in General...

. V.-Tree Chming

.. VI.-Chiff Climbinc; $\ldots$

\section{II.--In a Spanish Laguna.}

CHAPTER I.-A DAY IN A LAGUNA

I1.-The Harriers

II.-The Common Crane (Gmis communis)

\section{II.-Across the Plains.}

CHAP'TER I.—A RIUE ACROSS THE VEGA .

II. - lime Great Bustard (Otis tuma)

,. III.-The Little Bustard (Otis tetrax

\section{IV.-Through the Woodlands.}

CHAPTER 1.-A DAY IN THE CORK WOODS

II.-Che hiths and Hawks ...

II1.-THe Booted Eagle (Visnëtus finatus) aNd the SNaki:

EAGLE (Circaïtus gallicus)

IV.-The White-SHouldered Lisge (Aquila adalberti)

V.-The Black VUlture (Vullur monachus) 


\section{V.-Along the Sea $=$ Cliffs.}

CHAPTER I.-A RIDE TO TRAFALGAR

II. - The Common Raven (Covmus covax). . . . . . $2+1$

" IILCTHE OSPREY (Pandion haliaëtus)

\section{VI.-Amid the Sierras.}

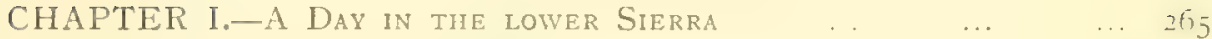

II.-The Lesser Birds of the Sierra... ... ... 2io

"III.-IN THE UPPER SIERRA

" TI. TN THE UPPER SIERRA ...

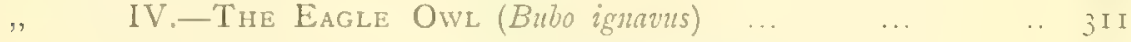

," V.-Bonelli's Eagle (Nisaïtus fasciatus)... $\quad \ldots . \quad \ldots \quad 330$

," VI.-The Golden Eagle (Aquila chrysaëtus) . . . . 355

"VII.-The Egrptian Vulture or Neophron (Neopluon

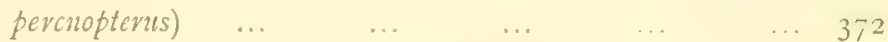

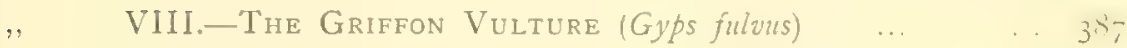

.. IX. - The Bearded Vulture (Gypaëtus bavbatus) ... . . to

, X. The Bearded Vulture (contimed) ... . . . . . 437 


\section{LIST OF ILLUST'RATIONS.}

\section{Getting Ready.}

Entering a Griffon Vulture's nest. Platc

IACi:

A Nesting-place of the South African Crow

Irontispiecc.

Pack horse with travelling kit

Quarters during a birdsnesting expedition...

Egg of Griffon Vulture (a long time exposure). Plate

$\Lambda$ climb for a photograph

Photographing a nest on a cliff ... ...

Nest of Griffon on open ledge (a quick exposure)

A Vulture's nest in deep shadow. $\ldots$. . to

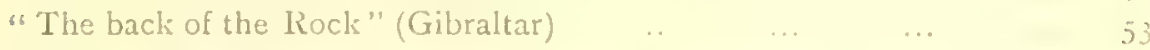

Climbing a big Spanish oak tree by the aid of a pendent bough s . ;

Climbing a tall fir tree with the aid of a rope

1 clear drop. I'lat

(Drazin by Ida Verner from photographs.)

Entering a nest inaccessible from above and from below

Climber in canvas sling ready to descend a cliff

Method of carrying a long piece of rope during a climb

The Laja del Ciscar

On the face of the Laja del Ciscar

\section{In a Spanish Laguna.}

White Stork (Ciconia alba). Platc

Nest of Purple Heron

Eggs of Purple Heron

NIarsh Harrier (Circus annginosus). Plate

Nest of Marsh Harrier ...

Young Marsh Harriers in nest. Plate

Common Crane (Gmus communis). Plate

Nest of the Common Crane

Nest of the Common Crane (nearer vicw)

Retriever in Crane's nest

Eggs of the the Common Crane 
xii. List of Illustrations.

\section{Across the Plains.}

A River in the Plains: evening ...

Great Bustard (Otis tarda). Plate

Nest of Great Bustard in bean-field

Eggs of Great Bustard

After a Great Bustard Drive

Little Bustard (Otis tetvax). Plate

I 46

Nest and Eggs of Little Bustard..

I 49

Eggs of Little Bustard ...

I 52

$15+$

\section{Through the Woodlands.}

Goshawk (Astur palumbarius). Plate

$$
\begin{aligned}
& \text { … } 150
\end{aligned}
$$

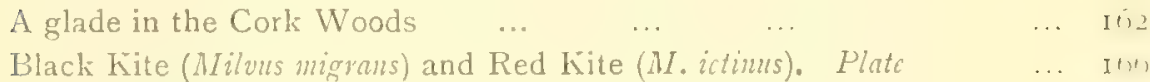

$$
\begin{aligned}
& \text { … ITI } \\
& \text { … } 17^{2} \\
& 1 ; 3 \\
& \cdots \quad 1 \% 9 \\
& \text {... I I I } \\
& \text { … } 158 \\
& \text {... I I) I } \\
& \text { 11) } 2 \\
& \text {.. I } 3 \\
& \text {... III } \\
& \text {.. Iyo } \\
& \text {... } 205 \\
& 210
\end{aligned}
$$$$
\text { Nest of Black Kite in cork tree }
$$$$
\text { Nest and Eggs of Black Kite }
$$$$
\text { Booted Eagle (Niscitus pennatus). Plate }
$$$$
\text { Nest of Booted Eagle in Spanish oak }
$$$$
\text { Egg of Booted Eagle ... }
$$$$
\text { Nest of Snake Eagle near summit of cork tree }
$$$$
\text { Nest and Egg of Sualke Eagle }
$$$$
\text { Ego of Snake Eagle }
$$$$
\text { Young Snake Eagle, aged I week }
$$$$
\text { Young Snake Eagle annoyed at being photograplied }
$$$$
\text { White-shouldered Eagle (Aquila adalberti). Plate }
$$$$
\text { Nest of White-shouldered Eagle in Spanish oak }
$$$$
\text { Black Vulture (Vultur monachus). Plate ... }
$$$$
\text { Black Vulture leaving nest (No. I.) }
$$

Doroteo reaches the first stage, to ft. from ground .

Doroteo nearing the nest

Author in Black Vulture's nest

Nest and Egg of Black Vulture ...

Black Vulture leaving nest (No.2.)

One of the Siete Picos, Sierra de Guadarrama 


\section{Along the Sea Cliffs.}

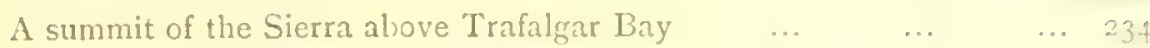

$\begin{array}{llllllll}\text { The Strand of Trafalgar } . . & \ldots & \ldots & \ldots & \ldots & \ldots & 238\end{array}$

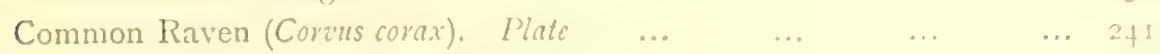

$\begin{array}{lllllll}\text { A Raven's nest in a deep fissure } \ldots & \ldots & \ldots & \ldots & \ldots & 247\end{array}$

$\begin{array}{lllllllll}\text { Raven's eggs } & \ldots & \ldots & \ldots & \ldots & \ldots & \ldots & \ldots & \ldots\end{array}$

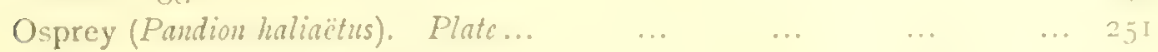

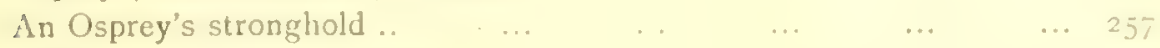

$\begin{array}{llllllll}\text { Descent to an Osprey's nest } & \ldots & \ldots & \ldots & \ldots & \ldots & 259\end{array}$

$\begin{array}{lllllllll}\text { The Ospreys' cliff } & \ldots & \ldots & \ldots & \ldots & \ldots & \ldots & \ldots & 261\end{array}$

$\begin{array}{lllllllll}\text { An Osprey's nest } & \ldots & \ldots & \ldots & \ldots & \ldots & \ldots & 263\end{array}$

\section{Amid the Sierras.}

$\begin{array}{llllllll}\text { Rock sepulchres and cistus } & \ldots & \ldots & \ldots & \ldots & \ldots & 270\end{array}$

$\begin{array}{lllllllll}\text { A Vulture's cliff } & \ldots & \ldots & \ldots & \ldots & \ldots & \ldots & 272\end{array}$

$\begin{array}{llllll}\text { The reverse slope of the summit of the cliff } & \ldots & \ldots & \ldots & 275\end{array}$

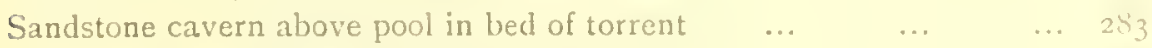

Sandstone cavern near a summit of the lower Sierra $\quad \ldots . \quad \ldots 280$

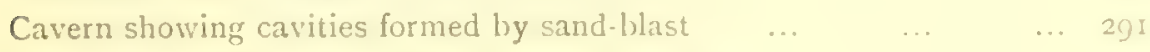

One of the old Moorish villages in the upper Sierra $\quad \ldots . \quad \ldots 297$

$\begin{array}{llllllll}\text { A gorge in the upper Sierra } & \ldots & \ldots & \ldots & \ldots & \ldots & \ldots & \end{array}$

La cueva del Gato (whence issues a subterranean stream) $\quad \ldots \quad \ldots 300$

$A$ big cavern in the upper Sierra (point where stream enters) _. 302

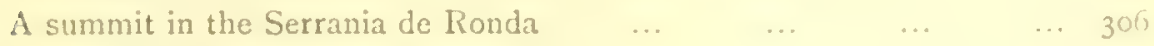

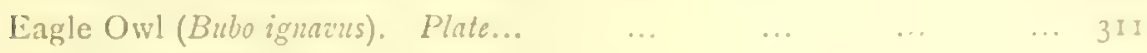

$\begin{array}{llllllll}\text { Nest of Eagle Owl on terrace on cliffs } & \ldots & \ldots & \ldots & \ldots & 316\end{array}$

$\begin{array}{llllllll}\text { Nest of Eagle Owl in cavern } & \ldots & \ldots & \ldots & \ldots & \ldots & 319\end{array}$

$\begin{array}{llllllll}\text { Young Eagle Owls in courtyard } & \ldots & \ldots & \ldots & \ldots & \ldots & \ldots & 320\end{array}$

$\begin{array}{lllllll}\text { Eggs of Eagle Owl in nest in cavern } & \ldots & \ldots & \ldots & \ldots & 321\end{array}$

$\begin{array}{llllllll}\text { Profile of Eagle Owl's crag } & \ldots & \ldots & \ldots & \ldots & \ldots & 322\end{array}$

$\begin{array}{llllllll}\text { Young Eagle Owls in nest } & \ldots & \ldots & \ldots & \ldots & \ldots & 324\end{array}$

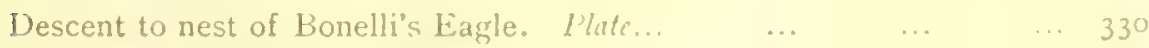

$\begin{array}{lllllll}\text { Nesting-place of Bonelli's Eagle ... } & \ldots & \ldots & \ldots & \ldots & 334\end{array}$

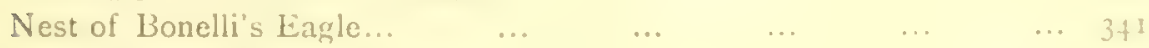

$\begin{array}{llllllll}\text { Eggs of Bonelli's Eagle } & \ldots & \ldots & \ldots & \ldots & \ldots & 3+4\end{array}$

$\begin{array}{lllllll}\text { Nest and eggs of Bonelli's Lagle } & \ldots & \ldots & \ldots & \ldots & 350\end{array}$ 
xiv.

List of Illustrations.

PAGE

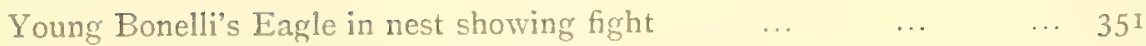

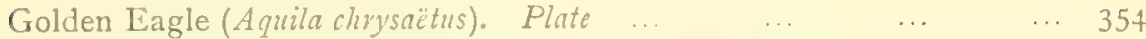

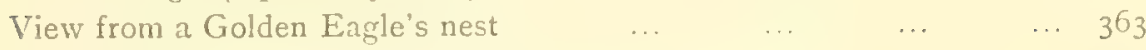

$\begin{array}{lllllll}\text { Nest and eggs of Golden Eagle } & \ldots & \ldots & \ldots & \ldots & \ldots & \ldots\end{array}$

Nest and egg of Golden Eagle (site " B ")... $\quad \ldots . \quad \ldots \quad \ldots \quad \ldots 367$

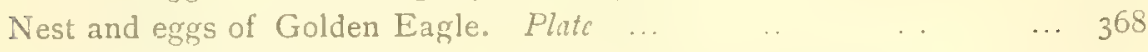

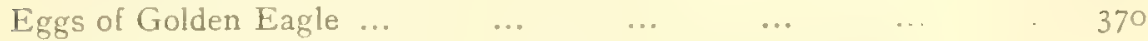

Egyptian Vulture or Neophron (Neophron percnoptemes). Plate $\quad \ldots \quad 37^{2}$

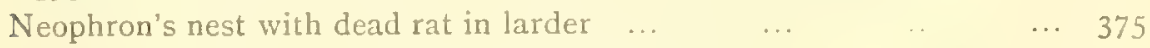

La cueva del Cuervo (nesting-place of Neophron) ... $\quad \ldots \quad \ldots \quad$.. 377

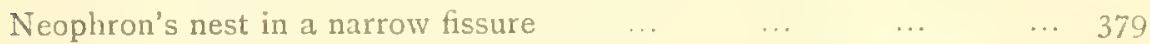

$\begin{array}{lllllllll}\text { A Vulture's cavern } & \ldots & \ldots & \ldots & \ldots & \ldots & \ldots & 38 \text { I }\end{array}$

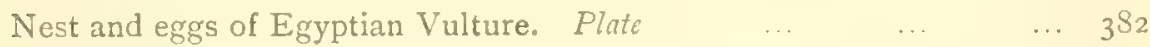

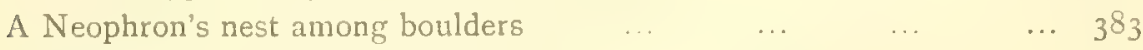

Griffon Vulture (Gyps fulvus). Plate $\quad \ldots \quad \ldots \quad \ldots \quad \ldots 38$

$\begin{array}{lllllll}\text { Nest of Griffon Vulture in a cavern } & \ldots & \ldots & \ldots & & \ldots & 392\end{array}$

Nest of Griffon Vulture in a deep crevasse. Plate ... $\quad . . \quad \ldots \quad$.. 394

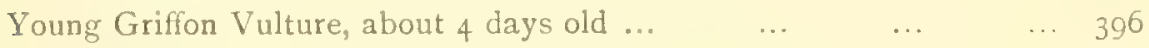

Young Griffon Vulture, about 2 weeks old, feigning death ... _ .. 397

Young Griffon Vulture, about 3 weeks old $\quad \ldots . \quad \ldots . \quad \ldots \quad 399$

Young Griffon Vulture, about 6 weelss old, feigning death ... ... 4OI

Young Griffon Vulture, about 8 weelss old : the offensive-defensive ... 402

Bearded Vulture (Gypaëtus barbatıs). Plate $\ldots . . . .4 \quad 406$

Bearded Vulture soaring around summit of crag $\quad . . \quad \ldots \quad \ldots \quad$. . 4 I6

Quebranta-huesos, the Bone-breaker, at work. Plate... $\quad \ldots \quad \ldots 44$

The Bearded Vulture's cliff, nest No. 2. Plate ... .. 440

Young Bearded Vulture, photographed at 24 in. distance $\ldots$. $_{4} \quad 443$

Young Bearded Vulture , , " I 8 in. , . . 444

$\begin{array}{llllllll}\text { Young Bearded Vulture attacks camera } & \ldots & \ldots & \ldots & \ldots & 446\end{array}$

The Bearded Vulture's cavern. Platc ... . $\quad \ldots . \quad \ldots \quad 448$

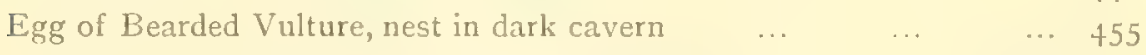

General view of Bearded Vulture's nesting station $\ldots$ end of book. 
HEAD-PIECES AND TAL-I'IECES TO CHAITERS.

Taking Weaver Birds' nests in Nile Expedition

Sailing Lifeboat off Irish Coast

A " time-exposure" on face of a cliff ...

Arricros and capsized mule

A Griffon Vulture's Crag, Tangier in the distance

Gibraltar from the Sierra west of Algeciras

Eluding Bluejackets in H.M.S. "Simoom"

Climb round "the back of the Rock"

The Raven's nest in the corkscrew pine

Climbing Irons, Casting-line and Lead

A slippery hitch on face of a cliff

Along a ledge to an Eagle's nest

Wading in a Laguna

Grey-lag Geese flighting at sundown ...

Marsh Harrier hunting over Laguna ...

Cranes on line of migration ...

Reconnoitring a Crane's marsh

Crane simulating disablement

Mounted cattle-guard on the Vega

Chased by a Toro bravo

Great Bustard falling to shot

A horse-load of Great Bustard

A cattle-herd on the Vega

Little Bustard on the wing ...

$\ldots$

An old cork-oak tree

Gibraltar from the Cork Woods

Red Kite on the wing

Jimena de la Frontera

Snake-Eagle

Egg of Snalie-Eagle

White-shouldered Eagle's nest in marsh

$\begin{array}{lll} & \\ \cdots & \ldots & \ldots\end{array}$

$\begin{array}{llll}\ldots & \ldots & \ldots & 22\end{array}$

... 23

... - ले

... 39

... +7

... 48

... 57

... 58

... 70

... 71

... 90

... 9 I

... 100

... IOI

... 106

... 107

... 122

... 123

… 130

... $13 \mathrm{~J}$

... I. 48

… 149

... 155

… 156

$\ldots 165$

... 166

… 177

... 178

… 195

Chased up a tree by a young bull

Black Vulture's nest in lofty pine

210

Photographing Black Vulture's nest on summit of pine... 
xvi.

Spanish Falucho off Cape Trafalgar ...

PAGE

A Raven's two-fronted residence ...

Gibraltar from the coast of Morocco ...

Sea-caves at the back of the Rock

Nest and eggs of Osprey

A natural tunnel through a Vulture's cliff

Cape Spartel and Atlantic from the Sierra

Lowering climber single-handed

Nest of the Black Wheatear or Pedrero

A Bearded Vulture's nesting-place ...

Gibraltar from the Sierra near Gaucin

A descent to Eagle Owl's nest without a rope

View from Eagle Owl's nest in cavern

Bonelli's Eagle

Photographing nest of Bonelli's Eagle

Descent to Golden Eagle's nest with rope

Egg of Golden Eagle

Egyptian Vulture and nest

The Sierra above the ruins of Belon ...

A wounded Griffon Vulture ...

Griffons fighting over carcass in water

Clearing a jambed rope on a cliff

Quebranta-lunesos, the Bone-breaker

A false descent on a big cliff...

Bearded Vulture looking out of nesting-place

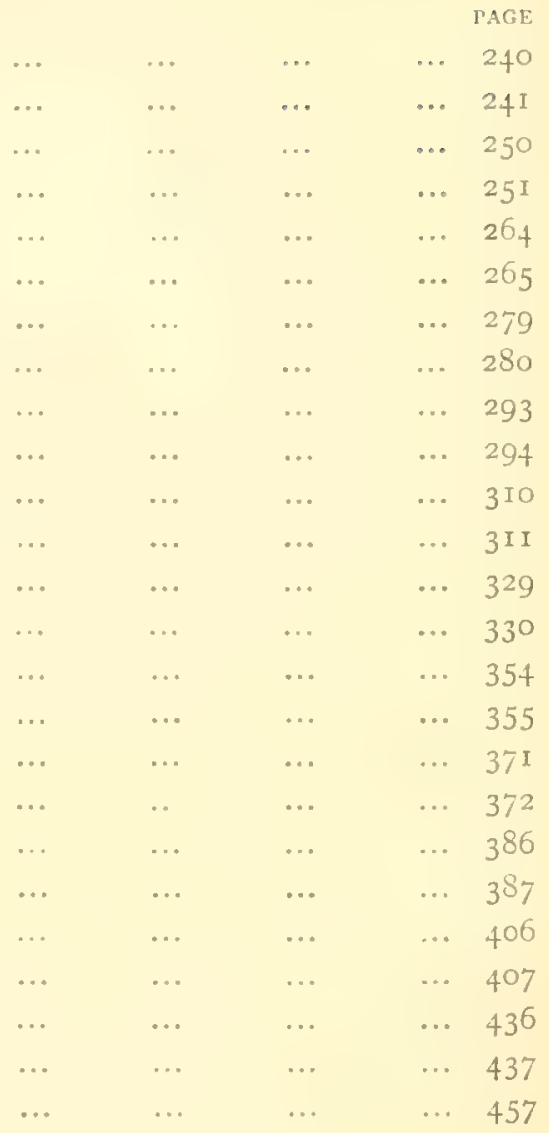




\section{I.-GETTING READY.}

\section{CHAP'TER I.}

\section{'THE STUDY OF IVILD BIRDS.}

Popular view of hirdsnesting - The true naturalist and the lestroyer of life. The egrg-dealer arsus the birdsnester-Bird destruction arous expr-taling - I lowe of hirds a matter of heredity-Keepiner cage-birds-Training Hawkis and Falcons-My first nests-First lessons in lird-watching--The tratining of a field naturalint - Irirst go to Southern Spain - Meet Lord Lilford-and Colonel Irby-"The Ornithology of the Straits of Gibraltar"-Crown Prince Rudolf of Austria's visit-Birdsnesting at Home and Foreinn Statims-In Nile Expedition, I535-In South Ifrican War, I $4 y 3$-Literature dealiner with Spanish bird-life-General arrangement of book.

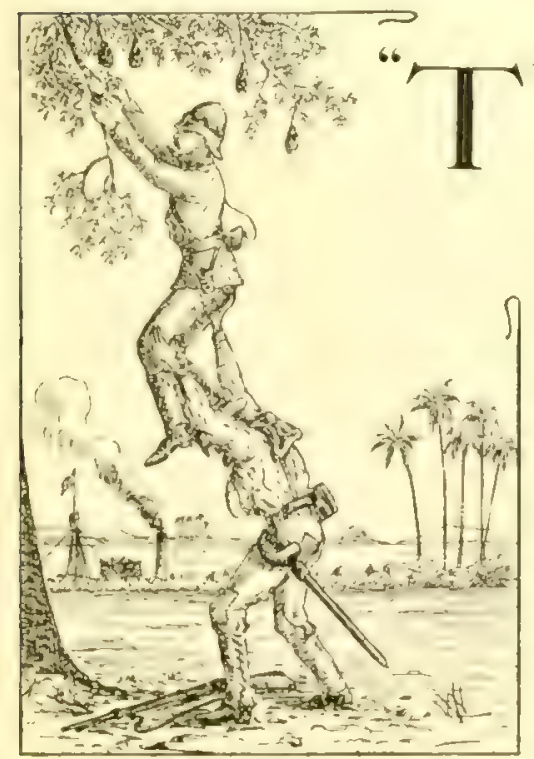

HANK Heaven, I'm not reduced to birdsnesting!"

It is many years since these words fell on my ears. 'T"hat they were uttered by an individual of no importance is immaterial; for me their interest and value lic in the fact that they express to perfection and in the briefest possible manner the attitude of the vast bulk of one's friends towarls the branch of ornithological study which I have pursued with unremitting determination ever since I was a very small lad.

The immediate cause of this profoumel remiut is mot whoment interest and may perhaps serve to point a monal to thone whe 
habitually deride that which is above their intelligence. At this time my regiment was quartered in Dublin; it was in Jume. Owing to the usual military exercises and work carried on during the summer months it was not easy to get away from the garrison, save now and agrin for a couple of days and rery often that could not be manatged. The inevitable consequence was that a large number of young officers possessed both of the means and the desire to go on endless rounds of amusement found themselves unable to take advantage of the seductive pleasures open to them. It is one of the curses of peace-soldiering that the work is so calculated or rather miscalculated ats to bring the minimum amount of advantage to the Service and the maximum amount of worry and waste of time to those engaged in its execution. Under such conditions anything which can conduce to giving officers and men a change from the red-tape and routine is of great value and the surest antidote to an attack of "grousing."

In accordance with the habit of my lifetime, since I had arrived in Inblin I had been lieenly on the look-out for some fresh locality where I could visit some of my beloved birds and learn more about their nesting habits and I had recently obtaned perinission from the owner of a rocky island off the cast coast of Ireland to visit it with that object in view. Accordingly I went to our barracks to enlist recruits for a forty-eight hours' expedition and had no difficulty in groting all I required. It was whilst engaged in the necessary instructions as to fooxl, equipment and ropes, that a sapient young officer mate the remark with which this story bewins, prior to calling for another cigarette and strolling out of the anteroom. The reproof thus conveyed to the party of miserable birdsnesters was none the less pointed in that its author proceeded to the Yacht Clule at Kingstown from the window of which he could look at other people's yachts at anchor and at stated intervals bore his friends by his views on the length of the boom of the Brilania or some other abstract nautical topic. 


\section{"Reduced to Birdsnesting"}

Suffice to say, my "reduced" party who had not been too proud

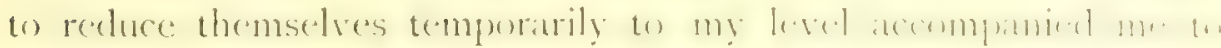
the island where we stopped for a night. We were rewarled for our two days explorations by some of the most splendid scencery, inmumerable wild thowers and some stanel clith where cinillemen. Razorbills, Puffuns and various Gulls nested in profusion. The following day it blew tos hated on the lamel for our chartered linhingsmack to come out and take us off, but this was but an adcled joy for it resulted in my obtaining the use of the coistentret's lifelente

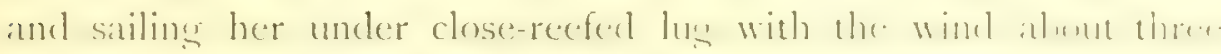

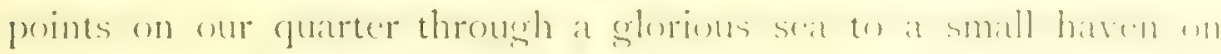
the mainland under our lee.

The memory of that clelinhtul axpelition cound it is in rert tmoth only one of many hundreds in which I have taken part) is ever

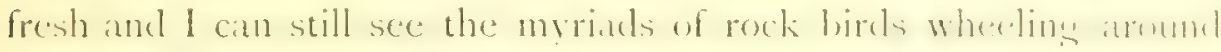
the precipices on the face of which we scrambled and hear the roar of their combined ten thousand cries. Nor have I forgotten the feel of the helm of the lifeboat as she strove to run off a big

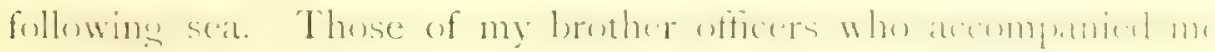

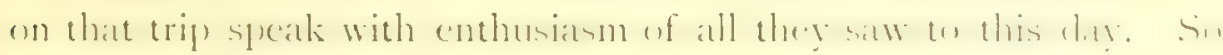

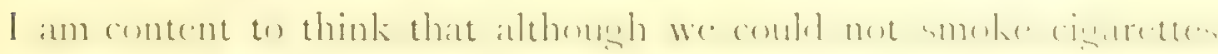

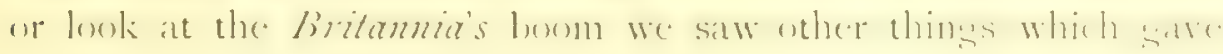
one an added joy in life.

'Those who read these remarlis on birdsnesting may very natu-

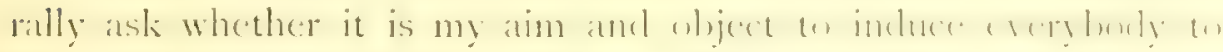

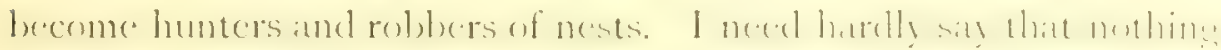
could be further from my intentions and that I should view with dismay any serious increase in the numbers of those who harry and harass wild birds especially the wikl birds of the british

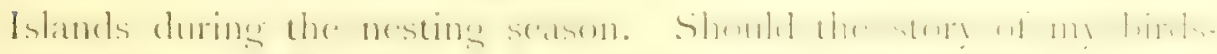

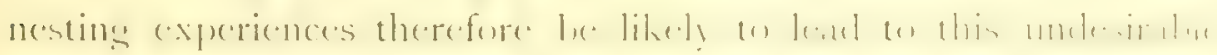
result, nothing would induce me to sive it to the world. I3ut all 


\section{The Study of Wild Birds}

my experiences lead me to an exactly opposite conclusion, for I am positive that the more men take a rational interest in the study of natural history in all its branches, the less desirous are they, without good and sufficient reason, to do aught which may tend to the destruction of rare and beautiful things whether they be animals, birds, insects or flowers. I have myself gone through all these phases and watched them over and over again in others. To cite my own experiences : a beginner, I was anxious to see and handle, skin and preserve any rare wild bird. This naturally led to the slaying of those that came within my reach. I had no one to dissuade me from such a course. Further in those days there were no good coloured illustrations of birds available for the ordinary student and the only way to get an exact idea of the colouring and plumage of a bird was to kill it. Very soon however I realized what a mistalie it was to clestroy wild life merely to gratify my own curiosity about certain matters connected with it. Added to which, the absurdity and inutility of doing so gradually dawned upon me. I became painfully aware that stuffed birds, save those set up by a master-hand with all their natural surroundings, regardless of cost and of space occupiced, were but pitiful objects. The late Mr. John Hancock of Newcastle, a great personal friend of my father, whom I had the privilege of linowing, first brought this home to me and when, some years later, I took a humble share in procuring and arranging some of the birds and nests for the British Museum (Natural History) I saw how utterly absurd it was-to put it on the lowest grounds - for the ordinary individual to attempt to form a collection of stuffed birds. As a consequence, for many years I have refrained from killing any birds save when repuired for cullections like our National one or for some other well-accredited museum or for naturalists of the type of Lord Lilford who require specimens for legitimate scientific purposes.

So much for the birds themselves. Now for their nests, eggs 


\section{The Varied Interests Involved}

and young. If a collector of enes restricts himself to tialin the

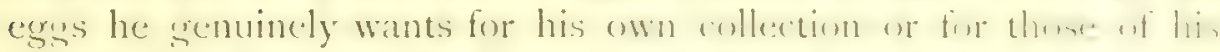
fricuds who maly ask for a particular species, very little ham will

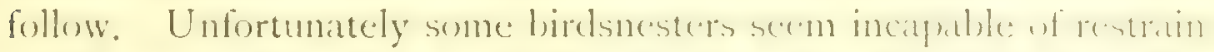
ing themselves and tialie all they tind on the ville plea that thes can "exchange" their superthoms specimens a plea wrothice w the postage-stamp collector than of the naturalist.

Even worse thatn the exchanging cicuse is the hathit of employing paid assistants to harry nests. Eirus thus teden are viluele.s. for such mercenaries naturally have no discrimination and sweep' a whole district of every esg without remorse. I linow of mon who have boasted of taking over a thousand ersiss of the rarer Waders, \&c., in a week or so.

Sfeer all, the whole fascination of the art of nest-finding is the personal experiences of the seeker. To locate a will hird, to study its habits, follow it to its nesting haunts and discorer its secrets, are the points which rive zest and interest to the acenple tion. If in adelition the student can secure photonguphs of the birels or their nests or luoth, there is a fresh factor af permanency to the operation. Lastly if the quest of certain species leads ¿t matn to climb mountatins, explore remote marshes ar molie adventurous seat trips, there is literally no limit to the variety al expericnces which are comprised in the single word "hirclsmestin.s.

for many years I have made it a rule to invite friends ur (ante with me on my expeditions and so far from my having hy the a. means adeled o the destroyers of bird-life. I am comvinced I halve dume the oppesite. In only one instince his my trust in sinte furple.

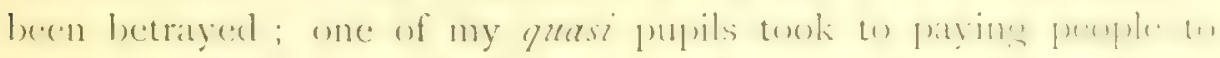

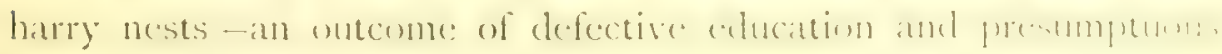
ignorance of the subject.

On the other hand I have demonstrated to scores of men how

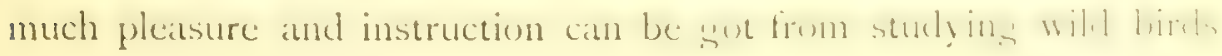


in their hatunts and further, how this pleasure can be gratified to the full without taking the esess or young or slatughtering the parent birds.

A favourite excuse with students for taking birl-life or robhing a nest is the natural and reasonable desire to verify some point about which they are in doubt. In these cases as in most others, every man is the best judge of his own motives and innumerable cases maty and do occur when such conduct is thoroughly justifiable. I3ut I would plead for the birds that whenever possible they should be given the bencefit of the doubt. The longer one lives the more one realizes how seldom it is necessary to destroy life. I can recall a case over twenty-five years ago when I found a small nest in some rank grass atid brambles. It was clearly either that of the Willow Warbler or of the Chiff-chaff. To watch the bird and identify it as it re-cutered its nest was impossible owing to its snake-like habits. To kill it was simple enough. The third way was to make a horsehair noose and adjust the loop over the entrance to the nest. In five minutes I had the bird fluttering in my hand, an undoubted Willow Warbler; next moment it was released. Where a species abounds and time presses, it may of course be reasonable to kill the old bird but this should be ever viewed as the last resource.

But I must explicitly disclaim any pretensions to merely being a bird-watcher, one who never molests a nest. I have robbed many nests, possibly those of more species than most people in proportion to the countries I have visited. But I have found most of them myself and taken nearly all of them with my own hands. The limits imposed by endeavouring to adhere to these two rules are much narrower than most people would imagine. In the few cases where I have departed from them it has been owing to pressure of time or the impossibility of my leing in the district at the season when the eggs are laid. Take for example several 
of the species which nest north of the 'Tweed; a country' I have never visited save in the shooting season.

In this case I confess to numbering in my collection a few egress

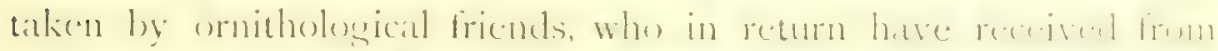

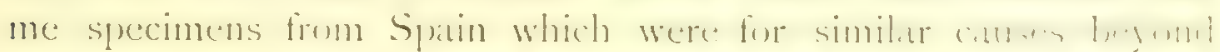
their reach. But "exchanges" conducted on so much narrowed and well-defined a basis are not to be classed with the havoc wrought by the man who takes twenty or thirty acts of some ran bircl's enges, on the around that some day in the future they may have a pecuniary value as media for "exchane."." setting aside. actual sale.

Your true birdsnester will ever view eggs obtained by ex-

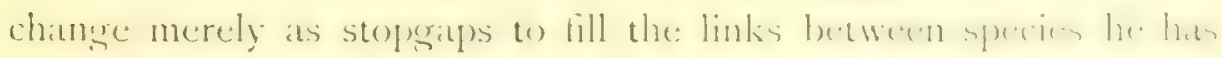

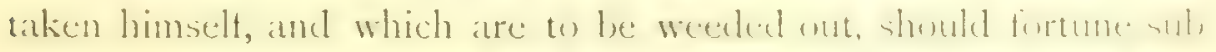
secpuently enable him to watch the bircls and get the sime "'s.'? himself.

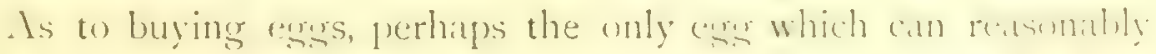
and lesitmately be butyht is that of the dimeat duk, fin it is clearly impossible to take it oneself or get others to take it.

It is not uncommon to hear men who are keen ornithologrists but whe for variens reasons such as want of time or of epprertumicy. physical inalility, lack of nerve or aty hat else, have nerer taken we

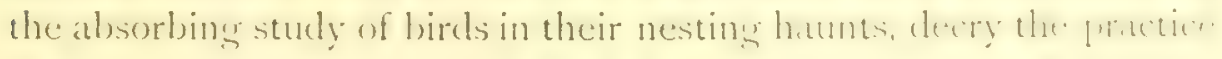

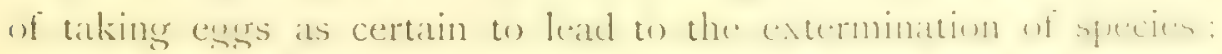
and at meetings of our scientific secieties 1 hate heard with whe amusement such men describe themselves evilkenty with conwinu

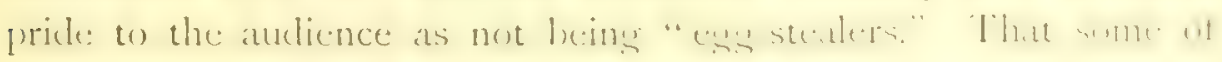

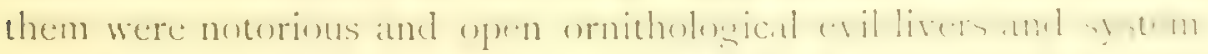

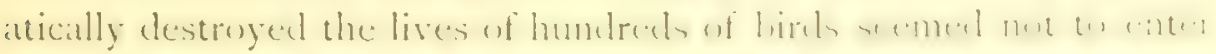
inte their minds at all. The histeric resule of killing the fown the

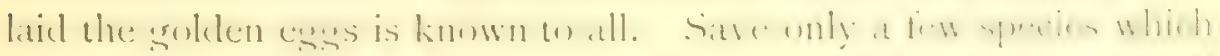

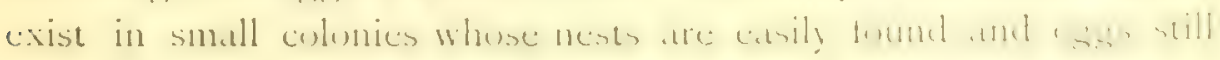


easily taken as for example the Sandwich Tern, it is safe to say that few birds have ever been exterminated by simply having their eggs taken.

It is where the slaughter of the old birds is mate the objective that the danger of extermination comes in. Such was the fate of the Great Auk and the wingless birds of the Southern I Iemisplere. But egsing like everything else must be conducted on intelligent and reasonable lines.

On this point I venture to assert that I have possibly more practical experience than most ornithologists and for the simple reason that as this book will show it has chanced that I have had opportunities for visiting and re-visiting the same breeding stations of certain birds at frequent intervals for over thirty years.

Briefly, my experiences are that no amount of egging will ever drive away birds but that the moment the gun and trap are employed to slay the parents, there is grave risk of their disappearing altogether from the district. True it is that for a time, especially in a wild country like Spain, a bird may find a new mate to take the place of its dead consort; but the process cannot go on for ever.

Probably most realers of this book who are not ornithologists will be surprised on reading how nests are occupied by the same species year after year for an indefinite period, but it is the regular custom of the larger and casily recognized species such as Lagles and Vultures and it is one very easy of proof.

In only three instances since 1875 amongst hundreds of nests visited and dozens robbed do I know of the nesting species disappearing from localities. Every time this was due to the slaughter - not by me-of the parent birds, not to the taking of their egrys or young. Most usually when birds egers are taken they will soon nest again. I have proved that this is the custom with most of the larger Raptores. Even where the second laying is 


\section{Keeping Cage-birds}

taken these birds will merely shift to an alternative site. for their next attempt the following year and no amount of harying seems to deter them from trying again and arain to nest in one of their three favourite spots-three is the usual number. I3ut when sun and trap or worst of all poison is brourht into platy their days are numbered and the wanderer like myself on revisiting some wild spot finds the favourite nesting-places untenanted.

I may mention that my views on the comparative damage

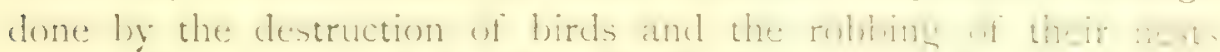

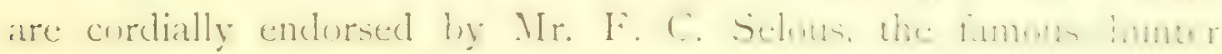
of bigr game and enthusiastic birdsnester.

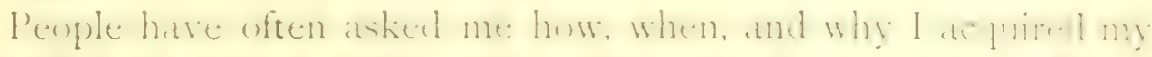

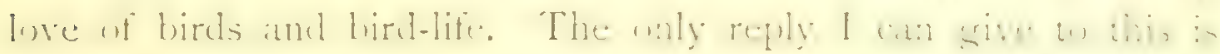
that it is apparently a question of "heredity."

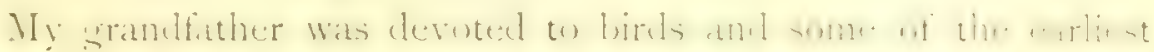

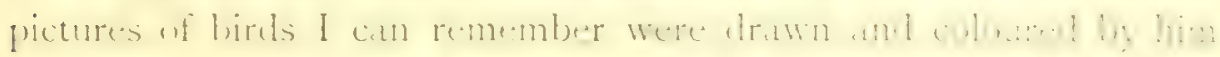

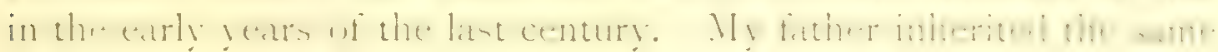

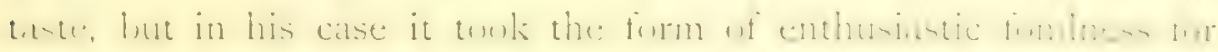

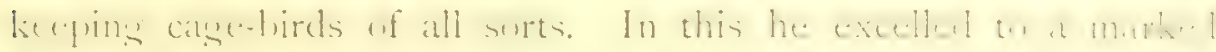

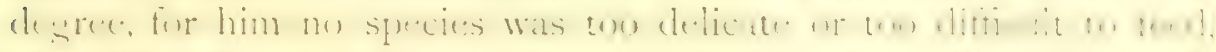

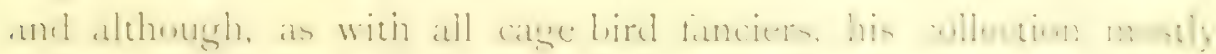

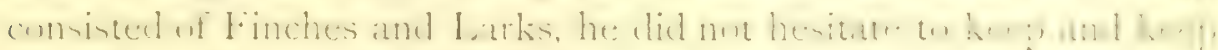

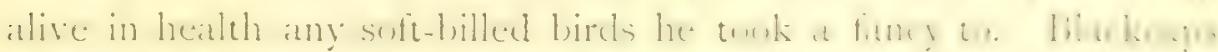

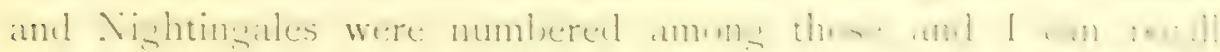

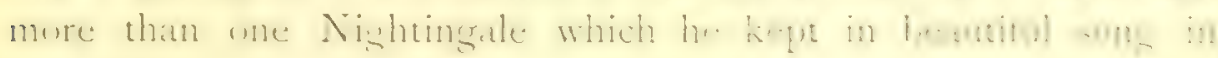
a small cage, no mean achicvement. "To accomplish this, some

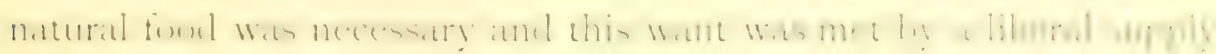

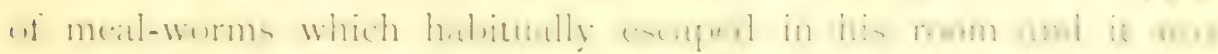
generally believed that it was due to the requirements of the

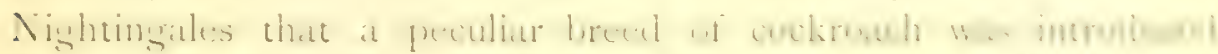

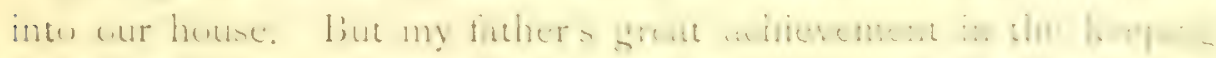


of birds, so long ats he hald health and strength, was on an altowether higher plane than cage-birds. He was one of the band of falconers who during the years between $1 \$+5-60$ pratetically revived the art of hawking in the British Isles. In the training of both hawks and falcons few surpassed him. His especial ally in this caluse was the late Francis Henry Salvin who died in I904.

The late Lord Lilford who wats ardently devoted to falconry, although debarred by his sad infirmities for many years before his death from personally taking part in the sport, told me how when a Jad he was taken by his father to Edinburgh Castle to see Captain William Verner (my father's) trained peregrines. This must have been about 1848 .

From my earliest days I can recall seeing leregrines, Merlins and Sparrowhawks, sitting, the former on their blocks, and the latter on a perch, fitted with jesses, swivel, bells and leash in approved fashion and I was taught from the time I could wall how to carry a trained hawk on the wrist.

I have dim recollections of a splendid Greenland falcon, of which I have a full-sized crayon portrait, drawn by a friend of my father. A traned Goshawk also fisured latgely in my early days and I well remember my father explaining to me how a sulliy nature made it doubly hard to train this species.

The last falcons trained by my father were a Peregrine and three Merlins. With the latter we had some famous flights after Skylarks and also the Crested Larks in the vicinity of Boulognesur-Mer. It is interesting to note that the trained Merlin is frequently unable to cope with the Skylark save when the latter is moulting, since it mounts rapidly and gets right away, whereas the Crested Iatrk hats a much less powerful flight. I remember my father's delight at finding in an olel French book on Falconry in the days of Louis XIII., written early in the seventecenth century that the best and most sporting quarry at 


\section{Training Hawks and Falcons}

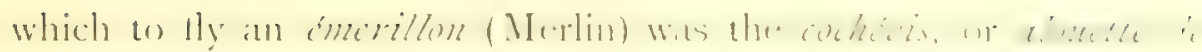
grands chemins (Crested Lark). He was doubly pleased at the

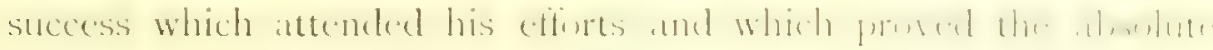
correctness of the old writer. The last hawk I trained under my father's tuition was a Sparrowhawk, this was in I868.

With regard to cage-birds, few men understood better the ant of keeping them in health and in song. He was conversant with

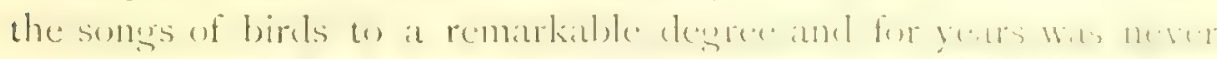

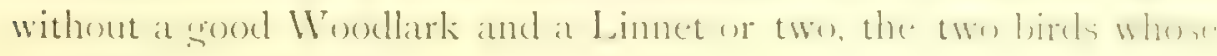
song he loved most.

This brings me to a curious phase in my father's bird experi. ments. He was an inveterate and enthusiastic breeder of mules (much to my horror ats an embryo naturalist); nut content with the

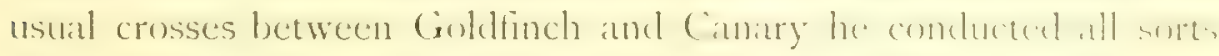

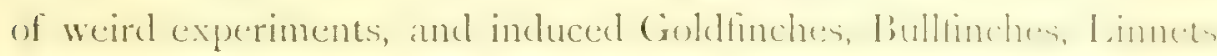
and Greenfinches to mate with species other than their wwn. Ihe also took an extratordinary interest in any atecienten varietien of wilk birds especially in those with some almormal miform collow tion such as at pale yellow-trown (ireentinch, ats well ats in thenes that showed traces of albinoism or melanism.

With regard to the cross-breeding, he was ever keen to try to develop by these means the singing powers of his loirts. In the case of pure-bred birds, he would bring up a youns lommet

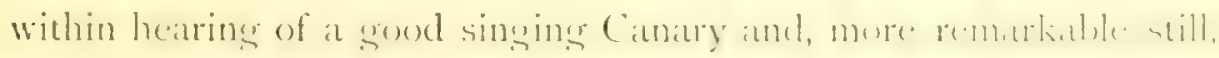
of at Woodlark, and he certainly succeeded in settims marrellow song out of his pets.

I think I have said enough to show that I was hroms he up trom my earliest days in a very atmosphere of bird-life.

My birdsnesting mania is not so easy to account for.

'The first wild bird's nest I ever found was a Linnet's in an eyot on the Thames near Hampton Court Palace. I broke the egers of course and suffered agonies. This was in 1857. 
In 1860 my father built a house in Quarr Wood near Ryde Isle of Wight and then I hat a chance of rumning wild and learning to climb. I remember well my first Song Thrush's nest and first Mistle Thrush's, both in the same tree in (Juarr Wood. 'This was also my first tree. I was then just $8 \frac{1}{2}$ years of age.

It was now that an old family friend, secing my mania for birds, presented me with a book on British Bircls' Egys with coloured figures, by Richard Laishley, published in 1858 .

That settled the matter and I read and re-read that book until I knew it by heart. Nor have I yet discarded it. Whether it was found impossible to leep me in clothes owing to my treeclimbing or whether it was considered possible that I might develop into an esging maniac. my father lost no chance from this time onward verbally to discourage me from birdsnesting. But it was tor late and as usual, I became more determined than ever to persevere in it.

But it was from my father that I drew both my love of birds and the elements of the science of nest-hunting. For when he was in want of young Linnets to place under a course of vocal instruction, it was he who took me out to the wild clowns in the interior of the Isle of Wight and lying down, field-glass in hand, soon located the nests of the Linnet in the prickly gorse bushes by watching the movements of the old birds from atar. I quickly profited by such admirable teaching and it was not long before I could find Yellowhammers and the rarer Cirl Buntings by employing the same tactics, without a field-glass.

A visit to Netley Abbey, in the spring of 1862 , brought me in touch with what I looked upon as an immense bird, the homely Jackdaw. They were nesting in the holes in the crumbling walls and my father hoisted me up on his shoulders and I gathered many eggs and conded up by slipping and subsiding upon his high silk hat with disastrous results to hat and eggrs. In those days gentlemen 


\section{First Birdsnesting Experiences}

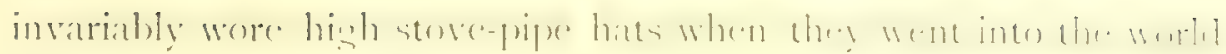
of fashion, even to pic-nics!

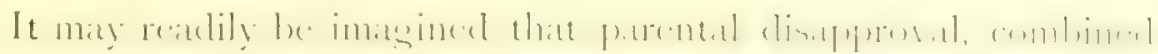
as it was with such entrancing object-lessons of how to ret nests,

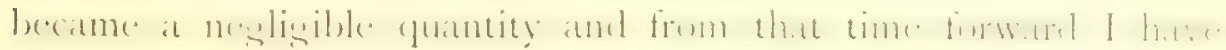

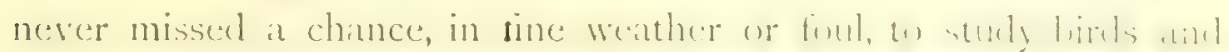
their ways and I know well that there was no man on earth who

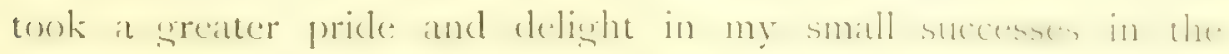
ornithological world than did my good father.

There was one other of m! father's old commalen whe, althroluh

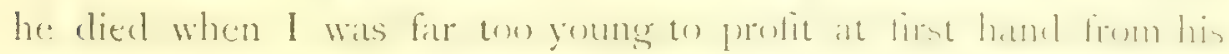

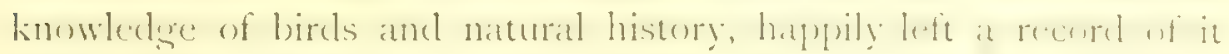
which did more to colucate mes in the elements of that delinhtial science than aught else.

This was none less than Chates St. John, whose fancinatinn

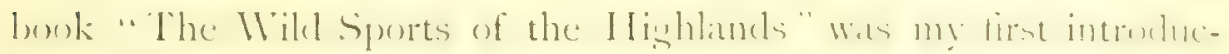
tion to innumerable branches of sport and matural history. St. John gave an original copy of his book published in $18+5$ to my father who entrusted it to me. It was "borrowed" lyy an

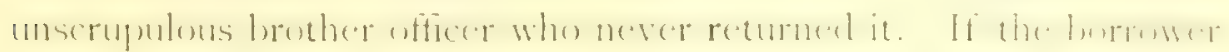
is not dead (as he certainly ought to be) and should he read this, I now call upon him to return me that book.

It was St. John who inspired me in a hundred ways to note the habits of wild beasts, birds, fishes and reptiles, and it was

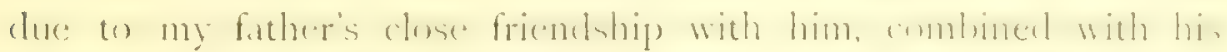

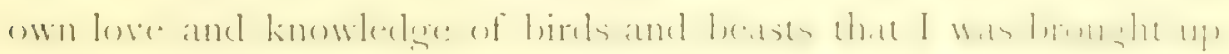
to take an interest in all appertaining to natural history, an interest which has stood me in good stead and afforded me endless joys and happiness often amid the most alverse and depressing surroundings.

Another very delightful book, which must have inspired

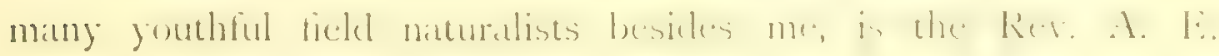


Knox's "Ornithologrical Rambles in Sussex," now, alas! sadly out of date. It gives most fascinating pictures of wild bird life in southern England in the "forties."

In 1874 I went with my regiment to Gibraltar and remained there until 18SO. In southern Spain and the coast of Morocco opposite I found unlimited field for ornitholosical research, the limits being the difficulties of ohtaining sufficient leare of absenese and deficiency of the sinews of war to conduct expeditions, for travel both in Spain and in Moroces is a somewhat expensive matter.

It was at Gibraltar that I first made the acquaintance of my father's old friend, the late Lord Lilford, who came out in his yacht on an ornitholonical expedition to the marismas of the Guadalquivir. Here, too, in $1 \$ 76$ I also first met the late Lientenant-Colonel L. H. Irby whose book on the "Ornithology of the Straits of Gibraltar" was published about the same time. From the day we first met, and for twenty-eight years subsequently until his death in 1905, Colonel Irby and I were constant companions in innumerable birding expeditions. In addition to his great knowledge of birds, he was an excellent botanist and an expert on butterties, hence our trips together were unusually full of interest.

In 1894 he brought out a second edition of the "Ornithology of the Sitrats of Gibraltar" in which were incorporated the notes I had made during the preceding twenty years and a number of illustrations from my photographs and sketches.

It was in 1879 that the late Crown Prince Rudolf of Austria arrived at Gibralta in his yacht, the Mirmmer, bent on an ornithological expedition to Spain. At the time I was a subaltern doing regimental duty and was not a little surprised to receive an invitation from the Gerernor, Iord Napier of Matgelala, to meet at dinner Ilis Imperial I Highness, of whose ornithological 
accomplishments I was at the time, I am ashamed to saty, quite unaware. Our meeting resulted in the Prince requesting me to

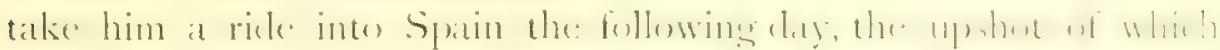
was that when the Miramar sailed for Tangier I was bidden

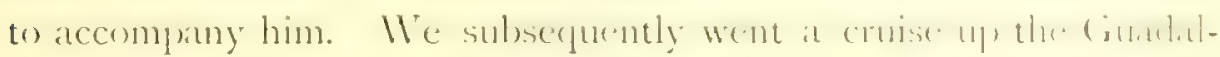
quivir when, thanks to the kindness of the late Henry Davies of Jerez and his comrades, we were permitted to explute then mant

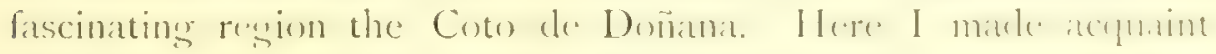
ance with the since famous "wild" camels and watherel wome cons of the filamingo. I was naturally much impressed with all I Saw and learnt, not least with the wild camels.

Thanks however to my mentors and advisers, Lord Lilford and Colonel Irby, I refrained from "discorring:" cither camely or Ilamingoes" exess in Eurepe, since I learned form them the story of how these camels had been imported form the (amatres many years before, and how, their owners having departed. the Spandun in charge of them had opened the stathe dexe and bid them depurt. As regards the Flamingoes, it is necessary for a man to be an enthusiastic onlogist to find comfort and bliss at I (n) w this d.u?

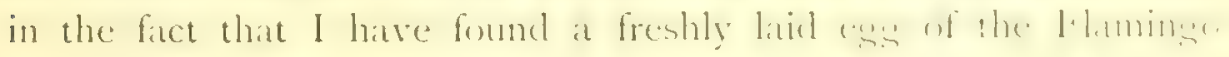
and further, bloan it, in spite of the appalling mul-luath it antailed owing to my horse subsiding.

After these delightful experiences in the fammus marianmes of the Cinadalguivir I accompanied the Crown Prince we Jene

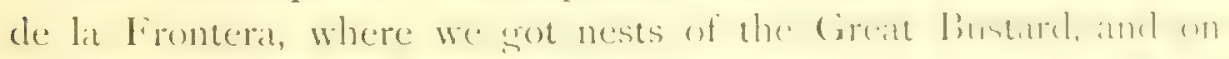

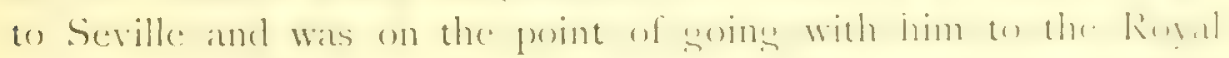
preserves in the Sierra de Grédos when the l'rince received a

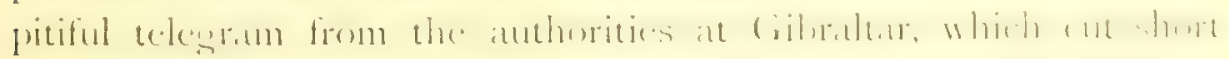
my carcer of absolute bliss and ordered me back to the Rock to "persecute my vocation" as a subaltern on the Waterport Guad. It was truly a step from the sublime to the ridiculous.

This was in 1879. I left Gibralta the following year, but since 
that time have repeatedly returned there solely in quest of birds and of sport for periods varying from two weeks to six months and more.

lint my experiences of birdsnesting and studying birds in their wikl state are by no means restricted to Spain. I)uring the course of my military career I have freepently found myself even when on home service, within striking distance of some favoured spot, such, for example, as Romney Marsh when quartered at Shorncliffe or Wolmer Forest when at Aldershot, where much could be done in the bird line at that time, whatever may now be the case. ()n foreign service, of course innumerable opportunities present themselves to the man who has sufficient knowledge of the birds and determination to seck them out. It would be hard to imagine a more detestable quarter for the keen ornithologist and sportsman than Malta. Yet even here I have found solace in seeling out and visiting the nests of the Great Shearwater and Stormy Petrel! Since all British operations for many years past have taken place in wild regions, it follows that, when time permits, the keen birdsnester and ornithologist who may take part in them has many opportunities of adding to his knowledge under conditions favourable to collecting. In some instances our Expeclitionary liorces have operated in districts where but little was known of the birds, as of much clse, including the conemy! As it is extremely unlikely that any of the-to me-most oljectionable species of the genus "militury prig " found in our Army is ever likely to read this, or, if he dicl, would have the wit to recognize a portrait of himself, I may say that I have at times taken malicious satisfaction in the stupeficel appeatrance of this type when, on my return from some reconnaissance, I have produced from the interior of my helmet a nest and eggs I may have chanced to come across. To them the mere sight of such a thing in my possession at such a moment was distinct proof of military incapacity. Yet, so long as a man does not permit his private tastes, such as a love of birds, to 
hinder him in the execution of his duties, olstimuly nuthin: lut

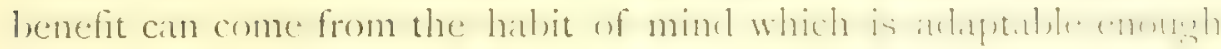
to realize what is and what is not of supreme importance at the

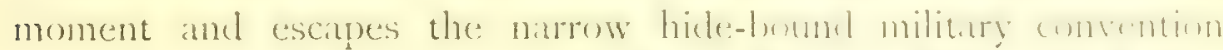
which prompts a man to view the Cireat Temple of Kitrmak at, "an old ruin which would make a soud station for Army signdling."

Since this book deals almost entirely with my life ammen the.

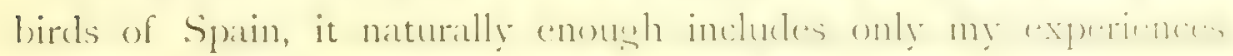
in peace. Still, sometimes when I have fumbl my reff committed to an unusually awkward cliff, I have recalled Mr. Jorruck immmot description of fox-hunting and have thought how much more applicable it was to an expedition after wilel hirets in a wikl commery where lons marches, transpurt diffeulties and lack of supplien. let

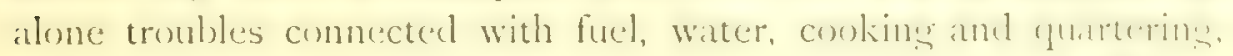
alike combine to present a by no means imperfect imane of wir. As to the precise percentage of danger incured in for humbing, witr. or cliff-climbing, I must leave it to the inclividual opinion of arery reader who may have experience of them.

I will only cite two eximples of birdsnesting on active service. which maty possibly amuse and at any rate will not shots m? rearlers. In January iss 5 the chances of war platerl me for a hrid

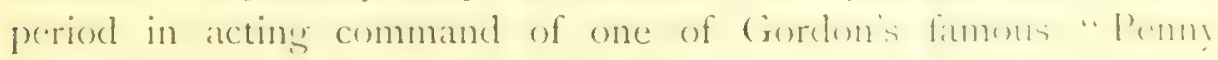
Steamers" on the reach of the Nile below the Sixth Cataract.

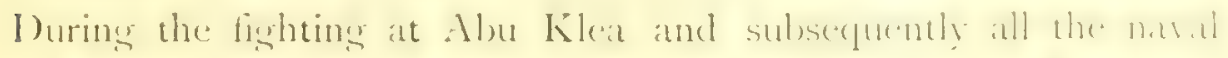

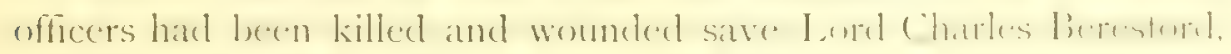

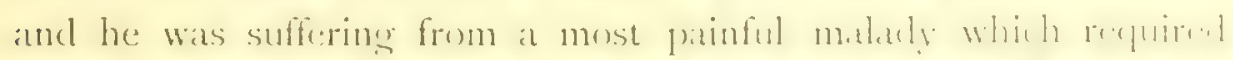

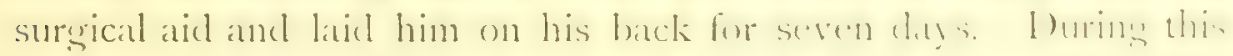
time, our twe small steamers were empleyed in reommerims and down the Nike and in collecting supplies and fuel. Hownes

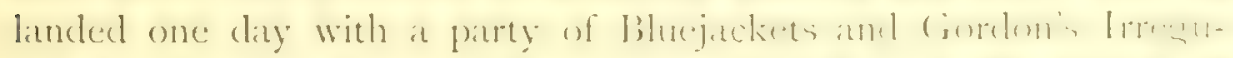

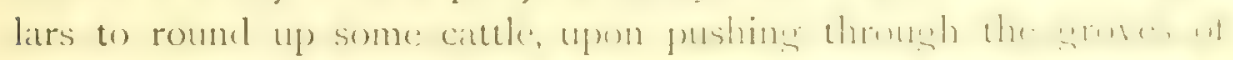

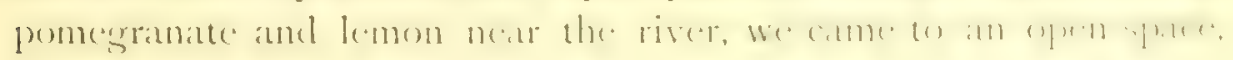


beyond which was a straggling village which was held by the Arabs whence they opened a sharp fire with their Remingtons. As we were out only for a day's cattle raid and the enemy were in force, I gave the word to fall back through the grove to our vessel. It was whilst thus engaged that I suddenly spied a lcmon tree with its branches festooned with the beautifully-woven nests of the small Black-and-red Weaver-bird! I had never seen one of them before in situ. Unfortunately, they were eight or nine fect up, and at the extreme end of the pendent boughs. Calling a Bluejacket near me I besought him to give me a leg up. He replied by seizing me by the legs and hoisting me with a jerk. I had just time to grab one nest and stuff it into my bosom when he let me drop and we raced bick together to the friendly plank which led aboard our "war-ship." As we shoved off, the Arabs lined the scrub on the steep bank and their bullets pattered agrainst the old boiler plates which formed our armoured topsides.

Events moved rapidly in those days and there was much to do and think about and it was not until four days later, in our bivouac at Metemmeh, that, feeling my shirt very scrubby, I put my hand in and drew out the Weaver-bird's nest squeezed as flat as a pancake! It however, recovered its shape and is among my treasures to this day, a memento of the furthermost point south on the way to Khartoum, where I was able to land, as well as my one and only experience of the nesting habits of the Black-andred Weaver-bird.

The second example was in November isge during the early days of the Boer War. I was with the Frontiel Force at Orange River Bridge and organized a train to support a reconnaissance towards the heights of Belmont then strongly held by the lioers. On reaching the high ground near Witteputs, I halted and pushed out patrols to get in touch with those to our front. IVe had brought with us a telephone from the station and the R. E. officer with me, 


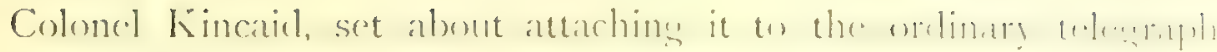
wires running along the posts near the railway.

Looking round for a convenient post I espiect a big nest luilt on top of one hard by. As far as I recall, there were only three

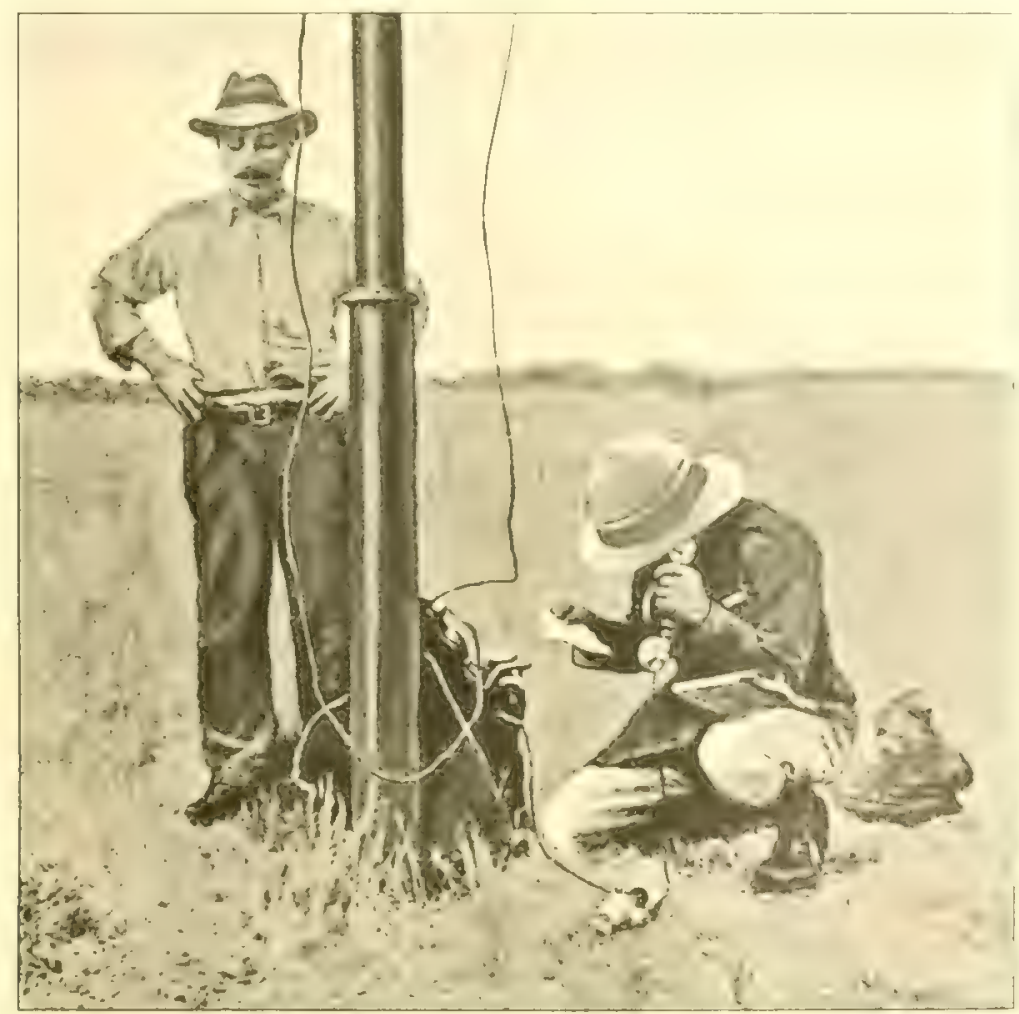

A NESTING PIACE OF THE SOUTH AFRICAN CROW.

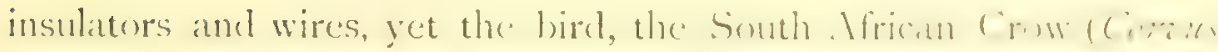

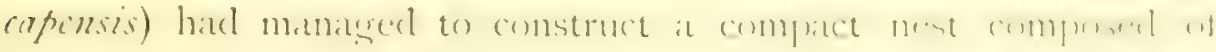

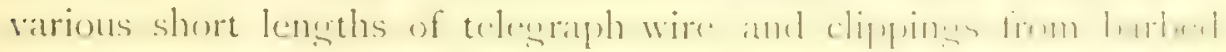
wire fences-both trees and sticks were scatre in then wecion. I 
Sapper shinned up and pulled out the big nest which was lined with velut grasses and wool and contained freshly-laid egrgs. The interesting point to me was that I instantly recognized them as similar to some unidentified egas brought to me when a small lad in the Isle of Wight from the Cape over thirty-five years before. They wore true Crows' errgs in shape and markings but, in place of being green, were red-brown.

We soon joined on a wire and got into communication with Orange River and I found myself speaking to an Inspecting General who had arrived in my absence at Orancre River in a real armoured train (mine was merely an "unarmoured cruiser") and expressed his intention of coming on to see what we were about. Somebody took the incvitable photograph of me when struggling with the telephone. Months afterwards, I purchased in Paris a reproduction of the photograph thus taken, duly inscribed "Le colonel Kekevitch se servant du téléphone de campagne en avant de Kimberley"! To me it recalled the whole situation, the telegraph post, the despoiled Crow's nest and the impassive Sapper taking mental notes of my telephone language.

When, owing to the very serious injuries I received during the war in South Africa, I was compelled to leave the Army, my thoughts at once turned to Spain, where the climate would suit me in the winter months and where I could continue and extend my researches in the wilder regions.

Since rgor I have spent half my time in Spain and before the troubles became acute made an expedition to Morocco also.

Hence the birdsnesting adventures in this book deal almost entircly with Spain. Owing to my intimate knowledge of many remote spots in this beautiful country, explored during many expeditions made before the war in South Africa, I am able, in spite of the serious handicap due to my injuries, with the aid of lorses or mules to re-visit these parts. Once on the spot, I can 


\section{Arrangement of Book}

still render a fair account of most cliffs or do at day's wading in a marsh, sufficient in any case to reach a nest 1 maty want to photograph.

The results of some of these expeditions will le tomml in thin book.

Those who know the works of Lord Lilford and Colonel I rby

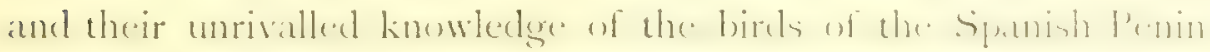
sula will easily realize how much this book owes to them.

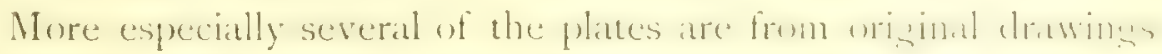
made for Lord Lilford and subject to his uncrims sorutimy and approval.

But besides Lord Lilford and Colonel Inty there hate hen

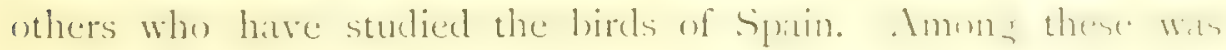

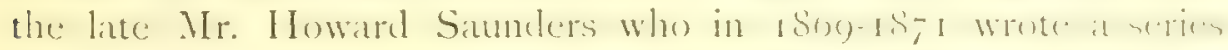
of papers to the lbis-Lord l,ilforl's first papers appeamel in

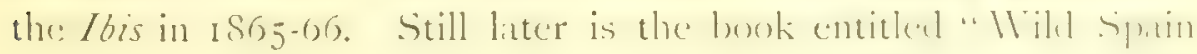
published in 1893 which deals in a popular and attructive m.uner not only with the birels and general natural history lut alus with a diversity of other matters such ats Spanish atrientume, wine. showing, bull-fighting and sipsies. All who are interented in spon

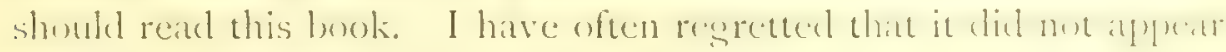
twenty years earlier when I first went there.

In the following pares no attempt hats bern make wh phat the

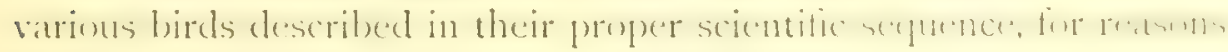
which will be sufficiently obvious to the reader.

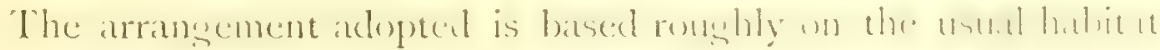

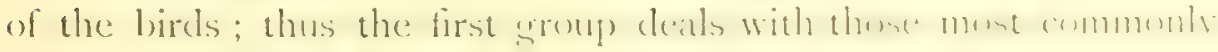
met with in the low-lyng matrshes of Spain and the seomel with

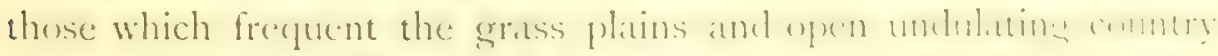

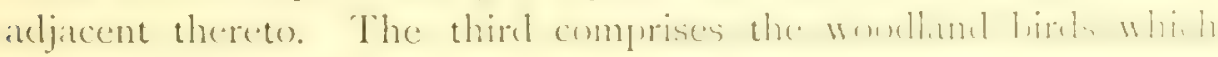

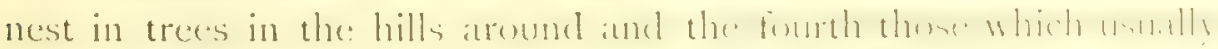
resort to the sea-cliffs. The Raven, although both a trec-nester 
and rock-nester has been included in this group, since the pictures fiven are of nests in cliffs and since Ravens are especially fond of sea-cliffs.

The fifth and last group comprises those birds which resort to the inland cliffs which are found in such extraordinary profusion amid the rugged sierras of Spain.

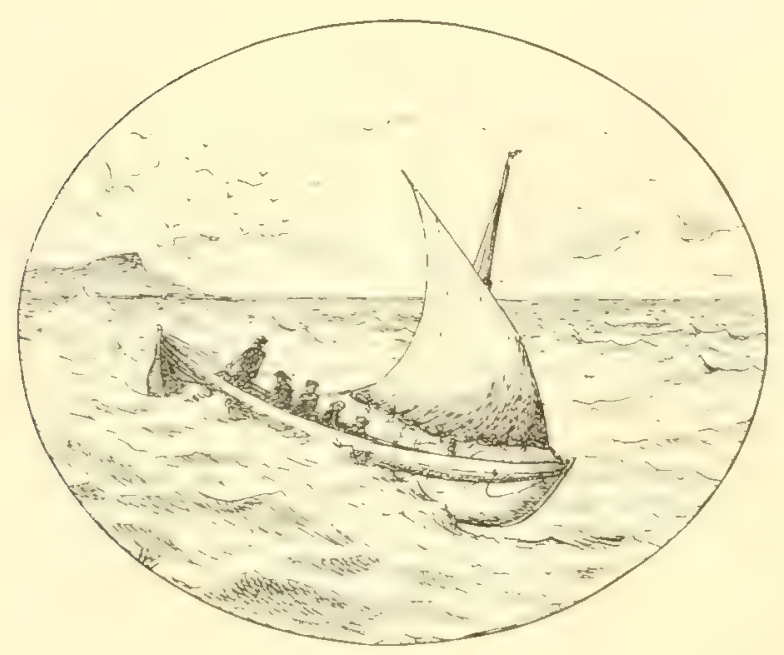




\section{CHAPTER II.}

\section{TRAVEL AND EQUIPMENT'}

Time, in bird-watching, a great factor for success-Travel in wild SpainCamping out versus country quarters-The minimum equipment necessary for comfort-Saddles, pack-saddles and saddle-bags-Importance of a complete equipment-IVhat a birdsnester should carry-Use of aneroid, fieldglasses, telescope and compass - What his assistants should carry-Bird traps and trapping-How to trap birds without injury - The joys of wandering in a wild country.

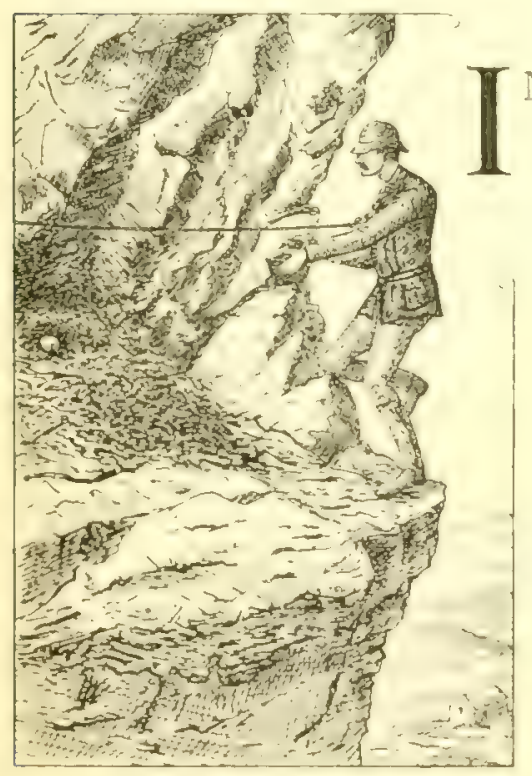

order properly to study the ways and habits of wild birds the main factor of success is time. Without ample and adequate time the fieldnaturalist will inevitably miss opportunities which may never occur agritn in a lifetime.

Few men however can spatre the time required for thorough research, so one can only malie the best use possible of the time one has. I cau recall various expeditions after birds and nests during the last thirty-five years, where, had it not

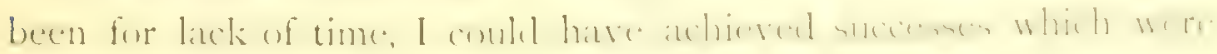

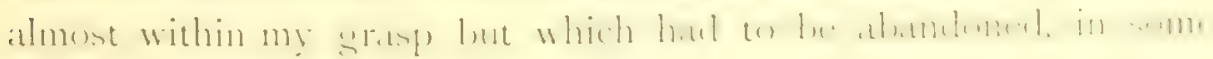
instances for ever. 
At no period was this more clearly brought home to me than during my six years at Gibraltar, between $187+$ and 1850 . That was in the days when no ralways or other facilities for travel existed in the vicinity (for even the road from Algeciras to Tarifa was not then constructed) hence every expedition from the Rock was limited to riding out between the hours of morning and evening gunfire, when the gates of the fortress werc opened and closed. And closed they indeed were and the keys were taken to the: Convent, the Governor's residence, and kept there.

Every expedition thus depended on the powers of one's horse to carry one far enough atfield at sufficient speed to leave reasonable time for sport or ornithology.

One result was that one became a past master in the art of packing one's kit on horselack, for guns, food, ammunition, ropes for climbing, and all other paraphernalia of the naturalist bad to be thus carried.

From time to time it was possible to get a few days' leave, generally five to ten days, and then pack-animals were called into requisition to carry our supplies and equipment. Everybody loas heard about the discomfort of travel in Spain, should the traveller leave the routes ustally followed. There are however denrees of discomfort in this as in other things. These can be modified to some extent by experience in rough travel and by a little forethousht, but it is ever a difficult matter to decide upon what maty and what may not be wanted for a particular trip. So long as one intends to stop, in small towns or villages, so long will this be the case, and cvery journey must be organized in view of the locality to be visited.

My own experience was that, unless a promising expedition was to run the risk of being wrecked for want of the bare comforts of life, the only sure way to achieve success was to look upon a birdsnesting expedition in a wild country much as a campaign and to prepare accordingly for every possible eventuality. 
This brings me to the subject of camping out, an occupation which has such fascination for these whe are andware of the tronhthe it means. Save in a few, very few, localities, such as certain Sierras and in some of the more remute ports of the murman. tents are quite unnecessary in Spain, for it is almost always

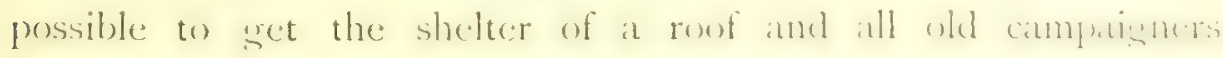
know what that means. Tents are unsuited for most travel in Spain, they are heavy and increase one's tramsport and are troublesome to pitch. In wet weather (and when it rains in Sprin it means business) they are miscrable and in hot weather,

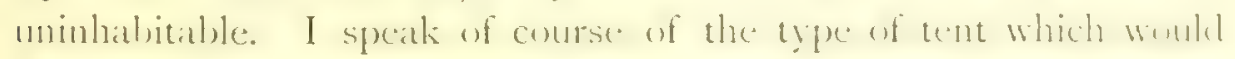
be carried by a man engatged in the cless of work descrituel in this book. On the African side of the Straits, on the other hand, they are absolutely necessary, since Monsish villuses or encampments are unsuited for Europeans. But to travel with comfort in Moroceo means taking a resular camp exuipment with plenty of tentage both for one's self and for one's servants and pur-

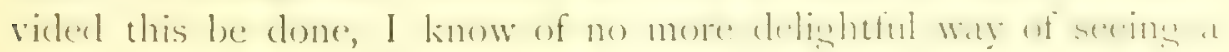
wild country, so long as the weather is passable. I start then

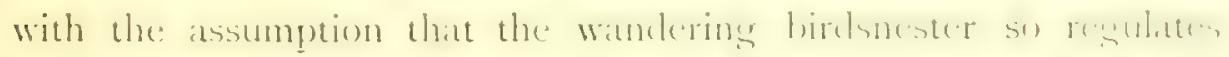
his morements ats an be within reach of some furmbenses or smell dwelling where he can induce the owner to sive him at rom on part of one.

In this, I have never yet failed, but simply because I let the sood people clearly understimel that I wane mething form them, save and except a shelter. They are extremely sensitive as to

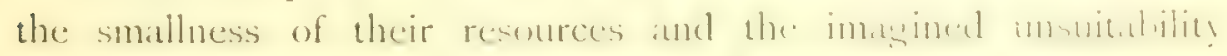

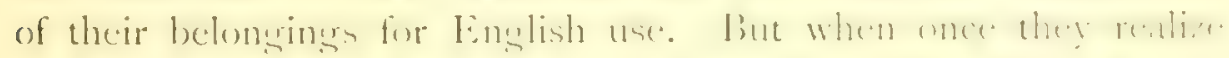

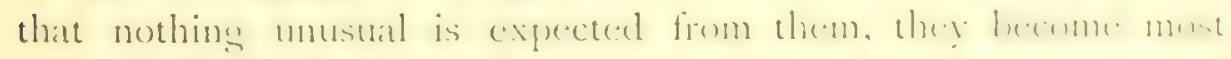

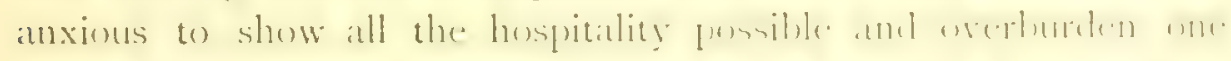

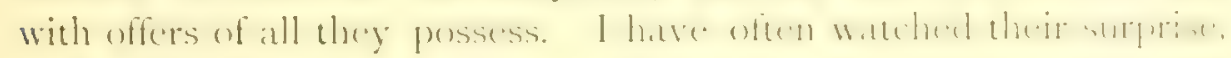

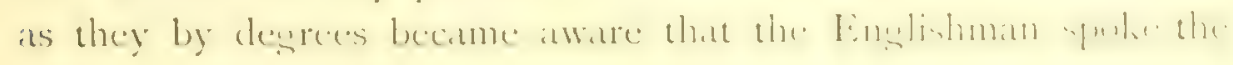


truth when he said he "wanted nothing." To want nothing sounds a great deal but in practice it is not so.

The secret of success lies in having the inclispensable articles ever with one, not because they are sure to be wanted, but because, in the event of their absence, untold misery and discomfort ensue. For this reason, I always carry with me in addition to a shift of clothes and a pair of canvas shoes, the following :-

( I) Light camp bed and blankets.

(2) Portable cooking canteen.

(3) Small luncheon basket with aluminium plates, forks, and spoons.

(4) Supplies for three or four days.

I thus am ever certain of a dry suit of clothes and a bed to sleep on and can likewise be sure of being able to cook my soup or make cocoa or porridge without upsetting the family arrangements.

In Spain, no matter how humble the dwelling or how remote from civilized parts, one can always reckon on fuel for cooking and good drinking water, also excellent bread and frequently eggrs and oranges.

In the accompanying picture my old arrioro Eduardo Villatva, a friend of twenty-eight years, now alas! gone on ahead, is shown with the whole of my kit packed for the line of march. In addition to the already-named essentials, this horse carried ropes, sling, escr-boxes, butterlly-net and a week's supplies. A reference to the pages in which I describe the equipment I carry when engaged in birdsnesting will account for the seemingly bulky appearance of the load. Of course, there is no necessity to reduce one's kit to the legal minimum and, truth to tell, every year one adds to one's comforts. 'Thus it is uncleniable that a canvas bath, a light folding table, and a portable chair are pleasant adcitions and render one independent of makeshift arrangements. 
When riding a horse, it is of course most desirable to have your English saddle with you. I have an old "Service" once with wallets and saddle-bags which, could it but speak, could tell both of our fighting in the Desert and reldt and is the confort of

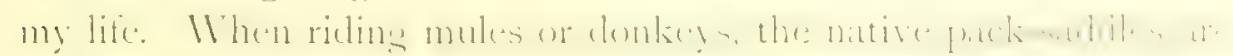

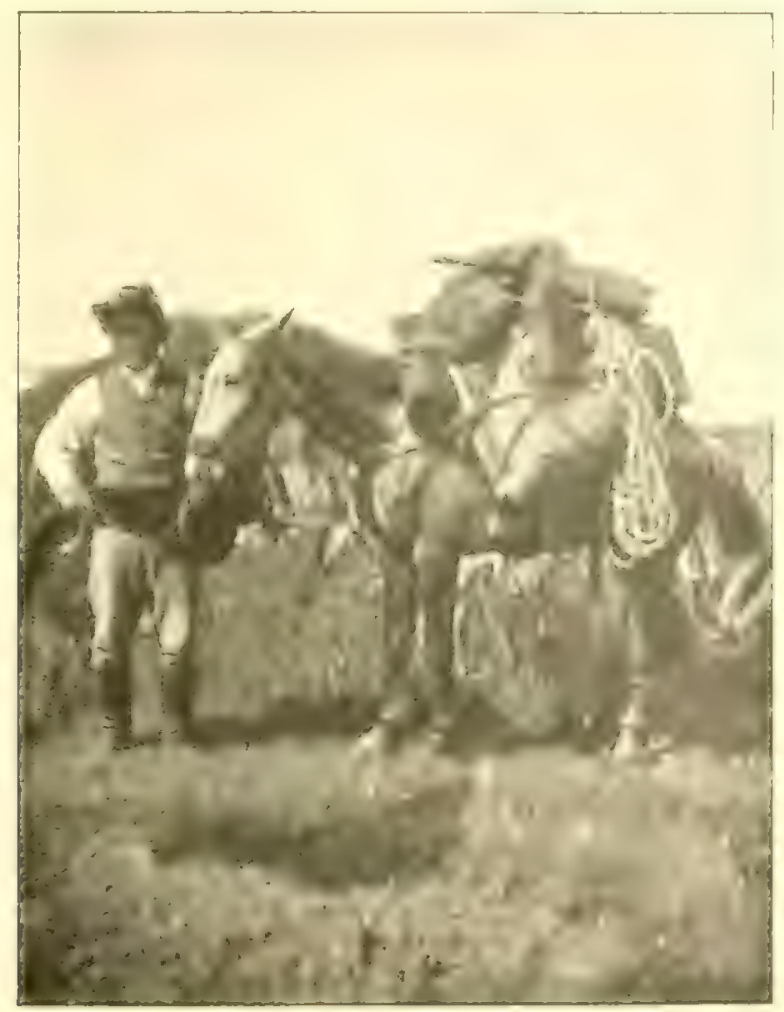

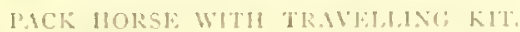

by far the best and one's saddle-bays can be thrown across these. A good supply of Spanish alforjas, or canvas saddle-bags are

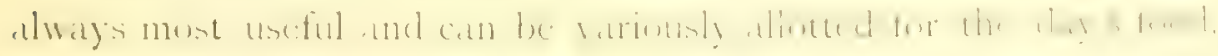
ropes \&c, as may be required. The great point is to licep the 
various parts of onc's kit separate and casily accessible. Among such are a good waterproof coat-no flimsy shooting cape will turn Spanish rain -and a warm suernsey to pull on over all when required.

It will be remarked that no reference is made to one's servants and cook. The reason is simple. On work such as I deal with in this book, there is no room for such people and the man who cannot look after himself had better adopt some other diversion. When pack-animals are employed, the arricro or mule-driver of course looks after them and feeds them.

I have had some amusing experiences in the hospitable ways of the good people of the Sierras. Thus, some years ago, when travelling with an Artillery officer we reached a house of a guarda or lieeper, who was most anxious we should stop at his place for the night. In accordance with custom, we had all necessary equipment. After I had cooked our dinner I asked our host to show us the room for our camp beds. He at once replied "Here" and brought them in. Protest was useless so we unpacked, undressed and turned in. Presently he followed suit and scrambled into a big double bed at the far end of the room, our hostess meanwhile having disappeared. She now returned and to our surprise likewise commenced to undress. The situation was novel. At the exact psychological moment she blew out the light! Next morning, both guarda and wife were up and dressed before we woke. This tale of my methods of travel in wilder Spain has reached the snows of the I Iimalayas and thence has come back to me.

I am writing this chapter in a small room in a cottage in wild Spain. It is mid-winter and a very wet day. The wind is howhing and the rain restricts the view to a few hundred yards. But the rowe is sound and the whitewashed walls and stone floon are dry and I am sitting in my own arm-chair at my own table and mentally 
thankful that I am not -as so many of my friends kindly and and under canvas.

In no sport or pastime, art or science, call it what you will. is it more necessary to have exactly the right gear at hand and at the right moment than in birdsnestins. more apecially when climbing is required.

To ensure a successful day's work, or, at any rate, onc which

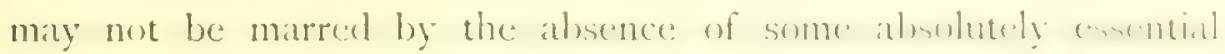
article, it is necessary to kecp) a list of what is repuired. Everylung will have his own ideas as to what to take: lut the following are my own, of which I keep it copy in my notebook and also one writ large in charcoal on the walls of my dwelling.

Worn or carried on person :--

(I) Aneroid, watch, silk rope and whistle.

(2) Hunting belt, swivels and knives.

(3) Notebook and pencil.

(4) Field-glasses, telescope and compass.

(5) Sketchbook and small hand camera.

Carried by assistants or on pack animals :-

(1) Ropes, canvas sling, casting-line and weight.

(2) Egg-boxes, cotton wool and egg-blowing implements.

(3) Traps (when required).

(4) Rope-soled boots, guernsey and waterproof.

(5) Photographic apparatus.

(6) I ishing creel, with forst, water-lutte and drinking cups.

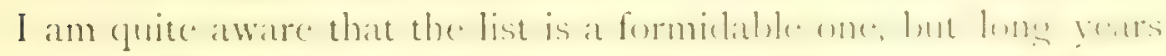
at the work have tatuht me how absolutely necessety mone wit the

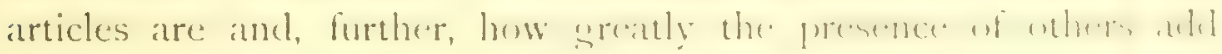
to the interest of a day's work, more especially in it wild and unmapped country.

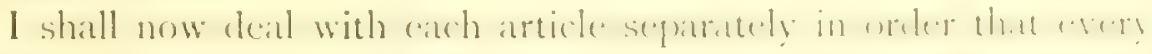

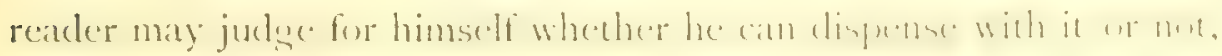
citing examples how and when I have found it useful. 


\section{(1) Aneroid, Watch, Silk Rope and Whistle.}

The most convenient sized aneroid for ordinary work is one with a $\mathrm{s}_{4}^{3}$ in. dial (watch size). For general use one which shows altitudes on the external ring over a range of 5,000 feet is most suitable since it permits of clear graduation by which differences in level can be read to within ten feet with little trouble. Of course for work in higher mountains an aneroid must be sraduated to show heights up to 10,000 feet at least, hut thereby the difficulty of reading off the dial is greatly increased and its value for determining accurately relative heights proportionately diminished.

Save when I devote a day to marsh work, I invariably carry an aneroid and, apart from the general interest of observing and noting the heights of mountains, cliffs, and nesting-places, on occasions it is of the greatest assistance in finding one's way on a precipitous mountain to some particular point. I will give an example. Some twelve years ago I visited a great range of terraced cliffs and noted a Vulture's nest at a certain point. But on setting to work to climb the cliff I soon lost my bearings amid the numerous gullies, projecting crags and ledges which at every turn hindered my advance or led me whither I did not wish to go. As frequently occurs in big climbs, I was soon completely at fault and had no idea whether I should try to go higher or lower along the face of the cliff and eventually had to abandon the attempt.

On the occasion of my next visit I recomnoitred the cliff more carefully and took the precaution of noting down a few points on the same level as the nest before setting to work to climb. On reaching one of these landmarks, a crass with some olive trees on it, I consulted my ancroid and found I had risen about $300 \mathrm{ft}$. I then strove to keep to the same level, but this soon proved to be impossible for I had to ascend in some places over $100 \mathrm{ft}$. and at others work downwards along steeply sloping strata, amid a 
jungle of palmetto and lentiscus. But the andend always tolle me.

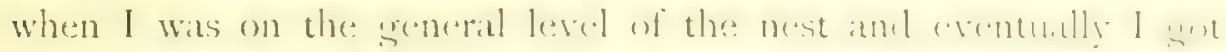
on a terrace which lect, most mexpectedly, rieht into it. It the time I had no good picture of a criffon's nest. It wits a splemelid subject, a fine nest on a sloping shelf with stepe rowk riving behind and on one side. There were heary chubls and wme rob and a lons time-exposure was wanted. With the aid of my silk rope I secured myself to the rock and backed out cautimaly till I sont sufficient distance, then pressing the camere with one hamel andinst the cliff, I took the photomaph. The camerat was ane with a fixed focus. I espite the dificulties I, or lather the comeri, got an excellent picture, so excellent indeed that I hat it enlaresed to so in. by $12 \mathrm{in}$. and have it now hanging in my sturly. Sis moth for "the uselessness of hand cameras." In this case the ancrovil was the prime means of my reaching the nest but without my silk rope the photograph could never hate been taken, since to wet it meant standing on the slippery rock at the extreme chene of a sheer cliff.

In time-exposures of this nature it often becomes a serious difficulty where to dispose one's watch so ats to kerep ath ye on

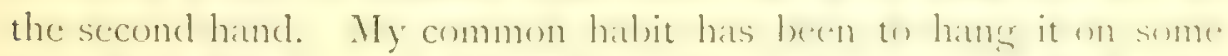
branch or lay it on a ledge, both clumsy axpelients. It is amb this year that I have become the possessor of a wrise wath fiucel with a third hand to indicate seconds on the disl. What anxions moments would not this simple contrivance hase sitred me in innumerable climbs in the past!

The importance of a good whistle when engaged on clitt work will be described later on and every sportsman lanws huw aweful a whistle can be in many other circumstances.

\section{(2) Hunting Belt, Sruivels and Knives.}

I am a sreat believer in a sheath-knife which is avalialle fir

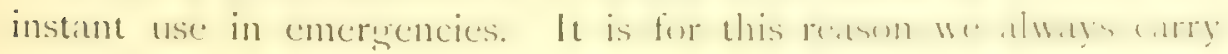


one in our war balloons. But I am no believer in the popular "sportsman's" clasp-knives containing every possible and impossible weapon, apparently designed to remove sections of skin and to excavate holes in one's hands if one attempts to do a tough bit of cutting. If a man wants to carry a corkscrew, small blade, cartridge-extractor or other tools, by all means let him have them in a small metal knife of the type popularly known as the "drunkard's companion"; I regret I do not know its official description. This, he can carry on a swivel on his belt as well as a small sheath-knife. The latter is invaluable for all nesting purposes, whether to clear away scrub on cliff, branches in a tree or to cut a lane through high reeds in a marsh.

The springs of all swivels should be double-rivetted, else the day comes when they slip and one's knife is lost. I always have several swivels on my belt, to facilitate carrying a camera, egg-box or such bulky objects, which, when slung over the shoulder are apt to get in the way. By clipping them on to the belt with a double swivel this is entirely obviated.

\section{(3) Notebook and Pencil.}

No naturalist, traveller or explorer can do without a notebook. One which will slip easily into one's pistol (or hip) pocket is a good size, say about 6 in. by 3 in. Pages should be prepared on which to lieep a record of photographs taken, showng subject, aperture, speed \&c.

\section{(4) Field-glasses, Telescope and Compass.}

For bird-watching, especially birds on the wing which it is required to trace to their nests, a good pair of ordinary binoculars is essential. For all-round work they are infunitely superior to any of the prism glasses since they can be used at all hours of the day and in all lights. They must have a fair-sized field, so as to make 
it easy readily to pick up birds on the wing and kethe whe the I personally use aluminium glasses of about five diameters ame with 2-inch object-glasses, which weigh in their case I lb. 7 oz.

But these alone are not sufficient for the birdsnester. When a bird has been sighted and watched to its nest of the whene, the

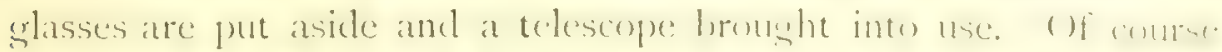

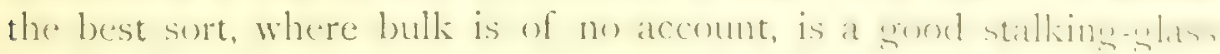
but I have for over twenty years clone all my work with a naval "watch officers" telescope. This is extremely powerful and, having only one pull-out, is rapilly focussed, a sureat proint. The. popular objection to it that it is tor long to camy is all nonemo: my own in its leather sling case is only 1 i. inches in lengeh and weighs under I $1 \mathrm{~b}$, I2 $\mathrm{oz}$.

In carrying field-glasses for bircl-watching, the wreat thing is to have them ever really focussed so that they can be hought inte use with the least possible delay. This can be provided for by the very simple expedient of having the leather cate malle home enough to hold them when focussed ready for use. Another must useful small adelition is to have a $\mathrm{U}$-shaped spring or clip fixed inte the bottom of the case, into which the glasses are pressed when returmed to it. In slimbing or riding, should the case hate been left unstrapped, the risk of the slasses falling ont is by this mein minimized.

It is an excellent plan to have at stud sewn on to the cast ats we di ats a buckle. since either of these by itself is liable at times and under rough usage to fail.

When birdsnesting in will coumeries I always carry a complase. (of course, if any way likes to saty this is because. I am the inventon of the Service Compass, he may) which I use both for generol pur

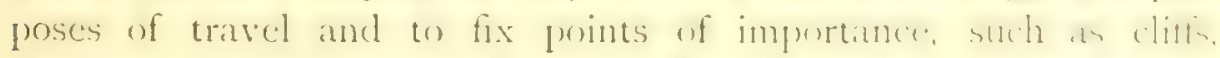
mountain wps, the trend of ralleys, \&e. ()wine th the small wath of the maps usually procurable, it is the only mans at times on locating one's position. 


\section{Travel and Equipment}

A compass also is most useful when engaged in any geological or archaological researches but I will not inflict on my readers a disquisition on these matters. Suffice it to say that many a day's birdsnesting, blank as regards nests found or birds seen, has brought me to places of absorbing interest where without aneroid, compass and (shall I venture to avow it?), a clinometer or level, I should have been unable to take advantage of sundry delightful opportunities for study and research brought unexpectedly within my reach.

\section{(5) Sketchbook and Small Hand Camera.}

These will be found described at length in the next chapter. Over and over again I have endeavoured to reduce the number of articles I carry (and consequently the total weight) by relegating one or both of these to the "second line" of my field equipment. But as often as I have done so I have sooner or later had ample cause for regret and have reverted to my original plan of never being parted from them. I can recall lost opportunities of a slietch of some glorious view or of a photograph of which the like will hardly occur again, both ascribable to the desire to reduce one's load.

So much for the lighter articles, now as to the more bulky, which are usually carried on pack-animals or by men. On arriving at any locality where any climbing or exploring has to be done, a redistribution of the gear is made and articles suitable for the task immediately before one are selected and divided out among the party to carry. Among these are usually the egg-boxes, the necessary ropes, rope-soled boots and the second camera and spare films.

\section{(I) Ropes, Canvas-sling, Casting-line and Weight.}

These are fully dealt with in the chapters on Tree and Cliffclimbing. 


\section{Trapping Large Birds}

\section{(2) Egg-boxes and Egg-blowing Apparatus.}

To carry eggrs I use sets of boxes of tin or aluminium which "nest." The only egg-blowing appliances wanted in the ficld are

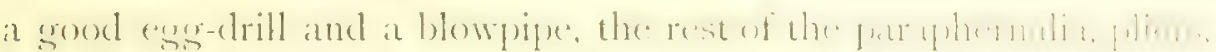
scissors, syringe \&c., can be left at home. It is always best,

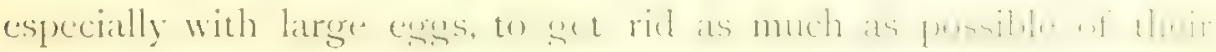
contents directly they are taken. Eggs thus treated, if properly

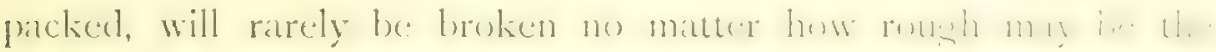

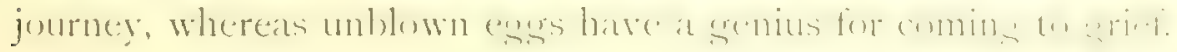

\section{(3) Traps.}

Most birds can be trapped on their nests without difficulty. I have never failed when I have given time to it save only with the Raven, which seems critically to note every detail and to see at a glance where a trap has been conccaled.

For big birds of prey the surest trap is an iron rabbit-gin with

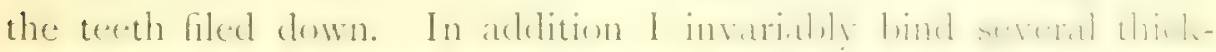

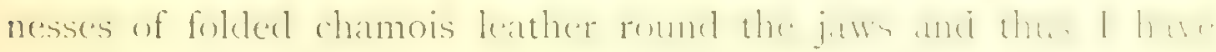
never injured a bird I have caught. It is most necessary to watch

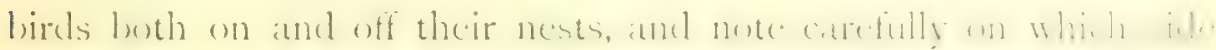

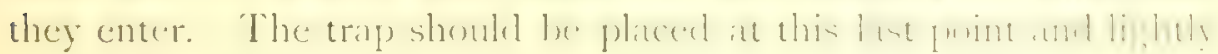
covered with leaves, twigs \&c. I invariaby attach the trap to a strong line which I lead down to the ground and secure to a loose branch.

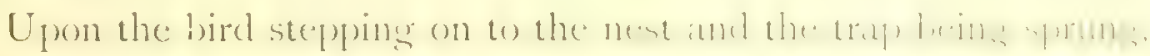

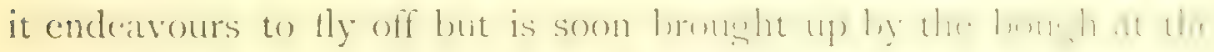

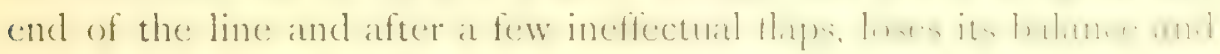

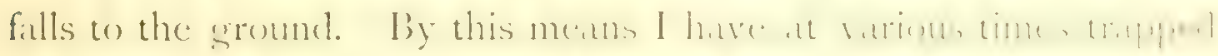

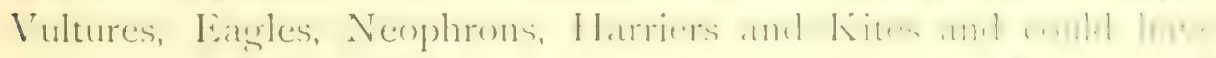

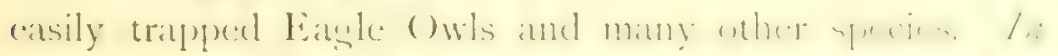

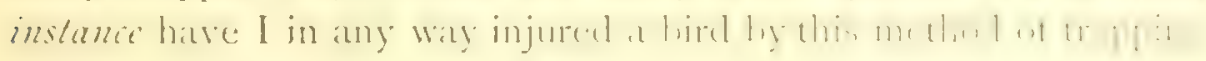
As a rule I have released them sooner or later. 
I describe the process because if it be required to obtain a bird cither alive or dead, it is by far the most merciful method to adopt. Shooting big raptorial birds off the nest, besides frequently damag. ing their plumage, is by no means a certainty and I can recall several instances where an Eagle after receiving several charges of shot, has gone away to die-a splendid life wasted-and I have read of many like mishaps. In this class of trapping the bird is not left to strugsle for an indefinite period, for the skifful trapper, having set his gin, retires to the shelter of some bush or rocks 300 yards or more from the nest, whence he watches until the bird returns and is trapped, often a matter of less than half an hour. A coat or rug thrown over the bird much simplifies the task of securing it.

\section{(4) Rope-soled Boots, Guernsey and Walerproof.}

The value of the Spanish rope-soled boots or shoes known as alpargaters, for cliff and tree climbing can hardly be exagyerated. Stockinged feet are well enough but if the rocks be sharp, they soon become bare feet and what between cuts, bruises, scratches and the presence of thorns of all sorts, it does not take long to get one's feet into a very unserviceable condition, and tender or sore feet are an element of danger when cliff-climbing.

Hence the alpargates. But the ordinary nailed shooting-boots shoukd only be taken off and the alfargatas chomed when the actual cliff work has to be tackled. For rope-soled boots on muddy hill. sides, when once they become clogged, are an abomination and, what is worse, are extremely dangerous when the rock-climbing begins.

In all mountain work the climbers are apt to get over-heated and often after a stiff climb it may be necessary to lay up for an hour or more and watch the wild hirds. Then a warm gucensey, loose enough to haul on orer all is invalualle. The alternations between heat and cold, in sunshine or in shade, out of or in the 


\section{Attractions of a Wild Country}

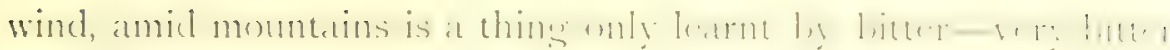
experience.

After all, the whole science of life and of living is how to adapt oneself to one's enviromment and one among the many charms of the wild life I have led at intervals for so many years is the knowledge one by degrees accumulates ats to what is and what is not

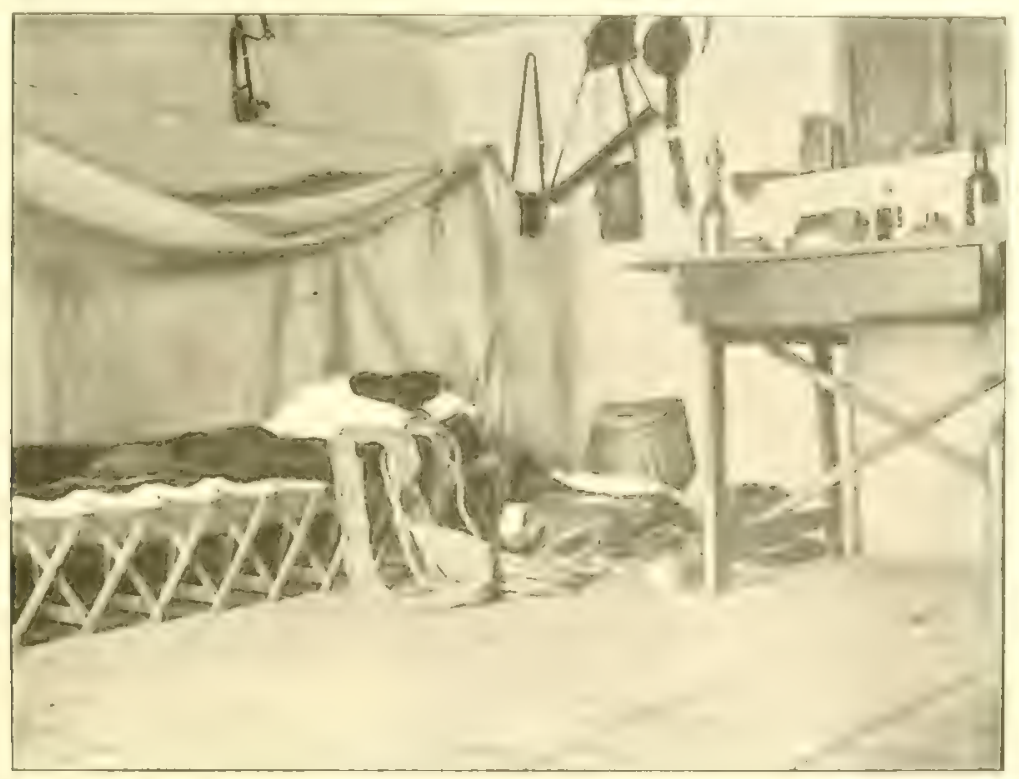

QUARTERS DURING A DIRISNESTING EXPLITION.

essential to one's existence. 'This is no place to expatiate on such matters, for every man has his own ideas of what is and is not essential. But there are some things to do without which spells misery, namely, those which concern rest, such as camp-beds,

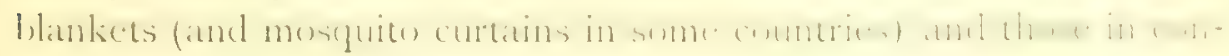
nection with food. The accompanying picture shows a corner of

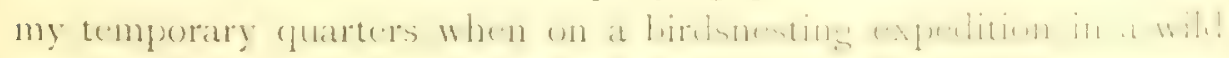
country. 
To me one of the delights of wandering about a wild country in quest of birds is the endless series of other attractions which from time to time draw one's attention from the main work in hand. For it not seldom happens that what may, to me, be merely a side-issue is the absorbing life-study of one of my companions, such for example as butterflies or botany. Thus it comes about that on some days I find myself wielding a buttertly-net and equipped with boxes and killing-bottles on the lonk out for specimens for my friends whilst never a day passes that one does not come across some rare flower or plant-a never-ending joy. Sometimes on such occasions I call to mind the words with which I commenced this book and whether it be after a successful foray among the birds, or some new experience amid butterflies, beetles or reptiles, or some fresh interest in botany, geology or aught else, I congratulate myself that, despite the cruel Fortune of II ar which so abruptly closed to me the profession of arms, I was spared at any rate to be "reduced to birdsnesting."

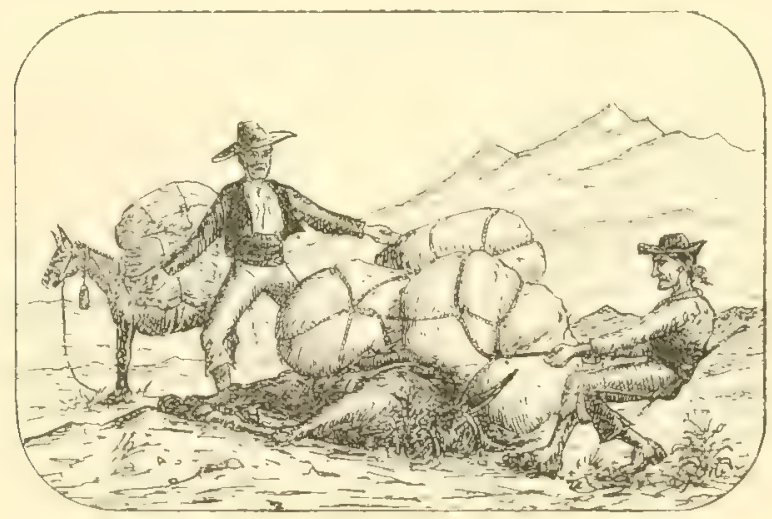




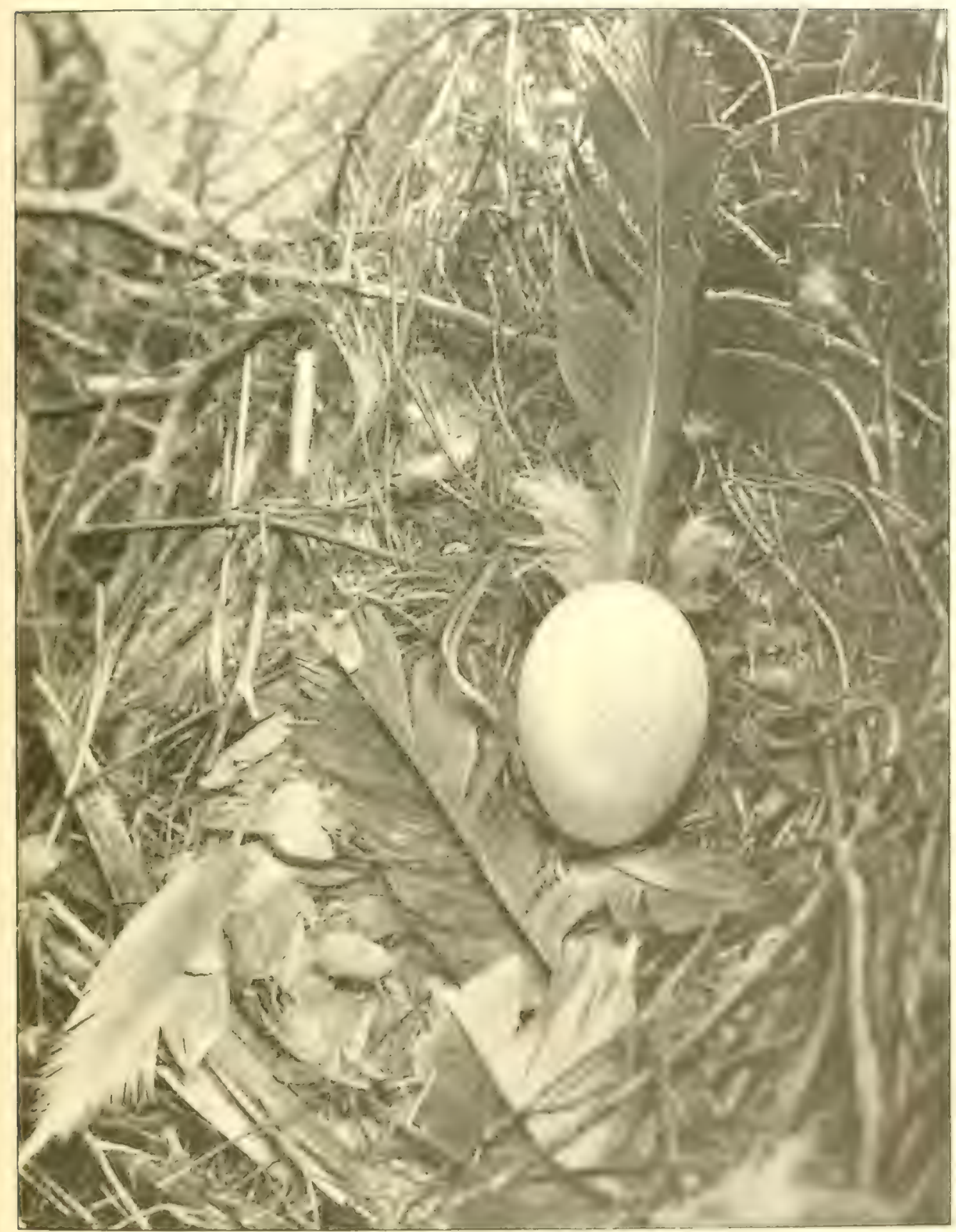





\section{CHAPTER III.}

\section{SKETCHING AND PHOTOGRAPHY.}

Superiority of sketches over photographs for general viens-- Value it thy li 1.1

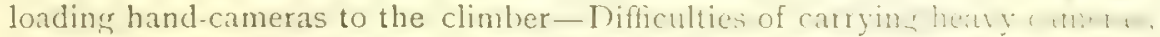

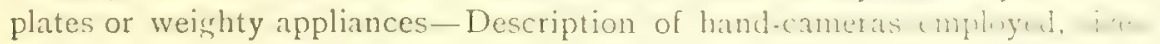
weights \&c. Advantages of working with two cameras-Lightness and portability the sole deciding factors-Difficulties of using a stand when climbing-Improvising camera stands-Pen and ink sketches.

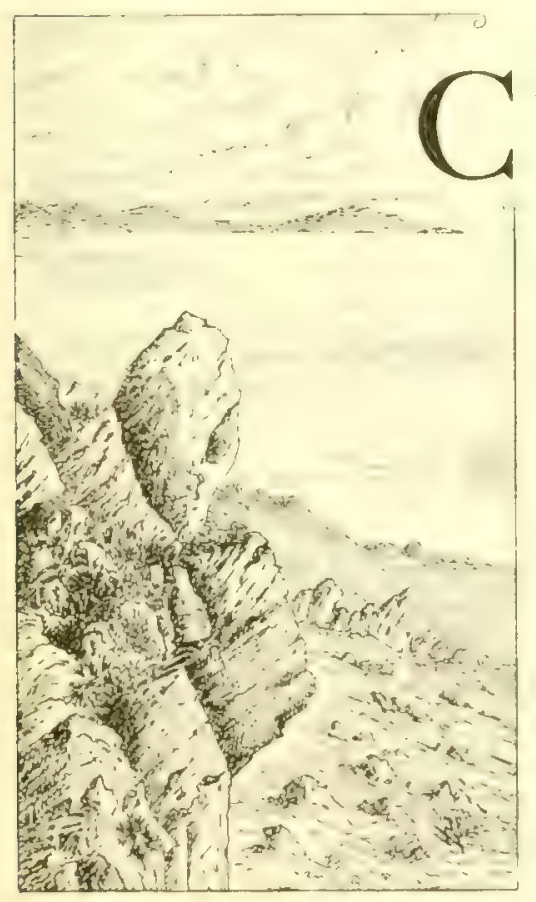

ERTAINLY one of the greatest joys in life to the successful birdsnester is to obtain a record of the places he has visited and the haunts of the wild birds he has watched. For nearly twenty years I never went on an expedition without making slietches of the localities visited and when possible, of the situations of the nests. MIy especial joy was to reach some Eagle's nest and endeavour to delineate with pencil and brush "what the Eagle saw:" Of course, I had to submit to the usual chaff to which every man and boy from "Martin" down has experienced in

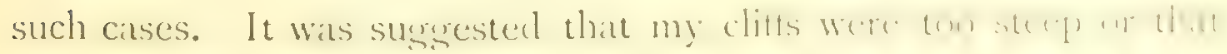
no man could get at such spots. Ithether this whe the en we whe 
I cannot say, I merely attempted to draw what I saw. With the advent of photography, absurdly enough, all this was changed and the average critic who had ridiculed a sketch was willing enough to accept a photograph as absolutely correct. It is needless to explain that distances and depths can be and are frequently grossly exaggerated in photographs, whilst mountains and cliffs are equally absurdly dwarfed. For this reason, as will be noted, I have given very few general views in this book, simply because the cameras I work with are not suited for such purposes. The exception is where in a photograph of a nest at close range some of the country immediately below comes in; here the impression produced is at times singularly realistic.

For water-colour slietching nothing can equal for compactness and convenience Roberson's "Combination" sketchbook and paint-box. The latter carries the eight necessary moist colours and brush and the book measures over all $4^{\frac{\pi}{4}} \mathrm{in}$. by $\delta_{\frac{\pi}{2}} \mathrm{in}$.

I have never been without one (or its equivalent) for over thirty-three years and before the present pattern appeared I designed a make-shift one of my own. The opportunities for sketching on such expeclitions as mine are simply boundless and in fact are only limited by the time available. Although, upon the introduction of the daylight-loading hand-camera, I instantly adopted it as an adjunct to my favourite pursuit, I still look back with satisfaction on the hundreds of water-colour sketches I made in all sorts of wild regions and remote spots of the glorious riews which lay before me. Inadequate and crude as are many of these sketches, they give an idea no camera work can pretend to of the heights and distances, atmosphere and colour amid which my beloved birds live.

But the camera is of course unsurpassed for the faithful delineation of all details. In my own particular line, although photographs may and do fail lamentably to show the majesty of 
a sreat cliff or the glorious scenery viewed from it, they are the only possible means of recording the structure of a nest or the conformation of the rocks adjacent to it. The ideal book on birdsnesting would be one in which the places and scencry were

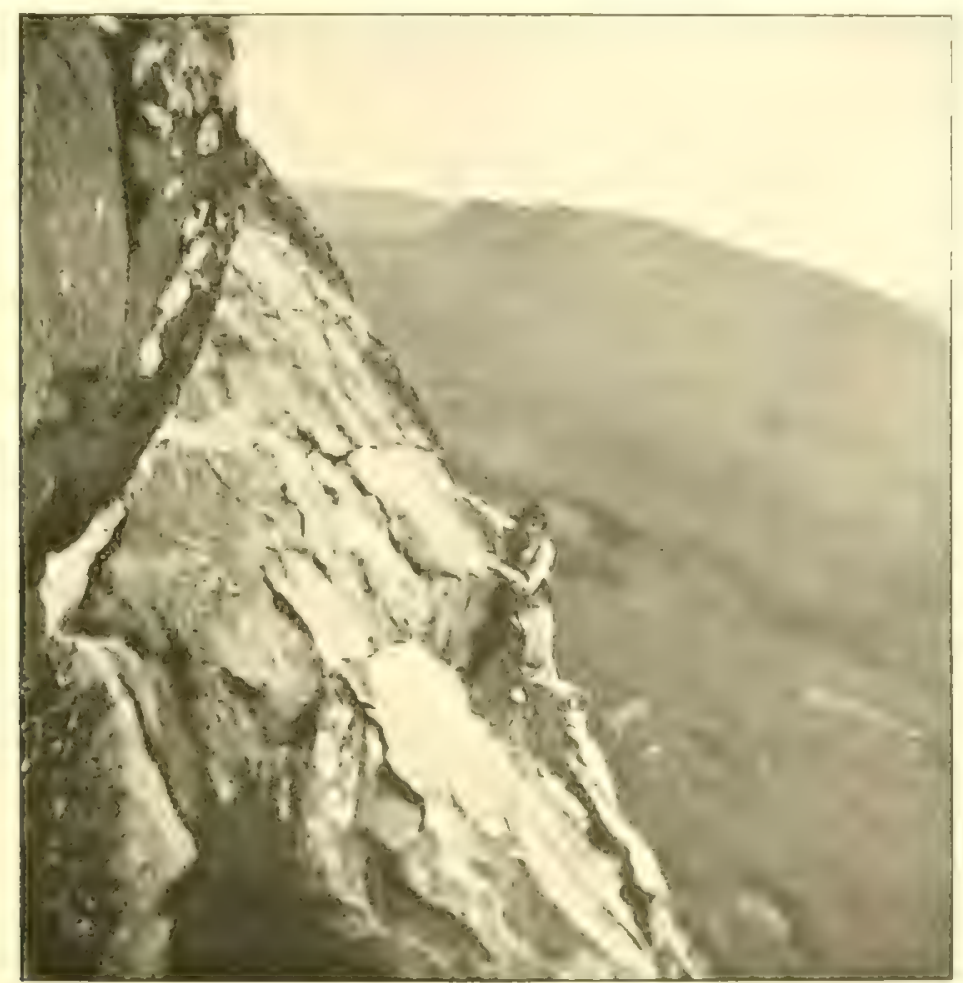

A CLIMH FOR A HHOTO(KRHH.

reproduced from water-colour slietches, and the actual nests and eggs, rocks, trees and reed-beds were shown in photograph.

It is no intention of mine to venture into a discussion as to what is the best camera for use in connection with birdsnesting. I shall merely describe the very simple appliances I have used

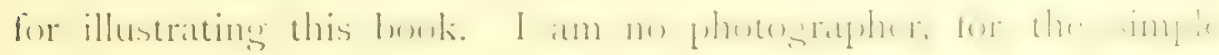


reason that I have been far too busy all my life to find time to devote to that alsorbing subject. Would it were otherwise!

For work on moor or marsh there is no limit to the size and weight of the camera and obviously in such cases all the modern luxuries of rellex cameras, focal-plane shutters, tele-photo lenses,

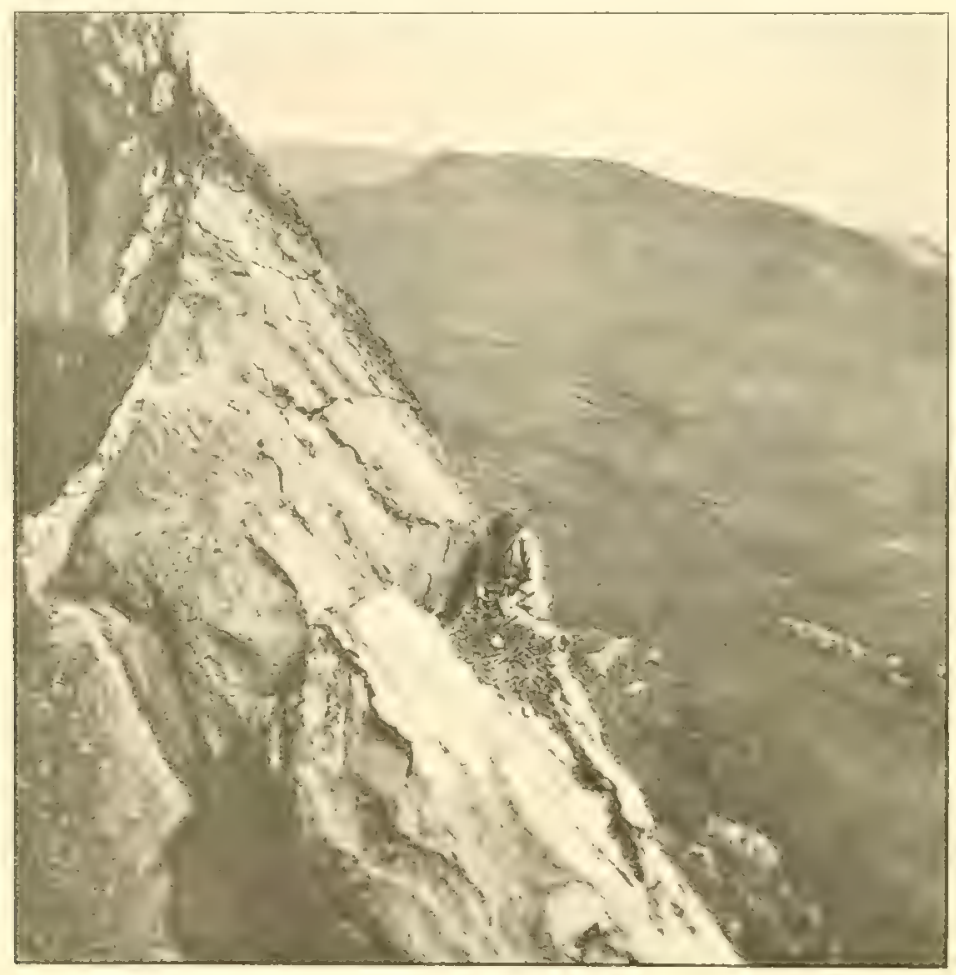

PHOTOGRAPHING A NEST.

rigid stands \&e. can be brought to bear. Such weighty and cumbrous contrivances are however entirely unsuited to mountaineering, cliff or big tree climbing.

Those whose experiences are limited to home birdsnesting or to a few castal trips abroad have frequently uresed me to adopt 
more perfect tools but to all such I retort that they have no idea what systematic birdsnesting and climbine in a wihl wnith : and On several occasions I have taken expert photographers with me

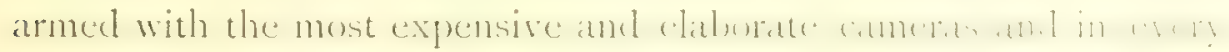

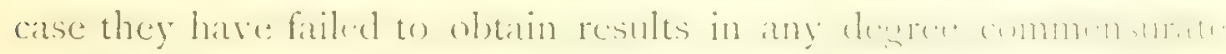
with the extra trouble involved, for they could not bring their

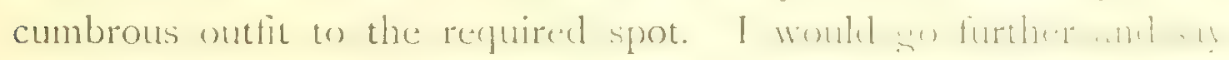
that in the class of work dealt with in this book. save in the

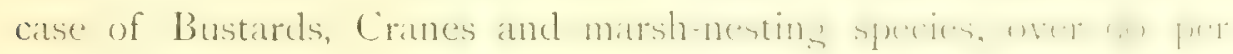
cent. of the pictures I have taken during the last fiftecn years could never have been obtained at all save by employing the very lightest and most portable forms of small hand-cameras.

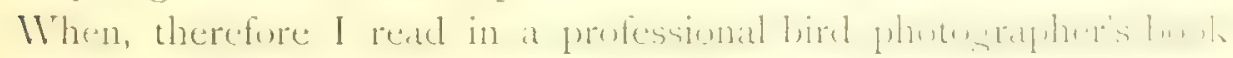
how after ten years experience he can only recall one instance where a hand-camera would have been useful, I merely bow to his superior knowledge and pursue my own way unmoved. For in very truth in my line of work it is not a question between the orthodox camera and a hand-camera, but lxewent hamb camer.t work and no work at all.

There is of course no funality in the marvellous advances in science and every year will see better lenses and more perfect appliances placed at the use of the lielel maturalist. Jiut theme

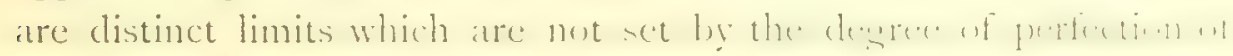

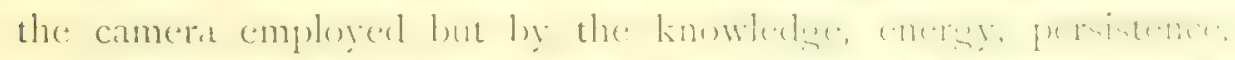

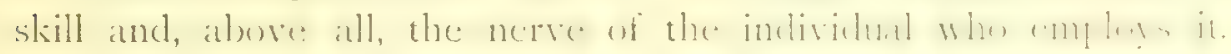
Hence, when I am told, as I often am, that no good work can be

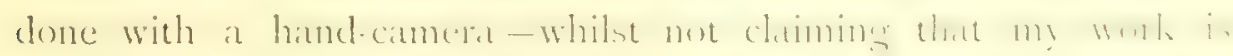
grood-I console myself with the fact that very few of those who lecture me could ever have reached the places I have pictured, burdened with the more cumbersome gear they recommend.

Now as to the cameras I employ. For six years I was content to use a simple box-camera measuring $4 \frac{1}{\mathrm{z}} \mathrm{in}$. by $5 \mathrm{in}$. by $6 \mathrm{in}$, and 
weighing I $1 \mathrm{~b} .7 \mathrm{Oz}$. or in its solid leather case, $2 \mathrm{lb}$. I $2 \mathrm{oz}$, known at first as the Blair "Bulls'-eye" and later as the Lodak "Bull's-

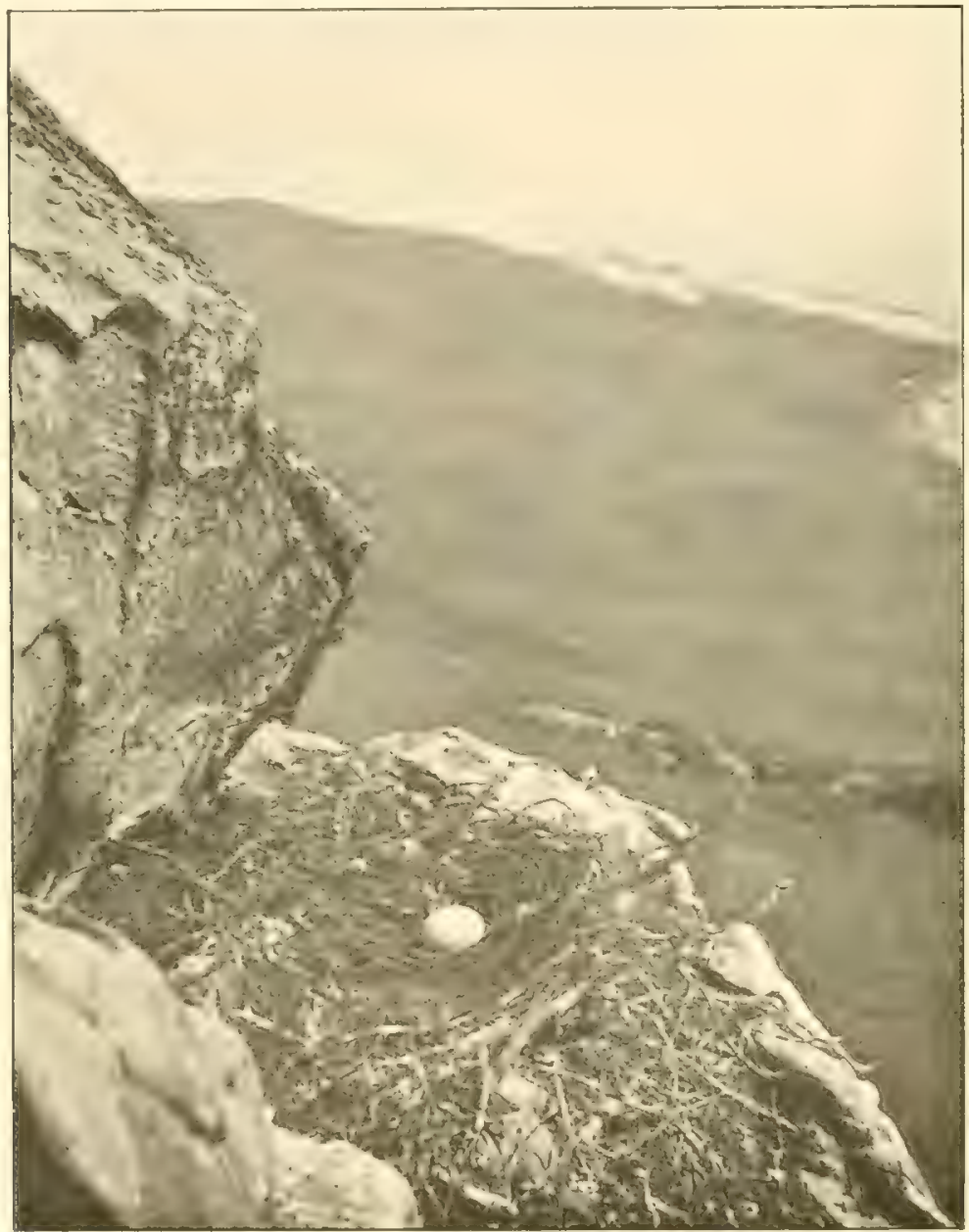

NEST OF GRIFFON VULTURE ON OPEN LEDGE.

A guick exposure.

eye" taking cartridge films of 12 exposures giving pictures of $3 ! \mathrm{in}$. by $3: \mathrm{in}$. With this I trook the photographs which illustrate Colone] Irby's "Ornithology of the Straits of Gibraltar." Owing to 


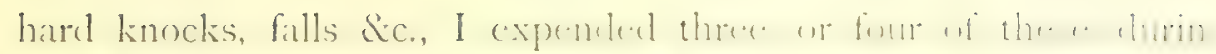

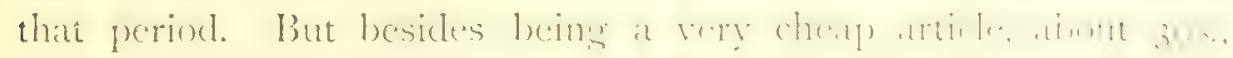
it was ill-suited to the work in hand, since its fixed focus of $9 \mathrm{ft}$. nominally, but $7 \mathrm{ft}$. in practice, made it unsuitalble for using at very

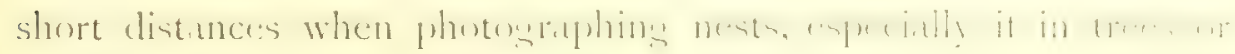
on cliffs.

My next advance was to a Kodak folding pocket-camera, No. 3.

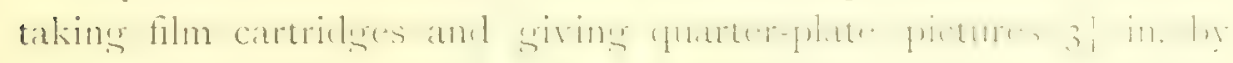
4. in. This focused from infinity down to $6 \mathrm{ft}$, a slight improvement but not enough.

I then procured another similar Kodak and, by removing the

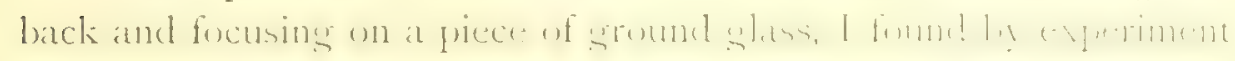
that it could be used at 5,4 , and $3 \mathrm{ft}$. distance. Then by having two small magnifiers made, one for $2 \mathrm{ft}$. and one for I ft. 6 in. to fit over the lens, I was able to work down to these close ranges.

The magnifiers I carried in the flap of the camera-case, fitted

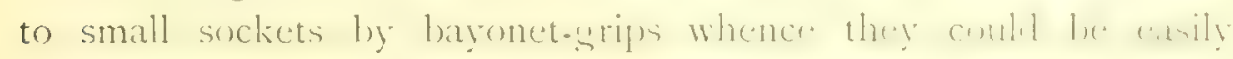
extracted when required. On several occasions owing to the difficult situations in which I was pllacel I have only hat whe hanl to work with, and it became necessary to hold the camera by the strap in my teeth whilst I fitted a magnifier. I commend the

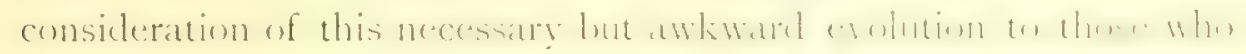
are perturbed because I decline to carry complicated cameras.

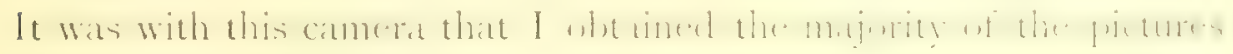
which appear in this book. It weighs I $1 \mathrm{~b} .9 \mathrm{or}$ and in its solid leather case with magnifiers $2 \mathrm{lb} .7 \mathrm{oz}$.

The camera I now employ is a Kodak No, 3 fitted with a Goerz lens and a maximum aperture of $f 6.8$ with a shutter with speeds from a second to $\frac{1}{i w i}$ second (nominally') and which focuses down to $2 \mathrm{ft}$. $6 \mathrm{in}$. Of course it is useless for birds on the wing but I am content to forego this rather than carry a more delicate camera which might fail me at the supreme moment, after an 
adventurous climb. This camera weighs I lb. I4 oz. or in its case 2 lb. $12 \mathrm{oz}$.

For six years I used the "Bull's-cye" only, then for six years I carried both it and Kodak No. 3 with magnifiers, using the first for "snap-shots" and the second for more careful work. I now carry the Kodak No. 3 and the improved pattern Kodak with Goerz lens. The object in carrying two cameras is of course primarily to ensure that if one fails, there is another to fall back upon. But

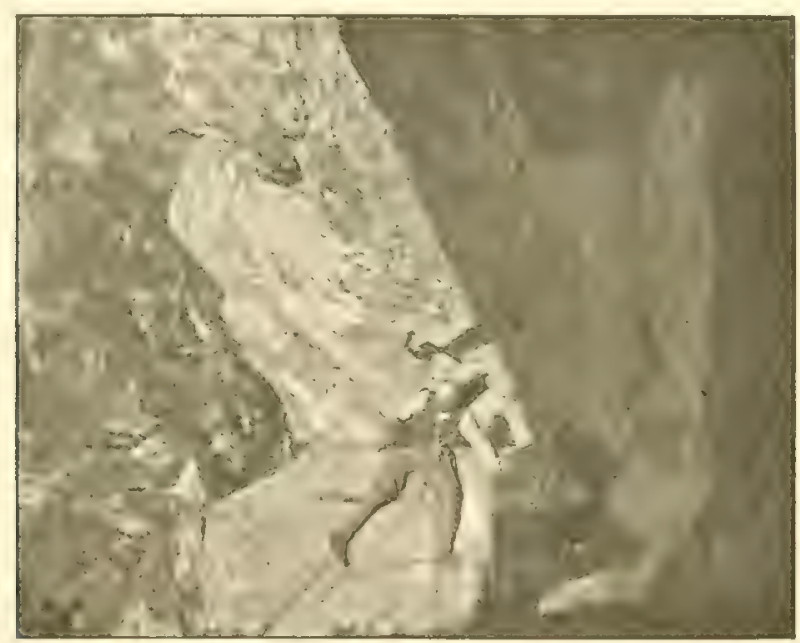

A VULTURE'S NEST IN TEEP SHADOW.

I also like having one so that, when opportunity arises, some idea of the size of a nest and its position and surroundings may be obtained by one of my friends photographing me at a nest.

As will be seen, this has very seldom been possible; whereas, in instances when it has been, there has been rarely anybody available to work the second camera. This is unfortunate, since it would have greatly added to the interest of some of the pictures, had it been possible to introduce a figure or two. Unfortunately also 


\section{Pen and Ink Sketches}

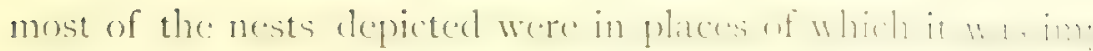

to get a general view, since they were out of sight of cverybody save the man on the spot.

For photographing nests on the ground or in marshes a camerit

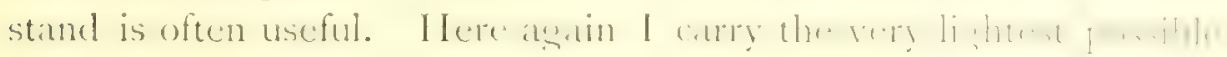
pattern and look to its rigidity of construction to minimize the vibration caused at times by the wind. Very seldom is a stand of any use in cliff work. In such places one has to be extemporized

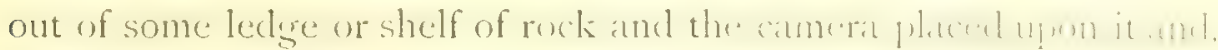

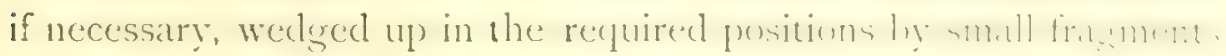

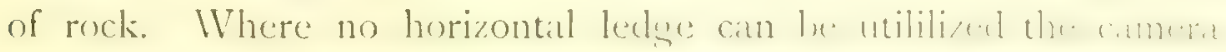

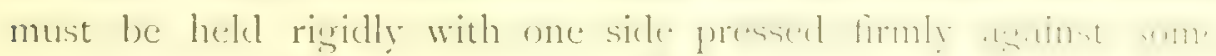

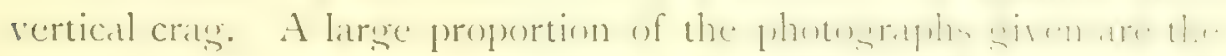

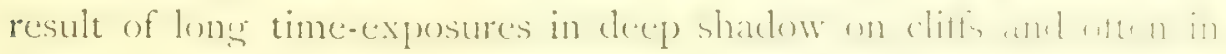
gloomy caverns and in no case was I ever able to use a stand, but had to extemporize one as described.

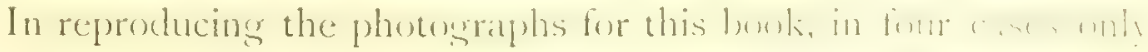

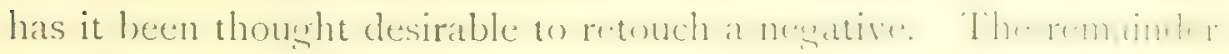
are as in their original state.

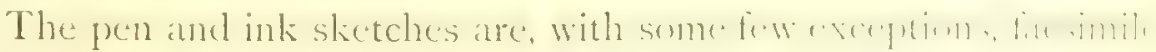
copies of the: water-colour claw whes mate ly me we the fut i win. the last thirty-three years.

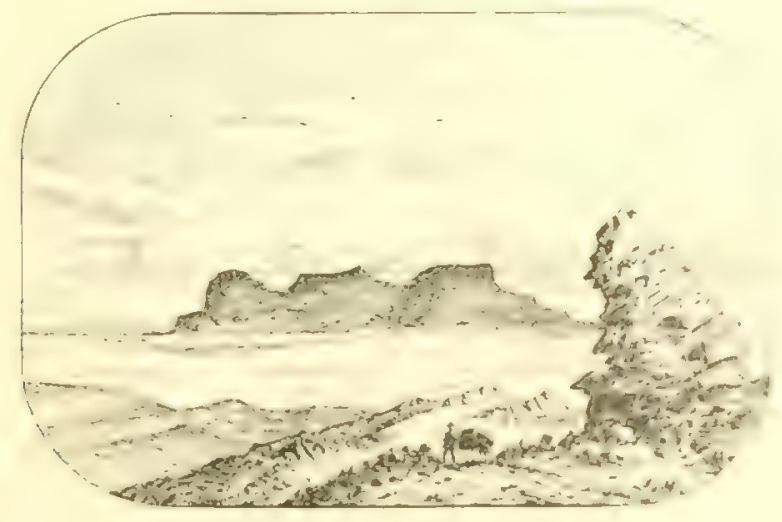




\section{CHAPTER IV. \\ ON CLIMBING IN GENERAL.}

First bird studies at Gibraltar-Climbing the Rock-The hogey of vertigo -Its cure-To the masthead in H.M.S. Simoom-Escape from liluejacketsClimb round "the back of the Rock"-A very awkward question: "Chucking out ballast"-Exploration of St. Michael's Cave, "Clincher Hole"-Descent into Europa Ravine Caverns-Subsequent Cave explorers and climbers and their fate-The "Unclimbable" fence.

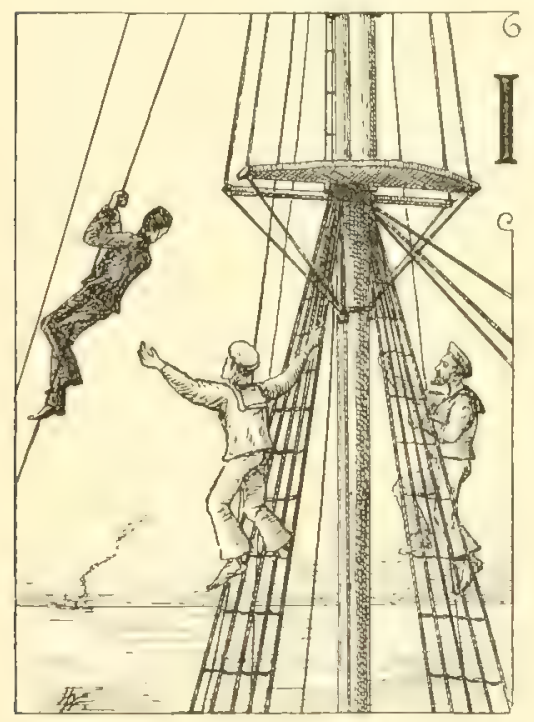

HAVE already briefly described how when I first found myself at Gibraltar in 1874 I devoted most of my time to the study of the birds of the country. During the first winter I was on the Rock I set to work to collect all the species new to me, which I skinned and preserved. Also I occupied the tedious hours when "on guard" (a recurring event at that date of every fifth or sixth day), in making water-colour drawings of birds from specimens obtained, condeavouring always to depict them in the attitudes in which I had watched them when alive. Of course with the return of spring I was ever on the look-out for nests and climbing in quest of them. And this went on during successive winters and springs on the Rock. But I did not restrict my climbing to the nesting season 


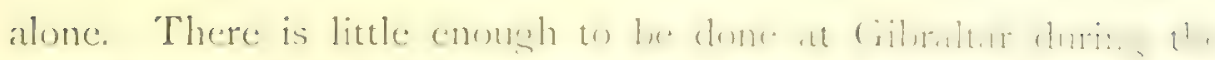

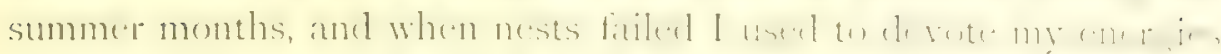

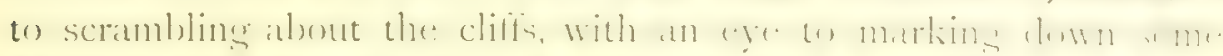

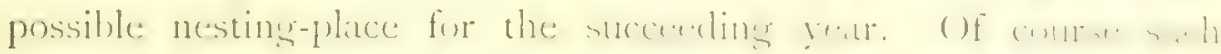
constant practice was invaluable. Several of these climbs had

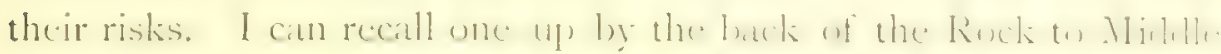
IIill laattery ats it was then styled. My motive that time wa not entirely birdsnesting. I hat reat how during the siene of 15.

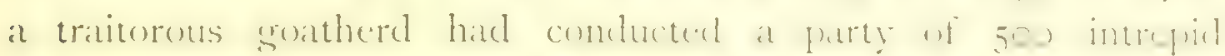

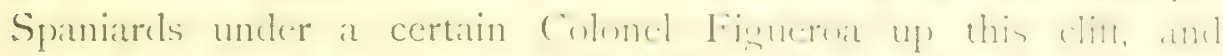
how they were attacked by the liritish soldiers at Midhile Hill and shot down, the survivers (?) being thrown aree the clifi, at fill of

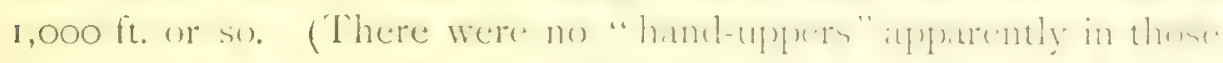
days.) I became possessed with at desire to sece for myself uhat sort of a path the gallant attackers hat taking, lut from what I then saw I am convinced that, subsecpuent wh the "restrutuble incident," the cliff must hare heen searjed and rendered mone difficult.

Like all beyinners at climbing, I hat alwaty before me the lueney

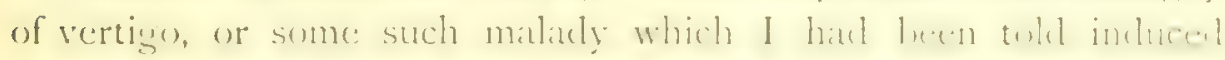
climbers, when they attained to any areat height to cant themselves down from it forthwith. Hence at first I was always a little nervous at looking down when in wery sterp and prentpitum places. Of course it was very silly and I adopted a drastic and most effectual remedy which removed such follies from ones brain once and for all.

This was going aloft at sea--there were masts and sails in

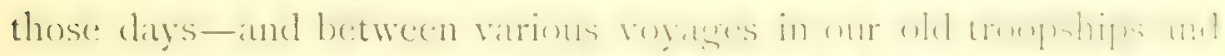

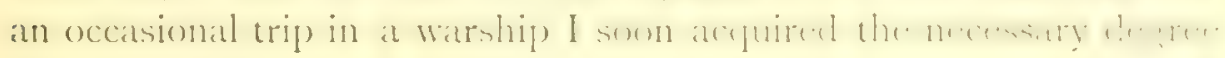
of confidence. I remember that I first went to the main-truck of a ship in the venerable old Simoom. I had taken the usual

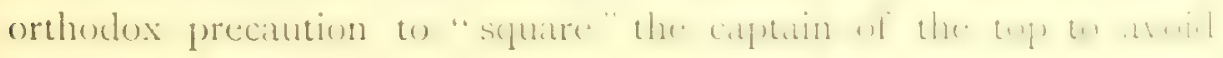


the ignominy of being lashed up and made to pay my footing in public and hied me aloft with a light heart. As I topped the futtock-shrouds I came on a couple of Bluejackets sitting in the maintop engaged in one of those inscrutable jobs in which a marlingspike figures largely and fully reckoning on the integrity of my chum the captain of the same top, I crawled up the topmast rigsing and Jacob's ladder and eventually strugseded up from the jack to the truck. It was whilst descending that on reaching the jack I suddenly became aware that I was being watched by all hands below on the crowded forecastle where the soldiers, seasick and otherwise, were massed, presenting a sea of faces. Glancing immediately below me (I had avoided cloing so before by reason of the old tale of vertigo), I spied the Bluejackets just below the topmast crosstrees one on each side of the topmast shrouds obviously waiting to catch me! I felt that explanation might fail and would in any case be derogatory, so I looked round for a means of escape and, spying a topgallant backstay, swung myself on to it and descended to the deck much faster than I liked or intended, landing safely amid the cheers of the soldiers.

But my glory was dearly purchased. In those days (and perhaps now) the sailorman had a hideous habit of "dressing" all the standing rigging with an evil compound of grease and Stockholm tar as a preservative. In my atrial descent I had yripped the backstay tightly with one leg hitched round it. Needless to explain that my immaculate and much be-laced and be-braided Rifleman's patrol-jacket was smeared from chest to hip with the black grease as were my overalls. But I never advertised my misfortunc and soothed myself with the congratulations I received especially from the faithless captain of the top.

To return to the Rock. During my stay there I made various attempts to climb up from the sandy slope above Catalan Ialy to the well-known nest of Bonelli's Eagle, which has afforded an object of interest to so many visitors to the Signal Station. 
In this I was unsuccessful. Curiously enough the climb, which is spoken of even now, was one which, at the time, neither I nor my companions considered of any importance. I had long cast covetous eyes on the Osprey's nest at the back of the Rock. It was in a bad situation and inaccessible save with a rope. Accord-

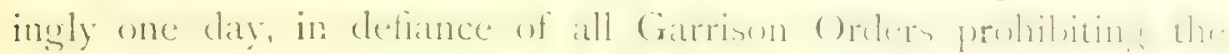
molestation of wild birds on the Rock, and acompunted he a natrel

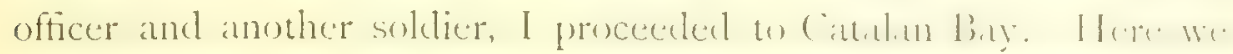
lunched with the I etachment officer and afterwarks started on ont

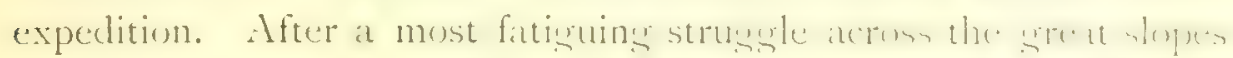

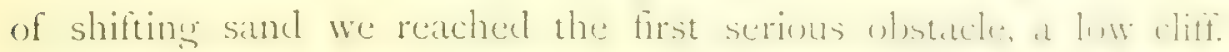
Skirmishing on aheal, I picked ont a praticable line amel we set to work to sidle alenes the narrow terraces, at times mo rory hidh up and at others several hemeleds of feet above the sete . Imonel above the Osprey's nest, we found a naty sloping terrice of low stones which made it dangerous for two men to lower at thirl, ath our rope was totally inadequate for such a purpose. My companions refused to lower me over, and I am not ashamed to saly I inwarelly rejoiced. for it would hate becu perfectly foulharly to attempt it in the circumstances.

Many years afterwards, I revisited the same spot but with proper appliances and, despite: all ordeds to the ontrory, tomk the eggs! That very night I chanced to be dining at the table of

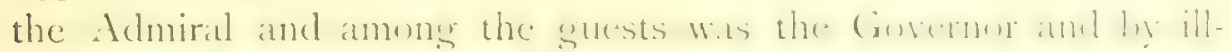

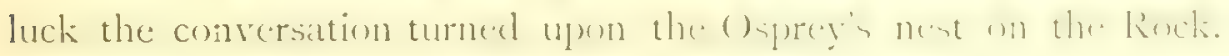
Somebody remarked that no man could get at it and I was

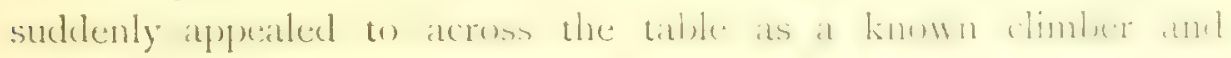
expert. To make thines morse, some of my sulte atomplice.

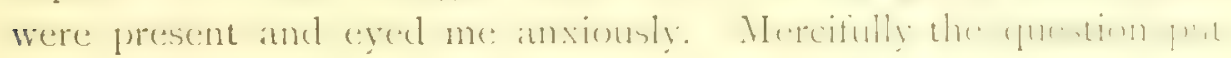
to me was whether I thought it was possible for anybody to take the Osprey's eggs? All eyes were turned on me, as with

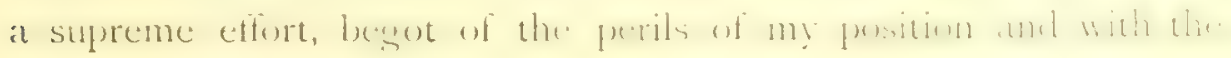


thought of those two lovely eggs still unblown locked up in my dressing-case, I replied "No. Sir, I feel sure that anybody who tries to take them will fail." I attribute my good fortune in thus extricating myself and my confederates from what might have been a most umpleasant position entirely to a prolonged study of how British Midshipmen in defence of themselves and their privilegres parry inconvenient questions on the part of the Commander.

But to return to our climb. When it was voted that the projected raid was not good enough, somebody suggested "Why go back? Let's go on!" "The very originality of the idea was prepossessing. For if one thing was more certain than another in the traditions of the old Rock, it was that owing to the difficulties and obstacles due to natural causes, supplemented by the dilettante hand of the Royal Engineer, nobody could climb round the back of the Rock. At this period, no tradition, let alone record, existed of its having been accomplished and within the preceding few years several attempts had been made and had incontinently failed. An especially gruesome one was fresh in all our memories. Two Bluejackets who had landed from a warship in harbour, with the usual crowd of "liberty men," had broken their leave and not returned. Some days later one was retrieved by the picket after a protracted jollification on shore. His comrade was still however absent and when questioned as to his whereabouts, he could only remember that they had started together to climb around the Rock, but that, not liking the job, he had turned back and gone in for a little amusement in the town. The clue thus given was followed up and the unfortunate missing sailor was found lying on a terrace with some bones broken. Here he had been for some days, needless to saly he did not survive his injuries. Such was the cheering precedent for our climb.

After leaving the Osprey's terrace, I struck well up the cliff and hitting on a grood leclye worked along it very steadily 
my companions following. After a time I fancied I heard at cry and glancing behind me found I was alone! It was an anxious moment, and all sorts of horrors obtruded themselves

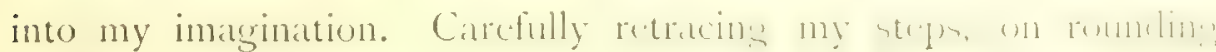

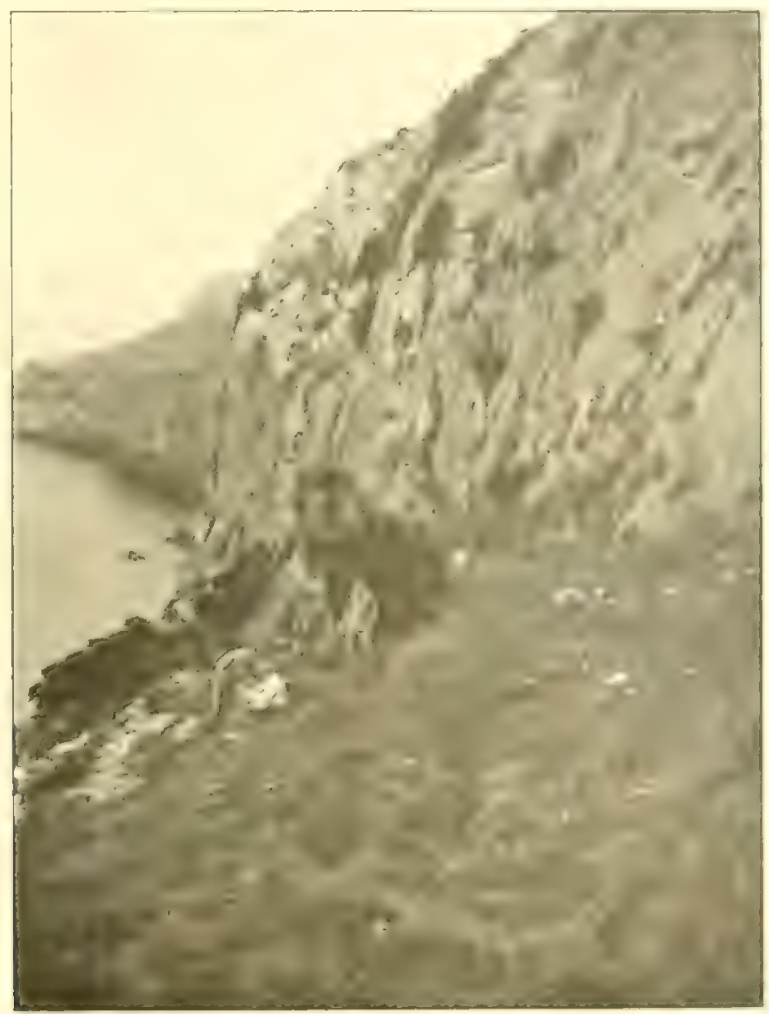

TIIE IB.AK OF TIIE ROCK.

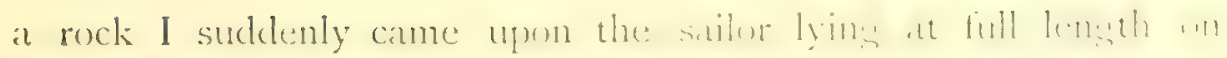
an extremely narrow ledge, violently sick! 'The soldier who

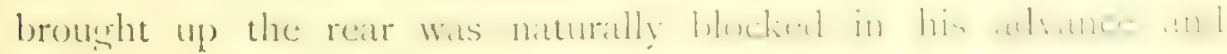
he it was whose shout I had heard. In reply to my anxious enquiries, the sick matu checrfully replial that he w... 
chucking out ballast"! To this day I have never been able to make up my mind whether it was the hot sun, the giddy height or the heary luncheon which had so alarming an effect on him.

He was soon in commission again and resumed his station and we went on. At places it became necessary to change from one terrace to another, perhaps 20 to $25 \mathrm{ft}$. below. This we effected by means of our rope, the last man coming down on the two parts of the rope hitched around some crag or palmetto bush, after which we overhauled it and proceeded on our way. It was very exciting work especially when it became a moral certainty that by no possible means could we retrace our steps! Eventually we reached the terrace above the Monkeys' Cave, near the Governor's Cottage, whence we soon made our escape and were once ayain treading the habitable portion of the Rock.

Like all such adrentures, the excitement and fun were due to the delightful possibilities of our getting into an impossible place, but fortune favoured us.

Another totally distinct class of climbing at this time was the exploration of some of the immense limestone caverns with which the Rock is in places honeycombed. This afforded great scope for rope-work and climbing. The first we tackled was the famous St. Michael's Cave, which according to tradition communicated with Africa below the Straits and formed the "Channel Tumnel" for the "Rock monkeys" (Barbary apes). My companion in this was Lieutenant Alfred Carpenter, R.N. (now Captain retired). With the and of some Bluejackets armed with ropes and a good supply of boat's lead-lines we reached the bottom or rather bottoms of the cave coming to pools of clear fresh water in every case. The last 20: ft. of the descent was down a chimneylike fissure in the limestone. At one point this narrowed so much that only the smallest of the party could get down it. 
Carpenter and myself and one other got through. The Bluejackets named it "Clincher Hole." It is interesting to record that upon reaching the bottom we found we were by no means the first who had done so, for on the limestonc roof above us

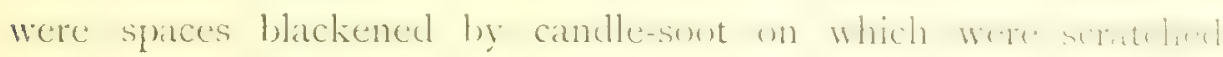
the names of officers and dates, some going back to Crimean days! In the absolute stillness and dryness of these depths these old records seemed as fresh as the day they had been scratched with the broken stalactites, which lay about w, wn the floor. My companion who was a scientific officer in the Hydro-

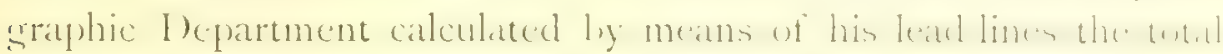
depth of the cavern from entrance to the pools of water to be $500 \mathrm{ft}$. or roughly $500 \mathrm{ft}$. above sea-level. 'The air was quite fresh and the only danger lay in the risk of our return passage being blocked by sliding débris from above.

Another famous cave I explored, with a party of the 7 Ist Highland Light Infantry was the one in the Lumplan Rume below the Chief Justice's House, known as Glenrocky. 'l'his cavern is the one where the reputed skeleton of prehistoric man was discovered. It is a marvellous place, and, being the light man of the party as well as the pionecer, I went in a bumline throush the hole in the "ceiling" and sained "the lowest stury" out of the three series of caverns we explored.

At this time my brother officers with one exception did

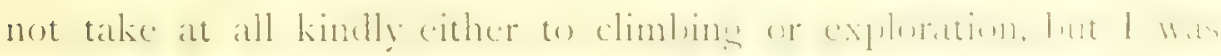
never at a loss to obtain good recruits from the Navy or 7 Ist Highland Light Infantry.

In the spring of I8so I left the Rock for our I)epot at Winchester. Not long after, I heard how the fashion I had set

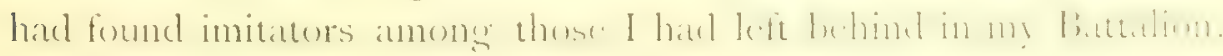
One party elected to explore St. Michacl's Cave with almost

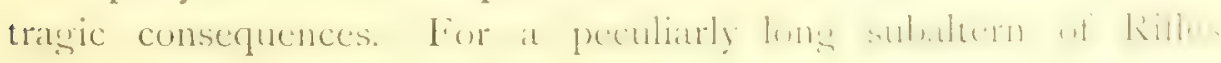


succeeded in becoming jambed in "Clincher Hole." In his case, it was not owing to extra width of shoulder or depth of chest as in that of the British bluejackets who had been unable to pass through it, and I imagine his sticking was more of the nature of a fish-bone across the gullet type. Anyway he became fixed, to the consternation of those below him who thus saw their retreat cut off. The tale goes that at one time it was under consideration to sacrifice him for the good of the majority and remove him piecemeal. Happily, he was eventually dragged out.

Equally bad luck attended another party of my brother subalterns who with more pluck than knowledge and less skill than cither gallantly attempted a climb up the back of the Rock, with disastrous results, for they finally got to the spot which somehow is always found by unskilled climbers, where they could not go on and dared not go back! Luckily their plight was noticed from the Signal Station and the alarm was given. After the inevitable report to the Town Major and his myrmidons, the services of the Royal Artillery and Enginecrs were invoked, ropes were procured and the luckless youths extricated from their predicament. It was after this that the Governor rose in his wrath and a Garrison Order was issued forbidding officers to climb the Rock.

But all this happened long ago. When in a sudden access of hysteric caution following on years of "go as you please" all the upper portion of the Rock was enclosed by a high spiked iron paling, some unimaginative official had the fatuity to style it officially "The Unclimbable Fence," and numerous Orders were drafted with respect to it in which it was thus described. It is hard to imagine a more direct challenge to a man addicted to climbing. At this psychological moment I chanced to land at Gibraltar on leave from England. I climbed that fonce, not for pleasure or for vanity, but as a matter of duty to the confraternity 
of birdsnesters. My "crime" was never taken judicial notice of, and here I was happier than the lucklens privale soldier, whe met

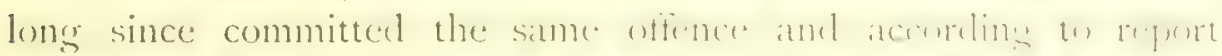
wats charged with "Neglecting to siley Fortress ()relers, in that he, at Gibraltar, on April I, 190-, contrary to the Fortress Order directing all persons to abstain from doing we timind tha Unclimbable Fence!"

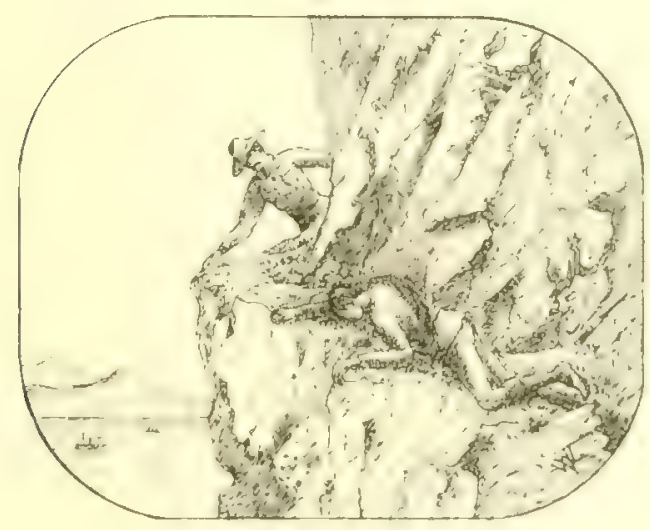




\section{CHAPTER V.}

\section{TREE CLIMBING.}

A classic example-Tom Brown's sound advice-The four requisites for a good tree climber-Swarming up branchless trees--Worling along spreading, horizontal or pendent boughs-A famous Raven's tree-An awkward climb-The " $S$ " and its difficulties-Reach the nest-Trees too large to swarm up--Value of pendent boughs in some cases-Tree climbing with ropes-Use of light casting-line and lead-How to get a rope over a high bough-Ascending with the aid of a rope-Arrival at branchesTransition from rope work to climbing-Extra large trees-Climbing by

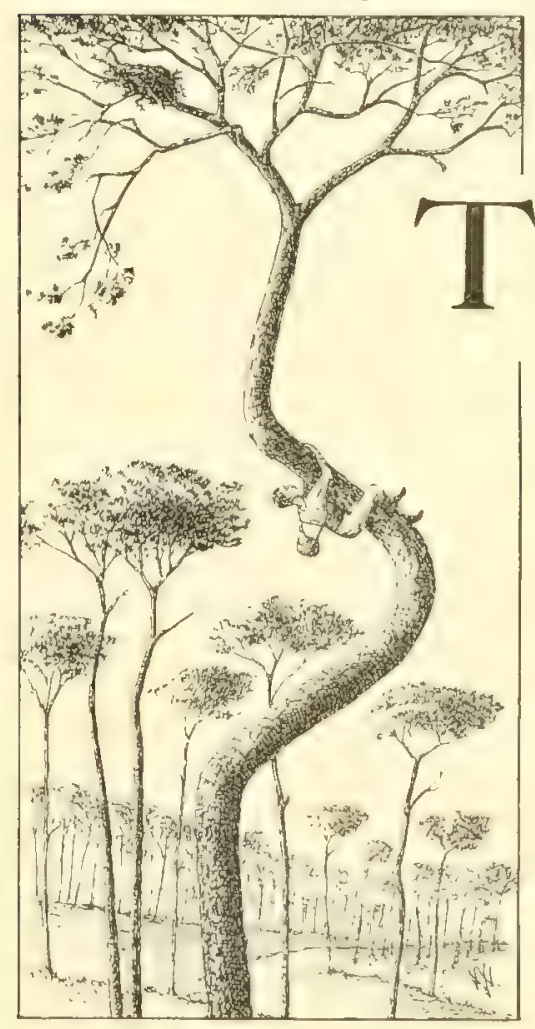
successive stages with rope-Climbing irons-A nasty accident-Irons and rope an ideal plan-Dress for tree climbing -Uses of light line and fishing creel.

HE art of tree climbing, for art it is, exists in an embryonic form in most schoolboys. Most lads however discontinue the practice just at the age when they are developing strength and skill enough to become fair climbers. No better advice for the youthful climber can. be found than in "Tom Brown's School Days" and the famous story of the Kestrel's nest in the tall fir in Caldecott's spinney has given inspiration to many a lad, whilst all through my life, whenever I have attained the "decisive point" in a big tree and felt sure of the nest, I 


\section{Tom Brown's Sound Advice}

have mentally ejaculated with soud laast ". IIl up with the wh Magpie now." Tom's precept, "You can't hurt if you get a good hand-hold. Try every branch with a good pull before you trust it and then up you go!" is unequalled in our langruage. To this I would add "Always get a hand-hold and frot-hold as near as possible the the trunk or branch you may le on." By keeping these two rules in mind I have comne with when out of many hundreds of awkward and dangerous trees. To

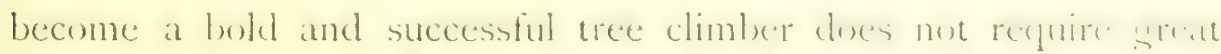
bodily strength, else I shoukl have never climbed at all, nor dene, it require powerful muscles. Wha is wanted is quickness, mility, ready resource and good nerve. The first three enable a man to work his way up many a tree which would defeat the mere symmast whereas the last prevents him from being detered hy possible dangers, and, above all, when he does get into troulde. helps him out of it.

When trees are not too large to swarm up or have branches enough to help the climber on his way, no accesories in the way of ropes or irons are wanted and I propesse 1 deal with this, the normal sort of tree climbing, first. The main obutacte te all tree climbing is the difficulty of surmounting the portion of the tree without branches. This exists in its most trying form in his fir trees and larches and here the gymnast is at an advintege. liar many years I used to swarm up lofty fir trees after Ravens' or Kites' or Carrion Crows' nests, many of them branchlens for in w $40 \mathrm{ft}$. The labour however is excessive and if many trees of such at type have to be visited in one clay, it is the letter th hate recourse to ropes, of which more hereafter.

When you have arrived among the hranches, the mature of the

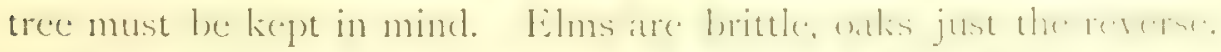
In fir trees rotten branches should be removed durime the and at: not uncommonly they atre rotten at the print of junction with the 
bole and give way suddenly. A good rule is never to trust a branch in a fir unless some green spines are to be seen growing on some portion of it. Where nests are placed away from the main trunk, some care is necessary. In case of most deciduous trees, such as oak, clm or becch, the branches where nests are usually placed rarely slope more than 45 degrees or so. In working up such places a very secure hand-hold is necessary as it may easily happen that the climber slips round under the bough. If this occurs, it is generally best to continue the climb along the underside until some branches are reached which make the process of righting oneself easy cnough. In fir trees, on the other hand, a nest is often placed on a bough of which the slope is anything between 45 degrees and the hurizontal. The former requires care and is best tacklecl by swarming along it; when a branch is horizontal, or nearly so, provided it is big enough, it may be better to sit astride and work out along it, as on a valuting horse. Where a bough actually dips downwards, always turn round and face the tree and slip down it.

The preceding are all taken from examples of climbs I have made. Quite the worst and most alarming of my climbs of this description was after a Raven's nest. This was in a tall fir tree which was popularly supposed to be unclimbable, close to the Duke of Kent's Farm near Gibraltar.

One evening at our Mess the conversation turned as to whether it was possible to get at this nest and in the course of it, it transpired that two subalterns had on that very day attempted it and had failed. One of them was an exceptionally powerful man. Both were given to scientific observation and they measured the height of the tree by means of its shadow as being $72 \mathrm{ft}$. As a proof of the impracticable nature of this particular tree they described how two Spanish herds who had joined them had alike been defeated in the attempt to scale it. Later on that same 
night, my particular birdsnesting ally and compuninon burn: me first five years in Spain, Harry James Fergusson, came to my quarters and propounded a scheme for taking the nest on the following day. I demurred, as I had not properly watched the

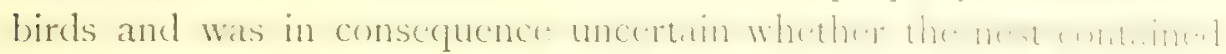

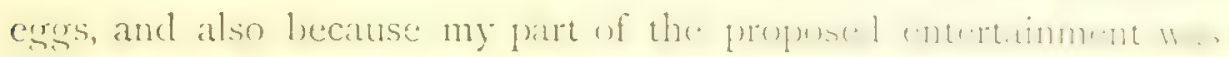
to climb the tree whereas his was to get the inevitable "risc" out of the others by subecpuently in the arent if my ancourling. pretending that we had failed. He was however at wilful man. and met all my objections by atssurances that he linew I walle ith it, if only I tried.

So next morning salw us walleping out alung the beach to the "First River" and onward. Arrived at the tree-a dead fir about

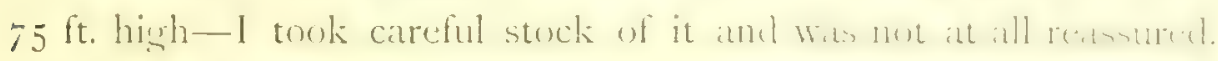
For $20 \mathrm{ft}$. it was just prossible to swam the trunk, after whin it bifurcated and was casy encught the purtion in which the me whes

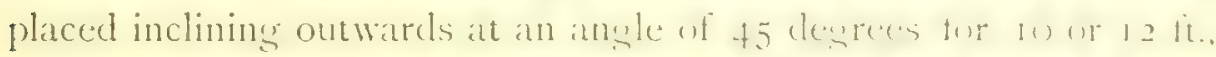

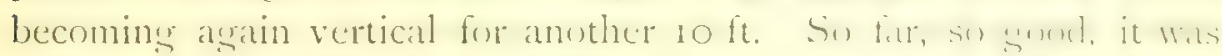

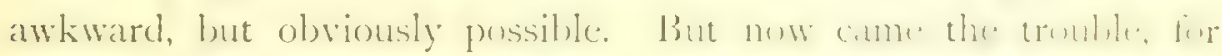
in the course of the next $20 \mathrm{ft}$. the tree-stem emulated a cork-screw

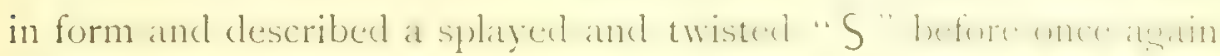

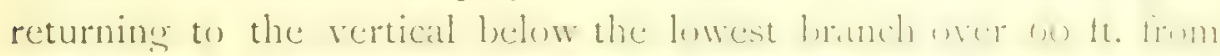
the ground. The steetch at the commencement of this chapuer is from one drawn at the time of our visit, and gives at betere delest of the awkwardness of the situation than dexs me dencripuino. It wats obviously fatirly simple to swarm up the tail of the S lut at the lower curve of it the trunk bulged ene it wak the hathwarl warn. The shape of the tree was however by no means the greatest obstacle to reaching the nest, for the hir trese, as 1 saw at a chane.

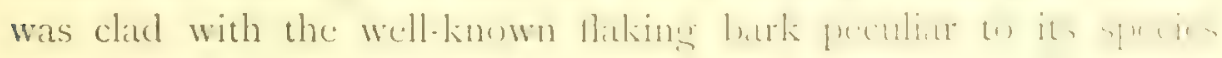
which made it extremely slippery if me changeroms. I hane a

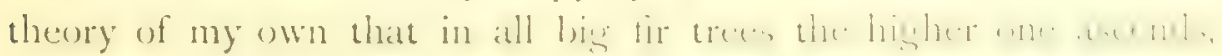


the more slippery do the branches become, at any rate they always feel so. Possibly this may be due to these upper branches being more exposed to the heat of the sun's rays than are the lower ones.

Now to the climb. I managed to tackle the first io ft. or so by mounting on Fergusson's broad shoulders, after which the trunk became more climbable. It was a stiff and slippery swarm, but all went well until I reached the lower bend of the $S$. At this point, as I was cautiously hauling myself over the hump and round the "corkscrew" portion, the treacherous bark slid in my grasp and so did I, swinging round under the bough. I held on like grim death, with fingers interlaced and legs twisted around it. It was horribly uncomfortable thus hanging back downwards with $50 \mathrm{ft}$. clear to the ground below and for a moment I was puzzled what to do next short of sliding back ignominiously. It was clearly impossible to regain the upper side of the slippery trunk so I made the best of a bad job and swarmed up along the lower side and was not a little relieved when I found myself at a vertical portion once again where I could regain my seat, so to speak, on the slanting part immediately below it. A few feet more and I gained the friendly spreading boughs near the nest. The latter contained five young Ravens. I am not ashamed to say that I did not embark on the return journey till I felt I had thoroughly recovered from my misadventure As so often happens, the return proved to be comparatively easy. It is superfluous to go into details of how at dinner that evening, our brother officers were cautiously led on to understand that we had found the tree to be too much for us and how, at the psychological moment, they were permitted by my aggravating comrade to become aware of the truth. But after all such victories are too dearly purchased and it took me some time before I felt anxious to tackle awkward fir trees. Of one thing I am well assured, namely that the Ravens in selecting this particular tree were perfectly aware of the difficulties it presented to the 
climber. For there were scores of other trees all round it some

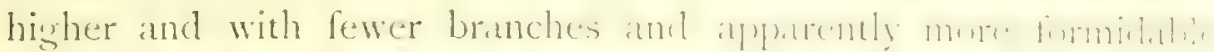

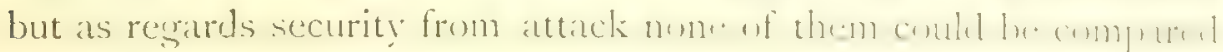
to the one the Ravens had built in.

There are very few large trees which cannot be climbecl with

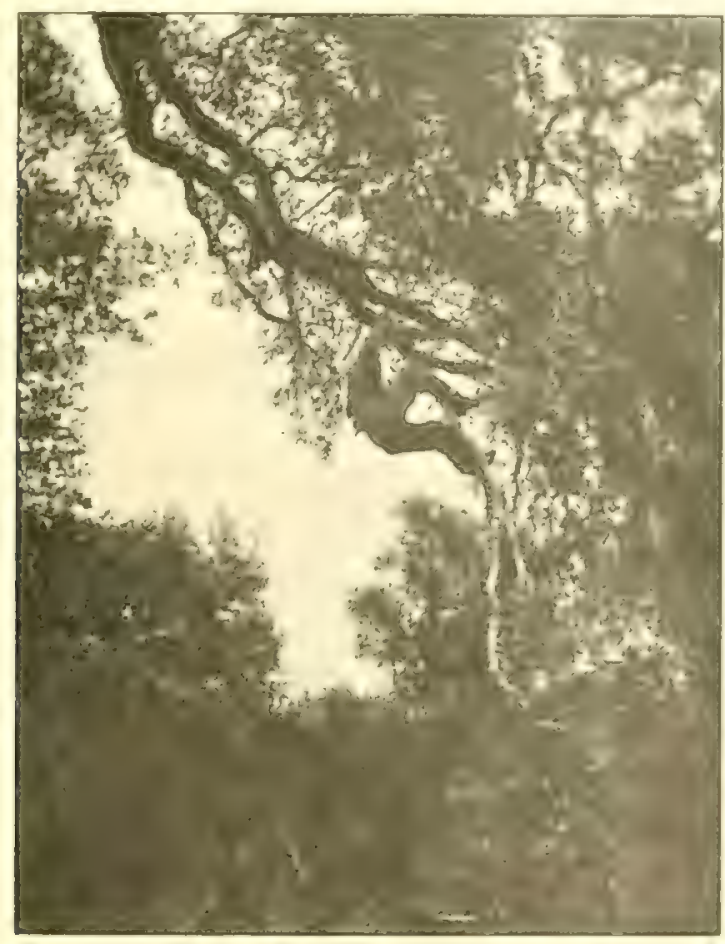

CLIMEING A BIG SPANISH OAK TRFI BY THE AID OF A IENIMNT HOUGIT.

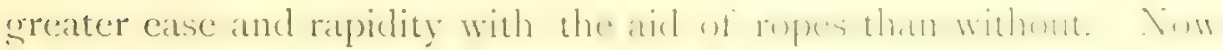

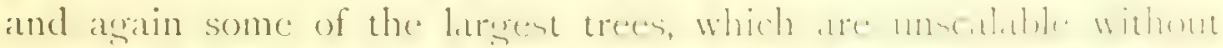

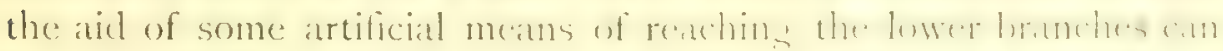

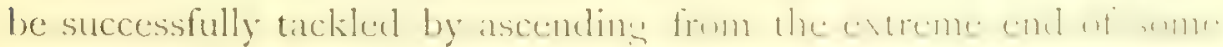

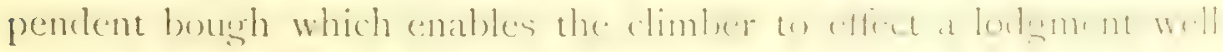

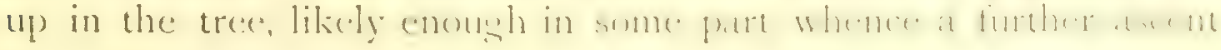
is an casy matter. 
I have visited several nests in very lofty trees by this means; ustally the only trouble is at the start but if the branch bears the strain then it may be reckoned on as a safe one throughout, and it naturally gets stronger every foot one swarms up it. A branch of this sort is climbed in a similar fashion to a rope but is, as a rule, easier.

When no such accidental advantage can be utilized, recourse must be had to ropes. For tree-climbing nothing can equal $1 \frac{1}{2}$ in. manila rope. It is pliable and "renders" well over a bough and its lightness enables it to be cast upward and over a bough at some height above the ground. One hundred fect of manila will do for most trees as it will serve to sway up a climber $45 \mathrm{ft}$., allowing Io $\mathrm{ft}$. spare for the bowline and the portion in the hands of the assistants.

But a $I_{2}^{1}$-inch rope cannot be cast over a branch $45 \mathrm{ft}$. overhead or in fact at anything approaching that height. For this purpose a light line is wanted, a deep-sea fishing-line of the pattern known in our Navy as a mackerel-line is as good as any. To the end of this should be attached a leaden weight of suitable size and form. After many experiments I have found a disc measuring about 23 in. in diameter and with an axis of $: 3$ in. bevelled off to $\frac{1}{4}$ in. round the circumference by far the most suitable for "shying." Its weight is $\mathrm{I}$ oz. A picture of this appears at the end of this chapter.

By coiling the line neatly in the left hand, with a few spare coils on the ground beside one, this leaden disc can be thrown up a considerable height. When it has been cast over the bough required, the line is jerlied until the weight overhauls the line and runs down. The weight is then removed, and the line made fast to the $1 \frac{1}{3}$ inch rope by means of a rolling-bend or a clove-hitch about a foot or so from its end, great care being taken to make a half hitch close to the point of the rope. 
This is very important, else when hatung up the line the rope may get caught, especially as it passes over the bough. The rope having been overhauled, the climber gets into a bowline (or a bowline-on-a-bight) or if the tree be very big and awkward, into a canvas sling, and is hauled up.

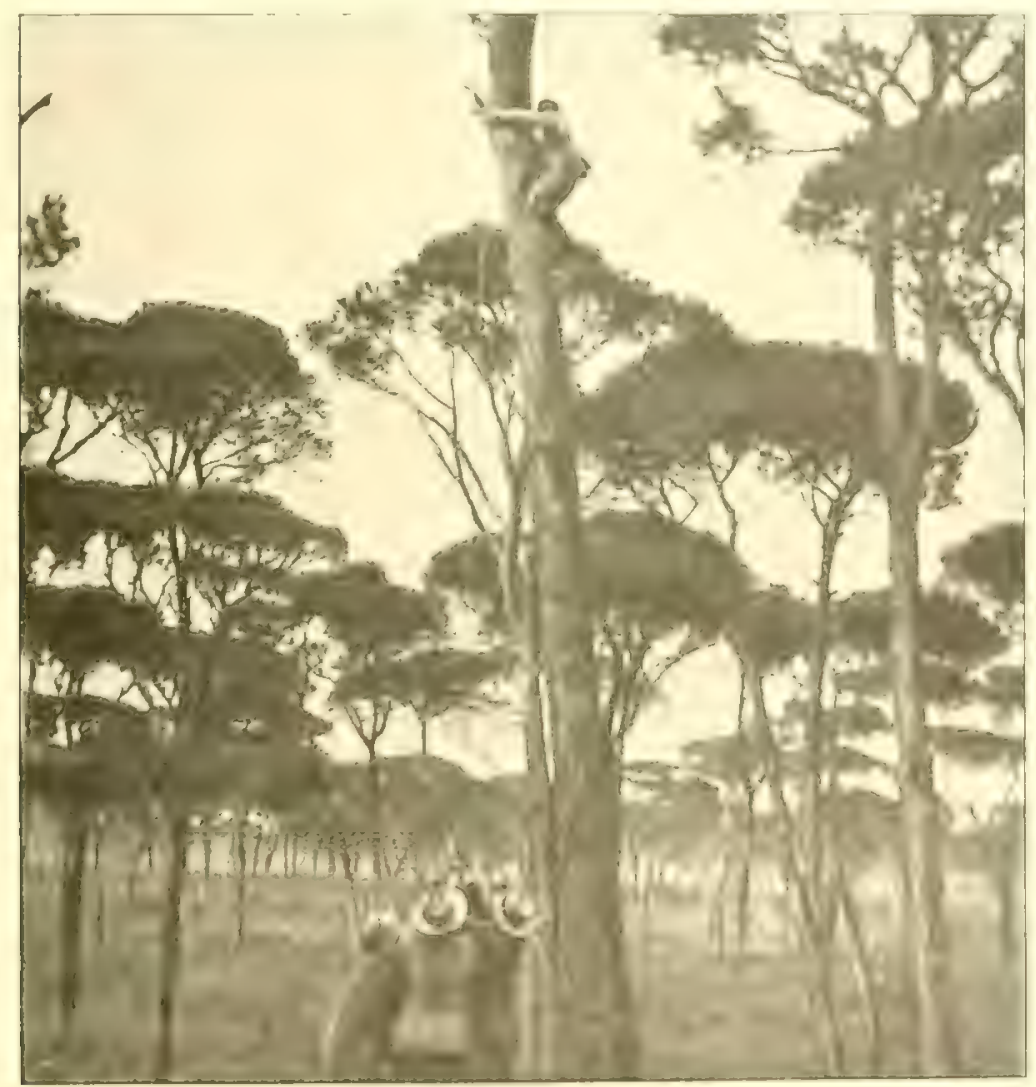

CLIMBLSG A TALL FIR TRFE WITH THE AII) OH A ROPE.

During the ascent he should do all he can to "lighten-up" his weight. As soon as the tree becomes small cnough for him to

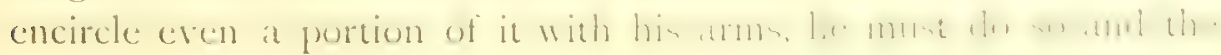


hauling-up party should watch him and second every movement he makes by a judicious pull. It is wonderful how easily and rapidly a skilful climber can thus ascend a tree.

I attach sreat importance to the climber thus seconding the efforts of the assistants, for by doing so he reduces the friction of the rope over the bough above and thereby minimizes any risks of a mishap. For by adopting such means not only does he get a good hold of the tree, should the rope part, but by reducing the friction and consequent strain, the rope is not nearly so highly tried. In the preceding picture a 12 -stone man is being run up a fir tree by three others weighing between them some 38 st.

The fir tree in this instance was about $60 \mathrm{ft}$. high and the lowest sound bough over which the rope was hove was $35 \mathrm{ft}$. from the ground. A much weathered and somewhat rotten stump on the opposite side of the tree to the climber affords a welcome rest to a man climbing without a rope, as I can speak from experience, having ascended it in 1878 and in 1879 . This photograph was taken in 1903 .

It requires little science or knowledge of the strains on ropes to understand that if the I 2 -stone man elected to hang like a sack of beef and left the 38 -stone weight to haul on him with all their united strength, a rope which fouled up above might break.

When the climber arrives at the bough, he must get a secure hand-hold and those below must quickly ease up rope enough (say 2 or $3 \mathrm{ft}$.) to enable him to swing himself on to the branch and come to a rest.

At this period of the struggle, it is advisable for all hands to take a rest. I invariably do so and repeat to myself the formula, "All up with the old Magpie now," or words to that effect.

Sometimes the transition from rope work to climbing involves some difficulties and risk, since the bough may itself be too big to afford a secure hand-hold. Hence it is most desirable, when 


\section{Ascending very Big Trees}

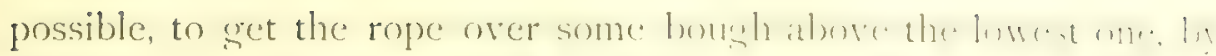
which means a man can be heisted right on to the Inwene It this cannot be done, the party belew must hatndle the repue ancoly at the instant the climber mounts on to the top of the lenehth, for an carelessness at this juncture might resule in him heing pullent w.

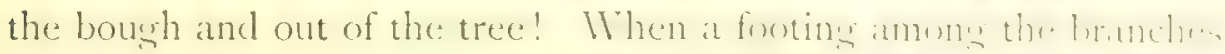
has been secured, the bowline (or sling) should be remowed and made fast to a bough and the ascent continued in the melinem way. But in a big tree, especially a huge oak or cork tree, it may happen that the final victory is ly no means asianed when the first bough is reached. For between it and the next one alwere there may be many feet of thick trunk, utterly unscilalule. Xow comes the opportunity for the man who is accustumed to work at heights and who, further, is skifful in the: homolling of rengen. for, after hauling up and making a coil of whut he: may recpuire. he makes a cast with the rope over the next bough above and either swarms up with the alid of the hand-hold thus arfinded, loy holding the two pieces of the rope, or, in more awkwarel situations, drops the fall of the rope to his commentes betow and malke; himelt fast to the hoist and repeats the operations alrealy dencribed. Sometimes it may be necessiry to do this several timus hefore. the tree diminishes in size enough for the climber to proceed by ordinary methods. The uninitiated may imanime that snch a procen

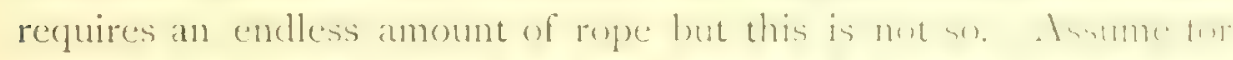
example that the climber has been heisted to a consengient luneh $40 \mathrm{ft}$. up. This repuires about $90 \mathrm{ft}$. out of the humiterd atailathe. He now sees that until he has ascended ammither in th. he common do without a rope and that half-way up, say $15 \mathrm{ft}$, alwowe him, there is another sood boush. To reach this nest stage hut sin it. i.

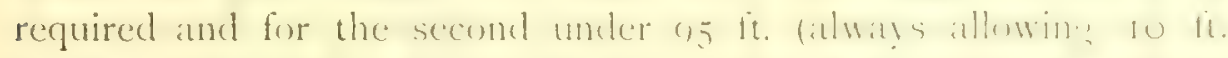

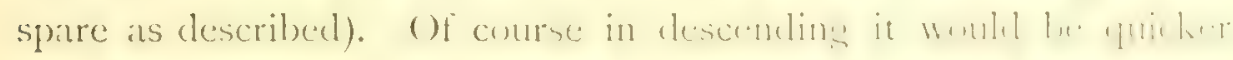
were he to be provided with $150 \mathrm{ft}$. and thus come down in one 
movement, but in practice the operation of stopping when half-way down and hauling up the rope and dropping it over an adjacent bough involves but little trouble. I have met with occasions when it was more convenient to throw the line and lead weight over a bough than the rope itself. When this is clone, the same process is repeated as at the first start and the rope is subsequently hauled up. Frequently in emergencies a small length of rope used as a life-line is of great assistance and for this I usually carry $20 \mathrm{ft}$. of silk rope.

Very likely some may have been surprised that I have hitherto made no mention of climbing irons. The reason is because I have for many years strongly discountenanced their use, save as an adjunct to climbing with a rope. I used them myself until i $S ; 6$. It was then that I first met with Lord I.ifford and it was owing to him that I gave them up. For he described to me how he knew of an unfortunate man who, having climberl a tall tree with the aid of irons, lost his hand-hold and fell backwards. His life was saved by the cause of his disaster, for one iron was so deeply set in that it held. But he hung head downwards with his weight on his dislocated ankle! To assist him by climbing to him was impossible. Fortunately the accident occurred in a civilized country where it was possible to fetch a lacleter and by this means he was rescued.

At the time of my meeting with Lord Lilford I was constantly riding alone into wild spots in Spain, picketing my horse and climbing big trees. After hearng the story I came to the conclusion that it was tempting P'rovidence to continue to use irons in a country where, if one came to grief, the chances were against being found and where, moreover, ladders did not exist.

For over twenty years subsequently I would have nothing to do with them; meanwhile, in $18 S 2$ I had taken to using ropes in trees, but it was not till 1898 that I once again became a 
possessor of a pair of climbing irons. I was at this time at the

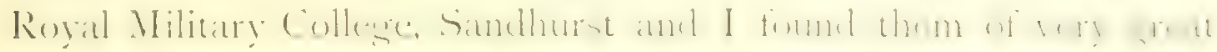

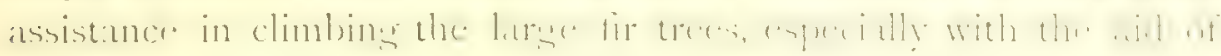
a rope. In fact, a combination of ropes and climbing irons reduces the risk and labour of fir-tree climbs to a minimum. 'They can be

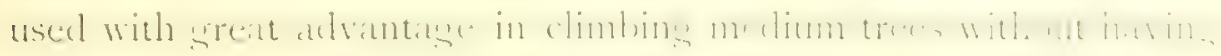

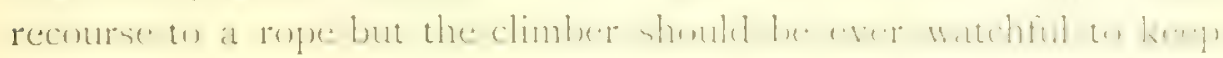
a good hold of the tree. I have seen careless climbers injure

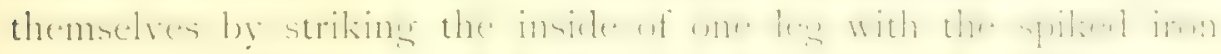

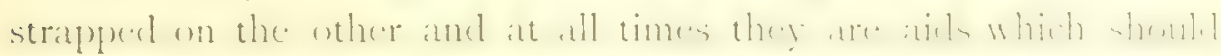
be used with extreme care. When scrambling high up among boughs, they are a source of danger and should be removed.

So much for the various ways of tree-climbing. Now as to the

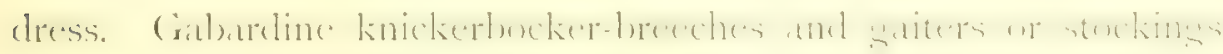
are as good as anything and a watistcout with close-fitting light

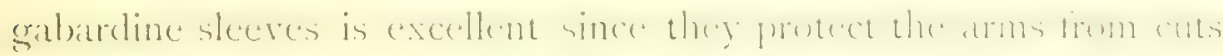

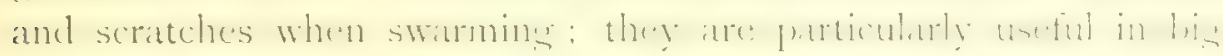
fir-trees. How often have I reduced the sleeves of a flannel shirt

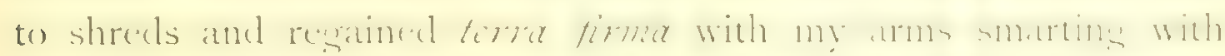

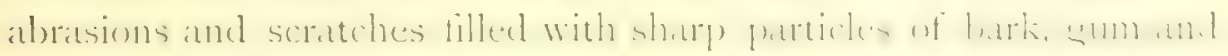
turpentine!

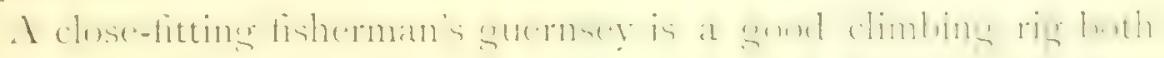

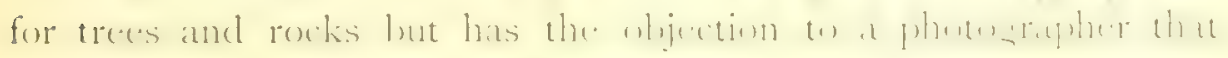
it is difficult, if not impossible to get at one's waistcoat pockets.

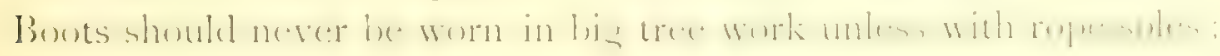
stockinged feet are usually best.

An essential part of the tree-climber's equipment is a strong line wherewith to communicate with the party below. For this purpose I usually take up with me my line and lead. The former is wound on a wooden reel made to fit in one's hip pocket where it can be stowed without getting in the waly. "There are rery few occasions when its services are not in request, whether it be to 


\section{Tree Climbing}

lower down eges or young birds or to haul up a camera or a birdtrap. A stout wickerwork fishing creel makes an excellent general receptacle on all such occasions and is less likely to gret caught up in the process of hauling up or lowering than is a bag or sack, besides being more easily packed and affording some protection to fragile articles such as egrs in boxes or photographic apparatus.

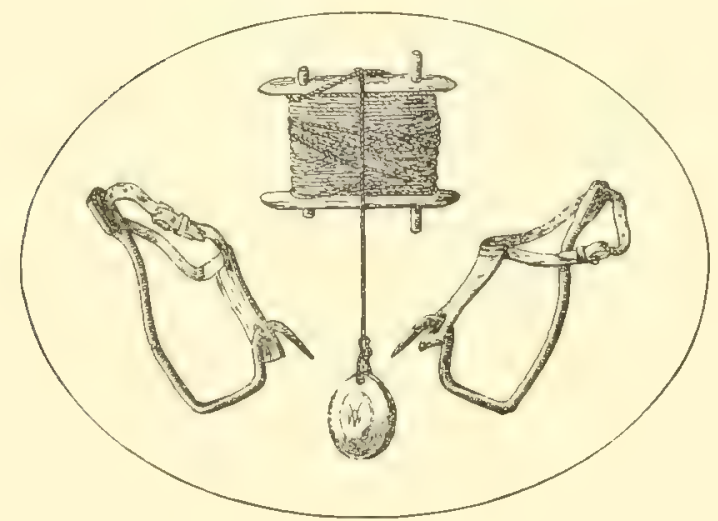





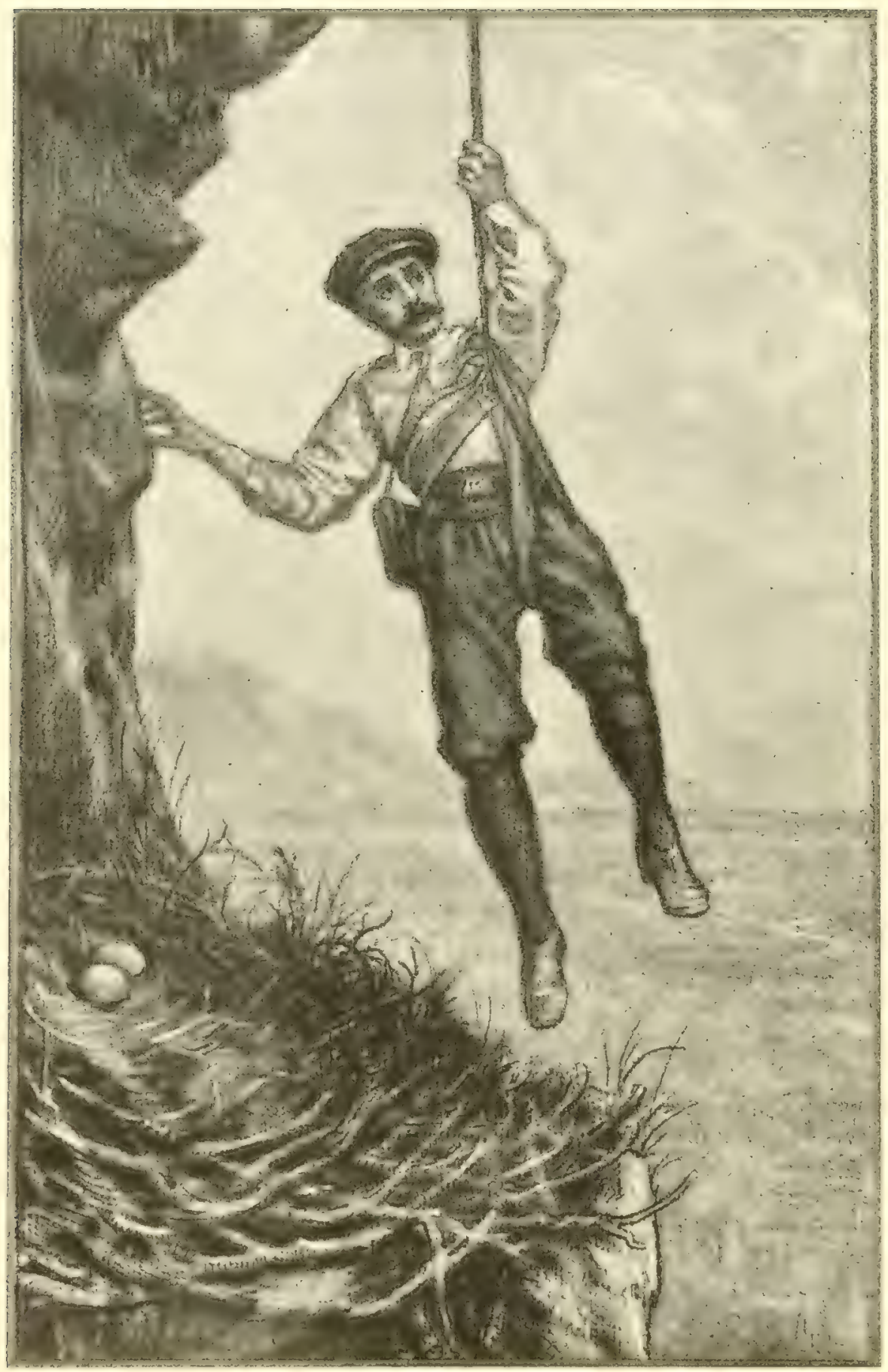

A CLEAR DROP. 


\section{CHAP'TER VI. \\ CLIFF CILIIBING.}

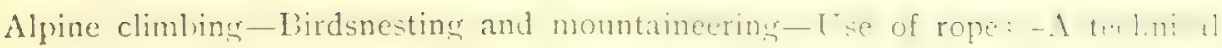
knowledge necessary-Uses of a "life-line"-Dislike of mountaineers to rope work-Risks of working a rope single-handed-Various uses of ropesCrossing a gully-Life-line and "traveller"-A naval development-Popular ideas of using ropes on cliffs-Carrying ropes in will countrite. Al pine Clut, ropes, weights, \&c. - Bowline-on-a-bight - Canvas sling-Carrying long ropes-The lowering party-Xumbers re puired-Cond drocipline e-ential Duties of the "captain" - Posting a lowering party-Use of whistleA simple cude of signals-General precautions - Importance of linotuma and "seizing"-A slippery hitch-Awkward situation-Tyrolean silk rope-Its manifold uses.

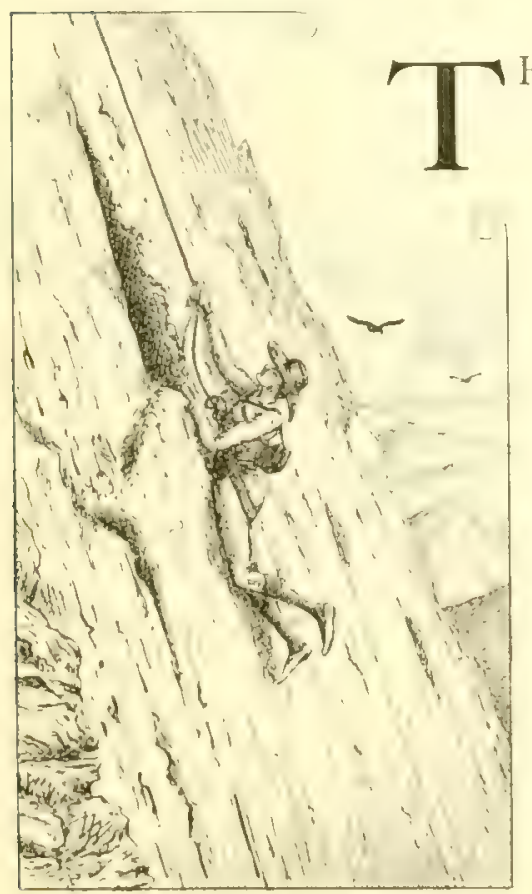

IE world-wide notoriety given to all matters connected with Alpine ascents has made many people imagine that climbing is a pastime exlusibly (1) juyed ly those whe visit Suiterland or similar mountainous countries. In fact that to be a mountaineer it is essential to form one of the band. who with the aid of guides and all modern appliances annually pene trate the eternal snows and attain the summits of remote mountain peaks. That such performances have great charm for many is undeniable and I look with the greatest admiration and respect on some of the genuine 
Alpinists who have repatedly given proofs of their nerve and endurance in their tremendous struggles with the forces of Nature. Unluckily the grenuine mountancer is aped by a host of paltry followers who have reduced the science of climbing to a point at times narrowly verying on the ricliculous. Nany of the so-called climbers are no climbers at all, and it shows their belief in themselves and their capabilities that they will submit cheerfully to be tied together like strings of donkeys and drasged, hustled and pushed through snow or across ice for the mere satisfaction of saying that they have reached some point a trifle higher than the rest of the surface of the earth in the immediate neighbourhood. Such people, to use the expressive phrase of a naval officer who has been my companion for many years but who shies consistently at big hills, would seem to find unbounded joy in ever "pandering to the sky-line." "The annual list of victims of both sexes of this class is painful evidence of the unfitness of many of the so-called climbers. The result of these popular icleas about mountain climbing is that when any man in the course of the pursuit of natural history or sport chances to be attracted to mountainous countries where climbing, in its more literal sense, is essential, he is at once supposed to be one of the confraternity of Alpinists and is assumed to adopt their ways. Thus many people, hearing of some of my expeditions into the mountains after birds' nests, ask me whether I always rope my party together and carry an alpenstock?

Without venturing to intrude into the sacred domain of the traditional Alpinist, or to criticize his methods, I am content to say that for the class of climbing I lave indulged in for so many years, to rope one's party together would be almost suicidal and that an alpenstock would, as a rule, be an unmitigated nuisance. At the same time I am lieenly alive to the advantages to be gained by a rational use of ropes, as also to the comfort and assistance to be got from an alpenstock under certain conditions. In fact, owing 
to injuries, I have of late years been compelled to make use of

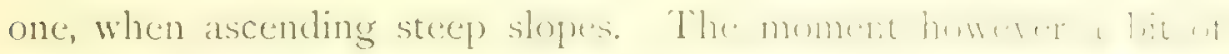

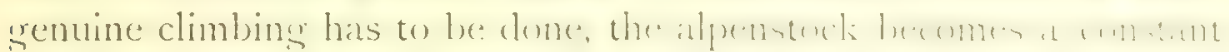
source of trouble and danger and in most instances has to be discarded at any rate for a time, until the actual climbing, as apart from scrambling up steep hillsides, is over. The fact is that in cliff climbing a man must depend upon his own nerve, eye and skill to carry him through. If these fail him or are likely to fail him, he has no business to be one of the party and I for onc

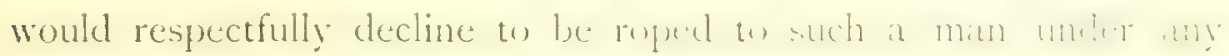
conceivable conditions.

It must be remembered that what may be useful and even

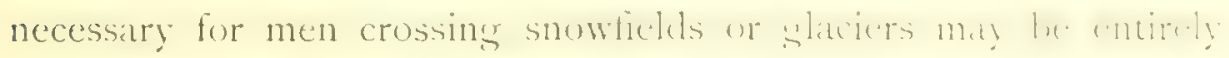
unsuited to the class of monntinecring required in himluneting. For as a rule, where the snow-line begins the bird-life, so far as nests are concerned, ends. I have only on three mathing when in

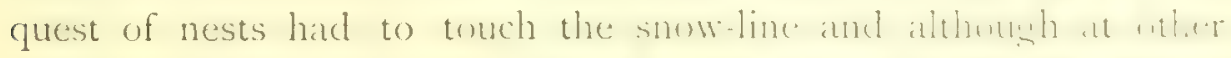
times the rocks may have been slippery with ice and the strumel whitened with snow, the conditions were totally dintinct from thene which have hourly to be faced by the restuldr. M lpine climber.

Ropes improperly used are a fertile source of hanere and my own experience is that very few men, save indeed some naval officers, know enough to use them in all circumstances with

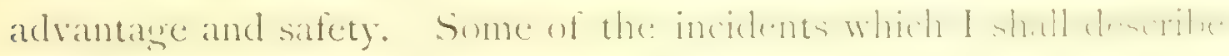
later will I think give point to what I here say.

First as to the use of a rope as a life-line, to ensure that a man who may slip at some awkward point may be saved from

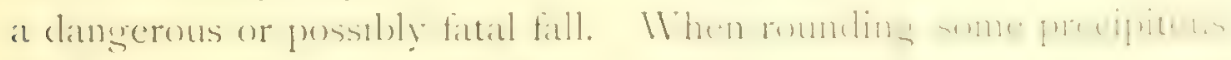
bluff or traversing some dangerous bit on the face of at crag

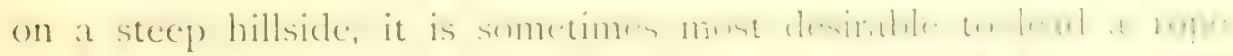

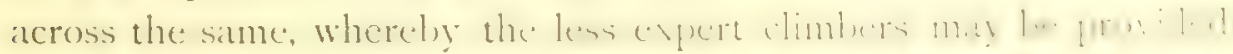

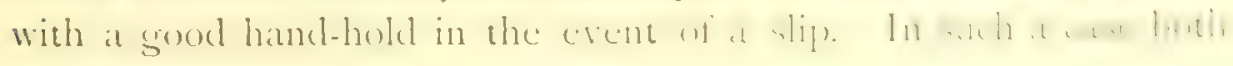


ends of the rope should be if possible made fast to the rocks or held by men who have found a good secure foot-hold. I never recommend roping at such a place. I have happily never had as companions men who could not avail themselves thus of a life-line with far better effect.

This incidentally brings me to a somewhat interesting trait I have noticed in many of the fine climbers I have met among the rugged sierras of Spain, their inherent mistrust of a rope of any sort. As a rule, if a goatherd cannot get past a bad place without a rope he will not attempt it at all. I imagine this dislike to be inherited, due to tales handed down of men who have been killed by trusting to ropes. Judging from the average condition and size of the ropes ordinarily available, those employed by the arrieros (mule-drivers), this seems reasonable enough.

Again, it may happen that a cliff may be reasonably safe to descend for a considerable distance and yet that here and there a rope may be of the utmost value to guard against a slip. In such cases it is of enormous advantage to get a trusty comrade to place himself at some point whence he can see most of the face of the cliff and tend a rope by the aid of which the climber can descend in a bowline.

The whole art here depends upon the comrade above neither checking the climber in his descent nor giving him too much rope. For the former may cause him to miss his footing and throw him off his balance, whilst the latter is doubly dangerous, for should the climber slip, he will be brought up at the end of the slack with a violent jerk which may prove awkward for the man above. Hence two men above to tend the rope is an advantage although frequently impossible to arrange for. To my mind the most dangerous method of using a rope as a life-line is to make it fast above with no assistant to tend it and to climb down, keeping a strain on the rope. It sounds perfectly simple and safe and so it is when 
the descent chances to be a clear one. This, however, is rare

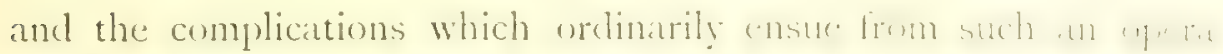
tion are as numerous as they are unexpected. I will mercly cite a few. In descending, the unused coiled-up portion of the rope

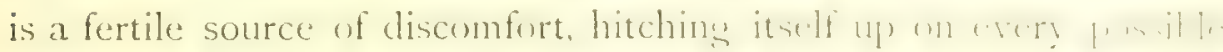

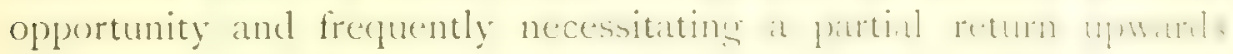
to clear it. Later on when a bad spot is reached and the services of the rope are needed, no sooner does the dimber's while we hit

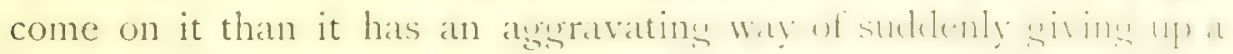
foot or more, owing to some temporary foul up above having rendered. So much for the joys of the descent, now for the ascent. On the return journey, if the free end of the ruge lu l, th to be hauled up after the climber, it often tinds some fllate to curl round and jamb especially if wet. If, on the other hand, the climber from time to time makes up the slack and carries the coil with him, at the most unexpected times a binht will hiteh itwit on some unseen protuberance of the cliff and, as he swing himedi upwards, he will suddenly find himself hathed hadk he the de ment bight violently pulling at his shoulder! This last eyerienee. the most perilous of all, actually happenel we me whice in the course of a few minutes when reatscending a cliti. the hatse af which lay 400 feet below me. Never again!

It would be impossible to describe all the occasions when at piece of good Alpine rope maty matic all the difierence lutwen success and failure.

Many years ano I discovered an Esyptian Vulume ne-time in .n

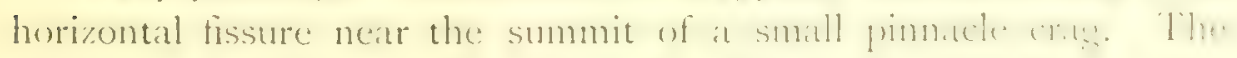

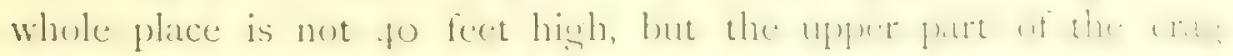
overhange, whereats the lower is ats perpendicular as a wall. I llow

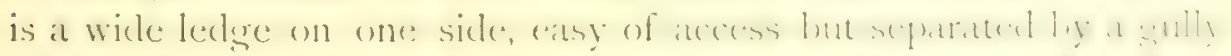

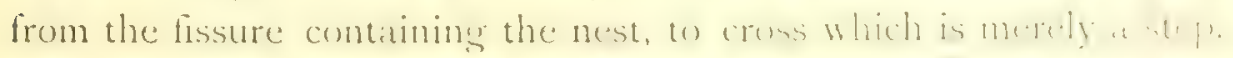
But herein lies the crux of the whole buthess. The whil hint 
which have resorted to this place from time immemorial are perfectly well aware that this one step across the sully is exactly what few men care to take, for there is 110 forthold on the far side. But although a rope will not help a man to ret at the nest either descending from the summit or ascending from the grassy terrace only 25 feet below, the ledge provides the proxerbial way round for I found it quite possible to pass my $M$ pine rope from the adjacent ledge laterally round the crag so that it led along through the fissure containing the nest and to join the two ends together behind the main crag. As I was alone at the time, I made my silk rope fast round my body and attached myself in a bowline acting as a "traveller" running along the fixed rope, thus securing myself against the results of a possible slip. Gripning the life-line firmly, I made a spring forward and, with a light touch of my stockinged foot on a small projection, swung myseli far enough to grasp the line well across the gully. Next instant I was in safety, lying at full length along the narrow lectyce. Although within a few feet of the nest, the process of worming one's body along between the rocks both above and below was awkward and painful. But the return journey was even worse, for it was impossible to turn so I had to back out of it and more than once in doing this I got jambed and could with difficulty free myself. Arrived at the sully, of course I could not see where to place my foot, and in consequence I slipped and, the life-line not being very taut, I went down some feet. The silk tratveller on the line however brought me up as I had expected and next moment I had hauled myself back again on the ledge. Some years later I took Rear-Admiral Arthur Farquhar to the same place and we repeated the process, but with improvement. For the Senior Service took the precaution to improvise a tackle with the spare enrl of the rope with which he got such a strain on the portion round the cliff that it more resembled a handrail than a line. He further rigsed himself with 
an inhaul to his traveller with the result that after achieving his

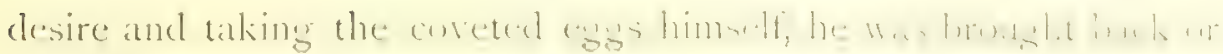

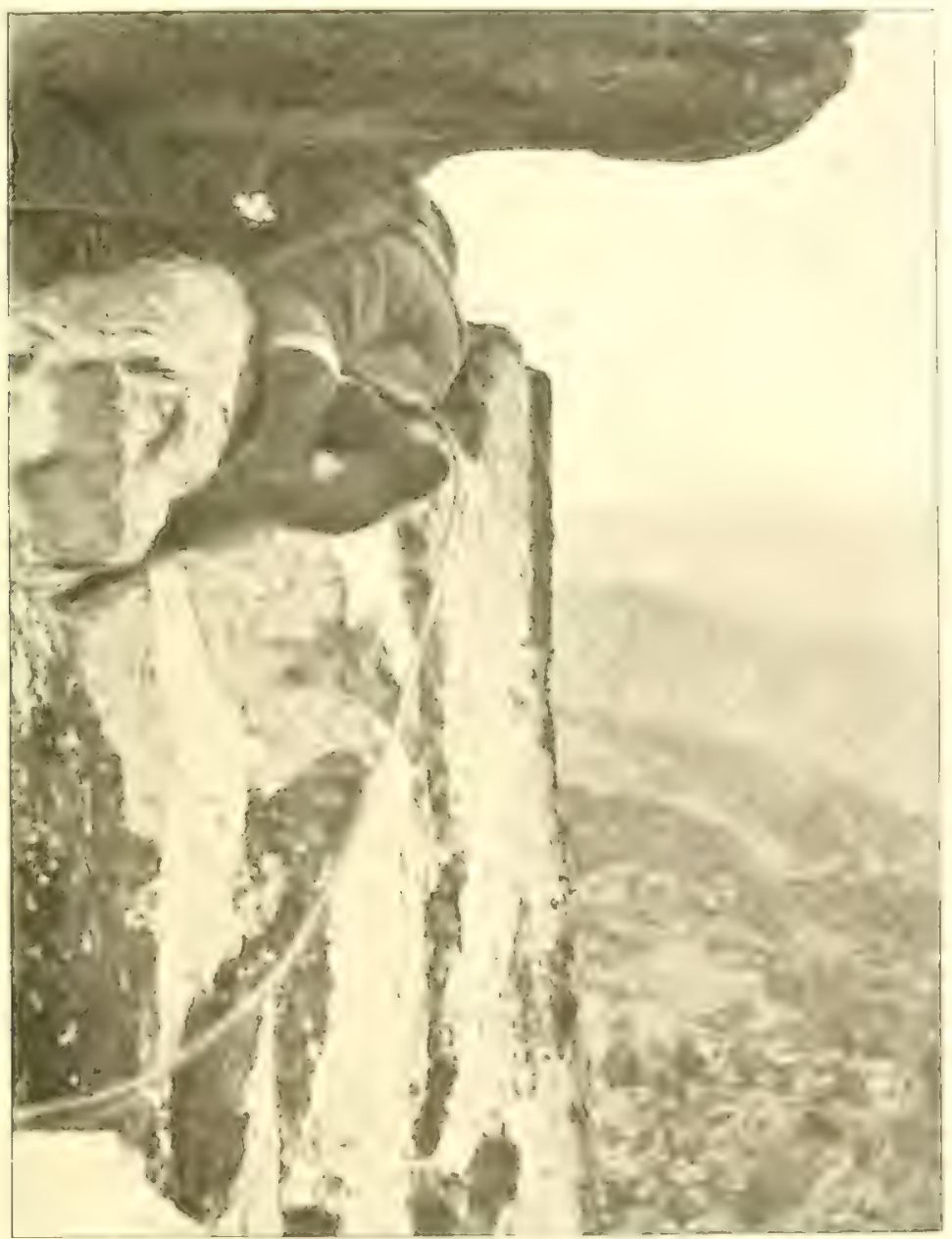

ENTERING A NEST INACCFSSIPT, FROM AIOVE ANI) FROM 1:LOW.

rather run inboard in style to a place of safety. I was able to take a picture of my comrade when thus happily employed. It is an 
excellent likeness but one which, it is unnecessary to say, he never presents to his country's foes.

I hope I have made it clear that ropes thus used by experienced hands are at times of untold value, whereas, when in inexperienced hands, they may prove a greater source of peril than of security. All the same, they are absolutely essential in innumerable cases, and nobody can hope to reach every point he may require until he has thoroughly mastered their use.

But if there is, as I believe, a certain amount of confusion existing in the minds of very many as to the relative spheres of action of the Alpine climber and the birdsnester, there is even more popular misapprehension with regard to the using of ropes for the descent of the cliffs.

How often have I been advised to go to Flamborough Head or St. Kilda or elsewhere and just see how the men do there. In reply, I may say I have been to various places on our sea-coast and have never yet seen anything which is the least applicable to the class of work which it has been my pleasure to devote myself to for so many years. To begin with, the conditions in the two cases are absolutely different; for the professional eggers know exactly what lies before them and having the experience of former descents, know precisely whence to start from, what points can be reached and what amount of rope is required; further, they know whether the cliff is a sound one or the reverse and arrange accordingly. Contrast the wandering naturalist. He has to find a way to reach a point above the nest, a matter in some cases of the greatest difficulty and danger. Having fixed this point, he has to make sure of a good footing for the lowering party, to ascertain whether the cliff is overhung and whether the nest is accessible or the reverse, how much rope will be required, what ropes it is possible to convey to the desired point, and, last but not least, whether the cliff be sound or rotten. This may seem a long list of contingencies, but there is not a single one 
of the half dozen that has not repeatedly cropent up durin a my an

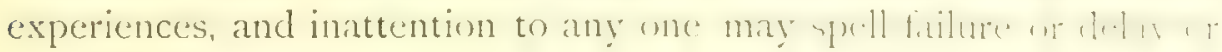
possible disaster.

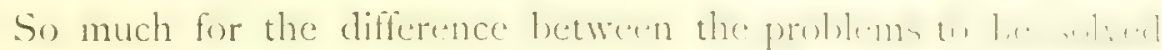
by the two classes - travelling nuturaliats and revide ne fithement. Now as to the material. The men who make the ir liveliturnel lis descending cliffs are equipped with all necenstry sear fir then work. There is practically norestriction for them in the manten an bulk and weight since they usually work within a reammolltw. distance of their homes and their ropes can in meny instunces l,

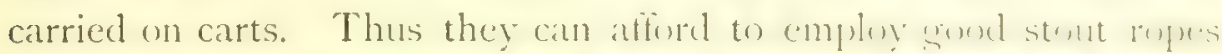

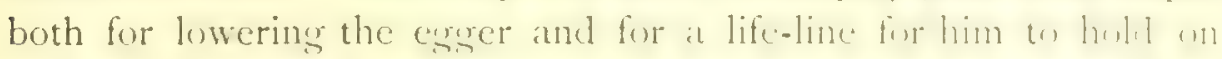
by and "lighten up" when he may require to do so. Not uncommonly such men have regulier canveds "brenches" wh seats made in which they are slung. Further, to prevent the rope thating as it is paid out over the eliff it is often run thromen a lenth of heavy leather hose-pipe or over a hig worken tray knuwn at a "tortoise," fitted with a roller and wheels. I.tstly the rup. it we th is paicl out round a stout crowbar firmly driven inten the amemel. Such are only some of the accessories of man! of the furtenentomal cliff-eggers.

Some years ago a gentleman in Ireland whe hut talion mom?

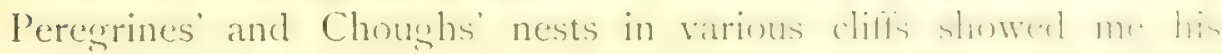
equipment. It consisted of a worden "tortuine" as abure, a cruwbar, a $3 \frac{1}{2} \mathrm{in}$. rope to be lowered in and a $2 \mathrm{in}$. rope to be used as

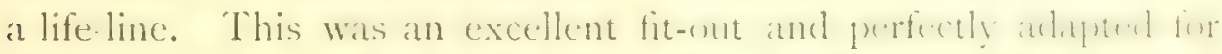

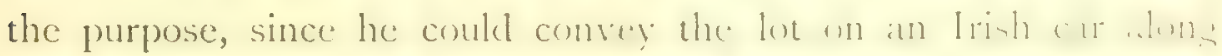

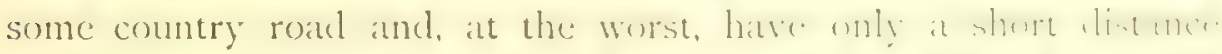
for his men to take it on their shmulkers to the witi. line we the naturalist wandering through a wild conntry secking ne tw, all wh refinements are of course utterly ont of the question. Winthe and

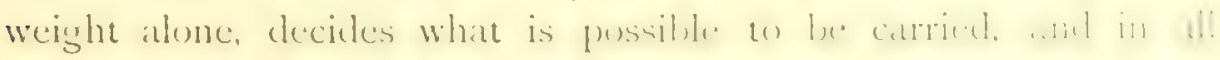


mountainous countries, such as the wilder parts of Spain where wheeled transport is unknown, the weights must be so adjusted as to enable their rapid transference from the panniers of the mules and donkeys to the shoulders of the men. As for many years I myself acted the part of one of the said men, and took my share in the weight-carrying, I can speak with feeling. I constantly worked alone, carrying rope, gear, food, glasses, \&c., and I found that the utmost that I could carry on a long day's tramp on foot through the sierras without being unduly tired was $26 \mathrm{lb}$. Thus it came about that at the time my friend in Ireland was using $3 \frac{1}{\mathrm{z}} \mathrm{in}$. and $2 \mathrm{in}$. ropes as his lowering and life lines respectively, I had perforce to be content with $I_{2}^{x}$ in. rope and naval cod-line. This rope is the manila rope in use by the Alpine Club $100 \mathrm{ft}$. of which weighs just $5 \mathrm{lb}$. I have a length of 30 fathoms of it, ISo ft. (9 1b.) which has done admirable service both on cliffs and in big trees for thirteen years.

It was with such an equipment that I have been over some very high cliffs, slung in a bowline-on-a-bight and innocent alike of crowbars or "tortoises" above me or the orthodox canvas breeches below me. The renowned bowline-on-a-bight is, in my opinion the only knot to which a man should trust his life over a cliff. After tying this knot in the normal fashion, with two equal-sized loops or bights, it should be carefully readjusted so as exactly to fit the body, one bight being the size of the man from the top button of his waistcoat, round the body just below the armpits, and the other long enough to pass under the thigh and up to the starting point. A normal size would be about to in. for the small bight and 50 in. for the larger, subject to subsequent adjustment. A man thus slung has perfect freedom of movement for both legs and arms and cannot fall out of the sling in the untoward, but ever possible, emergency of his being stumned by a falling stone dislodged by the rope from above or injured by any other 


\section{A Good Canvas Sling}

mishap. It is as well to fold a waistcoat and with it pad the lonecer bight, else it is apt after a time to fecl rather sharp, especially if a thin rope be employed.

Owing to the risk of a thin rope becoming frayed on a cliff, I have during the last ten years often employed $2 \mathrm{in}$. rope in place of the Alpine I $\frac{1}{2} \mathrm{in}$. which I have relegated to tree work or for

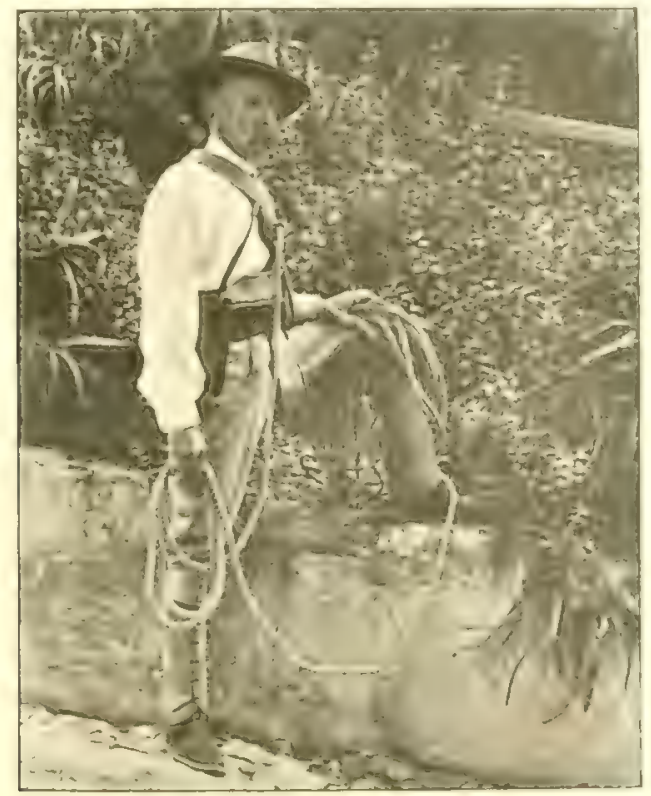

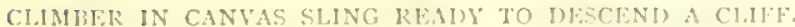

use as a life-line and for general purposes as hereafter described. One hundred feet of 2 in. manila weighs about 9 1t). and, owing to its bulk is as much as a man can carry with comfort when climbing among rocks. It enormously adels to the comfort of the climber if in place of making a descent in the bight of the rope, whether it be $2 \mathrm{in}$. or bigger stuff, he be provided with a canvas sling. This is nothing more than a belt of folded canvas 
sewn with bolt-ropes, $3 \mathrm{in}$. broad and about $3^{\mathrm{S}} \mathrm{in}$. in length, which is joined at eachend to a second one slightly wider and about $44 \mathrm{in}$. long. At the ends are a couple of thimbles eyeleted. This belt is adjusted to the body in a manner exactly similar to the bowline on a bight, the longer canvas loop being passed under one thigh and the shorter one round the body under the armpits. The rope is then rove through the two eyelets for about $4 \mathrm{ft}$, the eyelets being brought together and secured with two half-hitches. The end of the rope is then passed over one shoulder and under the other and secured agrain to the eyelets, so as to prevent the sling slipping down. In the preceding picture the method of adjusting the canvas sling to the body and of attaching the rope is shown.

Among very hig cliffs where there is a chance of a rope jambing or fraying andinst any sharp edge I would strongly recommend the employment of $2 \frac{1}{\mathrm{in}}$. rope as a lowering line and of $\mathrm{I}$ in. as a lifeline. The first is a cumbersome affair to carry, but it is as well to have in big places tackle which is beyond suspicion.

A most difficult problem at times is how to carry sufficient length of rope to ensure no join being necessary. Up to 1906 I usually carried three lengths of $100 \mathrm{ft}$. apiece and on an cmergency joined them up. If the latter process be effected by means of a long-splice, well and grood. But the exigencies of time and place as often as not prohihit this, and recourse must be had to bending the ends together. Under nomal conditions this may be all right but in going over a strange cliff, it is impossible to know what difficulties may be encountered and it is most unwise to take unnecessary risks. When a long piece of rope is required, say 200 or $300 \mathrm{ft}$. or more, the hest way is to have it in one piece male up into separate coils of $100 \mathrm{ft}$. each, with 6 to $12 \mathrm{ft}$. drift between each coil. Each man of the lowering party can then sling soo ft. round the body and follow in Indian file. In the picture a lowering party are shown thus carrying 50 fathoms $\left(300 \mathrm{ft}\right.$.) of $2 \frac{1}{2} \mathrm{in}$. rope. 
When awkward places are reached, it is usually better to sling the coils on the outer shoulder since it may be necessary from time to time to pass them from hand to hand and deposit them on ledges or other projections whilst some difficult bit has to be climbed. It is essential that ropes should be neatly coiled and

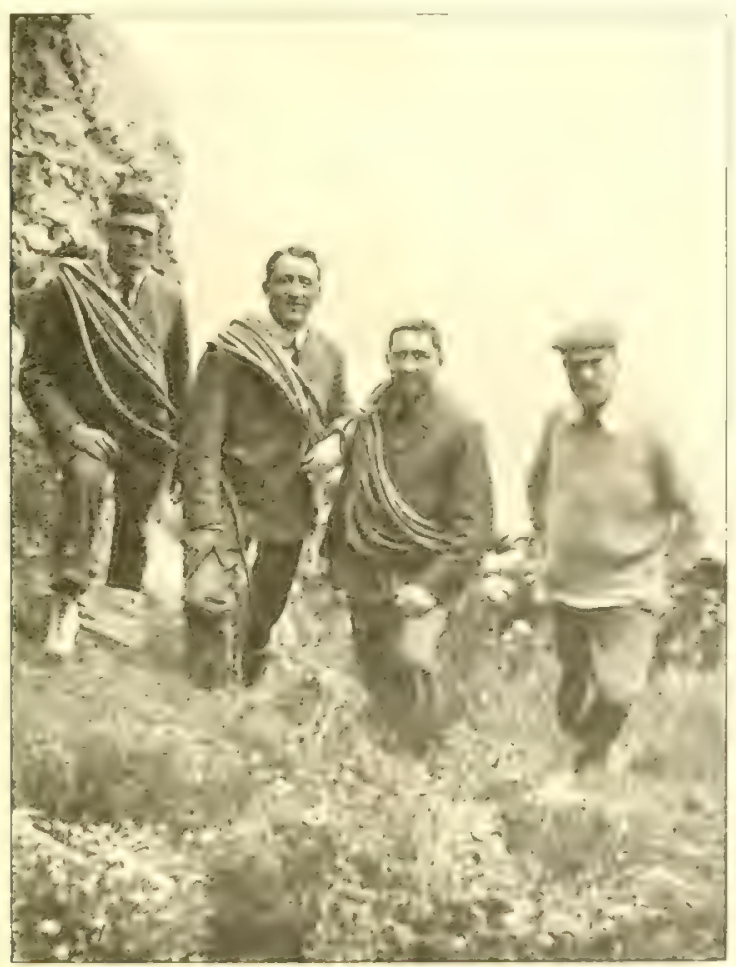

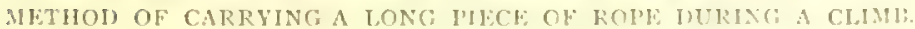

seized round with string or yarn at several places so as not to

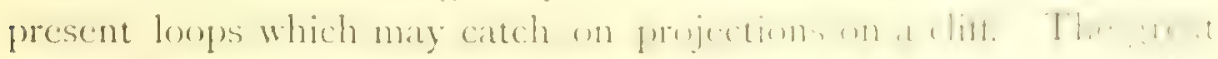

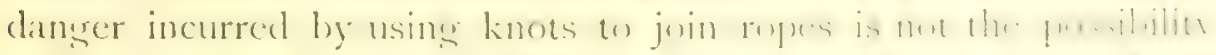

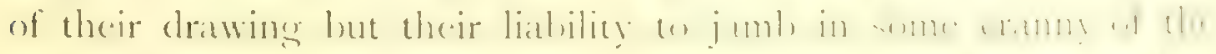

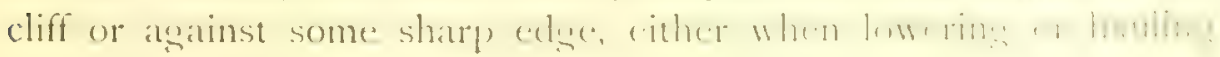


up a dead weight. An awkward experience of this very thing occurred when I was descending to the nest of a Bearded Vulture. On this occasion the ready resource of a comrade alone got me out of what might have been very serious trouble. Hence I am now somewhat shy of using ropes knotted together.

The very essence of good cliff work is absolute discipline throughout the undertaking, especially as regards no talking or "back chat." To ensure this, before descending I invariably appoint one man "captain" of the show and impress on the others that there is no danger unless they wilfully cause it by inattention to the instructions I have given them. For a small cliff two men are sufficient to haul a light man up but three is a better number. I have frequently been lowered over small places by one man but do not recommend it. It is all right if all goes right, but if things go wrong it may lead to trouble.

The captain should see that the end of the rope is (whenever possible) strongly secured to some adjacent cray. This at times is of great use on an emergency arising. He then settes himself down in a sitting position as close to the edge as he can safely find a secure footing, and passes the rope under his right arm, Nos. 2 and 3 prolong the line behind him in a straight line from the strain in similar attitudes. Firm foothold of course is essential. Sometimes, if a cliff be peculiarly dangerous, it is very useful for the captain to post himself at the very edge, whence he can either see or hear the signals of the man down the cliff.

This course is especially useful when a cliff is so shelving near the brink as to make it unsafe or impossible for the lowering party to obtain secure positions anywhere near it. The captain in this case should be himself in a bowline and when he has settled himself on the very edge of the cliff, his rope should be securely made fast to a rock.

As a matter of fact it is unusual to find a cliff either in a lime- 
stone or sandstone country where a rope cannot he thut anmel; it

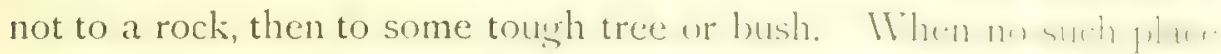

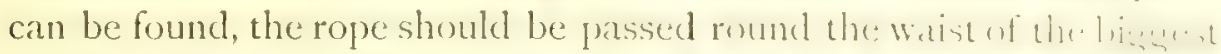

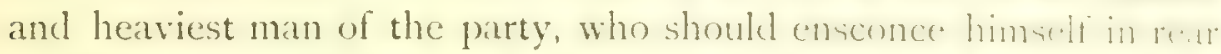
of the rest in a billet whence he cannot be omstud by a smliken jurt. I have adepted this plan with excellent resules when working arer

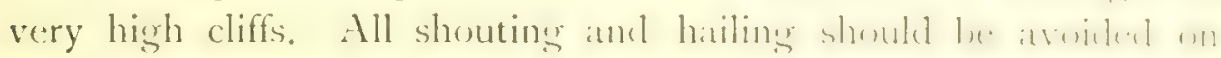
the part of the man down the rope. I always carry an "Acme" doy whistle on a short lanyard round my neck. ()ne blant sisnitien "Hold hard." Two blasts: "Lower away." Three blasts: "Iaul up." Where there is reason to apprehend any complication, the whistle should be carried in the mouth. It is casy then, if in sudden troubie, to give one blast and cause the party above to hold hard.

It is marvellous how clearly a whistle can be heard when the human veice some little way down a cliff is utterly monuthinile. to those above. Nothing is so demonalising to at hownering furty as to hear a man far out of sight shouting inarticulately; in such cases it may male all the difference in the worhl whether they chance to do the right thing and at the right moment.

The climber, having been lowered over the cliti andil he arrise. at the nest or at a cavern or ledge which conducts to it, maty find it necessary to move laterally atlong the face wi the chot for some yards. If the local comditions permit, the sitfest compe in fin him to give the signal "Lower away" and, after hauling in all the slack he maty repuire, sigmal "I Hold hard" and will wown the

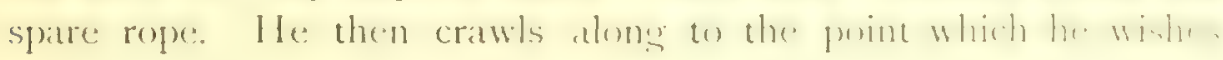
to reach.

But sometimes there may be a very extensive terrace or

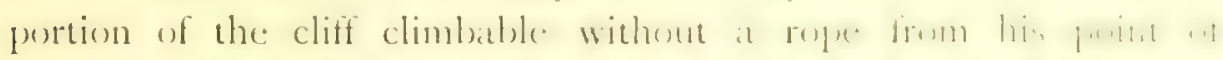

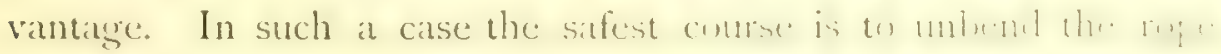
and make it fast to some bush or crag and then proceed to 
explore the cliff. Having finished this he returns to the point whence he started, bends on the rope ayain, and holding firmly on to the cliff, signals "Haul up." It is always best, as soon as the slack has been taken in, to signal "Hold hard" before making the final ascent. This gives time to the party above to get a fair strain on the rope and enables the man below to make a comfortable exit from his ledge. Disregard for this small rule has resulted in my being jerlied off swinging in mid-air by over-anxious friends above, an event as alarming for them as it was unpleasant for me.

In ascencling, a skilful climber will soon pick up the rhythm of the haulers and whenever the cliff permits, will, by catching hold of it with his hands, "lighten up" his weight. It is marvellous how even a couple of fingers on a ledge at the right moment will ease the efforts of those above in hauling up.

During an ascent of this description a climber should never "get ahead of his rope"; in other words, he should always keep a strain on it. A rope attached to a man which is allowed to sag down may very easily catch on some projecting rock just below him and when the men above give the next pull he may find himself being violently hauled downwards, a most unpleasant predicament.

I cannot too emphatically caution all would-be climbers as to the possible dangers of meddling with the ropes unless they are skilful at knots. Even the most practised and expert hands may get into trouble by this means, for long familiarity with danger makes all men at times careless. I will cite but one example. In IS94 I descended the big cliff known as the Laja del Ciscatr.

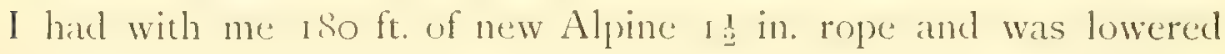
by two Spaniards. It was by no means a sheer descent, save now and again for $20 \mathrm{ft}$. or so, where a vertical fissure ran down to a ledge which in turn sloped outwards until it merged in the general surface of the cliff. When near the end of the 


\section{A Slippery Hitch}

rope I noted to my chagrin a Vulture's nest only $20 \mathrm{ft}$. below me. so re-ascending a few feet to at point where I could get a secure foot-hold, I unbent the Alpine rope from my sling, joined on my silk rope, attaching the latter to my sling, and was lowered to the ledge. I took a photograph of the Griffon's nest and exys (which subsequently appeared, by the way, in Colonel Irloy's

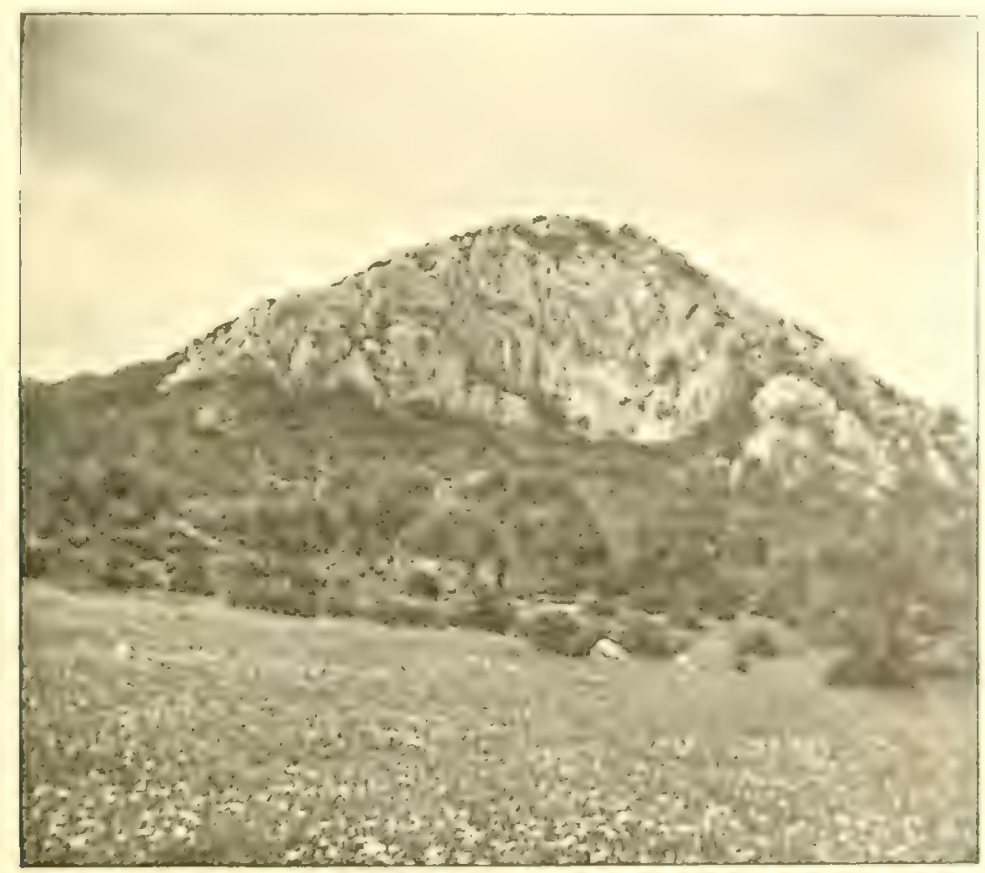

TIIE I..J IJAL, CISCAR.

(Stmmil 620 fl. aboite striam al hasc.)

second edition) and then signalled to be hatuked up. It was more of a scramble than a regular ascent, but after going up 20 or $30 \mathrm{ft}$. I bethought me that it would be wiser to recover touch with the Alpine rope, so I unbent the silk rope and attached the Alpine rope once more to my sling by two half-hitches, well hardened down. 
During the ascent I stopped several times to explore some other nesting sites, the rope hanging slack. Finally I signalled

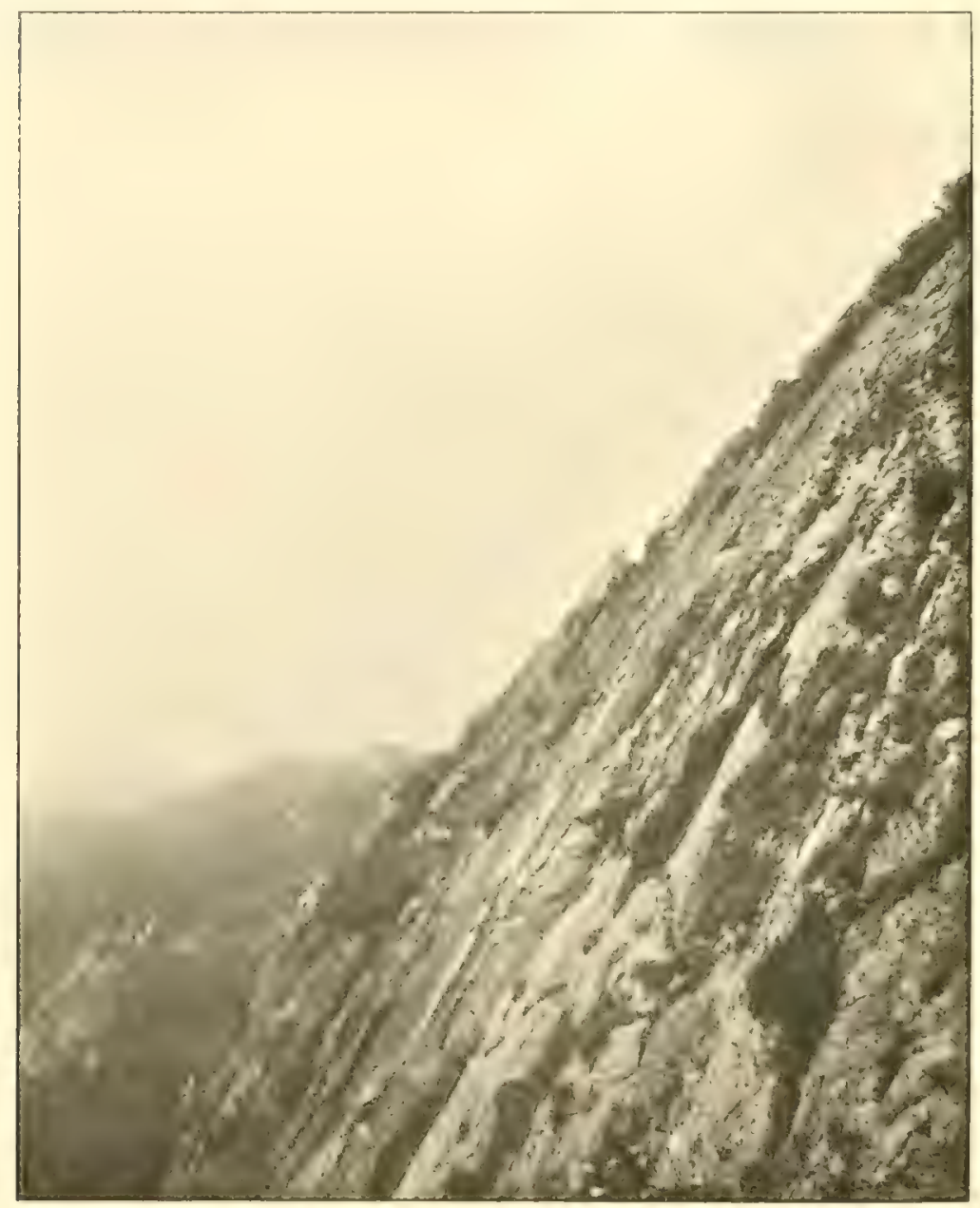

ON THE HACE OF THE I.AJA DEI. CISCAR.

"Haul up," and started upwards. It was whilst I was being dragged up one of the steep slippery gullies with my whole weight on the rope that my eye chanced to fall on the knot which 


\section{A Famous Silk Rope}

secured the rope to the sling. This was about on the lexpl an my middle waistcoat button. I had started ats atreaty dewerilued, with two half-hitches and a foot of roper tos spatre, and, als my eye caught the knot, I realized that one of the hall-hitchen, wh, grone and that the other was slowly drawing and lacked only a few inches to run clear! I quickly grasped the rope aluse me with one hand and somehow got hand-hold on the next ledse almen. but only just before the knot drew! It wats a frighteful experiene. and due to sheer carelessness, for I had not taken inten accommt the "curl" in the new rope when it was hameing shats nor the effect of the hot sun upon it. Eventually I pot more mpe: (ated down, and after making a secure knot this time: was hauled up.

It all happened long ago but I can still recoll my semsitions when, as I steadied myself on the friendly ledece, I glanced down that steep slope to the foot of the cliff. The moral of the tiale is that no trust should ever be placed in two half hitches, apucially in the case of a new rope, unless the free end be scized on to the standing part.

No account of the ropes I employ would be complete whtome a description of my silk rope, already incidentally referred w, which has been my constant companion for nigh thirty years. This is one of those carried by 'Tyrolean spertsmen and is my mont cherished memento of the happy birdsnesting days I spent with Crown Prince Rudolf of Austria in the spring of $18-9$. The l'rince wore-as did his chief companion, Count Ilans IVileneli fa fumous sportsman) the Tyrolean Jiger costume, and buth insiridhly carried these silk ropes in their ribksates. It was after a particulaty

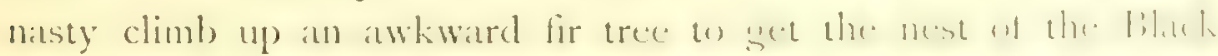
Kite that The P'rince insisted on my having one of the silli repenes they carried to use as an atel in any such emergencies in the futma. This rope is of strong plated raw silk over $20 \mathrm{ft}$. in lengh with a loop at either end, well spliced and served. It is almost anutly 
I in. in girth and weighs less than $1 \mathrm{lb}$. It can be carried in the pocket and occupies little more space than does a bandana handkerchief. As regards strength, I have now and again made it fast to a bough and two men weighing over 20 stone between them have sat in the bight, swing-fashion. Both when working out along the slippery branch of some lofty tree or when sidling along some narrow ledge on a precipice have I used it on countless occasions as a life-line.

Since I have taken to photography it has often given me the only means of securing myself when endeavouring to work the camera with effect in some dangerous situation. Its lightness and compactness have also frequently made me carry it when no climbing: was imminent and it has in turn performed an endless succession of duties, of which slinging Great Bustard across a saddle, picketing a horse and towing a duck-punt are but a few chance examples. One winter I made a pioneer skating trip for over 20 miles along the Hythe canal whilst the ice was yet thin and reputed to be unsafe. Luckily I accomplished my task without going through but the rope in my pocket gave me no little confidence. From time to time allusion will be made to this famous rope in describing various birdsnesting adventures where it has stood me in good stead.

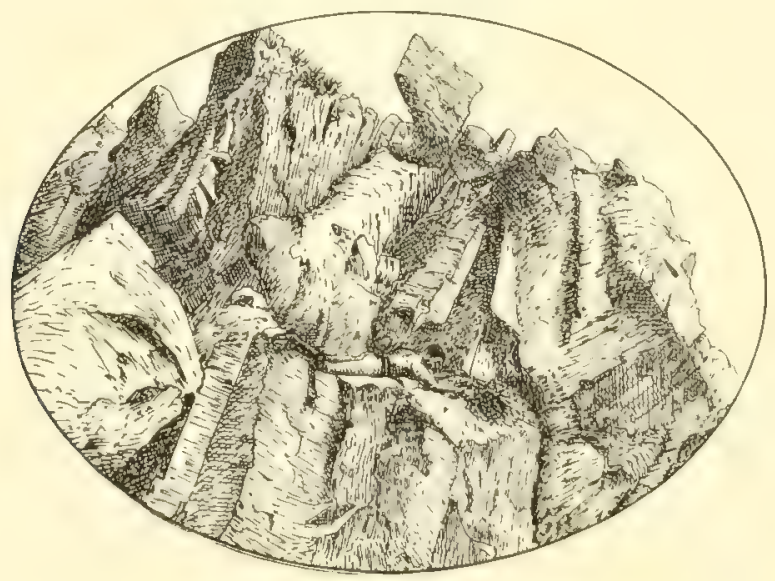





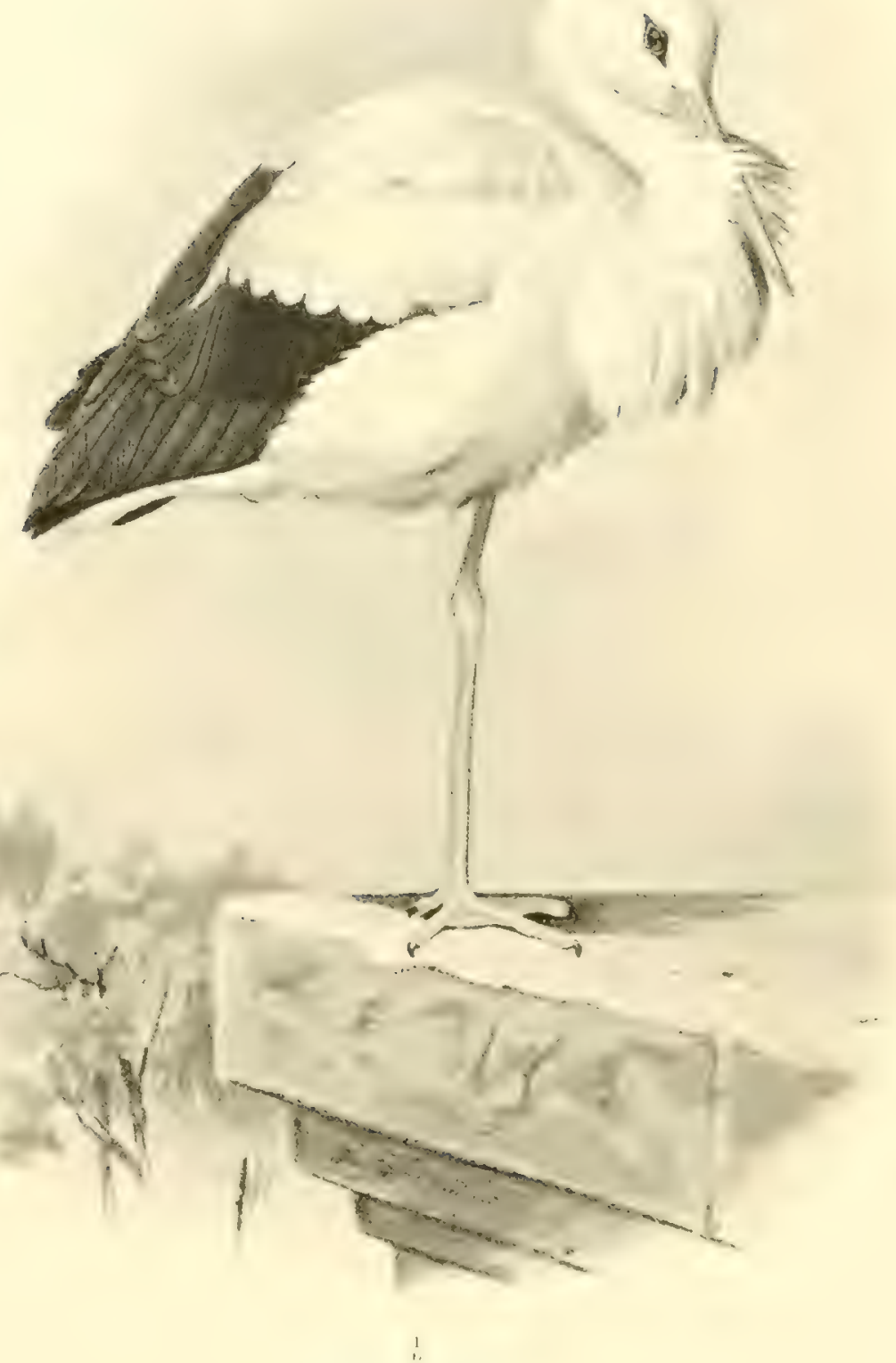

WHITE STOKK.

Ciconia alba (Bechist). 


\section{II.-IN A SPANISH LAGUNA.}

\section{CHAPTER I.}

\section{A DAY IN A LAGUNA.}

The lagunas of southern Spain-Dense growth of bulrush and reed-Some unpleasant residents-Herds of swine and their work-Storks-Buff-lacked Eyrets and their occupation-Water tortoises and snakes-P'urple Herom Marsh Harriers-Undesirable neighhours-Wading through the water channels-Purple Gallinules-Bitterns-Great Reed Warblers Whislesed Terns-A floating lake dwelling - Bulls and other cattle in the marshes.

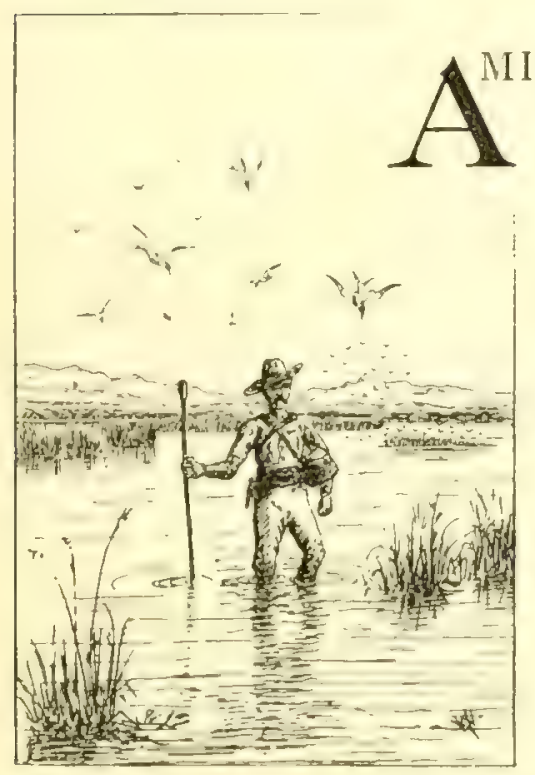

the marshes of southern Spain a great variety of birds find suitablo nesting-places. The size and exact locality of these swamps vary from year to year and depend upon the amount and time of the rainfall during the winter months. But there are certain low-lying portions which usually remain flooded for months after the shallows around have become expanses of sun-baked mud. There are places of this description near my dwelling and since the quest of nests in such spots is unlike birds nesting in any of its more normal phases, I shall give an account of one here.

To begin with, such places ustally have at hithy hatrel and herel 
bottom, and can, as a rule, be traversed with all reasonable security. Between the months of April and June they are densely overgrown with enormously strong and tall bulrush (Scirpus lacustris) (not the great reed-mace [Typha latifolia], by the way, which is popularly thus styled), which make all movement through them a continuous struggle. I have taken various enthusiastic bircisnesters to such places, among them my indefatigable comrade, Admiral Arthur Farquhar, and have seen one and all of them eventually reduced to a condition of complete exhaustion. Should a fresh breeze be blowing, the big reeds get a "lie" which makes it almost impossible to force one's way through them "against the grain" so to speak, and the explorer is compelled to alter his course and be content to drift with the line of least resistance through the biggrer patches until, upon emerging on open water he can work his way up to windward and thus to some extent recover his lost direction. Wandering thus, perhaps up to your waist in water and with the feathery rushes waving high above your head, it is often difficult to keep) your bearings. In theory, the direction of the wind and position of the sun should be sufficient guides, but in practice it often happens that it is no easy matter to work your way out of the sea of reeds and rushes which encircle you. After one or two such experiences, including being caught in a heavy rainstorm which for a time made observations impossible and obliterated all landmarks, I took care to put a compass in my pocket before diving into the reeds.

Such localities ever abound with leeches and nobody who does not require extensive blood-letting should enter them without taking precautions as to his dress. Stockinged legs are of course about the worst thing possible. But besides the leeches there is a mysterious and to me unknown water-beast-I call it such for want of a more definite name, but whether it be reptile or insect I cannot saywhich inflicts a most serious bite or sting. The immediate effect 
is to raise a very painful swelling, the skin assuming the culnot of a ripe rasplerry for some inches around the wound--the fuin lasting uswally for twenty-four hours. I hare known men indulling

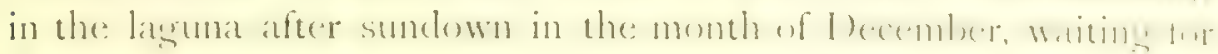
duck, to be bitten by this mysterious thing and I mention its existence as an additional warning to those who may wade in Spanish marshes to take the precatution to wear pronective alenhing.

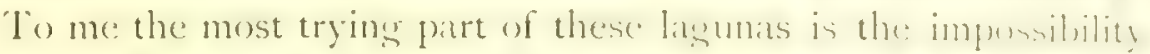
of resting from time to time. Now and atselin semes more soliblly constructed nest of Heron or Harrier maty offer a tempentary seat, but it is usually only a question of time before your weinht catlas the nest to sink below the water.

But in saying that the bottom of these latgunis is level, I m mitted one rather important proviso. It is true there are many humeleds of acres which are as level as a well-mate polo-eround, but there are ayain many hundreds more where the rast herels of ping wheth

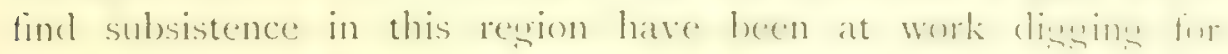
tubers. I Juring the months of the year that the plains are eithere

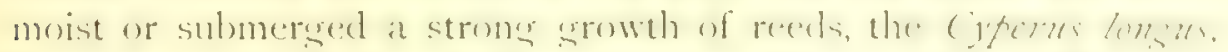
(known to the Spaniatels as castamuelas from castand a chentmut). having round tuberous routs, covers artain putions al the plain and the systematic way in which the pies convert steh spents inte a scries of shallow craters separated by low hanlis is surprining. So long as these excavations can be seen they are of ne wrat account, although tiring to walk across. But when cowered by t few inches of mudly water they are intenedy exteperating and

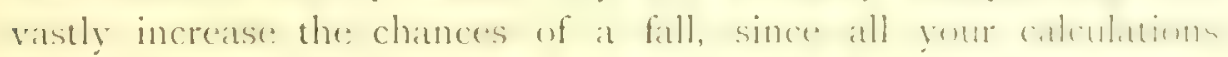

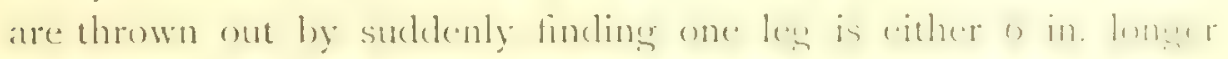
or shorter, as the case may be, than it may reasonably be assumed to be. A stumble and fall umber such andigima aton

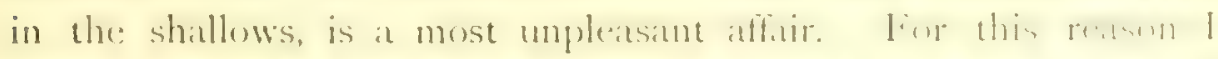
invariably carry a long iron-spilied herdomans stick when wh whth expeditions. 
It would be beyond the scope of this chapter to mention all the birds seen during a day's work in the marshes and I shall restrict myself to describing some of those which are most noticeable. As you approach the lower portions of the plain near the laguna, White Storks (Ciconia alba) are to be seen busily engaged in their search for frogs and other reptiles as well as for beetles. These birds of course do not nest in the marsh but they form so conspicuous a portion of its bird-life that they cannot be left out. Although many resort to the big towns to nest, others build in trees or on the tops of the small reed-built cottagres or chosas of the herdsmen. I saw such a nest only this year on the summit of a small stack of straw close to a large cortijo or farmhouse. The old birds had taken extraordinary pains to twist and turn the first big sticks they brought so as to weave them securcly into the binding withes of the straw stack and thus assure themselves of a sound foundation upon which to rear the usual big platform of sticks. Another marsh-frequenting bird is the handsome Buff-backed Egret (Ardeold russata), which are in constant attendance on the herds of cattle which pass so much of their time amid the rich pastures around the lagunas. These birds stalk gravely around the beasts or perch on their backs seeking their favourite food, the parasites which infest all animal life in warm countries. The local name for these birds is Purga bueyes, or " cattle cleansers," derived from this habit.

Leaving the muddy shore, you splash along through the shallows amid a scattered growth of reeds and water-plants. As the water deepens and the reeds grow denser, many Coots' nests, some with six or seven eggs, are to be seen. On a hot day every nest not in occupation by the Coots is usually tenanted by two or three water tortoises (Clemmys liprosa) which invariably scuttle overboard as one approaches. These reptiles literally swarm in the rivers and lagunas of southern Spain and are one of the many foes of the 


\section{Water-tortoises and Snakes}

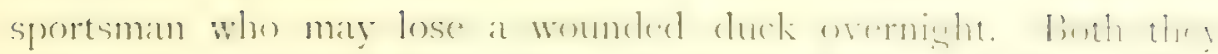

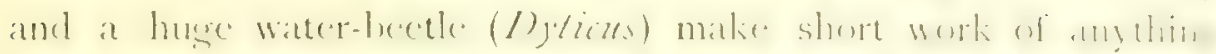
they have a mind to devour.

As you work your way forward towards the big reed-beds from time to time, Mallard and, more sehem, Wild l huck spring from the reeds, but this is no place to look for their nests which are hisklen amid the standing corn or atphodel-corered hill-sides miles atway I have often come upon Wild D)ucks' nests when riding acrum the hills in quest of Bustards and it is ever a marvel how they manage to conduct their tiny atoms of newly hateded ducklings across the long stretch of hard dry ground alive with vermin of all sorts, both four-footed and winged, besides predtacentus smalsers and

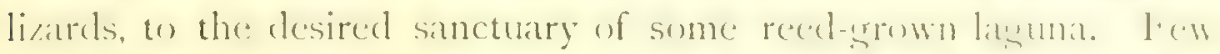
fricondly streams lead (1) the marshes betow, for in spolin in the

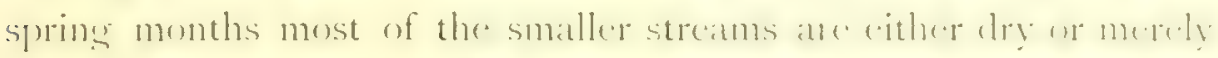
a succession of pools with steep vertical sides, ill-adlapted as

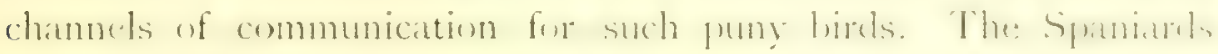

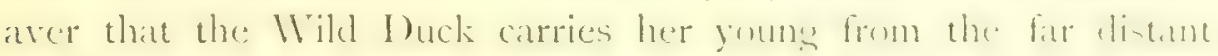
nests to the laguna on her back.

Now and again you come upon masses of decaying recels alluse the eneneral surface of the water, and here you see man! wation basking in the sum, sometimes a dezen tereether. These are the

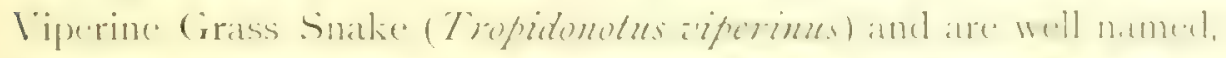
for although hermless, like the Common Cirass Snatie, in sire, builet.

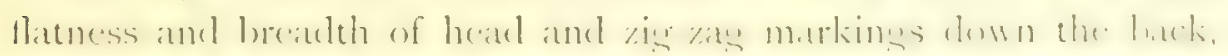

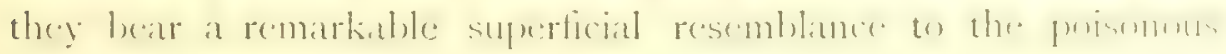
Viper (Vipera latasti).

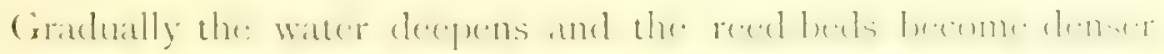
and taller until you arrive at the great tract of bulrush which forms the sanctuary for so many birets. Combitering the number

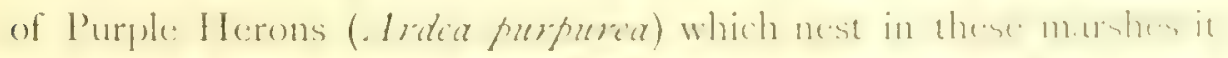
is curious how little one sees of them and hem easy it is w mi... 
their nests. As in most kinds of birdsnesting, I have found it far better to go to some commanding point whence I could watch a marsh with my glasses from a distance and thus decide upon the best part to search for Herons' nests than to tramp aimlessly through it on the off-chance of finding some. The essence of success in all such operations lies of course in lieeping to the required direction when one leaves the higher ground and enters the big reeds. Marsh Harriers (Circus crmginosus) abound in such places and as you work through the reeds they frequently rise from some temporary resting-place amid the beaten-down rushes. Owing to the cover from view given by the high reeds these handsome birds often pass close by; the creamy white of their beautifully marked heads and the delicate tints of their ash-coloured shoulders, wings and tails, when thus flying in the sunlight, can hardly be imagined, certainly not realized, from a stuffed specimen in a museum. One day I saw one of these birds make a sudden stoop and disappear among the sparsely growing reeds within 40 yards of me. As there were at least $2 \mathrm{ft}$. of water and the reeds were not at all thick, I was considerably puzzled by the manouvre and proceeded quickly towards the spot, only to find it had alighted in a Coot's nest with eggs which the rightful proprietor had left owing to my near approach. No harm was done and, the Harrier having departed the Coot as quickly retook possession. From this it is tolerably evident that the Coots can protect their eggs so long as they do not leave their nests. No doubt the Harrier, upon seeing the Coot depart, thought the opportunity too good to be missed and thus came within easy range of me and in fact did not leave until I was close to the nest.

Purple Herons sit very close and often spring from the nest within a few yards of the intruder. The nests are simply collections of dead bulrush, the base being usually formed of last year's growth, brown and withered, still standing as it grew but bent and beaten 


\section{Purple Herons}

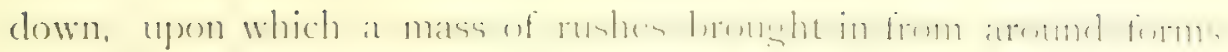

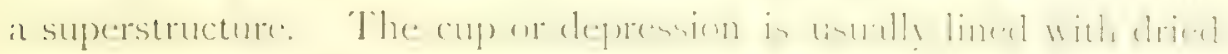
reeds and is raised from 12 to $30 \mathrm{in}$. above water-level. The exces

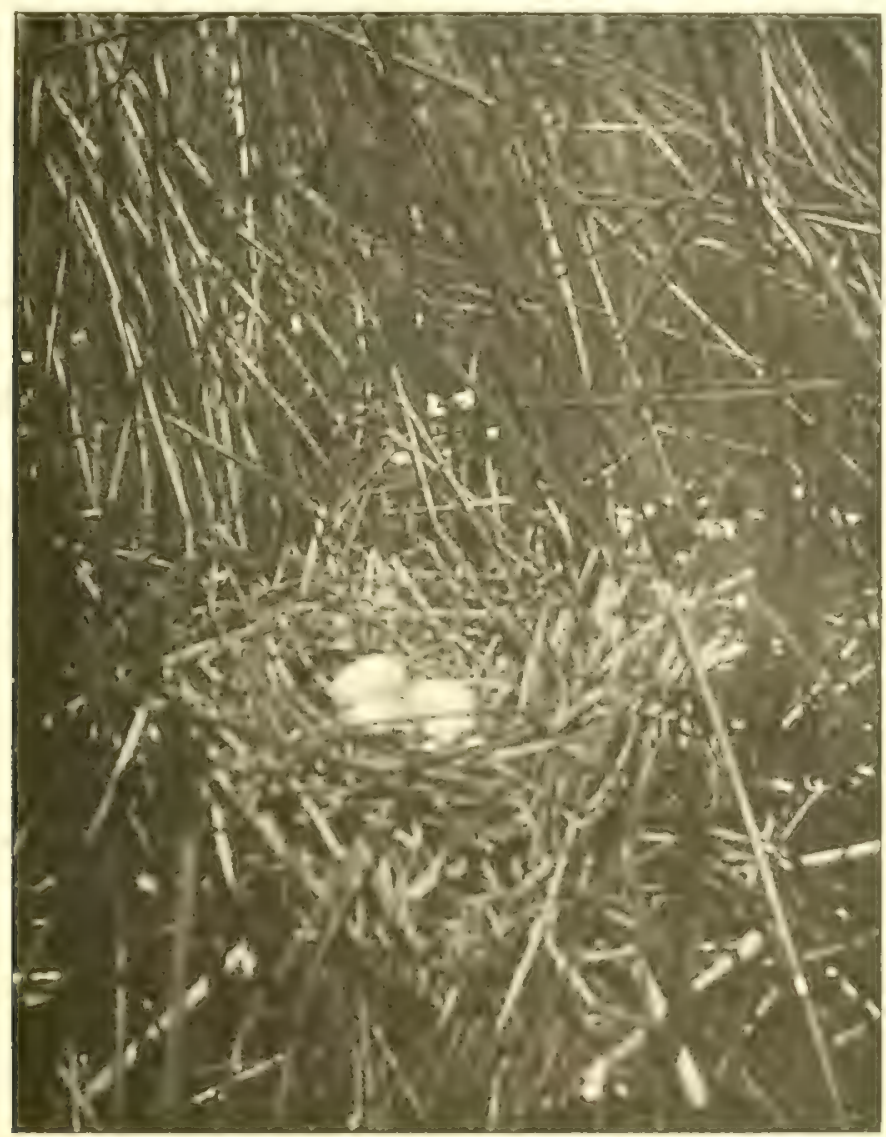

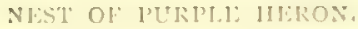

are from three to five in number and of the well-known delicate pale blue of the Common Heron's. Once I found a nest with seven

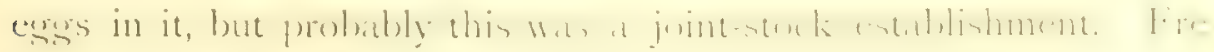
quently nests will be found with only one or two hard-set eggs. 


\section{A Day in a Laguna}

In such cases I have good reason to believe the Marsh Harriers have devoured the others. More than once when I have put a Purple Heron off its nest I have seen a Marsh Harrier dash down and commence to eat the cgoss, and I have sometimes disturbed one of these robbers in the act.

On 26 April I903 I found a number of Heron's nests containing from one to four eggs all hard set (I tested them in the water to find this out) and all stained with blood, showing that the Harriers

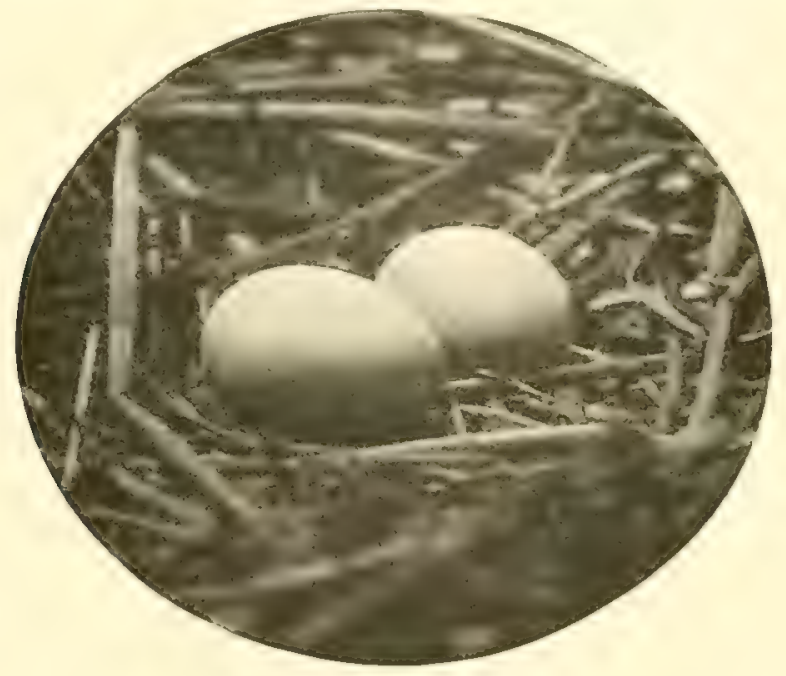

EGGS OF PURPLE HERON.

(Size $2 \%$ in. $\times$ I $^{\circ} \mathrm{in}$.)

had been at work among them. The Harricrs seem to take toll of the first eggs laid, for curiously cnough in another year I visited on I 3 May a number of nests in the same marsh all of which (save one with five) contained perfectly fresh eggss. The Harriers frequently lay their eggs in the Herons' nests and must surely be most undesirable neighbours.

At places in these lagunats there are extensive pools of open water and ayain narrow and sinuous channels which always look 


\section{A Floating 'Terns' Colony}

peculiarly deep and dangerous but are seldom so. It is a curious sensation wading alone along these water-lanes with the high

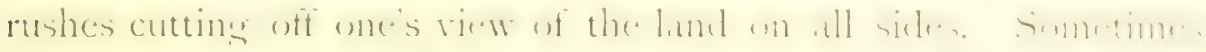

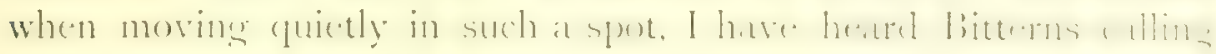
in the dense reeds close by or been startled by the curious cry of

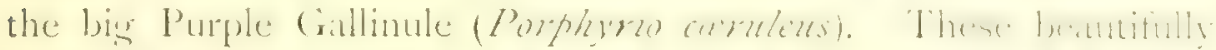

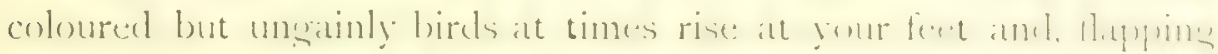
away for a few yards, subside into the reeds again. Once I cane round a corner almost face to face with a Great Crested Grebe. The fine (ireat Reed IVarbler (. Icrecephalus turdodides, which builds at most artistic nest suspended amid the bulrush. l,renth in this marsh and its powerful song can be often hearl at when quarters.

In the more: ngen parts of the lagund, away from the hish reeds and where the whole surface of the water is whitened by the thwer.

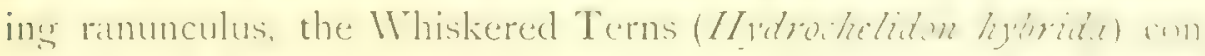

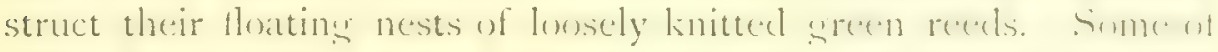
these thimsy platforms are held by their surroundings and are thow lightly mored, but others again are attached to nothing and triti with the wind. Thus one year in Maty I came: upon severd sorme of nests scattered about among the young reeds and upon resinting the place a few days later found that the majority of them hat beren blown by the wind to the lee side of the layguna, where the were

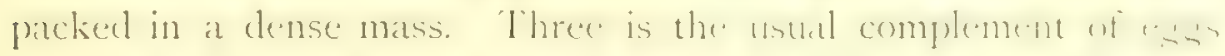

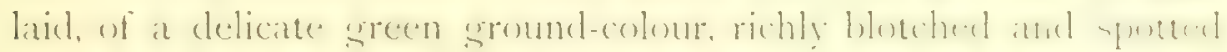
with black and brown. The oled birels ane singularly bantiful an

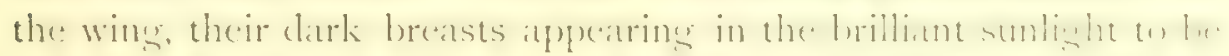
guite black and contrasting with the ir silvery arey back and wins. So long as you are in the neinhlourhemed of ome of the ir lahe dwellings they keep up a great commotion and induldere in whi-

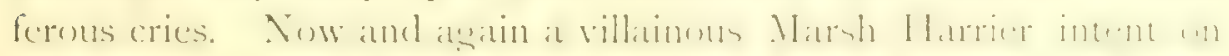

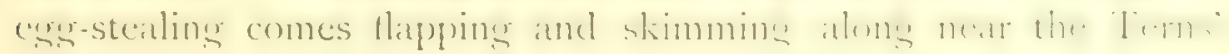


sanctuary, upon which the wallant little birds make up a party to mob and harass the big intruder, clipping and striking at him from above until he makes off.

As already mentioned, when wading about in these lagunas I carry a long stick such as all cattle-herds use in Spain. It enables me to plumb the depths, and saves many a fall either from the uneven bottom or when the reeds and water-plants wet around my feet. When carrying photographic apparatus, a fall in $3 \mathrm{ft}$. of water may spell untold disaster.

Very often when working about these marshes you come right upon bulls or cows which have betaken themselves to the reed-beds to avoid the flies and heat of the day. On such occasions a grood bull-stick affords at least some moral support and one which has at times extricated me from awkward situations. What would be its precise effect on a bull which meant to be disagreeal)le I cannot say and I hope never to test. I once asked a famous old bull-herd whether in such an untowarl case, I could not with my steel-pointed garrocha intimidate the brute. He replied, drily, "Ya vendrá mas pronto," "He'd only come at you all the quicker"; not very encouraging to the amateur bull-fighter!

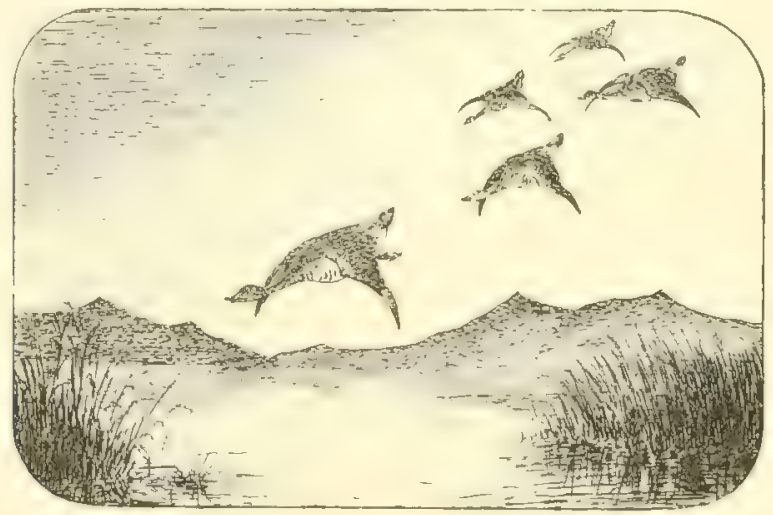





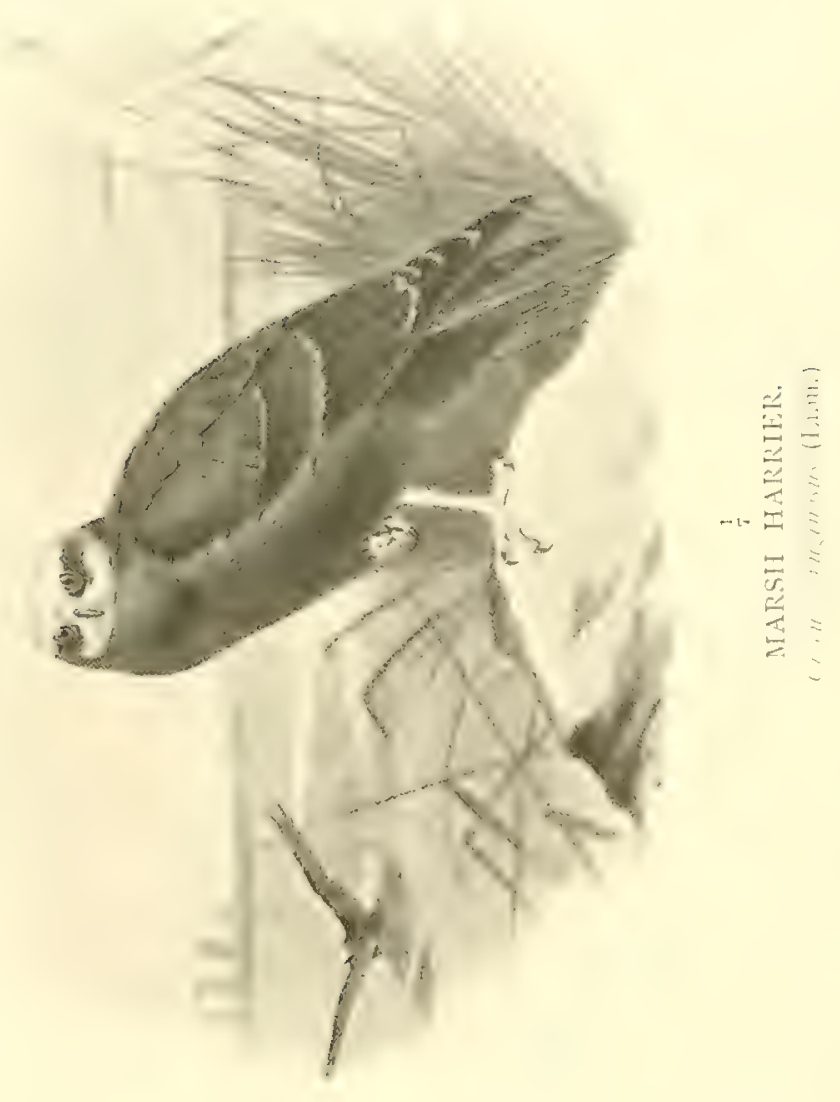




\section{CHAPTER II.}

\section{THE HARRIERS.}

Narsh Harriers-The most indefatigable of hunters - A constant trial to the sportsman-Semi-aquatic labits - Beautiful adult plumage - Montagu's Harrier - Hen Harrier - Pale-chested Harrier - Marsh Harriers' deep engrossment in search of quarry-Their boldness and strength-() uickness of vision-Relative quickness of vision in birds-The small Gulls apparently the quickest - Colonies of Harriers - Young Harriers in nest - Their pugnacity-An unlucky day's birdsnesting.

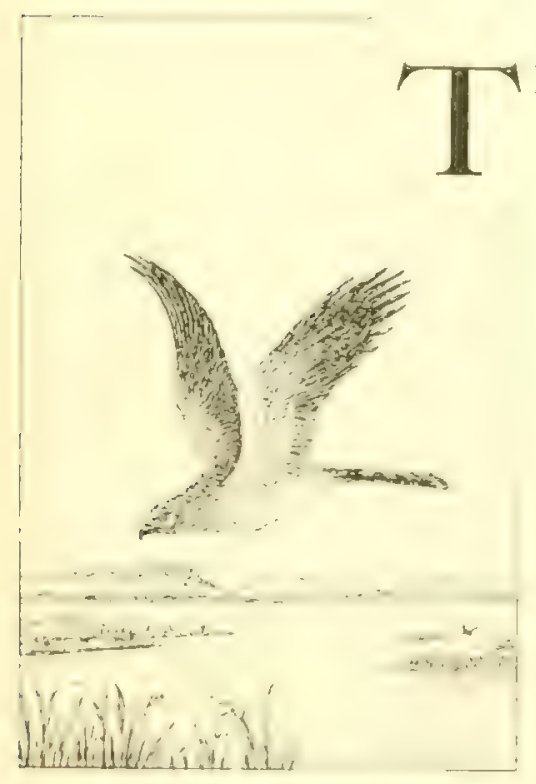

Is boatiful family is well represented in southern Spain. The Marsh Harrier (Cimcus comginosus) is especially abundant and is to be found in great numbers in all the low-lying and marshy districts. Throughout the year and in all weathers, from carliest dawn to the lingering lighe after sundown, they are to be seen patiently quatering the reed beds and swampy portions of the plain in quest of anything that may turn up), for nothing scems to come amiss to them. "They" are par. ticularly fond of the fresh-water tortoises which abound in such localities; they are also famous egg-stealers and in the spring months, as already described, exact a heavy tribute from the nests of the Purple Iterons and Coots. 
To the sportsman they are an ever-present trial, for they are constantly on the look-out for wounded wild-fowl or Snipe and they have a knacli of suddenly appearing from nowhere and annexing a wounded bird within sight but beyond shot of the grunner. Any bird not immediately picked up by the shooter is sure to be devoured by these diligent scarchers. The rapidity with which they do this is both surprising and annoying. Not long agro I dropped a IVigeon dead on the top of a yrassy bank about 50 yards across a river; not having my retriever with me I walked down to a ford not half a mile off and crossing, returned along the opposite bank to pick up the bird. But in the brief interval a Harrier had been down and had eaten the best part of the Wigeon's breast! It may be taken as a rule that any duck shot at evening flight which are not picked up at the time will be found by the Harriers at dawn and devoured. Now and again, if a goose or duck chances to fall on its breast amid the reeds, it may perhaps escape notice for a few hours, but the sportsman who has failed to pick up his birds overnight will in most cases find them picked clean when he reaches the spot next day. What between the prowling foxes which carry off any wounded birds that may reach the shore and the water tortoises, which devour those which may fall into the dense reed-beds, the chances of recovering wild-fowl lost over-night are indeed smail.

I do not know any bird of prey which is so thoroughly at home among the waters of the big lagunas as the Marsh Harrier; many pairs may be described as being semi-aquatic in their habits. I) uring the winter months from my shooting punt I see them habitually resting and roosting in the clumps of dead reeds a mile or more from the foreshore, whilst in the spring they invariably nest in the clense beds of bulnush or reeds, which at this time of the year are usually $S \mathrm{ft}$. to $9 \mathrm{ft}$. in height. Most commonly they seize upon the nest of some luckless Purple Heron, adding insult to injury by first eating the big blue eggs of that bird. 


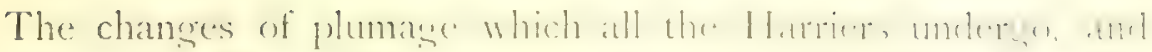

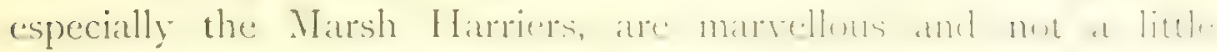
perplexing. The difference between the sexes too, as is well known, is very remarkable. An alult male Marsh Harrier with

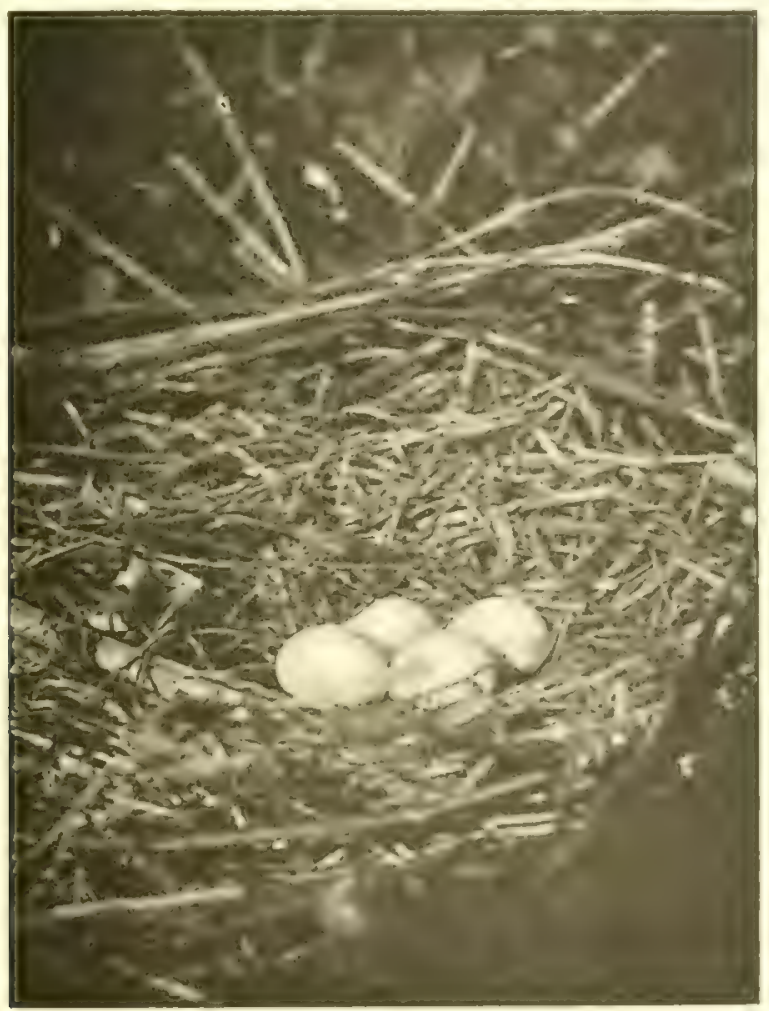

NEST OF MIRSH HARRIER.

its ash-coloured markinges on wings, shouklers and tail is rery

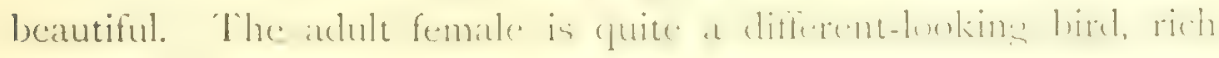
chocolate brown in colour with a palc yellow crown; so very pale at times as to appear quite white. 'This is the plumage figured in the plate. 
Next in point of numbers to the Marsh Harriers is Montagu's Harrier (C. cinerecers), a species not alwilys eisy to tell on the wing from the Hen Harrier (C. Gancus), the best-known English species, and the Pale-chested Harrier (C: mamms). In all these three the adult males are of a delicate slate grey with black tips to their wings, whilst the females are generally brown in appearance. Montagu's Harrier, whilst at times nesting in marshes, also resorts to heaths and dry localities. Colonel Irby found a colony of over twenty pairs breeding in a marsh in Morocco.

Although I have constantly come across all these species, my daily companion at all times of the year when in the low-lying country is the Marsh Harricr. Watching them as I have, at all seasons and in all sorts of places, now when waiting for duck to flight or perchance in spring-time when watching some marsh-birds nesting or again when crouching low during a Bustard or llild Goose drive, one marvels at their undefeated pertinacity and unceasing efforts to find their prey. That they are extremely quick-sighted is platin from their mode of life and methods of huntins. All the same, I have frepuently outwitted them when I have been lying prone; then, while I remained perfectly motionless, they have sonetines been so engrosicel in their minute inspection of what lies below as to pass within close shot. Their boldness is at times remarkable. In Janary rgo7 I was lying up waiting for wild-fowl, concealed amid some matted scrub and herbage. I had killed a Grey-lay Goose and some duck and had set them up on forked sticks to act as decoys, close to the foreshore and within 30 yards of my position. Presently an adult male Marsh Harrier came beating up wind along the water's edge and upon spying the decoys made a dive at them, but apparently suspecting that something was wrong, alighted within a few feet of a Pintail dralie. I was curious to see what he would do as I imagined he would hardly be able to lift so heary a bird. Next moment the 


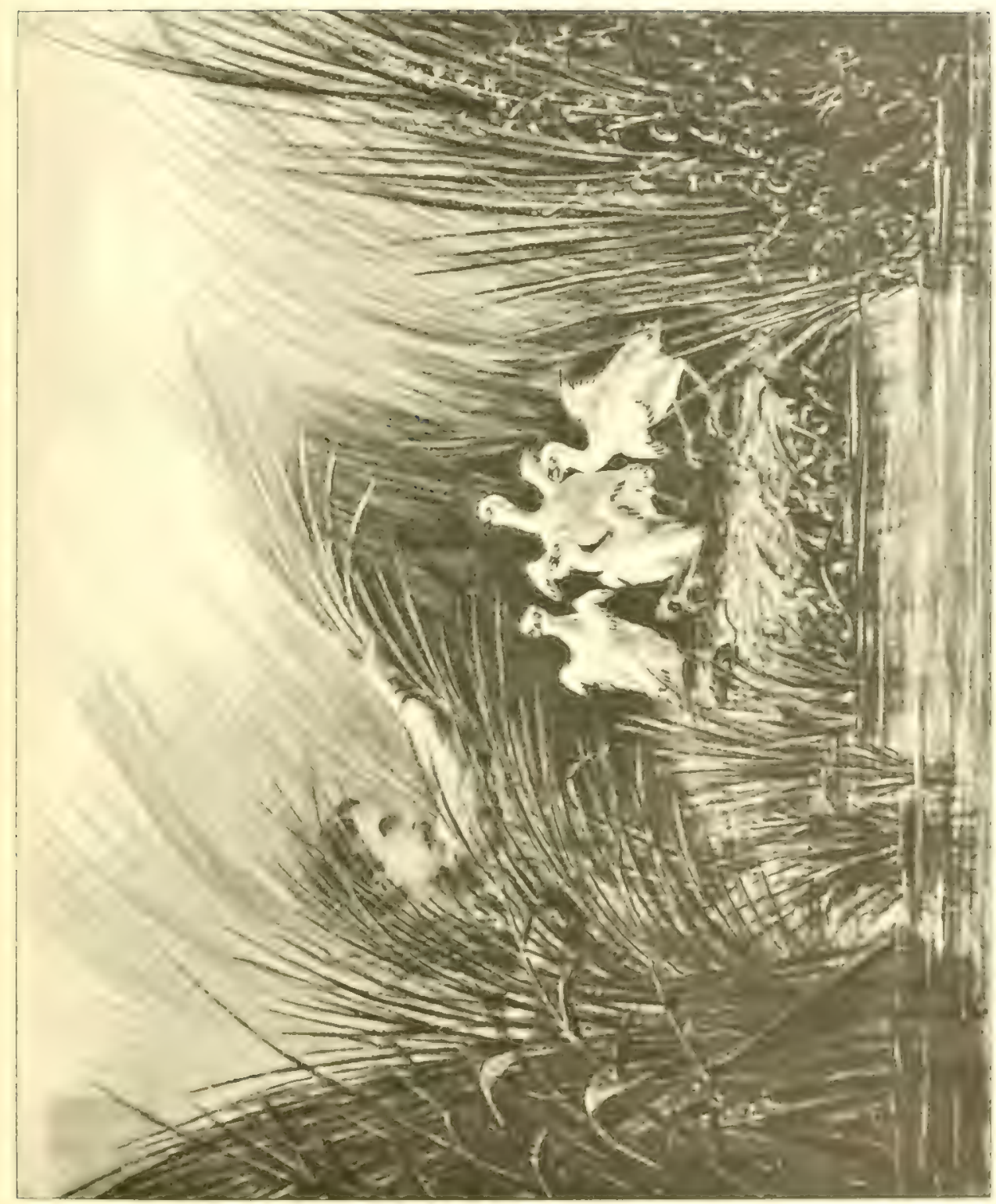





\section{A Nest of Young Savages}

Harrier ran at the defunct bird and literally jumping on its back, seized it and, taking wing, was about to make off, when, in order not to lose my duck, I shot him.

The comparative quickness of vision of the various orders of birds is interesting to study. My own conclusions are that none see quicker than the smaller species of Gulls, and after them the larger Gulls. The most wary of birds, such as the Great and Little Bustards, Curlew and various raptorial birds, have now and again all come past me within easy shot, when lying concealed. Not so the small Gulls, which ceaselessly drift up and down the waters of the lagunas in winter and which somehow always detect one's presence before coming within shot and swerve off.

In some of the large tracts of bulrush Marsh Harriers nest in colonies and even in small marshes it is no uncommon thing to find two or three nests within 20 to 40 yards of one another. As far as I can judge, they seem to prefer to occupy some other bird's nest to building one for themselves, but I know of several

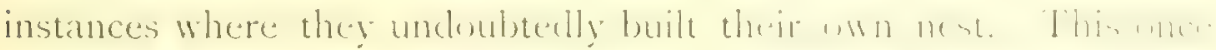

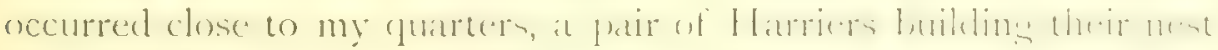
in the reeds not 10 yards from the bank of a reed-grown pool.

It is many years since I found my first nest of young Harriers, and it cost me dear. I was riding alone near a marsh, and secing some Harriers enter a high patch of bulrush I dismounted and, picketing my horse, waded in. 'The water was $3 \mathrm{ft}$. deep and the

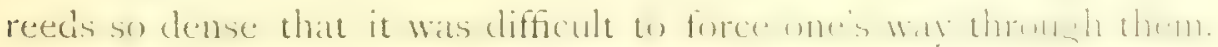

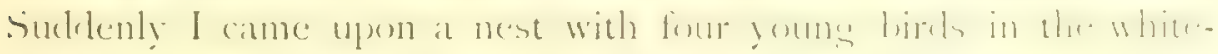
down stage with their primares just lubleling. The indunt the? saw me they sprang up and showed fight, assuming various attitudes of defiance. It was a novel and interesting sight to see these little savages in their home anid the waters. Upon my attempting to pick up one of them to examine it closer, it struck

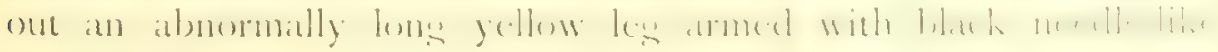


claws. In fact every time I tried to yrab one of them I was met by similar tactics accompanied by fierce digs of their sharp little beaks. It was in truth difficult to find any spot left unguarded by the four beaks and thirty-two sharp claws of these little wretches. Owing to their weight, the nest had got flattened down and was more like a raft on the surface than anything else. In it was a half-eaten water-vole and the remains of some small snakes and fross. I made a water-colour sketch of it, of which the picture here reproduced is a facsimile.

This was one of my unlucky days. True it is I got some Harrier's egoss (there was a second nest hard by with five egys), also I made the acquaintance of young Marsh Harriers for the first time. Unfortunately during my absence in the marsh, my horse picked up some poisonous herb which caused its death within two days, a sad loss to me and one which seriously interfered with my ornithological work during the season of 1879 .

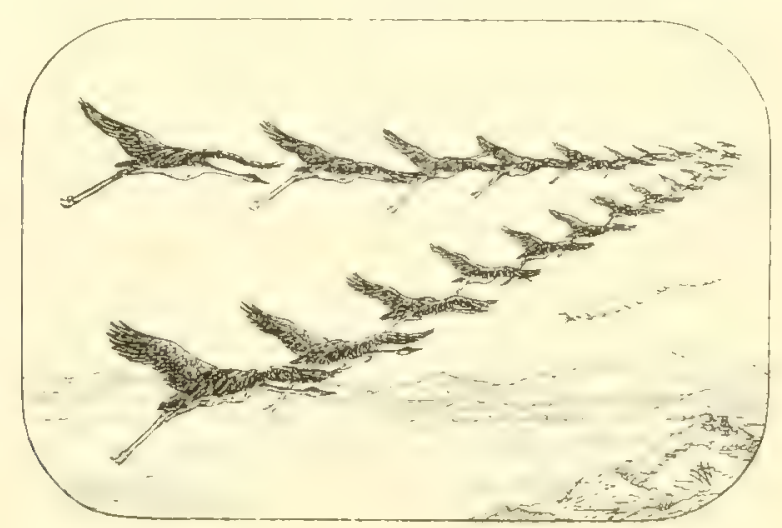





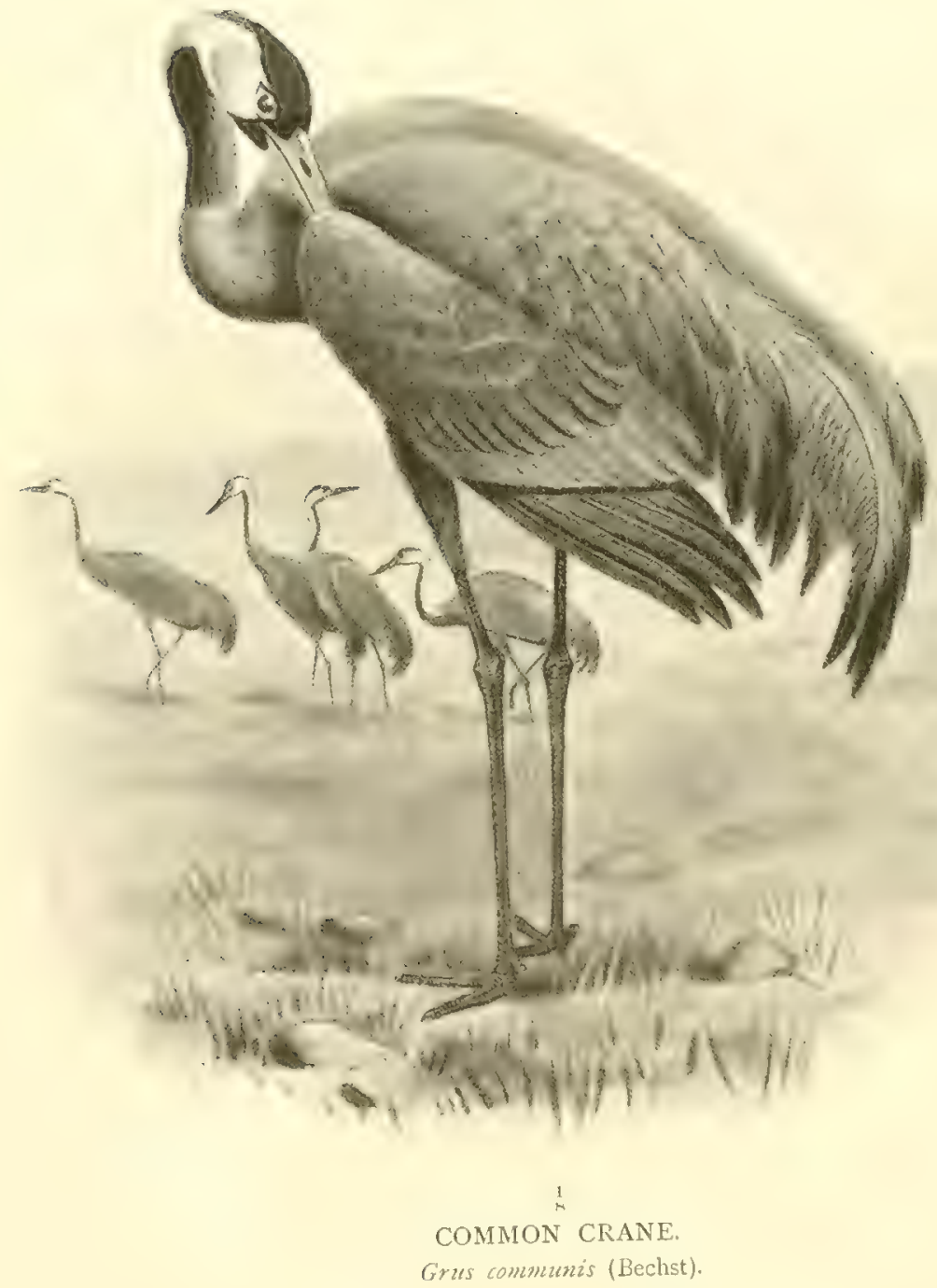




\section{CHAP'TER II. \\ THE COMMON CRANE (Gm commmis).}

I conspicuous feature in the marshes-Flighting at sumet-Lack of caution after dark Musical call- hast migration in spring and autumn -Crane for. mations-Exact compass-course of misration-Decreasing numbers of nestin: birds in Andalucia-In quest of the Crane's nest-l'nwelcome intruders:I'nseasonable destruction of birds - A second day's observations - Indecisive results - I third day-I'rotest by other hird-residents - I he Cranes appearDifficulties of "marling" in great reed-beds - Idvance towards the birdsCranes simulate disablement-Cranes' nests and Cranes' paths-1m batfled - The fourth day-Value of a cross-bearing-Find the nest with eggsl'hotographing under difficulties - Retriever and Crane' nest- Youngr Cranes.

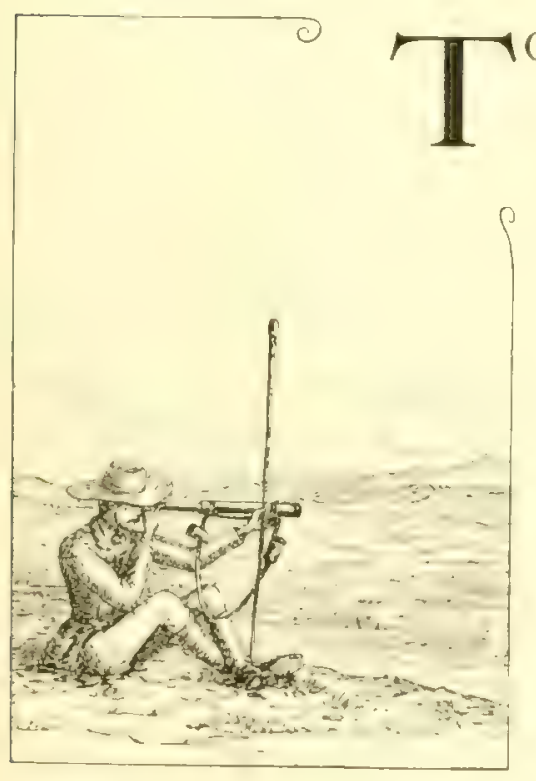

both the naturalist and the sportsman in the low-lying parts of southern Spain the most conspicuous of birds is the Common Crane and his note is the most familiar. Wherever large marshes are to be met with they are to be seen either in pairs or in small parties, walking through the reeds and rushes with the dignified slow step so characteristic of the family, ever and anon pausing to investigate some matter of interest in the shape of a luckless water insect or perchance a fros or other small reptile which may come within their purview. It other times they ma! be went ficeling 
along the low hillsides bordering on the marshland, where they seem to find many beetles and other morsels to reward their rescarches. But they are by no means wholly insectivorous, and are at times somewhat destructive of the newly sown corn and, later, of the bean crops. These truly noble birds were once common in our fenlands lut have lons since disappeared, their title in many parts of the British Isles being now conferred on the Common Heron, a bird which, although lupe in the eyes of Englishmen, is considerably less than half the size of the rightful owner of the name.

I) rring the winter months considerable thocks of Cranes congregate in favourable regions in southern Spain, and it is no uncommon sight to sece parties of fifty or more thighting of an evening to the marshes to feed. By day they are ever on the alert and hence, happily, are rarely shot; but after a nightiall no bird is so confiding and all who have wated for duck after sundown in these parts can testify how on such accasions, provided the sumel remains still, these great birds will placidly fly within 25 yards of him, their curious creaking cry having well alvertised their approach some minutes before they come in sight. In such circumstances nothing could save them form extemination sare: the fact that their flesh is very coarse, and that few beyond the very poorest of the country folle care to eat it. It is indeed a sin to kill these mannificent birds: for magnificent they are as they stalk solemuly through the reeds, the brilliant sun of Andalucia illuminating the lustrus silver grey of their backs and the splendid black tertial plumes which deck their sraceful forms. Their strangely melodious and far-reaching cry, so constantly heard by day, is also indissolubly connected with the wilder side of life in Shain and has viven interest and pleasure to many who were ignorant whence it came. But besides these mumerous winter visitors to Indalucia and a few summer residents, enormous numbers of Cranes pass in the autumm through Norocan 
returning northwards along the same route in the month of . Warch. The numbers that are sometimes seen on these occasions are well-nigh incredible. Colonel Irby and Dr. Stark, both most trustworthy observers, have recorded how on onc occasion they reckoned that over 4,000 had in one day passed over the spot which I am about to describe. This was on I March 1874 , and it is

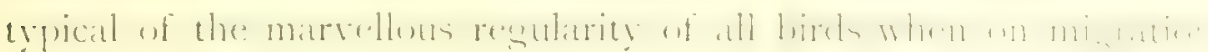
that upon the same day in 1907 , exactly thirty-three years later. the passage of the Cranes northward was once again at its maximum at the same place. The well-known $V^{\top}$-shaped formation in which they usually fly varies in composition from a fell individuals to fourscore or more on either side. At times they drop the I' formation and move in long undulating "slieins."

The direction taken by the successive flocks (as well as of that of the Storks, which pass northwards in flocks, at times numbering from 400 to 500 each, but some weeks earlier than the Cranes). in accordance with the observations made by me for many years in the same district, is almost invariably the same, namely a line which when plotted on the map passes about 6 miles west of the old town of 'Tarifa and runs from $\mathrm{S}$. by $\mathrm{E}$. $\frac{1}{2} \mathrm{E}$. to $\mathrm{N}$. by $\mathrm{W}$. 11 .

From this region they seem to spread all over Europe, their

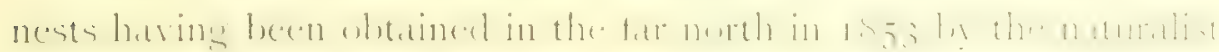

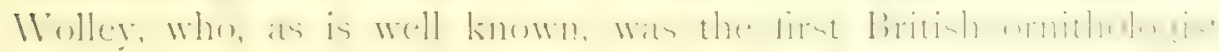
to find the nest; his delightful description of it amid the birchgrown bogs of Finland has given pleasure to very many. They have also an eastern stream of migration which I lave myself witnessed in the Levant.

About thirty years ago, considerable numbers of Cranes remained to nest in south-west Andalucia; but constant curging by professional "collectors" has sadly reduced their numbers. In

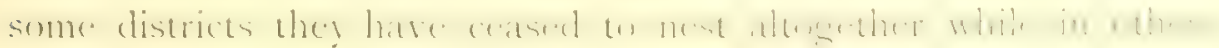
where I can recall seeing over thirty pairs in the nesting season 
there are now hardly half a clozen to be found during the summer months. In such circumstances it becomes almost a crime to rob their nests.

In 1906 I was especially keen to find once again a Crane's nest, as I was anxious to obtain photographs of the nest and egos for the purposes of this book.

The very difficulties of the whole operation as I knew well from past experiences gave additional zest to the undertaking. The region where some few Cranes still nest comprises many square miles of marshland covered with luxuriant reed-beds, and owing to distances, topographical obstacles and the lack of accommodation this district is decidedly difficult to reach and to explore thoroughly. The whole of the lower lying lands are submerged by the winter floods, and as these dry off vast areas remain which in some years are still under water until the summer. It is due to this variety of levels that the reeds in some places attain to a great height, in others owing to the water draining off earlier in the spring, are only $4 \mathrm{ft}$. or $5 \mathrm{ft}$. high and in others for the same reason again still less. The particular ground selected by the Cranes is usually where there is water from 9 in. to $\mathrm{S}$ in. in depth, and where the reeds are not too high to prevent these wary birds when they stand up on the nest from seeing the approach of anybody through or over the tops of the reeds. How rast and apparently interminable are these reed-beds can best be realized by those who have set themselves the task of traversing them. At places they are so luxuriant and strong in growth that it requires considerable excrtion to force one's way along even for a few yards at a time.

It was on one of the early days of May that I rode out to a part of the marshes where I had noticed several pairs of Cranes on more than one occasion during the previous month. This portion satisfied the conditions I have described as a brceding-spot for the Crane, and, further, was of reasonable size, extending for over 
2 miles from north to south and rather less from cast to west, in all some 2,500 acres, without a bush or stone or any other landmark in its whole extent, and for this reason admirably adapted for at nesting-place. Arrived at my destination, I hobbled my horse in a grove of wild olives and lay down on a low hill, about is ft.

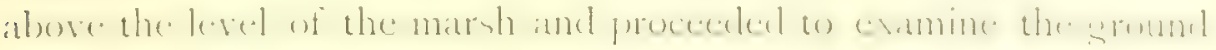
before me with my field-glasses, but was not a little vexed to see the heads of two men above the reeds about a mile distant. 'Their unwelcome presence of course made all bird-watching, for the

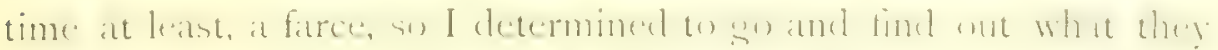

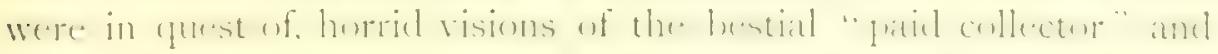

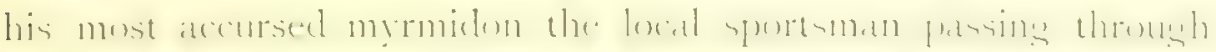
my mind as I did so. Upon the two men detecting my advance and imagining no doubt that I was a grarda of sorts, they

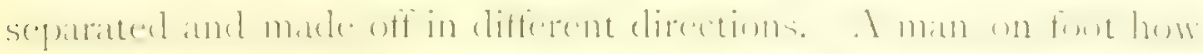
ever has no chance against a Spanish horse bred in the marismas

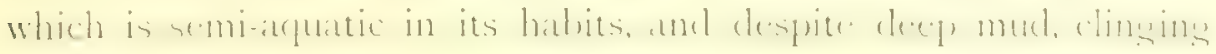
reeds and much water it took but a short time to ride down one of them. He turned out to be a man well known to me from a village about $S$ miles distant. He was carrying a sun and

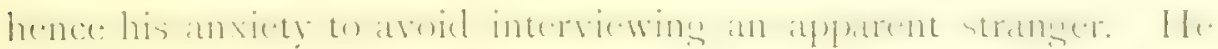
assured me he was merely egging and produced from a sack a number of Coots' eggs in proof of his statement; for all

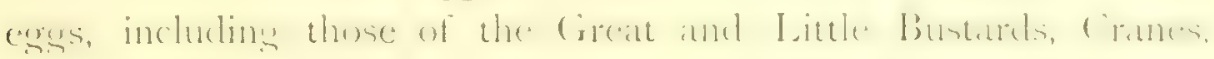
Stone Curlews, Wild Ducks, Herons or 'Terns, are eaten indiscriminately by the folk about here. Upon being pressed, he

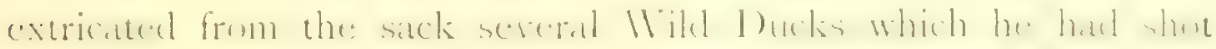

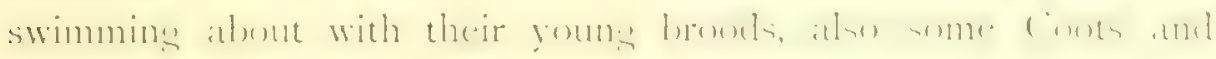
Whiskered Terns; It was of course useless to point out the

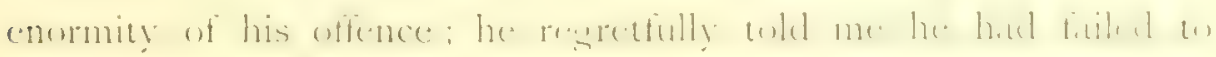

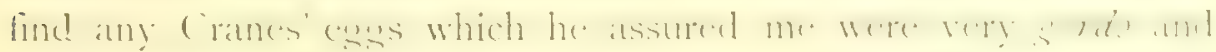
excellent to eat, for how was a poor man on foot to see over the 
accursed reeds? If he only had a horse all would be well, for then he could see what he was about.

Two days later, I paid a second visit to the Cranes' stronghold, but this time selected another point about two miles from my first station and to the east of the marsh, the former being on the south side of it. A careful reconnaissance of the great sea of waving reeds shortly disclosed to me two patirs of Cranes, whose movements I watched most carefully for nigh two hours without being able to form any opinion as to their meaning beyond that one pair had apparently some definite object in view whilst the other seemed to be quite irrational in their methods and movements.

I was unable to revisit the place for some days and then went to the olive grove whence I had commenced operations on the first day. For a long time no Cranes were visible, but other bird life was to be seen in abundance. Immediately in front of me. and between my position and the edge of the marsh was a sun-baked expanse of dried mud over which a colony of Pratincoles (Glariola toryuatar) liept wheeling, ever and again coming up to mob me in protest of my invasion of their sanctuary. In the shallows along the edye of the water some Squacco Herons (-Ardea ralloides) in their glorious nuptial plumage were wading, whilst beyond them the graceful Whiskered Terns eddied up and down. The incessant querulous cries of the Pratincoles and the sharp call of the Terns intermingled in an amazing confusion of sound but its meaning was perfectly clear: Nould I and my horse and retriever kindly go somewhere-anywhere-but at any rate go away, at once or sooner if possible? After a long wait, two Cranes arrived from the north and alighted in the marsh nearly a mile and a half to my front. After much manourring and changes of position they proceeded to walls through the reeds southward. I'resently one disappeared the other halting and posting itself on sentry duty. It was not difficult to come to the 
conclusion that these birds must have a nest and that the exros

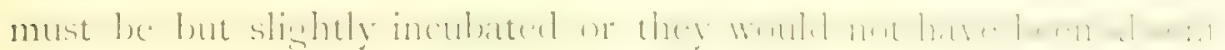
for so long.

After taking a most careful bearing of the spot where the bird had become lost to view, not only on a grey stone nigh two miles off on the far side of the math but on a rocky patch in the sierra twenty miles beyond, I mounted my horse and proceeded to ride the line. Upon descending into the marsh and entering the reed-beds, I at once lost sight of my suiding stone ahead. Luckily, the mark in the sierra stood me in good

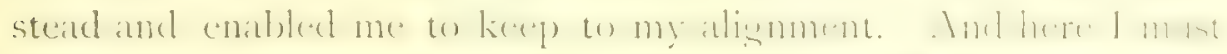
digress for a moment to explain a technical puint wi nu whell innent in this matter of "marking." When a sportsman or naturalist marks the position of a bird or other object, the first and principal thing of course is to ensure that not only is a correct alignment taken from the perint of oberevetion hest that thinalian

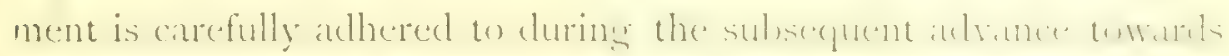

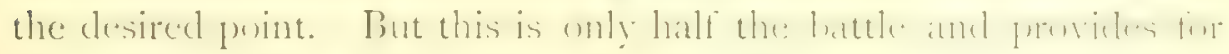

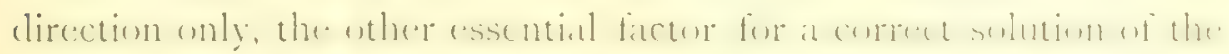
preblem being that of the clistance to les trasersed an reate the objective. This in the case of the sportsman is usually 30 to 50 yards or at most, with a wounded and dropping bird, 100

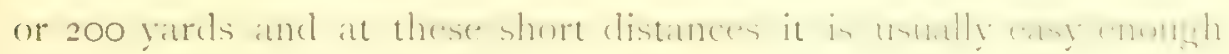
to identify some tuft of rushes, bush or what-not. But in the

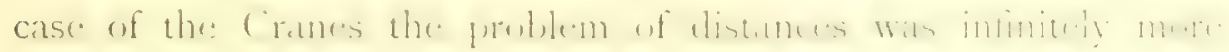
complex. To begin with, the distance was rery great, so great that save with a telescope it was impossible to see the birds at

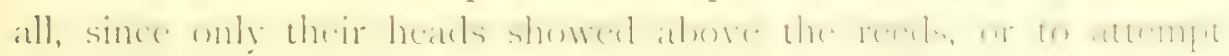
to iclentify the point they were at. Added to this, the vast extent

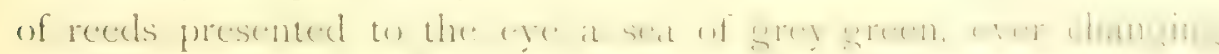

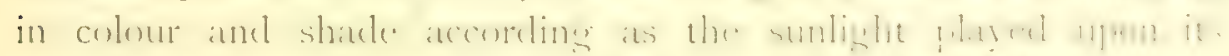

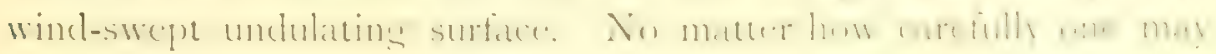


have noted any particular portions of such an expanse through one's telescope, the moment one lowers the latss and tries to pick up the same point by direct vision, the chances are twenty to one that the eye becomes hopelessly confused and the result is failure. Here however, fortune unexpectedly favoured me, for scattered at intervals throughout the great marsh were small belts of young bulrush, forming to the eye bands of slightly darker green. By such adventitious aid I was enabled to locate approximately the desired spot as being somewhat to the left of the fourth or fifth patch of dark rushes. So far, so good. But the moment I descended from my hill and entered the marsh the apparent position of these dark patches underwent a complete change and they seemed all to merge into one mass, and I had to trust to a dead reckoning of my course, somewhat aided by the dark rushes, but also somewhat complicated by them, for on entering the reeds I found bulrush growing sparsely all over the place. As I neared the spot I had marked, both Crances suddenly rose from points wide apart and after flying about a quarter of a mile alighted together and watched my proceedings. As I was curious to see what they would do if I approached them, I marked the spot where I suspected the nest to be by planting my long iron-shod sarrocha in the mud and rode towards them. And now I was witness of a spectacle for which I was not prepared. First one and then the other of the great birds gave me a gratuitous exhibition of what it was like to be: a wounded Crane. No Lapwing ever did the trick with such adroitness. It seemed almost discourteous to disoblige them by ignoring their efforts, and I spurred my horse on as if to overtake them.

It was quite touching to note the desperate earnestness with which they suddenly acquired a broken leg or at stiff joint and tumbled over (much as a boy does who having attached a stilt on one leg, strives to walk), eventually having recourse to their wings 
to recover their equilibrium. Again as I clrew nearer, they woukd

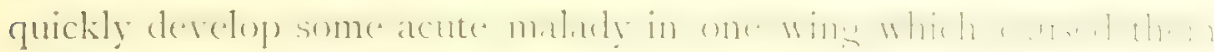

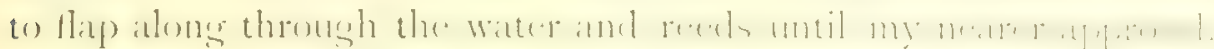
wrought a perfect cure and opening their grand wings, which spread for over $7 \mathrm{ft}$., they sailed off to a safe clistance, ready to repeat the performance should I attempt to follow them.

I now returned to my bull-stick and picking up the old alignment worked along it until I came upon what was obviously an

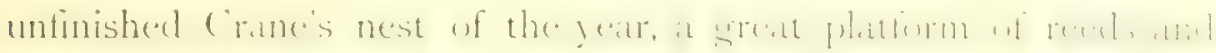
rushes, $5 \mathrm{ft}$. across, raised to the level of the water which was here about is in. deep. Several well-defined "Cranes' paths" led up to this nest. It did not require any profound bird-knowledge to realize that this could not be the nest of the birds which had

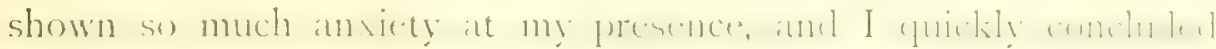
that they must have egges or possibly young not far off. Conse.

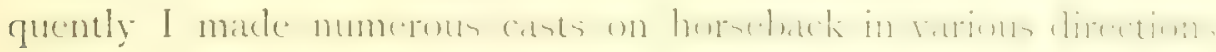
all about the place but without success and eventually returned

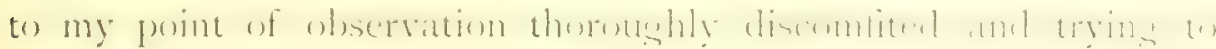
persuade myself that the Cranes had hatched off in the nest I

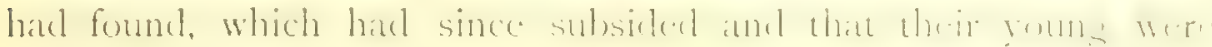
skulking in the reeds.

After half an hour's further watching the Crancs once auain

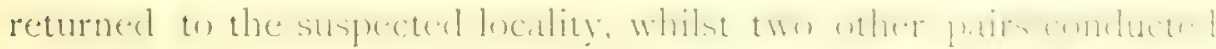

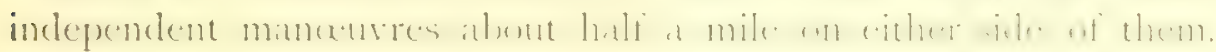
The most patient study of their movements howerer elicited

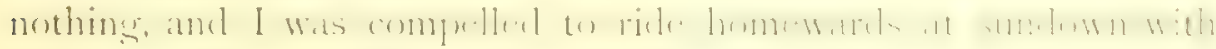
the feeling that I had been completely bafiled.

The following day I once again returned to the attack and proceeded to the hill to the east of the matsh, since I was well assured of the accuracy of the aligmment of the day before, and

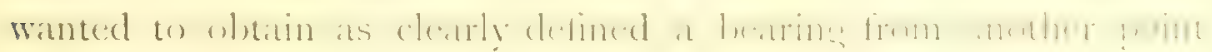
Sure enough there were the Cranes feeding in an arroye, or 
Watercourse about half a mile to the north of the point where they had viven their acrobatic performance of the previous day. Presently they beran to move south-westward and after a time one

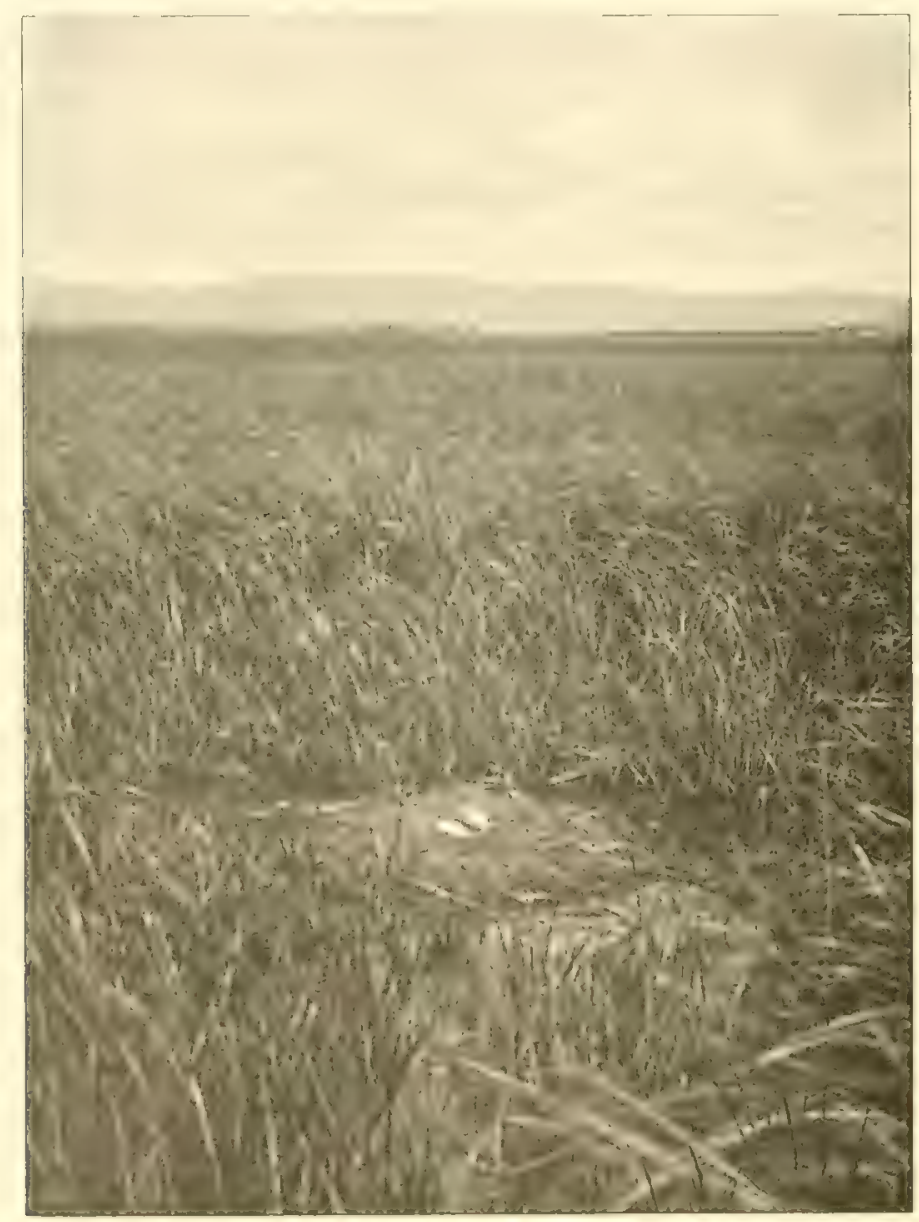

NEST OF THE COMMON CRANE, (Photographed from the saddle.)

sucklenly disappeatred whilst the other took wing and alighted about a quarter of a mile beyond and at once took up a position on semtry duty. I felt convinced that the bird which had disappeared 
had crouched in the reels and rum to its nest, and so allowing some yards for this evolution I took most precise bearings of the supposed spot and resolutely rode the line. After about threequarters of a mile of splashing through the reeds and water, the old Crane rose some 40 yards right in front of me, and pressing forward I came on the nest some 20 yards nearer. Glancing around I found I was on the identical cross-bearing of the previous day. How and why I failed to find the nest on that occasion it is hard to say, for a short ride around brought me to the unfinished nest. It is a good example of the difficulties attending the funding of these huge nests despite years of practice, the aid of glasses and other resources of civilization.

There lay the nest in the middle of a small pond of open water, here only about $9 \mathrm{in}$. deep. It was merely a platform of recels, $3 \mathrm{ft} .6 \mathrm{in}$. in diameter and raised 4 in. above the water-level. In a slight hollow in the midklle of the platform lay two huge egess of the usual type, very much elongated, and of a dull creamy brown colour with rusty spots and blotches and faint brown undersurface markings.

They lay some inches apart, pointing the same way and with the larger ends inclined outwards. Wolley has recorded how in

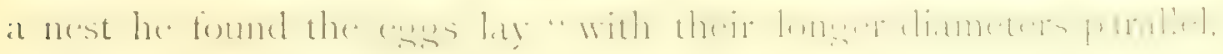
and there was just room for a third exge to be placed between them." It is just possible that the Crane arranges its egres in this position in order to cover them more effectually during the process of incubation. Nost people know very well the colour of the exgs of the Waterhen or Moorhen. These great esess of the Crane have

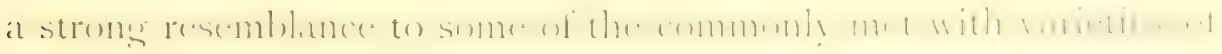
Moorhen's eggrs.

Of course the chief diffeulty in the matter of photographing the nest with the apparatus at my disposal (an ordinary hand camera) was caused by the surrounding mass of waving reeds, 


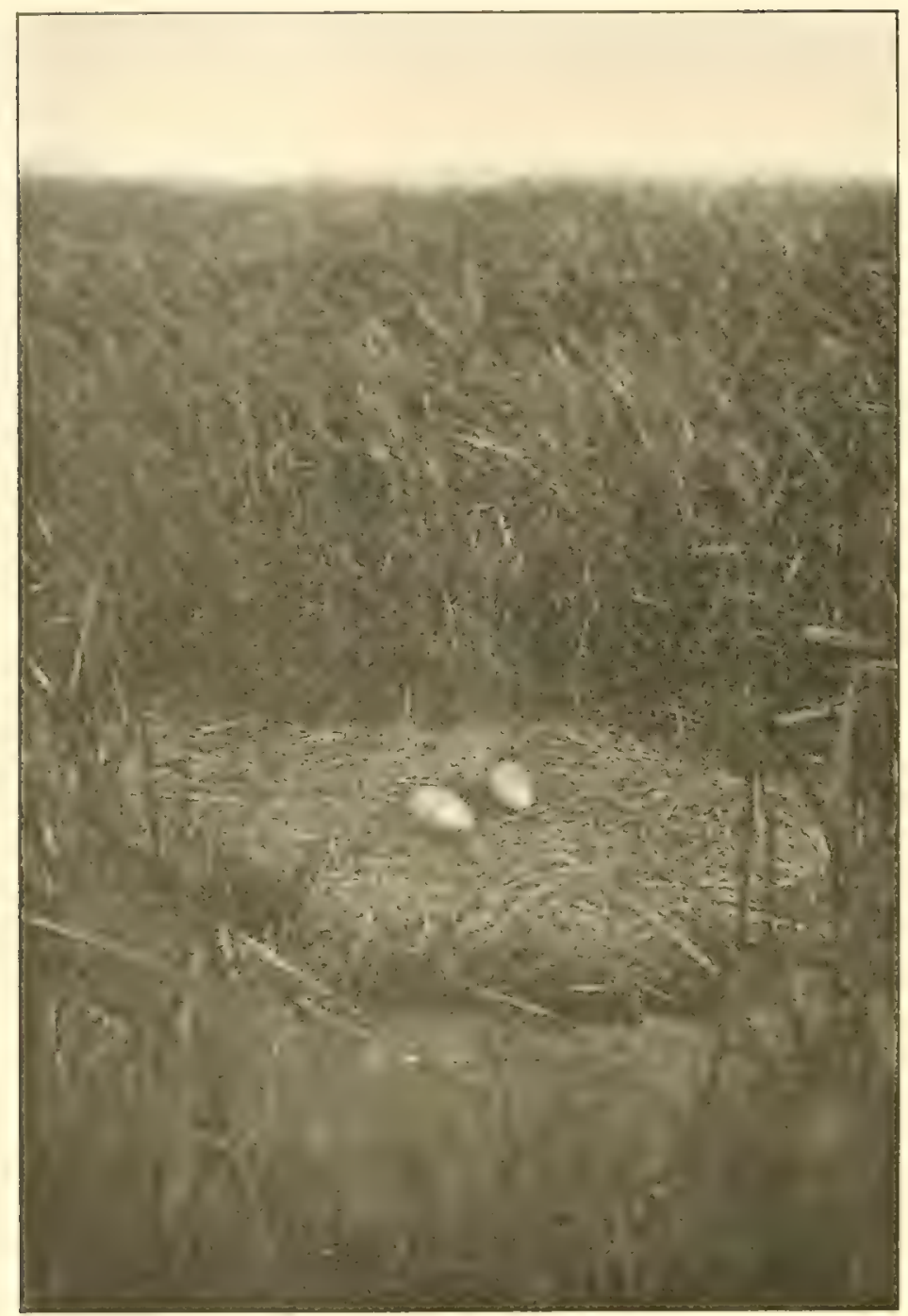

NEST OF THE COMMON CRANE. (l'hotographer standing in water.)

which not only impeded the view but cast moving shadows across the esgis: hence it was necessary to dismount and clear a passage by bending down or cutting away the intervening reeds. 


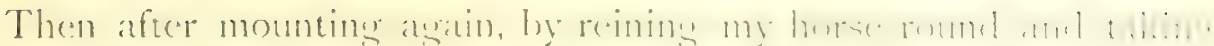
a snapshot, I was enabled to get a general view of the nest and vast expanse of reeds beyond.

In the first picture given the low line of hills in the midelle

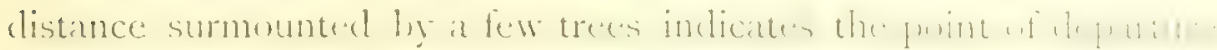
whence I made my final advance on the nest, the outline of the

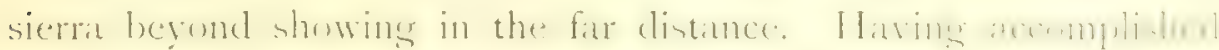

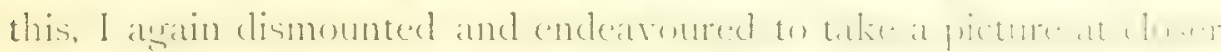

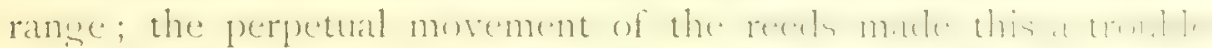

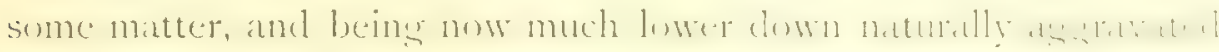
the difficulties. I was, however, so far successful as to be able to show the pool with the nest in the middle of it, my horizon being now limited by the masses of waving reeds.

Lastly, I detached my tripod stand from the saddle and, mounting my camera on it set to work to take photographs of the eggs at closer quarters. It was whilst thus engaged that the

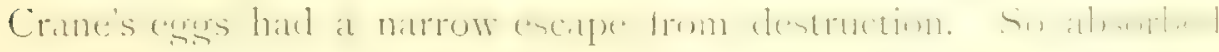
had I been in watching the movements of the birds and subsequently in riding their line and in photographing, that I had

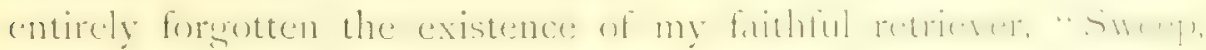
who had not only followed me for hours across the marshes, but for a considerable time had been forcing his way through the

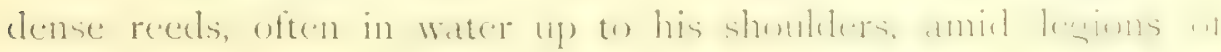
leeches.

It was whilst looking into the finder of my camera that I suddenly became aware of a black object moving among the adjacent reeds and glancing up, I was horrified to see the don scrambling into the big nest with the obvious determination of obtaining a drier billet! A frantic shout, "I)rop!" caused the poor beast to recoil and drop on his haunches on the half-submerged portion of the nest where he sat shivering in the water in mute protest at my forgetfulness. The camera being directed on the 
nest enabled me to place on record at one and the same time his obedience and my own selfishness.

Subsequently I took photographs of the egus at $2 \mathrm{ft}$. and at I 8 in. distance, but the size of the nest and the distance apart of the eggs did not lend themselves to such a process. During the

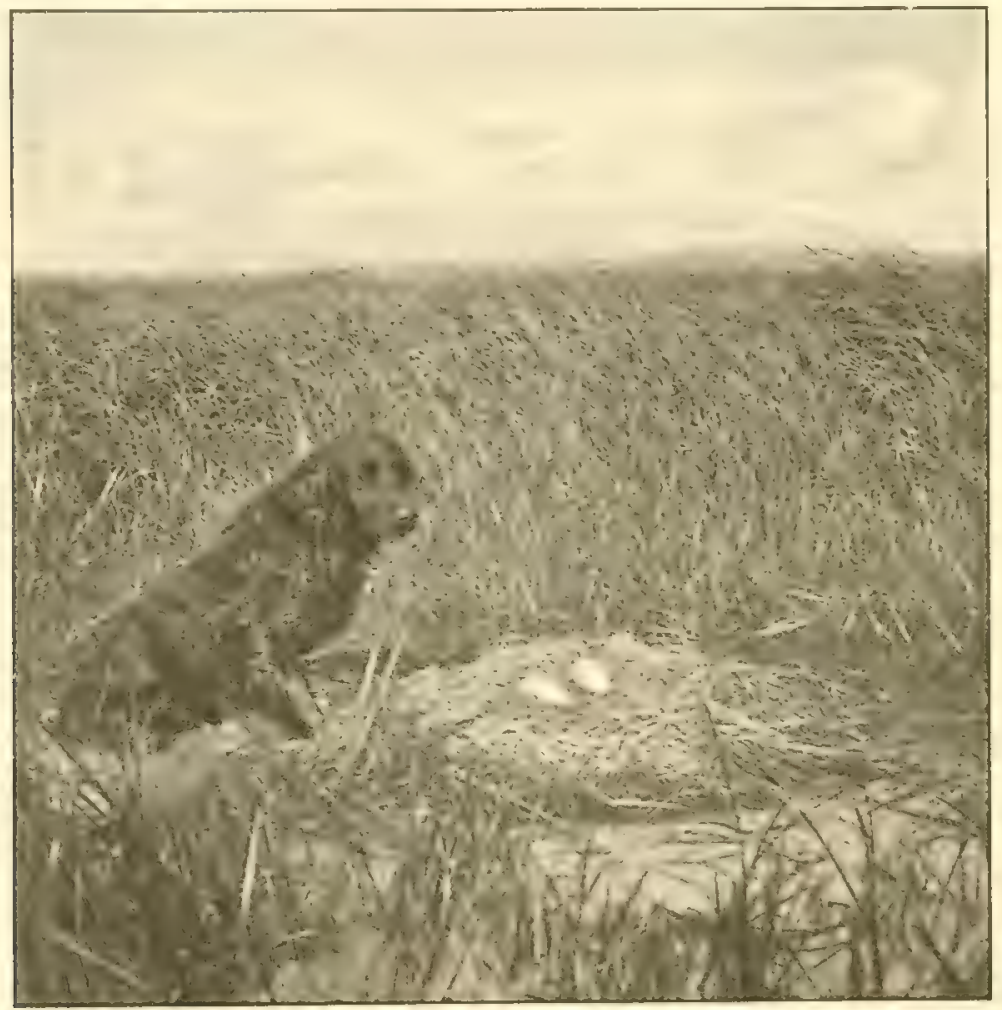

RE'TRIEVER IN CRANE'S NEST.

exposure, a peculiarly vicious insect of the horse-fly family, which hatd been pestering my horse for some time, alighted on one egg and so immortalized itself.

In conclusion, I may say that I subsequently located the other 
Cranes' nests. One of them, belonging to the pair which had caused me such perplexity by their cvasive and indeterminate movements upon my second visit to the marsh, had obviously been robbed, and it was their nest which I came across on the occasion of my third visit.

With regard to the third pair, unless their exws were found and eaten by my friend the predaceous local sportsman, after my

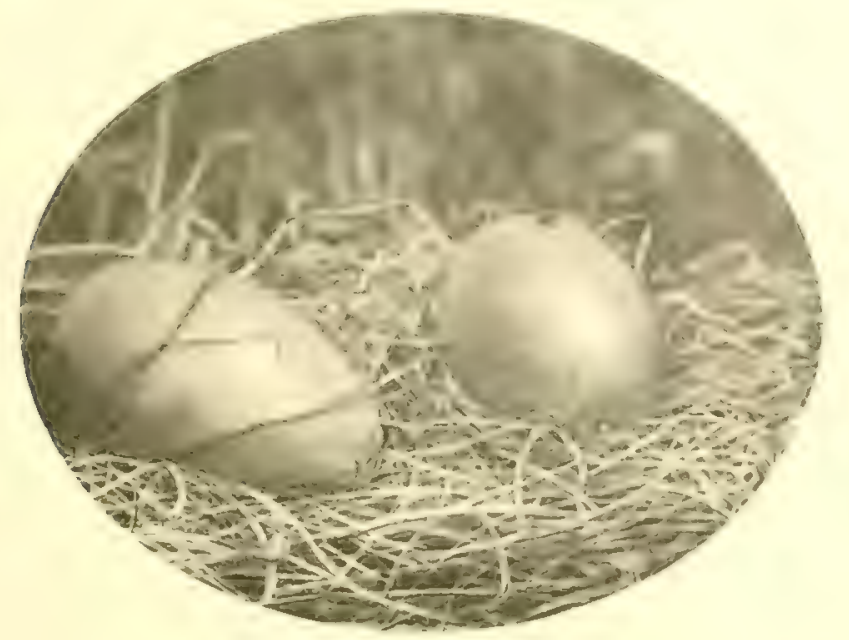

LGGS OF COMBON CRANE (photographed at is in.), showing relative position of two esis, with inclination of larger diameters. Size $4 \mathrm{in.} \times 2.5 \mathrm{in}$.

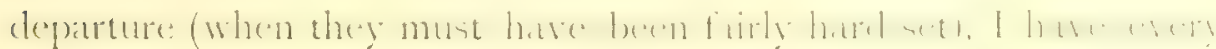
hope and belief that they hatched off in safety.

It is illustrative of the vicissitudes of the wandering naturalist in

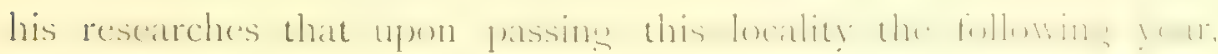
I found that owing to the lack of rainfall in the carly spring after

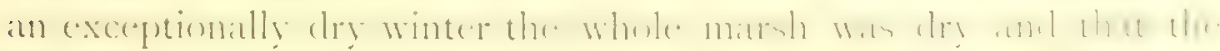

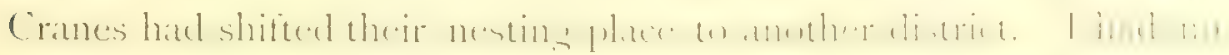
wish to disturb them in their new quarters and so left them to carry out their domestic arrangements in peace. 
I have never had the good fortune to find the young of the Crane. No doubt they are able to run very soon after being hatched out, at any rate I have never seen the young in the nest nor have I ever met with anybody who has. Wolley has described finding the young in Finland some distance from their nest; when he saw them they were much about the size one would expect newly hatched birds to be, judging from the size of the Crane's eyg. Once and once only did I come across a Crane which unquestionably had young. I knew of a nest in a rather wet marsh where the reeds were unusually dense and high and rode out to try to see the young. The nest however was empty. As I circled round the place on the chance of coming across the young, one of the old birds actually rose within $5 \mathrm{ft}$. or $6 \mathrm{ft}$. of the horse of my arriero who was riding a few yards on my flank. I instantly went to the spot but despite the most protracted search could malse nothing of it. Unfortunately, I had no retriever with me, else I feel confident I should have found the young. That they were skulling in the dense reeds and that we rode over them $i$ have not the slightest doubt for not only did the old bird's behaviour in allowing us thus to come right upon her show that she had young but she subsequently settled close by and gave unmistaliable signs by her anxiety that her young were not far off.

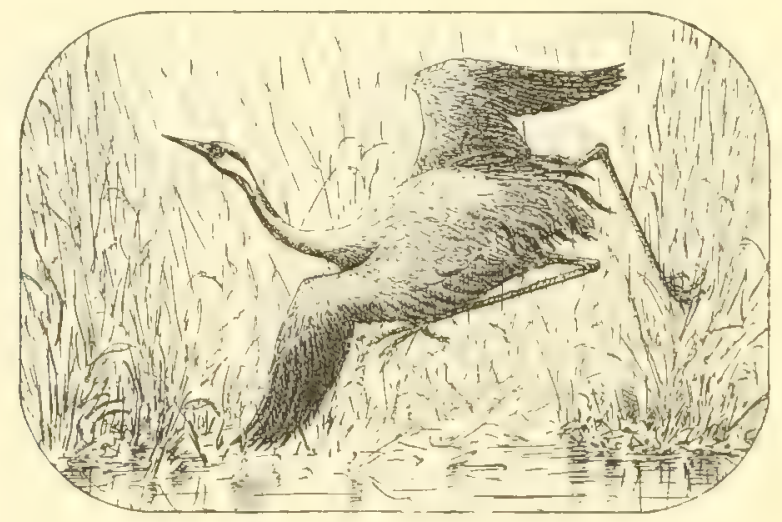




\section{III-HCROSS THE MI.ATSS. CHAPTERI.}

A RIDE ACROSS THE THGiA.

The plains or vegus-The rivers in winter and summer-The weallh of flowersSpring-time on the vega-Herds of mares and cattle-The herdsmen-... "bad cow"-_Lagartijo"-Bulls - A toro brazo-A chase and an escape - Storks and Cranes-Little Ringed Plovers-Pratincoles-Stone CurlewsThe Larks, Calandra, Crested and Short-toed-Fantail Warblers-Buffbacked Egrets-Ocellated Lizards and Grass Snakes-Hatred of retriever for these reptiles.

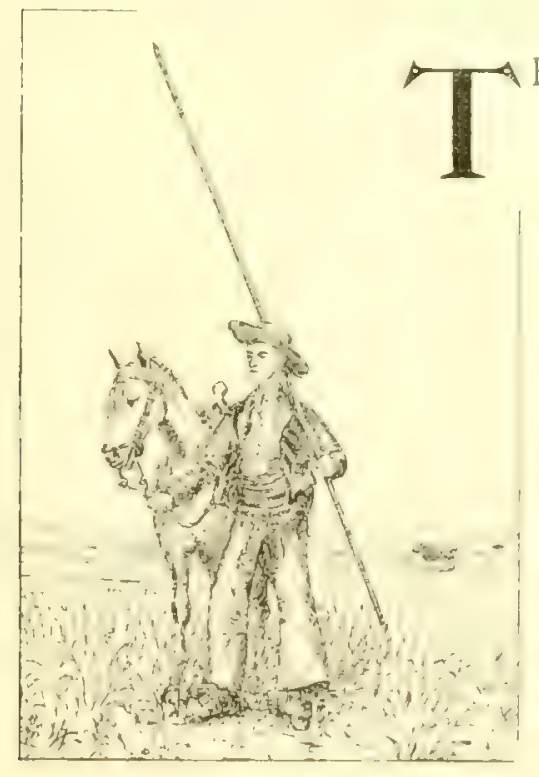

HE great alluvial plains of southern Spain are tenanted by many species of birds which are cither resident throughout the year or migrate thither to nest. Certain lower portions of the plains are annually submerecel during the winter months and then become the resort of thousands of wild geese and duck of many descriptions driven south by the stress of climate. Is spring approaches, the wild-fowl start on their return journey northward and as the flood waters subsicle the Bustards and other normal occupants

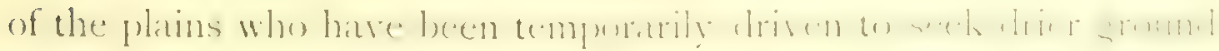
on the low undulating hills around, return to their accustomed haunts. 
Iere and there, some of the lowest-lying ground remains under water until the torrid heat of the August sun effectually dries it up; the dense reeds are then cut by the inhabitants for thatching their cottages or are exported to be made into bottle-casings.

These isolated pieces of water or lagunas so long as they last form sanctuaries, not alone for many water-birds but for numerous fish and reptiles.

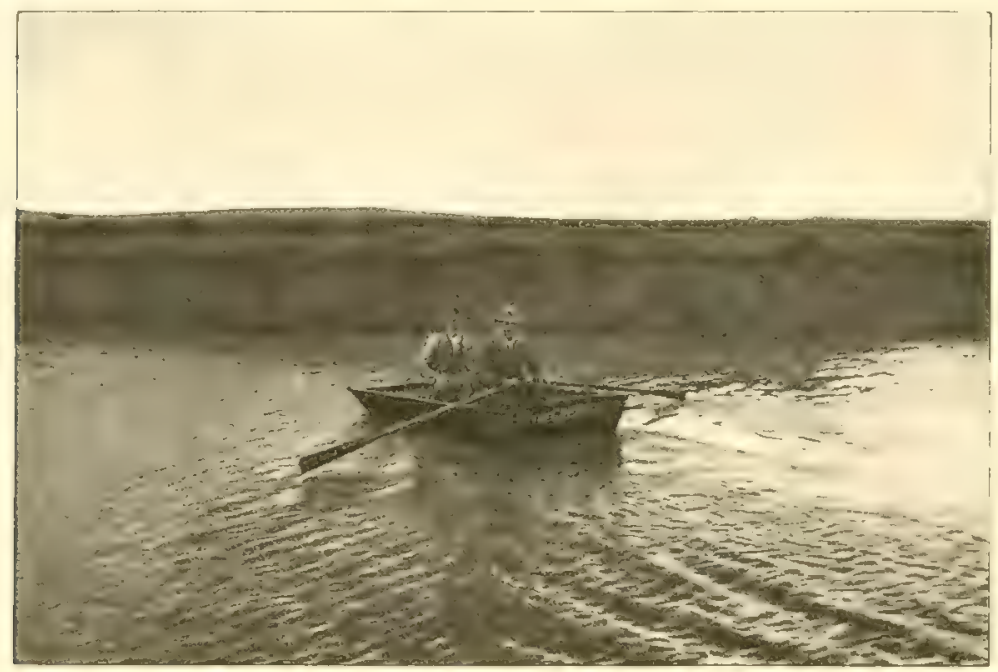

A RIVER IN THE PLAINS: EVENING.

The plains are intersected by small rivers which, owing their supply as they do to the rainfall in the distant sierras, are usually full from the time of the autumnal rains until the spring. Every heavy rainstorm causes them to flood bank-high and not seldom to owerflow. Since the waters when in flood are heavily charged with suspended matter, which quickly settles whenever the current is lessened, the effect of these continuous overtlows is to make a deposit of silt and mud along the top of the river banks, which are by this means at places raised several feet hisher than the 
plains through which the rivers run. Generally the river banks are cut vertically, or nearly so, for some feet by the rapid current, but at the bends sand spits are formed which afford good restingplaces for the wild-fowl in winter and likewise for various nesting birds in summer. The rivers are of considerable depth, some of the small ones even being from $\&$ to ro ft. deep at many spots and with few fords. These are of course well known to all the arricros or muleteers, since in the absence of bridges their condition from day to day regulates all movement along the country

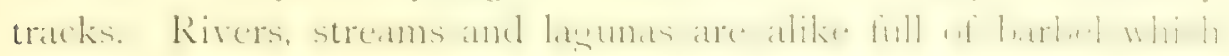
grow to some size. As the waters recede and the streams dry up, the fish make for the lower reaches but these in turn become dry and towards the end of a hot summer most of the smaller rivers are reduced to a series of stagnant pools of putrid green water which are literally alive with barbel and water-tortoises. What becomes of these when the pools finally dry up is one of the

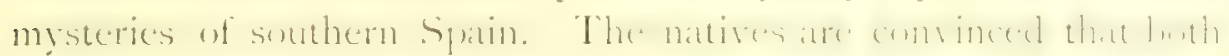

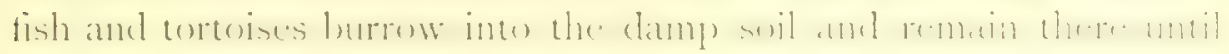
the autumn rains. Certain is it that there is never any falling off either in the numbers or size of the barbel and tortoises when they reappear in the autum.

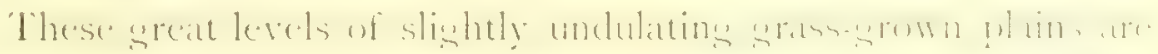
known to the Spaniards as vegas and in the spring months their appearance is very beautiful. The higher portions, not liable to

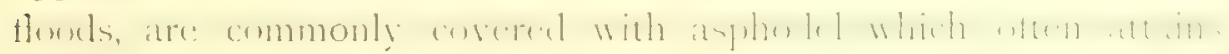
a height of $3 \mathrm{ft}$. to $4 \mathrm{ft}$, and at places the handsome dark-leaved

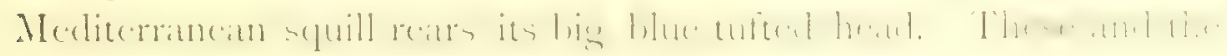
White Iris blossom much earlier than do the majority of the plants.

To see the $\operatorname{veg} a$ at its best, it should be visited in the month of May when the vivid green of the herbage is almost blotted out by the brilliancy of the masses of spring flowers. Nothing is more striking to the eye than the lavish manner in which 
Nature applies her colours in such districts. Riding across the vega, at one time you may traverse acres of golden marigold, perhaps half a mile to the right the land is pink for hundreds of yards with a beautiful larse madder or asain, crimson with tre-foil, whilst to the left, malbe, it is as white as snow with waving camomile. As you leave the grasslands and traverse the lower spurs of the fallows, whole hillsides are covered with bright yellow mustard or big white daisies. Perhaps one of the most remarkable effects is that produced by the small blue, yellow and white convolvulus (Coniolintus tricolor) with which the ground is carpeted so closely as to malie the hillsides at a short distance appear light cobalt blue. In addition to these great masses of colour the whole plain abounds with other flowers which astonish and delight the traveller. Large purple iris and the diminutive paler-coloured one abound as does the crimson gladiolus and a hundred other brilliant blossoms of all shades and colours.

Such is the country which it is my happy fate to traverse whenever I ride out from my dwelling of a spring morning. The plain is usually covered with herds of mares and cows with their calves and, at certain places, young bulls. Unfortunately of late years, vast numbers of pigs have been introduced and their unceasing digying for tuberous roots has gone fat to spoil entire districts. The herdsmen in charge of the various animals remain out with them in all weathers, night and day and I number many old friends among them. Rarely it occurs that the men who thus guard the cattle are injured by one of them. Guarding semi-wild cattle is not altogether without its risks. As a rule, the cows are more dangerous than the young bulls and when a herdsman is damaged it is usually the act of a vaca mala, or "vicious cow." Only last year an old friend in charge of some mares was sudelenly attacked from behind by a cow and badly tossed, alighting on his head. I was sent for to administer 
"first aid," a rôle which constantly falls to me, and found the poor old man with a nasty wound in the thigh caused by a horn and with his head and face badly cut. Among these wild folk

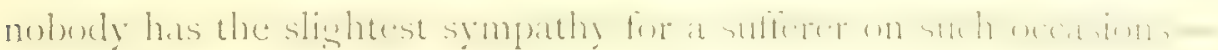
in fact, it is looked upon ats a hugre joke, and in this case the old

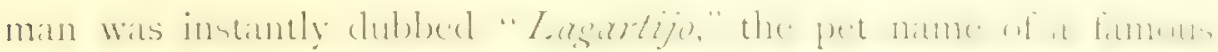

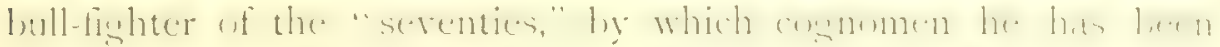
since known and his mishap is crep the somere of mush ammentment.

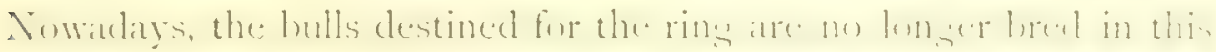

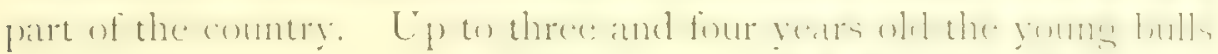
are compatatively hambles, all the same it is lest nut (1) renture. among a herd, if on foot. But in every herd there are a few old bulls of six or seven years and these should always be avoided on principle, and in no case approached save on horseback.

To be chased by a bull on the open eega is a species of sport which does not appeal to me. Nany years ago when with Harry Fergusson of my regiment we were crossing a plain, he on foot and I on horseback and we noticed an old black bull about a mile off watching us intently. At that time there were toros bravos or bulls of the fighting strain in the district and

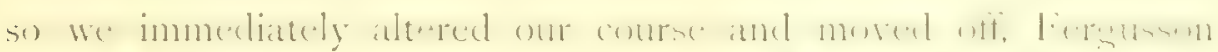

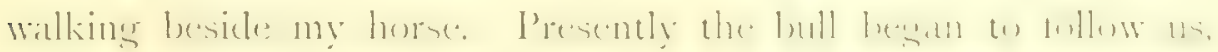
at first at a walk and then at a trot. 'This was too much, so

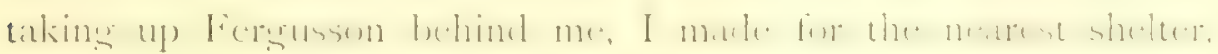
the bull following us at a gallop. We were over a mile and a half from an old stone drinking trough on the side of a rocky hill and by the time we gained this point the bull was uncomfortably close behind us. In fict, he followed us to the foot of the hill and then, turning, trotted off. Our old Spanish attendant, Juan Palo, an inveterate wag, told us subsequently; in response to our inquiries as to why the bull had been so

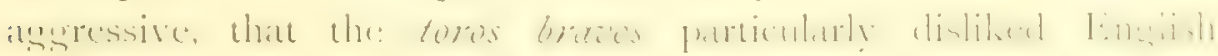


officers as they thought they might take their farourite cows away from them!

Riding across the a'esa, from time to time you see flocks of Great Bustard feeling on the rich young wrasses or catching rrashoppers amid the thistles and herbage. White Storks are dotted about the plain and now and again a pair of Cranes may be seen among the waring reeds. Along the sandy banks in the river beds beautiful Lesser Ringed Plovers (. Eiralitis curonica) are running. These little birds after the manner of their fimily make no nest but lay their three small sand-coloured ergs, spotted with black, in a small cup-shaped depression in the sand. At places where the receling winter floods have left bare patches of dry mud, the Pratincoles are congregated, sitting motionless until your horse is almost upon them when they rise with shrill cries and mob the traveller, settling down again only a few yards off, as he passes on.

At rare intervals in these alluvial plains there are small outcrops of rock, generally of disintegrated sandstone. Here amid the loose scattered stones the Stone-Curlew (Gidicnoms scolopax) delight to nest, laying their two stone-coloured ergss, and hard indeed are they to find. It is rarely worth the trouble to look for their eggs unless the old birds are seen on at least two occasions at the same spot. when it may be assumed that they are nesting hard by.

The Grass Snake (Tropidonotus natrix) attains to great size in southern Spain; and on the a'ega I have often seen specimens $5 \mathrm{ft}$. to $6 \mathrm{ft}$. in length and of proportionate girth. Sometimes when I have dismounted in order to catch one of these larerer reptiles they have shown fight and upon being approached have raised them. selves up as if to strike, but their bite is of course harmless. Even more punacious are the Ocellated Lizatrds (Lacerta ocellata, which, when pursued and overtaken by a man either on horse or foot. 


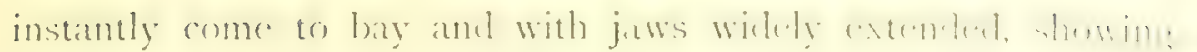
cavernous pink-lined mouth and throat, front the assailant and make a gallant spring at him as he closes on them. Ny retricver "Sweep," who, alas! succumbed this year, after four seasons of

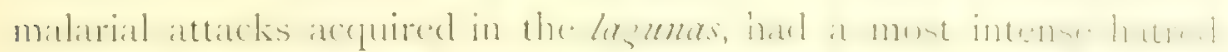

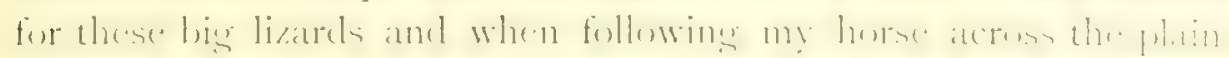

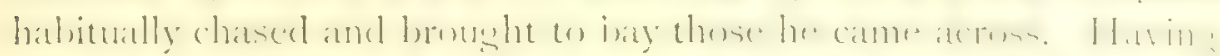

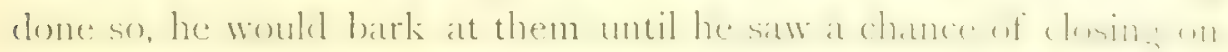
them when he: would seize them and threw them hish in the ar and many a severe bite did he receive when thus employed. Often enough he would seine the unformante reptile ly the thit with the ustal result of its owner quickly parting with it and

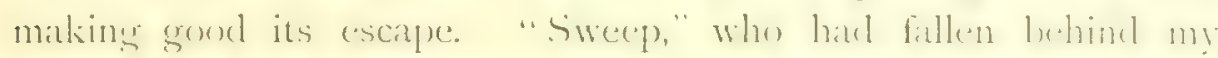
horse during this eperation, would then wallepe after me carryines the writhing tail of the reptile in his mouth in trimmos sometimen for lone distances. (of snakes he hat an expal hatred and hilled many, often causing me no little anxiety.

Among the smatler birels which abound on the aese in symen

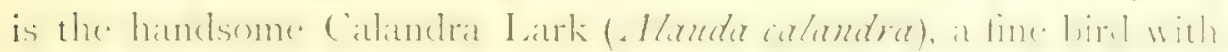

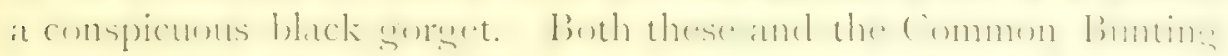
are very numerous. The pretty little Crested Lark (Galerila

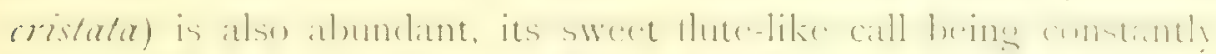

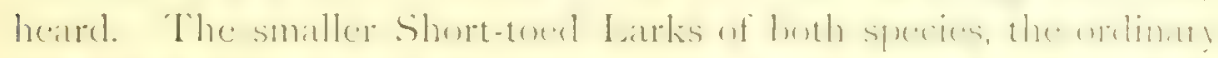

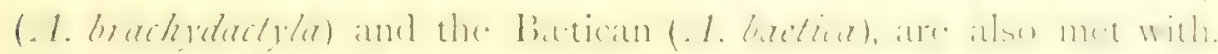

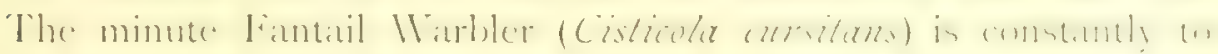
be seen and heard, its curious jerky flight and sharp staccato call making it easy to recognize. This little bird makes one of the most beautiful of nests of any of the Iiuropean birds, pealyshaped, with a small entrance at the neck, woven of thistle-down

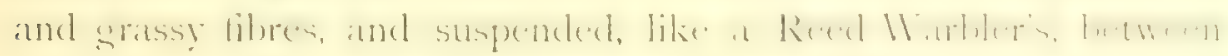
the stems of long grass or standing corn. The little eggs are

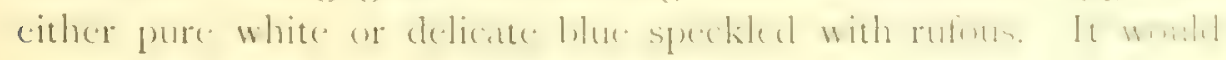


be easy to prolong this list indefinitely with the Pipits, Wagtails, and numerous other denizens of the rega.

High above the great plain in the blue zenith, the Vultures are to be seen circling, ever watchful for some defunct beast, and now and again the sharp bark of the Eagle is heard as he calls to his mate. Ncedless to say, the Harriers are ever with one, incessantly quartering the plain and at intervals dropping into the reeds in quest of prey and Kestrels are diligently secking the insects which are in such profusion.

As you ride past the herds of mares and cattle, the White Egrets tlutter off the backs of the beasts they are tending, whilst others stalli round the recumbent animals, from time to time making quick thrusts with their bright yellow bills at some tempting object. Big Ocellated lizards, as well as smaller green and brown ones, and snakes of all sizes which have been sunning themselves, make off at speed on our approach. The air is full of the hum of insects, and the liquid tinkle of a thousand concrros, the big copper bells worn by mares and cattle alike, makes an harmonious accompaniment to the hundred and one sounds of the Andalucian spring-time.

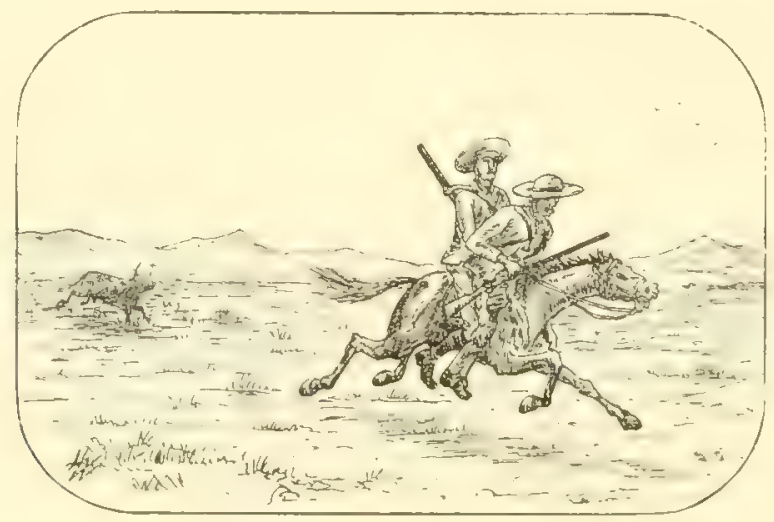





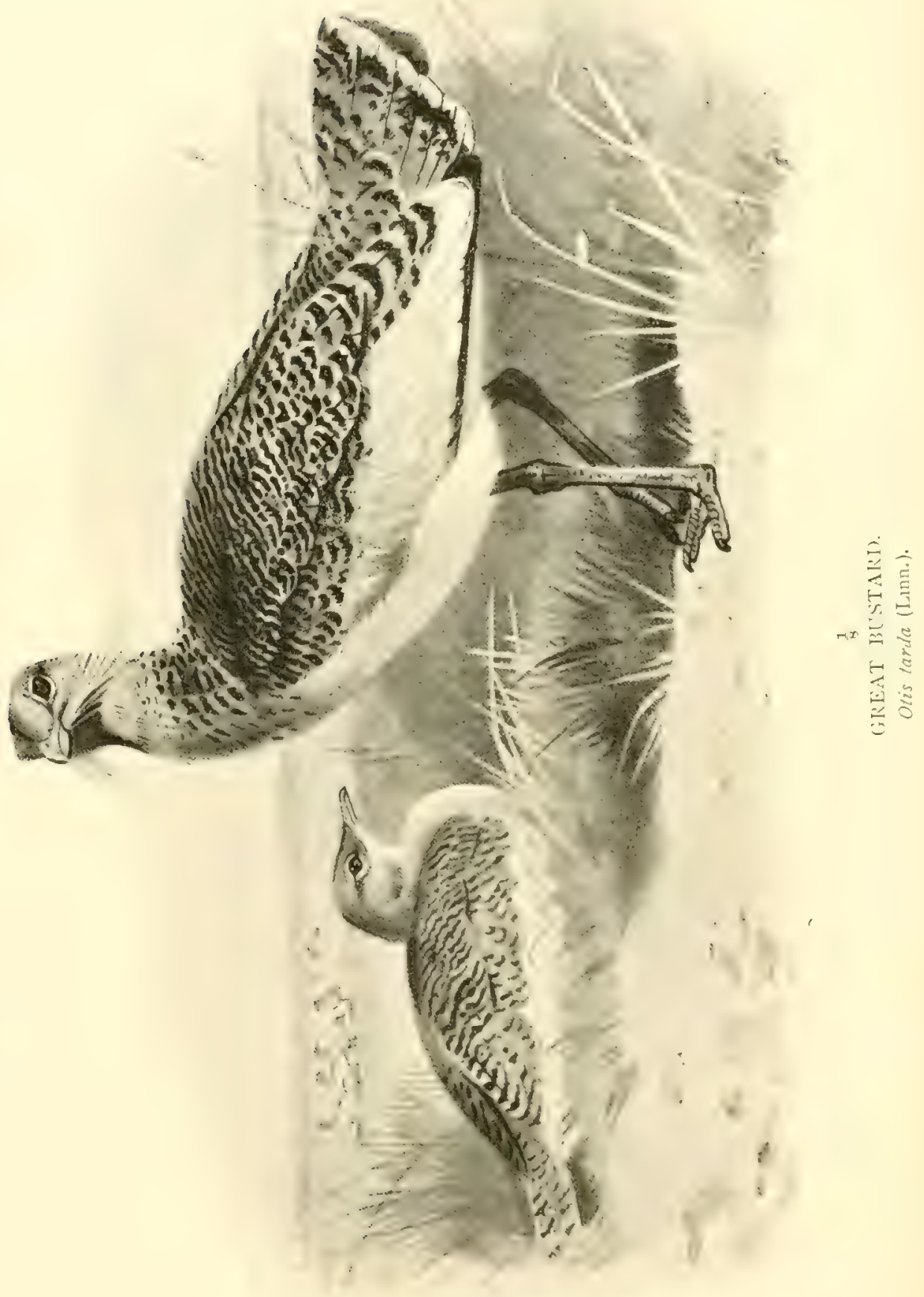




\section{CHAPTER II.}

THE GREAT BUSTARD (Otis tarda).

Seen to perfection on the Spanish ients-Chanere of puaters. summer and winter-Question of migration-Local colonies or bandas-Remarkable white appearance when flying--Habits during courtship-And after-Nestingplaces-Leaving nest-IVholesale taking of eggs-Number of eggs laid by Great Bustard-A popular fallacy-Small size of eggs-Hatching outGreat Bustard in barracks-A "steady old soldier" in charge-Deplorable results! - Weight of Bustards-Abnormal weights in late spring-The gular pouch-Extraordinarily powerful flight-A very silent bird Eagle and Great Bustard.

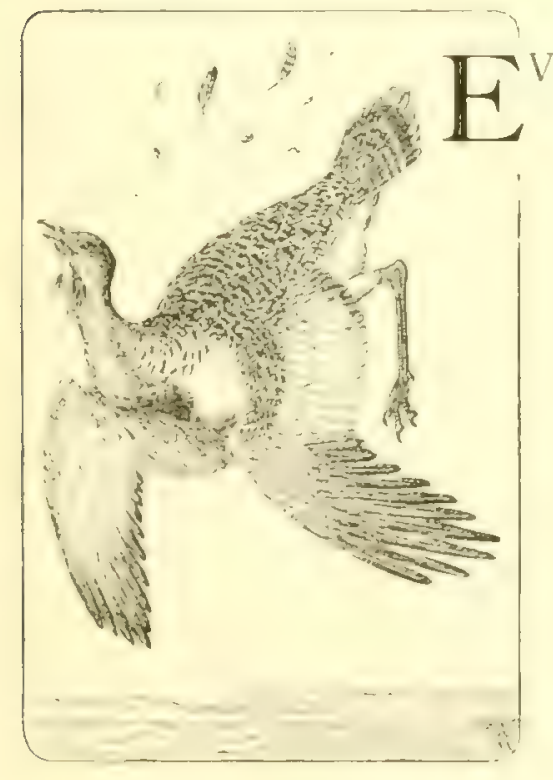

EN the least imaginative of persons though neither sportsman nor naturalist must take an interest in the Great Bustard, the largest of European game birds and one of the finest feathered of all the fowls of the air. A hundred years ago it was still to be found in small numbers in parts of England but it sradually died out between 1830 and 18.40 ; since then it has only appeared as a rare visitor. It has also been driven from France by the constant encroachments on the wide open spaces which are so necessary for its existence. In some parts of Germany it is yet found, whilst in south-

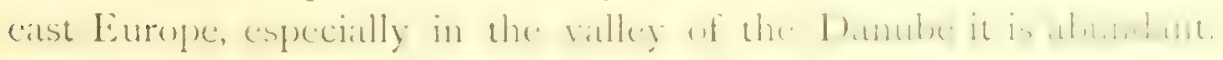


But the nearest point to our islands where it still lives and is likely to endure for many years to come is in Spain.

Numerous writers have described how this bird inhabits the great corn-growing districts in the Peninsula, and what a splendid sight they make. Much as the Great Bustard is to be admired amid the young corn of early spring, to me, who have lived among them for so many years, there is one sort of country and one alone, which belongs to them and to which they belong, the grassgrown and flower-strewn vegas or plains of Andalucia. To me the sight of a Great Bustard in a comfield, however admirable, is a picture as unsatisfying as a red cleer in a park, for in each case bird and beast lacks complete separation from man and his works; and without this separation its native wild beauty cannot tell truly.

Many of these grass-grown plains of southern Spain are liable to floods and in some places during the autumn and winter to total submergence for months at a time. It is at such periods that the Great Bustards desert the level country for the undulating hills around, where they are practically undisturbed and but rarely seen, since few people traverse these districts during the winter months. English sportsmen in quest of wild-fowl or Snipe have often asked me where the Great Bustards go to during the winter, since they are so seldom to be met with. My own explanation is that owing to the vast extent of ground which is suitable to their habits and also owing to the difficulty of exploring the same during the period of the year when the torrential rains occur, the Bustards simply avoid observation. I am aware that this is somewhat of a neyative arsument and in support of it I have only my own experiences to draw from. These are brictly as follows. On the occasions when I have ridden over the hills I describe during the winter months, I have almost invariably come across small parties of Great Bustard. With the approach of spring they suddenly 
reappear in small flocks on the plains and are to be seen fecding on the portions whence the water has recently retired and where: the young grasses and herbage are now vigorously sprouting. Referring to my journals I see that this usually occurs about the end of January or early in February.

Upon being disturbed at this time of the year they invariably Ay off to the adjacent low-lying hills where it is no casy matter to

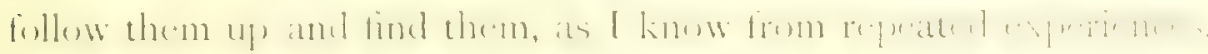

Two-thirds of these hills are under cultivation at a time, one-

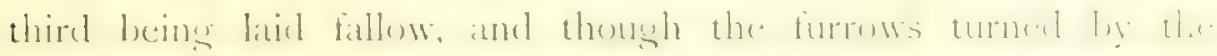

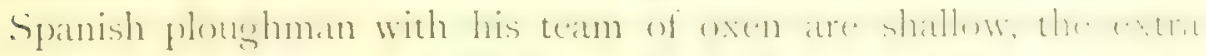

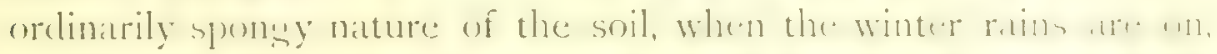

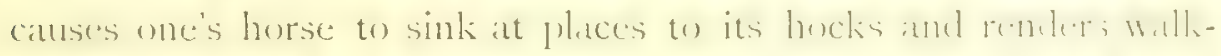

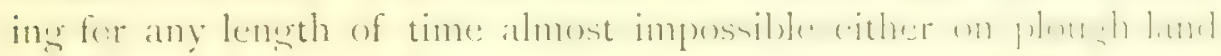

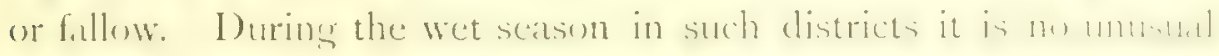
thing for communication to be cut off for datys at a time between

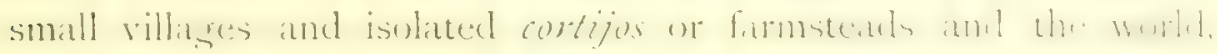
owing to the absence of roads and the awful condition of the weredas or tracks and, as I have said before, there are thousands

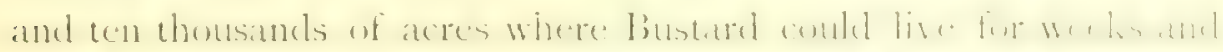

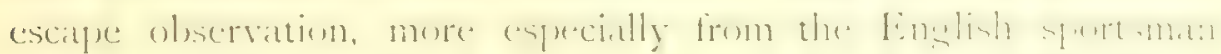

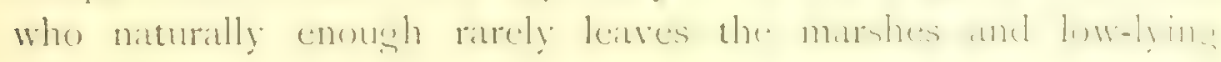
ground.

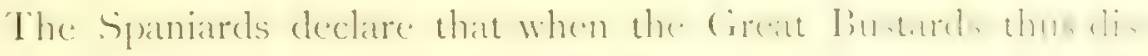
appear from their usual haunts they go "to the Moors." 'Ihis, by

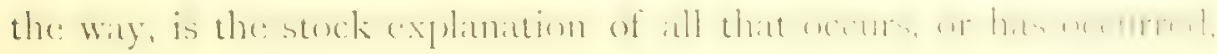
in Spain which it is difficult to account for otherwise. Some writers have asserted that the Great Bustard is unkmown in Morocco but this is incorrect; although my own wanderings do not extend more than 80 miles south of 'Tangier I have come

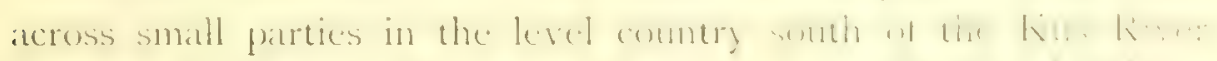

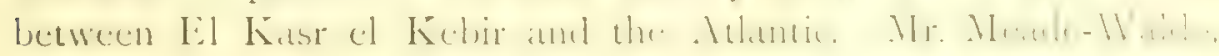


who has vastly greater experience than have I of Morocco reports seeing a grood many Bustard in the spring months, including one band of twenty-three. But it seems certain that at no time do the numbers in Morocco in any degree approach those which are met with in Andalucia.

Colonel Irby never noticed any migration of the Great Bustard in southern Spain, whereas in the Crimea he saw large flocks passing south during the autumn migration. My own view is that like all so-called resident species in any country, they shift their quarters from time to time and that these morements are dependent on questions of food, seneral convenience and nesting. But that the Spanish Bustard are a migratory species in the same sense as the Crane and others I do not believe.

These shiftings of quarters may involve considerable thights. Thus during the last eighteen years several Bustards have appeared from time to time on the plain between the Palmones River and the Guadarranque River ncar Gibraltar, which implied that they had crossed the Sierra for at least twenty-five miles from the nearest possible Bustard country. They have also been seen crossing the Serrania of Ronda, some 60 miles from the plains near Cadiz, but such tights do not necessarily imply a true migration, but rather a change of ground.

It is, of course, no distance across the Straits of Gibraltar, but it seems almost inconceivable that were there a migration of the nature seen by Colond Irby in the Crimea, neither he nor others like myself who have been many years in the country should have seen anything of it.

Bustards seem to group themselves into small colonies which systematically attach themselves to certain definite districts, which as a rule they do not leave for any considerable period. IThen in the natural course of secking their food they fly to outlying places, sooner or later they return to their own piece of country. 


\section{A Magnificent Spectacle}

I have had evidence of this extending over many years. Every one of these flocks is known to me as well, as to those few of the inhabitants who take any interest in such matters, by the name of the district it comes from. Thus 2 miles south-west of where I dwell there is a flock of thirteen birds known to us as Lat banda de - A Again about 4 miles east I know of another of seventeen and again 4 miles to the north, of another and yet another beyond. At times these bandas join up, and one is afforded the splendid sight of several score of these magnificent birds together. This combined flock on 30 Narch 1876 numbered sixty-seven birds, and of recent years I have on several occasions seen it at about the same strength and more than once at seventy-four!

On the roof of my dwelling in Spain I have established a look-out whither I often betalie myself with telescope and fieldglasses. About I,200 yards from this spot is a slight rise in the ground which is usually covered with rich young grasses a few

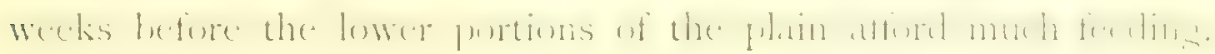
In extent it is only some 4 or 5 acres, but on a fine spring morning it is usual to see it tenanted by several Great Bustards; sometimes by both the local bandas of seventeen and thirteen

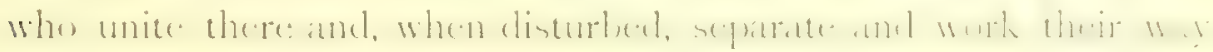
back each to its own particular district.

To see the Great Bustard in all his glory he should be sought in the months of April and May when the acga is covered with spring flowers. At places there are great masses of thistles with gorgeous heads whilst all around the silver-grey slicletons of last year's growth, calcined by the torrid sun of the summer, stand up in stiff sparse clusters. These thistles, whilst affording cover from view for the Bustards when taking their siesta at micl-clay;

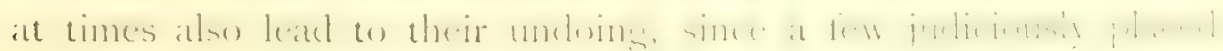
often serve to conceal the position of the gunner lying prone 
during the course of a Bustard drive. For those wary birds, whom nothing can induce to fly over any sort of "hide" or "blind," will cross recklessly over scattered clumps of thistle's on the open plains.

On the wing the Great Bustard often appears to the eye to be almost white, which causes surprise to those who see it for the first time and whose knowledge of its colour is got from stuffed specimens with closed wings. For despite the tints of its lavender neck and the marvellous variegated colouring of both back- and wing-coverts, in which almost every conceivable shade of rich siennas, browns and russet reds barred with black is presented; when the bird is on the wing, an entirely different impression is produced. For then white is the prevailing colour, both breast and under-parts are a pure white whilst the vast expanse of wing, over $\& \mathrm{ft}$. across and broad in proportion as becomes a game bird, is largely marlied with white above and is entirely white below. In fact, Great Bustards at a distance, when on the wing are to the eye as white as a Gull.

Many writers have thrown a doubt upon their polygamous habits, but to my mind nothing seems more manifest than that they never pair in the true sense of the word. Every banda I have seen consists of a few old males, with a proportion of from double to treble the number of females and no doubt young males. When the eggs are first laid in the standing corn I have occasionally flushed an old male in company with the females, but as soon as the hens have settled down to incubate, they seem to be entirely abandoned by the males which collect in flocks and keep away from them altogether.

The habit of the old male Bustards, as the breeding season "tpproaches, of "showing off" to the females has been often described. Their actions on such occasions in many ways aproach that of the domestic Turkey. But the Bustard, owing 


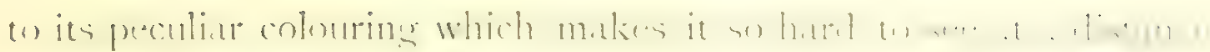
when at rest and so conspicuous when on the wing, when it sets about its antics in one instant completely metamorphoses its appearance. For, when one of these "paroxysms of courtship" comes upon it, the head and neck are thrown back and the tail turned forward, whilst the wings are trailed and inverted and every feather of the axillaries stands on end. The effect is instantly to convert a hitherto brownish bird into a mass of snowy white, double its natural size. Often when riding across the plains have I suddenly detected the presence of a big banda of these fine birds which had hitherto escaped my eyc, owing to

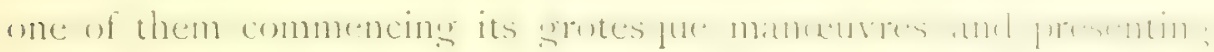
a large spot of white in the distance where before nothing was visible. Another and yet another cock quickly respond to the challenge until a whole party of males are engaged in these absurd antics. Those who fail to follow my very inadequate

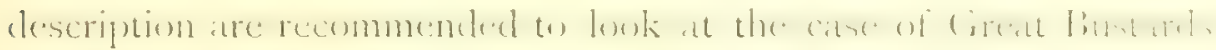
at South Kensington, where one is admirably set up in this extraordinary attitude.

One of the most perplexing traits in the Bustard's character is that he by no means confines the period of these antics to the

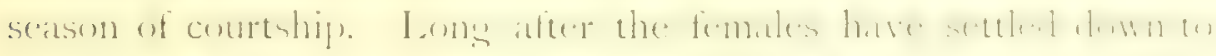

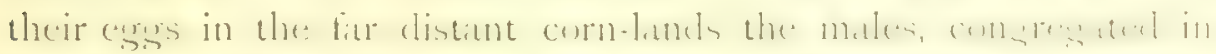

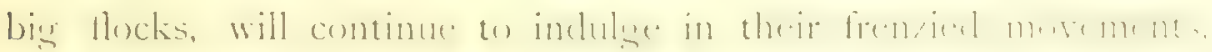
which, so far as I have ever been able to see, are purcly games of "bluff" and "swagger," which never lead to more than at momentary encounter-at sort of collision and "fend off" with another bird, after which both turn about and continue their absurd mosements independently. When one watches such an encounter, one can almost imagine one inverted old cock saying to another: "You be off!" "I won't," replies Number 'lwo. "What! you won't?" thunders Number One, rustling up to him with creaking 
primaries and a cenerally appalling appearance. "No!" says Number Two, equally crackling all over and strutting around ferociously. "Then stay where you are," remarks Number One, wheeling about and adroitly evaling the difficulties of the situation.

The favourite nesting place of the Great Bustard is amid the corn-lands, this is especially the case when the season is an carly one and the young barley or wheat is adranced enough in the month of April to afford good cover. In backward seasons the Bustards seem to prefer the bean-fields, which, although not so high as the young corn, are of thiclier growth and yive better protection to the hen bird when sitting on her exgs. The great reed-grown plains which have been submerged in winter also offer suitable places for them to nest and I have also found nests on the open grasslands at places where a few dead thistles and some coarse herbage served to grive shelter to the old bird. ( )n the fallows, especially when covered with mustard or any other rank weed, nests may at times be seen. The way in which a female Great Bustard will slip away from her egys and run for some distance before taking flight without being cletected by the sharpest of observers is ever a marvel. When the young corn is $2 \mathrm{ft}$. or so in height, one can realize the possibilities of such a mancure, but among still younger corn or scattered beans not a foot above the ground these great birds are equally expert in not divulging the position of their eggs.

The reverse proceeding is adopted when they return to their egres, for then they alight a long distance off and somehow or other manage to reach their nest unseen, and despite many hours of watching with field-glass and telescope I have never yet succeeded in actually fixing the precise situation of a nest right awaty, and it has required a most diligent search before I could find one.

Nest proper there is none, the eness being deposited on the bare ground; at times, especially when they are amid barley or 
wheat, a few dried stalks may by chance be pressed down and form a sort of apology for a nest, but this seems to be a mere matter of chance.

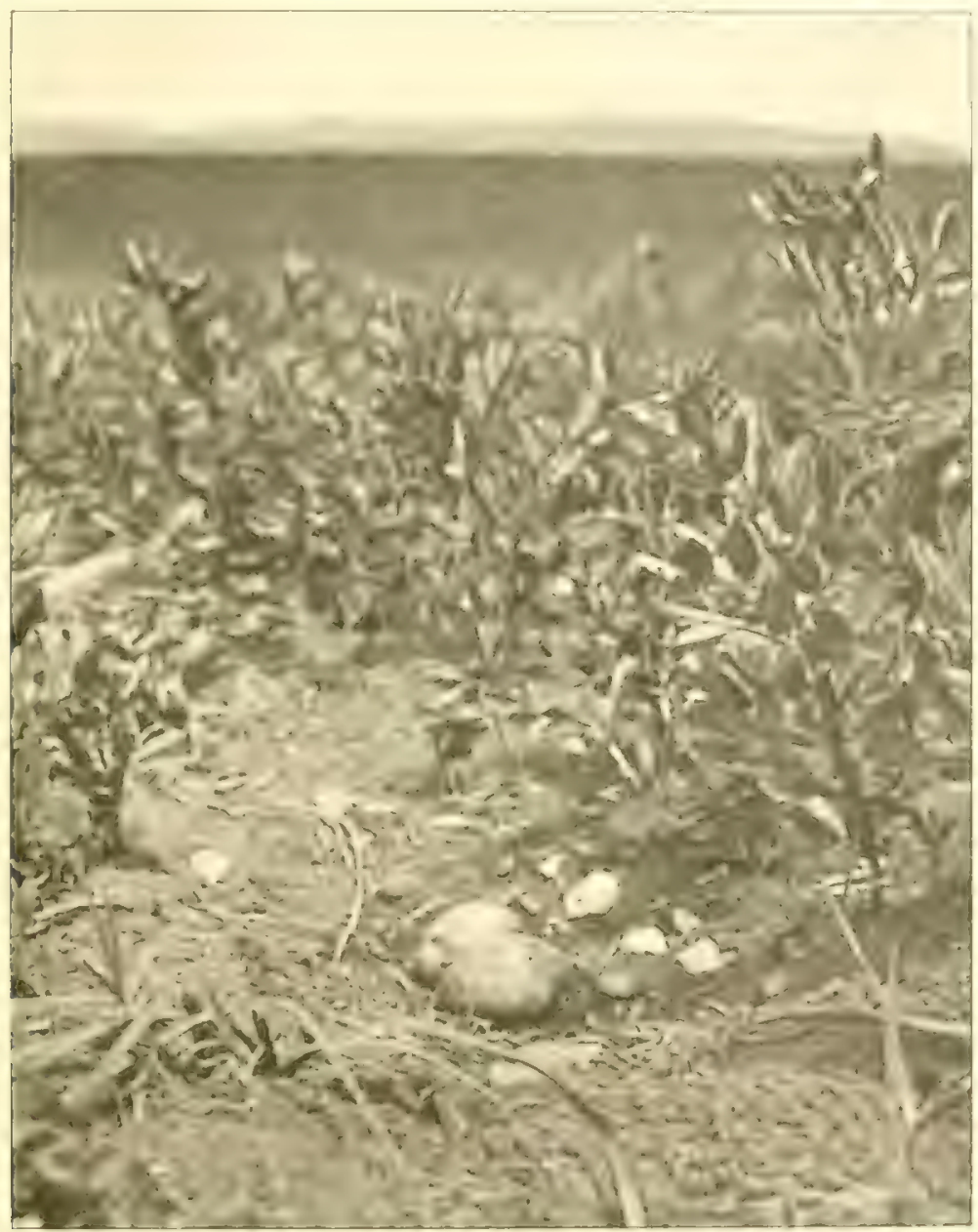

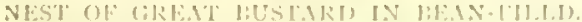

How any Bustards' nests escape being robbed is a wonder w

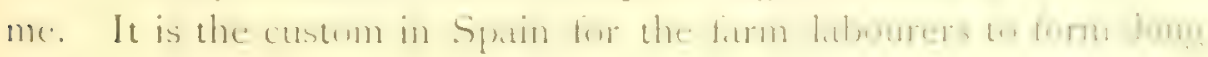


lines of twenty to thirty men armed with hoes, with which they traverse systematically every yard of the young standing corn in order to eradicate the rapidly arowing weeds which would otherwise choke the corn as it is ripened. These parties are unfortunately always at work in the months of March and April and, consequently, come upon many nests and all fresh Bustards eges are invariably taken by them to eat. Those Bustarels which resort to the beanfields are even worse off, for when the beans are pulled (about the first week in May) every nest is inevitably found and even if not taken the birds desert the egess owing to the destruction of all cover around them.

Be it as it may, possibly owing to the immunity which those birds enjoy which wisely resort to the reeds, fallows, and grasslands to nest, the numbers of these splendid birds in South-IVestern Andalucia, judging from my own obstrvations, have not decreased during the last thirty years. It would, indeed, be, from the view of the bird lover, almost a European disaster if they were to die out.

It is well known to all interested in bird-life that when once a "fact" regarding natural history has been duly recorded, it takes a long time to disprove it, successive authorities being content to quote from one another without seeking for further information. Among such is the grenerally accepted statement regarding the number of eggs laid by the Great Bustard which has been recorded as two from time immemorial with the explanation that when four egrgs are found in a nest "no doubt two females have laid" in it. In consequence when I first saw a nest with four eggs I cluly noted the fact and entered the usual stock explanation in my diary. By good chance my notes some years later were read by the late L.ord Lilford, undoubtedly one of the best atuthorities on the birds of the Spanish Peninsula, who very kindly pencilled across the page: "The Great Bustard often lays four and rarely five eggs. L." 
Some years later I met with a second nest with four cures as recorded by Colonel Irby, but the old fable as to two eges only died hard and has been repeated in the most recent books.

After Colonel Irby's book appeared I on several occasions found Bustards' nests with three egrs, not four, sometimes considerably incubated but it was not until last year that after a long interval I chanced to be among the Bustards at the right time. In May, 1907, in one beanfield I came across no fewer than four nests

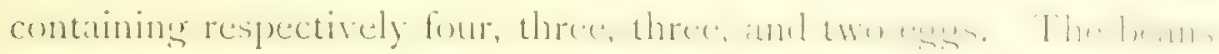

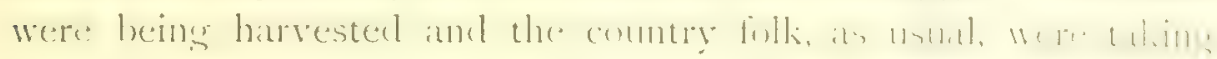
every Bustard's egg that was fit to eat. At my request they left these nests for me to see. The set of four were somewhat incubated, as were one of the sets of three, the remainder being

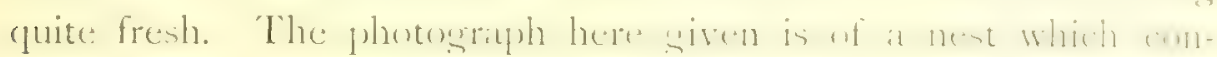
tained three eggs. Unluckily my horse trod upon one as I cance upon the nest.

But what is absolutely conclusive as to Bustards lalying at any rate three egess is that out of a variety of nests with three cergs I have from time to time inspected, not only has the ground colour

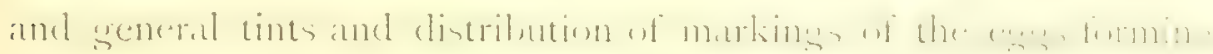
each particular set been alike but the lexture (if I maly use the word) of the surface of the eggs has been recognizable almost at at glance by anyone who had made eggs a study. In other words, it has been perfectly simple to pick out the egres belonering to a series of sets and to place them in their own proper groups. In the case in point I had marked in pencil on each separate seat of four, three, three and two, and then got a friend to "shuffle" the uwelve eggs and place them with the marks downwards, after which I proceeded to pick out the various sets without the slightest trouble.

The set of four which I found in 1907 were of peculiat interest since three out of the four had their shells covered with small excrescences. In adclition to this these three were exactly alilic 
in size, shape and markings. The fourth egg was less granulated and was somewhat larger and more elongated and was also marked more distinctly.

That the three were laid by the same bird is beyond a doubt, whilst the fourth, although thus varying as described, had the unmistakable "family" similarity to the others which would have induced any skilled oologist to class it with them. I am quite content however with the unmistakable proof of the three eggs having been laid by one bird, for if three, why not four and what becomes of the story of the Great Bustard only laying two eggs? Of the two sets of three, one had the usual opaque greenish brown ground colour with exactly similar markings in each case, whilst the other set had the far rarer cliar greenish brown ground colour with nuch brighter blotches of burnt umber and purplish undersurface markings.

My conclusion, based on many years' experience, is that Great Bustards commonly lay three or four eggs, but in some instances they only lay two, though in others even five eggs.

The remarkably small size of Great Bustards' eggs has surprised many and is directly in opposition to Hewitson's theory that those birds which run from the moment of being hatched lay larger eggs than do others whose young are hatched out in a helpless state. I have often seen Great Bustards' egres which were very little larger than a Curlew's, yet the first bird weighs ten to fifteen times as much as the second and in both castes the young run from the egg.

Young Bustards, as is well known, like young Plovers, Turkeys or chickens, run from the egg. On one occision, now many years agro, my brother officer, Harry Fergusson, found a Great Bustard's nest with four eggs; two of these were blown and were found to be fairly fresh, the other two we placed under a hen and installed her in the corner of his one room in barraclis. Here she sat steadily 
and our hopes and fears were so far realized that, after a weck, careful cxamination showed that the exgs hat not suffered from the forty mile journey on horseback, and were "set." After twenty days, one eventful morning a faint cheep was heard from the box and to our great joy we found a young Bustard had commenced to chip the shell and was in a frir way to release itself.

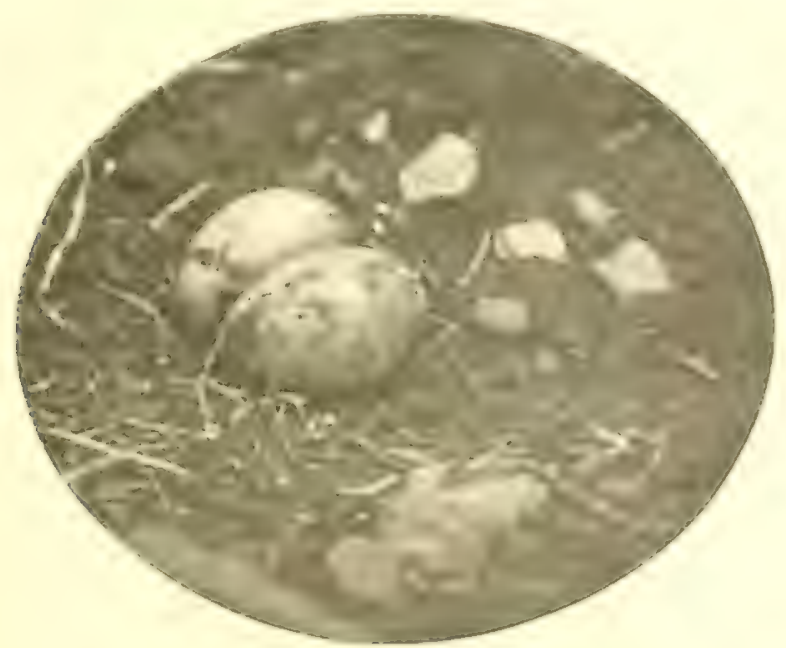

EGgS OF GREAT bUSTARD. (Sizc $333 \mathrm{in.} \times 2 \cdot 1$ in.)

We passed that forenoon in intense anxicty, being reassured from time to time by a more checrful cheep. In the afternoon we both had to go out, but as a matter of precation installed a servant, one of the type known as a "steady old soldier" of the long-service days, to mount guard over our precious charge. To our horror, on our return we found our old soldier diligenty at work with a piece of stick removing the shell from one of

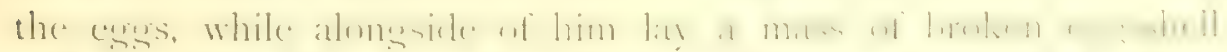

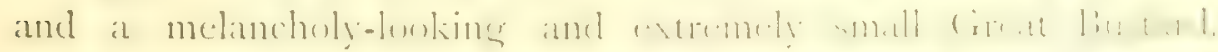
which he had already extracted from the furst egg. 
It is hardly necessary to say that the unhappy chick on the floor quickly succumbed to the maltreatment it had received: the second one, despite several injuries from prods with the stick, survived for four days. It was a weird-looking little creature, an atom of down with a big head and long legs, and had a most plaintive and resonant call, out of all proportion to its climinutive body. During its brief existence it fed well and ran about at extraordinary speed around the barrack-room, taking cover amid the rows of boots arranged along the wall.

The weight of a Bustard is a subject of which very varied accounts have been written. Apparently the unfortunate stragglers which have from time to time visited England and been prompty slain must have been very young birds. Yarrell records males of only $16 \mathrm{lb}$. and females of $9 \mathrm{lb}$. to $10 \mathrm{lb}$., whereas the males in Spain commonly weigh between $20 \mathrm{lb}$. and $30 \mathrm{lb}$. and the females I $2 \mathrm{lb}$. to I $8 \mathrm{lb}$. Professor Newton mentions $22 \mathrm{lb}$. to $32 \mathrm{lb}$. as the average weight of European Bustards. The remarkable variations of weight in birds shot out of the same flocks and in the same Incalities lead me to believe that Bustards talie very much longer to reach maturity than is popularly imagined. Again, they seem to vary enormously in weight according to the season of the year. Out of a number of Bustards I have weighed and examined, those lilled in the winter months have averaged only about two-thirds the weight of birds killed in March and April. The smallest Great Bustard I ever saw killed was a young female in the month of February, and which weighed only i $21 \mathrm{~b}$. This bird must have been at least 9 months old.

Of course not many Great Bustards are shot by Englishmen in April, and then only, as a rule, birds required for skinning, for at this time they are in their most splendid plumage. The old males at this time have their necks enormously distended whilst the coloration of the feathers on either side of it is of 
extraordinary richness, the delicate lavender srey of the head and throat forming a beautiful contrast to the rich russet sorget below which in some birds almost approaches a vinous red. It is at this period that the birds seem to attain their maximum weight. Six old male birds shot by a party of three guns, of which I was one, in the month of April, averaged over $3+1 \mathrm{~b}$. cach, the heaviest being $37 \mathrm{lb}$; no doubt the contents of the crops

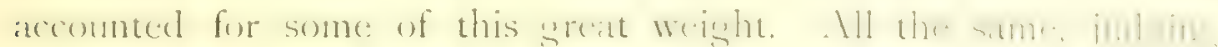

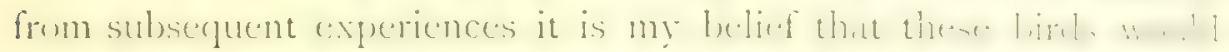
have scaled very much less had they been shot a month carlier. Certain is it that during the months of March and April the

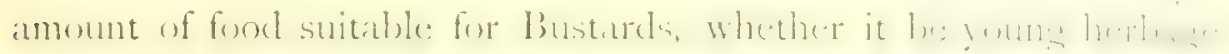
or insects, increases day by day to a marvellous extent, as all those who know Spain in spring-time catn testify. 'The orop al these birels were full of tine grasses and ween herthete, h. in : the appearance of spinach in its mashed condition. They al w

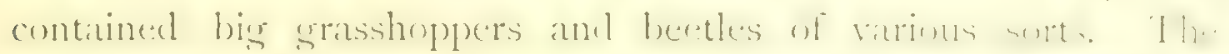
mysterious gular pouch, only present in aluh mule., hasins is.

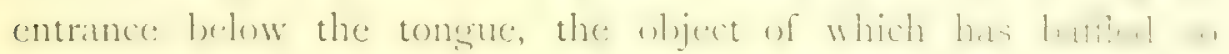
many scientific naturalists, is at this time of the year at its

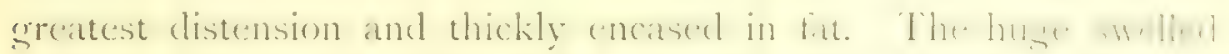

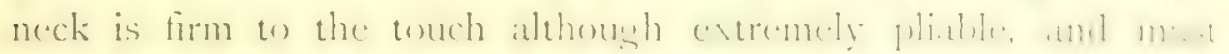

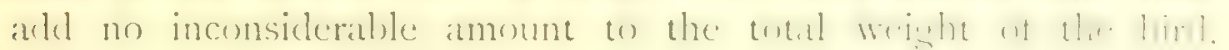
I regret now that I have never weighed the head and neck of an old male bird shot in April and also one killed during the winter months, for I feel sure that the difference between the two would be very great. 'The story that the sular pouch was an adaptation of Nature to carry it water-supply for the female and young is of course not true.

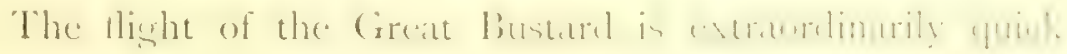

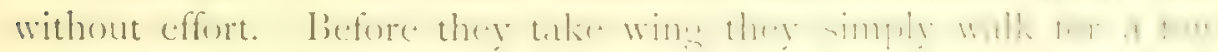
paces - no attempt at a run-and, opening their snowy white wings, 
flap) away in what appears to be a most leisurely manner. Save when there is a strung wind, or when coming off higher ground, they rarely fly more than 30 yards above the ground and hence, when they take the right direction, afford grood driving shots. Nothins, lowever, is more deceptive than the pace they fly at, for owing to the steady beats of their immense pinions, some $8 \mathrm{ft}$. across, they seem to the eye to be moving slowly; but they are not.

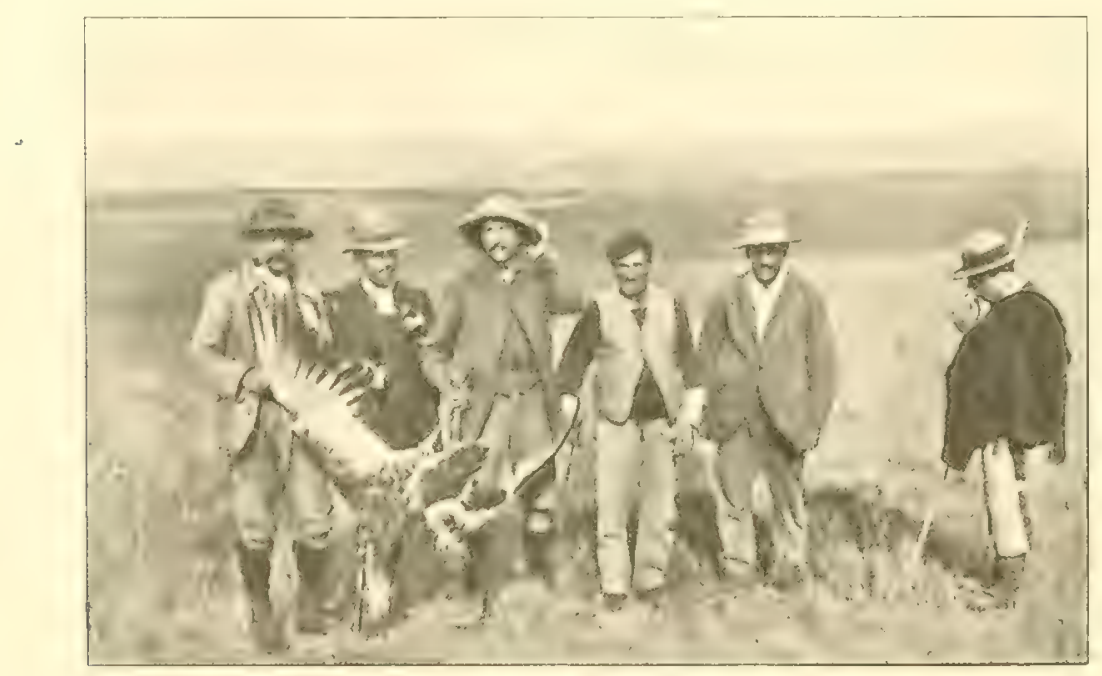

AFTER A GREAT WUSTARD DRIVE.

It has fallen to my lot to organize many Bustard drives and despite the fact that I invariably caution every sportsman who has not seen them before to shoot well forward, it is a remarkable fact that no bird is oftener or more easily missed. This is the experience of everybody I have ever met. To appreciate the extriordinary speed they travel at it is necessary to have a bird pass close over one. More than once, when lying absolutely prone on my face amid a few dead thistles, after a long wait for the drive to come off, a Great Bustard 


\section{Encounter between Eagle and Great Bustard}

has passed only a few yards over my lair, at times coming from behind or from some unexpected quarter whilst all one's energies were concentrated in the direction whence the driven birds were expected. On such occasions before one can alter one's position and rise to shoot, it has passed out of shot! Unlike so many

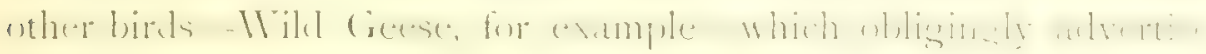
their intentions when being driven by their clamourings, Grent Buntarels are absolutely silent buth when fereling w whe wh whe wing. True, their wings make some noise but not enough to give warning of their approach. A wounded Bustard will show fight and at such times will hiss and utter a snorting sound,

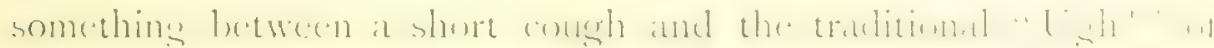
the Redskin. On one occasion only have I ever heard a Bustard give vent to any cry and that was when it was attacked by an Eagle, as I shall shortly describe. Owing to the velocity of

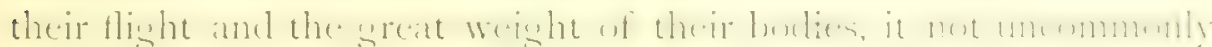
happens that a Great Bustard if flying at any height when shot, on striking the ground, bursts itself and in most instances a mass of feathers is knocked out by the impact of the falling bird.

One of the most memorable sights I cver witnessed when amongst the Bustards was in the spring of 1878 . $1 \mathrm{Ve}$ were posted for a drive, and the great birds, as so often happens, refused to be driven and elected to swing in their flight and passed clear of our line of guns. At this moment a White-

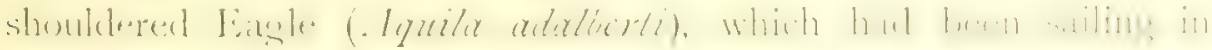
great circles high over the plain, suddenly descended and with

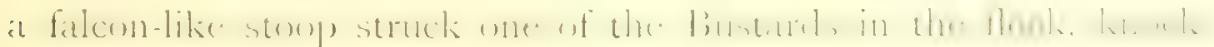
ing out a cloud of feathers. The Bustard gave vent to a series of loud squawking cries and tumbling over for some 20 or 30 yards struck the ground violently. Recovering itself, it ran for some yards and eventually took wing and followed the rest of

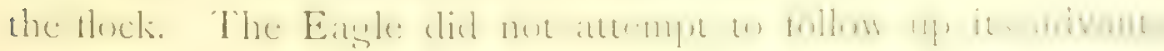


and sailed away, apparently entirely unconcerned. Arrived at the spot below where the Great Bustard had first been struck, Ferrusson and I found a number of the rich russet and black barred feathers which adorn the shoulders and upper part of the back of the Bustard, also a short way beyond was a mass of white feathers from the breast and lower parts which had been linocked out by the impact of its $30-1 \mathrm{~b}$. weight as it struck the ground.

It is hardly necessary to say that the Eagle probably had no idea of attempting to kill the Bustari and that he struck it out of the sheer exuberance of its feelings. A very similar spirit is at times shown by Peregrine Falcons, which in pure wantonness will stoop and strike some luckless Gull which chances to come across their path when they are returning to their nest on some sea-cliff.

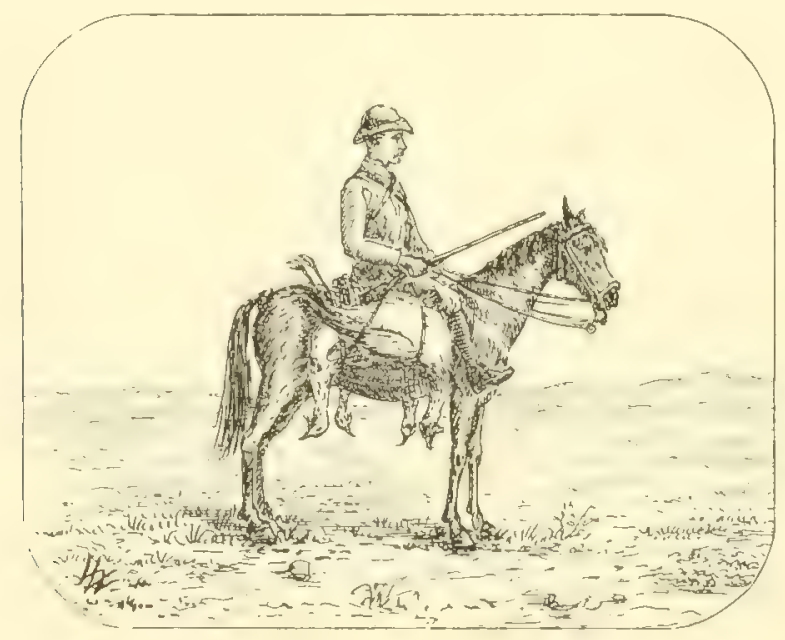





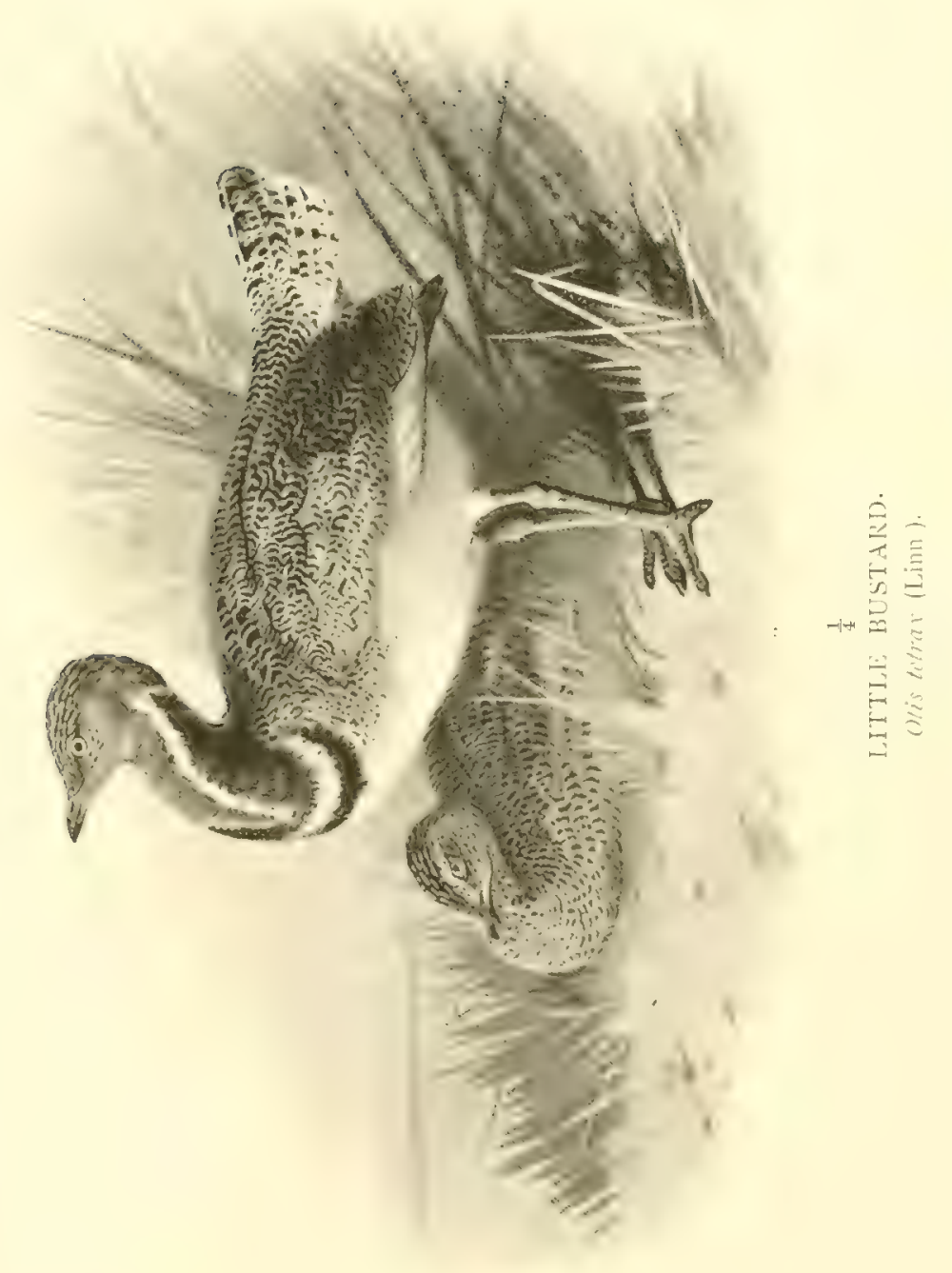




\section{CHAP'TER III.}

THE LIT'TLE BUSTARD (Otis tetrot ${ }^{\circ}$ ).

Most difficult birds to get near-Impossibility of driving them-IBentiful plumage-Peculiar sound produced by wings-Inconspicuous when on ground-General wildness-Methorls of approaching them-Nesting habitsDifficulty of finding nest-Cunning of old bird-Curious cry when alarmed.

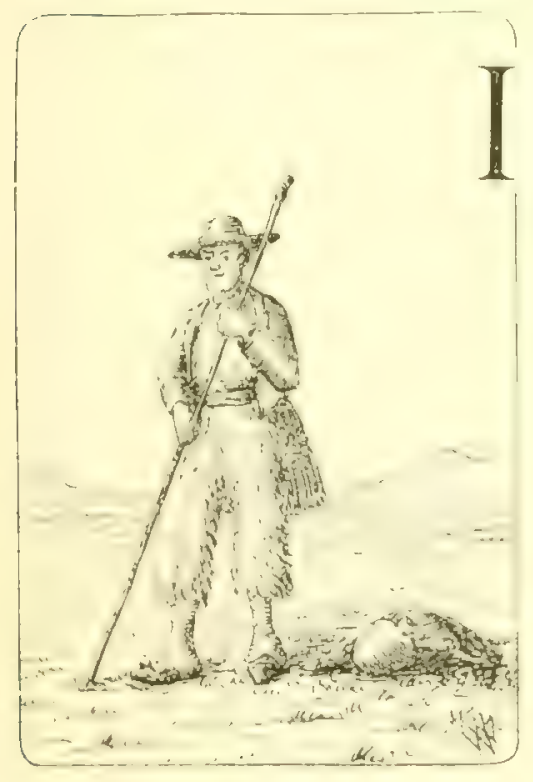

$N$ its full nuptial plumage, the male of this species is to my mind the most beautiful of game-bircls found in Europe. It is extremely abunclant on the low undulating hills and rassgrown plains of south-west Andalucia, but owing to its peculiar habits of flight is very rarely shot by the sportsman. For, when alarmed it almost invariably secks safety by rising rapidly to a great height fatr out of shot before making off. lior this reason save on rare occasions it is impossible to drive Little Bustarel.

It is a common sight to see flocks of these birds, varying from a few dozen to over a hundred, manouvring high in the arr, somewhat after the manner of Golden Plover, often at such an alciude as hardly to be identified were it not that they had been watched previously. 
Like the Great Bustard, they appear very white when on the wing, only even more so. For in their immature plumage, as well as in their winter dress, both sexes have the breast ats well ats the under parts pure white. This gentral whiteness of appearance is intensified by the primaries and all the secondaries being white as well as the under surface of the wings. The adult male assumes the truly beautiful black-and-white gorget and delicate lavendercoloured throat only upon the approach of the brecting season in March, losing it again in August.

Their flight is effected by extremely raphid beats of the wing.: noticeable eren at great distances, owing to the flashing of the sunlight on the white portions. 'The noise produced by their quick motion is one which once heard can never be forgotten and can be likened to a quick sibilant sound of "see-see-see-see," sugrestive of that produced by the steam of a railway engine as it gathers way. Probably the Spanish name for this bird of Sison (pronounced "see-sone") is derived from this peculiarity as well as the Moorish name of Sirk-Sirk.

The general appearance of these birds when on the sround, with wings closed, is rery inconspicuous, so much so that it has been stated that they are rarely seen on the ground.

Close to my dwelling in Spain are many hundreds of acres covered with asphodel and it is no uncommon sight to see the Little Bustard run out of this and across the patches of open ground. Again I have often watched a party of twenty or thirty feeding on a grassy hill-side or amid the asphodel not 200 yarcls distant and I have now and again, by making a wide détour followed by a rapid advance, under cover of the brow of a low hill, closed to within shot of them.

It is only on such ground that it is possible now and again to out-manceuve them, on the open plain they are as impossible to stalk as they are to drive. 
Single birds, and more rarely pairs, are sometimes more approachable, and if disturbed where there is cover will often only fly a few hundred yards and pitch again. When this happens I have killed them by walking quickly towards the spot, allowing 20 yards or so for their habit of running after alighting and the: instant they rise firing at them with heary shot, No. 3 for choice. By this means, they can at times be cut down at long distances and they are well worth the trouble and chances of failure.

Unlike the Great Bustard, they are greatly addicted to ruming and it is a common experience of those who attempt to drive them to see them suddenly take wing several hundreds of yards from the place where they had been marked down. Once, when posted for a drive and with all my energies concentrated on the spot to my front, whence I momentarily expected a flock of some fifty to risc, I had the mortifying experience of haring them rise close behind me, after having run with great swifuess under cover of the asphodel between me and the next grun. Small wonder is it, then, that with such perplexing habits very few are ever shot.

Young birds and females have the head, neck, back and wing. coverts of rich shades of brown, spotted and marked with dark browns and black, somewhat resembling Great Bustards. The adult male's plumage is of a more delicate shade of brown, closely pencilled or vermiculated with the same tints, this plumage he retains in winter.

Now and again, during the winter months, when lying concealed waiting for duck or geese, I have had a tlock of Little I3ustards, in their usual dense formation, swirl past me within a few yarls. So sudden has been their appearance and rapid their flight that I have never yet been able to do full justice to such an opportunity: Again, during the hottest time of the summer, single birds will at times lie close; I have also lilled them at such a seasun late in the afternoon when they flight into the marshes $w 0$ drink. 
It is interesting to note that I found these cunning birds, although wild round Tangiter, much more approachable three or four days' journey south of that district, sometimes rising within shot. No doubt this is due to their being much less molested in that wild country.

Few nests are more difficult to find than are Little Bustards',

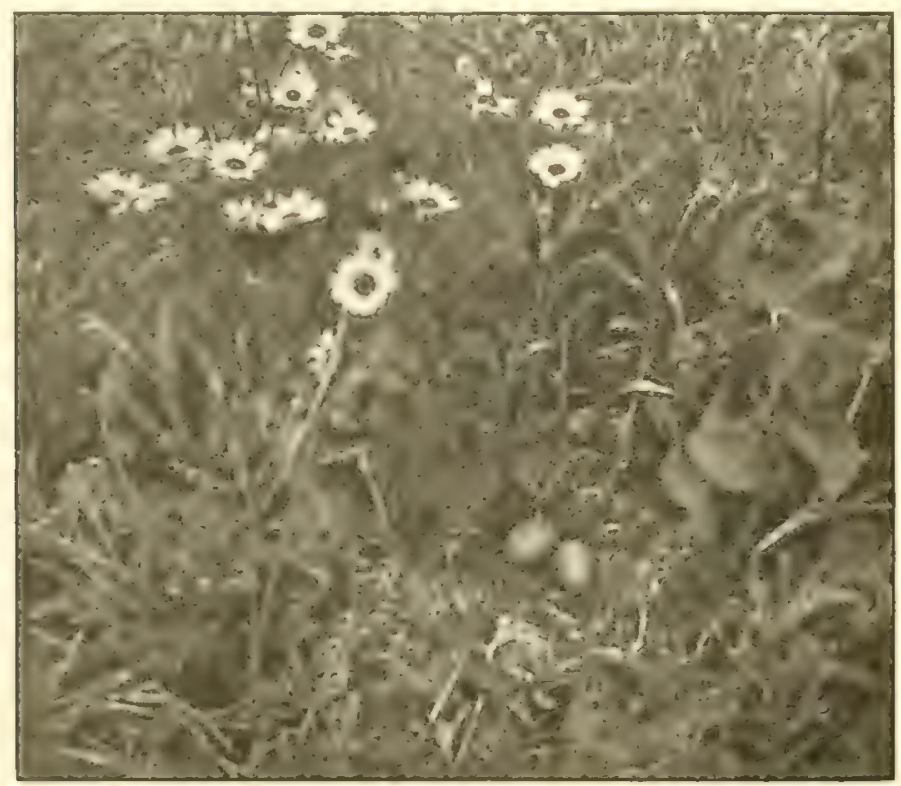

NEST AND EGGS OF LITTLE BUSTARD.

especially when they are amid the rank herbage on the fallow lands or the asphodel, when they are as well concealed as a Partridge's or Quail's. They are almost equally baffling when on the plains among the thousands of acres of waving reeds, $2 \mathrm{ft}$. or $3 \mathrm{ft}$. in height, which permit of the old bird running for an indefinite distance from the nest before taking wing. The same remark applies to those placed amongst the standing corn.

The nest varies much in its size and construction, being at 


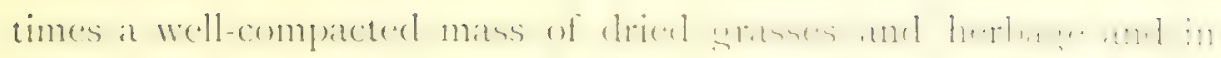

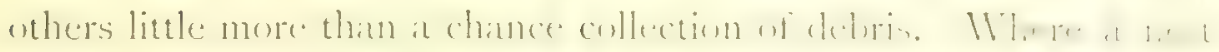

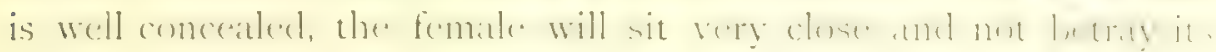
situation until almost trodden upon, whereas in more exposed

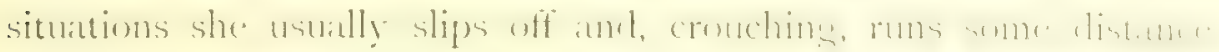
before taking wing.

The nest here shown was amid a dense growth of coarse

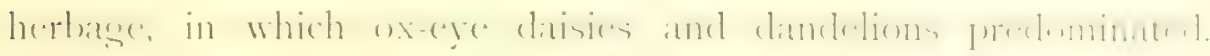
The bird only left when I was within 2 ft. of her and in her scuftle

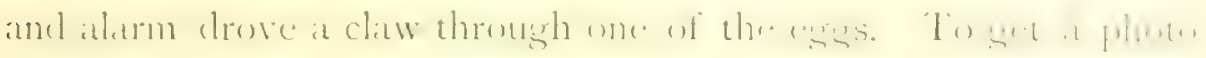
graph of this nest, we had to cut a lane towards it and clear away much of the surrounding herbage. This nest was only a slight

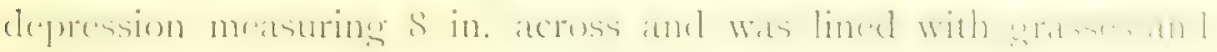
herbs pressed down around it. The two egoss it contained were

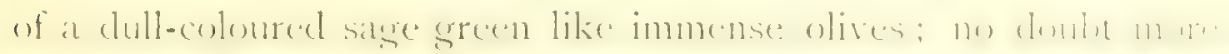

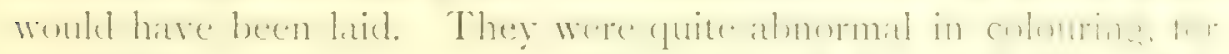

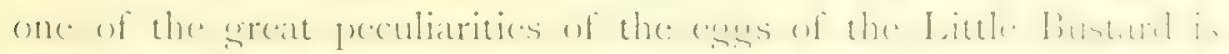

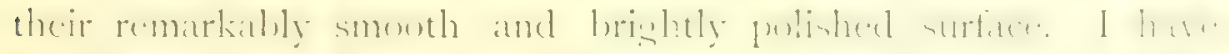
eggs over thirty years old which still retain this lustre. The

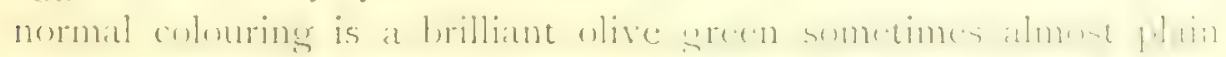

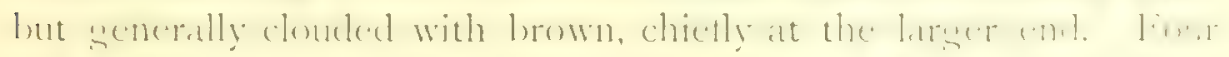
is the full complement laid, hut I have kmonn wi ments with the. egres and some in which only two egges were laid.

The day I found this nest with two egres was dull and wet with

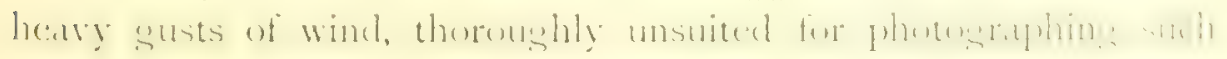
a subject. It was is May, and by a remarkable chance, eminently

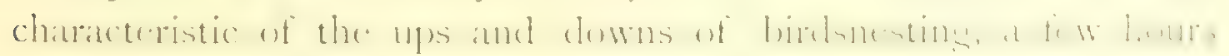
later on the very same day, I came across a second nest about 3 miles from the first one. It would be hard to imagine a meater contrast than it presented, for it was on a bare and open hillside.

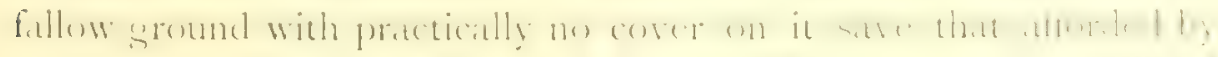

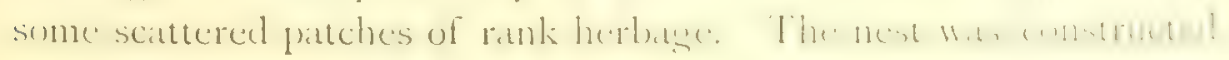


in one of these patches and was quite open to view to any passer-by as can be seen from the picture. The cup of the nest was much deeper and better finished than the cup of the first one being well

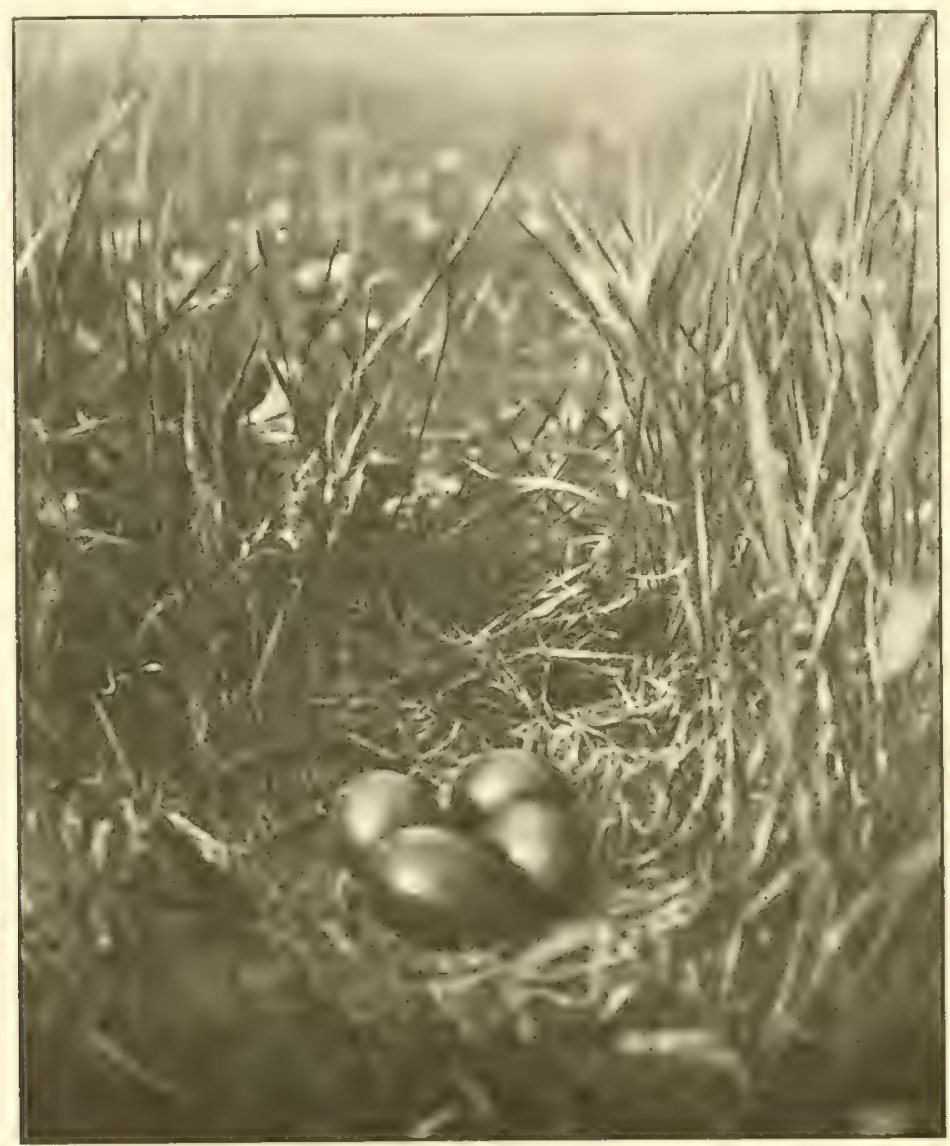

EGGS OF LESSER EUSTARD. (Size I.9 in. $\times$ I $^{\circ} 5 \mathrm{in.}$ )

lined with grasses. It contained four richly coloured and shiny engs probably laid about 7 to I I May, judging from the state of incubation. The adroitness of the Little Bustard is shown by the fact that clespite the open nature of the ground around this nest 
and of my keeping a sharp look out, we never saw her leave it and she took wing from a point just 23 yards (measured) from once side of it. I imagine she saw us when a long way off and stepping off the nest ran out to a thank and crouched, with the distinct purpose (in the event of her being forced to take wing, as actually occurred) of misleading us as to the position of her nest.

When alarmed, as for example, when suddenly disturbed from off its nest, it utters a loud guttural rattling cry, somewhat similat to that of a grouse calling in early morning and even more like that given by the Bustard which we came across on the veldt between the Orange and the Modder Rivers during the eventful days of November, 1899 .

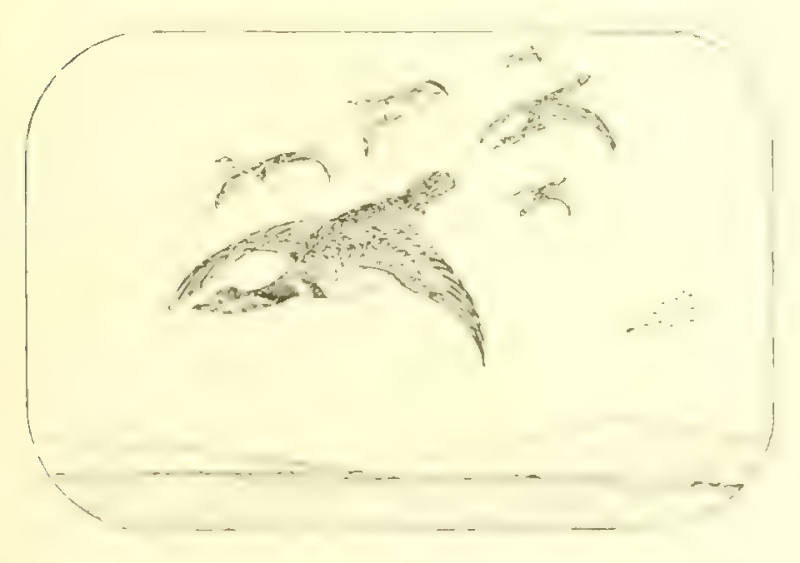




\title{
IV.-THROUGH THE IVOODLANDS.
}

\author{
CHAPTER I.
}

\section{A DAY IN THE CORK WOODS.}

Great variety of birds met with-Winter residents-Some tardy migrants-The Warblers: Cetti's, Bonelli's, Melodious Willow, Western Orphean, IVestern Rufous and Nightingale-Blackbirds--Serin Finches-IVoodchat ShrikesGolden Orioles-Protective colouring of Orioles--Artistic nests-Difficult of access-Climbing a tree-top-Scops and Little Owls-Tree-tapping and its results-Hoopoes-Bee-eaters-Their subterranean nests-How to reach them-Cork-oak trees-Game preserving in Spain-Value of the Raptores as assistants-Predacious reptiles and four-footed marauders.

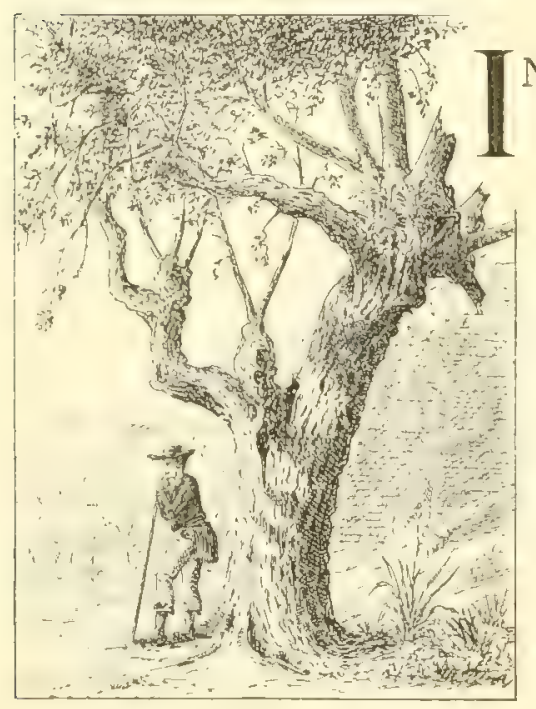

$N$ Spain, where the naturalist in the woodlands meets with the great treenesting species I describe in this book, such as the White-shouldered Eagle and Black Vulture, as well as the many lesser Eagles, the Kites, Hawks and Ravens, he is almost inclined to overlook the host of smaller and less conspicuous birds which make the trees and undergrowth their home during the breeding season. The Warblers alone, though abundant, and heard on every side, are so elusive in their habits and cunning in their choice of nesting-places as to make their separate study and the finding of their nests the work of a lifetime. 


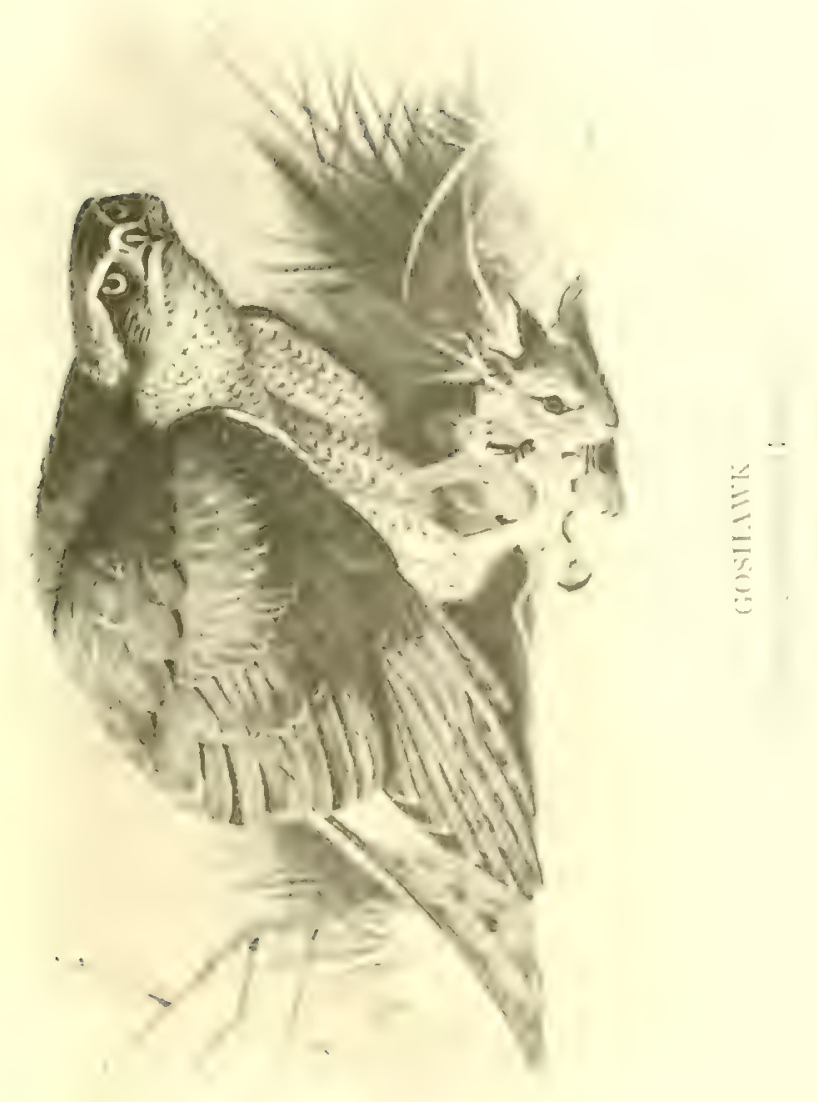





\section{Among the Warblers}

During the winter months the woods are more or less deserted.

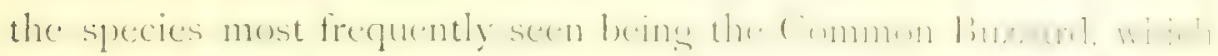

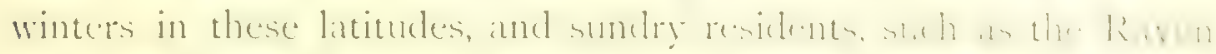

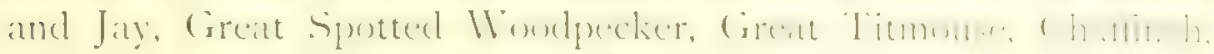
Goldfinch and Serin Finch. But as spring approaches all is changed. Owing to the temperate nature of the climate and warmth of the sun, even in winter certain migratory species, such as the Common Swallow, never entirely leave the country, and no

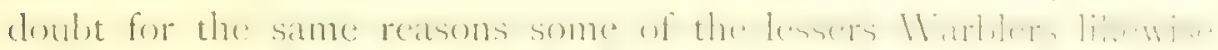
linger there. Thuse acquainted with the dintinctive a the of the

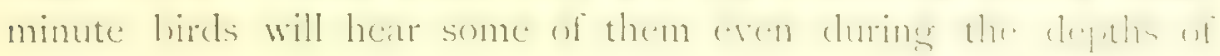

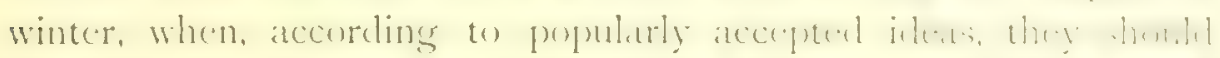

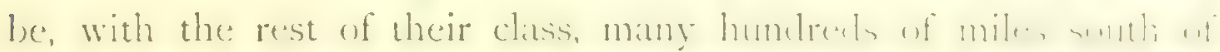

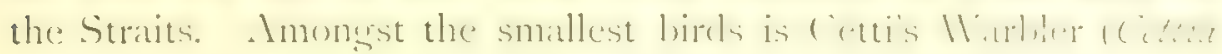
cetti). It has a loud and penetrating cry, which, when once

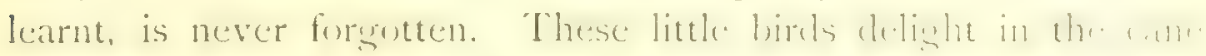
bralse and brambles which cover (every moist spot, amil whin

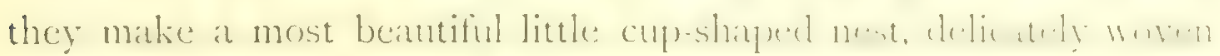

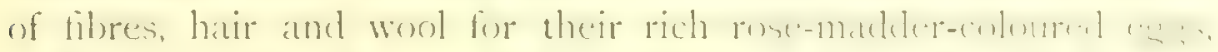
quite the reddest of any small eggrs I know.

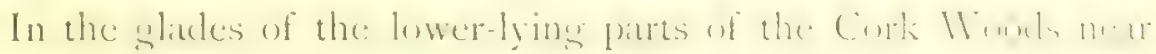
Gibraltar there are deep sotos, or swamps, in fact miniature lasunas, the placicl surface of which in carly spring in where with

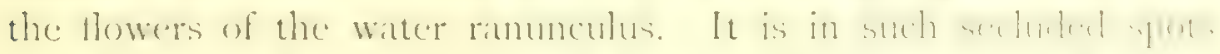

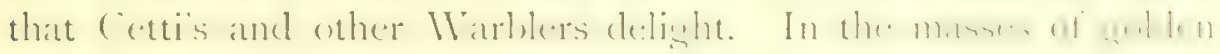
cytisus around these swamps another minute bird, Bonelli's

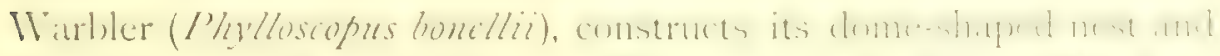

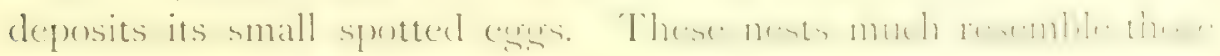
of our Common Wren. It is very probable that this little bircl,

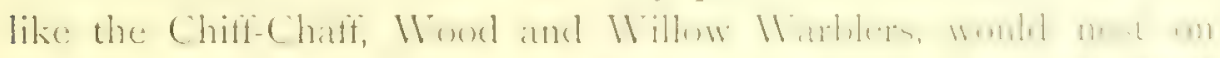

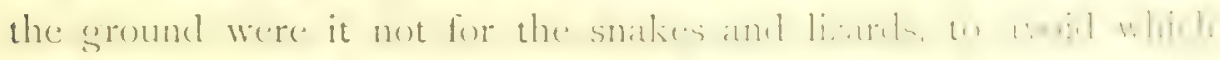

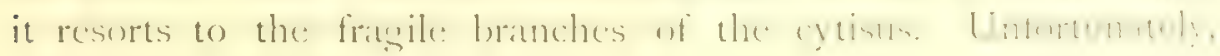


these delicate shrubs offer small resistance to either man or beast who may wish to penetrate them; hence, on several occasions, I have known of nests of Bonelli's Warbler which have been destroyed by passing cattle as they forced their way through the undergrowth in search of pasture.

In the closer-growing bushes along the elge of the streams a beautiful little Warbler, one of the Melodious Willow Warbler group, known as Hypolais polyglotta, from its rich and varied song, also nests. A widely distributed specics is the ITestern Orphean Warbler (Syliza orphea), which builds a cup-shaped nest on the branches of the smaller corl trees about $S$ to ro ft. above the ground, and lays egers closely resembling those of our Garden Varbler. Needless to saly that in Andalucia, from the first week in April and onward, the voice of the Nightingale is heard from every clump of brambles or jungle-covered marsh. All the nests I have come across have been invariably placed in bushes some little height above the ground and not on the ground as in England. Probably here again the birds endeavour by such means to aroid the predatory reptiles which are so abundant.

One of the most frequently seen among the spring arrivals is the bright-coloured Western Rufous ITarbler (- Tïdon gralactodes). They are particularly partial to the big aloe hedges which at many places skirt the patches of cultivation and by their lively actions and conspicuous plumage attract the eye far more than do any of the other Warblers. In many ways they rescmble the Nightingale, but are larger and far brighter coloured and, as they flit from bush to bush, erect and expand their tails, which are rufous in the centre and have the outer feathers white, barred with black at the end. This peculiar habit induced Colonel Irby to style these birds the "Cock-tail IVarbler" and a very descriptive name it is.

The Common Blackbird swarms in southern Spain, and nests 
in the dense lentiscus or wild olive trees scattered throurh the cork forests. Curiously enough they seem never to lay more than three eggs in place of the four or five usually found in nests in England. I mention this because I have never seen or heard of a nest with more than three eggs.

Among the upper branches of the cork-oak trees, the Serin Finch (Frmilla somms) nests, a sort of diminutio whil (.mant. its weak sibilant song being heard on all sides.

One of the commonest of the woodland birds is the Woodchat

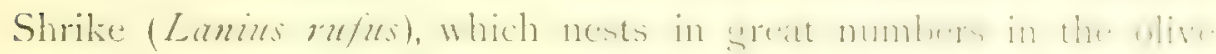

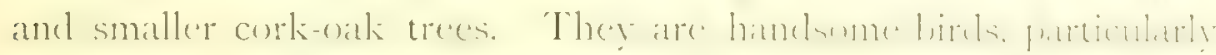
the males, and on their first arrival are very noticcable as they

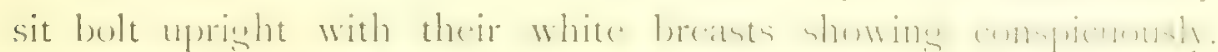

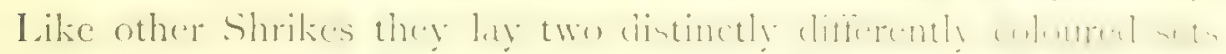
of exgs, one heing of warm stone-columed around and the wher pale green, both alike being much spotted at the larger end.

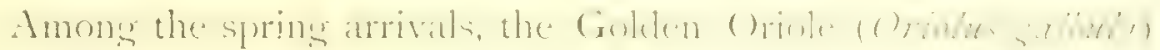

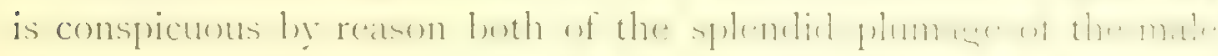

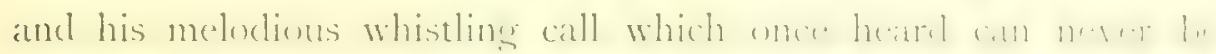

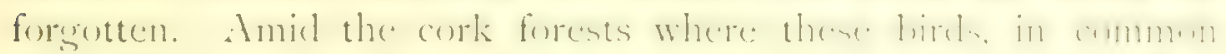

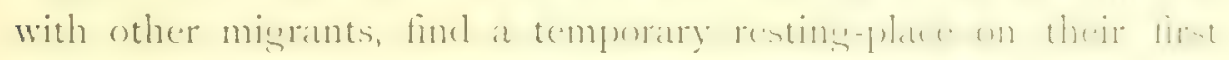
arrival from southern latitudes, there are numerous grass-grown glades adjoining the sotos or swampy portions. Mlong such

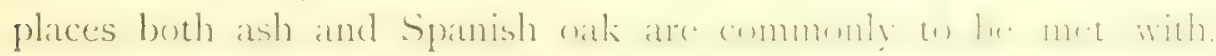
which at the time of the arrival of the Orioles in the month of

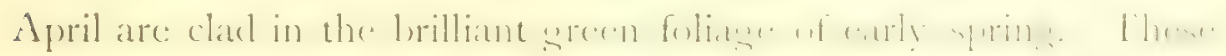
trees seem to offer peculiar attraction to Orioles and often have

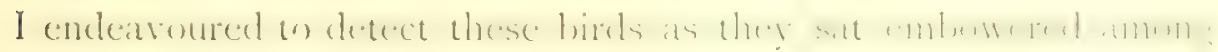
the green leaves, uttering their tuneful calls. In the brilliant

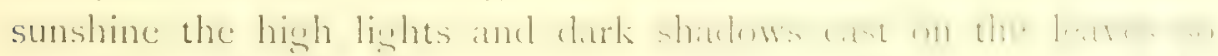

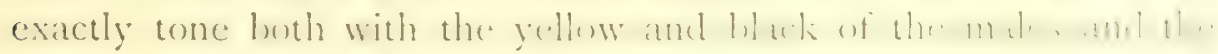
green and dark brown of the females as to make it a hard task 
to pick them out even with the most powerful wass. When alarmed, the Orioles, upon quitting such a natural sanctuary almost invariably thread their way with undulating flight to a similar tree. passing by those such as cork-oaks and olives which are of more sombre tint. I have repeatedly watched this for many years past, and am convinced it is no mere chance but a regular habit and it may be taken as an axiom that if Orioles are heard to be calling on a wooded hillside it is almost a certainty that they will be found perched in the most vividly-foliaged trees in the neighbourhood. A certain number remain to nest in southern Andalucia and all the nests I have seen have been suspended to the branches of the Spanish oak, usually towards the extremity of some pendent bough.

These nests are beautifully constructed of fine mosses, lichens and fibrous roots woven around the twigs and lined with horsehair and wool. The eggs are white, delicately spotted and blotched with purple. In I906 I found a nest among the smaller branches near the summit of an oak, about $40 \mathrm{ft}$. up, and ascended the tree. When still some $\mathrm{I} 2 \mathrm{ft}$. below the nest, it became clear that the branches would not support my weight. I was most anxious to take the eggs and so set to work to get at this secmingly inaccessible nest. By climbing up an adjacent and somewhat stouter branch which shot upwards for a few feet, I reached a point whence I was able to pass the end of my silk rope round a second branch near the one supporting the Orioles' nest. I then extemporized a tackle and by its aid hauled the two boughs together, making them fast with the end of my faja, or sash. I now used the two branches as a second point of support and ascending them yet higher, got my line once again round another branch, and hauling it in, also made it fast to the other two. By this means I eventually reached a point on the level of the nest whence I was able to pass the end of my silk rope round the branch containing my prize and, by hauling it in to 
my somewhat precarious perch, bring it within my srasp. It was an interesting bit of work, and afforded a good refutation of the reputed inaccessibility of nests of the Orioles thus placed amid the smaller branches of high trees. From my experience on this and other occasions, I believe that, given sufficient lighe rope and ordinary skill at climbing and using ropes, no nest of this description is safe from the determined birdsnester.

Among the nesters in the hollow cork-oaks and alders are the

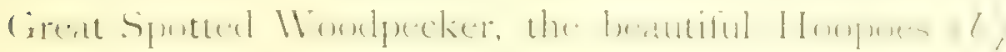
and the Scops and Little Owls (Scops giu and Carino nochu).

I know of no more elusive birds than these dwellers in old trees. Many years ago Colonel Irby found several nests of the Scops Owl by tapping the trees and in consequence wrote: "The nest is easily discovered by going round and hammering at the old cork trees with a stick."

For over thirty-four years I have sought the nests of these small Owls and have ridden and walked hundred of miles and tapped thousands of trees in their quest. Further, I have induced innumerable friends to go and do likewise, and without result, for never yet have I put an Owl off its nest by such methods. It was after one such day with some naval officers that somebody remarked that if Colonel Irby had realized the flow of appalling bad language which was the direct outcome of his advice to hammer the trees, he would probably have thought twice before placing it on record.

One of the most mysterious of the calls amone the dense woods is that of the Hoopoe. It consists of a curiously soft and hooting cry of "Hoo, Hoo, Hoo," repeated at short intervals. Although

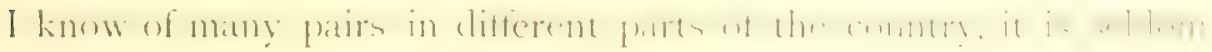
indeed that one is able to find the nest.

But of all the spring migrants which herald the approach of the nesting season none is more rematiable or more constant than the brilliantly coloured Bee-eater (H/mops apiankr). 
These lovely birds arrive with most extraordinary punctuality year after year, at first in small parties of a dozen or so and then in continuous streams. Their call is unlike that of any other bird, a curious liquid double note, which at times, when many are passing over, seems almost to fill the air with its sound. And

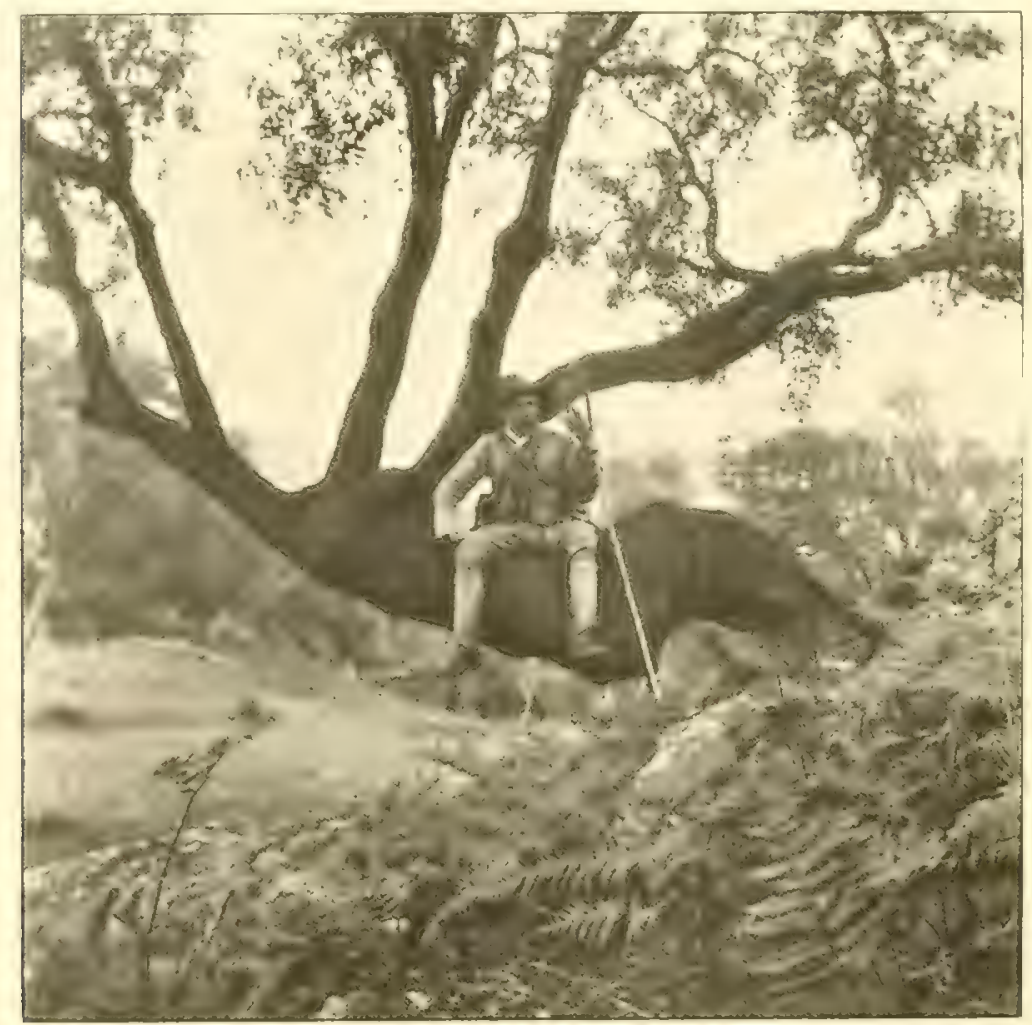

A GLADE IN THE CORK WOODS.

a very joyful sound it is, for it is an unmistakable proof that spring is upon the land. The first arrivals are usually heard about 4 to 7 April and from that date onward parties pass overhead for weeks, scattering all over southern Europe. The climax to the migration, according to Colonel Irby's and my own 
observations, is about 19 April; hence, following the Spanish custum he christened it "St. Bee-eater's Day" and ats such it has been known for years to all who had the happiness to wander in the wilds of southern Spain with that truly admirable ornithologist. In the small garden surrounding my little dwelling in the wilds there are placed many of the cork bee-hives, known in Spain as colmenares, and yeat after year have I been awaliened at an early hour during the first days of April by the well-known liquid cry of the Bee-eaters as, pausing in their first flight from the African shores, they proceed to take toll of the luckless bees swarming about the hives. The number of bees one of these birds can devour is almost incredible.

1 know of few more fascinating occupations than at ricle or stroll through the cork forests, now threading onc's way through dense woods, now emerging on some grassy glade, across which the roe-deer dart silently, following the sinuous tracks made by many

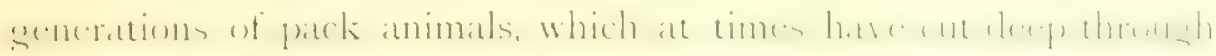

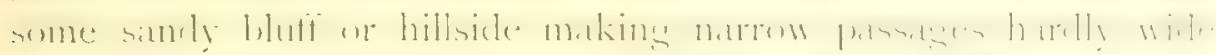
enough for a laden beast to pass. In the vertical sand-banks thus formed, the Bee-eaters burrow their deep tumnelled passages, often for $10 \mathrm{ft}$. or more, Sand-Martin fashion, and deposit three or four shining round white eggs in a small chamber at the far end. The simplest way to get at these nests is to watch the birds entering and leaving the numcrous holes, until one which is in occupation is detected. Armed with a telescopic fapancese fishingrod, I have plumbed many such burrows and when one is found which trends upwards so as to be within reasonable reach of the surface of the ground above, by carefully measuring the length of the burrow and noting its direction, I have clug down from above and reached the nest with but little trouble.

There are various perplexing points in the Bee-eater's halbits. Thus they make many more burrows than they recuire; possibly. 
on meeting with a stone or hard stratum which bars the way they abandon the task and try afresh elsewhere. Again, some nests are placed in a chamber mid-way down a burrow and not at the end. A few weelss after the Bee-eaters have settled down to their nesting stations their long, sharp-pointed bills are worn down considerably from constant work at excavating their burrows. Very favourite nesting stations for bee-eaters are the sandy banks of rivers and other natural cuttings in the open country.

The cork-oak tree is unquestionably a very picturesque object. and the ravages mate on it by removing the external bark every seventh year in a way add to the beauty of the vistas seen through the woods. For the trunks, bereft of the cork, are of the richest chocolate red, and the effect of the sunlight and shatow playing through the leafy canopy on the dark rugaged stems, dotted here and there amid the brilliant golden blossoms and green foliage of genista and high bracken, is a joy for ever. It is curious how deep and chequered are the shadows cast by these trees, and how hard it often is to discern cither man or beast moving through the scrub below them.

A native wearing the favourite dark brown chocolate jacket, standing leaning on his long stick, as is their habit, assimilates so perfectly with the surroundings as to make one start on suddenly becoming aware of his proximity. I have always thought that the chocolate brown uniform worn by the Portuguese Caçadores in the Light Division during the P'eninsular War was probably chosen for this reason of its invisibility in wooded and broken country. The trunlss of the larger cork trees, above where the cork has been removed, are usually covered with mosses and hare'sfoot fern, and make a very beautiful spectacle.

Of the flowers and flowering shrubs met with in the cork forests, together with the butterflies and teeming insect-life, I can only say, go and see them in April and May. 
It is sad to have to record that of late years, owing to the extension of the custom of game preserving in Spain, wat of extermination has been declared in many places a tatinst the Fingles, Falcons, Kites, Harriers and Hawks. That some of these do

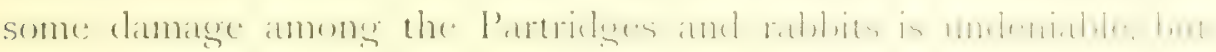
the majority of them habitually feed upon the snakes and huge lizards which are the deadly foes of all winged game and likewise devour their eggs. Hence in no country should the birds of prey be more encouraged and protected than in Spain.

But the greatest enemies of all game, both winged and fourfooted, in Spain are the numerous predaceous animals which in some districts literally swarm. Besides lynx, foxes and badgers there are wild cats, ichnemmons, genets, martens, polecats, stoats and weasels, to name only some at random. I mention this subject here as, on the chance of this book falling into the hands of those interested in game prescrvation in Span, they will possibly be led to devote their energies to the destruction of the four-footed marauders and to enlist the services of the Eagles, Kites and Harriers in keeping within bounds the deadly manges of the reptilia.

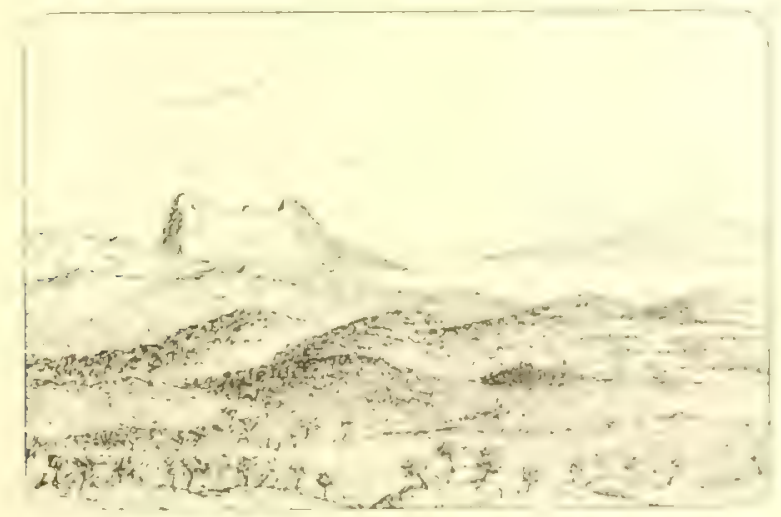




\section{CHAPTER II.}

\section{THE KITES AND HAWKS.}

THE Red Kite (. Hilvus iftimus)-Marvellous powers of flight-Important part played by tail-A Kite's nest-A stiff climb-Trapping the old bird-Revisit nest twenty-four years later - Kites and reptiles - Immense damage wrought by reptiles in Spain-Raptorial birds the principal check on their numbers.

The Black Kite (Milqus migruizs) - Simple means of identifying on the wingSpring migration-A colony of Black Kites-Nesting-places-Curious predilection for rags and paper.

The Goshawr (Astur falumlurius) - Retiring habits-Constancy to same nestingplace-A doubtful nest - Failure to identify bird-A stratagem and its result.

The Sparrowhawe: (Acifitor misus) - Nest in Booted Eagle's tree-Climbing ivy. clad trees.

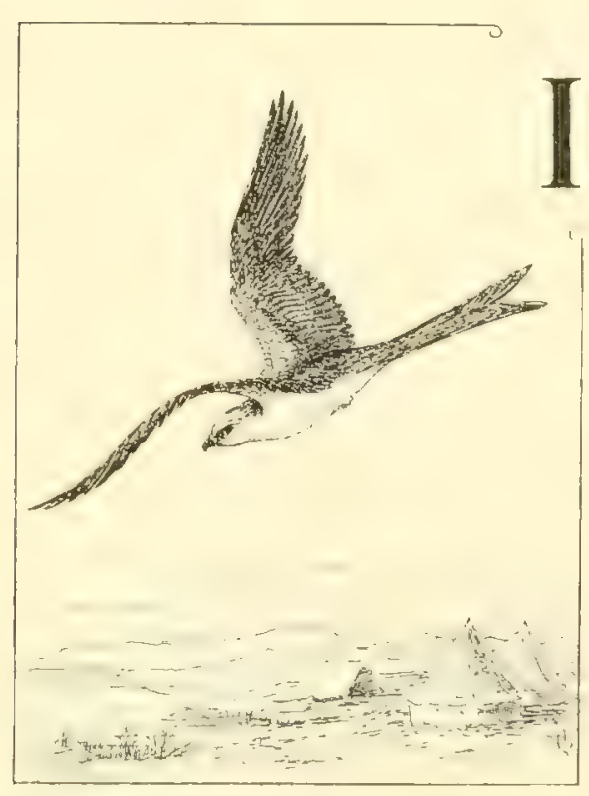

THE RED KITE (Milrus ictinus).

T $T$ has often occurred to me when watching Kites on the wing that few birds afford a more instructive exhibition of the art or mechanism of flying. Whether this be due to some subtle combination of wing-power, relative weight or peculiarity of build it is hard to say, but it is certain that the Kites leare the im. pression that they can move with greater ease and precision than do most other birds.

The Red Kite owing to ceaseless persecution in our Isles, is rarely seen and naturally enough is arerse from being watched 

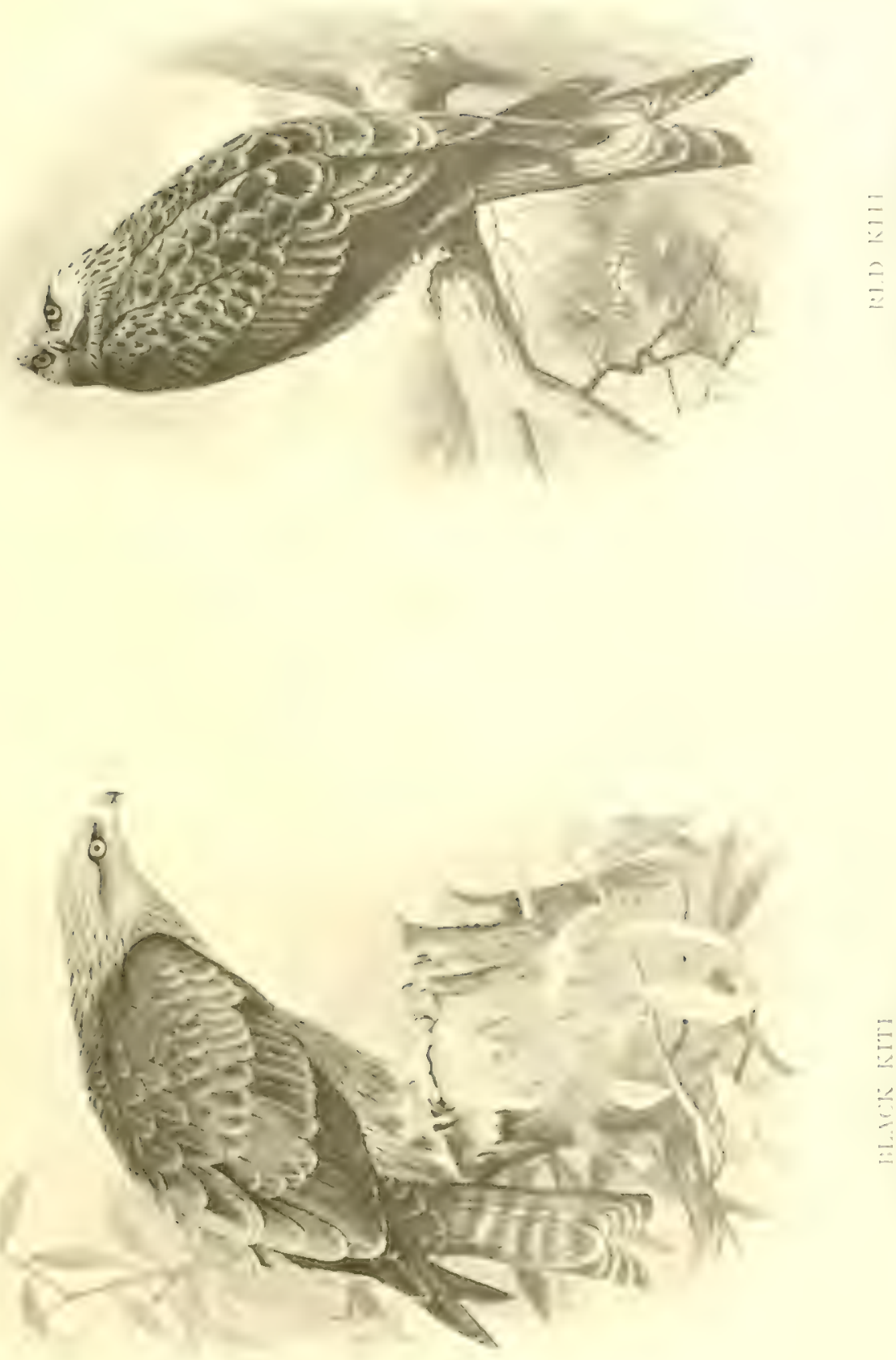

政 

by its arch-enemy, man. Fren in Spane, where it is so abundant and so little molested, it is not always eatsy to watch its aracefol

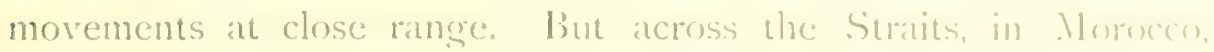
it ceases to have any foar of man, and to me: one of the ardeded pleasures of camping out in the wilder parts of that country is to watch the Kites on the wing at close quarters. It was not until I had such an experience that I appreciated the marvel of precision and grace combined which characterize the least movements of the Kite. When on the march in Moroco 1 found it interesting to note how soon after we got our pack animals unladen and tents pitched, a parir of Red Kites would appear and constitute themselves the guardians of the spot, circling often not $20 \mathrm{ft}$. above us and kcenly watching for any fragments worthy of their attention. After a few easy strokes of its wings, no laboured tlapping, one would glicle slowly past on motionless pinions, with head inclined and bright yellow eye closely examining all below, and, as it passed between us and the sun, the delicately coloured forked tatil seemed almost transparent and assumed a bright rufous tint. Sucklenly, with a quick but well-defined motion the angle of the tail woukd be altered and, obedient to this movement, the course of the birel would be changed with mechanical precision until a second guick turn of the tail brought it back to its former course ar caused it (n) sweep round, as the case might be. Watching a Kite so close at hand makes one realize what a vastly important part in the mechanism of the flight of birels is played by the tail. ()f course the amount which is brought into use varies areatly according (1) the habits and llight of vatious orders of birds and rery probably there may be many which make even more use of it than does the Kite. But owing to the conspicuous colour and almormal lengeth and shape of the Kite's tail, which attracts the cye of the leatst observant of people, the effect it produces on the morements af the bird is far easier to realize and enables the spectator" to appreciate 
the connection between cause and effect. Besides the quick lateral alteration of the position of the tail, there is another movement wherelsy the height of the flight is regulated, and yet argain another, the sudden expansion of the tail like an opened fan, whereby the speed is instantly checked. It is after watching the Kites thus gliding, seemingly without effort at all angles and in all directions, that one despairs of the audacity of man's attempts to convert himself into a tlying machine.

It was one of the many red-letter days in my birdsnesting life when I first succeeded in marking some Red Kites to their nestingplace at the top of a tall pine. The tree was without branches for over $35 \mathrm{ft}$., with the exception of a small rotten-looking stump about $20 \mathrm{ft}$. from the ground. At the time I was innocent of ropes or other appliances for tree-climbing. So I set to work to swam up the big slippery trunk and after a severe strugsele reached the small stump where I rested to recover my wind and then resumed the ascent. I shall never forset my joy at seeing the two beautiful engs lying on the dirty platform of old rays and goat's hair with which the nest was lined. Sending down my prize in a box on a line, I hauled up my trap, an iron one with blunted teeth and padded jaws, a present from I ord Lilford, and set it in the nest. After covering it with some of the lining, and placing a hen's exy beyond it, I descended and concealed myself in the cistus scrub some 200 yards distant. Very shortly the Irite returned and, entering the nest, sprang the trap. Next moment she dethed off, but the line on the trap soun brought her up and she came to the ground. It was my first attempt at trapping a big raptorial bird and I was mightily pleased to find she was caught by one of her centre toes and absolutely unhurt. It is hard to imagine the beauty of a wild bird thus caught alive and unharmed. It surpasses beyond belief the appearance of birds kept alive in confinement or mounted by the most skilful of taxidermists. 
I kept this bird in barracks for about three weeks after which she was released and I had the pleasure of secing her, together with her mate, when riding past the pine wools some days later, still wearing the leather jesses I had put on her legs, but no doubt they very soon dropped off.

This was in 1879; many years afterwards, in May, 1903. I took Admiral Farquhar to this nest and found it again occupied by a Red Kite. 'The old bird was sitting so close that she declined to move until my lead weight struck the tree close to her. IV soon got a line up and ran one of our party up to the nest. This nest contained a young Kite about 2 weeks old and a second, a weels old, besides one eges, a curious proof of the irregularity of laying of some birds. There were also the remains of an ()edlated I izat about ! 8 in. in length. Those sportsmen, and alis! there are many, who adrocate the killing of these Kites, Harriers and Fingles in Spain on the pitiful pretext that they are 'so destructive (o) game' would do well to consider the enormous amount of assistance they receive in the protection of game from these same bircls. The havoc wrought by the vast number of big snalies and lizards in the Spanish Peninsula among both birels and the smaller mammats is well-nigh incredible. Both classes of reptiles not only derour both eggs and young birels but, when opportunity offers, the parent birds as well. In fact, the only thing which leeps the mumbers of these most predaccous reptiles at all within bounds is the persistent preying on them by so many of the lareer raptorial birds. In fortunately the misdeeds of the birds such, as iaking a l'artridge or a rabbit, are done in the light of day and are at times seen and animadverted upon, whereas the reptiles work quietly and unsecn. often by night and always under cover. Hence the extent of their depredations is generally unappreciated. lior onc luclitess rabbit pounced upon by an Eagle, scores of young ones are swallowed wholesale by the reptiles who exploit their burrows. Hence all 
and every means of reducing the number of the snakes and lizards tends ultimately to increase the amount both of winged same and rabbits, which are held in high esteem in Spain.

Upon the amount of good done by the whole family of raptores in this way nobody can speak with such decisive authority as the birdsnester and above all one who habitually visits all the nests himself and is accustomed to take note of what he sees. The outcome of my own personal observations extending over thirty-four years is that with hardly an exception all the so-called gamedestroying Eagles and Hawks habitually prey upon the larger reptiles, as is well shown by the fact that it is rare to find one of their nests without the remains of a snake or big lizard, particularly the latter. whereas it is the exception to find rabbits and still more so to see Partridge's feathers.

\section{BLACK KITE (Milvus migrans).}

Closely allied to the Red Kite is the Black Kite, the former however is a resident in southern Spain whereas the latter is one of the many spring, migrants. As can be scen from the Plate of the two species there is a strom family resemblance between them. ( )n the wing it is not difficult to identify either species, for even at a considerable distance the more decoly forked tail of the Real Kite is clearly distinguishable, whilst, should the birds he werhead, the Red Kite's wins are much lighter on their under surface and are marked with a conspicuous dark patch upon each. I alstly, the Black Kite, besides being darker under the wings has a distincty darker appearance all over than has its relative, wherice its name.

Every spring great numbers of Black Kites pass northward over the straits. The first of the migration usually eccurs during 
the first week in March and it is at its height durine the lit. week. Some few remain to breed at various places in the vicis. but the bulk of them pass further north and nest in colonies. In May 1879 I visited one of these in the Coto de I monana with Crown Prince Rudolf, and I climbed up and tooli sereral nests. On one occasion I saw no less than twenty-two of these hirds

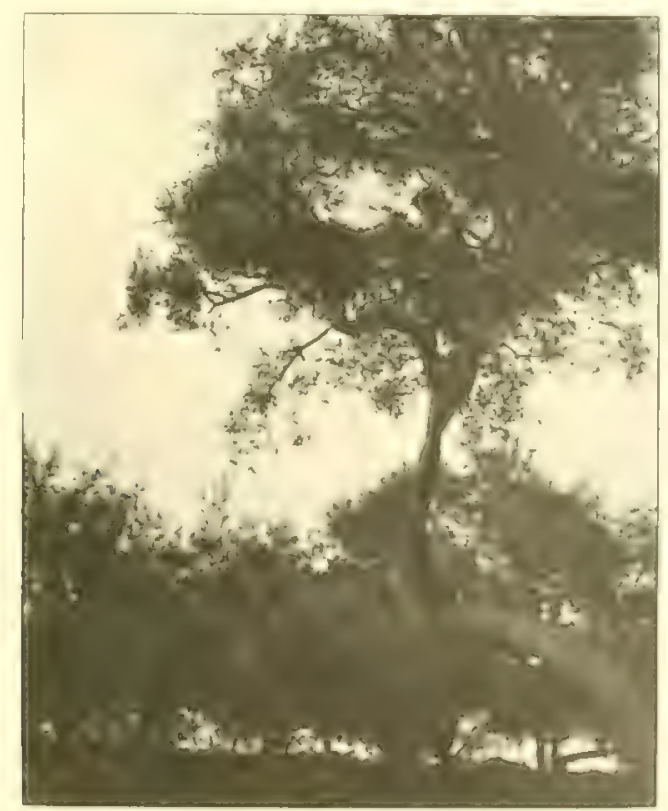

NHT OF JIACK KITH IN COKK TRH

congregated on one of the sum-baked mud flats amid the sand hills and pine woods of the marisma. It was near the end of May and the ground was bike iron and the herbage burne up by the fierce rays of the sum. I'et these birds secmed to be feeding upon something, possibly small grasshoppers of sorts. When dis turbed they gave a sharp tremulous cry as they took wime

Both Black and Red Kites often nest in companatively smat 
trees. I have found several nests placed in cork trees $20 \mathrm{ft}$. to $30 \mathrm{ft}$. from the ground. They would seem whenever possible to prefer using the deserted nest of some other bird to going to the trouble of building one for themselves. Thus, those in the cork-oak trees

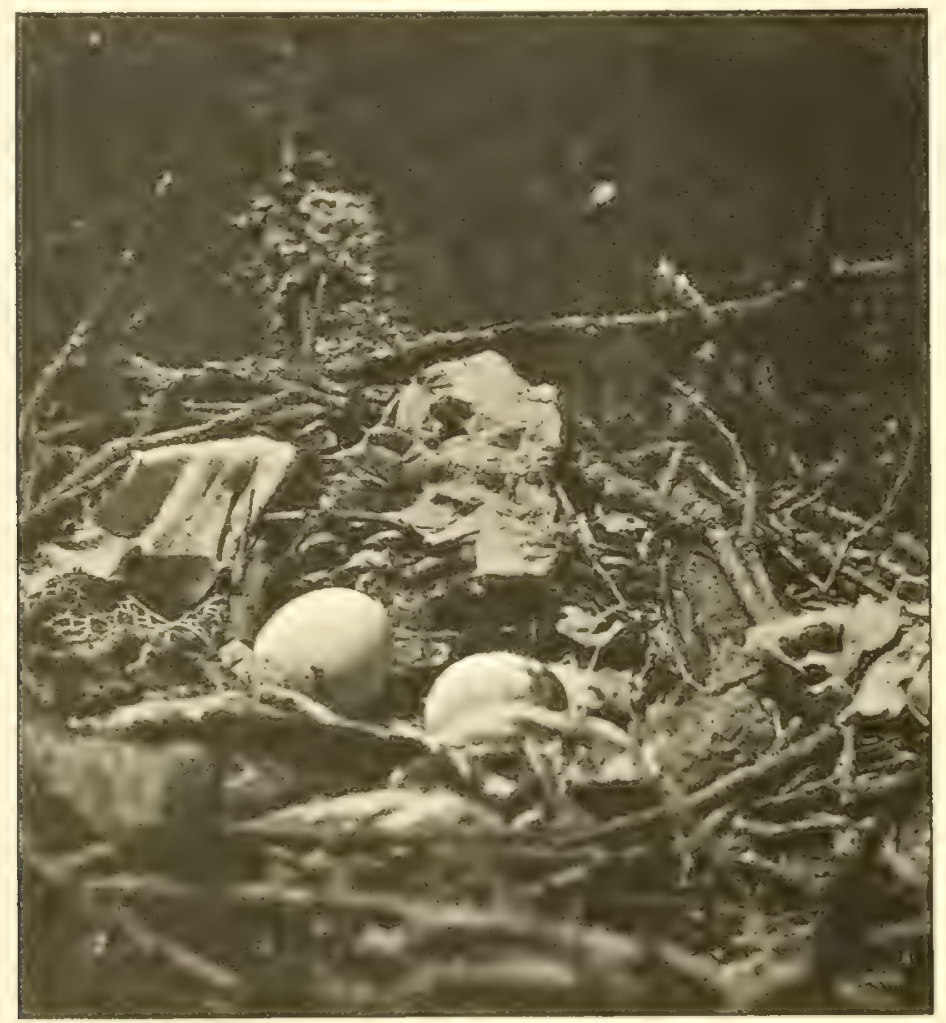

NEST AND EGGS OF HLACK KITE.

were invariably disused nests of the Snake Eagle which I had seen tenanted by those birds in former years. The nests in the Spanish oaks were similarly those of the Booted Eagle and most, but not all, of those in the pine trees were old Ravens' nests. The nest shown on the preceding page is in a cork tree about $30 \mathrm{ft}$. from 
the ground and was originally built by a pair of Snake Iangles. The sharp turn taken by the branch in which the nest is placed gives some slight protection against the casual marauder but none whatever against an expert climber.

As is well known, Kites are much addicted to lining their nests with pieces of rag and paper and all sorts of curious and unconsidered trifles. The Black Kite seems to possess this curious mania to a marked degree and some nests I have visited have been literally festooned with such rubbish. The classic cxample of this was narrated by Lord Lilford to me in 1876 . It was in 1870 that he visited a Black Kite's nest in a remote district and found in it among other things a fragment of a Spanish newspaper in which the assassination of the unfortunate General I'rim wats announced.

I can pretend to nothing so interesting in the Kite's nests I have visited. In one instance I found a delicate cambric handkerchief which must have been brought from afar, since the good folk of the sierra do not indulge in such luxuries. In this nest. of which a photograph is here given, there were many coloured ragss including a piece of curiously worked brocade which was spread out alongside the egres ats shown.

\section{THE GOSIIWK (Astur palumberius).}

In the more secluded portions of the large forests of curk-vati trees in Andalucia the Goshawk lives all the year round buc owing

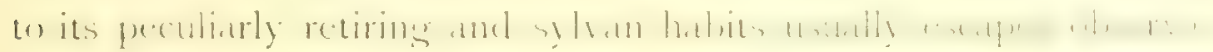
tion. Thus I have known of some which have recularly nested in the same district since 187 , when Colonel Irby first found the nest, yet never once have I seen these fine short-winged Hawks save when I have put the old bird off the nest. It would be difficult to give better evidence of their unobtrusive habits. 'The 
nest of $187 \mathrm{I}$ was in an alder tree only $15 \mathrm{ft}$. from the ground, or rather water, since it was in the midst of the almost impenetrable jungle which covers the deep sotos or marshes in the woodland districts. Twenty years later the Gonhanks still nested in the same locality if not in the same tree and the last time I visited the spot, in 1903 , they were still there. In the interval the old nesting-place had been disturbed owing to the work of clearing the soto, and, alas! of draining it too. The alders had been cut down and the Goshawks had resorted to an ivy-covered poplar, where there wats a clisused nest of the Booted Eagle alout to ft. from the ground. I was at the time unable to climb, and so regretfully delegated the task to a naval officer who took from the nest three eggs. It was on 2 May, and they were somewhat incubated and staned all over with yelow and pale brown like a Grebe's exs, exactly as described by Colonel Irby in the nest he took thirty-two years earlier from the same platee. Since 1902 the work of clearing the jungle has been continued and the Goshawks have been obliged to seek other quarters.

In April 1906 when walking thrown a very thickly wooded portion of the cork forest within a mile of the old nesting-site, I put a big bird off a nest near the summit of an ivy-grown Spanish oak. A friend with me climbed up and reported two engs which I suspected to be Goshawl's, since he described them as being of a bluish tinge. I was most anxious to take some Gushawl's engs with my own hands, in accordance with the rulk. which I have set before me throughout life where my own exscollection is concerned, but it was useless to touch these unless I could identify the bird for certain. So after leaving the spot for some hours so as to give the old bird plenty of time to return and settle down, I again approached the nest quictly and again put her off it. Owing, however, to the dense foliage which formed a regular canopy overhead, it was impossible to say for certain 
whether it was a Booted Eagle, a Goshawk, or some ofher laweo Hawk. So I concealed myself carcfully under a mass of bramble at a point whence I could command a view of the nest and wated patiently until near sundown, but the old bird never returned.

Two days later I revisited the spot and again put the hird off and again failed to identify her. It was becoming past a joke fon I was extremely anxious to make sure of the exess. I clid non want to shoot the bird, that panacea for all ornitholocrical cloulu which has led to the unnecessary slaughter of so many ratre birds. nor did I feel equal to the task of trapping her, since this might involve several troublesome climbs for which I was not strone enough. So I did what I should have done sooner-had recourse to a stratagem. My various futile attempts at identifying the bird had taught me that when she left the nest she invariably followed the same course, threading her way at speed between the tops of the surrounding trees. Following up this line, I shortly came upon an open glade and it at once struck me that this must be the route she took when making her retreat unsecn.

The following day I returned to the wood and making a wide detour cntered the glade about a quarter of a mile from the nest. and moved down it catutiously until I could command the point whence I reckoned that the bird must emerge after leaving her nest. Concealing myself in some scrub not 200 yards from this point I sent my Spaniard round with orders to approach the nest from the far side, making just sufficient noise to induce the bird to slip away quictly. Half an hour had elapsed when I heard my man's voice singing to himself one of the wild caldences known as malaguenas, after the custom of his kind when tratelling alone,

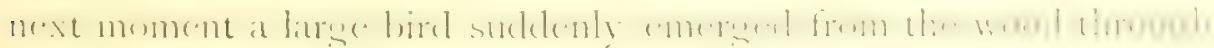
the top of the trees to my front at the exact spot I wats watching

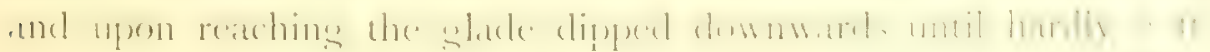
above the ground and came skimming right townds me. Next 
instant I sprang to my feet and we met literally face to face. An ummistakalole female Goshawk! So close were we that I could see crery marking on her richly barred breast as with outspread tail she violently checked her thight and swerving round dashed off out of sight through the woods to my right. The identification was absolute. So proceeding to the nest I climbed up to it with no small difficulty and took the egess, three in number, for she had laid another since my risit three days earlier. But any attempts at photographing the nest or exps were foredoomed to failure. It was a beautiful day with a fresh breeze, and the whole upper portion of the tree was swaying to the wind. In addition the canopy of green leaves above the nest, bending to every fresh whast of wind, cast a chequered shade on the exgs which varied every instant. My camera was a one-speed Kodak, and it was clearly hopeless to look for success under such adverse conditions. Nor did I achieve it. Descending, I endeavoured to obtain at least a picture of the tree and nest from below. This proved equally hopeless, for the tree stood in a densely overurown and shady part of the forest and was surrounded by others festooned with swaths of wild vine and sarsaparilla, which, surging in the wind, impeded the view from every side. The nest itself was almost concealed from view by the iry below it and was not visible at all in the finder of the camera. Experience of many nests in similar positions has taught me the inutility of attempting to photograph them, since. no matter how clear the prints may lee, the whole subject is on such a small scale as to render it of very secondary interest.

\section{THE SPARROWHAWK (Accipiter uisus).}

This well-known british species is rather scarce in south-west Andalucia despite the sreat extent of woods and country suitable to its habits. I fancy, however, it is commoner than is supposed, 
for in my wanderings in the sylvan districts I now and again come across one. The first nest I found was on $\$$ May $1 S 78$ in the disused nest of a Booted Eargle, near the summit of a very tall ivy-covered oak. It contained thee beautifully marked exs. wheh I have in my collection.

Three years previously the Booted Fasgles had occupical this same nest. The tree itself wats pratctically unclimbable withoun ropes, owing to its great size. 'Thanks, however, to the matsses of encircling ivy I was able to overcome this diffeulty and obtatin a lodgment at a point where the girth of the aree permitted of regular climbing. With the menories of this climb still fresh within me, I would advise all who essay to climb big arees by the aid of ivy stems to be extremely careful how they depend upon these for support, for they are extremely treacherous, and it at times happens that seemingly strong and healthy ivy stems upon being put to a strain snap off like carrots.

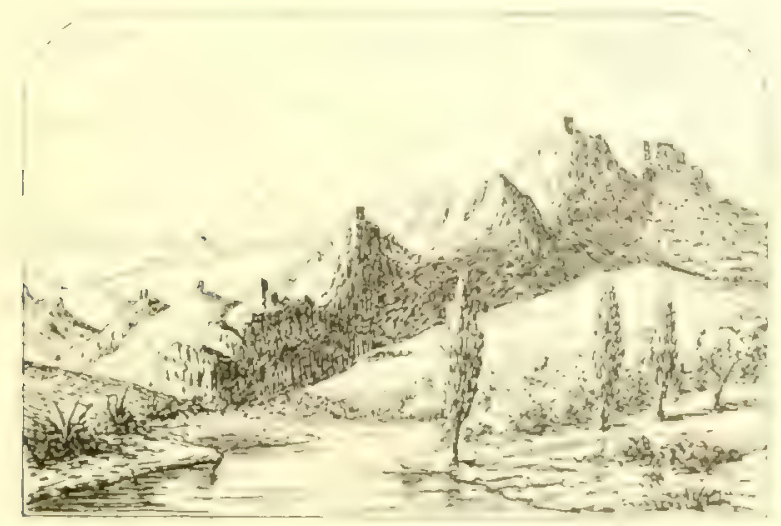




\section{CHAPTER III.}

THE BOOTED EAGLE (Nisaëtus pennatus) AND THE SNAKE EAGLE (Circaëtus gallicus).

The Buored EAgLe-Nesting habits-Eaglets-An indignant mother-Rearing Eaglets-Their sulky nature-A hard struggle_-" Operations of War" Flying Eagles to the "lure"-An Eagle overboard.

The SNare Eagle-Remarkable brilliancy of irides-Flooded out reptilesNesting habits of Snake Eagle-A fallen Eaglet-A close sitter-Uses for a catapult-Awkward Photography-Hatching out an Eaglet-Photographing Eaglets-Trapping an Eagle-Taming an adult Eagle.

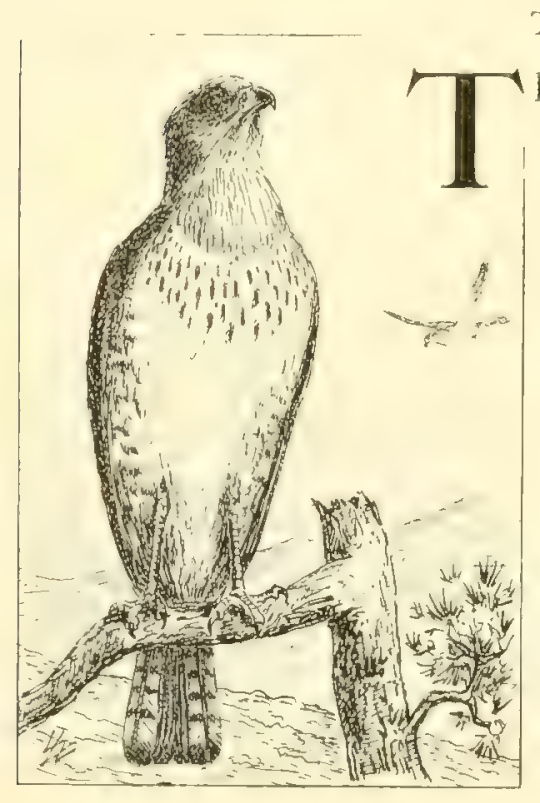

THE BOOTED EAGLE (Nisaëtus penutus).

HIS is yet another of the tree-nesting Eagles of southern Europe, and is found in abundance in the cork forests and pine woods of Andalucia. It is a beautiful little bird, in size very little larger than a female Peregrine, but as regards structure and plumage every inch an Eagle. It owes its name of Booted to the closely growing light brownish yellow feathers which cover the tarsus to the foot.

Essentially a summer visitant, it crosses from Africa about the end of March, nesting about a month later and returning again south in September. Considering the large number that nest in the great cork forests it is remarkibie how comparatively seldom it is seen 


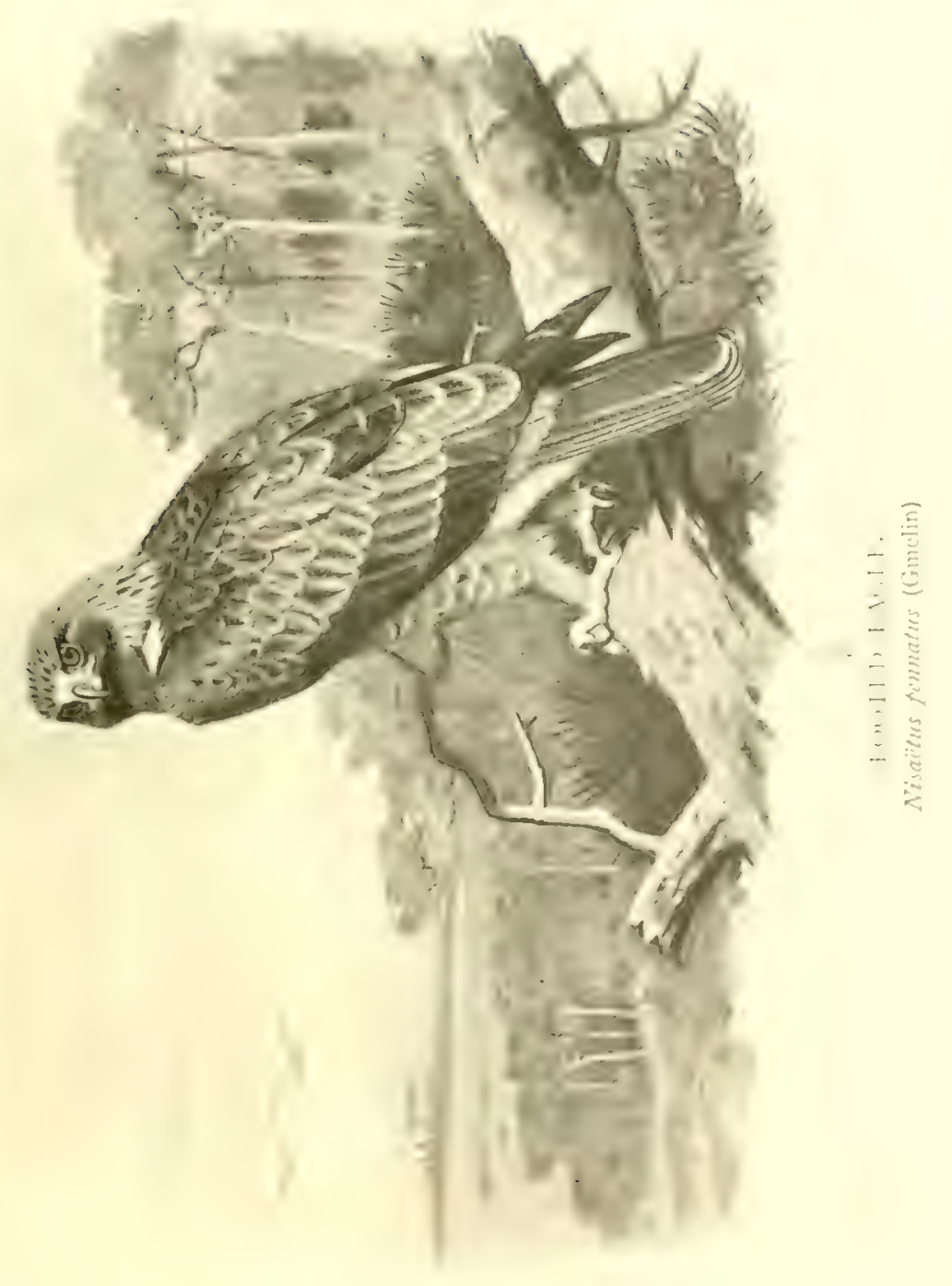





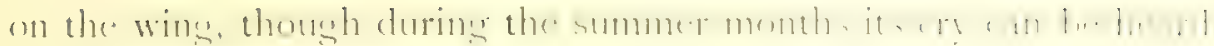
at intervals throughout the day.

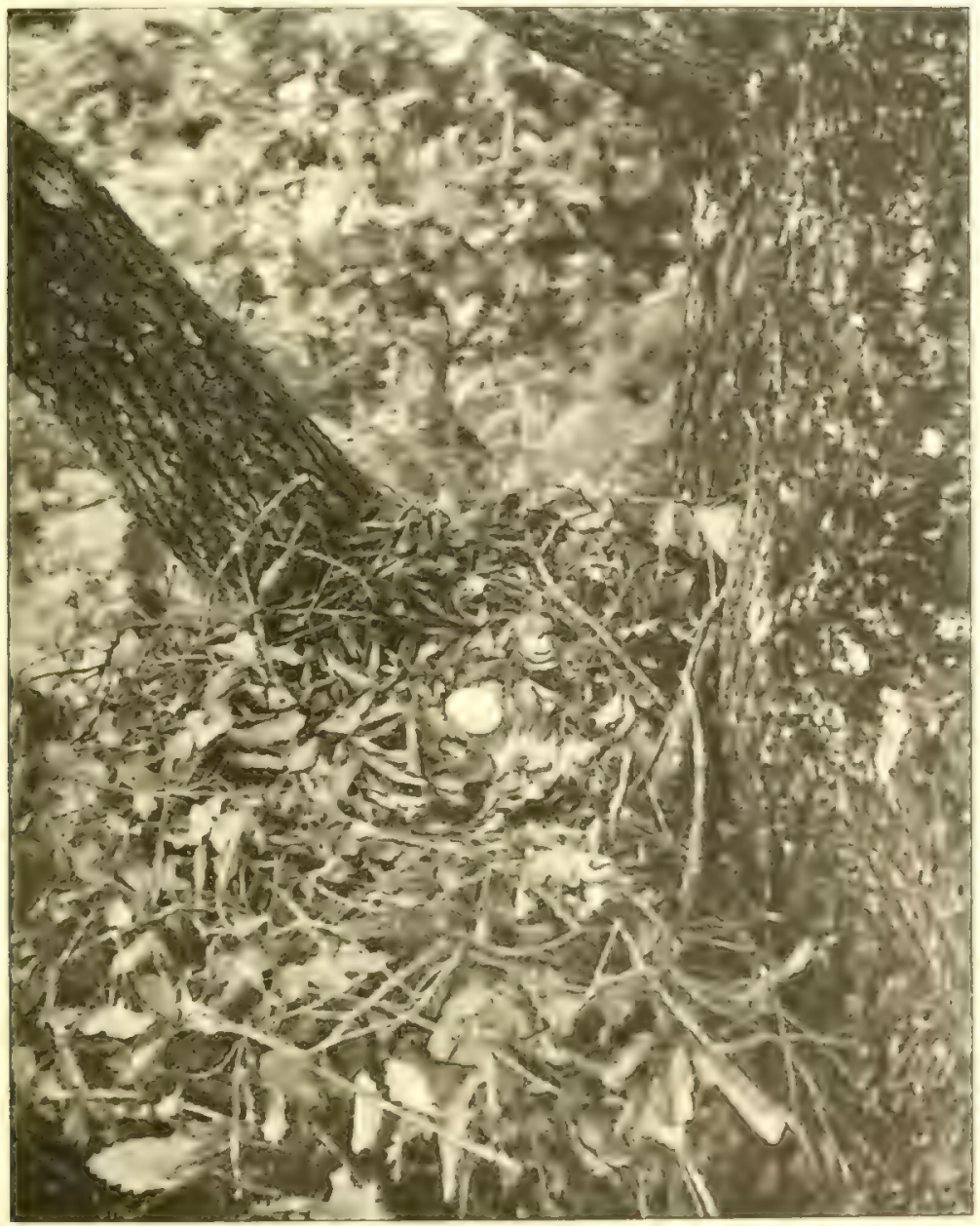

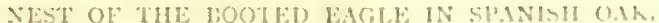

It often nests in some ivy-grown tree, preferably an oak, bu at other times in a cork tree. 'The nest is small and often dilticuls to see on account of the ivy. A favourite situation is in the furtion 
a bough close to the bole, thus differing from the Snake Eagle, which habitually builds its nest well out along a bugh. bonted Eagles will at times lay in the disused nests of the Snake Eagle.

They usually select a tree which affords a good site for a nest, $30 \mathrm{ft}$. to $40 \mathrm{ft}$. from the ground and they scen to have a particular affection for trees growing near the summit of a steep hillside. At times they will resort to lower sites, thus the nest of which a picture is given was placed in the fork of an oak tree not i $5 \mathrm{ft}$. from the ground, the tree, however, was near the top of a steep bluff, full $60 \mathrm{ft}$. high.

I have never yet seen a nest of the Booted Eagle that I could not climb to. For a few a rope was required to surmount the lower portion of the trunk, whilst in other cises this condel be effected more conveniently by climbing a pendent bough.

The picture, given in II., Chapter IV on p. 63 , on TreeClimbing, of ascending a tree in this fashion is of one that has been used for years by Booted Eagles and is still in their occupation.

All the nests I have visited, and they are many, have been built of branches of mak bearing the deat leares, thickly lined with fresh green oak leaves. The care bestowed hy these Eateles in providing a plentiful lining to their nests is well shown ly the accompanymen picture which was taken when the first egg was laid and all the leaves composing the lining were recently plucked. They lay from one to three white egens. much the same siece and shape as bantam Fowl's. Two is probably the most usual number laid and several days usually pass between the laying of the first and second egers. They are somewhat irregular in their date of nesting, thus I have found a nest with freshly laid cons as early as I 2 April, and others again so late as 25 May. Again I have found a nest with a young bird only 2 or 3 datys old on 27 June and another containing two fully thedged young, certainly 6 weels old on I July, only four days later, in the same season. 
I first made the acquatintance of the Booted Fategle in May 1875 when I found a pair nesting in a very tall ivy-covered oak in the

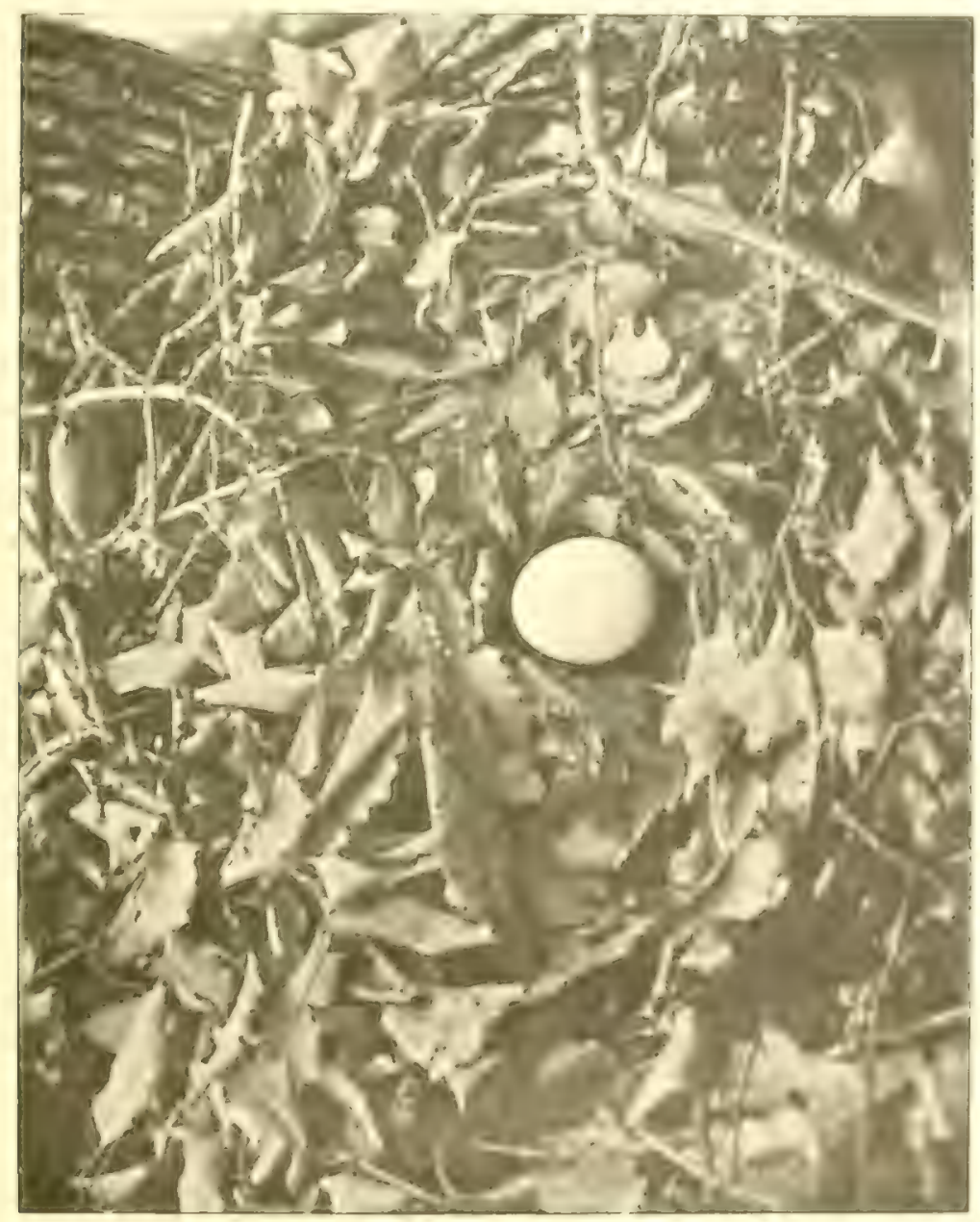

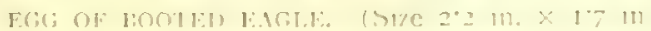

Cork Noods near Gibraltar and the successors of this pair still nest in an almost similar tree only a few hundred yards lim them site of the first one which was cut lown many years ago(o. 
The young birds begin to shoot their quill feathers at the end of the third week, thus the nestling of 27 June, already described, had its quills just budding on I7 July. On this visit the old Eagle, which had left the nest as I climbed up, upon my reaching it came sweeping round and alighted on a branch not $30 \mathrm{ft}$. from me. Here it remained with all its feathers raised and wings expanded, scraming vigorously for so long as I was at the nest. This is the only instance which I have experienced of a parent Eagle making even a show of protecting its young.

When a Booted Eagle is sitting in its nest and is disturbed it makes upon leaving an extratordinary headlong dive, at times almost touching the wround before it curves upwards and flies away. I have no doubt in my own mind that it is this habit which induces these birds to select for nesting-stations trees growing on the sides of steep hills, which afford especial conveniences for this mode of retreat. It is curious how very easy it is to miss shooting an Eagle when making this dive; of this I have seen repeated examples. Booted Eagles are very easily trapped on the nest for they return to it very soon. I have taken them thus for purposes of examination and identification and subsequently released them none the worse.

Their favourite food is young rabbits, lizards and snakes. Their eggs are often stained with the dye from the freshly gathered oak-leaves, which form the lining of the nest.

The greneral colour of the old birds is brown above and light tawny yellow below; the young in their first plumage are usually very much more rufous in colour, but some are as light as the adult birds.

I have reared the young from the nest on several occasions and with complete success. In the year $1 \$ 79$ I had three, two from one nest, and a third from a second nest. I took them all just before they were able to fly and in consequence had no trouble 
in rearing them, as to cramp and other aliments. Thery soum became very tame and would take food from my hand but it few weeks later developed the true aquiline characteristic of sulking. I had prior to this placed jesses on their leos and hept them secured by swivel and leash to their blocks, and had further, accustoncel them to being carrised on my wrist in falconer's lashion. 'To all this they submitted quietly enough but with the hour of feeding came the trouble. So lones as I remained near them. even if the food was placed close in front of them, they would refuse to look at it. 'Things grew worse and eventually it became a regular trial of endurance between us as to whose detemination should obtain the mastery. In vain did I starve them for several days hoping thus to reduce them to subjection. My feams of doing them permanent injury by inducing "hunger-traces" in their" beautiful plumage caused me to desist from this. On their side, they reckoned on my becoming tired of standing watching them and here they were right, for my time was of peculiar value at this period of my career. I was reading for the Staff Collece. It was now that I hit upon the happy expectient of armanging a seat in the shade of my hut so that I could study " Iamley's Operations of $1 V_{a r}$ and keep a watchful eye on the recalcitrant trio, tethered in front of me, at one and the same time. This farirly wore them down and finally, one day, after an hour or more of distracting study with one eye on the fenat Camparisn and the other on the three rebels, I heard a flutter and first one and then the others dashed at the portions of rabbits in front of them. and seizing them, instantly turned their backs and expanded throir wings and tails so as to conceal their weakness from my eyc. My victory was but half complete for when I sought to watch them feeding they shuffled round so ats always to present to me their back view. Baffed in this, they dronpect their heals. and drawing their wings round in front, completely screcencel 
their food from my view. I resumed my seat, and from time to time one woukl aradually relax its phumage and tear savargely at its food but the slightest movement on my part caused it to resolve itself once asain into an animated bell-tent of spreading feathers and remain motionless. I remember that at this critical period of the Easgles' training, according to Hamley, "Soult was at Gera," but for the life of me I have no recollection now of what happened to him after, although I can recall distinctly every movement of the Eagles.

Slowly but surely I obtained the mastery over them and at last they would not only feed in my presence but come to me for food and tly on to my shed hand, holding a temptingly garnished falconer's "lure." Finally I was so confident of them that I ventured to release two on the Europa Flats and fly them to the lure. This I did with complete success and although it was anxious work, having regard to the peculiar locality, I feel convinced from their behaviour that I could have entered them to fly at rabbits without further trouble.

On my homeward voyage to England in the P. \& O. ss. "I combardy" in the following November I lost nne of these birds in the most tragic manner. I had tethered it on deck under the lee of a skylight one afternoon and in my temporary absence a meddlesome passenger, endeavouring to clear the leash, which had become caught up, let it go! Even then the Eagle only moved a few feet across the deck. Just at this moment I returned and was about to take up the bird when another unspeakable passenger ran at it. Of course it rose and flew overboard. We were off Cape Finisterre at the time, and were steaming about eleven knots, with the wind two points on our starboard bow. The poor bird, after flying to leeward for a couple of hundred yards, swung round and mate for the ship. But unused to Hying, and being weighted by the long leather leash and 
swivel, it could not overtake us and, after steadily following in oum wake for a time, gradually sank lower and lower until it only cleared the curling crests of the successive waves. Eventuatly it sank into the trough of the sea just astern of us. It was a most pitiable sight and I was within an ace of following it overboard. Unfortunately I was too upset to report the matter to our sood Captain Wyatt, who, as soon as he heard of the catastrophe some time afterwards, at once offered to abont and lower a boat so as to try and pick the bird up. It was then, alas! too liate. Even after this lapse of time it is most painful to write of this most pitiful scene.

TIIE SNAKE EAGLE (Circaitus gallicus).

Next in point of size to the large White-shouldered Fande among the various tree-nesting species which are found in Indat lucia comes the Snatic Eagle, known also as the Short-toed fiate. It is a fine handsome bird and casily recognized when bying owing to its very white breast and under surface of wing which has earned for it the name of fean-le-blane in liance. In Sipatin it is known as culebrere or the snake-hunter. The slicteh at the beginning of this chapter is of a Snake Eagle I watched one day at fairly close range.

It is widely distributed throughout southern and midelle Europe wherever big woods are found, arroing in southern Span in considerable numbers during March and retuming somblawed in September. According to my own observations, a few hirds remain for the greater part of most winters in the sheltered glates of the cork woods of south-western Anclalucia, but the vast majority, without question, migrate southwarl as soon as the autumnal weather causes the reptiles upon which they prey (1) retire to their shelters. It is a lazy bird when on the wing. save 
when engaged in circling aloft in quest of foud; and in its flight when disturbed, as well as in the softness of its plumage, it much resembles the Buzzards. On several occasions when out with the Calpe IIunt in the Cork Woods during the winter months, I have seen one of these big birds, upon some horseman passing close to a tree in which it was sitting, reluctantly leave it and flap slowly to another tree, perhaps only 150 yards ahead, which it would in turn quit when again disturbed, only to seek yet another perch not far off. The most striking thing about this species is, without doubt, the great size and rich yellow colour of its iricles which almost equal those of the Eagle Owl in their brilliancy. The resentful look in the big Hashing eyes of a wounded snake Eagle is a thing not easily forgotten.

Some birds are very large I have seen a female which measured close upon $30 \mathrm{in}$. in length, and a span of whose wings was over $6 \mathrm{ft}$., yet this bird was under $4 \mathrm{lb}$. in weight, a good proof of the softness of their plumage, which causes them to bulk so large to the eye. They can at all times be easily distinguished from other large birds of prey by their long unfeathered tarsi. The species earned the name of Short-toed Fagle, by which it was known for years, from its remarkably small feet. Both foot and unfeathered tarsus are well adapted for seizing and holding securely the writhing reptiles upon which it preys. Its favourite food is the large Ocellated I izard, as well as all sorts of snakes, and, as has been already said, the movements of this species, as well as of a host of other raptorial birds which seek their prey amid the teeming reptile life of southern Spain, are largely modified by the habits of the snakes, which are in turn influenced by the seasons and also by the weather.

Living as I do from autumn to spring in successive winters in Andalucia I see much of the ways of the laruer reptiles. As a rule both large lizards and snakes are but seldom seen during 
winter but any unusual rainfall and consequent flooding of the lower districts at once brings them to light. Thus during the verv

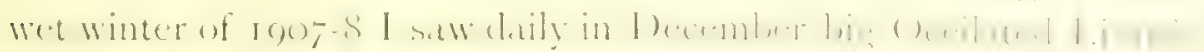
no longer of a brilliant metallic green with azure-spottect sides, as in the spring and summer months, but of a dull dirty brown and often caked in mud, clear proof both that they had been roused from their lairs by the inrush of water and also of the effect. which an absence of sunlight has upon the hue of these vividly coloured reptiles.

On 28 December when lying up for Wild (jeese on a promon. tory anid the waters of a rising lagma, I saw several bic lizards and snakes basking on the sunny and sheltered side of the lentiscus bushes around me. They were in a semi-torpid state. But I was most particularly struck by the imnate spirit of self-presersation.

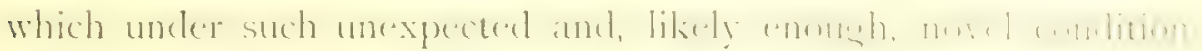

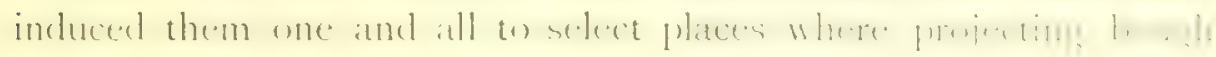

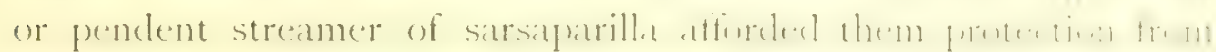

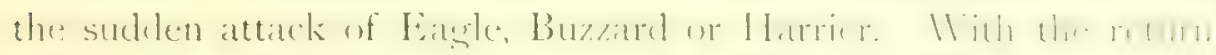

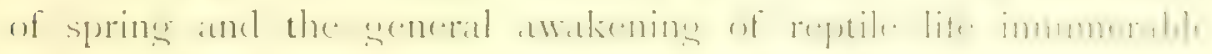

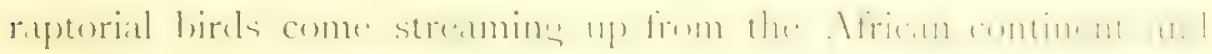
the sight of them as they pass, either singly or in small scatuereal parties, almost continuously for days at a time, when the wind suits

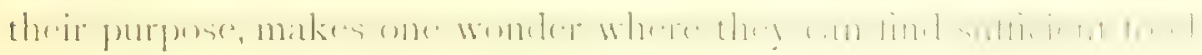

The nest of the Snake Eagle is remarkatbly small for so larese a bird. Like all the raptores, when conclitions are lavourable it occupies the same sites year after year, but, unlike most of them, owing to the peculiar situations it selects, it cannot always reckion upon finding the remains of a last year's nest upon which to build a fresh one. 'The vast majority of nests I have visited, probably. over 90 per cent., have been placed far out along an horizontal of even on a pendent branch of a cork-oak tree and it is obvious that nests in such situations are peculiarly liable to be destroyed by 
the winter wales. When this accurs, the Eankes either build ayain in the same site or select some adjacent tree, for no amount of

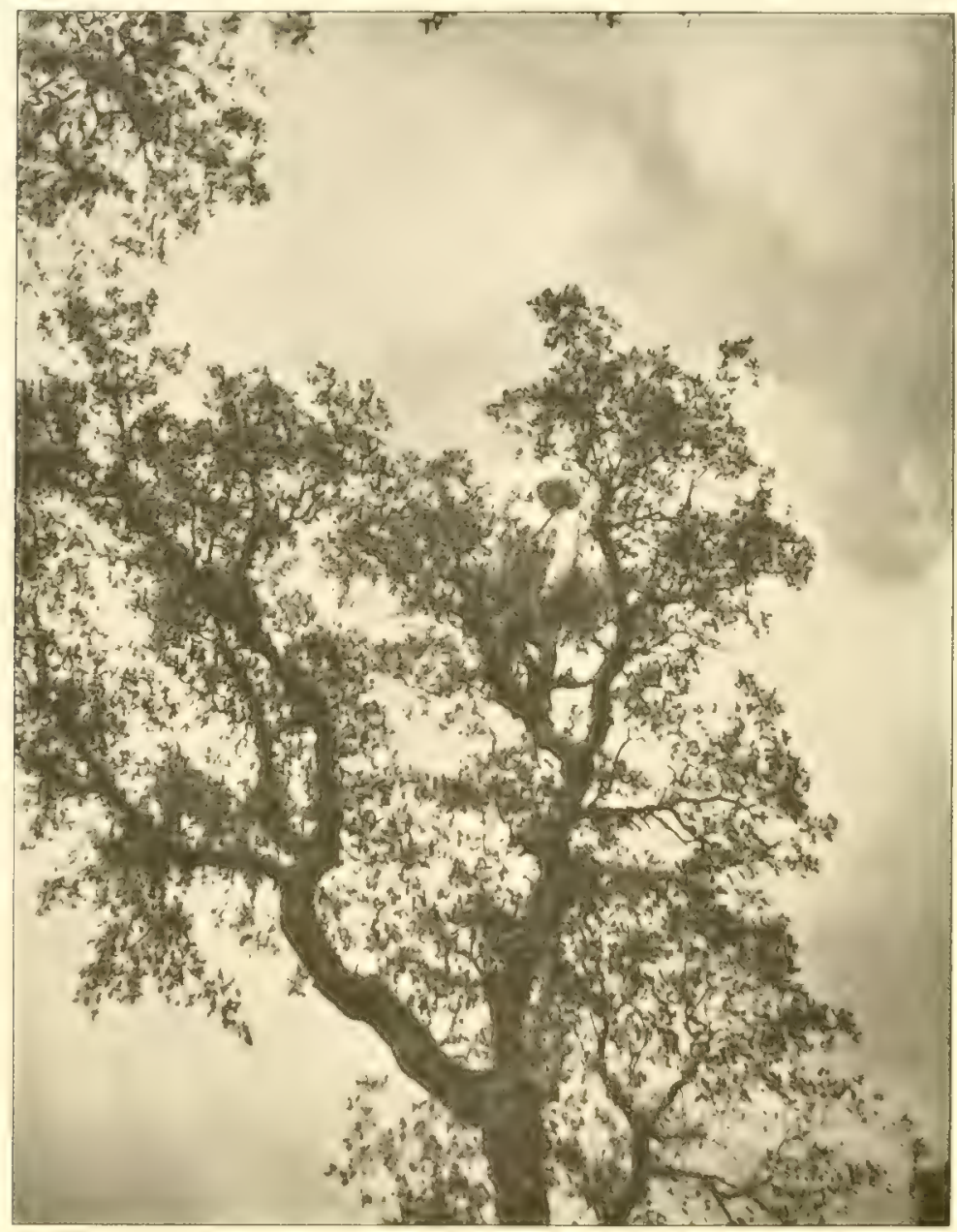

NEST OF SNAKF, FARIE NEAK SUMMMIT OF CORK.OAK TREF.

bullying or interference would seem to cause them to forsake any particular locality which they have elected to make a breeding station. To such an extent do Snake Eagles at times carry this 


\section{A Precarious Nesting Place}

habit of nesting at the extremity of at bengh that I have lean compelled to secure myself with a rope before crawling ont allong the slender branch supporting the nest. At times, nests plateed in such situations become dislodecel and fall to the sround. I knew of such an instance in Igo6, when a nest placed at the extreme end of a pendent cork-vak boush gradually slipped throush the supporting branches. So long ats the old birel was sitting, the disaster was postponed although it was obvious conough that the nest might drop through at any moment. In due course the young bird was hatched out and with the increased weight as it grew latroer the stratin becance too great and one day the incritable occurred and both nest and young bird came to the ground. 'The distance was short, about $12 \mathrm{ft}$. to $15 \mathrm{ft}$, and no harm was done and the old birds continued to feed their offspring ats it satt on the eround in the remains of its nest amid the gum-cistus bushes. The Snake bagle is essentially a tree-nesting species, only once have I found a nest on a cliff and then it was built in the spreading boughs of an arbutus growing from a cranny in the face of the crase. Colonel Irby howerer once found a nest in Morocco in at lentiscus bush with its base actually touching the eround. Now and again I have found nests high up in the fork of a really big tree, secure from molestation save from one of the guild of invelerate birdsnesters who decline to admit that, given time and appliances, any tree is impossible.

Fvery nest I have visited has been constucted in exactly the same manner, the base of sticks and twigs and some dead leatere lined with freshly cut green boughs of cork-oak or ilex. Some of the newly built nests are little more than as small platiorm of sticks, not $18 \mathrm{in}$ a across, with at slight hollow in the middle. Nests of former years which have been repaired and added to are sometimes double this size and effecually conceal the: old bird from view when sitting on her eger or young. $11^{\circ}$ hen a nest 
is sufficiently larese to prevent the bird seeing the approach of any intruders, it will at times sit extraordinarily close and I have known birds refuse to leave the nest in spite of repeated hammerings on the trunk, perhaps not $20 \mathrm{ft}$. below it. Sometimes, indeed, nothing seems to dislodge them save a stick or stone striking the nest itsclf. This induces me to remark incidentally that in the case of all tree-nesting birds nothing is so effective as a means of ascertaining whether a nest is in occupation or not as a catapult and a supply of marlites, old sparklet capsules. or pebbles. By such means have I discovered the secrets of Ilawks, Carrion Crows, Owls, Kites and other species innumerable.

The egg (there is only one) is usually laid, according to my notes, between $26 \mathrm{March}$ and $16 \mathrm{April}$, and is invariably pure white and very round in shape. There are two types of eggs, one with a coarse wranulated surface and the other very smooth. Some eggs are considerably romeler than others. The largest I have taken measured $2 \cdot 85$ in. by $2^{\circ} 4$ in. and the smallest $2 \cdot 8$ in. by $2 \cdot 25$ in. It is interesting to note that although this species only lays one egs in Morocco, Spain and France and elsewhere in Europe; in India, according to Allan Hume, it usually lays two eggs.

( )wing to their habit of nesting far out on branches, few Eagles' cogs in their nests are more difficult to photograph. For in addition to the awkward and frequently insecure position of the photographer, there is almost invariably some movement of the tree caused both by the wind and the cxtra weight of the climber on a resilient bough. Hence, no time exposure is as a rule possible. Added to these drawbacks, for some inscrutable reason Snake Eagles are most partial to building a nest on the western side of a tree. Such has been my experience. Of course the result is that in nine cases out of ten the sun will be found to be shining into the lens. Desperate cases require desperate remedies and I have sometimes been compelled to focus my camera at is in. distance and, holding it out on 
the far side of a nest so as to face me but at the same time to gy the sun behind it, have made the exposure. Since it is, of cours

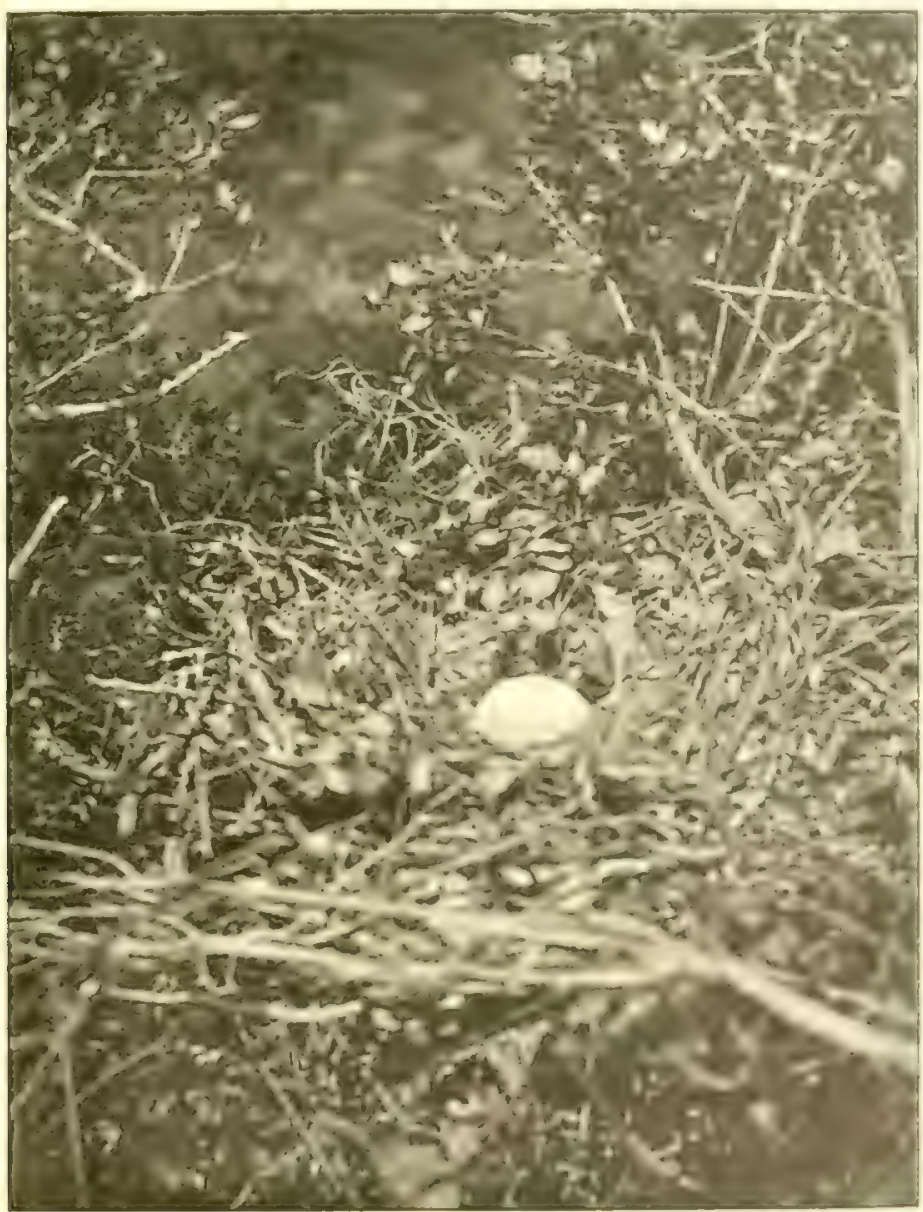

NEST INI) IG(; OF SNAKl: LAGLE

impossible to look into the finder in such a situation there is delightful element of uncertainty. Sometimes it hats met witl qualified success as can be seen by the exse figured at the whe 
of this chapter. The picture on the preceding paye is of a nest near the summit of a diminutive cork-oak which permitted of my getting a view of it from an adjacent branch.

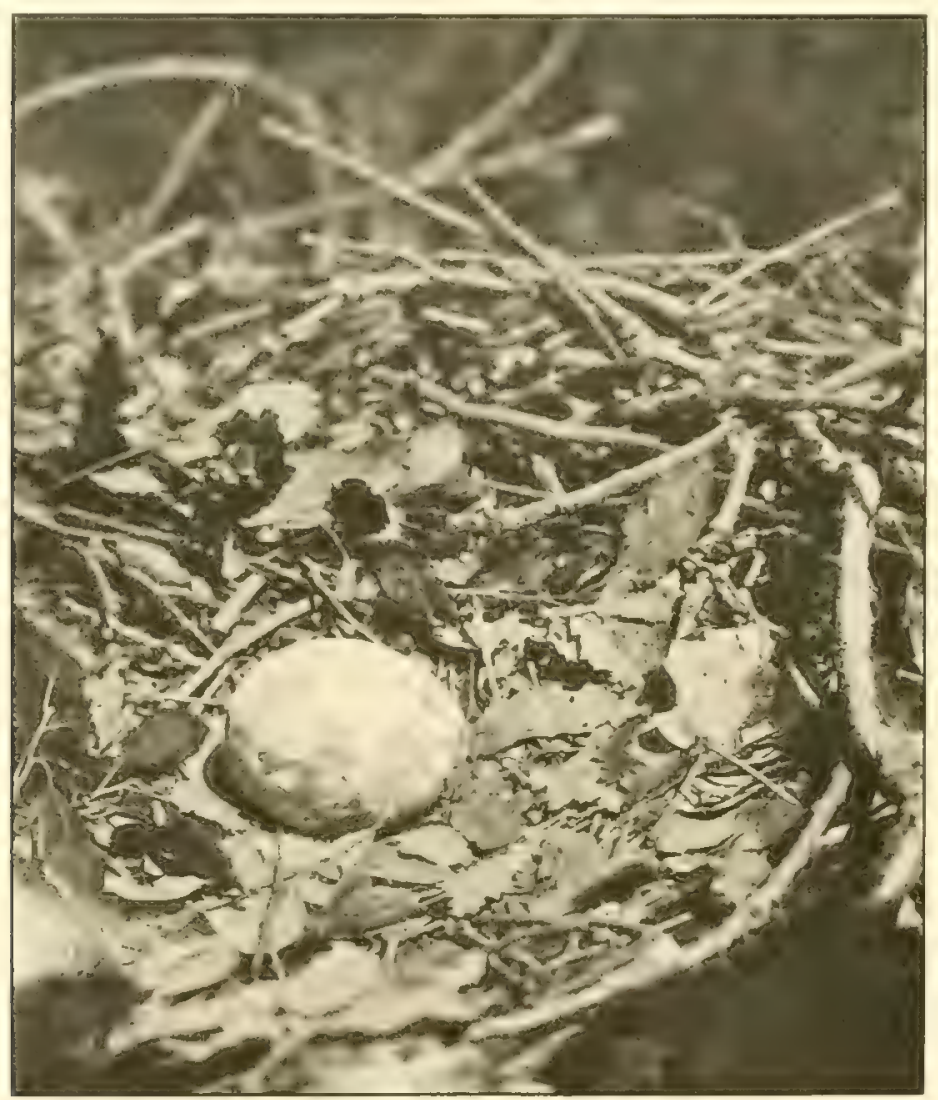

EGG OF SNAKE EAGLE (much strinct). (Size $2.8 \mathrm{in.} \times 2.3 \mathrm{in.}$

I took my first escy of this species in company with Colonel Irby in 1877. On climbing to the nest I heard a faint cheep and became aware that it proceeded from the egg which was on the point of hatching. As the female had been shot, I took the egg, only to discover on our arrival at home at nightfall that the young bird had hatched out during the return ride. 
Few Eagles are more faithful to a particular locality than is this one. Year after year they will nest in one of three or four sites in rotation, all situated close together. Should a tree be cut dewa they will select one close by and build a fresh nest. In spite of their comparative abundance I have never known of more than onc pair being in occupation of the same wooded valley, although they seem to have no objection to the Black or Red Kites buikling in their vicinity.

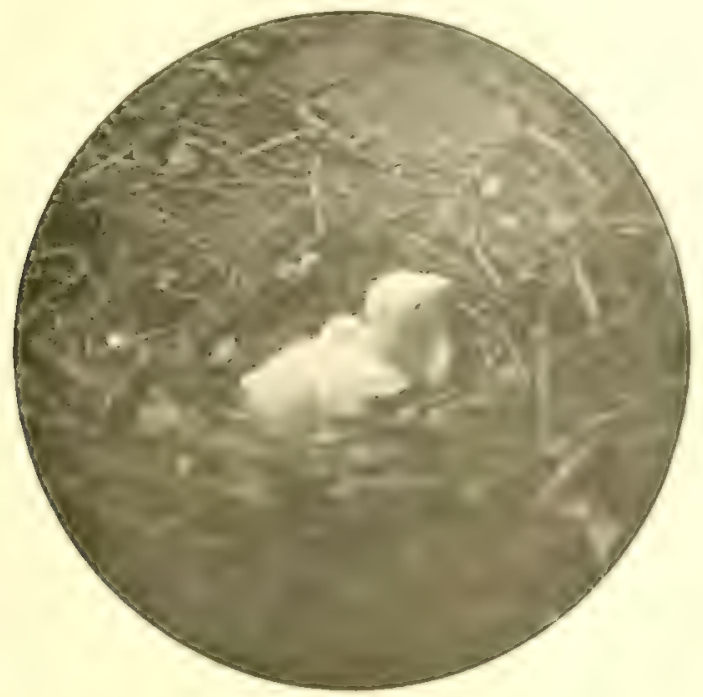

VOUXR SNAKH FACIF, ARER I WIEK.

The eggs very soon after they are haid become stained with the green leaves in the nest and also with reptiles'blood. It is at common thing to find the remains of a snalic or lizard in the nest of a sitting bird.

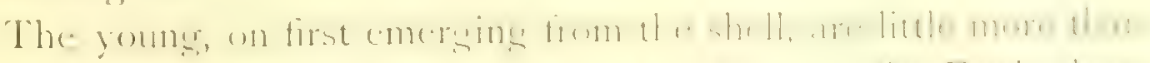

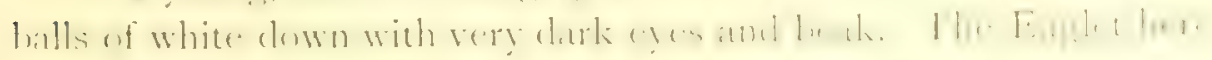
shown was photographed on so May, when just a week old. 
As usual the nest was in a cork-oak which was swaying in the wind. Having taken the first picture apparently unobserved, I stooped down out of sight and prepared the camera for another attempt. Placing it on the edge of the nest I raised myself acently on the chance of not alarming the little fellow but he had detected my presence and turned on me furiously. It was comical to see such wrath and indignation concentrated in less than + in. of white down.

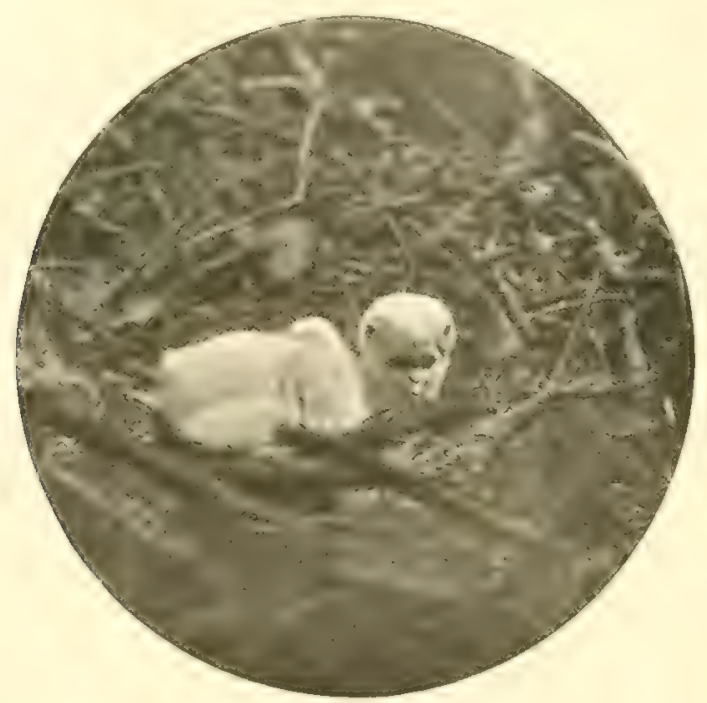

YOUNG SNAKE EAGLE, ANNOVED AT BEING PHOTOGRAPHED.

Kept in confinement this species soon becomes very tame and tractable, even when trapped as an adult bird. On 6 April is 79 when riding through a slade in a corls wood where these birds nest annually, a female came circling overhead, calling out sharply, as is their habit when their nest is approacled. I could make nothing of it on this day, but subsequently found it about 300 yards from the spot where she had given the alarm. It contained one egs, rather set. This I replaced by a hen's egg and trapped 
her entering the nest within ten minutes. She was a very fine bird and having secured her by throwing my coat over her I tied her up in it with my faja and rode homevards. The old male bird, who

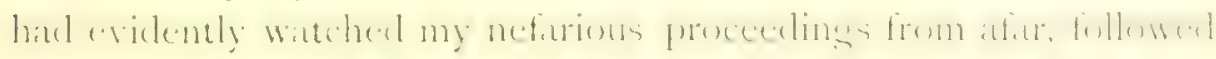
me throush the corte forest and ont inte the platin leyonel for ower two miles, circlins hish oserhead and from time en time calling queruleusly. My bird soun became reconciled to here confinement and in less than three wecks would allow herself w be carrical in filconer's fashion without any trouble. I erentually atre this hirel to Crown Prince: Rucklf, who took it with him in his yathe the. Mrimare back to Austria and the last I heard abuut it, wome: years later, was that it was alive and well.

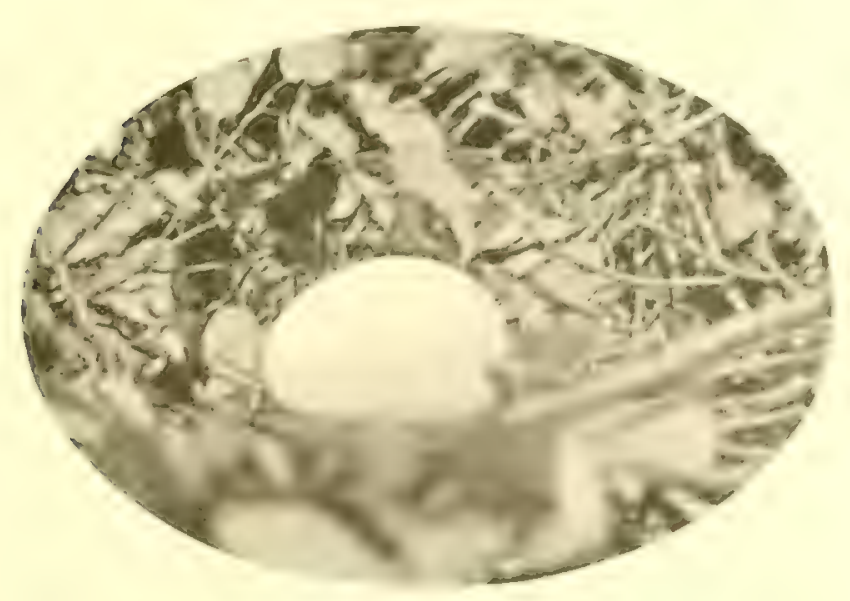




\section{CHAPTER IV.}

THE WHITE-SHOULDERED EAGLE (Aquila adalbrti).

The largest tree-nesting Eagle. Means of identifying at a distance-Comparison with Golden Eagle-Perplexing changes of plumage-A nest in a marshPugnacity of Eagles-Nest in black poplar $-A$ bull-fighting interlude - "Mild-mannered" bulls and the reverse. Beautifully coloured eggsTrapping an Eagle, a lucky escape-Food of Eagle-Habits-The "Black Eagle"-A Regimental Trophy.

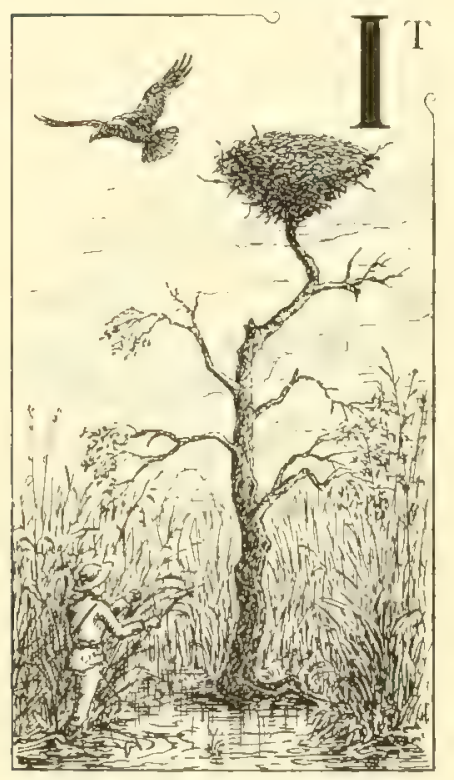

is one of those curious anomalies so constantly met with where the habits of wild birds are concerned that in southern Spain where great cliffs abound which offer secure nesting-sites for Eagles, out of the five species of Eagles most frequently met with two, and two only, nest in cliffs the others invariably resorting to trees. And not only do they nest in trees but often in extremely small trees, in some cases only i $5 \mathrm{ft}$. or so from the ground.

Foremost and largest among these tree-nesting species is the beautiful White-shouldered Eagle, or as it is also called, the Spanish Imperial Eagle, the western representative of the Imperial Eagle (Aquila mogilnik) of Eastern Europe. This bird in its structure, flight, general appearance and habits closely resembles the Golden Eagle. It is however of a lighter and less 


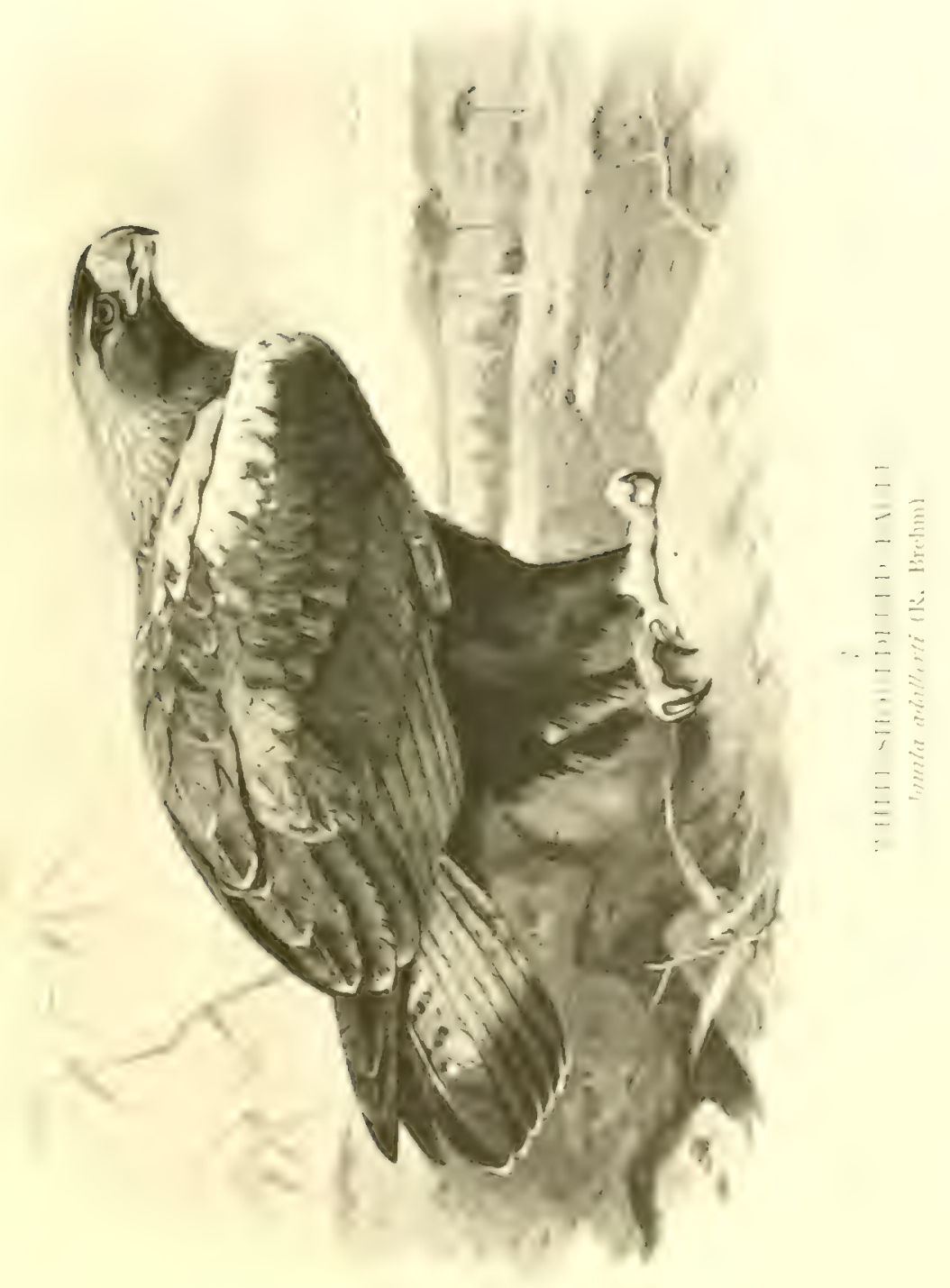





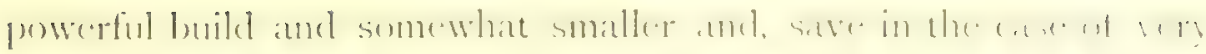

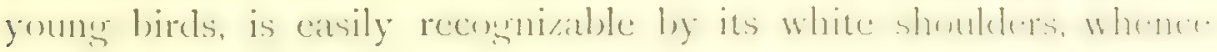
the name.

When flying at a distance or high overhead it requires a quick eye to identify it and, personally, I am never satisfied when watching a soaring bird until I see it turn so as to show its bate and upper wing-coverts, when the white shoulders, it present, at once show the species.

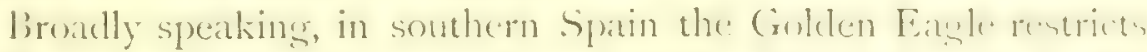
itself to the higher sierres, where it seeks for its guary on the open hillsides where trees are few and scattered, whereas the White-shouldered Easte frepuents the low-lying around and is usually seen circling over the plains and marshes or leating along the low scrub-covered hills adjacent to them. But there is no hard and fast rule in the matter and I have from time to time: found nests of the White-shouldered Eagle in secheled wanded valleys at a greater altitule than those of the (iolden liatele in cliffs in the same district.

I) spite: the rescmblance of the twe species when on the wins

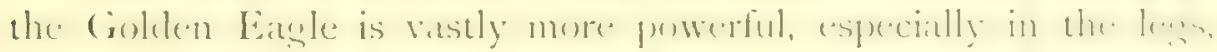

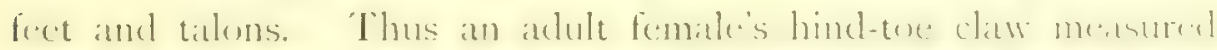

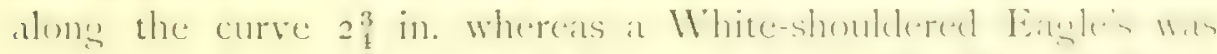

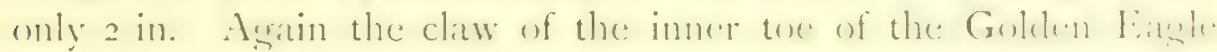
wits 2 ? in. whilst in that of the: White shouklered it wis only i $: 3$ in.

This bird undergoes somewhat perplexing changes in its

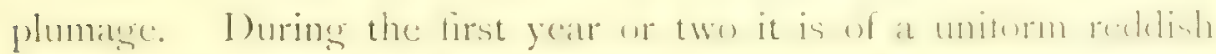
tawny colour, then follows an intermetiate stage when the t.1wny is spotted with black and lastly, the alule phumate af a rish

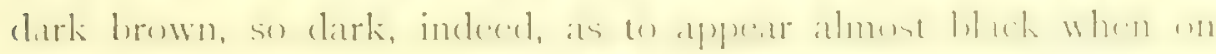
the wing. For a long time whese immature tawny birds were

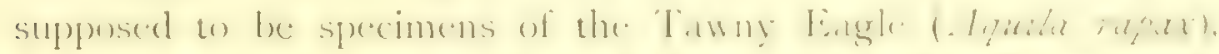

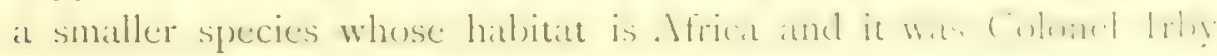


who first pointed out the mistake. The white shoulders are apparently not acquired until the third year, but, as do some of the other raptores, these birds sometimes pair and breed in immature plumage. Dr. Stark noticed this in 1876 and I have heard of other cases since. In the perfect adult plumage some birds are intensely black and hence the species is widely known to all the country folk in southern Spain as Aguila nesra = "Black Eagle." I have seen old birds which in certain lights looked as black and almost as shiny as a Raven.

I first met with this species in a curious and unexpected manner. In the month of May 1875 and in company with Fergusson I was hunting some beds of sedges in a marsh for nests of Savi's Warbler (Locustclla luscinzoides) when we chanced to see a big nest perched on the top of an alder tree some distance out in the marsh. On proceeding towards it, we found it was surrounded by a dense jungle of alders, sallows and canebrake, the whole so matted and interlaced by long trailing briers and creepers as to be almost impenetrable. Below the trees the soft black mud was over knee-decp and at places were deep pools which we crossed by stepping along the gnarled roots of the alders and grasping from time to time a friendly branch or tree-stem. It was small wonder that the Eagles imagined themselves secure in such a fastness. Whilst struggling to force our passage through this labyrinth of water-plants, we were joined by two Spaniards who were engaged in leech-catching, and with their assistance we cut a path through the jungle towards the tree. On nearing the nest, which was less than $20 \mathrm{ft}$. from the water, a White-shouldered Eagle, which had been sitting close in it, raised itself and stood up in the nest. I had never scen a live Eagle of any sort at close quarters before and I regret to say that I shot her. The sketch at the beginning of this chapter of the nest in the dead alder tree is from one I made at the time 
in my note-book. Thirty-three years have clapsed since I com-

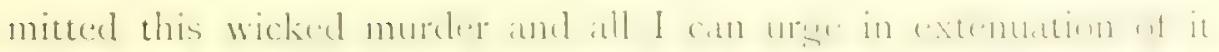
is that in spite of numerous opportunities since then I hate mener again killed a White-shouldered Eagle.

Upon climbing up to the nest it was no easy matter to look into it, since it overhung the summit of the alder on all sides.

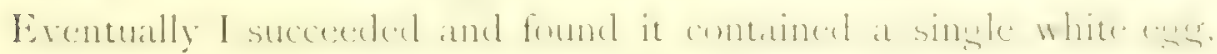
smaller than a Marsh Harrier's. 'This, when I came to blow it, proved to be yolkless and of almomal thickness and romghnese of shell. As the old bird was sitting so close on this, I have no doubt that her nest hat been robled of the enest or youme some

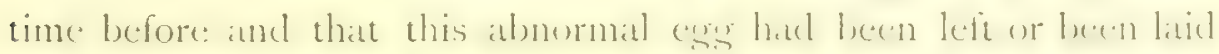
subsequently.

The nest was a great pile of big sticks and boughs and, was

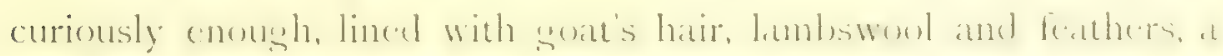

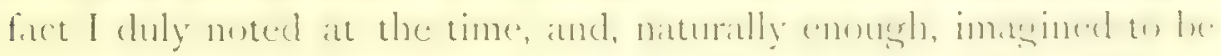
in accordince with the ustal custom of this spectes. The old hird. a female, wats in the uniform clark brown plomatere wot the blatek

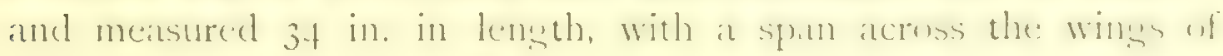
So in., her weight being $8 \mathrm{lb}$.

Two years later I hearl from Colonel Irly that he haul visited

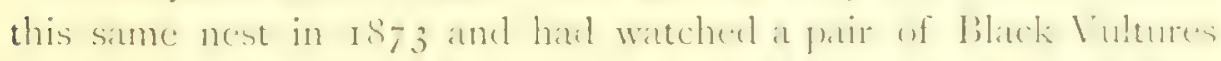

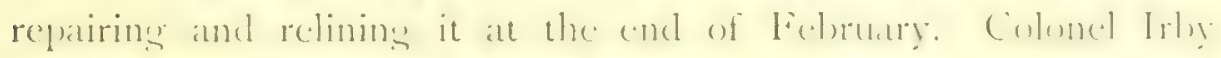

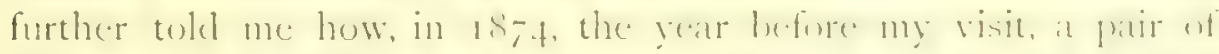

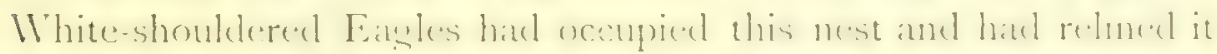

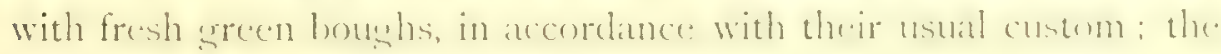
nest when he saw it, contained no eggs.

The reason of this we learned from our Spanish attendant,

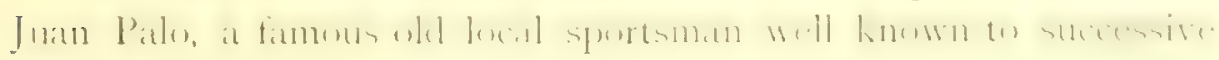
shooting parties from the Rock between 1869 and 1879 . He told us how in this same year he had taken three exress from

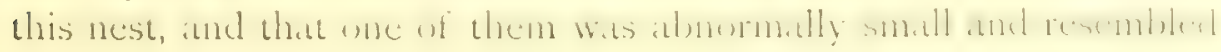


the yolliless erge we had found. Since 1875 I have visited many nests of the White-shouldered Eagle, and every one of these, without exception, has been lined with fresh green branches of cork or wild olive. Hence I can only imangine that the nest we found had been repaired and lined by Storks.

The Eagles nested in the same tree in the marsh in 1876 and on several occasions I saw them circling above the plains near it. Later in the summer the old alder and a greater part of the jungle was destroyed by a big fire and the Eagles thereupon occupied an old Stork's nest in a lofty tree not half a mile from their old sanctuary. On 23 February 1877 when snipeshooting I visited this spot. The tree was growing on the banks of a stream and close alongside a ford much used by peasants who tended the flocks and herds in the neighbourhood. It was a strangely frequented spot for Easles to choose but they no doubt, relied upon the awkward nature of the tree. This, a fine black poplar with wide-spreading boughs, had no branches for some 12 to $15 \mathrm{ft}$, and was almost too large to swarm, its girth at over $5 \mathrm{ft}$. from the ground exceeding 70 in. Somchow I managed to get a grip of the bark and after a slippery scramble reached the lowest bought, after which my progress upwards was easy enough. On arriving at the great nest I experienced as before some difficulty in surmounting the edge, since it projected overhead like the top of a sailing ship. It was freshly lined with green branches but without eggs. As I had to return to the Rock next day I gave my henchman, Juan Palo, solemn injunctions to visit it later on. This he did, but was unable to climb the tree or find anybody who could.

My descent from this tree was marled by a ludicrous episode which it would be hard to experience in any country save Spain. I had just slithered down the big trunk to the ground and was in the act of picking up my gun which I had rested against a bush before my climb, when I was startled by a frantic yell from a 


\section{Hunted by a Young Bull}

Spaniard and, on looking round, satw a young bull - a two-year old with short but sharp horns-coming straight at me. When I caught sight of him he was coming down the track leading to the ford and not ten yards from me and was closely followed by a

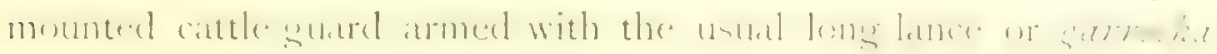
who was riding his horse out for all it was worth in his endeavour to turn the young bull before it reached the ford. I made one bound at the tree and in spite of its size managed somehow to get a grip about $6 \mathrm{ft}$. from the ground but could clo no more, not even turn my head. There I clung much as a cat does when hunted up a bigr tree ly a dex and incapable of further effure. The bull passed close below me with at rush scattering mud and

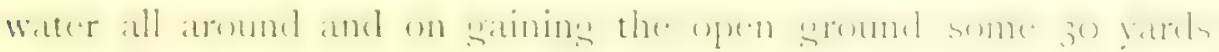
beyond wheeled round and came to bay. As his pursuer

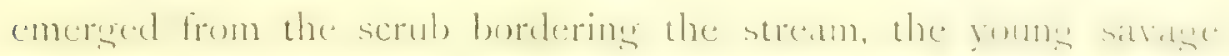
made a gallant charge on him, but was turned easily by the

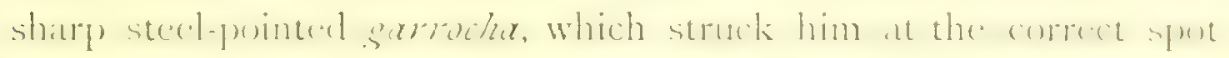

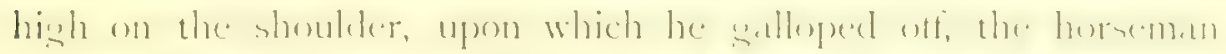

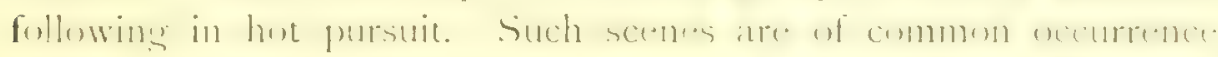

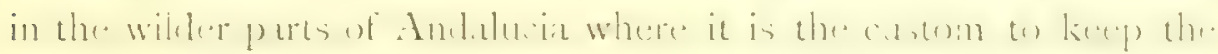
young bulls in herds until they are 3 years old. From time to time

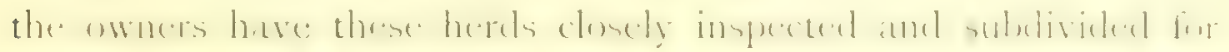

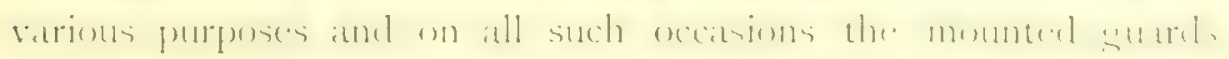

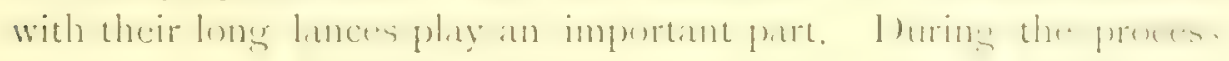
of "cutting out" some particular young bull from the midst of at herd it not uncommonly happens that it breaks away and has to be pursued and rounded in, and it se shanced that upun the dist

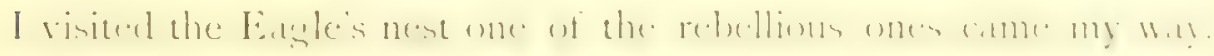
At this time a famous herd of bulls, a fighting strain known as that of La viuda Varbla, occupied this portion of the country and after sundry adventures and escapes we learned to regulate our

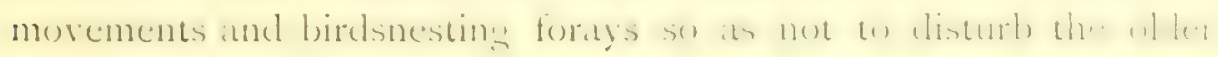


bulls, which alone were troublesome. Nowadays bulls destined for the Plaza are no longer herded in this district and their place has been taken by more peaceful animals politely described as being mansos, "mild-mannered" or "gentle," in contradistinction to their more formidable relatives who are known as bravos, wild or savage. But I am forced to say that this term is but a relative one, and from an intimate knowledge, at times far too intimate, of the ways and customs of Spanish bulls in the more remote parts of Spain, I would strongly recommend any wandering Englishman to give any he may meet a wide berth. Living as I do so much among these animals, I naturally enough have learnt how to carry on my own pursuits without annoying them. But it may be taken as an axiom that it is better not to approach any bull, no matter how "mild-mannered" he may be, if on foot. There is something in an Englishman's clress and voice which irritates the Spanish cattle; this, added to the peculiarly English habit of stopping and pointing a finger at an object of interest is calculated to upset the equanimity of the "mildest" bull. A fine seven-year-old bull, an old friend and neighbour of mine, who endurea all such familiarities, and was reputed to be absolutely manso, was however unable to submit to the impertinence of being snapshotted at $25 \mathrm{ft}$. Luckily there was a wall hard by!

But I must return to my tree, where I left myself clinging. On descending from my uncomfortable perch I went to pick up my gun, but it was gone! I could scarcely believe my eyes for less than a minute before I had seen it peacefully resting ayainst the bush. Since it was clear that neither the bull nor the man had carried it off, I surmised that somehow or other it must have fallen into the stream hard by. There was a deep pool close to the bole of the tree and so, wading into this, nigh waist-deep and feeling with my feet, I eventually trod on something hard which proved to be the gun, It was evident that the bull as it rushed past me, 
had artistically "flicked" the grun from its position with his horn. Fortunately he was too much occupied to paty any attention to me. My shooting companions, who had been lunching in at place of safety roo yards from the tree and who hat at full view of the exhibition I had so unexpectedly provided for them now joined me and were naturally much amused which was, considering the condition of my gun and myself, more than I was.

Early in February 1878 I saw this same pair of White-

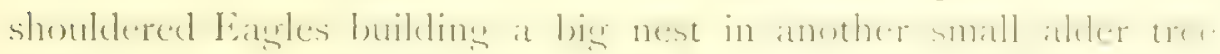
in the wreat marsh not far from the tirst nest I described. From this three most splendidly marked enges were taken, w which ome

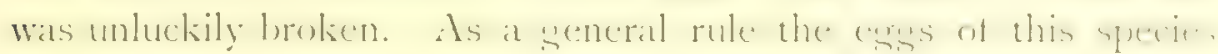
are usually white with a few faint rufous marks. But on no less

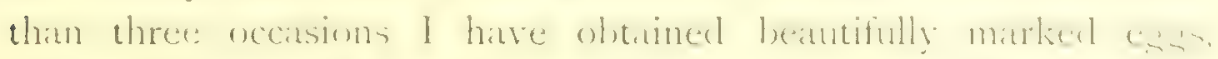

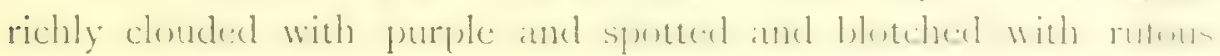
brown. In size they are as a rule, decidedly smaller than those of the Golden Eagle, the largest I have ever taken,

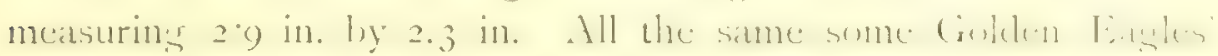

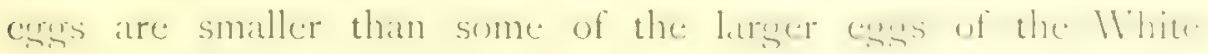
shouldered Eagle.

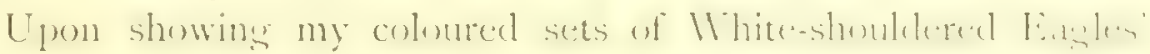

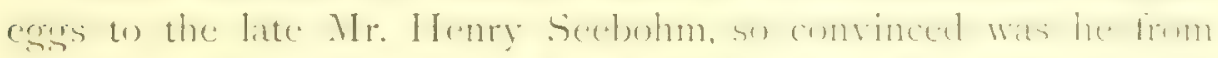

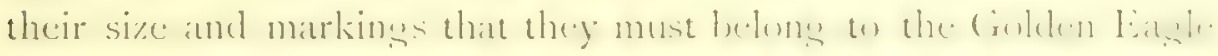

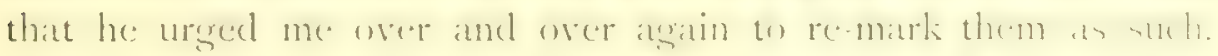

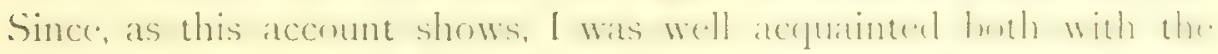

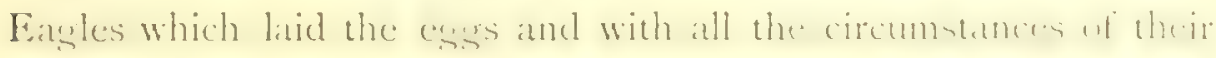

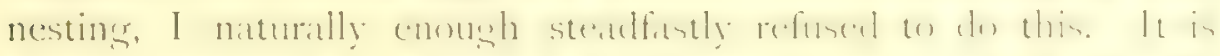

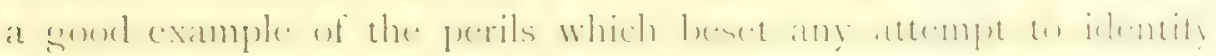
eggs by their markings and size and has made me ever since

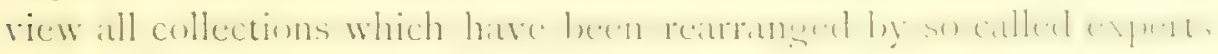
with suspicion.

In 1879 these Eatgles nested in the big tree of $157 ;$, whene I 
obtained two very finely-coloured eggs. These I gave to the late Crown Prince Rudolf.

It is now thirty years since I have molested these Eagles. During that time the deep morass I describe which served as a regular paraclise for Savi's Warbler and other birds of similar habits has been drained and the dense jungle cleared away and the whole country become much more frequented. The Eagles have however remained faithful to the locality and from time to time I have seen them sailing overhead. In rgo7 I spent a day at the old spot and was rejoiced to find that they were still nesting in the vicinity.

I will now give my experiences of another pair of these grand birds which bave nested to my knowledge in the cork-oak trees in one of the great ravines in the sierra for thirty-five years. I first saw them in $1 \$ 75$, but five years passed before I got their eggrs, a handsomely-coloured pair, in March isso. Fourteen years passed before I was once ayain in this same valley and there, sure enough, were the Eagles nesting peacefully in a cork tree not $30 \mathrm{ft}$. above the ground. This nest was the largest I ever saw measuring $\& \mathrm{ft}$. $6 \mathrm{in}$. by $5 \mathrm{ft}$. and was evidently the result of many years work, the newer and inhabited portion being built on the edge of a former nest which had slid from its position, hence the elliptical shape. It was lined with masses of freshly cut cork-oak branches and contained two encrs, hardly marked at all, in fact, of the normal colour. At the time I was anxious to secure a live Easte of this species, so having replaced the eggs by a couple of fowl's eggs, I set my trap-a circular pole trap without teeth and with the jaws well padded with chamois leather-at the spot where the Eagle entered the nest. According to my usual custom the trap was secured by about 30 yards of stout line to a dead bough which lay on the sround below the tree. Concealing myself in some high heather about 300 yards distant, I waited on events. 


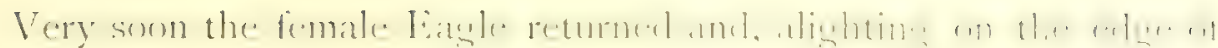
the nest, walked in. Next minute she datshed off, and for a second I imagined that she had seen the trap and taken alarm. Not so, however, for after flying about 25 yarels, she becan to flap

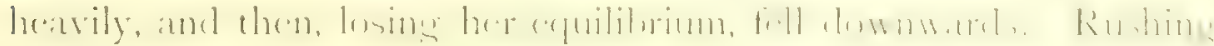

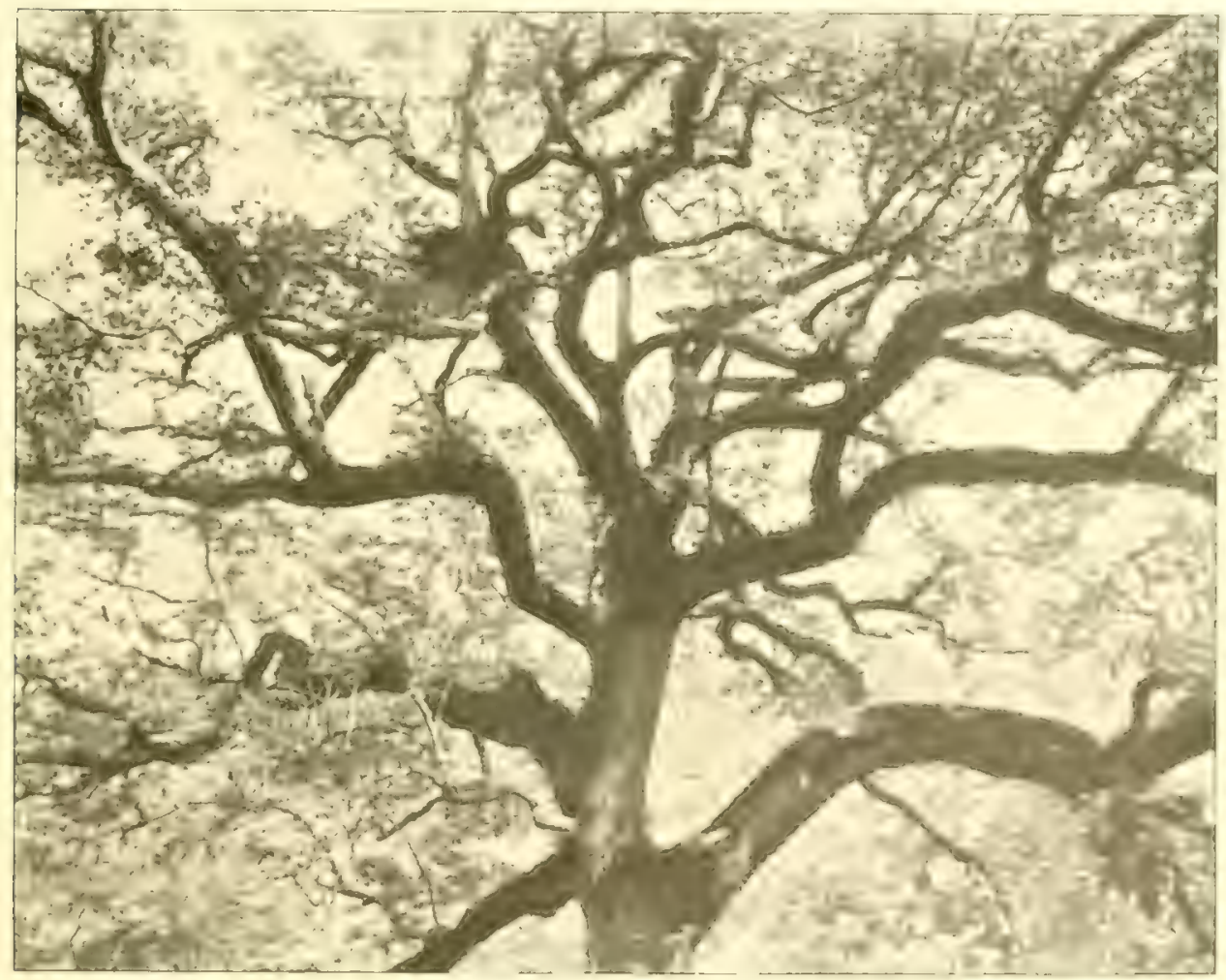

NEST OF WHITE-SIOUIIEREI) EAOIA IN" SIMNISII O.IK.

up to the spot, I found her dangling, some $6 \mathrm{ft}$. clear of the wround and held in the trap by one foot. Is I closed on her I cndeavoured to tear off my coat to throw over her, but missing my footing took

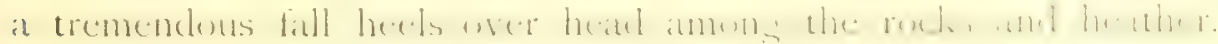
When I recovered myself and looked up, she was gone! 
Apparently my near approach caused her to make a supreme effort to free herself and free herself she did and got clear away unhurt. Although at the time I was sorely disappointed, I have never since ceased to be glad that she escaped me. In fact I can hardly ralize now how I could ever have attempted such an act of crutely as trapping an adult bird accustomed from its earliest days to roam above that glorious country.

This Eagle was in the normal adult plumage, very dark brown all over, save for the nape of the neck, the white shoulders and the richly barred tail of greys and browns. Its mate, which I constantly watched perched on a rocky summit hard by the nest, was, on the other hand, of sheeny blackness.

The pair still frequent the same district and I have seen them in occupation of four alternative sites, all in the same valley, and all in cork-oak trees varying in height from $\mathrm{I} 5 \mathrm{ft}$. to $30 \mathrm{ft}$. I have only once molested them since 1894 , when the nest contained three dirty white eggs, much stained with yellow (which I take to be from the fresh green cork-oak leaves), and with a very few faint red markings. One of these egres had been perforated by the Eagle's sharp claws, a not uncommon occurrence with egess of raptorial birds.

Their farourite food is hares and rabbits, they also take Partridges and other birds. In one nest I found a Green Plover whilst Dr. Stark found a nest containing the remains of no less than seven rabbits, three Partridges, and a Black-winged Stilt. When lying up for seese and duck during the winter months I have constantly seen them hunting over the lasmas and swampy lands adjacent, but I have never had the rood luck to see them pursue or capture any waterfowl although their appearance always seems to strike terror into the big flocks of Wigeon and Teal, causing them to rise with a roar of wings and settle again.

being essentially birds of the plains, they are much addicted 
to alighting on some stone on the summit of the low molulating hills bordering on the marshes, where they remain motionless for an indefinite period, prior to resuming their circlings overhead. Only last November, when riding across some hills on my waty to shoot Snipe, I saw one in such a situation, and so intensely blacli did it appear in the sunlight that until I got out my field-glasses, I imagrined it to be a Raven! Simply as a matter of curiosity I tried

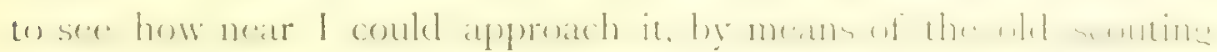
stratagem of pretending not to notice it so long as I was in view, and, when once out of sight under cover of a fold of the sround,

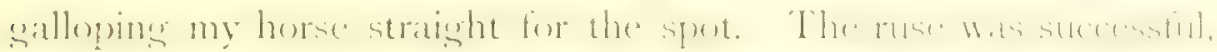
and so completely decended wats this most waty hirel thet l rime within 30 yards before it saw me. It was blowing half a gale at the time and the Eagle having to rise against the wind came flapping within 15 yards of me. It was truly a magnificent

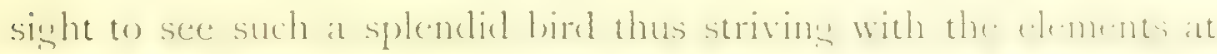

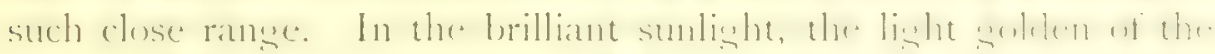
nerk and the snowy whiteness of the shouldere formed a wiling contrast to the rich black brown of the back and wings. Small wonder is it then that the Spaniards all know it by the name of Agmila negra, the Black Eagle.

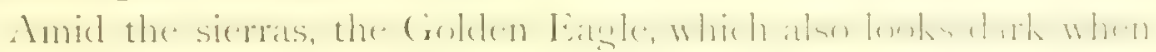
on the wing, is known by this name, whilst in the regions where

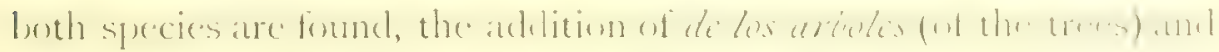
of de las rocas well describes their normal halbits, whilst now and

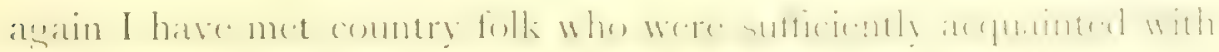

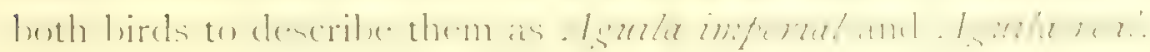

As a naturalist it has often struck me how cvery nation is

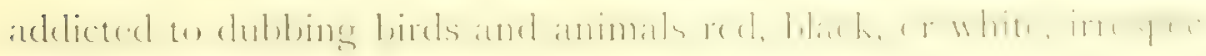
tive of their actual coloration. No doubt such descriptions are

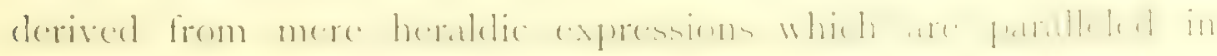

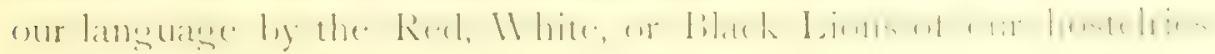


Everybody has heard of the Prussian Orders of the Black and Red Eagle and of the difficulty certain folk have to avoid one or other of these honours, which according to report is only equalled by that of escaping death. But in some parts of Europe the existence of a real Black Eagle not mercly of an Eagle which in certain lights and in a certain condition of plumage has a black appearance. is with many an article of fath. Nowhere is this more implicitly accepted than among the ranks of a certain regiment in our Service, which was awarded as a distinctive badge a "Black Eagle" of heraldic fame, in recognition of its services.

Many years ago I chanced to be dining with this regiment and, as ill-luck would have it, was asked if I had ever met with the famous Black Iaggle during my ornithological researches. I was obliged to say "No," and weakly added that I had never yet made out what bird had given rise to the heraldic title. The officers hastened to assure me that the Black Eagle was a well-known although extremely rare species only to be found in a remote part of the Carpathians and that their late colonel had gone to immense trouble and expense to obtain a specimen to present to the regiment. Sonn the mess sergeant appeared bearing a framed and glazed case in which was an embroidered satin cloth bearing the "Honours" of the corps and in the centre a most imposing black bird set up in heraldic style with wings outspread on either side of its head and legs and feet in the approved attitude. Black it was most certainly, inky black, in fact, there was a great deal more black than of eagle about it. Suffice to say that the wily purveyor of this weird and hitherto undescribed species had obeyed the peremptory military order of the colonel to provide him at all costs and without delay with a Black Eagle, by artistically attaching a pair of Raven's wings, legs and feet to the head of a hideous Egyptian Vulture which he had dyed black as a coal. There was no possible escape from it. 
Some of the most conspicuous and unmistakable external

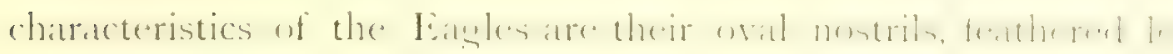
and long powerful claws, but here was the loathsome white Vulture, so well known to all travellers in the last, defiantly parading its peculiarly elongated beak with narrow slit for a nostril, whilst its partner in the deception, the Raven, unblushingly exhibited its shing black bare lens and short hlunt wanc.

I sometimes wonder how far the resourceful provider an this unique species penetrated into the Carpathians!

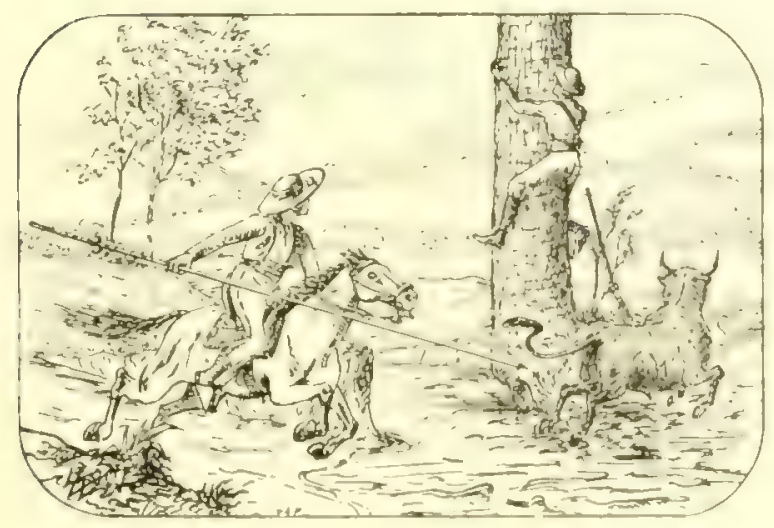




\section{CHAPTER V.}

\section{THE BLACK VULTURE (Vultur monachus).}

The largest tree-nesting raptorial bird-A difficult stall-Size and weightSeeking the nest-Expedition to Old Castile-Great pine forests-A prolonged search-Find a nest-An awkward tree-A repulse-Doroteo the woodman-Return to the attack-Ascent of tree-Marvellous rope work - Find a second nest - An interesting ascent-Description of nest and eggPhotographing with "fixed focus" hand camera.-On the tree-top. How the distance was obtained-Find a third nest-Tree I30 ft. high-Kite flying as a means of reaching nests-Captain D'Arcy Irvine's line-throwing gun-A ride through the pine forest--Los Siete Picos-Puerto de Guadarrama.

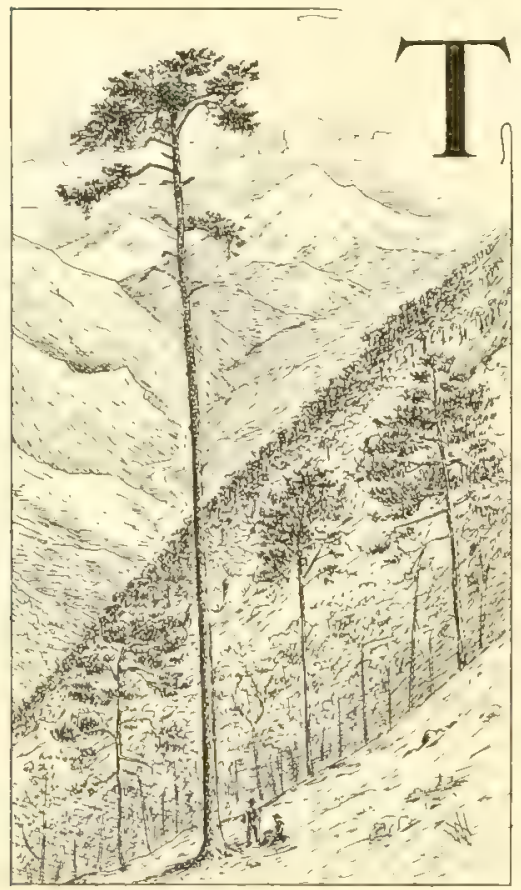

IS majestic bird is perhaps the best example of the paradoxes which so often confront the students of wild birds in their haunts.

The popular belief that all the great European Vultures habitually resort to cliffs for their nestingstations is in the case of the Black Vulture rudely shattered. For although the majority of Vultures do certainly nest in cliffs, the Black Vulture as regularly resorts to trees. In Europe the Griffons invariably nest in cliffs, as do the Bearded Vultures, and the Neophrons (or Egyptian Vultures) usually resort to the cliffs. But the Black Vulture is 


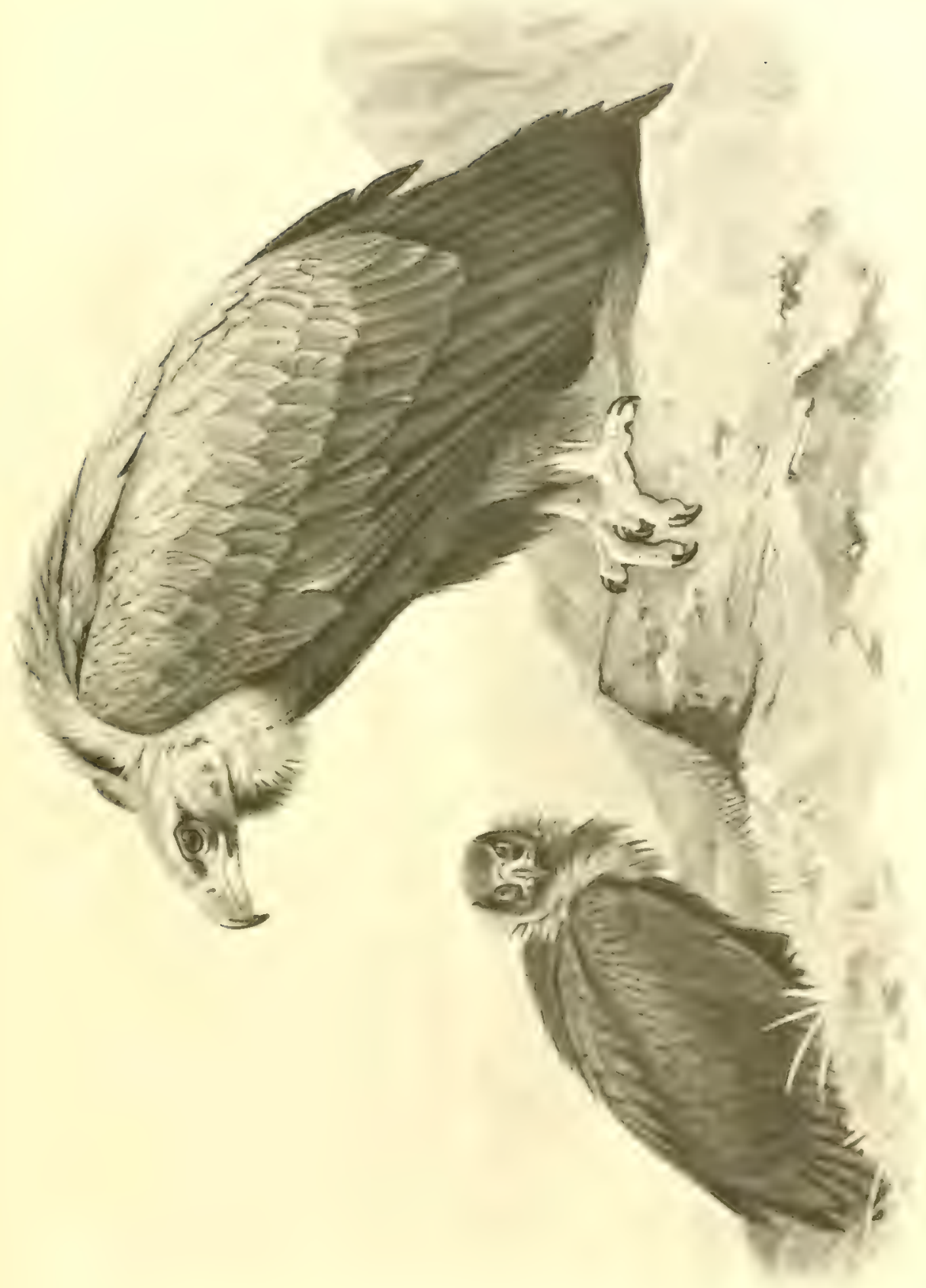



always it tree-nester. In situations which firour the species, such as the great pine wools of Central Span, it commonly selects some tall tree on which it constructs a great fabric of sticks and bouths. But, failing big trees, it will resort to smallex mes. and I have myself seen one in a stunted alder tree not $20 \mathrm{ft}$. above: the seound, and have heard, on the excellent anthrity of the late I)r. Stark, of another in a small corls tree at almut the: same height. The laback V'ulture, whether by nature of its salbe plumese or seneral appearance, always gives one the impresion of being somewhat of a higher-class bird than the Griffon. Its heald, although not feathered, is covered with close-growing darts brown down, which, combined with its dark ruff, gives it some:thing of the appearance of wearing a friar's cowl, hence its name: of monathes. The result is that it is less repulsive than is ciph fulius. It belongs to the family of the true Vultures, whereats the (irifton is merely a poor relation of these more ausust birch. still, it cannot lee denied that in habits and customs there is nothing whatever to choose between them. In fact, the (iritfima. in the southere part of the P'eninsula, and the Bblack Vulures. which are found in their greatest numbers in midelle spain. carry out identical duties in the necropolis line in the resions the! respectively occupy.

The first time I set eyes on a Black Vulture I was riding across the great plain of La Janda on an autumn day and became awatre of a bery of Griffons engaged on the carcatsis of a horse, amons them I saw what I imanincel to he a karen. Is I drew nearer, a fracas arose among the big birds and they scattered outwards whilst my supposed Raven was left in possession of the carcass, and I then saw it was a huge lihuh Vulture. Reining up, I watched the Grifons closing in arumel and cach time they interfered with the solitary black lind it made a lunge at them and drove them back. I rode clese enough 
to see the sable plumage and great size of the bird in contrast to the two dozen or so of Griffons around him before they all took wing:

At the time I was ignorant of the existence of the species, for they are rarely to be seen in south-western Andalucia. Since then, from time to time I have come across them in that region but, so far as I am aware, there are only one, or at most two, pairs which thus venture to intrude upon what is universally admitted by the well-regulated laws of Vultures' society to be the freehold property of Gyps fulvus.

Two years after this my first sight of the Black Vulture, I was shooting duck down the banks of a river when I sighted a huge black bird in the open plain, some hundreds of yards distant. The plain was absolutely level and had been recently ploughed up and it was clearly impossible to find any cover to aid me in getting within shot. After lying down and watching the bird for some time, I noticed that it was facing the wind and seemed to be intent on some object to its front. The idea struck me that possibly I might be able to approach it from behind and so I retraced my steps along the river bank until I arrived at a point exactly down-wind of the great bird and some 300 to 400 yards from it. Lying down, I commenced a long and exhausting stall, ever keeping my eyc on the bird and when it turned its head, which it did at intervals, lying prone and waiting on events. Finally I got within 40 yards before it detected my presence and, as it rose, I gave it two barrels of No. 4 shot. By chance I severed some tendon in one of its great wings, for it crashed down and after striking the ground recovered itself and set off to flap away across the plough-land. Then ensued a rare chase, I following in hot pursuit and firing ineffectually at it from time to time. At last it stopped and turned, and as I closed on it it made a gallant attempt at a charge. It was an immense female, 
dark brown above with richer browns on its wings, the big primaries and tail feathers being bownish blak. It weiglant I8 lb., being $45 \mathrm{in}$. in length with an expanse of wings of just under $9 \mathrm{ft}$. I skinned and preserved this bird and have it now stuffed in my house. It was fasting when I shot it, and so its seeming letharyy was not due to a recent heavy meal an might have been imatgined. Rather would I attribute it allowing me. to creep up within shot to the fact that a westerly gale was blowing and the bird had alighted to rest in the midale of the sreat level plain and suspected mo danger. It was the tirst and last Black Vulture I ever shot at.

In Spain the Black Vulture always strikes latrger on the aye than does the Griffon and as far as my observation goes, it always is a larger bird, being several inches loneer and with a wider expanse of wing. On the other hand, according to colonel Irby and others, in India the ciriffons are of a lares race than those in Spain, whilst the Black Vulumes are of the same size as those found in Europe.

Allan Hume, in his "Notes on Indian Birds," is one of the very few writers on ornithology who has placed on record the sizes and weights of the birds he has described. I would commend a study of this book to all sportsmen or naturalists who are interested in the size and weight of birds.

Hume gives the weight of the Black Vultures in India as from $12 \mathrm{lb}$. to $20 \mathrm{lb}$, with $14 \mathrm{lb}$. as an average; this is much the same as that of the Spanish bircls. Neverthetess it has bern

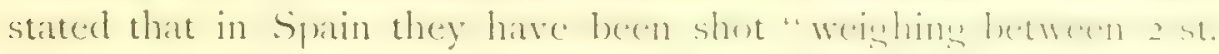
to 3 st." (2S lb. to $42 \mathrm{lb}$.), but in justice to those concerned it must be admitted that the weight thus given was merely "estimated."

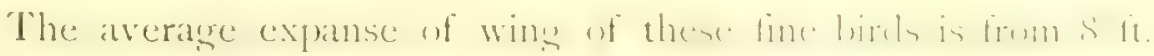
$6 \mathrm{in.}$ to $9 \mathrm{ft}$. Hume records a big female of $9 \mathrm{ft}$. $10 \mathrm{in}$. 
The term "Black" Vulture, although quite appropriate to the birds when in their haunts, is by no means borne out by those often seen in museums. The young birds are very dark, so dark indeed at times as to appear at a distance as dark as Ravens. As they reach maturity they gradually grow lighter until old adult birds are quite light cinereous brown, especially on their shoulders and scapulars.

To visit the nest of the Black Vulture was for many years one of my most earnest desires. So far back as the spring of I875 I came across a disused one.

This nest was destroyed in a great fire, as described in the last chapter, the following year. The Black Vultures thereupon moved to a small cork tree in the adjacent sierra.

Afterwards from time to time I came across one of the birds, now sitting out in the plain or perched in a cork tree in company with Neophrons and, once only, on a cragr in the romote sierras. But I could not locate the nest. Eventually it became evident that if I intended to take with my own hands the egg of this species I must seek for it in the districts of Spain where it was most commonly to be met with. As events proved, it was fortunate that I did so.

It was in the spring of I 899 , when serving on the Staff at home. that I managed to get two weeks leave of absence on "very urgent private affairs" and the question arose how best to employ the precious hours at my disposal. After much consultation with Colonel Irby and Dr. Stark, and reference to Lord Lilford's notes, I came to the conclusion that my best chance was to strike straight for Old Castile, where on the pine-clad slopes of the mountains the Black Vulture was known to nest. There was no time for paltering with coasting steamers and having secured a companion I set off across Channel via Paris and Irun, for Segovia.

The extensive mountain range, known as the Sierra de Guadar- 


\section{The great Pine Woods of Old Castile}

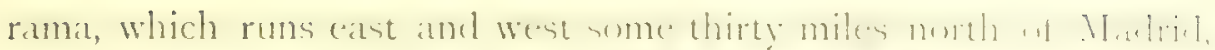

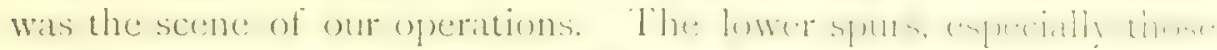

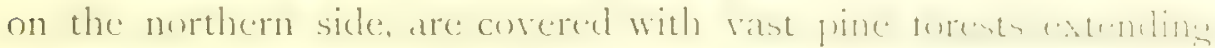
for many square miles. At the time of our visit there was still

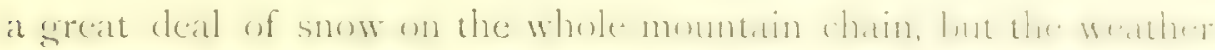

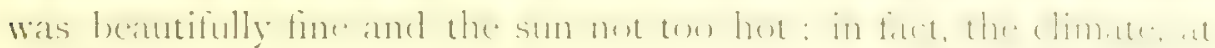
an elevation of $3,000 \mathrm{ft}$. to $5,000 \mathrm{ft}$. above the sea level, the usual height for our expeditions, was as near perfect as possible.

The forests we explored are Crown property, and are most

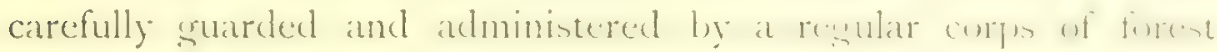
guards. They are dressed in a very smart dark brown uniform

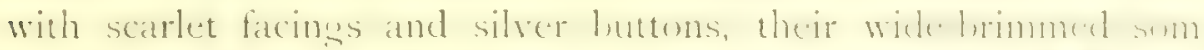

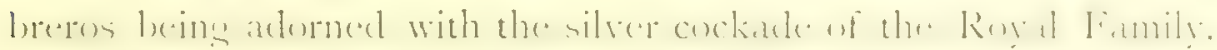
They are all mounted and carry at small-bore carbine in a bucket on the off-side of their saddles, and on the near-side a heavy woodman's axe, used for blazing trees.

'The methods of forestry in these districts are simple enough, and, like most Spanish systems, are based on leaving Nature to do as much as possible of the work. As the pine trees grow up, the lower branches are lopped off at about $6 \mathrm{in}$. to I ft. from the trunk with the result that thousands of pines of all sizes are to be found, with stems of marvellous straightness and free from branches.

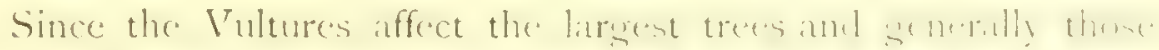

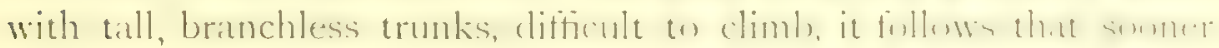

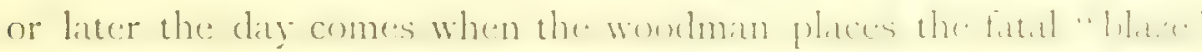
on the stem of some promel momareh of the forest which hat allumbel a safe asylum to the great birds of prey for scores of years. And so, year by year, the older and more favourite nesting

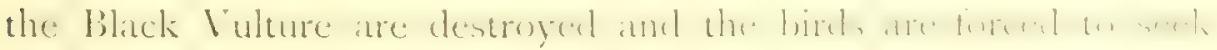
fresh sites in other districts.

Having established ourselves in quarters some miles from 
Segovia, and well up in the sierra, we set to work to make the best of the time available-one week only-before returning northwards. One morning early in April we started on horseback with our local guide (a woodman), in quest of the coveted nest. I'e had already experienced several defeats, having for three days unsuccessfully explored various portions of the forest adjacent to our quarters. After following the high road for a couple of miles, we struck to the right through a small village. Beyond this we entered the oak-scrub, which covers the low foothills in this recion. It was a delightful morning, cool and fresh, although the sun, even at 9 a.m., was warm enough on our backs.

After ascending for about I, $200 \mathrm{ft}$. we struck into the pinar or pine forest. This, like most forests of a like nature, has very little undergrowth; hence movement is possible in every direction, save where the steepness of the ground or some outcrop of rock or mass of detritus from the crags above renders a detour necessary.

The utter absence of all life in these great forests is very remarkable and must impress even the least observant. The only small birds seen were the Chaffinch and Great Titmouse. From time to time the sharp cry of the IThite-shouldered Eagle or the querulous call of a Buzzard or Kite broke the silence. Now and again a roe-deer might be seen watching us from a distance before it darted away noiselessly through the labyrinth of great pine trees.

After following a track for some miles we came to a valley where the gzardas, or Royal foresters, had reported Black Vultures to have nested in former years. We now spread out to about 200 yards apart and rode silently through the wood, carefully examining the tops of the larger trees for nests.

Fortune shortly favoured us, for suddenly our woodman, who rode in the centre between us so as to indicate the direction of our adrance, gave the pre-arranged signal and on joining him we 


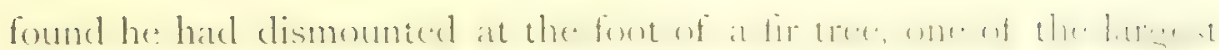
in that portion of the forest. It was well over $100 \mathrm{ft}$. in height and at the summit was an immense nest of sticks. A glance showed us that it was a nest in occupation, for it bore unmis-

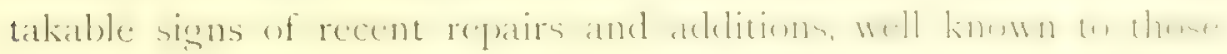

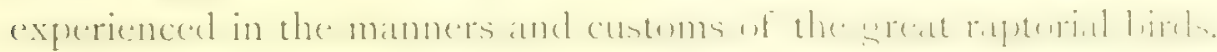
But the next question-by no means easy to answer-was whether it was merely repared ready for use or whether it alleady antanded the much-desired ess, for Black Vulumes, like (iritums, only luy one egg.

Haring picketed the horses and ascended the sterp hillable

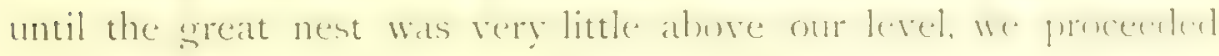
to make a careful inspection of it. My companion, who carrical

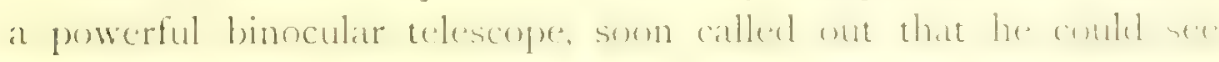
a "yellow thing" in the nest, which he declared seemed to movo upon the trunk of the tree being vigorously struck with an axe.

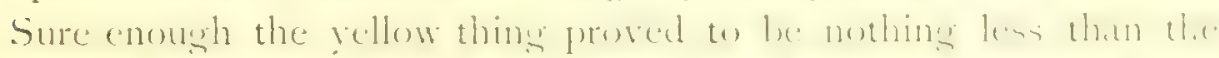

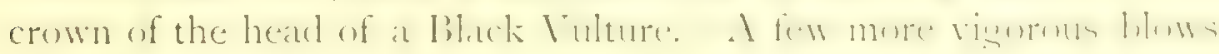
of the axe caused the bird to take alarm. Raising herself in the

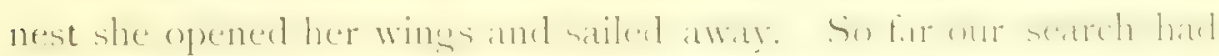

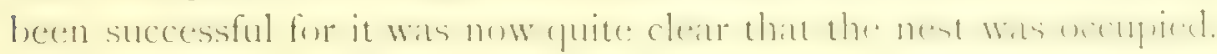
The next thing was how to get up to it?

The tree was about $8 \mathrm{ft}$. in circumference at the height of a man above the cround and arew smaller imperecetibly. Xin sumel branch broke the smoothess of the trumk fin over wo th. Int at

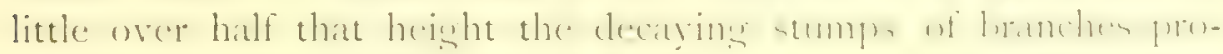

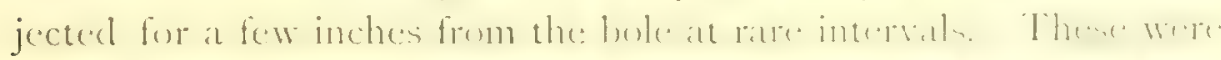

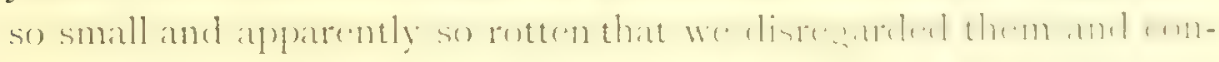

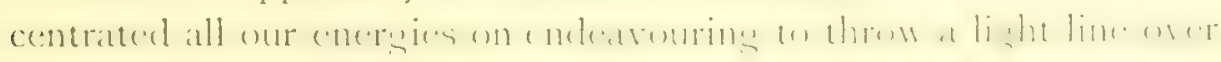

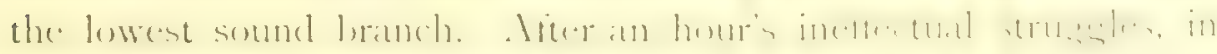

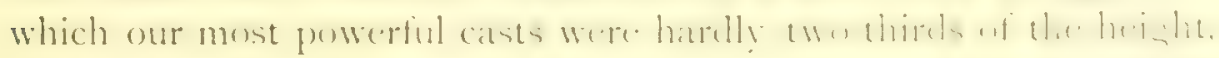

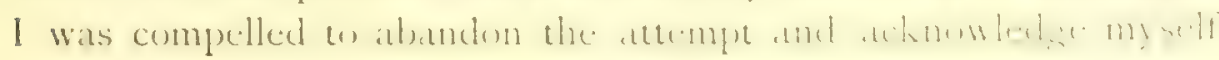


fairly beaten. What that meant to a keen ornithologist, who had for over thirty years been accustomed to climb to and take every nest he wanted, no words can describe. Whilst we were engaged in these futile efforts, the old Vulture returned several times and swept past the nest not 50 yards above us.

Knowing that the woodsmen were in the habit of climbing the trees when engaged in lopping off the lower branches, I besought our guide to find me one who could escalade the big pine, which

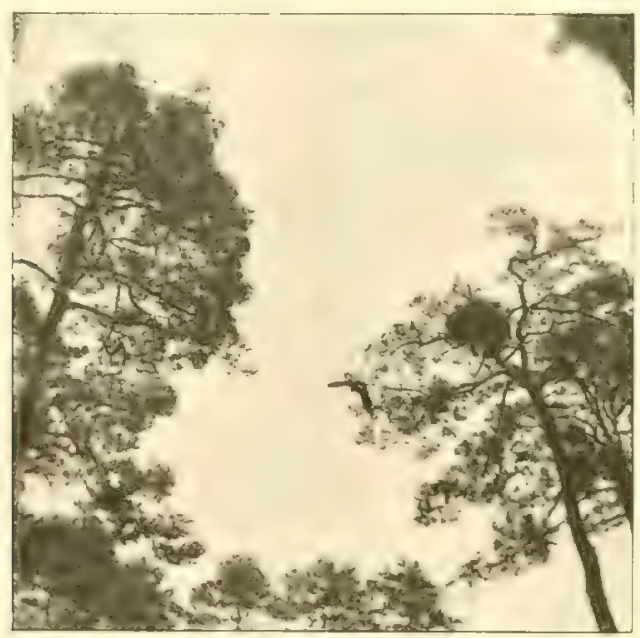

BLACK VULTURE LEAVING NEST.

had, so far, baffled all our endeavours. This, however, was without avail, for he roundly declared that no living man could climb such a tree. Remonstrance was useless, and my assurances that, if he could only find a man who could throw a rope up, I would myself gladly ascend, were received with the response that if I did such a foolish thing I would be most certainly killed, and that he would be no party to the affair. Our return march that night is one of the things one would gladly forget. I had embarked on a 
journey of some 2,000 miles with the definite purpose of taking the exs of the Black Vulture, and here I was in the wretched position of having found the nest and seen the bird, linowing well that the nest contained the object of my desires, but batiled by a wretched pine tree. Horrible misgringe as to whether it was really such an impossible tree would persist in intruding themselves upon my mind.

As a forlorn hope on my return to our village that night I sent round word that I wanted a man who could climb a fino which was reputed to be unscalable and that a suitable reward would be bestowed on anyone who could do it. After a truly miserable night, during which dreams of impossible trees with rotten branches and of inadequate ropes which at intervals landed me in appalling situations, made any attempts to sleep almost une-ndurable, I got up at dawn and made some cocoa for myself and comrade.

Whilst completing preparations for our start I was acreeably surprised to receive a visit from our guide of the previous clay who said he had found a man who could climb any tree in the pinar! The latter was at once introduced-a hard-faced and somewhat well-fleshed individual of any age between 25 and 50 . He told me he was a woodman who had been engaged in loppling the pine-stems since he was a child. His name was Doroteo. To my anxious query as to whether he could pass a rope over the branch in the Vulture's tree, he made the truly Spanish reply of P'ucide se', "Maybe." The still more aggravating national response to my question as to whether he: could climb the tree (which hes professed, by the way to know well) was, \& () ut sé jo? livemos. "How can I tell? We shall see."

Arrived at the scene of the operations of the previous day, I sighted my camera on the nest, whilst Doroteo made the woods resound with blows from his axe on the great tree. Soun the old 
Vulture took alarm and launched herself from the edge of the nest, my camera duly registering her in the act.

And now began a performance which for slill, nerve, daring and readiness of resource I have never seen surpassed. Taking a $100 \mathrm{ft}$. length of my Alpine rope ( $\frac{1}{2} \mathrm{in.}$ ), I oroteo, by a skilful cast, hitched it over one of the small rotten-looking stumps projecting from the trunk some $30 \mathrm{ft}$. above the ground. Holding one end firmly, by a neat underhand throw he caused the

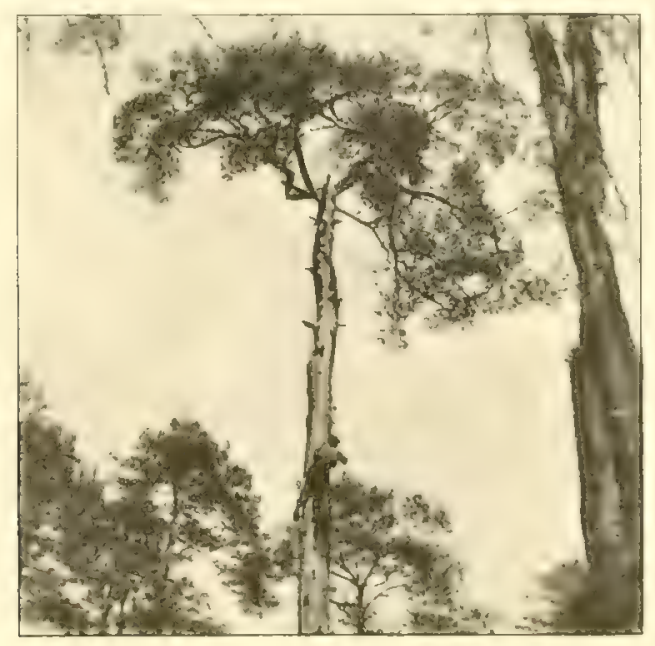

DOROTEO REACHES THE FIRST STAGE, to FT. FROM GROUND.

rope already hitched overhead to run up the trunk and catch on a second stump some $6 \mathrm{ft}$. above the first. Then walking round and round the tree with the ends of the rope in either hand and carefully studying the shape of the stem and the relative positions of the stumps above, he slowly and surely, by a succession of the most artistic jerks and casts, caused the rope gradually to creep up the huge bole, like a thing of life, until it was securely looped over a stump, about $6 \mathrm{in}$. in length, over $48 \mathrm{ft}$. above the ground. I men- 
tion $48 \mathrm{ft}$, for I noted at the time that there was under I yard of the IO2 ft. of rope (doubled) left in Doroteo's hands.

This was the conclusion of Act I.

Act II. commenced with a careful testing of the strength of the stump on which the rope now rested, by means of a steady pull and a few sharp jerks. After this Doroter warely handed the two ends to our other matn Augusto and proceeded to pull off his boots and replace them by a pair of alpargatas or rope-soled canvas shoes.

Our woodman, Augusto, now weighed down on the rope with all his strength whilst I)oroteo, moistening his palms, ascended it hand over hand with his less around the tree in the most approved fashion until he reached a small stump about fo ft. from the round and a few feet below the one over which the rope was hitched. Standing now erect on one foot on this precarious support, and with the left arm round the tree so as to steady him, he carefully orerhatuled the rope until only a few feet remained overlapping the branch above. Next, by an adroit twist, he jerlied it off this branch and proceeded to arrange the portion of rope in his hand into a loop some i $5 \mathrm{ft}$. in length.

These proceedings we watched from below with breathless interest, for it secmed physically impossible for mortil man to ascend any higher owing to the thickness of the trunk, which, even at that great height from the ground was far too big for any man to swarm.

Doroteo, having arranged the rope to his satisfaction, now manipulated the looped portion as does at sailor when about w heave the lead from the chains of a vessel, and having by this means got on a sufficient swing, he cast it upwards at a small stump some I $2 \mathrm{ft}$, above him. The cast failed-by an inch apparently! Again and again he sathered up his rope and essayed to throw it up, but without success. It was only too 
clear that he was getting pumped, for the expenditure of energy on the part of a man thus balanced on one foot only, in such a situation, and using all his strength, is very great.

Just as we were in despair as to his ultimate success the rope, which he had kept circling round and round, struck the bough, and the loop overlapped, it hanging down a foot or so. To us below this seemed to be a failure only in another form, but we were vastly mistaken. Letting go one portion of the rope he

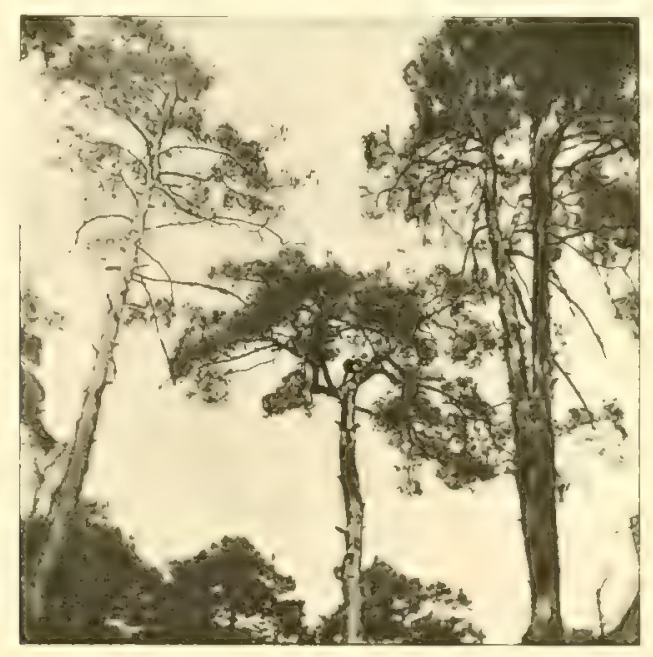

DOROTEO NEARING THE NEST.

arasped the other as low as he could reach, and by a combined turn of the wrist and upward jerk, as impossible to describe as it would be to imitate, he deftly made one part of the loop " flick" off the end of the stump, thus causing the bight of the rope to remain securely looped round it.

After testing the strength of this new point, he grasped the two portions of the rope and climbed up as before. Repeating this extraordinary process once or twice again, he at last reached the 
lowest branch of the great tree. Here, after carefully securin: his rope-for without it his return to carth, sare in the form af a meal for the Vultures, would have been improbable -he leisurely climbed up the remainder of the tree and reached the nest. The enormous size of the latter can be realized by noting the fisure of Doroteo in the accompanying photograph. In fact it was nu, easy matter for a man to get into it, since it overhung on crery side some $3 \mathrm{ft}$. or $4 \mathrm{ft}$. However, by breaking away a portion immediately above him he at last effected an entrance, and shortly afterwards we had the satisfaction of secing him hold up the well-won egg for our inspection.

I was anxious to follow Doroteo up the tree with the aid of the rope and photograph the nest, but was dissuaded by my comracle, who wisely remarked that the tree was very unsuitable for photographic work, and that in all probability we should find another nest where a hand-camera with a non-focusing lens, such as I then carried, could be used with better effect.

We now sent up a bag containing a tin box, in which to pack the ergs safely. It speaks for the height of the tree that $102 \mathrm{ft}$. of rope only just sufficed to lower our prize. I) oroteo now effected his descent in the same splendid style in which he had previously ascended.

Mounting our horses, we proceeded along the steep declivities through the apparently interminable moe of pine trees in puest of more nests. Nor were we disappointed, for within a mile of the first nest we came upon a second, placed on the very summit of a pine tree, the top of which had been apparently struck ly lightning, or broken off during one of the furious sales which sweep the valleys of the Sierra fuatarrama in winter time. Whatever the cause, the result had been to form allmost an ideal spot for a big nest, the branches of the sureat pine spreating out and offering convenient support to it. 
So steep was the hillside along which our horses were picking their way that we could easily see the old bird sitting on the nest on a level with us, and not Ioo yards away. This tree was somewhat easier to escalade than the first one and before long we had a rope securely passed over a bough about $40 \mathrm{ft}$. above the ground. With the aid of this I was soon able

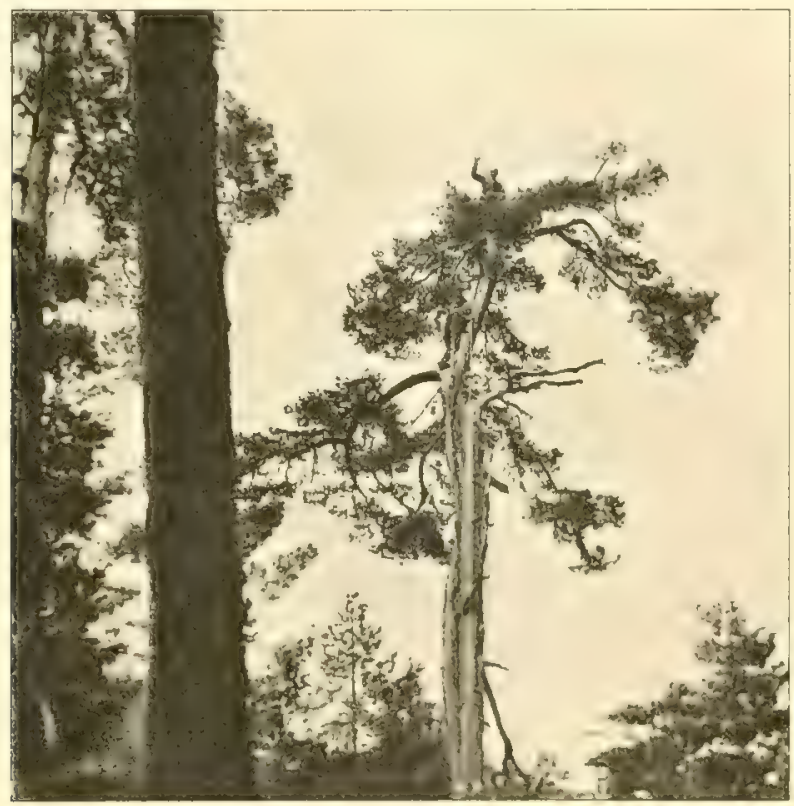

AUTHOR IN BLACK VULTURE'S NEST.

to ascend the otherwise unclimbable portion of the tree. Doroteo, to whom such exercise was a matter of daily routine, accompanied me and suggested that he should save me further exertions by ascending to the nest. This proposal naturally did not commend itself to me, as niy primary object was to take an egg myself.

Leaving my satellite at a convenient point, I made my way up the limbs of the pine, smooth and slippery with the sun of 


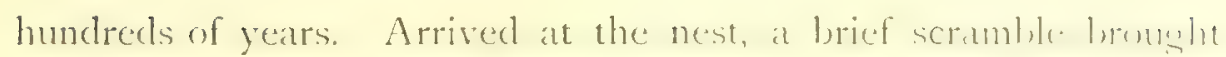
me over the edge of the great platform of hig sticks, and I $4.11 \%$ before me the object of my travels - - at Black Vulture's c...en! The nest was about $7 \mathrm{ft}$. in diameter with a good-sized depression in the middle, lined with tufts of fine grasses, such as commonls

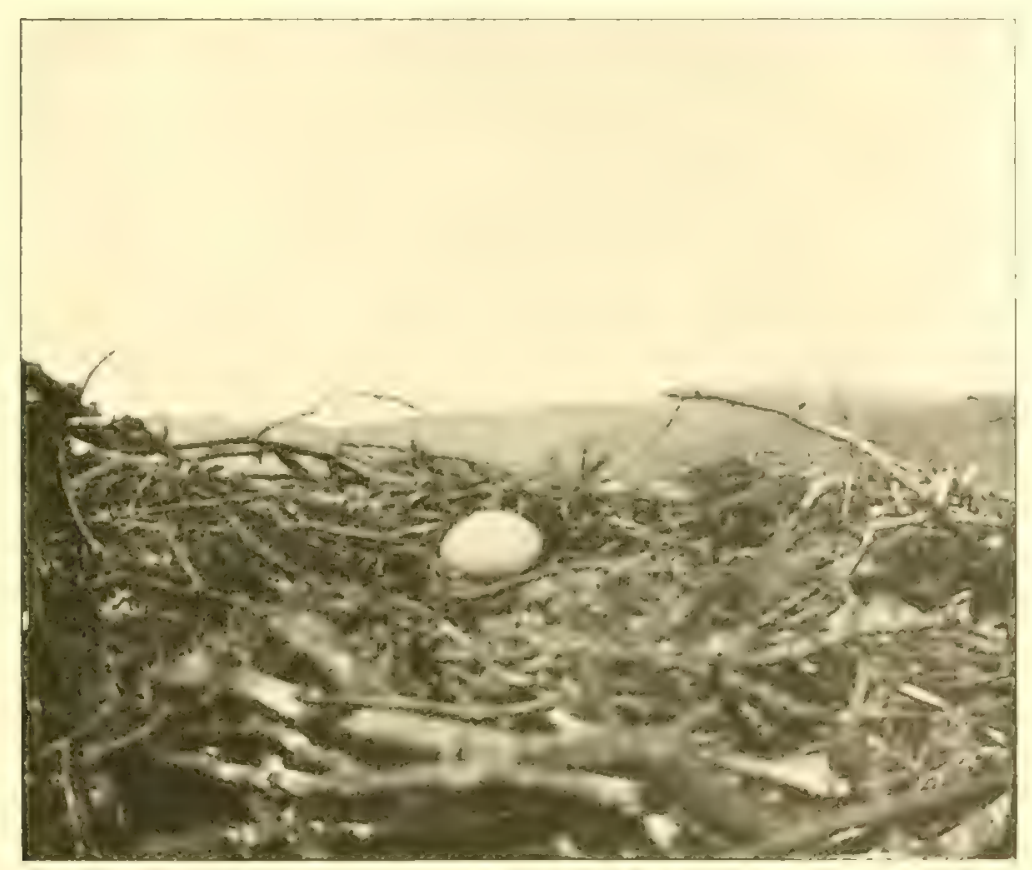

NEST AND EGG OF BLACK VULTURE.

From a fholograph at aliout $7 \mathrm{fl}$. dislance.

grow on stony hill-tops in Spain. In the centre of the hollow lay the egg, whitish in ground colour and marked with dark ferruginous spots, the possession of which hat beren my desire for so many years.

I climbed on to the nest and had a grood look round and it was interesting to note what an extraordinarily commanding site the 
Vultures had selected for their nest. So strongly was the big nest built that it was an easy matter to stand on it. although the slight oscillation of the tree made it somewhat awkward. My friend took a shot at me with the camera at the moment when I was triumphantly holding up the egg for him to see.

Sending down the line I had brought up with me, I hauled up my camera. The difficulty which now presented itself was to get at a sufficient distance to work with the non-focusing lens. For this I required at least $7 \mathrm{ft}$. but from my position at the edge of the nest the utmost distance I could gret from the eag was only $3 \mathrm{ft}$. Looking around, almost in despair, for some means of increasing my distance, my eye fell on a branch which, starting from the main trunk only $3 \mathrm{ft}$. below the nest ran out almost horizontally. Not only did this branch thus afford a conveniently situated foothold, but it ran in the direction of the sun. In other words, if only I could work out along it for $5 \mathrm{ft}$. to $6 \mathrm{ft}$., I would be able to take a photograph of the exg with the sun behind me.

The branch itself was none too larure to stand upon, about the thickness of a man's thigh at first, but it rapidly got smaller, about $6 \mathrm{ft}$. out dividing into two branches, which drooped downwarls. I saw that if I went out along it more than $2 \mathrm{ft}$. from the nest I should have no handhold to depend upon. Clearly the only possible chance to work out along it with reasonable safety was to bring a rope into play. Here again luck was on my side, for projecting through the nest was a gnarled stump, evidently a por tion of the top of the shivered trunk. I was still wearing my canvas sling round my body to which was attached my Alpine rope as a life-line in case of a slip. I now passed a bight of my rope round this stump, and gaining the branch, I stepped a's cautiously backwards, paying out the rope with one hand and with the other keeping my balance by a light touch on the edge of the nest, so long as it remained within reach of me. When less than $6 \mathrm{ft}$. from 
the egg the bough began to bend under my weinht, and reallizing that it was unsafe to go out much further without being secured, I returned and measuring $3 \mathrm{ft}$. more along the rope so as to give me the legal minimum, viz., $7 \mathrm{ft}$., I made it fast at this point

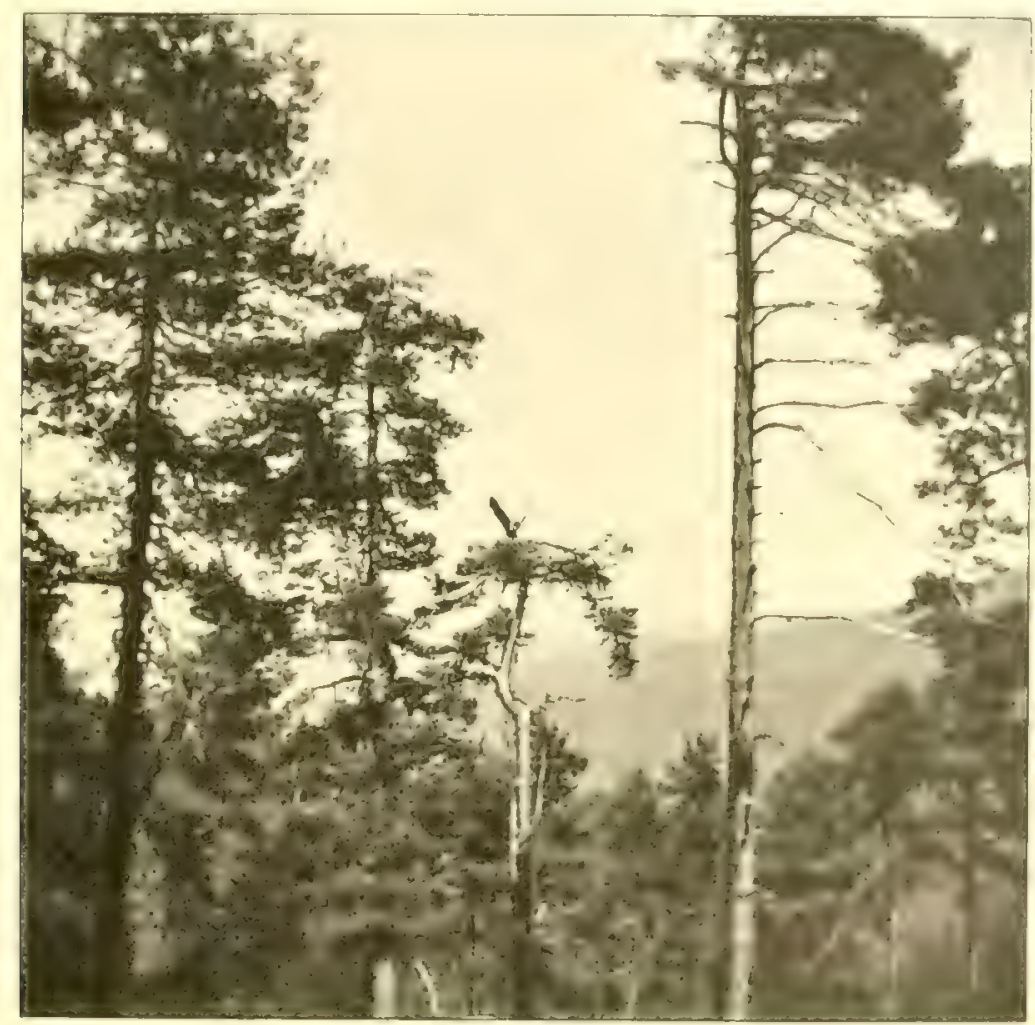

BLACK VULTURE I.EAVING NEST.

to my canvas sling. Then, gently withdrawing my "Bull's-eye" from its leather case and hanging it round my neck ready for action, I arain edged out backwards, taking the strain on the rope slowly and steadily until it became taut. I was now over $7 \mathrm{ft}$. from the egg. It was a breathless moment as I pressed 
the camera against my chest and pulled over the lever. In order to make sure of my task, I repeated the whole process thrice and was fortunate enough, in one case, to get not only a picture of the nest and egg in the forenround, but of the snowy summits of the Sierra de Guadarrama in the far distance beyond. It is unnecessary to expatiate upon the relief it was to regain the nest and once again to feel something firm to hold on to. I now descended, and we ate our luncheon at a point about roo yards from the tree. During this time the old Vulture returned and proceeded to sit diligently on the empty nest as though her egg was still in it. On going towards the tree again, she rose up in the nest, and, extending her great black wings, sailed away. I obtained a photograph of her at this moment, the nest and bird standing up in good relief against the snow-clad slopes of the Sierra on the far distant side of the valley.

Before leaving the district we came across several other nests only one of which was tenanted. This was at the summit of one of the loftiest pine trees I have ever seen, by rough measurement over $130 \mathrm{ft}$. in height. A sketch of this tree, taken on the spot, appears at the beginning of this chapter. For over $60 \mathrm{ft}$. there was no friendly stump over which to cast a line, and the first sound branches were well over $100 \mathrm{ft}$. from the ground.

Ve found this nest by watching a valley on the south-western slopes of the Guadarrama from a point high up on the hillside, considerably above the level of the nest. With my telescope we watched both old birds enter and leave it, but the distance was too great to make sure whether it contained an egg or not.

From the movements of the birds it seemed as if they were still engaged in preparing the nest for laying, and, subsequently, we made our way to the foot of the tree. Owing to the great girth of the trunk of this pine, and the absence of branches, Doroteo at once declared the tree to be, without question, impossible, and 
we did not even attempt it. And impossible it doubtless wis firom his point of view, and a more intrepid and skilful tree-climber I never met.

Owing to the somewhat lonely position of this tree, siven a fair wind, it would be quite possible to get a line over the top of it by means of tlying a kite, and had we remained in the neighbourhood a few days longer I should assuredly have tried this. To those who have not heard of it I may say at once that the idea is not origrinal. I first obtained it, many years aso, from reading how a British Bluejacket, during our occupation of Egypt following on the campaign of ISOr, succeeded in climbing Pompey's Pillar at Alexandria by such means.

This kite-flying method of getting a line over an awkward tree is, of course, not suitable if it be surrounded by others, as with the first Vulture's nest we visited. To set a rope over such a tree my own panacea would be to employ one of the late Captain D'Arcy Irvine's line-throwing guns. ITere I at the beginning, instead of nearing the end, of my tree-climbing career I should certainly look upon one of these ingenious weapons as an essential article among my birdsnesting equipment. With the aid of one, lent me by the inventor in 1895 . I found it quite simple to throw a line with accuracy over a selected bough in a lofty elm tree. Once the line, which is carried by a stick, has been shot over the required spot, it is, of course, a simple matter to haul the necessary ropes over it and to make the ascent.

I left these beautiful wooded mountains of the Guadarrama with genuine regret. Brief as was our stay among them, they daily gave us new experiences, and we sitw much of absurbing interest.

Very fresh in my memory are the rides in the great pine forest through apparently never-ending ristas of huge and serried tree-stems, as now we threaded our waty moiselessly orer the derep 
soft carpeting of sweet-smelling fir-needles, or another time urged our horses with noisy clatter across the face of some steep, rocky slide of débris from the crags far above. From time to time our advance would be barred by some natural obstacle which obliged us to make a wide detour. Thus the hillsides at places became

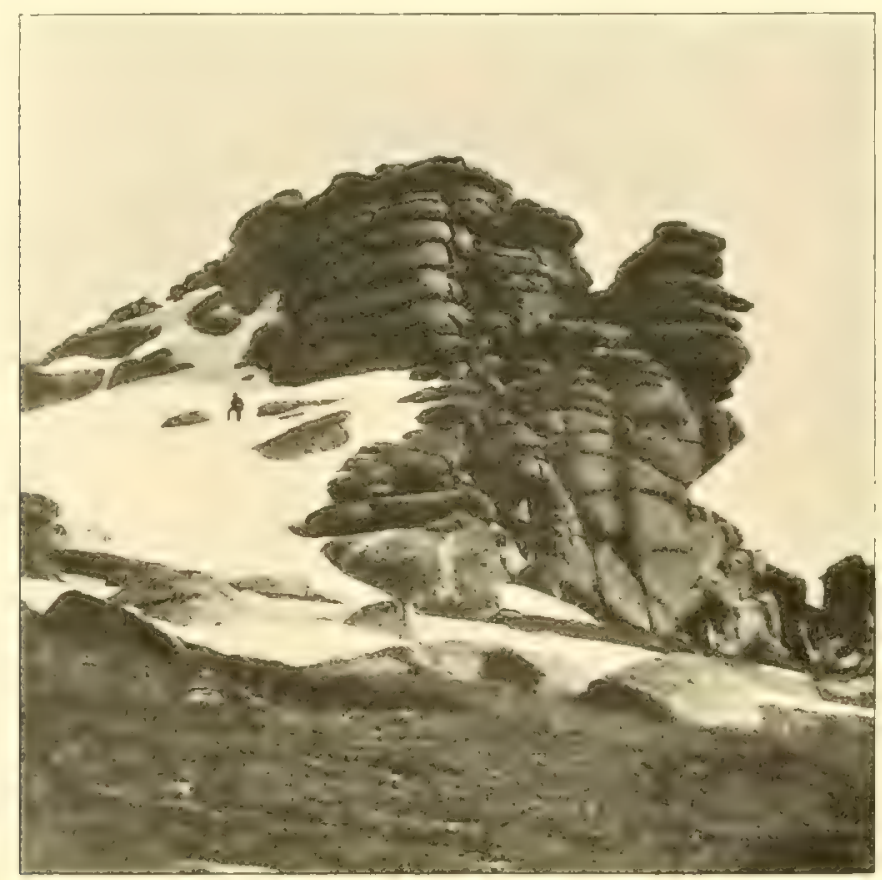

ONE OF THE SIETE PICOS.

A Summil of the Sierra de Gualdarama.

so steep as to be unrideable and compelled us to seek a less slippery track. At others, fallen pines lay about in wild confusion, some prone on the ground, over which our horses could step, others supported at various angles by trees still standing, and under which we passed. Or, again, we would come to a combination of the two olostacles, where an avalanche of loosened rock from 
the steep crass high above had swept a path throush the pines, tearing many of them from the ground and creating an impassable barrier.

Sometimes our path would follow the course of some noisy torrent, forcing its way down amid wreat masses of yrey boulders, and at places forming quiet pools in which were small trout. We learnt that these streams had repeatedly been stocked with fish, but that before they could attain any sise, some: predaceous native, armed with the inevitable dynamite, came on the scene and clestroyed them.

Through the dark masses of foliage the snow-clad hillsides above us could from time to time be seen, whilst over our heads was always the intensely blue cloudless sky of Spanish spring-time.

The scenery is magnificent. From one of the summits of the Siete Picos, a mass of black granite rocks, rounded and weathered to the smoothest surface, and built up in horizontal masses, around which the snow still lay deep, we could survey the plains of Castile, seemingly at our feet.

One diay, with the aid of a field-glass, we saw the dim outlines of some of the larger buildings of the capital, distant from us some thirty miles, whilst the famous Escurial, its massive walls and vast rambling construction giving the appearance of at town of itself, lay grlittering in the sunlight on the southern slopes of the sierra below us.

Nor were historic associations wanting, for close at hand lay the famous pass, the Puerto de Guadarama, through which the tide of French invasion rolled in asos, as well as those other mountain roads which had witnessed the passage of the hosts which Napoleon, in his wrath, had dispatched to amihilate the audacious Moore, and which same roads, four years later, saw the triumphant advance of Wellington's army on V'itoria and Iirance.

Vhilst we were enjoying our marvelhous bircl's eye view from 
this lofty post, some $8,000 \mathrm{ft}$. above the sea, and 5,000 ft. above the plains below, a Golden Eagle came sailing past us and perched on an adjacent pinnacle rock. Later on, a splendid Bearded Vulture appeared, hunting sterdily along the snow-line and paying no attention to our presence, on the look-out, most probably, for any carcass. or remains which might come to light as the snows melted under the warm rays of the April sun.

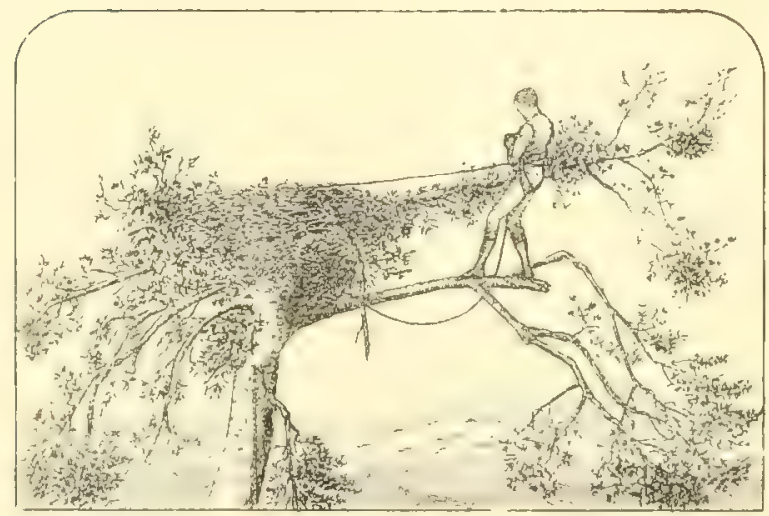




\section{V.-ALONG THE SEA-CLIFFS.}

\section{CHAPTER I.}

\section{A RIDE "TO 'TRAFALGAR.}

A by-gone race-Remains of ancient cities-In quest of Sea Eagles - An interesting ride-The cliffs of Trafalgar-Ravens, sea-birds and Ospreys - In ideal spring day-Arrival of migrants, Hoopoe and Great Spotted CuckooFlamingoes-Some cliff-dwellers-i marvellous panorama-Scene of the greatest of sea fights.

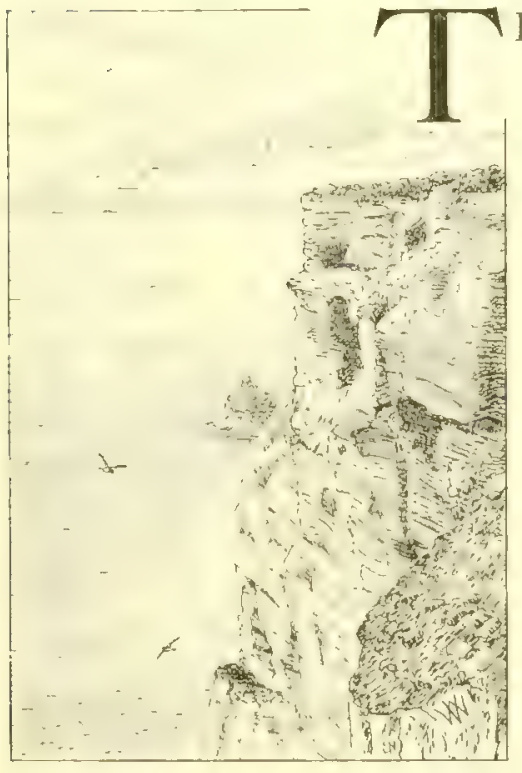

Straits of Gibraltar by daylight will recall the yellow sandhills along the coast of Spain and their background of jagged sierra between Cape Trafalgar and Tarifa. Few however realize that at one time these now desolate wastes were inhabited by a great race and that more than one populous city existed between Gades, the ancient Cadiz, and Carteia, the Phœnician city at the head of Gibraltar Bay.

In my wanderings among these hills skirting the Atlantic, especially near the foreshore, I have come across remains of great antiquity, fragments of walls, adededucts and temples. There are also the ruins of a great amphitheatre which according to the Jesuit Father Julius Furgus, who visited them recently, could accommondate 50,000 persons. When this great city was destreyed and 
who were the human destroyers is unknown. At present the sea has encroached on one side and the great wreaths of wind-borne drifting yellow sand have werwhelmed it from the other and little is left visible to the casual visitor.

I rode along this coast on a brilliant day early in March I9o8 in order to risit the cliffs near Cape Trafalgar where it was reported

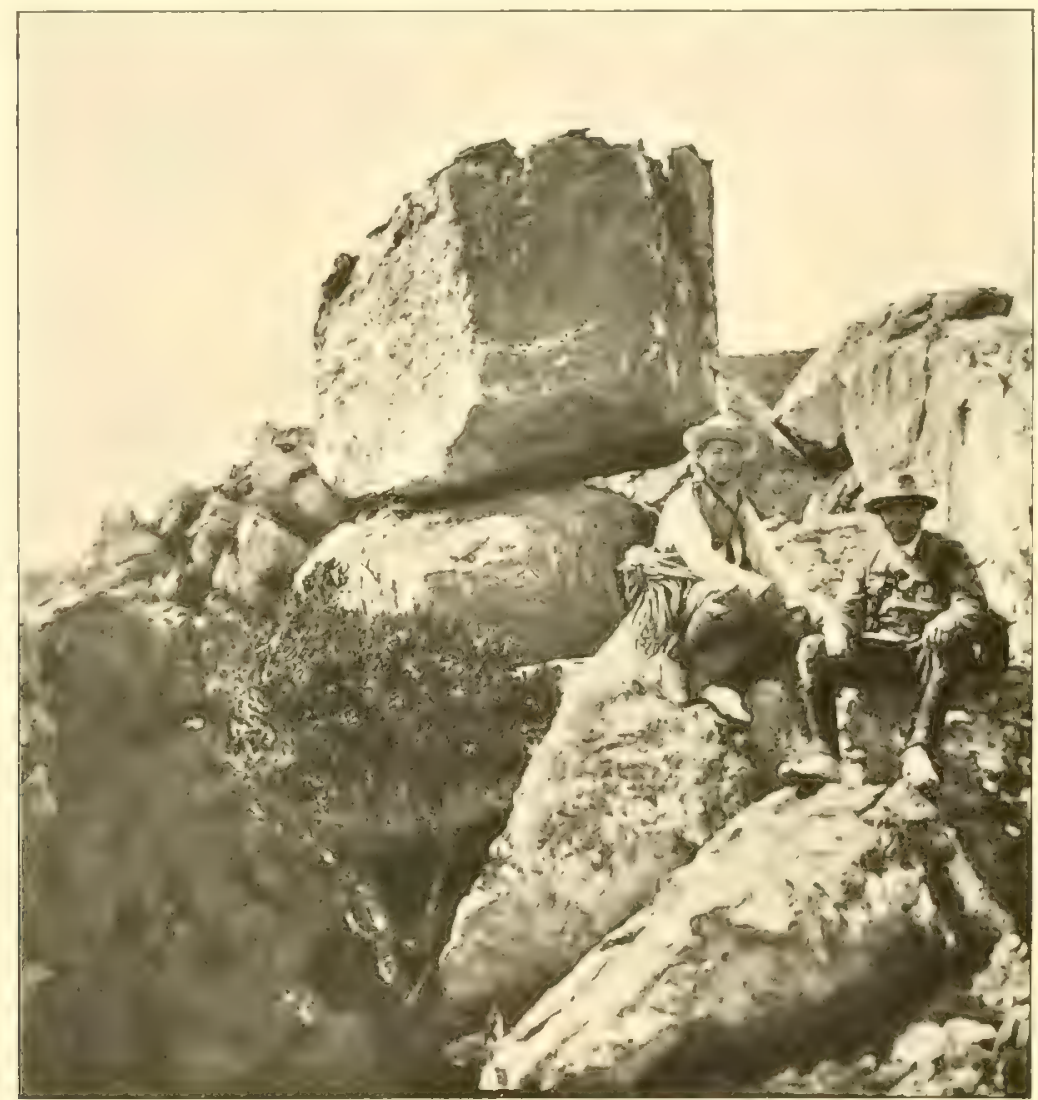

A SUMMIT IN THE SIERRA AEOVE TRAFALGAR DAY.

that a pair of Sea Eagles nested. The story, an old one, dating back for thirty years and more, was ever disbelieved by both Colonel Irby and myself, still it was worth investigating more especially as it made a very interesting expedition. 
Starting at 6 o'clock, I reached the shores of Trafalgar Bay two hours later near the ancient Moorish walled town of Zira or Zahara. At a mountain cortijo near here I picked up some Spanish friends, a farmer and his henchman, and we rode along

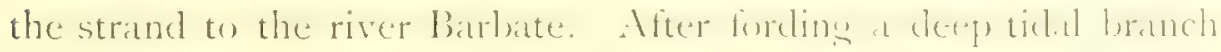
of the river, a ferry-boat took us across the main stream to the small town of Barbate, famous for its tunny fishery. Leaving Barbate we followed the strand again for some distance until it narrowed and we reached the point where the cliffs commenced, with the waves lapping at their foot. It now became necessary to strike upwards so as to gain a track along the summit. The low cliffs here are of yellow and red sandstone strata surmounting beds of blue slider clay which had been exprused by seat action and is in a constant state of disintegration. Northward of this the cliffs become perfectly vertical and are of an older and harder formation, but rotten and crumbling and very dangerous to climb. The country immediately bordering on the sea-cliffs is overgrown with cistus, lentiscus and cypress, wind-swept and stunted. The ground is very rough and uneven, forming innumerable sheltered dolls in which there wals, at the time of our visit, a great wealth of colour, masses of pale purple and white rosemary, crimson snapdragon and large red thistles stowing in the grassy glates amid arbutus and butcher's brom. Further inland are many square miles of sandhills corered in plices with a dense growth of stone pines, many of the trees being of considerable size. Upon gaining the top of the cliffs, about $400 \mathrm{ft}$. above the seat, we dismounted and giving wur horeses to our attend dont to lead along a track at a safe distance from their edge, proceeded to examine the cliffs. It was a matter of no small difficulty and some risk to approach near enough to the edge to hook were but by taking advantage of sundry re-entrants and headlduds formed by big slips at various times and of smaller slips among the upper 
strata, we succeeded in thoroughly examining the place and a very interesting task it was. Soon the croak of a Raven told us that these wily birds had an establishment in the vicinity and before long we saw their nesting-place in a small sandstone cavern weathered out in the face of the cliff above an horizontal slab. Ravens are particularly addicted to sea-cliffs and like our Hooded Crow of northern latitudes seem to find much to interest and occupy them among the detritus cast up along the foreshore. On the African coast I know of several nests thus situated in the same range of cliffs. It may be a mere accident, but in southern Spain of the many Ravens' nests I have seen and visited the greater majority are within a few miles of the shore. Possibly owing to the numerous convenient nesting situations to be met with amid the cliffs, only a comparatively small number nest in trees.

A few pair of Lesser Black-backed Gulls were nesting upon the detached rocks along the foot of the cliffs and other common sea-birds, such as Green Cormorants were also to be seen. Presently the well-known cry of the Osprey was heard and we saw one of these birds tying along some distance below. From our successive points of vantage we had literally a bird's-eye view of all below us and during the morning saw five Ospreys' nests, of which only two were occupied. Doubtless the others were alternative sites used in other seasons since there were only two pairs of Ospreys in possession of the locality. But no Sea Eagles did I see, nor did I find any site which would have suited that species nor could I find any report of any larger "Eagle " than the Osprey having ever been seen in the vicinity. A pair of Peregrines were nesting on a ledge not far from us and were exceedingly wroth at our presence; there were also many Kestrels and Blue-rock Pigeons, as is ever the case in these parts.

It was an ideal Spanish spring day and circumstances all agreed to make one take it in an ideal Spanish manner, in other 


\section{A Flight of Flamingoes}

words, to fund a comfortable spent amid the sweet-smelling cintus and enjoy life whilst one could. It was now one o'clock and after lunching I lit a cigar and waited and watched and very pleasant it was. In the scrub around us the checry little Dartford Warblers were ever on the move, and now and arain a brilliant I Impexp, junt arrived from its winter sojourn in Africa, woukl tlit past us with its curious undulatory thingt, showing the conspicumes black and white barred wings; and, once, a beautiful cireat Sponted cuekon (Coucystes slemdurims) also only just come ashore, alighted on a pine tree close to us. Almost vertically below us the white surf of the Atlantic swell was breaking against the masses of lonst sandistone fallen from the cliffs alonere, the water was intensely blue and clear, with here and there pale shates of green and dark purple showime the presence of strips of sand and rock far below the surface. Presently we espried a great crowd of hig birds somewhat rencmbling Wild Geese, thyng close to the surface of the sea from the firr dintant African shore. As they neared us the sun struck on their backs and they became a mass of rose colour and we realized that they were

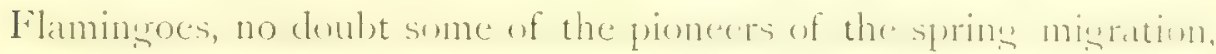
wending their way to the marismals of the Cimalalquivir. Asthey passed below us, flying close torgether, so close indeed that at plices their black-tipped wings seemed almost to touch and overlap, they presented an extratordinary spectacle -surely one rarely seen ly the wandering naturalist-of a moving mass, crimson and rose and white, streaming over the dancing ble watelets befow, which changed its shape and size from one moment to another as the birds in their thight closed into a dense boxly or opened on andin into sinuous lines. Their course took them inside the low sandy

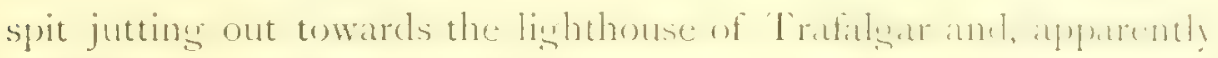
unwilling to trust themsches oret the land, they altered the ir comber and in long unclulating lines tlew bedelly seaward. It was indeed an unusual spectacle seen from such a perint of lintage so fiur almere them. 
Now and again huge portions of the cliff had become detached and had fallen in disordered masses below. (On these were grassy

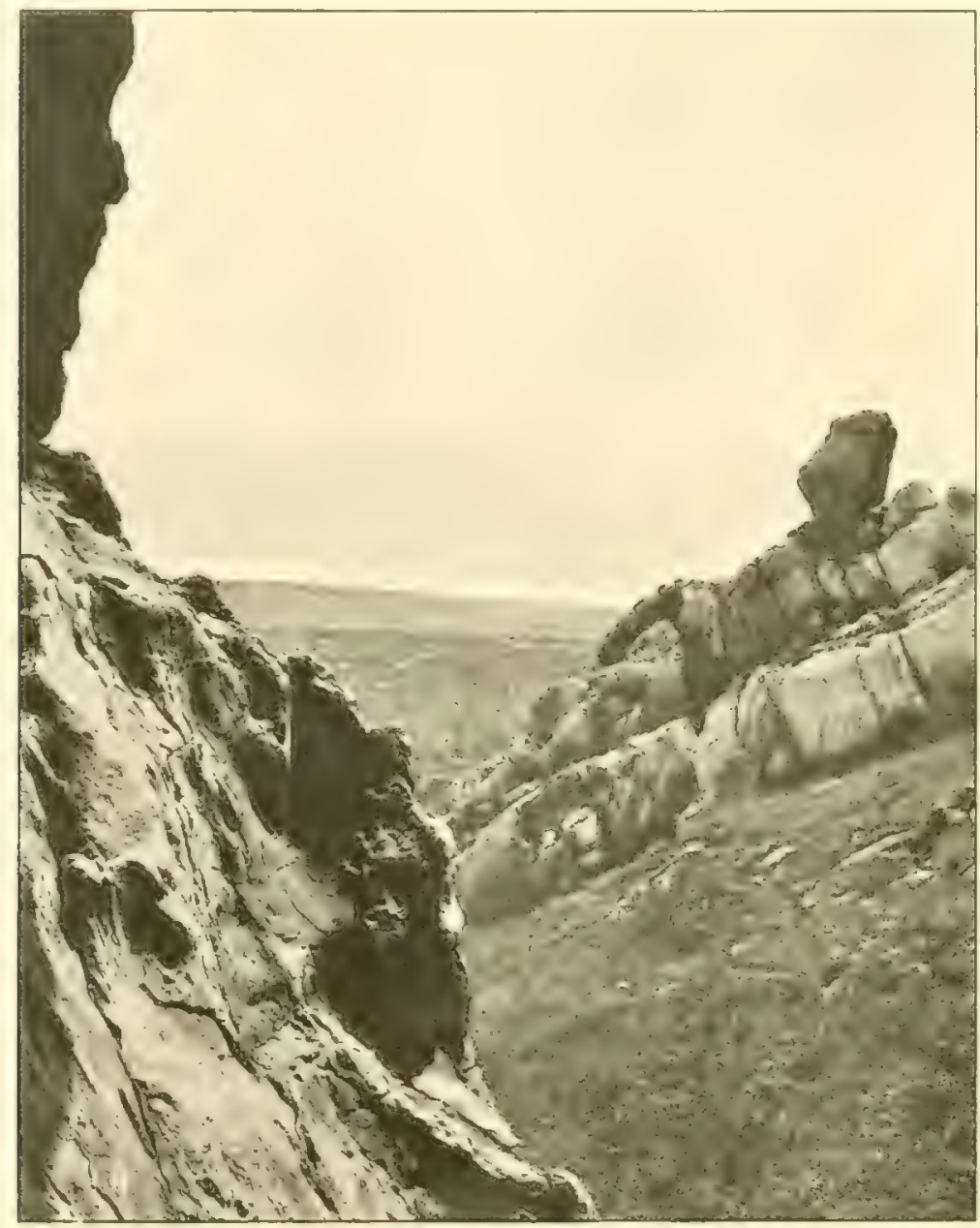

THE STRAND OF TRAFALGAR.

Tiezo from I'ulure's Cażem in Sierra aboztc.

teraces, some of them denscly overerown with brambles and lentiscus scrub. Whilst peering over the edre at such a spot, we saw several rabbits scrambling about the face of the cliff. These 
little animals must surely spend their whole lives there, fore with the. steep overhanging cliff above them and the seat washing helew, there would seem to be no means of escape. It was whilst watching them

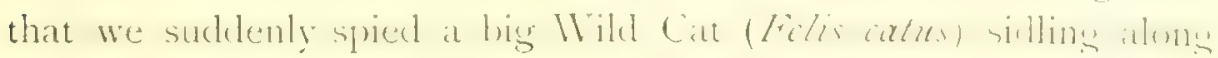
a narrow shelf of sandstune until it disappeared into the tamended mass of scrub. It was quite unconscious of our presence and was evidently intent on a rabbit for dinner.

The view from the summit of the cliffs of Trafalgar is one of vast extent and surpassing grandeur. We were fortunate in having a very clear day. The whole of the African side of the Strats from Apes' Hill, opposite Cibraltar, pret Tampier to the hlue. headland of Cape Spartel far out in the Atlantic lay before us. Beyond Spartel, the Atlantic coist down to Arzila, Latralue and southward stretched away into space. Tarifit itself wats hieleden by the spur of yellow sandhills which enowlf the old Phunician city of Belon. Northward the whole strand past the white town of Conil and onward to the Isla and Cadiz was visible, whilst eastward, the rugged outlines of the Serrania of Ronda, over zo miles distant, were clearly silhonetted, as were the nearer I lathe of Gaucin, the Sierra Bemeja near Fisteprema and beyond thene the Sierra Blanca and far distant Malaga Mountains. Truly a marvellous panorama. From the spot I occupied I could see

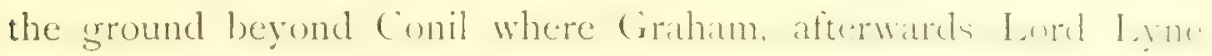
doch, marched to fight and lefeat the lench at Burosin in I I I .

But the chief historical interest naturally centred in the sheet of glittering water immediately below us, for we were exactly opposite the spot, "Cape Trafalgar bectring 10 miles cant," whene the sreatest of naval battles was foupht. What a view the inhaliftants of these wild hills must have had from the point we now occupied, over $500 \mathrm{ft}$. above the sea, on that 2 I October as Nelson's twenty-seren ships bore down on the strateline line of French and Spaniards heading for Cadis. With the wind 11 . X. 11 . 
as it was on that day, the smoke of over 4,000 guns must have drifted right over the cliffs where I stood. I remember now many years ago an old Spaniard describing to me how as a small lad tending goats on the sierra he had heard the roar of the guns and scen the weat column of smoke rising above the contending fleets, and as I surveyed the actual scene of that mighty contlict stretched out below me, I saw it in my imagination crowded with white-sailed line-of battleships enveloped in drifting smoke and locked together in that death struggle which for over a century has secured for us the command of the sea.

Nor did I fail to conjure up to myself the scene all along the coast below, strewn with wrechage and dead bodies, for many a crippled ship was driven ashore and totally lost in the gale which followed the battle. My companions, simple country folk, were sorely puzzled at my remaining so long in meditation and gently reminded me that they must leave me as they were bound to re-cross the Barbate before the tide rose. So I bade them farewell and, mounting my horse, rode homewards alone through the ligg stone pines, many of which must surely have been silent witnesses of the day of Trafalgar.

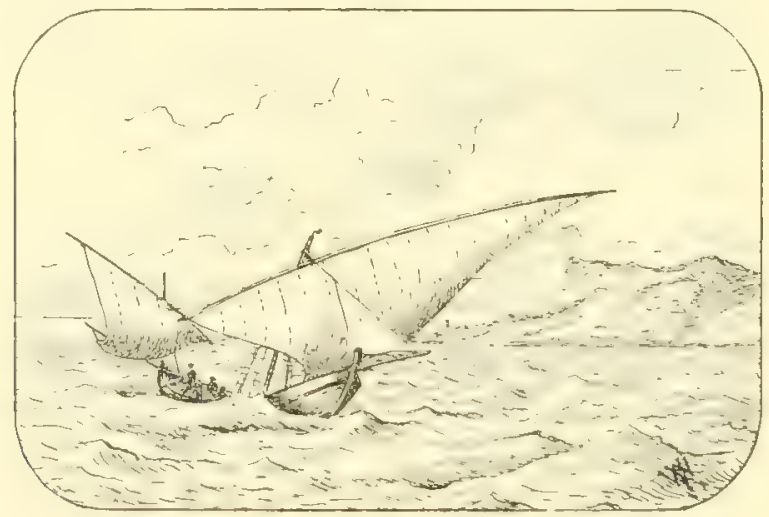





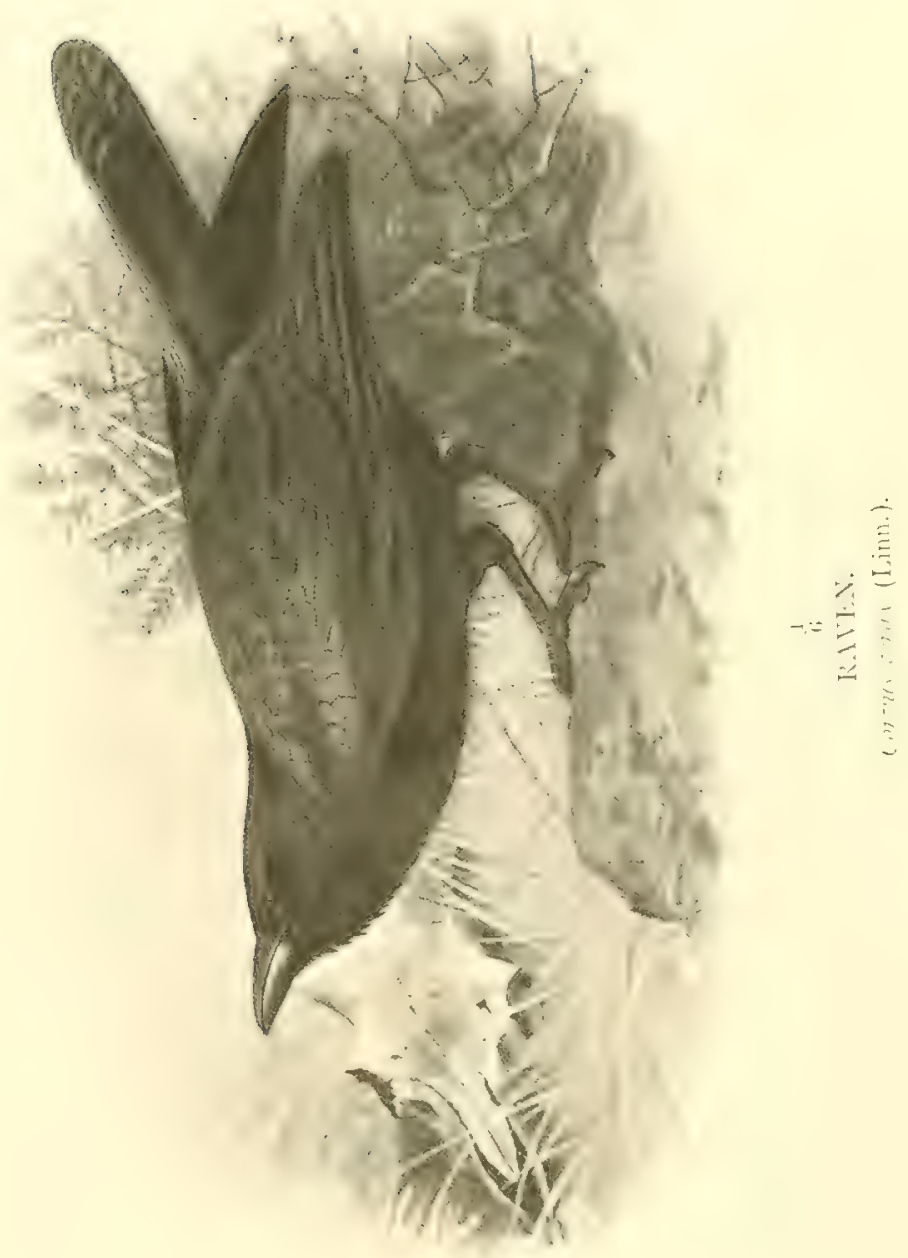




\section{CHAPTER II.}

\section{THE COMMON RAVEN (Comms corr.r).}

Late nesters in Spain-Curious habit of congregating-The Tangier or Brownnecked Raven-A nest in a pine tree-Raven trapping-Artful choice of nesting quarters - A two-fronted residence-Nest in a deep fissure-Awkward photography-Arrangement of eggs in nest.

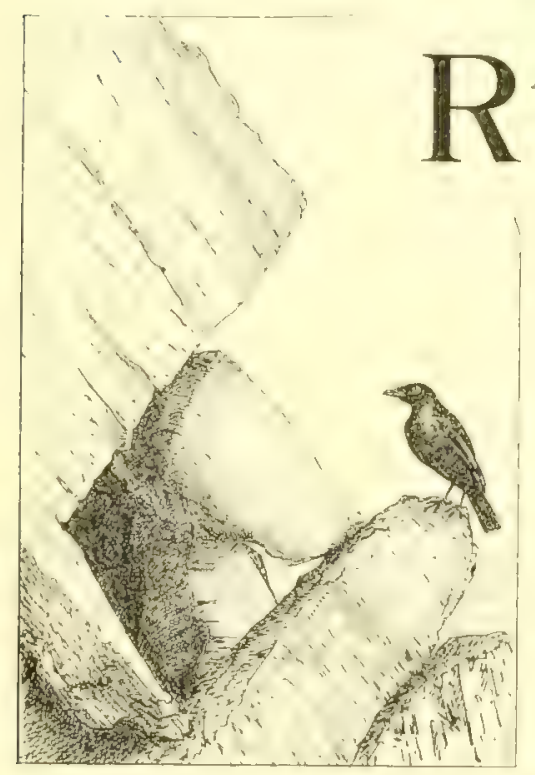

AVENS are extremely abundant in southern Spain and are even more so in Morocco. Despite their wellknown appearance, flight and call, which render them unmistakable at almost any distance, few birds have caused me greater perplexity in my attempts to understand their ways or the reasons which regulate their movements. 'To begin with, in southern Spain, where, according to our British standard of climate, an almost perpetual summer reigns, the Ravens nest, not, as might reasonably be assumed some weeks earlice than in our Lolundi, but on the contrary, at least a month and frequently, more than two

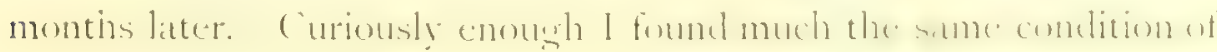


things in the: Island of Crete, where, out of many nests visited, only one contaned eggs during the last week of March 1856 , the rest being still in course of construction. Why it is that in the exposed and almost arctic climate of northern Scotland as well as in the wet and storm-swept shores of Ireland and the west of England these birds should eiect to lay in liebruary and why in sunny Andalucia they should clefer doing so till the middle of April is, to me, an insoluble problem. Yet again, as to the number of eggs laid, whereas in our Islands, three or four would seem to be the usual complement, in Spain, six is the number commonly found and next to that five.

Another puzzling habit of Ravens in Andalucia is the manner in which they, from time to time, collect in considerable numbers for a brief period and then as suddenly disperse. On such occasions they are invariably in pairs and their movements are obviously made in accordance with some well-defined ulterior object. What this can be, I am unable to say, for in all my wanderings in wild Spain I have never met with a large party of Ravens collected around the carcass of an animal, nor have I ever heard of such a gathering. I mention this, because, when Vultures are seen to be moving towards any defined point, it is invariably to foregather at one of their banquets.

To give an example of these assemblages of the Common Raven. On 18 April, I906, I was riding along an open river valley and noticed a pair of Ravens, coming from the north, settle on a pine tree to my front. Soon a second pair arrived from the same direction followed by another and yet another. Meanwhile the lirst arrivals hat moved on and disappeared through a pinewood out of sight and were in turn followed by their friends. Before I had passed this line of flight, no less than seventeen pairs of Ravens had proceeded along it. Now what could these birds have hatd in view? Although Ravens are numerous in these 
parts, they never nest in colonies as do the Choughs. Ruther du they keenly resent the intrusion of any of their species and each pair of Ravens establishes itself on some cliffor tree at some distance from others. From my own particular knowledse of the district where I saw these birds, I can vouch that there are certainly not more than six pairs nesting within a ralius of five miles of the spot where these birds congregated. In view of what I am about to say about the Tangier Raren, I may add that I am positive that all these birds I saw were Common Ravens and further I draw a distinction between a processional movement of pairs of Ravens of the type I describe and a cetneral assemblage of birds, such as one sees at times among the Ravens in Morocco, or Rooks in our own Islands.

Over thirty-five years ago, the existence of a small species of Raven in Morocco was noticed by Colonel Irby and was first described by him in the Ibis of 1874 as Cormes tingitanus.

According to Irby, this species is decidedly smaller than the Common Raven and its note is different, whilst so gregarious is it in its habits that it is no uncommon sight to see flocks of these birds feeding on the refuse along the sea-shore near Tangier. During my travels in Morocer I have secn such assemblages of Ravens myself but I have never shot any birds with a view to establishing their identily. The Tangier Raven has also been described as the Brown-necked Raven and Irby notes that many specimens are marked, more or less, with rusty brown on their wings and tail, although this colouring is of no importance in determining the species. In the task of identifying birls on the wing, especially when at a distance, size is one of the most difficult factors. Everybody who has attempted to pick out any particular species of Gull will know well what I mean. In such a case the appearance of some well-known species, such as an adult Lesser Black-backed Gull, at once gives a "scale" 
whereby to judge the size and species of others. Hence although in the case of a Common Raven $2+4$ in. in length seen in company with a Tangier Raven only about Is? in. long. it is easy enough to tell the larger from the smaller species, when severd! of the same species only are seen together at a distance it requires more skill than I can pretend to, to know which they are. It is owing to this difficulty that I have to confess that I have failed to establish the fact of the nesting of the Tangier Raven in Span. As regarels the ordinary methods of identification, shooting on trapping, such is the perversity and cumning of all Ravens that it is no easy matter to shoot them, even from the nest, and as far as my experience anes they consistently decline to be trapped, preferring even to abandon their eggs to walking into a trap concealed in the nest. In the words of an old Spaniard who witnessed my discomfiture by a Raven which obviously detected my evil intentions: Sabe el cuervo mas que el hombre-"The Raven knows more than the man." Hence such evidence as I have to produce is of the negative type, or, in other words, where I have clearly verified the species nesting, it has not been the Tangier Raven. The one exception to this occurred in 1879 , when on 24 April, chancing to be riding past within view of the pine tree where I had trapped a Red Kite three weeks previously (as described in the chapter on Kites), I saw a Raven fly out of it. On climbins up, I found the Kite's nest had been completely remodelled by the Ravens, the sides had been raised by a well-linit parapet of sticks and enclosed a deep cup, thickly lined with goats" hair, in which were tive lisht green egss, closely marked with brown and to my eyes decidedly smaller than any Ravens' I had then seen. Whilst I was in the nest the old birds flew around and seemed to be not nearly so big as the orcinary Raven. All attempts to trap the old bird failed. Three days later I returned to the nest and found a sixth egg had been laid. On this 
occasion the old bird slipped off the nest when I wat far distant from the tree and such is their usual way.

Since then, I have visited very many Ravens' nests and have seen eggs innumerable, but I have never come across any which exactly resembled this set of six, which are much nearer in shape and size to some of the eggs of the Carrion Crow I possess than to any Common Raven's.

On various occasions I have seen considerable assemblages of Ravens, which, so far as I could juelige, seemed w be of the small species. The curious part of it is that these gatherings were generally at the height of the nesting season. Thus in April Is;8 I saw over forty small Ravens in the plain north of Tarifa, on 29 April, I879, about fifty near the River Guaddarranque, and again over forty near the Palmones River.

Irby expressed his belief that the Tameier Raven nested somewhat later than the Common Ratren on the Sprunish side, namin: 20 April as their usual date. From the following datat taken from my notes, it would seem as if this was also the average date of laying of the Common Raven. Of eight nests visited in recent years, the earliest date for the laying of the first eng was 1.3 April and the latest 26 April. Two of these nests contained four eggs, one five, and five six. The average date of laying would appear to be about 20 April.

As regards the dete of hatching wat I have found nestline only a day or so old on 2I, 24 and 26 May and this would appear to be the average date of their appearance in southern Spain.

I know of no large and conspicuous bird, such as the Raven, which, when circumstances demand it, is more adroit at concealing its nesting-place. Of course, when it neste in trees, this hardly applies. All the same I know of several nests which have eluded detection year after year owing to their similatity to one of the chance collec tions of fir spines which are so common in some of the pine trees in 
Spain Some nests rely solely on their inacessibility combined with the remoteness of their situation, and are placed without the slightest attempt at concealment.

The Raven excels most in the art of deception when it nests in some of the smaller crags which it frequently resorts to because they are inconspicuous and provide caverns or fissures in which it can conceal its nest. As a rule nests built in such situations are constructed so that no portion of them is visible from below.

Quite the most artistically concealed and cumningly placed of the many Ravens' nests I have visited was one placed in a small domed cavern near the summit of a crag not $50 \mathrm{ft}$. high, vertical on one sicle but sloping so gently on the other that anybondy can scramble up to it. In this the Ravens nested for over thirty years. In 1877 I shot one of the old birds within 20 yards of this spot, thinking it was a Tangier Raven, but no nest did I see. Year after year I passed close under this crag but there were no signs of a nest, although the constant presence of the Ravens told me they must be nesting hard by in one of the many rocky ravines. At last in I903 I chanced to be passing the crags with several friends and sent two of them along the ravine below the cliff whilst I proceeded along the shelving side. Presently I heard a shout and was told that a Raven had just town out of the cliff close to me. Looking over the edge I could see nothing, but upon rounding an angle of rock hard by I spied a hole on my side of the crag which led to a cavern in which was a Raven's nest with four eygess. The secret was out. The wily bird had so arranged its establishment that no matter which side the enemy, man, appeared, it could always slip out on the other side unseen. Small wonder then that upon the innumerable occasions when I had passed along the goat-track below the nest since 1877 , when I first saw a Raven there, it had quietly departed by the back door as I approached 
the main entrance and rice versa. It was a pure chance that upon this occasion, as Admiral Farquhar and I neared the back

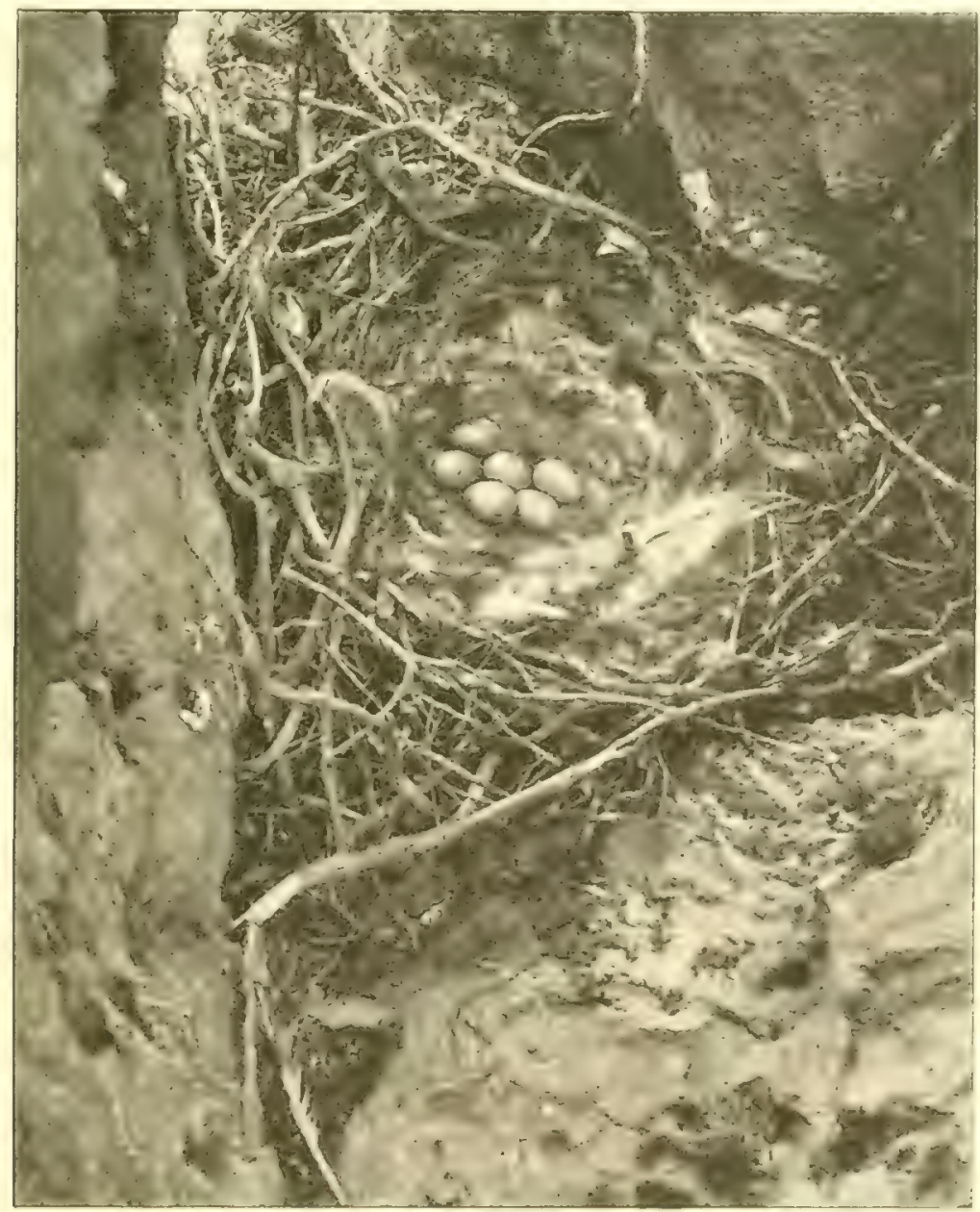

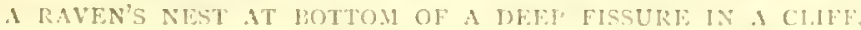

door, the rest of our party were in the ravine the other side commanding a view of the front door. But never again. She and her 
mate still nest in these rocky ravines but not in the old double fronted situation, a sletch of which appears at the beginning of this chapter.

It was not until I obtained conclusive prouf on this cunning habit of the Raven that I paid any attention to the matter. Since then I have revisited several nests known to me for many years past : and in two instances have I found a precisely similar arrangement whereby the old bird can slip off her nest unobserved, by means of a back-door. One of these is in a cragknown as La Cuead del Cuerou. which has been occupied recently by a pair of Egyptian Vultures. A picture of this nesting-place will be found in the chapter on Egyptian Vultures. I now know why it was that I never saw a Raven leave this crag when they nested there.

()wing to this habit of resorting to recesses amid the rocks it follows that most Ravens nests are somewhat awkward to photosraph. The picture given on the preceding page is of a nest most artistically placed in the depths of a fissure on the face of a small cliff about $100 \mathrm{ft}$. high and not $\mathrm{o} \mathrm{ft}$. from the summit. Entrance to the nest is gained through a narrow fissure immediately in front of it, through which the light is seen to be shining in this picture. To set at this nest I had to descend from the top of the cliff through a narrow chimney which widened out at the bottom and this photomphol was taken standing with my stockinged feet and knees presied, chimney-sweep fashion, on either side of the gully and with the camera jammed against the rocks at a point to ft. above the nest, where some slight protuberances made it possible to hold it perfectly steady for thirty-five seconds. Having taken this general view of the nest as seen from above, I went down lower and holding the camera fimly against the rocky wall shown near the left hand top corner of the first picture, only is in. above the engs, wok the second one with an exposure of forty seconds, I may mention that the hrst picture was taken with a Goerz lens 
and the second with my ordinary Kodak with magnifier attachment. It was a troublesome business and took over an hour to arrange

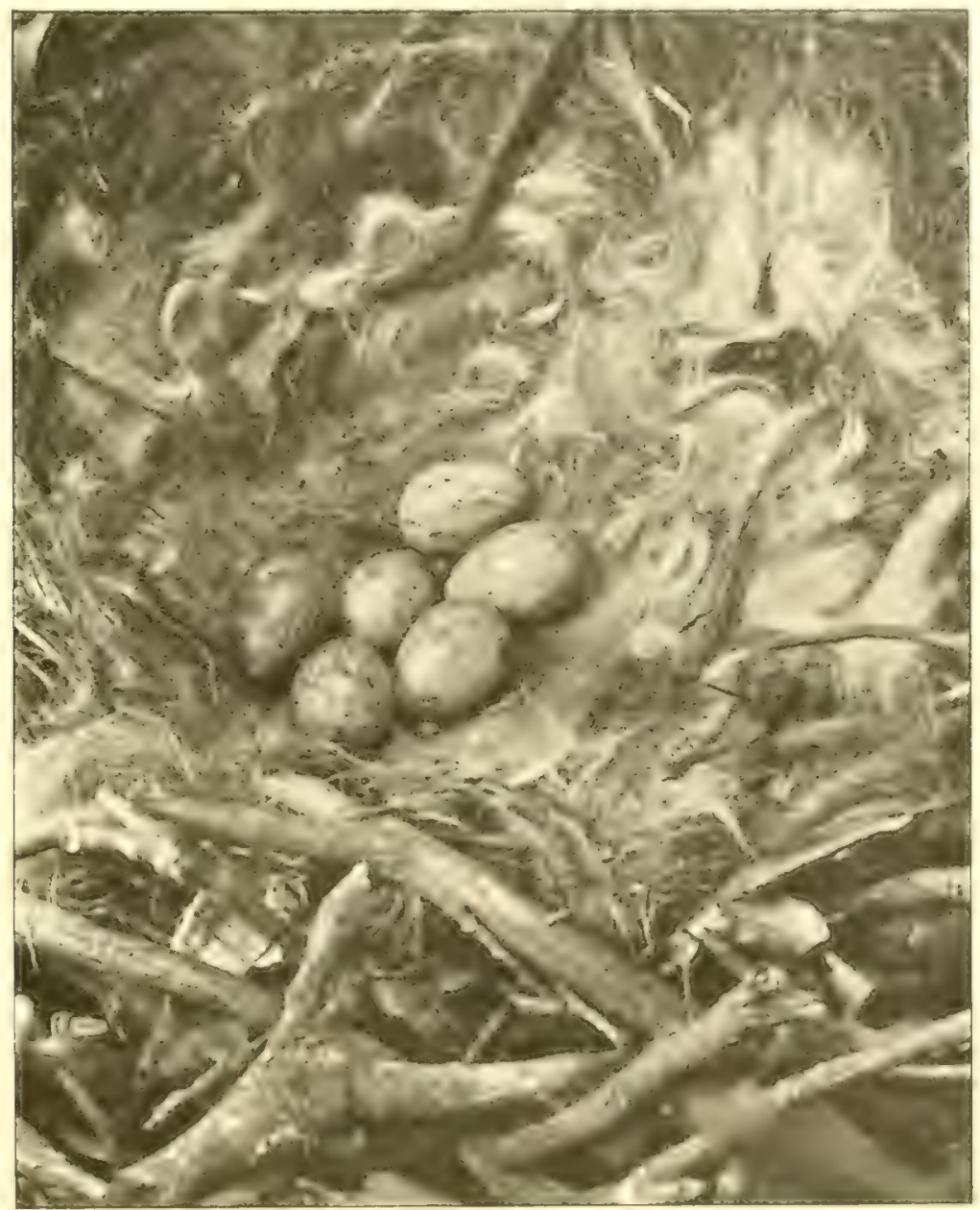

R.ATEN'S ECGS, (Size 2'O in. 1.3 in.)

and it was not accomplished without some failures. In one of these I failed to hold the camera steady owing to my constrancel 
position and in another my foot slipped and I narrowly avoided tumbling down into the nest.

I would call particular attention to the arrangement of the exgs in these pictures, which is characteristic of the Ravens' method when she has six egse trincubate and is probably the only one which enables her to cover them in a satisfactory way when sitting. I have seen similar arrangements in other nests.

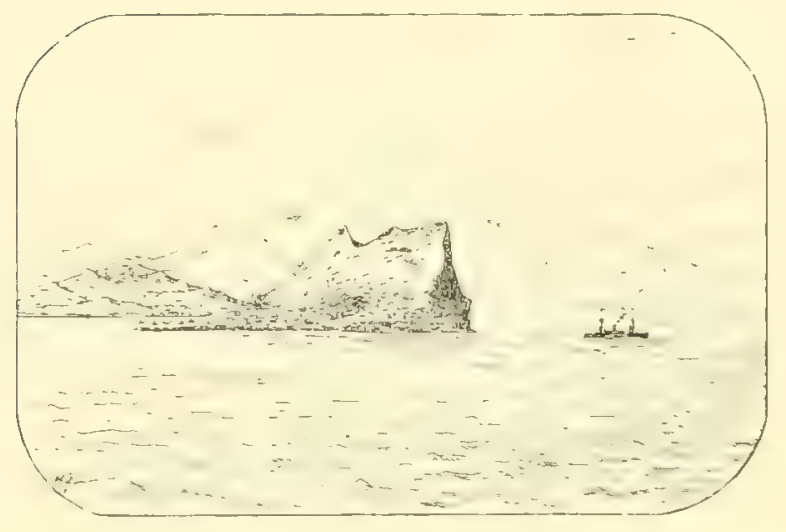





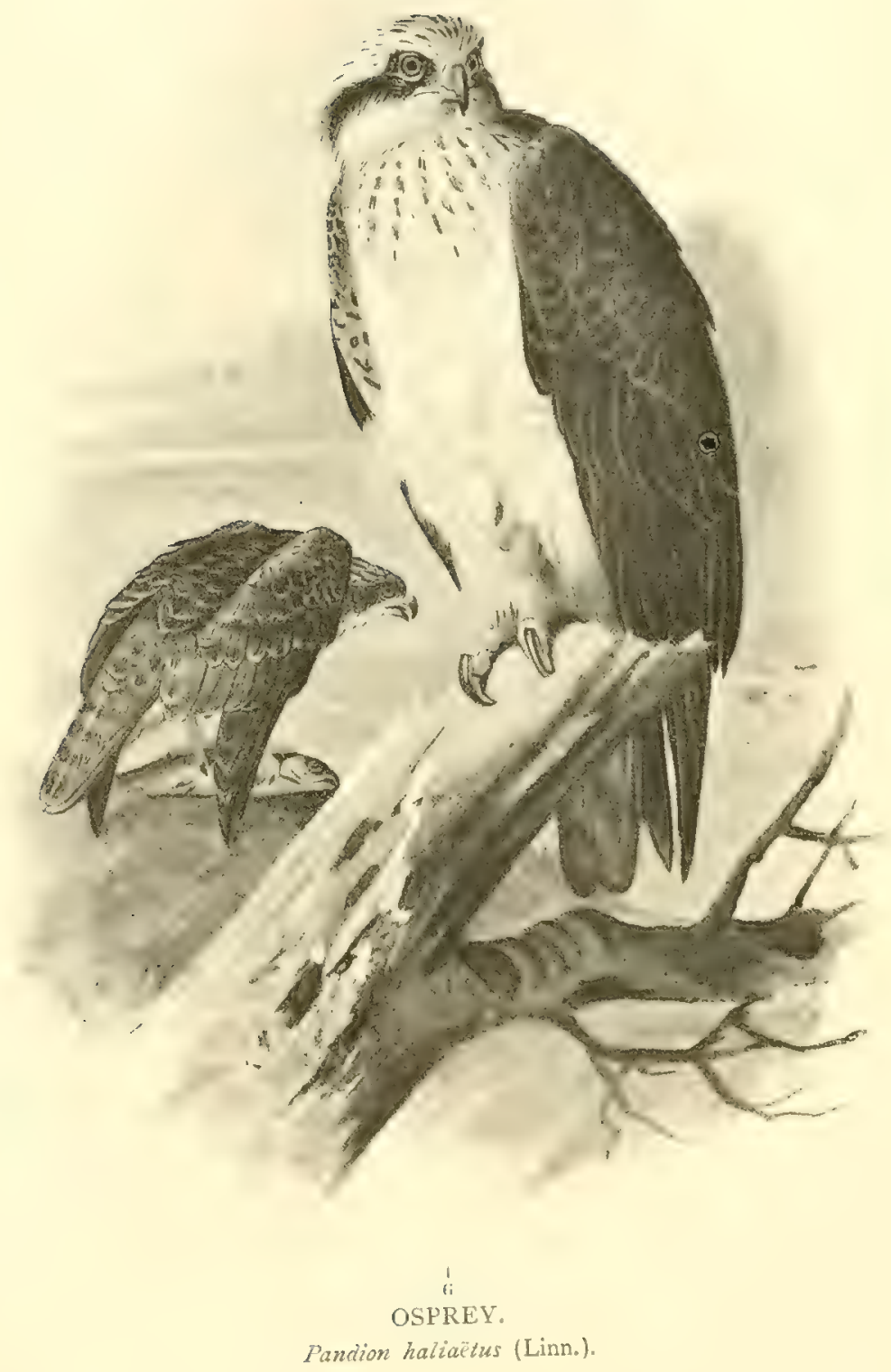


THE OSPREY (Pandion haliaëtus).

Common about Straits of Gibraltar- Nests on the Rock-Mentioned hy Mhat. of Selborne in 1776-Same site occupied in 1876-And now-The Osprey's foot-Methods of fishing-Transparency of water seen from above -An Osprey's breeding-station-A flower-strewn islet-A difficult situation - Use of a fugleman - A difference of opinion - The "Senior Service"-A terraced cliff-Prickly pears-Repeated failures-And final success-A big nest-Unpleasant results of climb.

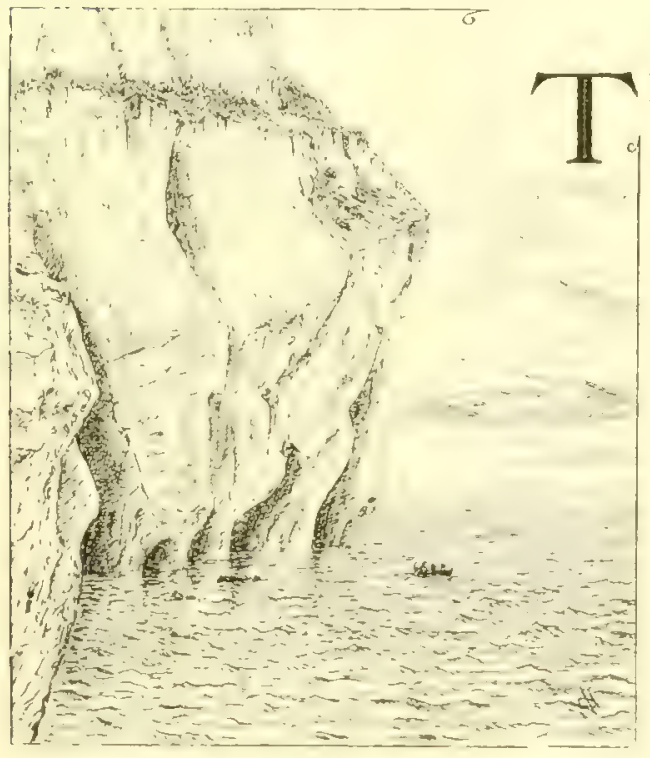

HIS is yet another of the larger birds which were at one time fairly abundant throughout the northern portions of our Island. Owing to their world-wide geographical distribution, they are to be met with in all suitable localities, and it is very certain that if only people could be induced to refrain from shooting them in the United Kingdom they would soon re-establish themselves in many of their old hamests. It is gratifing to kimm that, thanks to the greater interest taken in wild hirels of late yearen. several large landowners in the north now jealously suard the 
Ospreys which come to nest on the islands of the big fresh-water lochs.

These beautiful birds are still fairly common in the Straits of (iibraltat. A pair have nested at the back of the Rock from time immemorial and were duly noted by the Rev. John White in a letter to his famous brother of Selborne in 1756. I first saw their nest there in IS7t, and have since then watched the old birds on innumerable occasions. In some years two pairs nest there and in one year very recently I watched three pars on the wing together, but do not think more than two nested.

Of the three sites I know one is not $40 \mathrm{ft}$. above the sea, on a leclge which is overhung by a big cliff some 3 co $\mathrm{ft}$. above it, and may be reckoned as inaccessible. A second site is in the same cliff and about $250 \mathrm{ft}$. above the sea. The third is in the roof of and near the entrance of one of the huge sea-caverns and is overhung.

An excellent standing Garrison Order of the old Rock forbids the wild birds being molested, but the surest protection for the Ospreys is the difficulty of getting at their nests.

I make no scruple about mentioning these nests since they are known to many. From one of the now disused old batteries near Europa Point the birds can be easily watched with a telescope on the nest, as can the young when they are hatched out. I spent one whole summer at "The Cottage," the summer residence of the Governor of Gibraltar. Watching the Ospreys both at their nests and when fishing in front of my windows formed not the least interesting of my duties as A.D.C.

The sketch at the beginning of this chapter is a copy from one made at this time and the positions of the upper and lower nests on the overhanging cliff are indicated by the birds shown flying opposite to them.

The persistency with which the Ospreys resort to these sites 


\section{A Long Lease of a Nesting Station}

is the best proof of their seneral immunity from attack. On the homeward voyage from Egypt in the summer of I 885 consequent on our withdrawal from the Soudan. I chanced to mention the Ospreys, and, as is so frequent when ordinary well-ascertained facts of natural history are told to the uninitiated, was chaffed a good deal when I asserted that without doubt we should see the Ospreys on their nest when we passed the Rock. The affair ended in the captain of our transport good-naturedly altering his course and steaming in close under the point. Every glass was directed on the nest and much was the jubilation at its being apparently empty, until the old bird suddenly rose from off her young and standing up showed her white breast to the Camel corps of unbelievers!

From time to time some thoughtless gunner has shot one of these beautiful birds. I know of five instances in the last thirtythree years, and of course there may be others, but the bereaved bird son finds another mate and all goes on as before. No iloubt there is an inexhaustible supply of eligible young (Ospregs, miale and female, to be obtained from the epposite coast of Africa (1) that side there is usually an ()sprey's nest wherever there are an! bold headiands or sea-cliffs. I hate seen three nests on one hearlland within a few hundred yards of one another. Here they are reasonably sale for, owing to the heary swell which sets in, landing is often impossible, and in addition ()spreys, unlike so many Eander, seem to appreciate the advantages of selecting awkward cliffs ats nesting stations. Also, entirely apart from the present disturbed condition of Morocco, some of these nests are on parts of the coast

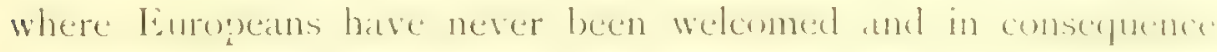
have very rarely been visited.

Many writers have described the structure of the () sprey font : how the better to secure its fishy prey the outer toe is reversible so that the foot can be either uscel, when perching, with thece wes 
in front and one behind (in the normal fashion), or, when a fish hats to be held, with two in front and two behind. Professor Newton gave an excellent figure of the structure of the foot in his Dictionary. Yarrell points out how the wide lateral movement of the outer toe enables the foot to hold an object on all four sides, and describes how an Osprey in confinement was seen to seize its food thus. I confess I have never examined the marks made by the talons of an Osprey on a captured fish, but after watching Ospreys seize their prey it seems as if it was always carried "fore and aft," or parallel to the body of the bird and not "athwart." In such a position the claws would probably hold a slippery fish most securely if they entered it from two points in its back and were "clamped by the two other claws, one on either side of the body. No doubt this matter has betn observed by other field-naturalists, but I can find no reference to it. With a fish thus held longitudinally, the marks of the claws of each foot would indicate either the four points of a St. George's or of a St. Andrew's Cross on the fish's back, according as whether they were distributed as I suggest, or "two in front and two behind."

The cry of the Osprey is of the well-known falcon or hawk type, such as Kestrels and Sparrowhawks use when scolding, only of course a good deal more powerful. When one approaches a cliff where they are nesting they will, from time to time, sail close past crying out in this manner, and very fascinating it is to watch them.

I have also often heard the cry at night, but seemingly from birds sitting in or near their nests. Ospreys habitually use the unoccupied alternative nesting sites as places to perch and feed in, and hence the cries may come from roosting birds. They remain out fishing till long after sundown, and on one occasion, when rowing homeward in the month of November from some sea-cliffs, a friend with me shot at and killed an Osprey when it was too dark to see what he was firing at. The unfortunate bird at the time was Alying into a cavern to roost. 
When an Osprey leaves its nest or perch among the cliffs, it usually flies seaward in a straight line for some distance, and then commences a series of wide sweeps and curves until it is out of sight. When fishing, it flies in circles with motionlens wings allout $200 \mathrm{ft}$. above the sea until it detects a fish below, when it momentarily checks its pace and flaps its wings and, if satished with what it sees, drops like a stone into the waters, generally disappearing altogether and throwing up a small column of foam. Next instant it emerses, rarty withent womething in its talons, and wings its way by a steady Happing thinht to the rock or point of vantage where it can make its meal in peace. Sometimes, just before it tonches the water, it suddenly checks its fill by a few vigorous flapes and then soars upward to recommence the chase. In such cases, in all probability the fish the bird had selected when circling hish above the water had either dived away or was found to be at too great a depth for a successful pounce.

Most people have heard of the remarkable transparency of smooth water when seen from a height above, which at times presents to the balloonist the optical illusion of there being no water at all in a pond. I first saw this when crossing the Frensham ponds in a War balloon. As is usual, the approach of the balloon cansed areat alarm to the fowls and elucks in the immediate neigh bourhood, the hens clucking violently and rumning off to take cover from view, whilst the ducks scattered about the surface of the water and dived vigorously. From the height we were, the diving ducks, when once they ceased to disturb the surface, hat the appearance of ducks thapping about on dry ground, for the weeds at the bottom of the shallow pond secmed to our "yes to he aymened to the air. No doubt the eye of the Osprey is traned to gauge correctly the depth below the surfice of the fish it contemplites making a meal off, hut it must be a very dedicate adjustment that permits of the necessary degree of accuracy. 
Wherever Ospreys are to be found, there is no bird which lends itself better to watching when engaged in search of its food since unlike other reptorial birels in pursuit of their quarry amid hills and woodland, it ever hunts in the open where there is nothings to obstruct a view of its actions.

I have met with it up tidal estuaries, where it pursues the same tactics as when at sed. but with the difference that in place of dropping like a stone on to its prey it sweeps down and, after the manner of a Gull fishing, lightly dips into the water and as quickly mounts again. ()f course, in such places many of the small fish are in extremely shallow waters over the mud-beds and sandbanks, where a vigorous dive might mean annihilation.

The Osprey is ustally creclited with selecting as a nesting place some situation dangerous of access, and I must admit that the statement, from my own experience, is correct, and that as a rule where the nest is not in a dangerous pusition it is only accessible by climbing, with or without the aid of ropes. Of course this does not apply to some of the nests on ruined buildings in the Scottish lochs, but to most of those one sees in sea-cliffs.

The simplest nest to reach I ever saw was one placed on a small projecting rock only $12 \mathrm{ft}$. or $15 \mathrm{ft}$. below the crest of a limestone cliff. The nest was visible from above, but below it the cliff receded, with the result that there was a clear drop between it and the sea some $230 \mathrm{ft}$. below. However unreasonable it may seem, a nest in such a place as this is ever more alarming to look at than is one placed in some really dangerous place, since nothing is here required to reach it beyond good nerves and good ropes. This nest contained three masnificently marlied fresh egess on 31 March. which is about the normal time for Ospreys to lay.

This expedition was one of the many red-letter days of my ornithological life. The Ospreys' stronghold was on a big detached rock some hundreds of yards from the mainland. All around it 


\section{An Osprey's Stronghold}

and between us and the shore the water was many fathoms deep

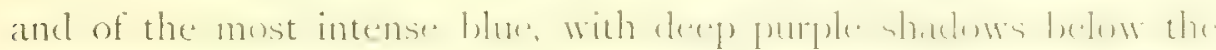
great cliffs opposite.

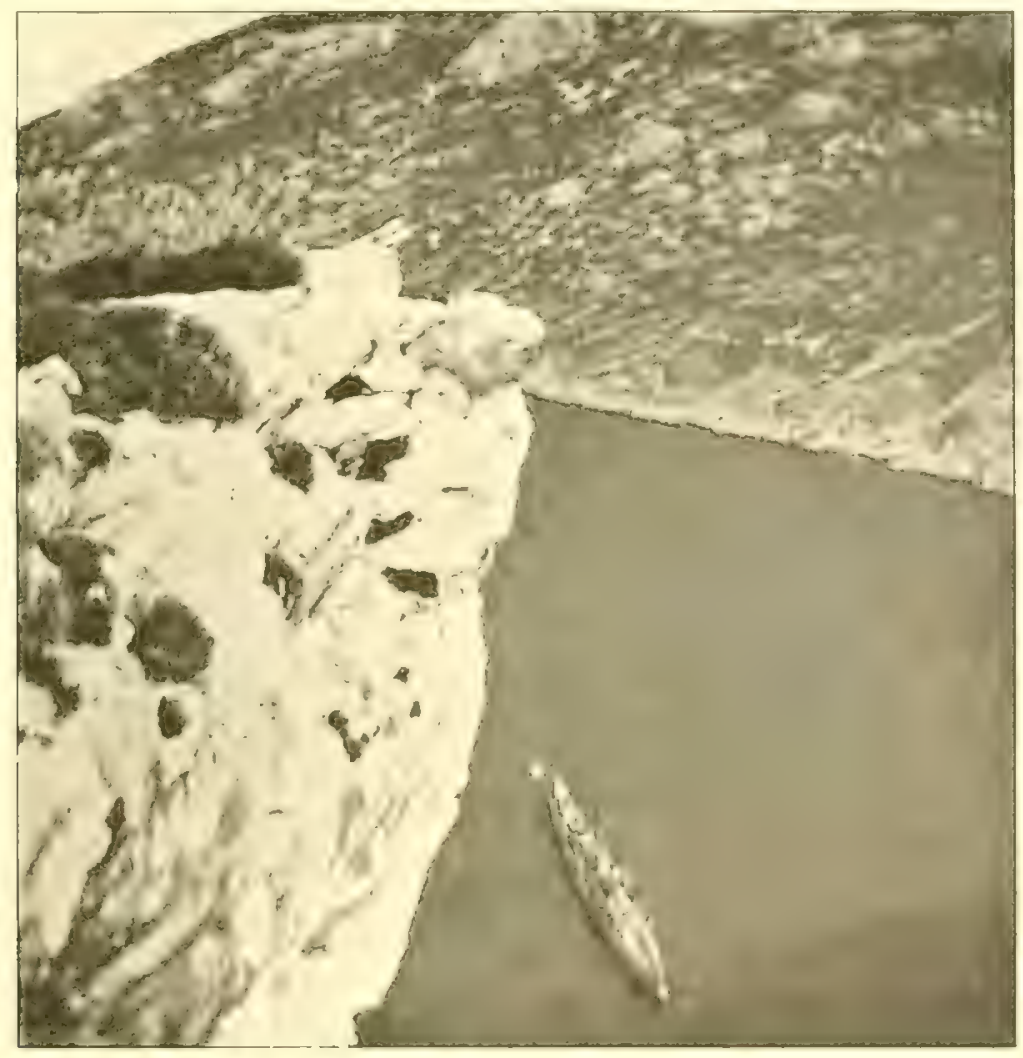

IN OSPREY'S STRONGHOLD.

To reach the summit we had to effect a landing from a dinghy on some slippery rocks in a deep cavern into which the swell was gently surging. This cavern was full of nests of the Green Cor morant, mostly at the time of our visit containing hatrel-set eggs or black sprawling maked chicks. It is needlens to insint on the amomet of the place. A scramble round some rocks and up a steep gully 
brownt us to the brilliant sunlight on the top of the crag. Although the serrated ridges of limestone scarcely permitted of our seeing the sround between them, throush the interstices of the rock grew an amazing wealth of flowers. Masses of wild parsley, red and white fumitory, marisold, catchlly, squill and fennel were to be seen on cvery side, whilst tall sprays of asphodel and big acanthus reared their heads above all. It was difficult to leep one's footing in places owing to the densely growing lentiscus bushes, shorn by the wind and fitting closely into the carities of the rocks, concealing deep gullies and fissures.

I will now describe a more difficult situation, that of a nest placed on a projection about $100 \mathrm{ft}$. down a cliff $350 \mathrm{ft}$. high. Here amain from the nest to the sea below was a clear drop. But the difficulty was that the cliff had no really defined edge, its top being a steeply sloping terrace of loose stones amid which happily there were a few palmetto bushes. These afforded secure foothold to the lowering party (in this case three grood men). Owing to the rounding-off of the edge of the cliff some $30 \mathrm{ft}$. below the point where the lowering party were ensconced, it was impossible to see how to proceed until one was orer the edge. In consequence, as a reasonable measure of security I was let down in a bowline to the very brink, whence I could act as fugleman and receive the signals of my friend when he was lowered rlown the cliff and pass my orders to the party above.

At the last moment one of those absurd incidents occurred which impress themselves for ever on one's memory. For many years previously, although I had constantly obtained the assistance of both naval and military officers, it had always and legitimately fallen to me to make the actual descent. This time I was debarred from descending myself, since, leing the originator of the whole conspiracy against the luckless Ospreys and many years older than any of my party, I felt that the responsibility of the whole affar 
lay with me. Hence my assumption of the most unpleatsant, and w me painful, duties of fugleman, for in cliff-worts it is always far worse to watch another man climb than to do it oneself. On this

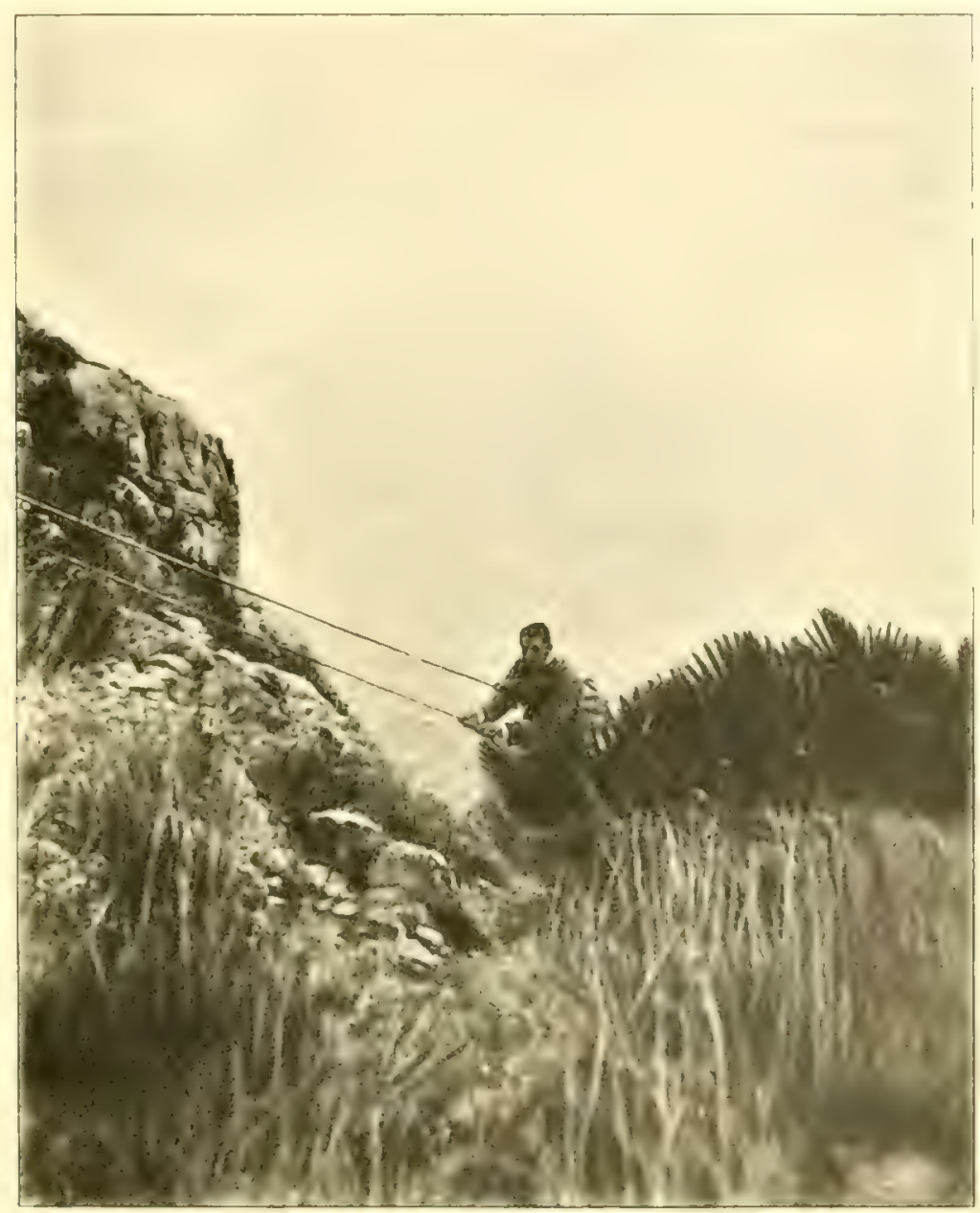

DESCENT TO AN OSPREY'S NESI:

occasion three of my party were naval men, two of them regular athletes, absolutely callous to any sentimental motions almut heights and the so-called dangers of cliffs. 
Having visited the same nest ten days earlier, when we found it empty, I had reckoned upon the same man who then descended, and who knew the difficulties of the job, repeating the operation. But I was mistaken. Noticing that there was a hitch in the proceedings, I called ont. The reply was that there was a difference of opinion as to who should $g$ over, each of my athletes insisting on his right to do so, the one because he had been before, the second because he had not been! It was no time to palter, and so, with the decision begot of military training, I orclered the senior officer to proceed, which he promptly did.

Those only who have been in really dangerous situations in big cliffs can appreciate the difference between having men as assistants who endeavour to dissuade one from an adventurous descent, as has frecpuently been my experience, or, as in this case, having men who actually guarrel as to which is to be the privileged individual to wo over! Irith such assistants as I had on this grorious day I would long since have had no more worlds to conquer, in a birdsnesting sense. This nest contained two fresh eggs on 10 May, and these in my opinion were a second laying, due to the first having been molested or destroyed in some way.

Another's Osprey's nest, of which I was fortunately able to get some photographs, was also on a sea-cliff, but in an altogether different position. In this case the Ospreys had as their defence not only a formidal,le cliff consisting of several terraces (always the most perplexing to tackle), but the summit of the cliff as well as the terraces was densely overgrown with prickly pear, making access most difficult. Adeded to this, below hay a steeply sloping talus of fine débris, fallen from the cliff above, which it was necessary for us to traverse from the point where we landed, hefore escalading the cliff at a weak spot. How dangerous was this talus in places was proved by Admiral Farquhar on another occasion; for one of his party, attempting to cross it gun in hand, found it impossible 
to proceed without the aid of both hands and after annultention with the others had to abandon his grm, which was deshed to piecess on the rocks far below. This talus in our instance proved ton much

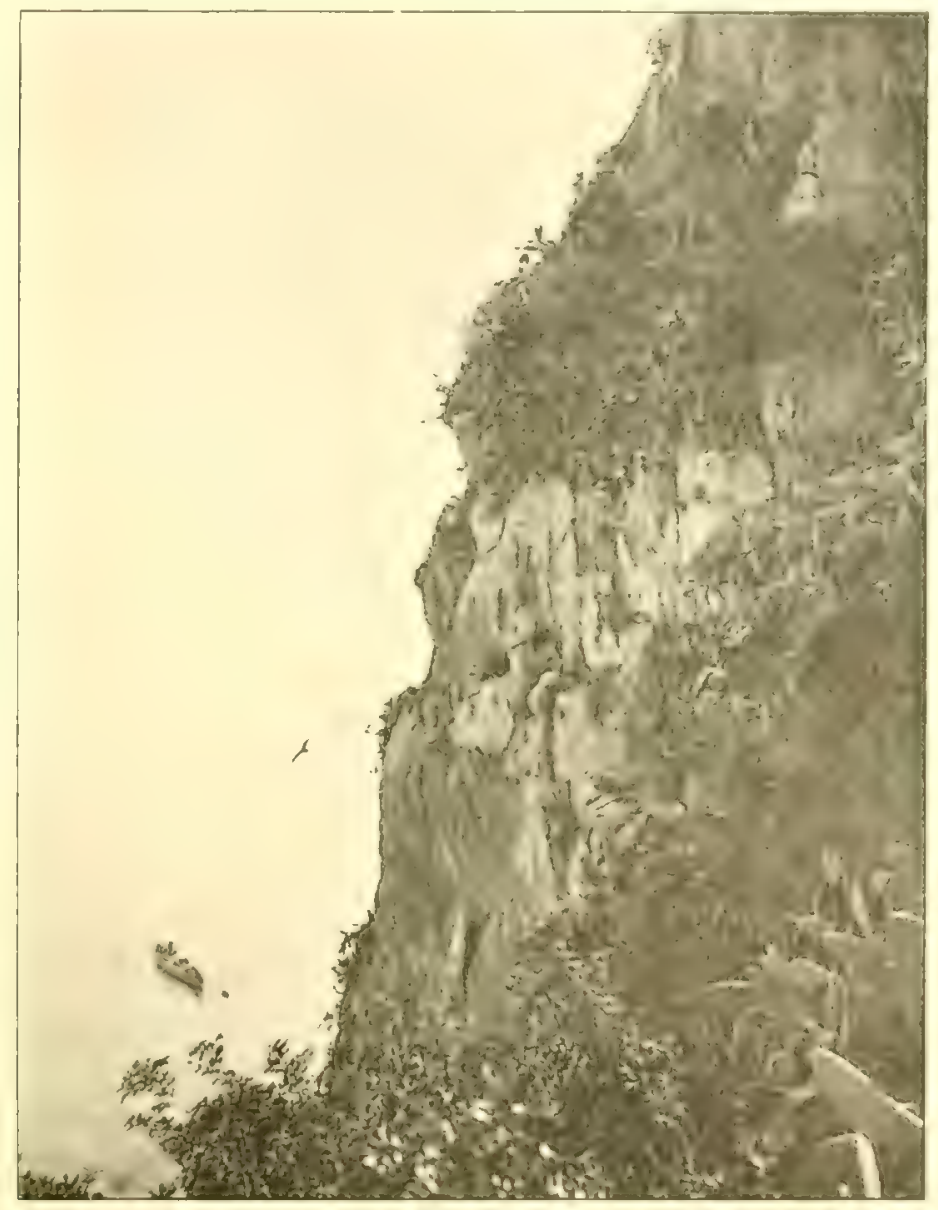

THE OSIREY'S CLIFE.

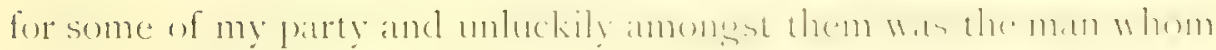
I had relied upon to signal to me the precise position of the nest when we had gained the summit. 
In this picture of the profile of the Osprey's cliff, taken from a point on the talus about $150 \mathrm{ft}$. above the sea, the Osprey is seen leaving her nest which is the dark mass on the summit of the prickly pears on the same level as the bird.

A careful reconnaissance with a telescope from the deck of our vessel had made it clear to me that my difficulties would only begin with our arrival above the nest. Once clear of the dangerous talus we got amongst dense lentiscus and brambles, also prickly pear, aloes and all the usual obstacles presented by a semi-tropical jungle. Finally we emerged, blown and exhausted, on the grassy summit, and lay down to get our wind. Next, we had to fight our way through the dense scrub to the print which we imagined to be above the nest and then work our way down the steeply sloping cliff until brought up short by a sheer drop of some feet.

Now commenced my work and I descended on my rope to terrace after terrace, forcing my way through thick rows of prickly pear-at most painful operation. And now we found that there was nobody below to signal to us where the nest lay. The inevitable result was that after descending over roo ft. I had to signal to be hauled up again, alway's through the prickly pear. Again did I descend and again did I fail to find the nest. On the third occasion I reached a recess in the great cliff whence, after unbencling my rope (and securing it to a bush for obvious reasons) I made a cast along a ledge to the south and reached a point which I identified as being not far from the nest as seen from below. So I retraced my steps, and regaining my rope was hauled up for a third time. During this operation I passed a ledge where a Peregrine Falcon was nesting. The old female swept close around with shrill cries and eventually alighted on the sandy shelf of rock within a few feet of me and with outspread wings and every feather standing on end, lowered her head and screamed 
furiously. I have no doubt that I was close to her young, but I had more serious work in hand and so I left her alone.

I now made my fourth and last descent and found myself immediately over the nest, but before I could go down to it the party handling the rope had to work their way down towards

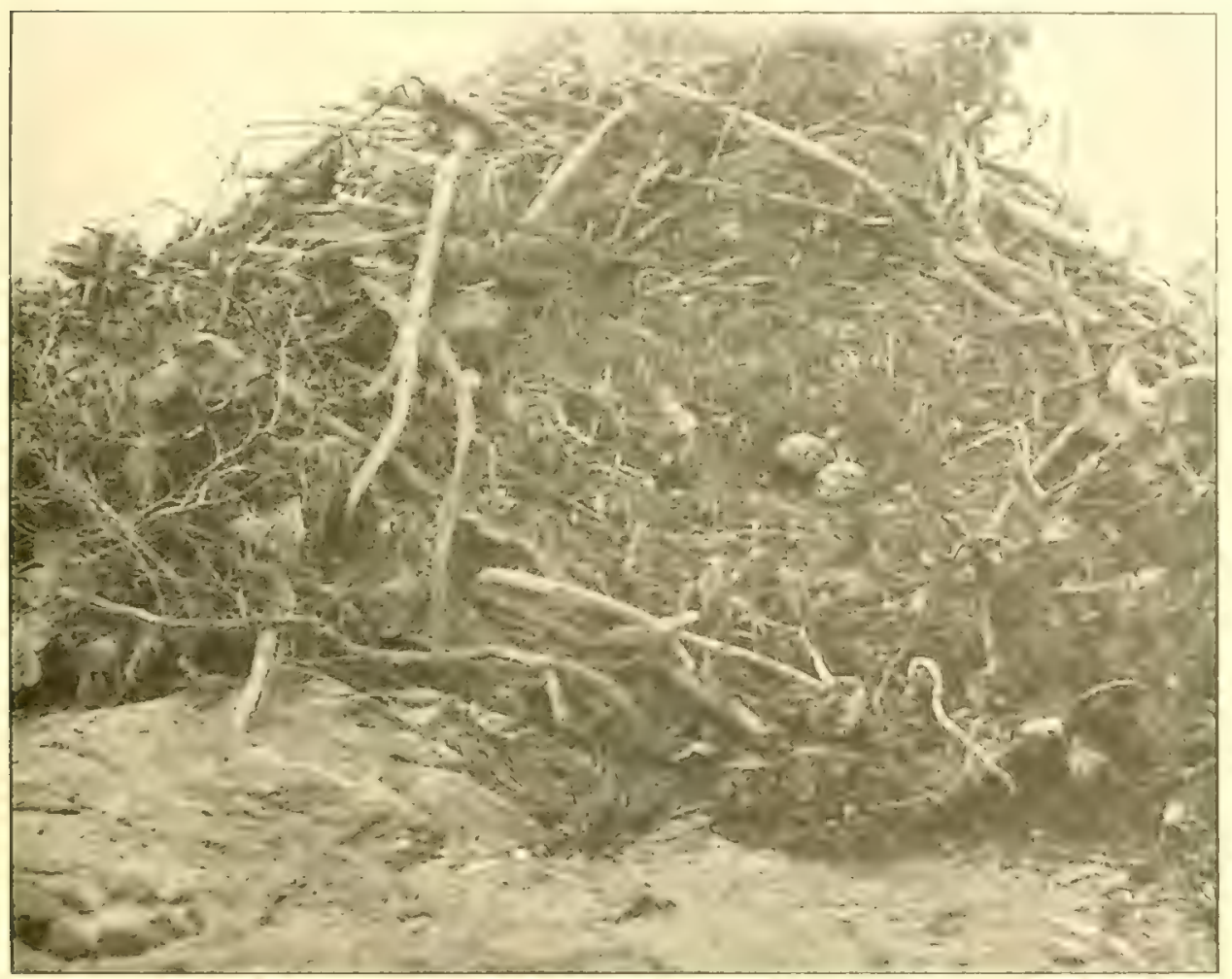

IN OSTREY'S NISST.

me since the rope was too short. Iinally I reached the nest, an enormous mass of big sticks measuring over $5 \mathrm{ft}$. across, and doubtless the result of many years' work. In it were two esgess much incubated. By standing on a ledge close to the nest and pressing the camera between my body and the face of the cliff 1 
was able to take some long time-exposures with fairly good results. It was near sunset and the cliff was in deep shadow, which did mot facilitate my task. Between the shaly nature of the cliff, the slippery terraces covered with loose soil and stones and the detestable prickly pears, I never had a more unpleasant or arduous task on a cliff before. But I have lived to endure worse experiences, although not so painfully protracted as were these.

My very curt entry in my diary summarizes the whole job thus: "Bad shale cliffs, vertical and dangerous, height of nest above sea $160 \mathrm{ft}$. Top of cliff $310 \mathrm{ft}$., the worst managed bit of rope-work I ever did."

With regard to the prickly pears, it was many months before the last of the poisonous spines I had collected in various pats of my boly consented to come out, and then only after first festering.

Such are my experiences of Osprey photography! Still I am quite prepared to hear some lorother worker assert that he usually visits Osprey's nests in places where one can trundle a wheelbarrow!

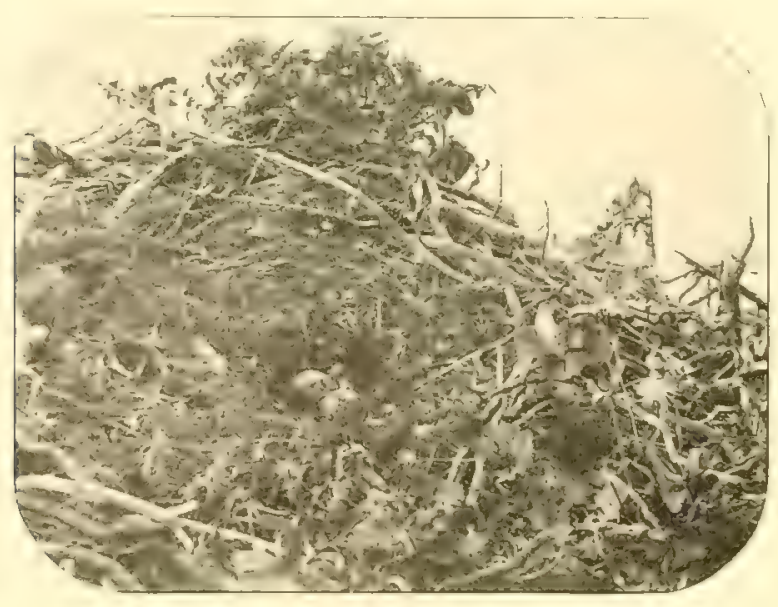




\section{V.-AMID THE SIERRAS.}

\section{CHAP'IER I.}

\section{A DAY IN THE LOWER SIERRA.}

A distant view in $188_{4}-\mathrm{A}$ registered vow-Repeated attempts to carry it out -A spring day's ride-Grass lands and cultivation-A watercourse and its occupants-An extensive view-The cistus scrub-Rock sepulchresTheir unknown origin-Reach the cliff-A Vulture's colony-A careful reconnaissance-Formation of cliff-A practical lesson in geology-Explore a cavern-A subterranean route-Among the Vultures' nests-Photographing young birds-Behaviour of their parents-Magnificent scenery-An ideal residence.

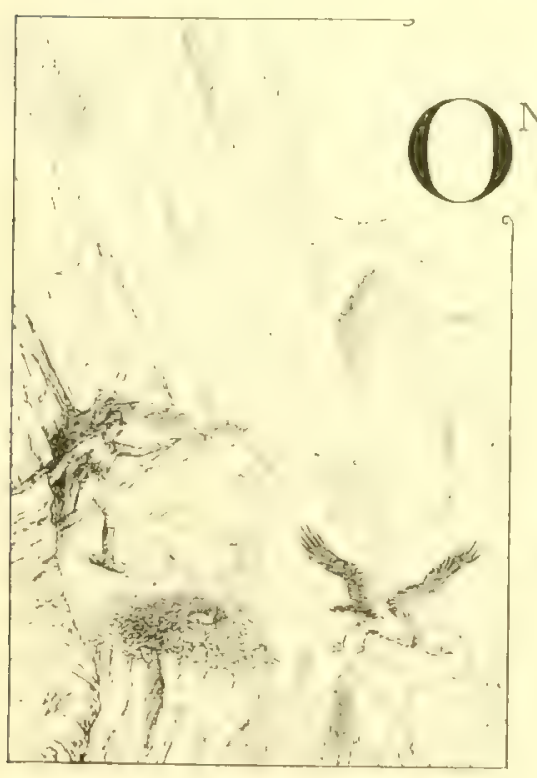

NE autumn day, so far back as the year 1884 , whilst crossing the Bay of Trafalgar on my way to Egypt and the Soudan, I was examining the mountainous country north of Tarifa with a telescope. I had already a tolerably good acquaintance with the topography of this district having made various expeditions into it, both for shooting and in quest of birds' nests during the preceding ten years. On this occasion however I detected a cliff of whose existence 1 had hitherto been ignorant, amid the broken and rocky slopes of 
one of the sierras which lie behind the sandy shores of Trafalyar Bay.

Referring to my diary of 25 September, is 4 I find the following entry anent this cliff. "This must be worked up some day." At the moment circumstances did not lend themselves to such a scheme. I was on board of a lo-knot "tramp" steamer chartered to convey some forty of the famous Nile whalers to Alexandria, by the aid of which sanguine spirits still believed it might be possible to lend a helping hand to General Gordon, at the time so sorely beset in Khartoum.

In ${ } 88_{4}$ the Soudan, with all its difficulties and perils was practically tera incognita, not only to us soldiers who were about to le launched into its wastes, but to the vast proportion of the civilized world to whom it was indeed but little more than a name. Nobody at that time had the slightest idea what lay before us, and as usual the only fear on the part of the soldiers was that there might be no fighting, a pious apprehension which subsequent events in the Bayuda I esert proved to have been entirely groundless.

Nearly a year later, when on the homeward voyage after our unsuccessful attempt to reach Khartoum, I once again saw the same cliff shining in the afternom sun, and once again registercal a vow to try to visit it some day, since my fancy peopled it with Vultures, and possibly Eagles whose eggs might help to enrich my collection.

But although frequently in Spain during the next twelve years, fate seemed to be against my ever attaining my object. On several occasions I made efforts to cross the sierra and reach the point, but was from some cause or another as often baffled. At one time, rains made both sicrra and the miles of soft clayey foothills below it practically impassable. At another, although successful in reaching the neighbourhood, I found that the hours of daylight 
remaining woukl not permit of my crossing several rused spurs and deep ravines which lay between me and the point where I reckoned the cliff must be.

It was not until May igor that I found myself once again within a day's ride of the part of the sierra wherein lay the cliff I had seen in 1884. April had been a month of extraordinary rains and lloods but for the last two weeks we had enjoyed splendid weather and the tracks and monntain passes were in exerdlent travelling condition.

It was on one of those glorious spring days, which to my prejudiced mind are nowhere so glorious as under an Andalucian sky, that we rode forth on our expedition in quest of the cliff accompanied by a couple of Spaniards, both old friends and companions in many similar undertakings.

In the middle of May, the time of our visit, the whole country was carpeted with flowers, pink mallow and brilliant blue con volvulus predominating. Birds of course alounded, the most conspicuous being Calandra Liths, a fine species, almout double the size of our own Skylark. Its song is more powerful in some parts than that of our bird and it sings, like ours, when on the wing, but not at such heights or with the sane persintence. Corn Buntings sat stupielly on thistles or sprays of defonct appluelel griving vent to their tedious call with atratrating momotony and allowing our horses to pass within a yard or two without showing alarm or surprise.

Soon we reached the arable land alutting on the level plain which at this seatson is covered with crops of barley and bearted wheat now nearly full grown, although still green. Our route usually ran along the edge of some tonturous waterenurse, at times striking across the undulating hills along a headland betwern the crops until it once atgain joind it watereourse. 'Ihe mumerous tracts of fallow land were corered with mustard, whose pulden flowers were in places more than $6 \mathrm{ft}$. above the ground. 
These watercourses in the month of May form a haven of refuge to a multitude of living things. True it is that the streams at their bottoms are usually trivial, but at frequent intervals the winter floods have hollowed out deep pits with precipitous sides which now form a succession of pools and afford an asylum for much animal life. With abundant water below and the sun of southern Spain above it may easily be imagrined that along these watercourses Nature simply runs riot. The banks are densely overgrown with rank grasses and herbage rendered gorgeous by the variety of tints of the crimson sanfoin and deep purple-blue cerinthe. Frogs of all sizes both green and brown keep up a noisy chorus which suddenly ceases as they detect the approach of a traveller and successively take headers into the pool below. Along the steep sunny side of the gully water-tortoises are to be seen chustered on the hard baked mud from which they scuttle or simply let go and fall into the water with a series of flops. At places the path is almost blocked by huge umbelliferous plants with white flowers over 9 in. across, and by a profusion of big yellow and purple thistles.

Between the flowers, plants, reptile and last, but not least, teeming insect life, a ride alon's one of these watercourses is to me ever a source of interest and yet it is merely a passing phase of similar, allecit differing experiences under the ever-varying conditions of travel in Andalucia.

As we gradually left the low country and ascended the rolling green hills which everywhere skirt the monte or scrub rewion, our view of the surrounding country rapidly extended. Behind us, the vast plain of the Laguna de la Janda stretched northward towards the far distant purple hills, amid which the old Moorish towns of Alcala de las Gazules and Nedina Sidonia sparkled white in the strong sunlight. Soon the Bay of Trafalgar with its fringe of yellow sandhills and steep sandstone cliffs came in sight. Far away 
to the north-west we could dimly see the white houses of the Isla glittering through the haze.

Turning southward we commenced the ascent of the lomer sums of the sierra proper, the track gradually grew more rocky and difficult and eventually it became necessary to dismount and leat our horses. The scrub grew denser and at places it was no easy matter to force our way through it along the narrow track. We were now in the rewion of the palmette, lentiscus and cistus; and what cistus! The slopes borderiner on the sandhills near Trafuluar Bay are covered with dense cistus scrub often $6 \mathrm{ft}$. high, bearing magnificent white blossoms, some of which measure fully 4 in. across. This was in full bloom at the time of our visit and hundreds of acres of hillside were coverest wath its heautiful dark sreen foliage, dotted everywere with these ghrous white flowers. Iligher up the mountains, a peculiarly heaturiful clwarf cistus with a rose madder ring encircling its centre was tolerably abundant as also were others with white, yellow and crimson blossoms.

Sixteen years is a considerable time to carry precise topoaraphical details in one's head, and it was therefore no rery areat surperise to me upen our gaming the crest-line of the rilue we were ascending to find that there was no ditf to be seen of the dimennitur I had noted in I884. Sure enough there was a crag or rather a series of crags to our front, but none of these was the onc we were in quest of. To these rocks we however proceeded ats it was probable that from thence a good view minht be ohatumel. Leaving our horses and men amid the cistus scrub below we scrambled up the rocks and were rewated hy seeing on the shy

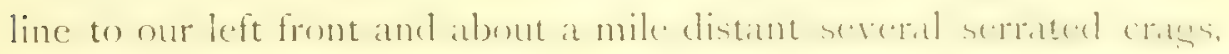

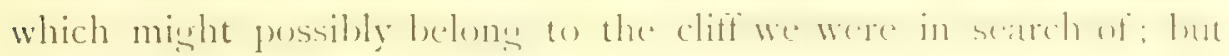
I began to have uncomfortable doubts of its existence.

It was whilst climbling these rocks that we came across at stries 
of those mysterious sepulchres which are so often met with in similar situations in Andalucia. These are invariably hewn out of

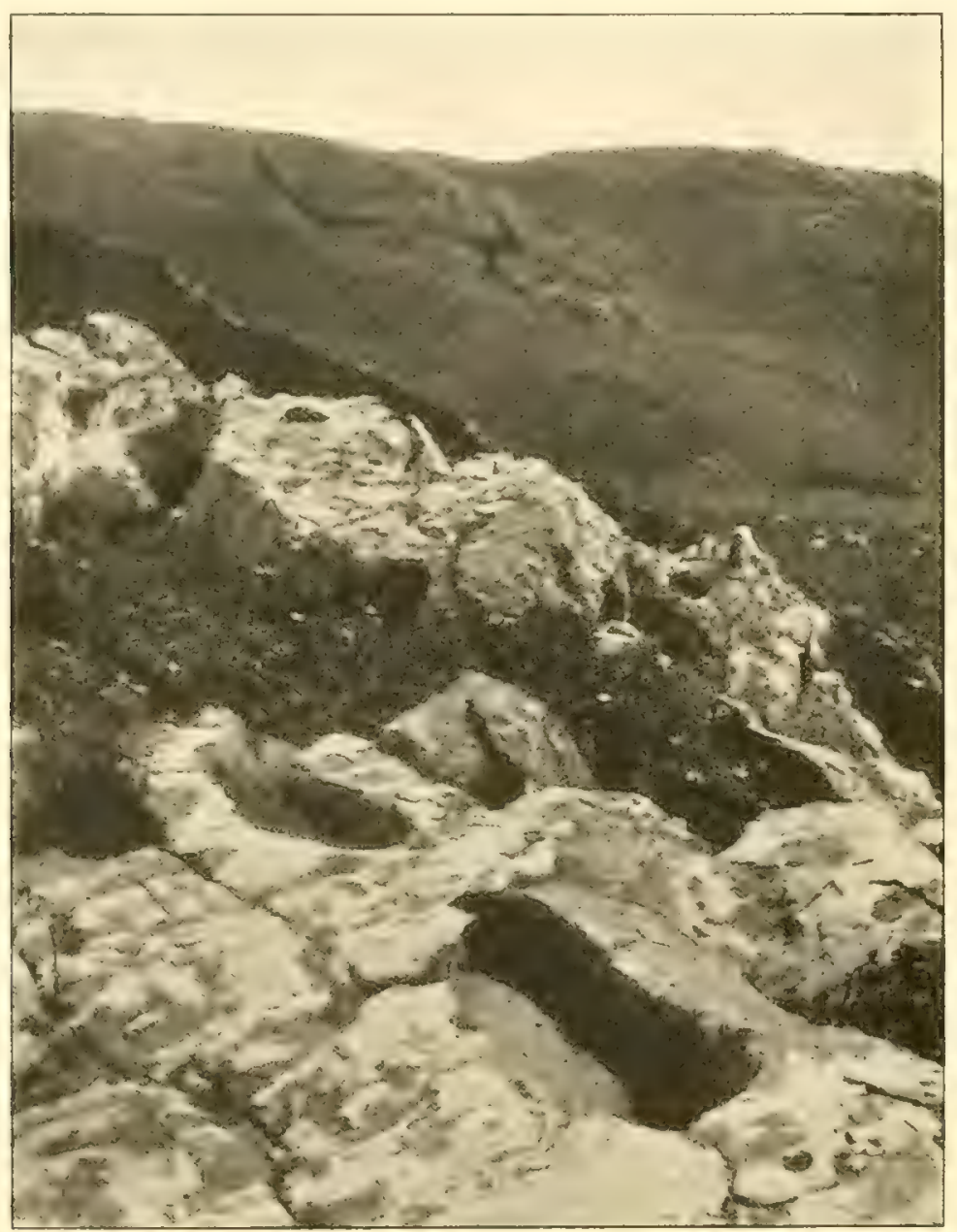

ROCK SEPULCHRES AND CISTUS.

the flat surface of the rock and measure the traditional $6 \mathrm{ft}$. by $2 \mathrm{ft}$. with a depth of about $18 \mathrm{in}$. These are the measurements of the largest, but smaller graves are also constantly seen, of all sizes down 
to that of a rery small child showing that these tomblas we we wed for

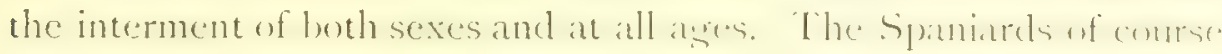
attribute them to the Moors, a convenient form they invariably apply to corything abust which they know wothing. The tomb

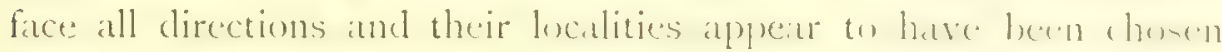
solely to obtain a good horizontal surface of rock, free from joint or blemish to work upon. I'ossibly these rock serulehers are of Phonician origin but this is a matter which requires further research.

To revert to the search for our cliff, although less than a mile from the serrated crass on the watershed beyond us, we were separated from them by a deep rocky valley with steep sides wrergrown with impenetrable scrub. It hecame: necessary therefore to seek a vereda or track down towards the coast several hundred feet below us, so as to cross the valley where it widened out and became more practicalle. This we effected and remountims wa horses commenced the toilsome ascent of the hill beyomet as we gratually mounted the slope, the feeling sere in me that I hat at last found the way to the cliff I sought, nor was I disappointed, for on reaching a plateau and rounding the cxtremity of a rocky bluff we suddenly came in view of a fine cliff some $300 \mathrm{ft}$. in height and fronting south-west.

Near its foot was a charming white cottage built on three sides of a patio or courtyard which I instantly recognized as a landmark I had noted down in I $8 S_{4}$ when on my way to Egypt. The desolate nature of these rocky hills and the ir inacessilitity may be ganged by the fact that it is easy for a comsiderable diff, such as is this, to be thus comfortahly hirklen awaly ont of sight of most of the surrounding country.

As may be imagined, the view of a cliff from the deck of a steamer some seven miles or more out at sea, gives one but a small conception of its size and more ceprecially of its acessilsility and I 
was gratified to note that the lons-sought-for cliff was obriously well suited as a nesting station for Vultures and was further not of

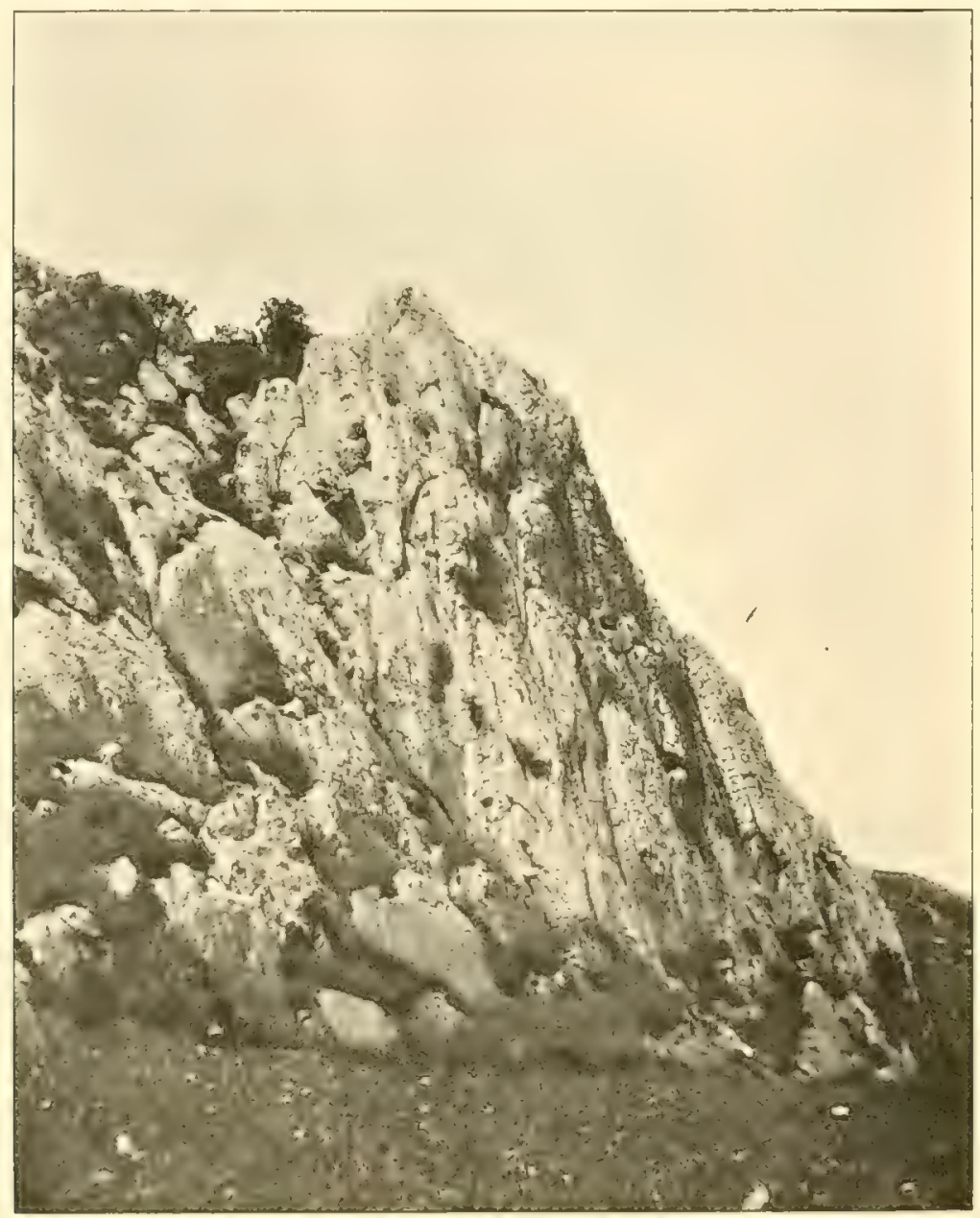

A VULTURE'S CLIFF.

so forbidiling a nature as to render escalade or descent a matter of impossibility for me, in my crippled condition of that time.

In cliff climbing, as in very many other occupations, nothing 
is more hurtful to ultimate success than undue hurry. So we went first to a crag some hundred yarels or more from the face of the cliff, whence with fickl-glasses and subsecpuently with a telescope. we carefully examined the face of it, so as to grasp its salient features as well as its weakest points.

It required but a very cursory glance to note that a considerable. colony of Griffon V'ultures were in possession of the carerns and fissures on the face of the cliff, several of the great birds were soaring around in front of it ats can be secn in the accompanying picture. A pair of Esyptian Vultures, with snowy white plumage and black-tiped wings, sated round the lower crays where they were nesting, whilst the warning croak of Ravens showed that they also had an establishment somewhere in the neishbourhool. No Eagles were however to be seen and at this I was not surprised, as Eagles particularly dislike any cliff affected by their bige relations, the Griffon Vultures. Possibly they are not proul of the relationship and so avoid them!

The cliff was of a formation very commonly seen in south-west Andalucia and consisted of enormous slabs (originally beds) of sandstone tilted up at a considerable angle, about seventy deurees in this case. Ages of denulation hat worn awe the orerlying soril and leosened the strata from the front and these now formed a steep slope or talus below, densely orergrown with scrub, amicl which huse rocks lay scattered. The back of the cliff wats likewise denuder for some 30 to 50 ft., the great slabs of solid rock slinting backwarels over it and forming in places a sort of pent-rouf. The rocky strouncl here was helel up by the natural revetment formed ly the matss of the cliff in front of it and extended for some 20 yarels or more (1) the foot of a second cliff, paralled with and of like formation we the first, only on a reduced scale. It is these seriess of parralled masses of rock, upturned ly some great cirth morement that sives the 
Spanish name of sicrra "a saw" to the rugged summits of the mountains in Spain.

In my earlier days of cliff climbing I used generally to get to work without delay, often by the admittedly risky and uncertain process of a frontal attack. But wicler experience has shown me the wistom of always seeking to find a way round. One lesson in practical seology begot of repeated experience is that in the case of any upturned strata, such as I have endearoured to describe, there arc almost invariably places where, either owing to want of homogeneity in the rock or other causes, such as resistless pressure, a general state of disruption has been brought about. In such localities great joints and fissures are to be seen and also places where the softer and less enduring portions of the rock have weathered out, leaving deep chasms and caverns not infrequently choled with masses of broken strata and fragments of rock from above. After a rather severe strugsle round one of the rocky flanlis of the main cliff where our course lay, now along a shelf of some slippery crag and again through the scrub which grew in such abundance upon the successive terraces, we at length reached the rear face of the main summit. Here we were confronted by huge masses of overhanging rock. By scrambling through a narrow gully between two great crags we gained a sort of natural lnok-out fashioned in the solid rock, probably the result of a slip or slide, the shelf we were on being the top of the moved bed. From this point a good view was obtanable both towards the flanks and below, and we saw that some hundred feet from the summit there was a series of broken ledges and semi-detached crays parallel to the strata of the general face of the precipice and forming the central portion of the Vultures' stronghold. Any further movement from this commanding point was however impracticable, save with the aid of a rope, the cliff below being sheer and unbroken, so we returned through the gulley to the rear 
of the crags and renewed our search for some way round. Presently amid the chaos of fallen rocks in the rear, I came on a small cavern and at once proceeded to explore its depths.

Before going very far, it became evident that it was but a portion of a great fissure or joint extending far down into the

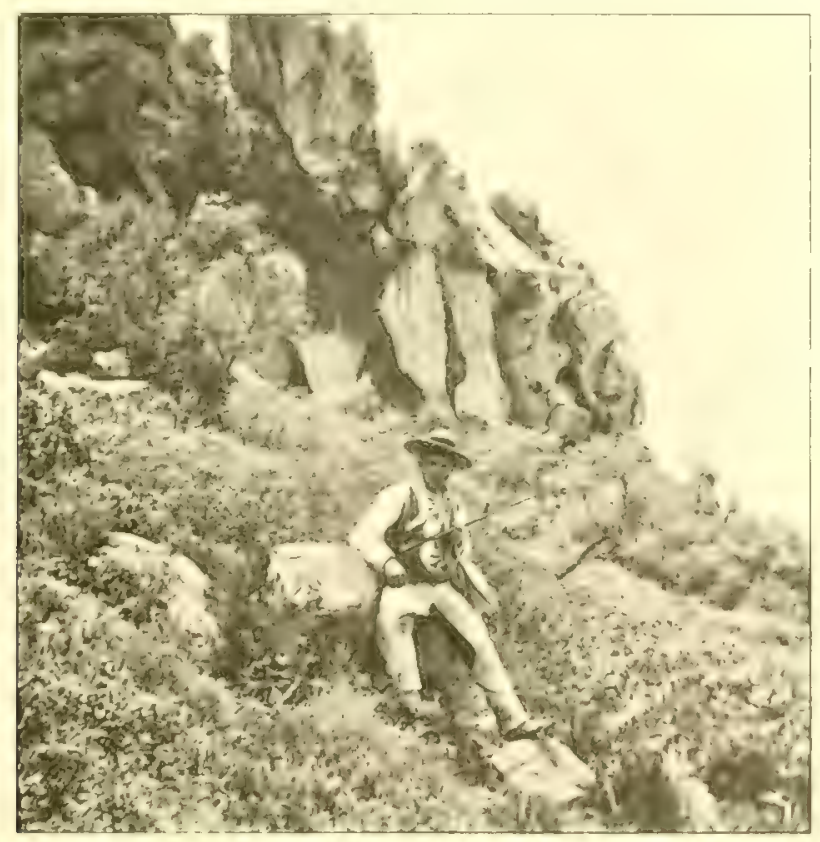

THE RHVERE SLOPE OF THE SUMMIT OF THE CI,IFF,

(The entrance to the suberranian fassage is immerintely atwete the man's hat.)

heart of the cliff choked with huse tranments of rockis perehed one above another. After creeping and crawling under several

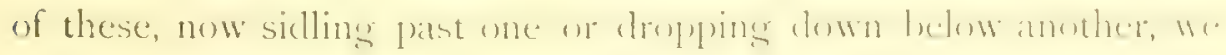
reached a point whence, in the dim light of the cavern we could see there was a fall of $15 \mathrm{ft}$. or so. Down this abyss, owing to the inequalities of the surface of the rock and the namownes al 
the passage, it was simple enough to descend chimney-swcep fashion and as I neared the bottom, I became aware of a gleam of light coming somewhere from the direction where I linew the face of the cliff must be.

This was most reassuring and next moment I found myself at the innermost end of a narrow but lofty cavern, the floor of which sloped steeply away to my front. Proceeding cautiously along this, on rounding a rock I saw in front of me the great untidy nest of a Griffon Vulture literally lying on the sloping floor and about a couple of feet from the mouth of the cavern, which opened out on the face of the main cliff. In it was a baby Vulture, about the size of a duck and covered with white down. The moment it caught sight of me, it, as usual, shammed death, laying its hideous ungainly head sideways flat on the bottom of the nest and remaining perfectly motionless in that uncomfortable attitude.

I was busy getting my camera into position when a great rush of wings tolkl me that one of the old bircls was returning. Next moment a Griffon with legs extended alighted with a mighty commation, on the shelving rock within a few feet of me and just beside the nest. Hardly had it folded its great wings and recovered its balance when it spical me and, turning, dashed off with a great rustle and rush.

Having photographed the young bird, I moved up to the nest and stood on the rock recently tenanted by the parent. I found I had emerged on the face of the cliff, some $2 \mathrm{co} \mathrm{ft}$. from its base and perhaps $100 \mathrm{ft}$. below the summit and was in the miclst of the colony of Vultures. On an open ledge across a chasm and only some $15 \mathrm{ft}$. from me was another baby T'ulture in its nest. Vith a view to secing what else was near me, I now gave a shout and immediately some half-dozen of these creat birds quitted the caverns and fissures in the cliff adjacent to my position. Now ensued a most interesting time for a lover of wild lirds in their 
haunts. The surface of the rock, though at places nearly vertical, was deeply weathered and afforded me admirable hand-hold as well as good foot-hold for my rope-soled shoes and I was able to traverse the face of the cliff in various directions and visit a number of nesting-places. Being late in the season none of the nests contained eggs, but I was able to get what I had come for, namely, a capital series of photographs of young Griffons in their nests in almost every stage, from the baby in white down, no bigger than a newly hatched gosling, to the lumbering full-

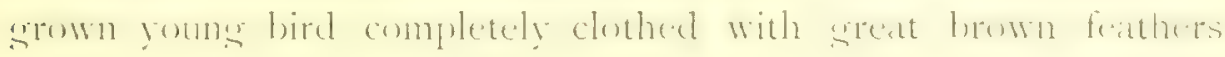
wating only the growth of its primaries to take wing and fly away.

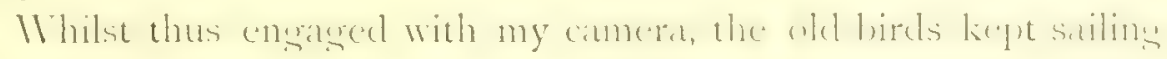
to and fro above the cliff, their immense wings spread out and apparenty motionless with the tips of the primary feathes widely separated. Now and again some anxious mother would come past a cavern I was in with a great swirl of wings and I was able to set several snaphots at such, as they came womels me and hefore they detected my presence and swumb oft with heary llaphing wings. Vultures like other large raptores do not realize their power as

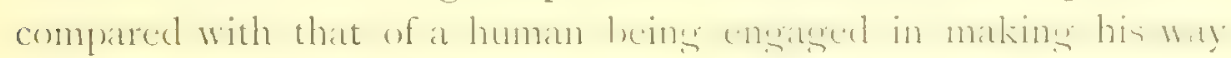
along some narrow ledge or across the face of a rough crag where

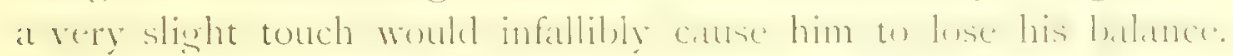

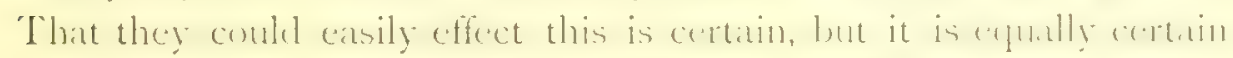

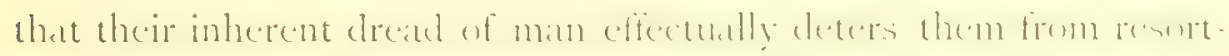
ing to tactics so disturbing to the egg-hunter or photographer. Leaving the cliff after a rough descent of the hillside even more umpleatsunt than the ascent, we at length reatherl the small white house below.

The view from the vine-covered patio was simply magnificent. Far below us the yellow sand of the coastline stretched away for 20 miles to the old fortress and linhthome of liarifu, whone white 
buildings formed a beatiful contrast to the deep blue of the Stratits beyond. Across the water we could discern every feature of the wild rocky mountains of the Barbary coast from Centa to Tangier drawn in sharp purple masses of light and shade, whilst the bold headland of Cape Spartel stood up in strong relief against the shining waters of the Atlantic, which seemed from our elevated position to stretch westward until sea and sky merged.

The owner of the ideally placed house I mentioned was a goatherd of some importance, pressessed of considerable flocks which found subsistence in the rocky hills of the sierra above. It would be difficult to inagine an instance of any man being in theory so near and yet practically so far removed from the influences of modern civilization. His only idea of civilization was the sleepy and decaying old town of Tarifa and to wain the only road leading thither he had to traverse some seren miles of a stony track, only passable in fine weather. And yet daily, and indeed almost hourly, at his very feet there passed huge ressels both of war and commerce representing the power and wealth of most cirilized States on their way through the Straits of Gibraltar.

Postal service, telegraphs, newspapers and the like were all things for which he had no use; he was content to live thus isolated in the glorious climate and to advert with justifiable pride to the billa wista from his patio, his one and only asset amid the supposed desiderata of modern houses.

Had he ever had a visit from an Englishman before? Yes, once, one had come to look for silver in the sierra where I had been after the Vultures, altho' God knows why silver should grow among rocks. However secking silver was a thing a man could understand, but Vultures? and pictures of Vultures? what was the use of them?

The Englishman had told him he possessed a hidden treasure or gold mine in his garden. But he had never returned. Ire bad 


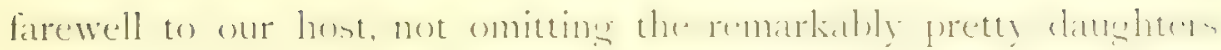
of the house which the prospecting Englishman may possibly have had in his eye when he spoke of the treasures in the garden.

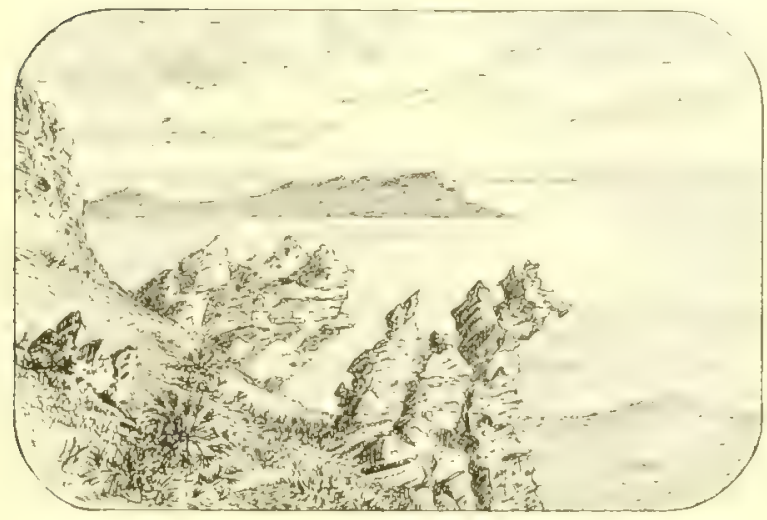




\section{CHAPTER II.}

\section{THE LESSER BIRDS OF THE SIERRA.}

The varied attractions of the Sierras-Moorish and Roman remains-A race of rock dwellers, a subject for antiquarian research-The Common WVrenThe Crag Martin-A swim for a nest-An unlucky "identification "-The Blue Rock Thrush-The "Sparrow alone upon the housetop "-Exceptional powers of dissimulation-An awkwardly-placed nest-Vain regretsYoung Blue Rock Thrushes-A sweet songster-Search in sea-cliffsNest in Charles V.'s Wall-Riflemen on guard-A long-deferred victoryThe Black Wheatear-A most retiring species-Repeated failures to find nest-The sentry-box and the Black Wheatear-The Pctrero-Curious habit of building nest with stones-A remarkable nest.

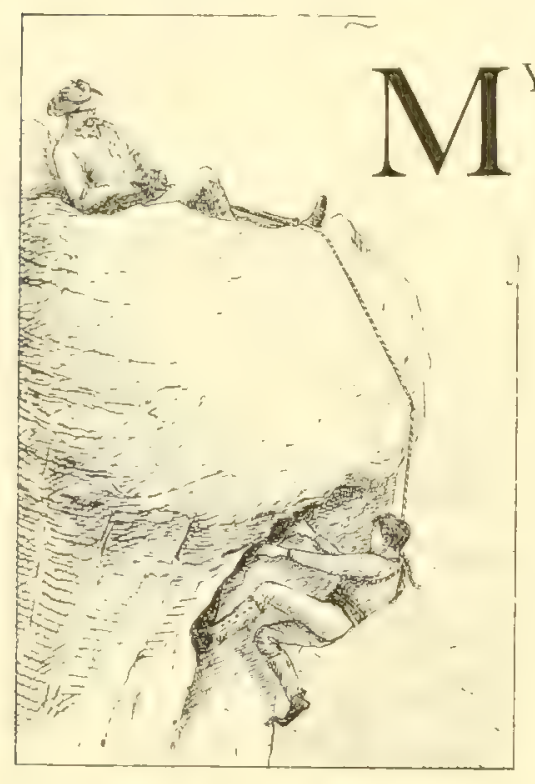

original object in penetrating into the more remote parts of the country was to see certain species of birds in their haunts; but from the very first I realized what exceptional opportunities were thus placed within my reach, not only as regards the birds and their nests but almost every other branch of natural history. In a wild country such as I have endeavoured to describe hardly a day passes without one seeing some animal, reptile or insect which cannot fail to arouse the interest of the most unimaginative. The extraordinary wealth of flowers and flowering shrubs, the diversity of those 
composing the so-called scrub as one penetrates from the lan lying country into the valleys of the sierras, alone makes a most fiscinating subject for observation.

And in addition to the Zoology and Botany; what marvellow seolonical formations present themsclves to the traveller imid the wreat tangled masses of the sierras and their sumounding fout hills. And again who could fail to draw inspiration from the mysterious remains of byenene ages which are to be found in the least frequented and apparently utterly uninhabitable parts of this country? Naturally enough Andalucia abounds with wonderful relics of the Moorish dymasties which endured for over 700 years and of which the most modern must date at least from some time in the fifteenth century. During some of my climls to the summits of remote and unsignified cliffs I have come across the remains of well-designed and strongly built forts, clearly the work of the Aral, invaders. Again I have met with elaborate Roman ruins clatins: possibly from 2,000 years back. liut beyond and in addition to these are the various rock fortresses, clwellings, sepulchres, cisterns with steps and fortified approaches, all cut out of the solicl rock, of the creators of which I have been unable to whtain any information at all, although I have spared no troulle in the matter. Who the races were who thus dwelt in these desolate sponts in the sicrrats, accessible only by tortuous goat-tracks and often involving some stiff climbing, is to me at present an insoluble mystery. I venture to mention the subject here in the lanpe that some reaclers of thin book may be antiquaries who will follow up the matter.

But I must go back to my birds. Amid the caverns and crannies of the mountains, both limestone and sindstune, there is a bird-life all of its own. True is it that some of the species, as will be seen, are found in other situations, but those which 1 describe form part and parcel of the life in the mone remote pliaces. where Vultures and Eagles seck for peace and security. First ant 
foremost comes one of the smallest of European birds, the Common Wren, which inhabits the wildest and most desolate hills and shares with the big Vultures the decp caverns hundreds of feet above the sea level. Itherever suitable sites are to be found, for example among the innumerable "pockets" with which the roofs of the sandstone caverns are pitted, there may the Wren be reckoned to breed, making its snug nest of the materials nearest at hand.

One of the things that most deeply impress my mind when, after a hard struggle, I have gained the summit of some great cliff, is the absolute silence around. The Vultures may glide overhead or sweep past hundreds of feet below, but never a sound do they utter. The same with Eagles or with the startled Rock Doves which dash out of the caverns hard by. Suddenly close alongside, the silence is broken by the shrill cheery song of the Wren! No height seems to be too great for this undefeated little bird. At the very summit of a sreat cliff, whose base lay in the cork woods over $500 \mathrm{ft}$. below, I have found a Wren's nest built in a hole in the same cavern and in close proximity to that of the huge Griffon Vulture. In this instance the II ren had constructed the external part of the nest almost entirely from the Vultures' feathers, the lanceolate ones from the ruff forming a feature in the architecture, whilst the lining was composed of the snowy white fleecy down which forms the underclothing of the Griffon.

One of the most widely distributed among the smaller birds of the sierra is the beautiful little (rag Martin (Cotyle rupestris), which to the uninitiated bears a lilieness to our own Sand Martin (Cotyle riparia). Some of these birds winter in southern Spain sheltering among the deep ravines low down in the sierras where they are protected from wind and weather. Their numbers are largely increased during February. They build a nest of cemented mud, cup-shaped similar to that of our Common Swallow (Hirundo matica) 


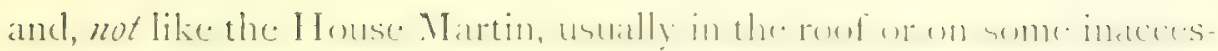
sible ledge of a cavern. Several pairs often nest together. The nest

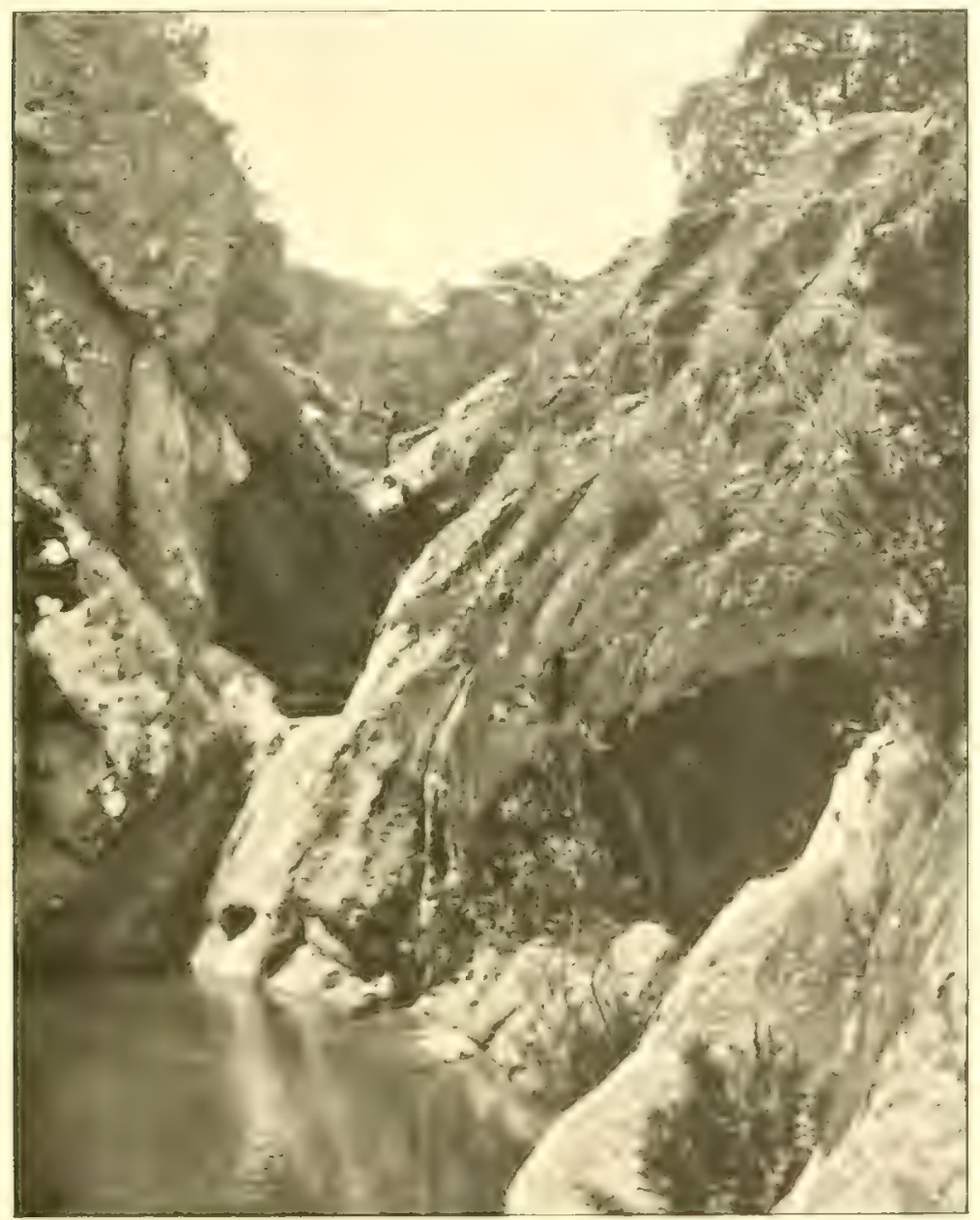

SANDSTONE CAVERN AIOVE POOI, IN IBED OF TORLLNT, NESTING-PLACE OF IHI. CRAG MARTIN.

is warmly lined with feathers amel the ages, fome to live in mumber. are white, spotted with grey and rusty-hom and chasly resemble. 
lighter coloured varieties of the Swallow's. Considering the abundance of this species it is curious how rarely its nest is found in accessible spots. After four years of disappointments, I watched a pair enter a rocky cavern below a waterfall in a deep water-worn ravine. To get at this nest I had to be lowered some $15 \mathrm{ft}$. to the pool below the fall and since we had no ropes, this had to be done with the aicl of our fajas (known to Anglo-Indians as cummerbunds) knotted together. I then swam across the pool and entered the cavern, in the roof of which was a nest with four exuss. Sad to relate, so obsessed was I with the idea that this Cras Martin built a nest similar to our House Martin and laid white egges like it and the Sand Martin that I imagined the nest and egres I had found belonged to the Common Swallow, of which there were sone also about, and so abandoned my prize! My disgust upon learning, some months later, that I had actually had the esges I longed for in my grasp may be best imagined. Owing to the fact that I am rarely in the sicras at the season when the Cray Martins lay, many years passed before I hat another opportunity of getting this nest and it was not until IgOI that I at last succeeded! Truly a little knowledge is a very dangerous thing, at any rate as regards the identification of eggs!

Besides the Cray Martin, the House Martin (Chclidon wrbion) nests in abundance in certain parts of the sierra.

Without doubt the most conspicuous and best known of all the cliff-haunting birds is the Blue Rock Thrush (Petrocossphus cyames), known to the Spaniards as Solitario from its habit of sitting alune, perched on the summit of some crays or, if near inhabited places, on the top of some commanding building. I believe I am correct in saying that it was this bird that David had in his mind when he described himself as watching, "as a sparrow alone upon the housetop," and further that some learned ornithologists attempted, but without success, to have this apparent error amended in the Revised Version. 


\section{A Single-handed Lower}

The Blue Rock Thrush is a clelingtful hirel to watch, alike in its wild state and when in an aviary. I have reared several from the nest and so can testify to their engaging habits. They are extremely wary, as all who have ever striven to find their nests will testify, and I verily belicre that when they have reation to suspect that they are being watched, they will so to great pains (1) misleat the enemy by simulating an immense interest in some cran where they are not nesting. Anyway such has been my experience, year after year, and I have repeatedly witnessed and suffered from such tactics. Naturally enough, as som as I mate the acquaint ance of these birds I set myself to discover their nests. Here for a time at any rate, I met with more than my match, and for three years in succession I was fairly beaten. Thus in I875 I was ignorant of their time of nesting and only found a nest on 22 May, when the young were fully grown and on the wing. In 1876 I was equally unsuccessful. In 1877 , when engaged in watching an Eagle's nest with Major Robert Vapier (mow Iord Napier of IIagdala), we noticed a pair of Thrushes which were evidently nesting not far off. Eventually, the hen carrying a contipede in its beak, flew up to and entered a deep vertical cramny in the cliff close to the Eagle's nest. The crag was not $40 \mathrm{ft}$. high and the cranny only a few feet below the edge and just

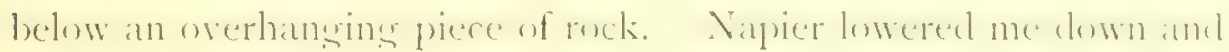
after some trouble 1 got my toes well jambed into the crevice and somehow managed to haul myself in under the rock and reach the nest which contained five young birls fully fledped: thene I transferred to the bosom of my shirt. The return journey upthere was not enough rope to lower me down-involved an

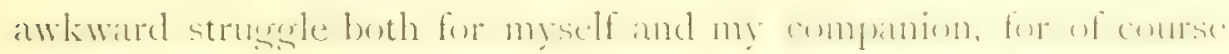

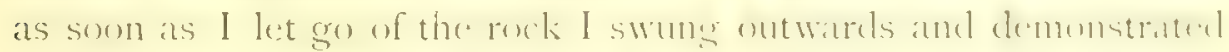

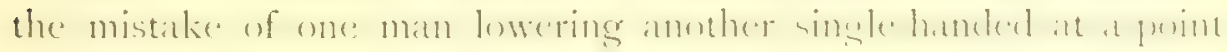
where there is no handhold for the climber. I made a sketch of 
this crag from which the head-piece to this chapter is taken, on the spot. I ever retain a lively recollection of the incident owing to my comrade upon some subsequent occasion when I annoyed him more than usual, having expressed his fervent regret at having "ever pulled me back up that cliff"!

The young Thrushes obtained on this day proved to be most amusing pets, eventually finding their way, some to the aviaries at Lilford and some to the Zoological Gardens, where they had more scope for their antics than when caged.

In 1878 my attempts to get the escrs of this bird were unceasing. On 23 March I found a nest ready for eggs in a low cliff, but the old birds, which watched me closely when I climbed to it, forsook it and moved elsewhere. On so May I recovered the lost clue and found a nest with five young just fledged within 20 yards of the nest of $187 \%$, and on $\mathrm{I} S$ May yet another nest with four young in a hole in the roof of a big cavern but still no eggs.

I reached this nest by the old birdsnesting expedient of building up a human pyramid of my brother subalterns, the base being formed by Henry Prittie (now I ord Dunalley), the middle portion by Fergusson, and the apex by me. Having erected the structure against the wall of the cavern, Prittie cautiously stepped backwards until I was exactly under the nest.

In 1879, warned by previous failures, I commenced operations earlier, and even on the days when I was prevented by my military duties from leaving the Rock I devoted all my available time, on guard or off guard, to watching suitable cliffs. At this time an old cock Blue Thrush in his beautiful plumage used to come daily to the cross on the top of the South Chapel and sit there for hours, from time to time uttering the short sweet song so often heard in the remote sierras. I watched him fly to Rosia Bay where I spent no less than six days in March watching the morements of a pair in the sea-cliffs. 
At this time Lord Lilford was at Gibraltar in his yacht the Glow-rom, and with the assistance of his son, Thomas Powys, and some of the crew I was lowered over the cliffs between the New Mole and Camp Bay in all directions. It was now that I learnt by painful experience the deceptive ways of the Blue Rock Throsh. One of their practical jokes was to simulate reat interest in some cavern or fissure in a cliff and to disappear into it for a considerable time with the result that I was committed to a perilous descent only to find that I had been arosily imposed upun. At last on 5 April we decided that there must be a nest in a cave below Parson's Lodge Bittery. This happened to be quite inacessible from above so I swam out from Camp Bay and scaled the cliff but found nothins. I realized howerer that between sharp rocks, barmacles and thorny scrub it was an overated amusement to go birdsnesting unclothed.

One day in April when subaltern of the Ragged Staff Guarel I noticed a pair of Blue Rock Thushes playing about Charles I's Wall high above the town. The next dey as som ats I wats relieveel from off stuard I went to Gardiner's Battery whence I could command a view of the suspected area and lay up. From what I there saw I moved on to the fort of the Jorth Flat Batstion and concealed myself in the scrub about 30 yards from the escarp. After an hour's waiting I noticel the old cock bird, which had been endearouring to attract my attention ly rarous weird antics on the top of the wall, become somewhat solicitous in his clementmour. Remaining motionless I had the anod luck to detect, ant of the corner of my eye, the hen as she slipped out of a weep-hole in the bastion about $30 \mathrm{ft}$. above me. I kept quiet and soon she re-entered the hole! I now made my way to the top of the bastion and, leaning over the wall, touched the weephole with at stick it was only a few feet from the top-when out flew the bird! I now felt certain of my prey. 
But even now I had to exercise patience, for the Duke of Commanght who was then serving in the Ritle Brigade was on a visit to Gibraltar on the occasion of his honeymoon and this sadly complicated my arrangements for we had to parade on the Alameda

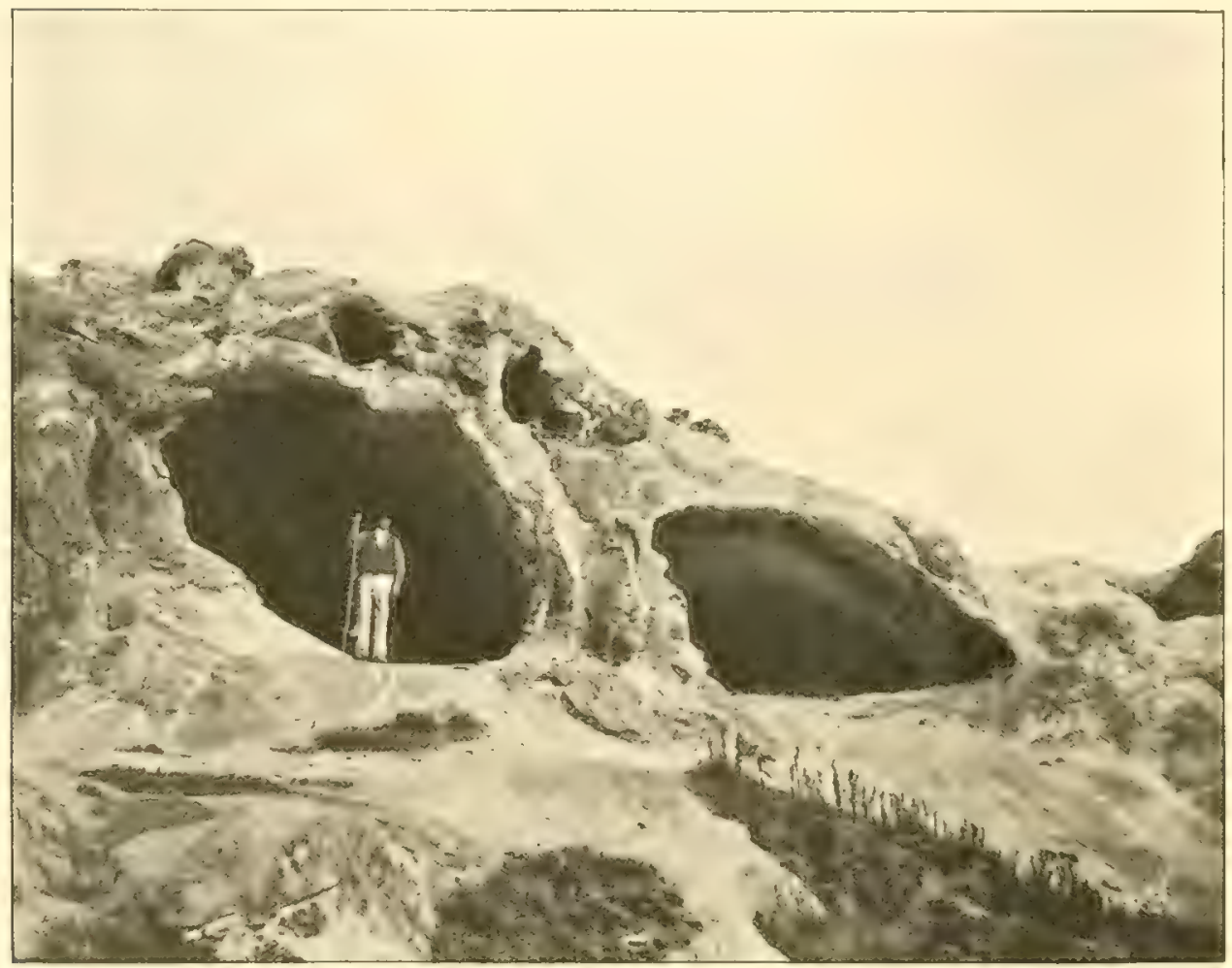

A SANDSTONE CAVERN NEAR A SUMMIT OF THE LOWER SIERRA. NESTING-PLACE OF THE BLUE ROCK THRUSH.

for his inspection. I recall now how whenever I was not "standing to my front" I had an eye trained on that weep-hole in the old bastion! Immediately after our return to barracks I got into plain clothes and, seizing my coil of rope, started off for the bastion. Here there was a Corporal and three Riffemen on guard. 
The sentry and inceritable conk deducted, this save me two men to lower me over the edge. As I came opposite the weep-hole I saw to my intense joy a nest of fibrous roots containing five beautiful pale blue eggs! These were, as is their characteristic, most delicately transparent, thus differing from the c...... of an Starling which are more opaque. Thus in the fifth year of my labours did I at last attain success. Since then I have, from time to time, when exploring caverns or working my way and crops or across the face of some biy cliff, come upon many nests of this l, ircl. ()wing to the peculiarly sheltered situations in which they builel, their nests remain for years in very fair preservation; hence the climber sces many more nests than there are pairs of hirds in the locality: On three occasions I have thus chanced upon nests with five eggs and on others some containing less, but none of these has given me the same sensations of victory achieved that I experienced on that day in April $1 \$ 70$, when hanging on my rope adown the face of the old bastion at Gibraltar I first set eyes on those blue eggs.

The Black Wheatear (Sirvicola lencura), although at times wy much in evidence, is like all the Wheateats a master at the art of skulking and keeping out of sight. The male is a handsome fellow, jetty black with a very conspicuous white patch above the tail whence his popular name of EL Sacristan; in the female the black plumage is replaced by a more sober brown. In many of there habits they resemble the lilue Rock Thrush, and they occupy identically the same terrain, nesting in caverns often at the very summit of the lower sierras.

My quest of this bird's nest was even more prolonged and difficult than the quest of the Blue Rock Thrush's, nor was it marked with the same success, for to this day I have never yet found a nest with the full complement of fresh eggs.

In March is75 I watched a pair in the Europar ravines and at I9 
length discovered the nest placed in a small hole in the face of a cliff. Most unluckily the female was shot before she laid and thus I lost the one good chance of my lifetime. The following year I was entirely unsuccessful in finding these birds in situations where I could watch their movements. In I 877 I noticed at pair frequenting the same ravine where I had found the nest in $1 S_{75}$. In the interval a big powder-magazine had been built close to the cliff where the old nest was and the inevitable sentry had of course been posted on the magazine, which, by the way, I rather think was empty at this time. For several days I watched these wily bircls without any result but I learnt from a Rifleman on sentry that, when I had gone away, the birds came down and played about the magazine and cliffs adjacent to it, taking small notice of him. The solution was obvious. I would take the sentry's place. So inducing him to extend his beat to the furthest legal limit I slipped into his sentry box and with my eye at the peephole in the side waited and watched. In a very few minutes a Black ITheatear appeared on the cliff not 50 yards off and, after watching the sentry turn his back, flew straight towards me and entered one of the red-tiled ventilators of the magazine! Procuring a ladder I went up it and found the nest placed a couple of feet inside the shaft. Alas! it contained four young birds just hatched out!

On I May of the same year, as I entered a cavern near the summit of a small cliff I was climbing, a Black IVheatear flew off its nest which was placed in onc of the sandstone "pockets" in the roof. This was the first nest I was able to examine properly and was naturally immensely struck at secing that the lower portion of the nest was composed of stones of various sizes, some as large as walnuts. At the time I had never heard of this singular custom of the Black Wheatear which has earned for it the title of Pedrero i.e. the stone-quarrier, among the folk of the sierra. The nest 
proper was built of bents and fibres and lined with woul and a few feathers. It contained four pale blue enes marked with a rufous ring at the larger end, in size they were between those of our Wheatear and the Blue Rock Thrush. They were alas! on the

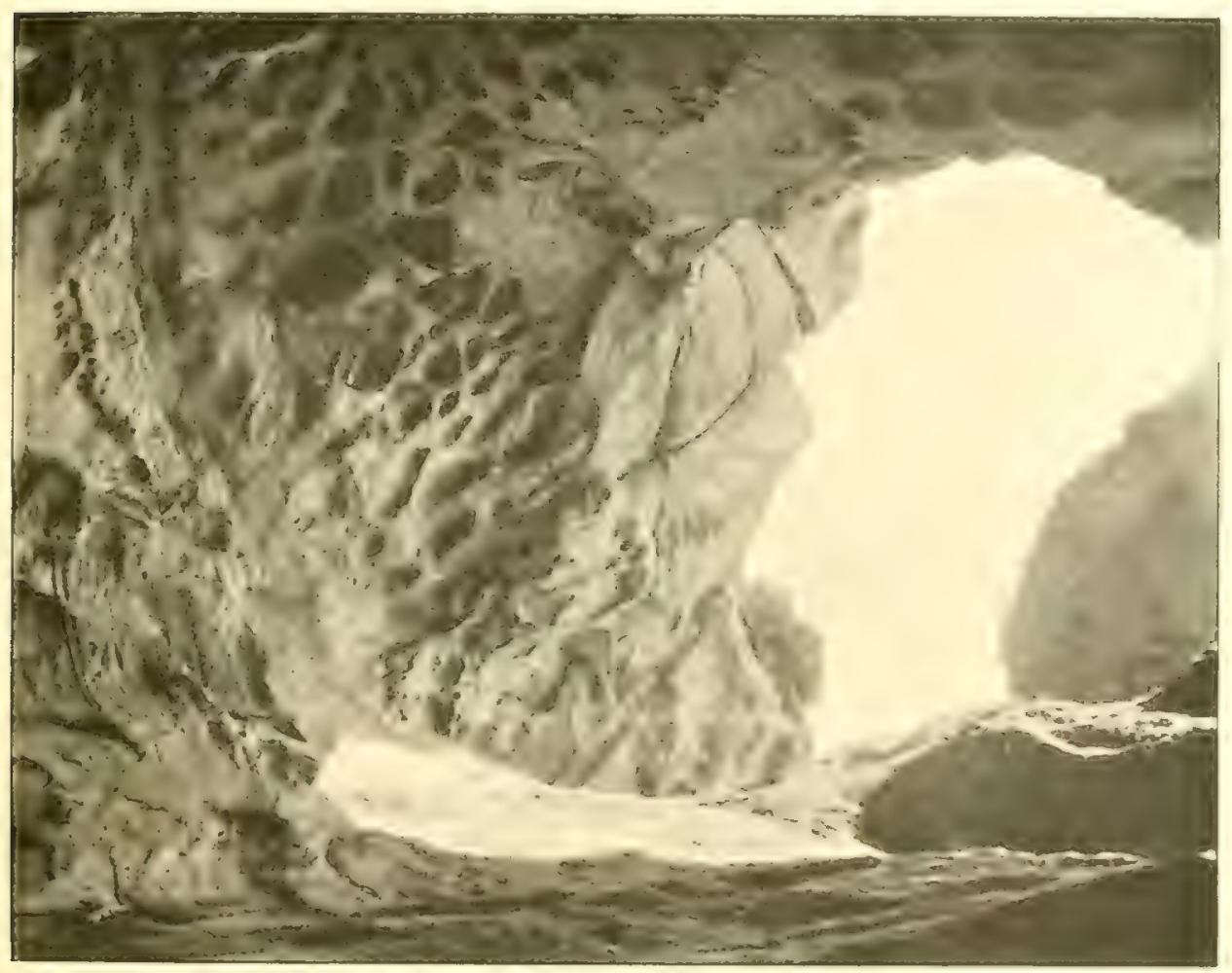

CAVERY NEAR A SUMMT OF THE LOWER SIERRA SHOWING CAYTIES FORALI) EY SAND-ILAST IN ROCK. NESTING-PLACE OF THE IBLACK WHEATEAR.

(The nest is in a carity immetiatily abov'e the felto-stasses.)

point of hatching; so I lost the only chance I have ever had of getting a perfect set of eggs of this curious bird.

Athough I have found many nests since, the majority have lecen compty and a few contained young birds; such are the upe and 
downs of birdsnesting. As a rule, it has been quite impossible to revisit those nests (which no doubt would shortly have contained eggs) owing to the remote situations in which they were placed and my being at the time on the line of march.

Some nests have merely a few stones below them, whilst others have a considerable number and others, again, a regular rough rubble wall built up in front of the nest.

One of the most elaborately constructed nests I ever saw was built in a cavern in a big sandstone cliff. I was exploring some crags at the time and had left Colonel Inby some distance down below. The cavern was almost circular and about i $2 \mathrm{ft}$. in diameter and $6 \mathrm{ft}$. in height and the walls and roof were, as is so frequently the case, honeycombed with small cavities, similar to those shown in the preceding pictures. In one of these, measuring 9 in. across, was this most interesting nest. Seeing what a remarkable one it was, I descended and induced Irby to come up and see it and with his aid made a careful examination of its materials. In front of the nest was a rough wall 9 in. long and $2 \frac{1}{2}$ in. in height and of some thickness. I removed the stones composing it and we found they numbered $2 S_{2}$, of all sizes from a walnut to a pea. We then lifted the nest out; it was built of rass and fibrous roots lined with the fine fibres of the palmetto. Below the nest was a foundation of seventy-six large stones making $35^{8}$ in all. The largest stone was $2 \mathrm{in}$. long by $\frac{3}{4} \mathrm{in}$. wide and $\frac{1}{2} \mathrm{in.}$ thick and weighed $2 \mathrm{oz}$ and there were many others weighing between $\mathrm{I} \mathrm{oz}$. and $2 \mathrm{oz}$. The total weight was over $4 \mathrm{lb} .8 \mathrm{oz}$. The most noticeable point was that, with the possible exception of a few small tlakes of sandstone, all these stones had been carried by the bird for some distance. How such a small bird conveys the larger stones found in these nests is ever a puzzle to me. That they do carry them and bring them from a considerable distance is capable of proof. Thus of late years, several 
pairs have taken to nesting in the weephentes of the tumnels af the railway in the Ronda Mountains. From one of these wcep-holes over $8 \mathrm{ft}$. from the ground I took a collection of stones, some being water-worn pebbles obviously brought from the bed of the gorge some $30 \mathrm{ft}$. below the railway line. 'The largest of these weighed $2 \frac{1}{2} \mathrm{O}$.

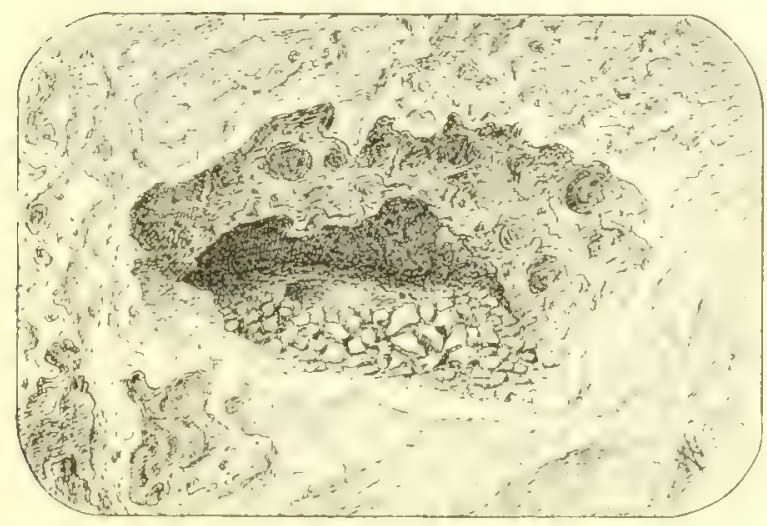




\section{CHAPTER III.}

\section{IN THE UPPER SIERRA.}

Lxtreme wildness-Changes in vegetation-Little-known traclis-Smugglers and their foes, the Carabineros-Cheery companions-The limestone mountains -Cultivation under difficulties-Tobacco growing-A fight for a cropNatural fortresses-The hidden Moorish villages-Nountain gorges-1 deep ravine-Subterranean streams-Old limestone formations-Dangerous climbing-An unpleasant experience-Denuded crags-El Cuihillo-Ibex-A lost opportunity-IVolves-A desert of rocks - Absolute solitude-Choughs, Alpine Accentors, Rock Buntings and Peregrine Falcons-Sierra de LibarBrigands-Secustradores-The brothers Bonel-The Guardia Civil- 1 forbidden district-- The fate of "Nonte $\mathrm{C}_{1}$ isto "- -The fascination of the Sierra -Marvellous panoramic views.

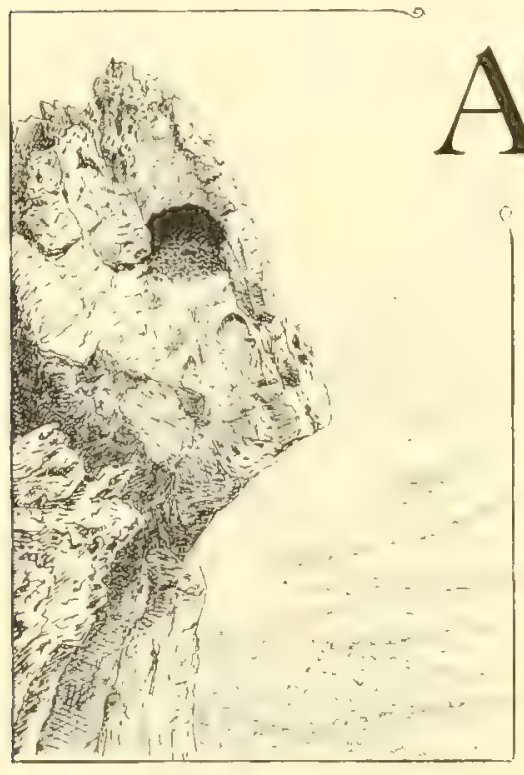

LTHOUGH the height of the lower sierra in south-west Andalucia only averages between I,500 and 2,500 ft. above the sea, the greater part of the country it includes is of extraordinary wildness. Less than $\mathrm{I}, 000 \mathrm{ft}$. up the whole of the flora and regetation undergoes a marked change and as one ascends bigher, the oleander, which fringes every stream in the lower-lying districts, is replaced by rhododendron, arbutus, laurestinus and other ever-green shrubs, giant white heath, often io to $15 \mathrm{ft}$. high taking the place of the red heather of the lowlands. Roads, in 
the ordinary sense of the word, there are none and the tracks available for pack-animals are few and far between; but there is a perfect network of veredas or foot-paths, many of which are unknown to any, save those who live in their immediate vicinity, or to the gangs of smugglers who habitually use them in their nocturnal marches. These daring fellows carry immense packs of tobacco, often weighing over IoO $1 \mathrm{~b}$, and in defiance of the legions of Carabineros or "preventive men" who picket the whole conntry with horie and foot in the most claborate manner. contrive by means of forecel marches by night and hiding amiel the rocks and high heather by day to run their cargoes.

Sometimes when climbing about near the summit of some lonely sierra, I have come across a gang of these wild folk, lying concealed in some rocky ravine. Although it is at times a matter of life and death to them shoukl their hiding place he discovered by their natural enemies, the Carabinoros, when I have suddenly come upon such a party, they have shown absolute confidence in me and have been most courteous and cheery. They are reckless light-hearted folk and usually malie jolies as to my eridently having been a contrabandista myself in my young days, for how clse could I linow their favourite ávedus ats I do? "No other Englishman comes to such places.'

Is the traveller works northward and castward from this recion the sierra gets higher and higher, the Serrania of Ronela being from 4,000 to 6,000 ft. above the sea. Eastward again it rises until the Sierra Nevada is reached of which the altitude in places is orer I I,000 feet. The lower sierra has been already described. In the higher parts, towards Ronder, the physical conditions are widely different from those in the lower sierrat. To beenin with, all this part of the country is of limestone formation and the slepes are fire stecerer and the cliffs more frepuent than in the sandstene receion.

Despite the enormous amount of rock there is a somel deal of 
cultivation in places. Every avalable piece of ground is cleared of loose rock and boukters, which are heaped up in cairns at intervals or built into massive revetments to hold up the soil in terrace above terrace. In the small patches thus cleared many vines are planted, also olives and almonds, whilst higher up wheat is everywhere grown.

Amid this extraordinary desolation of rocks now and again when tratersing the upper sierra you come upon a natural basin of rich soil, surrounded on all sides by biy rocky hills and cliffs. These spots vary from only a few rods of level ground to twenty acres or more. Owing to the soakage of the ranfall from the surrounding cliffs these are often well watered and bear excellent crops. I kinow of more than one such place where I have found tobacco being srown in defiance of the Carabineros and all the myrmidons of the law. Indeed at one spot, not many years since, the wild folk of the sierrat absolutely refused to discontinue their illicit cultivation and reinforced by various parties of smugglers resisted by armed force the detachment sent to overawe them. The scene of this iffray was a remote mountain village perched amid the hills, access to which is along a steep mountain path, so steep as to necessitate stone steps at places. This track leads through a narrow rocky gorge, only a few yards wide, easily defensible in the olden days by determined men armed with sword, spear and arrows. Modern weapons have however rendered this and many another similar mountin-fastness difficult to hold, since in such rugged country there are ever points within rille range which command them. Hence they have lost their traditional security from attack.

One of the many interesting things in this interesting region is the numerous old villages of Moorish oring hidden away in secluded valleys in the higher part of the sierra ; the names of many of them are reminiscent of the centuries of Moorish occupation, each one owing its situation to some guod natural supply of water such 
as is found at intervals in this marvellous limestone country.

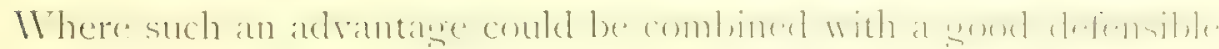

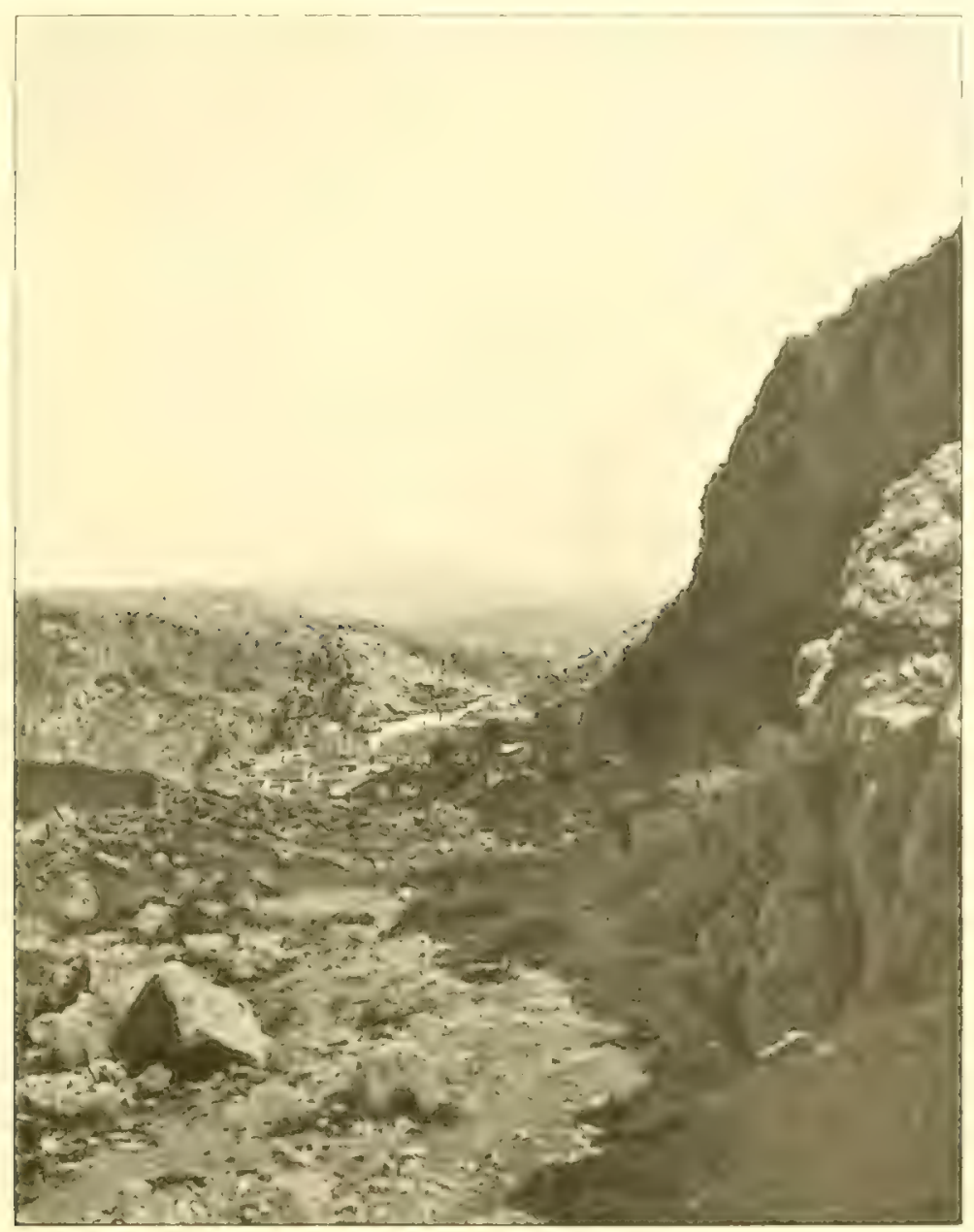

ONE OF THE OLT MOORISU VILLAGES IN THE UPPER SIERRA.

post, large villages sprang up. Each one of them was in communication with at least one other, either by direct view from some building or by the construction of some watch tower on a com- 
mancling point to link up the two places. Sometimes, on reaching a high point on some big cliffs, a compact little town with whitewashed buildings surrounded by ruined walls has suddenly burst upon my view, nestled away in a secluded valley many hundreds of feet below, of whose existence I had hitherto only known by report.

Judging from the number of these villages-in one district there are no fewer than sixteen within a seven-mile radius-there must have been a very lare population here in the days of the Moors. Now, many of the villages are more than half in ruins and I know of at least one extensive villawe which is almost deserted, the chief inhabitants being a small detachment of Guardia Ciall and those few engaged in the cultivation immediately around.

The rivers and streams of this region are most interesting to the geologist. The Guadiaro River which divides the famous Tarjo or cliff at Ronda has lower down in its course eaten its way through the limestone mountains in a marvellous manner. The most remarkable point is near Gaucin where it passes between two vertical cliffs only a few yards apart and foo ft. in height. So close do these great cliffs approach one another that here and there a big crag fallen from above is wedged in and forms a natural bridge. Here, the Guadiaro, after passing over a series of cataracts talies a final plunge into a dark abyss and emerges about a quarter of a mile lower down soo $\mathrm{ft}$. below the level of the entrance. Several friends of mine, during dry seasons when there is little water in the gorge, have endearoured by swimming and wading to pass upwards through this mysterious natural tumel but have been invariably baffled by a series of slippery water-worn weirs of natural rock in the gloomy caverns into which they have penetrated. Were I sound in wind and limb I should certainly try to pass through from above with plenty of rope to secure my retreat.

The view of this gorge from the lower side is most magnificent. 
A small colony of Griffon Vultures hats nested there and doubtess will continue to nest there for all time since few chimbers woukd feed

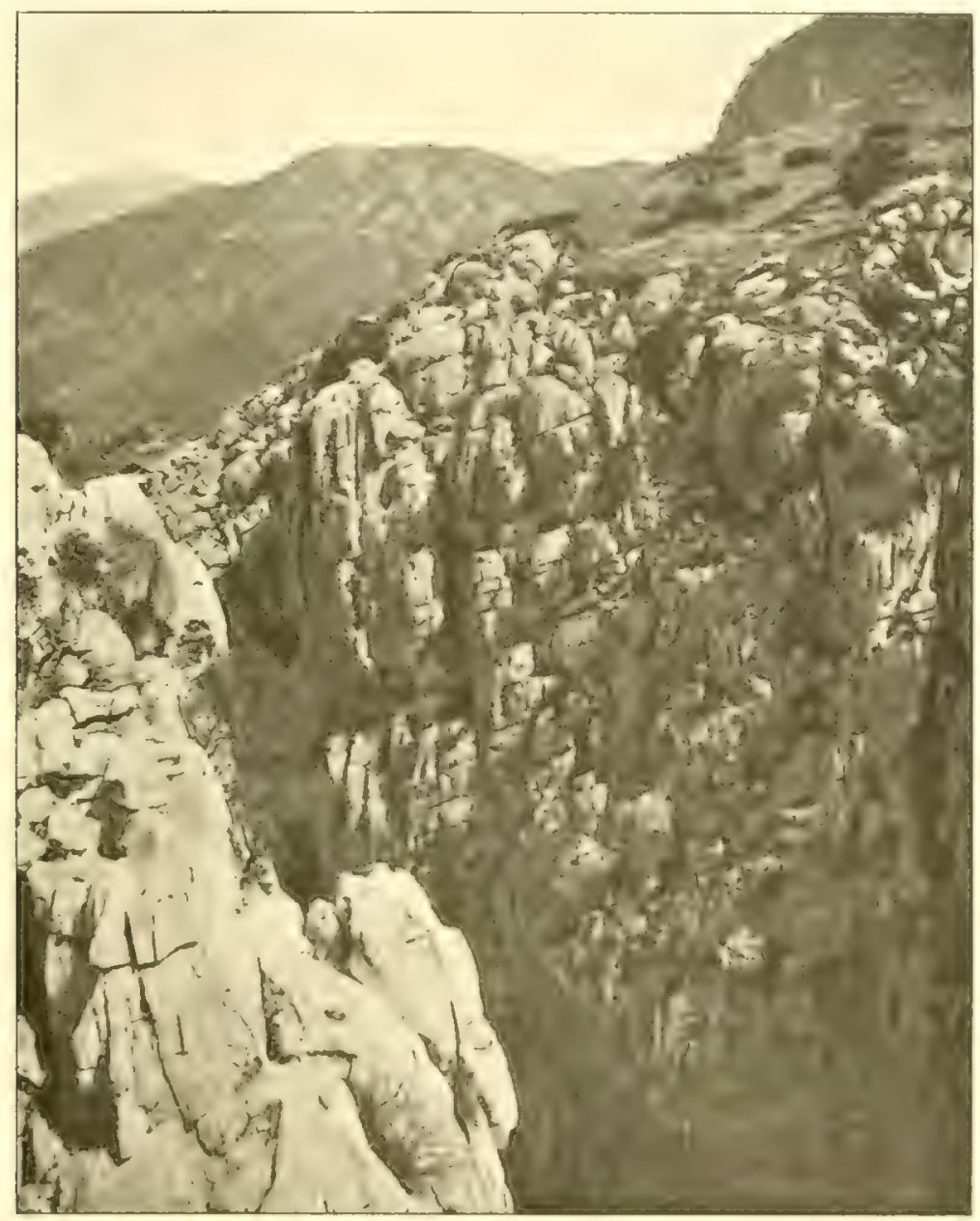

A GORGE IN THE UIPIK SIFRRA.

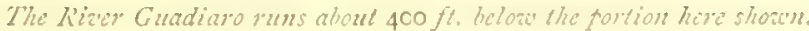

inclined to molest some of their brecting-stations. There are fow places so casily accessible to vicw ats this beatiful arore for those 
who wish to see these wrand birels on the wing. A pistol-shot will always cause them to come sweeping out of the chasm they frequent as well as heries of Rock lowes who also find security in these fine cliffs. On several occasions I have seen Cormorants fishing in

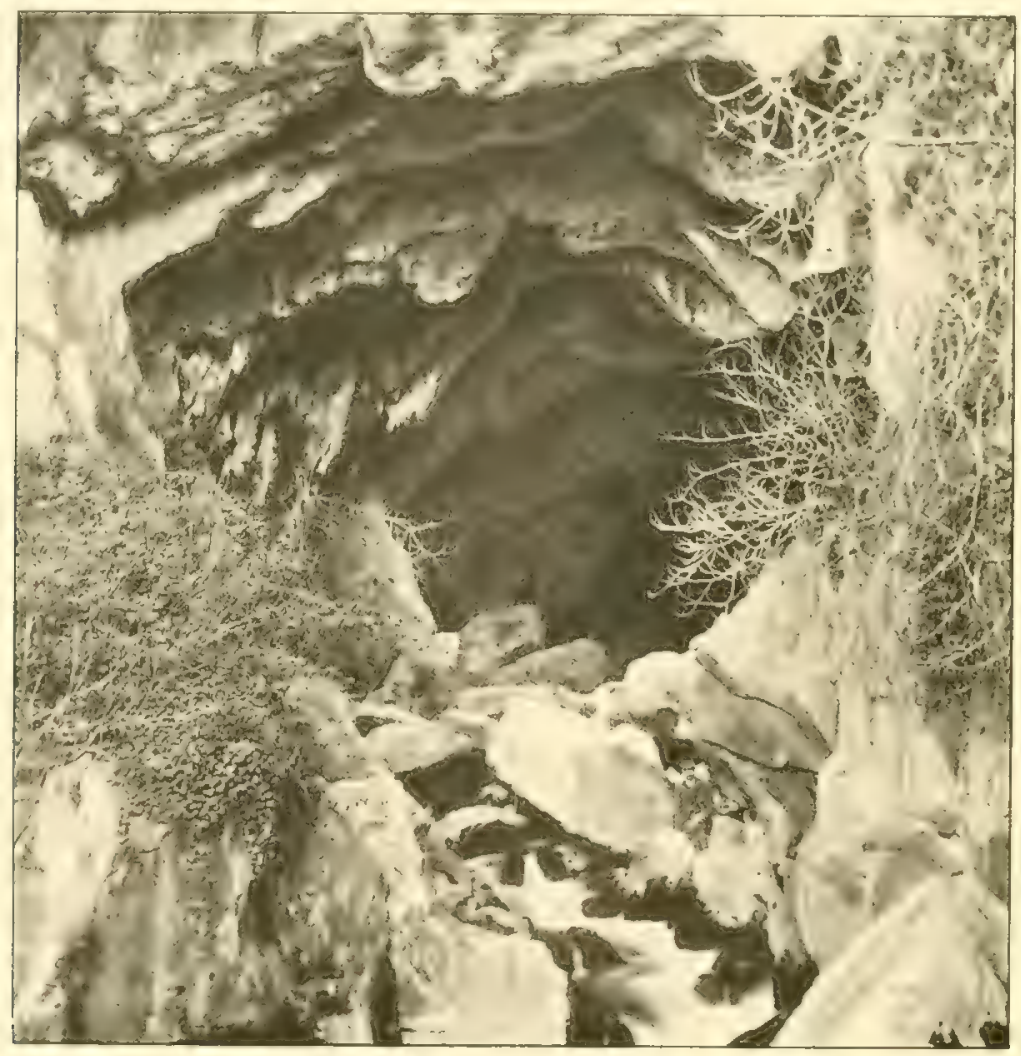

I,A CIJEVA I)EI, GATO.

blience issues a subterancan stream.

the cataracts below and when disturbed they have flown upwards and circled aloft many throusands of feet above the sicrra, after the fashion of Vultures, before making off sea-ward.

The most impressive view of this rorge is from a projecting 
crag close to the summit known as El balcon, a natural balcony of

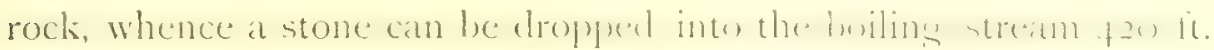
below.

The most interesting subterranean stream I know is one not far from Benaojan which emerges from a huge cavern, over $60 \mathrm{ft}$. in height, known as the La Cueve del Gato (the cat's cave) due to its supposed resemblance to a cat's head and eyes. The roof of this cavern is closely studded with hundreds of the mud nests of the House Martin, which are built close together, in many instances overlapping. The general effect of these as viewed from the stream $100 \mathrm{ft}$. below is that of a mason-wasp's nest on a gigantic scale. This stream emerges in considerable volume at a point about $\mathrm{I}, 450 \mathrm{ft}$. above the sea. For a long time I was uncertain whence it came, but a few years ago, when travelling through the sierra some miles to the north, I came upon a swift-flowing stream which I was assured disappeared into the earth. Two years later I had an opportunity to verify this and chancins to be in the neighenuroud in the late sprins when the water was low, we followed the stream down until it entered a narrow gorge between vertical clitis. Niorking alome the tup of these we at length reached the edge of a deep ravine ending in an amphitheatre of rocks. It was truly a weird spot; we were walled in by a series of cliffs $300 \mathrm{ft}$. high or more and alkere these

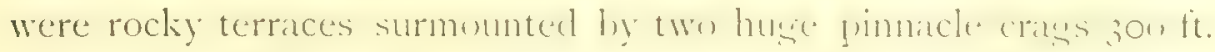

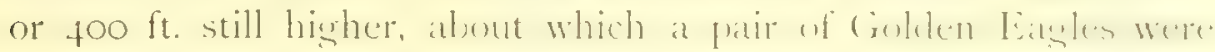
playing. Descending the cliff for $320 \mathrm{ft}$. we reached the stream which here enters a huge vertical chasm over $150 \mathrm{ft}$. in height and disappears from view round an elbow of rock. It was a most remarkable spot, for from the whitemed and poli-hed rock in the bed of the stream where we stood we could look up and see, over I, 000 ft. right above us, the dark peaks, with the brilliant blue sky and drifting masses of white cloud above all. 
That this stream is the one which emerges at the Cueva del Gato, some miles distant, I have no reasonable doubt. The

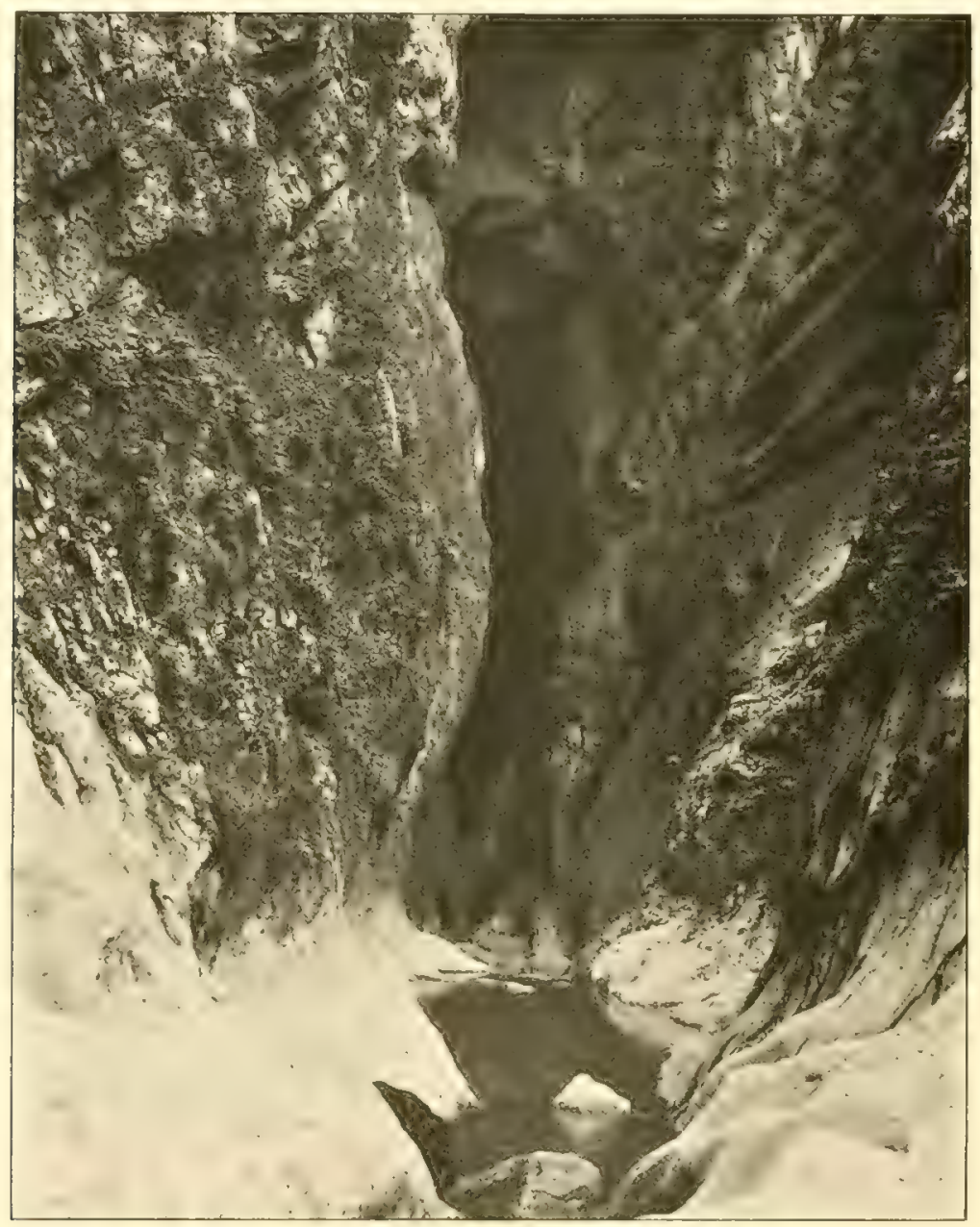

A BIG CAVERN IN THE UPPER SIERRA.

Point where subtoryanean stream enters.

difference in level, according to barometric readings, between the points of entrance and exit is about $450 \mathrm{ft}$. 
During my wanderings I have come across several such subterranean streams but in no other instance have I been able to trace their exit. Of course at many places, espectally near villates in the sierra, it is a common sight to see an abundant stream issung from some cavity in the living rock, sometimes tuming the big water-wheel of a flour-mill, only a few feet from its source.

Doubtless owing to the great age of the limestone and the extreme alternations of temperature between tropical heat and winter frosts it must have undergone: for countless centuries, many of the sierras near Ronda are in a very disintegrated condition which makes them particularly dangerous for climbing as will he seen in my accounts of taking sundry nests in this district. Rocks which are thus weathered assume most fantastic shapes and are frecfuently known to the people of the sierra by appropriate names. Sometimes, near the very edge of a cliff a most inviting natural halcony will proffer itself as a point of vantage whence to get at gomel view of the precipice below. I was standing on one of these in the sierra north of Marbella and, anxious to examine a carern which looked like a nesting-place, leant my weight on the natural parapet in front of me and craned over. Suddenly I felt a tremulous motion and by a great effort threw myself backward just as my stone balcony, weighing several tons, slipped off its loclue and disappeared with a roal several bundreds of feet down a simpularly nasty precipice. It was my first experience of this sierra and caused me to make a vow to be more careful in future.

Not far from the same cliff is a curious saddle-back or "nek" of uptilted strata joining two big hills. Centuries of demulation have: caused the rocks and soil on either sicke to fill awaty until the track along the summit has been narowed at places to a ferl feet. Such is the optical illusion caused by this spot that when crossing it, particularly on a windy day and with drifting chouds

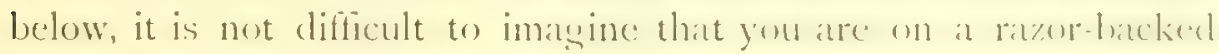


ledge, in fact the Spaniards style it and similar spots El Cuchillo. the knife-edge. To anybody accustomed to heights it is of course a place of no account, yet I have known good sportsmen, who have been compelled to cross it in pursuit of ibex, speak of it with bated breath. My Spanish companions on the occasion of my visit, men of the sierra, regaled me with a story how once an Englishman, finding himself in the middle of it, had laid himself down and held on to the mountain with both hands!

This mountain is one of those-there are many-where the Spanish ibex still holds its own. On various occasions when secking nests or watching Eagles, I have come across these animals, sometimes in considerable numbers. One day I chanced to sce about twenty-five feeding together on a rocky hillside on the grassy patches amid the cistus scrub. I was high above them and they had no idea of my presence and presently began to move off slowly westward, feeding as they went. My route home lay along the bed of a steep rocky gorge and reckoning that they must cross this I worked along it very quietly, leeping a sharp look-out, and hat the good fortune to intercept the herd and get within 60 yards of it. There were nine bucks, three with very fine heads (of course, larger than any I had ever seen), two ordinary and four smaller ones. It was 17 March. I had no rifle with me and so after watching them for some time at close range, I showed myself, when they made off slowly up the hill.

When I first went to Spain there were still a few wolves in these sierras but they have been almost exterminated by poison owing to their depredations among the sheep and goats. The last one to my knowledge was seen by the late Major Harry Fergusson when out after ibex and passed close to his comrade who, despite Iereusson's adjurations, refrained from shooting it as he imagrined it must be a big dog! Irom what I hear, the numbers of both Bearded Vultures and Eagles have been sensibly reduced by this habit of laying poison for wolves and foxes. 
Some of the summits of the Serrania de Ronda present an almost unique scene of desolation. Countless ages of climatic intluences have so denuded the surface of all soil that there are at places many square miles where the surface is of rock and rock alone.

In addition, the action of rain and snow hats enlarged the: juints in the rock surface, in some cases to inches and in others to several feet in width, whereby the general surface is divided and sub. divided into innumerable detached masses separateal by verticallysided ravines. At the foot of these a certain amount of soil has been formed, and here fine grasses as well as flowers are to be seen. Now and again a particularly insistent wild olive finds sustenance at the bottom of one of the fissures and its upper hranches appear above the general waste of broken-up rock.

Save for a passing Eagle overhead, this region has hardly any bird-life. Rarely is the silence broken by the cheery call of the Chough (Pyrrhocorax graculus). These birds, both in their cry and sociable habits, very much resemble our Jackdaws. They nest

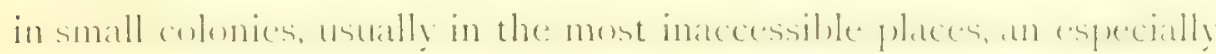
favourite one being a cavern or shelf of rock below some big overhanging crag. One of the few species met with in these stony wastes is the Alpine Accentor (Accentor collaris). They are extremely tame and usually appear to be so engrossed in their search for ford about the small grassy patches amid the rocks as to puy but little attention to the passer-by. Another species haunting the higher sierra during the nesting season is the Rock Bunting (Emberisa ciat), a bird which is assuredly more stupielly tame than the Corn Bunting and will often continue to hop alwoul the surface of some rock and feed unconcernedly within a few yards of anybody who may pause to watch its movements.

Peregrine Falcons (Falco peregrimus) are to be met with at

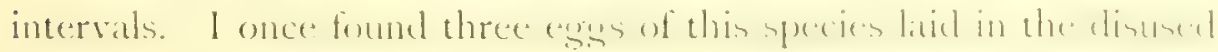


nest of a Bearded Vulture. Kestrels are, as might be expecteel. ubiquitous as also are Rock Doves.

The higher summits of these limestone mountains are composed of a series of pinnacles of horizontal strata much weathered, as can be seen by the accompanying photograph of the summit of the sierra near Jimera. This was taken at a height of about $4,100 \mathrm{ft}$.

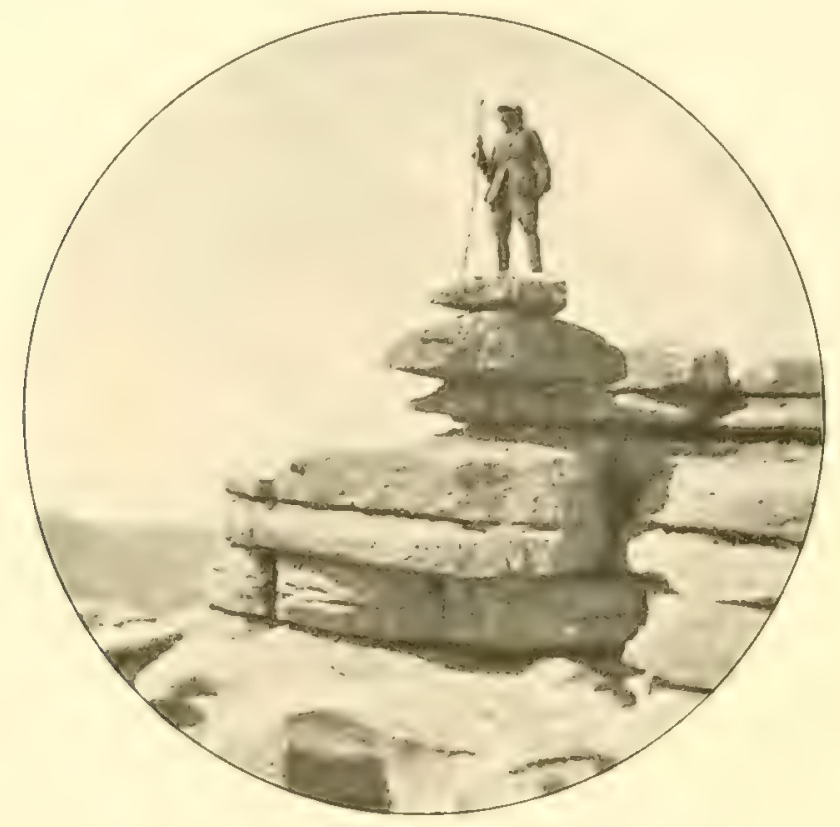

A SUMMIT IN THE SFRLANIA DE RONDA.

(Carboniferous limestone.)

One of the largest of these desolate stony hills is the Sicrra de Libar which rises to considerably over 5,000 ft. For many miles around, its white stony surface bare of any herbage, dominating this portion of the sierras can be singled out from among the sea of surrounding mountains. On most sides it is scarped by precipices or by steep slopes of broken rocks fallen from above, making access to its higher parts difficult and toilsome. A few rarely used 


\section{Brigands and their Ways}

veredas pass through this waste of rocks. It was here that " famous brigand, popularly known to his admirers as ". Monte (rintw," or as "Cristo," was eventually brought to bosk. I am atwe that a book on Spatin without some account of brigcincls is pupularly considered incomplete as one which aleals with the l'eninsulat without a description of a bull-fight. I espite many years of wandering in remote spots, I have no adventures with brigands to retail and I make the confession with equanimity, for it is at best at very one-sided game to platy at. Of course during my time there have been instances of brigandage and the old system of capture for ransom by the gentry known to the inhabitants as scanstratura. has been put into practice from time to time. When I first went to Spain, the famous incident of the capture and ransom of the brothers Bonel had only just been concluded. This occurred literally under the guns of Gibraltar. I met both brothers constantly and it was always a standing joke that after their unpleasant experience they ceased to take any interest in riding out intu Spain and were content to take their daily horse exercise within the British Lines.

Probably the reason why I have escaped any trouble is first, because those engaged in the interesting tals of capturing people and holding them for ransom have an extrenely shrewd idea as to the monetary value of their quarry and, secondly, they are quite sharp enough to realize that as a general rule it is best to leave Englishmen alone, owing to the probability of energetic action beins taken to put a stop to their trade.

That admirable body, known as the comodia (Cirl, make it their business to look after the safety of any travellers, cspecially aravelling Englishmen; and since their motte is eminenty "pre. vention is better than cure," they take steps to prevent people wering into any district which they know to be infested by dimperous characters. Thus, some fifteen years algo, I wats anxious to explene 
a certain sierra for some nests, but in reply to my enquiries the Guardia Ciail absolutely forbade me to gro into it on account of a well-known partida or gang under a certain José, I forget who. Two years later when again in the same district, I received a visit from the Guardia Ciail and was told that I might go where I pleased. "What about José?" I aslied. "Oh!" replied the corporal with a smile, "he is all right, I shot him: see here," with which he produced with great delight the small book carried by these excellent fellows in which they enter a full clescription of the folk they have to deal with, either as "wanted," "prisoners" or "how disposed of."

The last occasion when there was any trouble in the Serrania was when the already mentioned Mnnte Cristo was conducting operations. After many delays, a determined attempt to calture him was made and his gang was broken up. Cristo and one commde took refuge in the wilderness of the Sierra de Iibar and one morning early was surprised in a goatherds' cottage or shealing in a remote valley near the summit. I chanced to be passing the spot some months later and had the tale from a man who had been in the Sierrat at the time and who printed me out the various points of interest involved.

Cristo appears to have received warning of the approach of the enemy and with his one remaining adherent bolted from the cottage and ganed cover amid a small mass of broken rocks on the open stony hillside a few hundred yards above. Here he turned to bay and when the Guardias attempted to close on him kept them at a distance with his Winchester repeating rifle. Numbers however prevailed and the Guardias gradually worlied round the flanks across the broken ground and brought a fire to bear on him from three sides. At last his fire ceased and they rushed in, only to find his comrade lying wounded and Cristo himself dead, killed apparently by the bursting of his Winchester repeating rifle, 
which had been struck by one of the (jumblas bullets. Ilis buely was tied npon a donkey and with difficulty, owing to the axtreme roughness of the country, conveyed to the valley below whenee it was taken to Ronda and exposed in the matret-phace for some ditys. in order to assure all concerned of the fact of his death. But it is hard to consince some people, and mot least, my uht fritencls of the sierra, for to this day it is satid and pupularly lediered that the man the Guardias slew was not Cristo at all, who they assert hul made: arrangements involving certain pecuniary considerations to set another man captured in his place, he undertaking to leatre the district for grood and all. Of the truth or falsity of this tale it is obviously impossible to determine, but only a few montly since when I asked a man who looked as if he might have been a disciple of Cristo how the latter fared, he smiled and with a wave of his hand replied genially "He is well, he's grone to the north."

It would be impossible for me to attempt to describe the fascinat

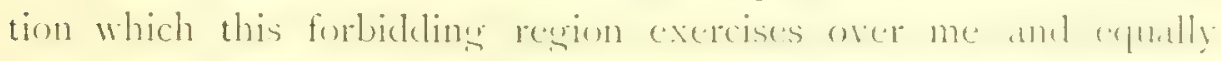
over those I have taken through it. I have seen it under all con. ditions; of a summer's day when the sun's rays strike on the rocks around and make the valleys a very inferno, or in mid-winter, either in the rainy season when every valley contains a roaring torrent or again in hard frost when even the quick-running streams are frozen over and the ice on deep ponds will carry the weinht of a man. Never were there such vicissitudes of temperature and climate.

In early spring the small patches of cultivation, rich hrown soil or vivid green pasture, usually with a clelicate setting of pink

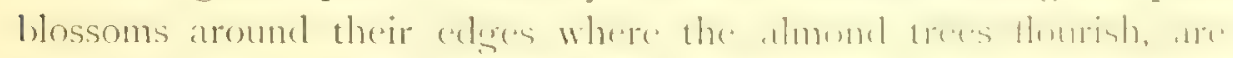
seen hundreds of feet below, surrounded by the eternal almost white crass. Later in the seison the more sheltered hillsiden are a blaze of colour with crimson peonies which grow in prent profunim amid the limestone. 
The distant panoramic views from some of these sierras are magnificent beyond description. Even from the Hacho of Gaucin, the summit of the conical mountain above that town and only $3,280 \mathrm{ft}$. above the sea-level a superb view is obtainable on a clear day. From this point and from many others like it the various streams that join the Guadiaro can be scen sparkling as they wind through undulating hills far below, their courses marked by bright yellow sand-banks and by sinuous lanes of crimson oleander which fade away into the distance.

The Mediterranean and Straits of Gibraltar have the appearance of a great lake, the Rock rising near the hither shore like a small grey cone against a background of blue water. The great height and size of the opposite Pillar of Hercules, Ape's Hill, comes home when thus viewed at a distance from a height, also the vastness of the great tumbled mass of mountains which skirt the Straits towards Tangier and extend southward to Tetuan and beyond. Beyond Ceuta the distant outline of the Riff Coast can be discerned and far, far beyond this, the magnificent chain of blue mountains-the Atlas-capped with snow, which rear their heads above the heat mist shimmering over the intervening region, which, to this day, is a sealed book to Europeans.

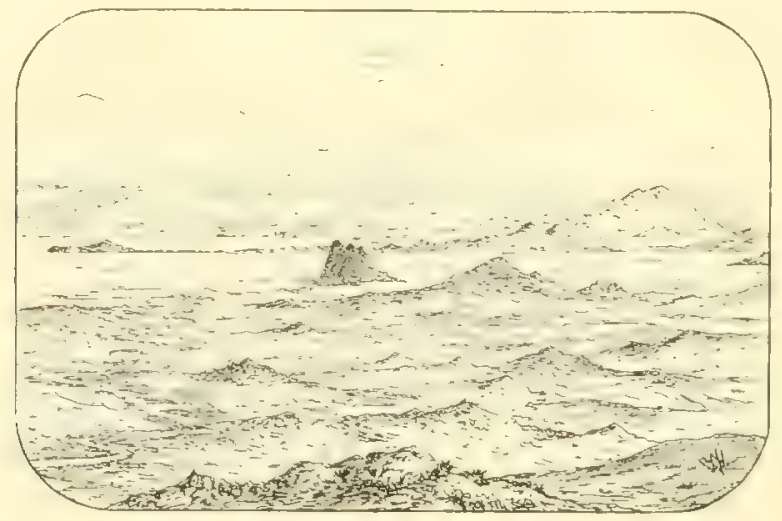





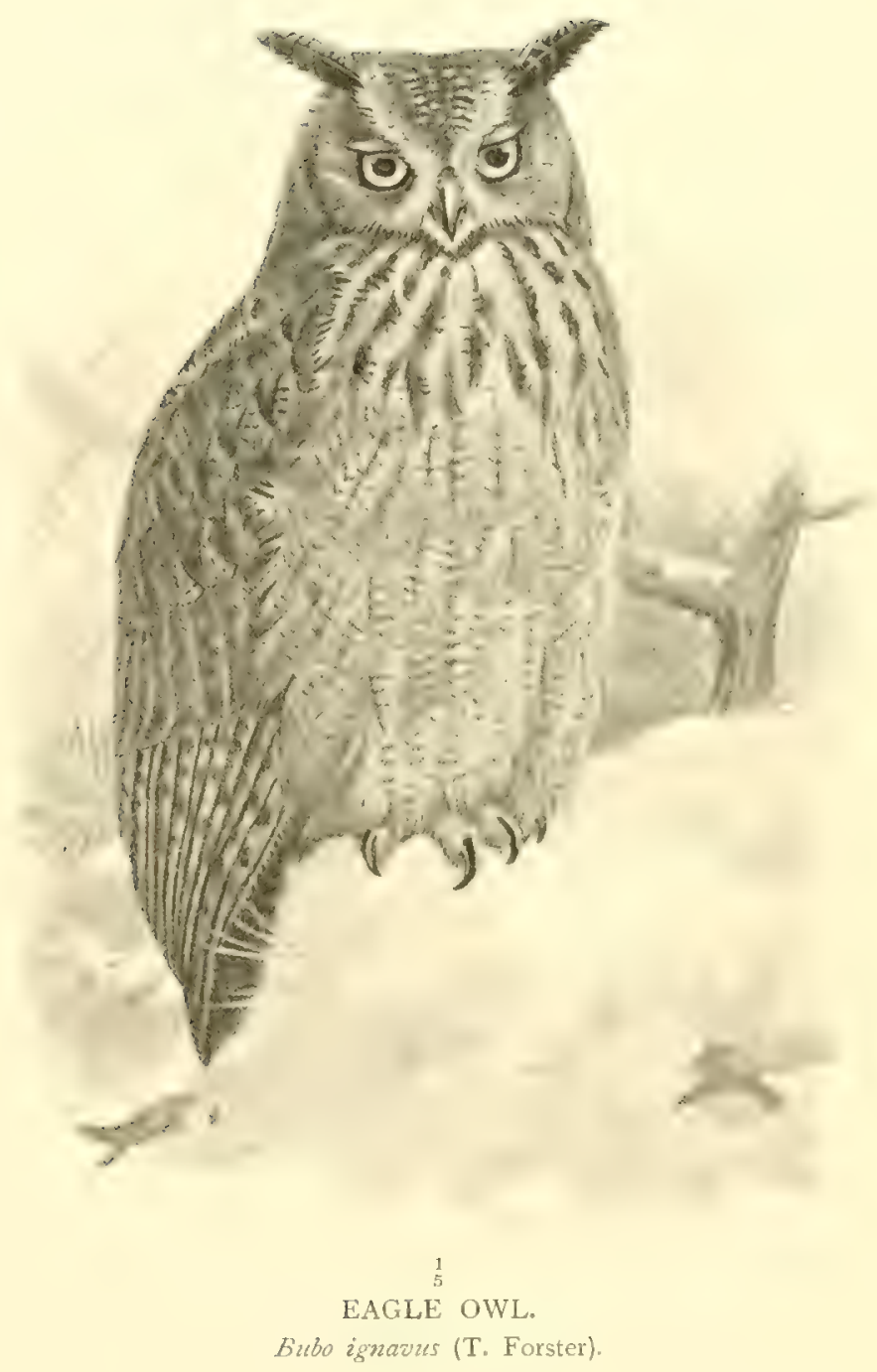




\section{CHAPTER IV.}

THE EAGLE OWL (BMbo isnarns).

Retiring habits-Residents of Gibraltar in 1776 - First acquaintance in wild state-Prolonged search for nest-Successful after nineteen years-An Eagle Owl's nest-An Owlet-Parental precaution-Favourite nestingplaces-An Eagle Owl's crag-Disadvantages of climbing alone-Descend to the nest-An Eagle Owl's cavern-Manners and customs of youngA lower to a nest-Retriever as an assistant-Photographing Owlets in nest-Eagle Owls' larders-Hunting at sundown-Kept in confinementSavage nature-Courage-Voracity-Deadly feud with Aberdeen TerrierEagle Owls' cries.

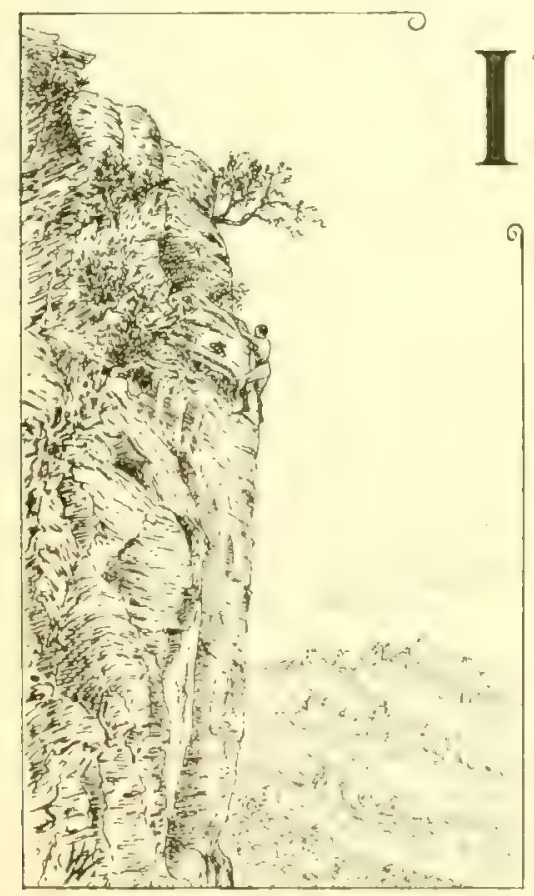

would perhaps be difficult to find any one of the larger raptorial birds so well-known to all bird-lovers and yet so seldom seen in the wild state - save indeed by the very few who may chance to penetrate into the remote districts it frequents - as the Eagle Owl. For unlike the Vultures, Eagles and Harriers which inhabit the same regions and which, owing either to their habit of soaring aloft or of beating a tract of country in quest of food, are often seen, the Eagle Owl delights in secluded valleys, beyond the bounds of which it seldom emerges by day. 
But although so parochial in its habits by day, by night it woes further afield, as is amply proved by the remains of some of the birds commonly found in its larder, whose habitat is far removed from the districts where Eagle Owls nest.

Despite its retiring disposition and marked predilection thus to limit its sphere of action by day to certain well-defined localities, its appearance is familiar to many owing to the ease with which it is kept in confinement. In fact there are few large collections of living birds where it may not be seen, whilst its great size and striking appearance always attract attention to it, whether alive in an aviary or stuffed on the shelves of a museum.

Its nocturnal habit-though it is far from being entirely a night bird in the wilder regions it inhabits-causes its movements to be but seldom seen. Thus, I know of a pair which have nested on the Rock of Gibraltar for wer thirty years and although I hate listened to their strange calls by night many times, I have only once seen one of the birds on the wing by day during that period.

To those unversed in the ways of birds, and more especially those who do not know the extraordinary persistency with which certain species frequent the same hochlites year after year, it may come as a surprise to learn that in 1776 just one hundred years before I first met with the Eagle Owls at Gibraltar, the Rev. John White wrote to his brother, the fumous Gilbert White of Sclborne. to report their presence there.

In the quest of all wild birds' nests, although at times chance may favour the seeker, it not uncommonly happens that years pass before the most diligent search for a nest is rewarded by success. It was my case with the Eagle Owl.

So far back as May i\$ $\$ 5$, when wandering with Ferusson up the watercourse of a gorge in a Spanish sierra, a big bird flew out of the heather-grown crags about $300 \mathrm{ft}$. above us and passing orerhead disappeared round the shoulder of the opposite hill. My 


\section{A protracted Quest}

companion cried out "Eagle Owl over." Neither he nor I had ever in our lives seen one on the wing but the bird was unmistakable. It was naturally a surprise to both of us to see a bird which we supposed to be nocturnal flying high across country in the brilliant sunshine, but later experiences showed me that this speriewould seem to have even less dislike to flying by day than has our own Short-eared Owl.

Having seen the bird, the next point was how to find its nest. Here we were hopelessly at fault: year followed upon year, and although I repeatedly came across what I imagined to be old nests of Eagle (Owls and uncuestionalily were phoces they habiually frequented, I was never rewarded by a sight of their eggs. In this I was not singular, for Colonel Irly has placed it on record in his "Ornithology of the Straits of Gibraltar" that, despite years of diligent search, he was never able to find their nests. Overe and over again did I come across the old birds, gencrally sitting in some shady carern in a sandstone crats, whence they would dash out on my approach. Once indeed I nearly succeeded in my quest in so far that $I$ found a pair had taken possession of a cave which had previously been the nesting station of a Boncelli's Eaghe. They had cleared out the Eatyle's nest, sticks and all, and excatrated at neat basin in the soft black carth forming the flowe of the carrom. This depression wals about $15 \mathrm{inn}$ across and of the form and shatpe of a shallow circular dish. All around its edges was a neat frill of whitening bones of rabluts, rats and linds which had olsiomely once formed part of the "castings" or peellets of fur, feathere and bone which all Owls and other raptorial birds reject the day following a meal. But the Eagle Owl never laid in the nest this year, possibly alarmed at my visit.

It was not until exactly nineteen years after my first sight of one on the wing that I was w be permited to accomplish the tank I had set before myself. In April i 894 I was once again in the 
sierra I had visited in 1875 , and I was scrambling along a steep hillside amid the deep cistus and high heath when an Eagle Owl skimmed past me carrying something and was quickly lost to view over a rocky hillside some hundreds of yards to my front. As the bird did not emerge from the valley it had entered, I reckoned it had most probably setted somewhers among the crags. So following it up I proceeded to examine several low cliffs near the summit of the hill which seemed to offer likely breeding stations. It was the identical spot where I had first seen the Eagle Owl on the wing so many years before. It was whilst forcing my way through some giant white heath, along a very steeply sloped terrace between some big rocks, that I had the grood luck to flush the Eagle Owl almost to my feet. In a few moments I had found the nest! It was nothing more than a shallow basin in the soft earth at the roots of the heather and under the shade of a big rock. Save for the steepness of the hillside and the difficulty of forcing one's way through the heath it was so placed that literally anybody could have reached it. In the nest was a fine young Owlet in the early "down" stage, about a week old, also an addled egg. Around the nest were many pellets of fur and feather whilst a freshly killed water-vole, the lower portion of a rabbit, a young weasel and the remains of a Peewit lay close alongside the infant which was about 6 in. in length. The Peewit was of peculiar interest since these birds, although extremely abundant in southern Spain in the winter, nearly all depart northwards in March.

My subsequent education in Eagle Owls and their ways may be said to date from this moment. Ten days after this I revisited the nest and found the young bird still in the "down" stage although it had doubled in size and had blue quills I in. in length on its wings, whence the primary feathers were just emerging. A week later, judging that the Owlet would have emerged from the "down" sufficiently to ensure its survival in captivity (for, as 
is well-known, nearly all raptorial birds succumb to cramp if talien when too young). I went again to see it. But the nest was empty! After a careful search all around I could only find a second empty nest almost exactly similar and similarly placed, less than 20 yards distant from the first, and likcwise a third undoubted resort of Eaght: Owls. It was quite clear that the old birds, resenting my intrusion in the first instance, had moved their young to a place of safety, and so it happily escaped me. I learned however from this cxperience that the popular ideas of Eagle ()wls nesting in stupendous cliffs or inaccessible caverns was a myth. Since then I have come across and closely watched very many pairs of Eagle Owls and have found numerous nests, many of which I have visited and in hardly a single instance has a nest been in a cliff where a rope was a necessity in order to reach it. The birds, in fact, look for immunity to the vast extent of the wild country they inhabit and in the rough nature of the ground.

The favourite locality for a nest would seem to be on a shelf or terrace on the face of a cragr some 10 to $50 \mathrm{ft}$. from the ground where genista heath or cistus grows in profusion and where, on the soft soil between the shrubs and the face of the cliff, the carthy nest is excavated sometimes 3 ins. in depth and the egrys laid. The eggs, usually two in number are pure white and of the size of a fowl's and nearly globular in shape. The picture is of a nest on a terrace amid some crags about $60 \mathrm{ft}$. high, easily reached from the top of the cliff and not more than $15 \mathrm{ft}$. from the sround.

The year following my first introduction to the young of the Eagle Owl I once again visited the cliff where I had found the empty Eagle Owl's nest, formerly tenanted by Bonelli's Eayle. This was in a small cavern situated about $20 \mathrm{ft}$. from the summit on the face of a crag 80 or $90 \mathrm{ft}$. in height. A picture of this cras is given in the chapter on Bonelli's Eatgle on p. 334 . 1 second showing the profile of the cliff will be found on 1 . 322 further on in 
this chapter. Arrived at the top of the crag I dropped some stones over and shouted and eventually sallied an Eagle Owl. As

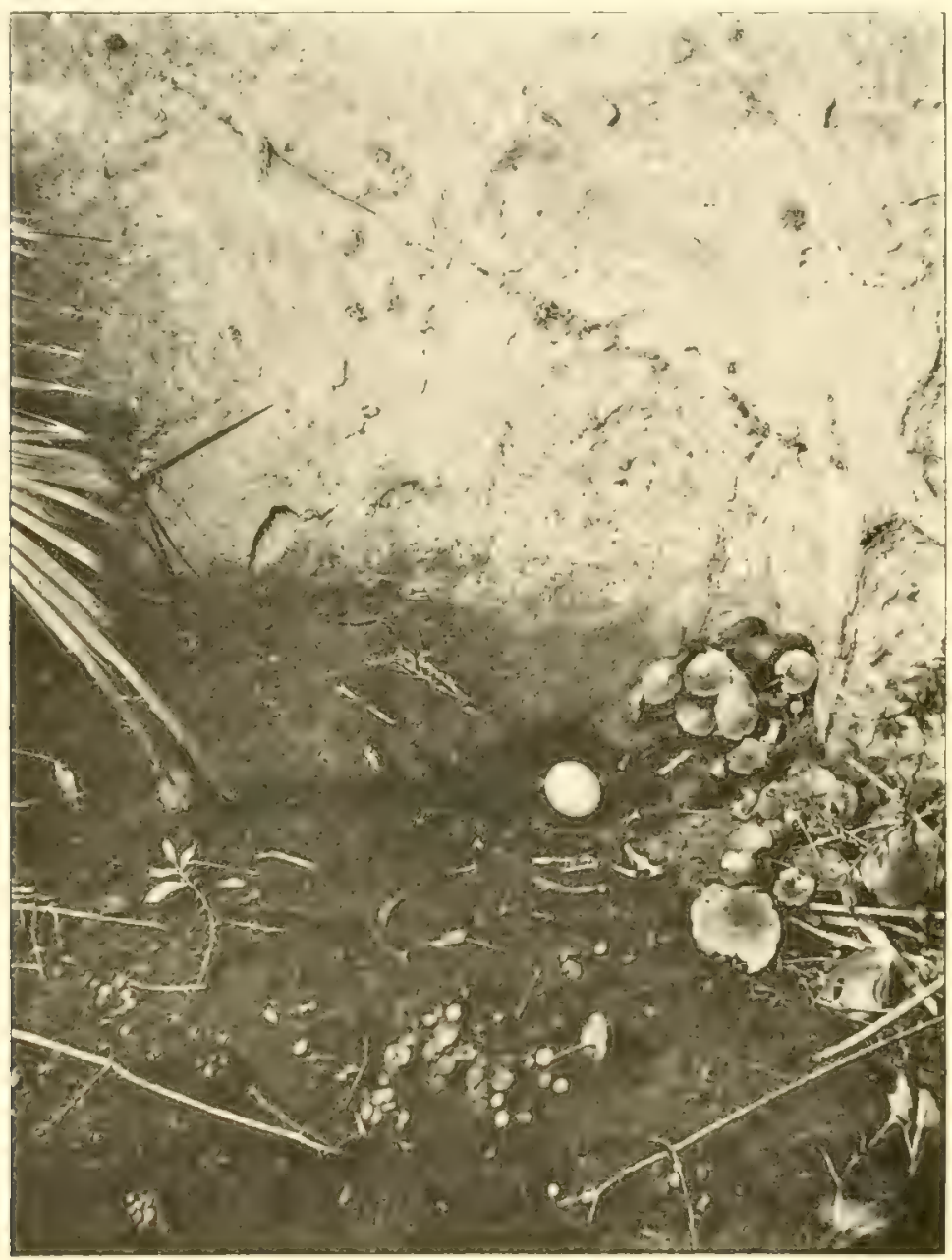

NEST OF FAGIL OWL, ON TERRACE ON CLIFF,

owing to the time of year it was almost a certainty that the nest must contanin ergers and as I still laclied a pair for my collection (having only the discoloured addled eng of the previous year), 


\section{To Slip or not to Slip?}

I was extremely anxious to descend to this nest. To reach it with a rope was a very simple atfair, a mere mater of beime howered some $20 \mathrm{ft}$. but I had no rope with me and further was all alone and, what was even more deterring, my whereabouts at the time were known to nobody. On the other hand, to postpone the descent and to return another diay with ropes was improsible as I was leaving the district early the following morning. The climb was just awkward enough to make one want a companion, for owing to certain experiences I have the sreatest dislike to the idea of running the risks of being disabled on some remote cliff. Many years previously when endeavouring to work aleng the face of a crag to reach a nest of the Blue Rock Thrush I had lost my footing and fallen, only a few feet it is true, certainly not more than ten, when I luckily brought up on a ledge, but the bruising and shaking I then got was so severe as to prevent me from attempting to move from that ledge for over an hour and the memory of such an untoward experience enclures for all time. Further I had ever before me when working alone amid cliffs the already mentioned tale of the Bluejacket who attempted to go round the back of the Rock alone. It was decidedly a case for clear thinking, so I sat down and had it out with myself. I reflected how it was a reatsonalile certainty that this next cont uned censes and that for twenty years I hat wanted sume for my collection and here I was now within $20 \mathrm{ft}$. of them. As regards the risks run and the disadvantages of having no friend at hand, after at further reconnaissance over the calge of the cliff, always by the way a most deterring operation when at dimber is of two minds, I came to the deliberate conclusion that: (I) the chances were even that I would not slip; (2) that if I did slip, the chances were a thousand to one that a companion would be of no use to me, nor I of any further use to a companion. So I took off my boots and

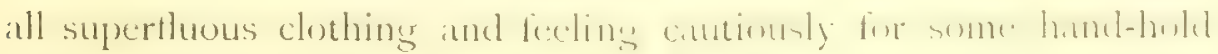


dropped over the edge and after a few anxious moments, found myself safe and sound in the cave! Nor was I unrewarded for the risk I had run, for at the far end of the cavern was the Eagle Owl's nest exactly as I had seen it in the same spot fifteen years before with the difference that, this time in place of being empty, it contained two eggs! My happiness was complete! But I then remembered with horror that I had no means of carrying my prize in safety during the return climb, for I was in my shirt and kneebreeches only! I tried to put one big egg in my mouth and only succeeded in putting a tooth into it! Eventually with the precious egrss slung in my socks held in my teeth, I commenced the ascent. This, as usual when climbing on good sound rock, proved much easier than the descent and I was soon in a place of safety and thankful to find that the injured egro was only damaged on one side and would make a fair show in my egg cabinet.

This time I had not attempted to take my camera with me and wisely so, for it would have greatly impeded my climb and as events proved could not have been used since it was the one with the fixed focus of $7 \mathrm{ft}$.

The pen and ink sketch at the end of the chapter is from a wacer-colour drawing I made from this nest many years ago when it was occupied by a pair of Bonelli's Eagle. Small as is the cliff, it will be scen from the sketch what an extensive view both Eagles and Eagle Owls had over the surrounding country. That at the beginning of the chapter is from another water-colour sketch and shows the climber at the moment of reaching the level of the nest.

I however, revisited the same spot on several subsequent years and found the nest always occupied by the Eagle Owls, and having now a camera which I could use with effect at short distances, I was able to get photographs of the nest and eggs with the remains of a rabbit conveniently disposed in the larder hard by. 
One year, it was in the spring of 1903 , on descending to this nest I found it occupied by two most delightful Eagle Owlets. They were about half arown and a mass of dheffy dewn and findy vermiculated feathers. In vain dicl I try to photegraph them.

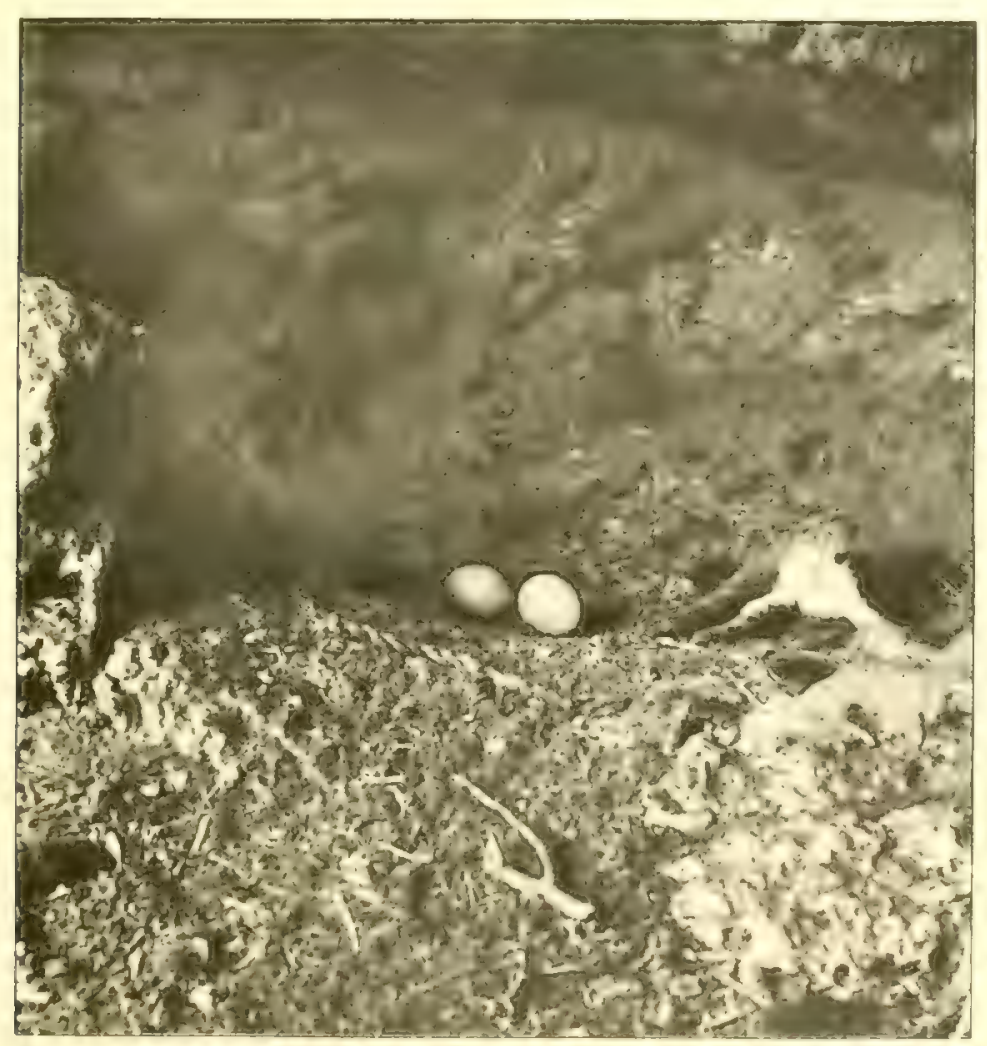

NEST OF VAGLE OWI, IY CAVERN ON FACE OF CIIFF.

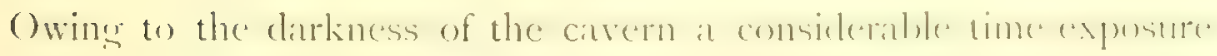
was necessary and it was simply impossible to get both to remain quiet. At times one of them would elect to resolve itself into a ball of apparently inanimate down for thinty seconds of so, but not so the other which would proced to expand its plumase. 
until almost double its ordinary size and then slowly subside to its normal dimensions to the accompaniments of vollies of loud snaps of its beak. No sooner had one gone through this manouvre and come to rest than the other would commence a similar performance.

I took these young savages and reared them successfully. From the very first they showed fight. When they were not

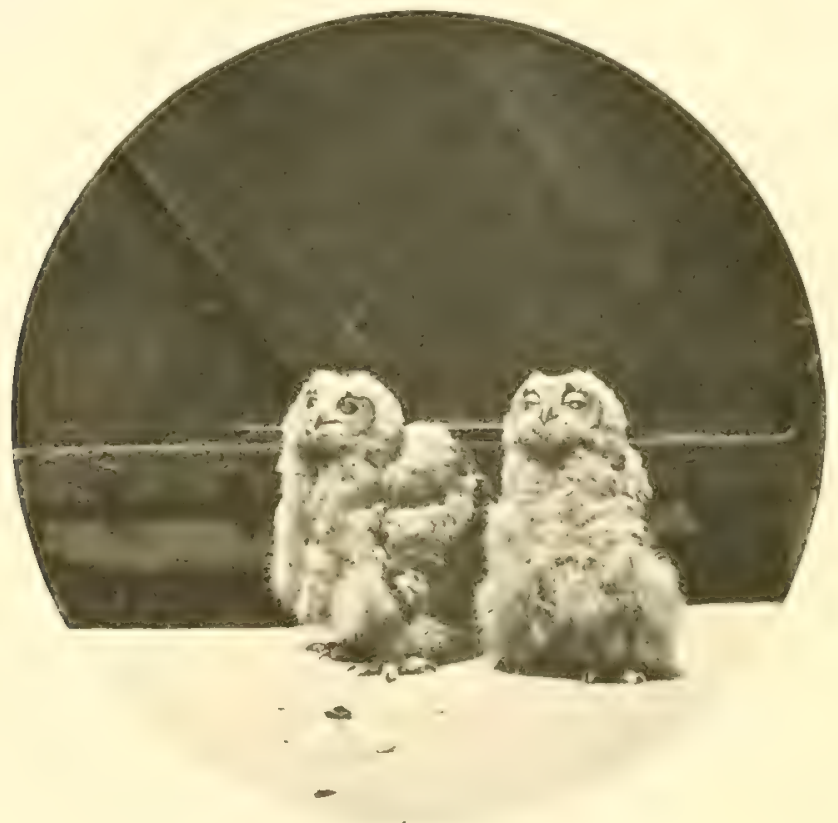

YOUNG EAGLE OWLS IN COURTYARD

more than a few weeks old I encleavoured to photograph them in the courtyard of the house where I was staying and the wath and contempt they erinced at my efforts on this occasion are in some degree reproduced by the picture then taken. The seince was abruptly closed by one of them, not the supercilious one, suddenly making a vicious run at the camera.

As already mentioned, two eggs is the usual complement laid 
but I have more than once heard of three young owls in an nest and have myself found a nest with three eggs. This was in I905 and in the same nest as the owlets of two years before. I went down the cliff this time on a light rope and, despite the room of the cavern, got the photograph of the three egos at is in. distance.

Having done the camera work I called out to Admiral Farquhar who had remained with the party who were handling the rope at

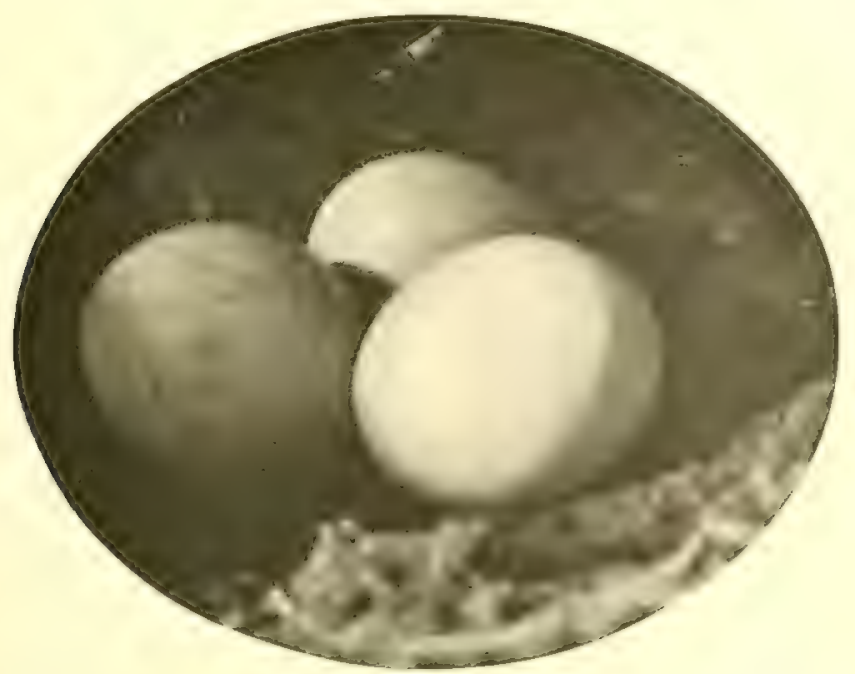

FGGS OF EAGLE OWL IN NEST AT END OF CAVEIRN.

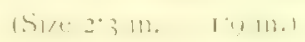

the top of the cliff to come down and join me as I hnew he was anxious to take some Eagle Owl's eges himself. This he dicl, and I ascended. As I came over the cliff I was met by my retriever "Sweep" who was sitting with his paws over the edge, showing his teeth and apparenty pleased to see his mantel sated! back. I had, prior to descending, taken the usual precaution of making one end of the line fast to a rock, a very convenient 
practice when possible, for several reasons, Chancing to look round as I was picking up my discarded gear, I was horrified to see that the rope upon which my friend was depending had been neatly cut through about a yard behind the point where two of the party who were doing the lowering work were grasping it. Of course a caution for them to hold on was all that was

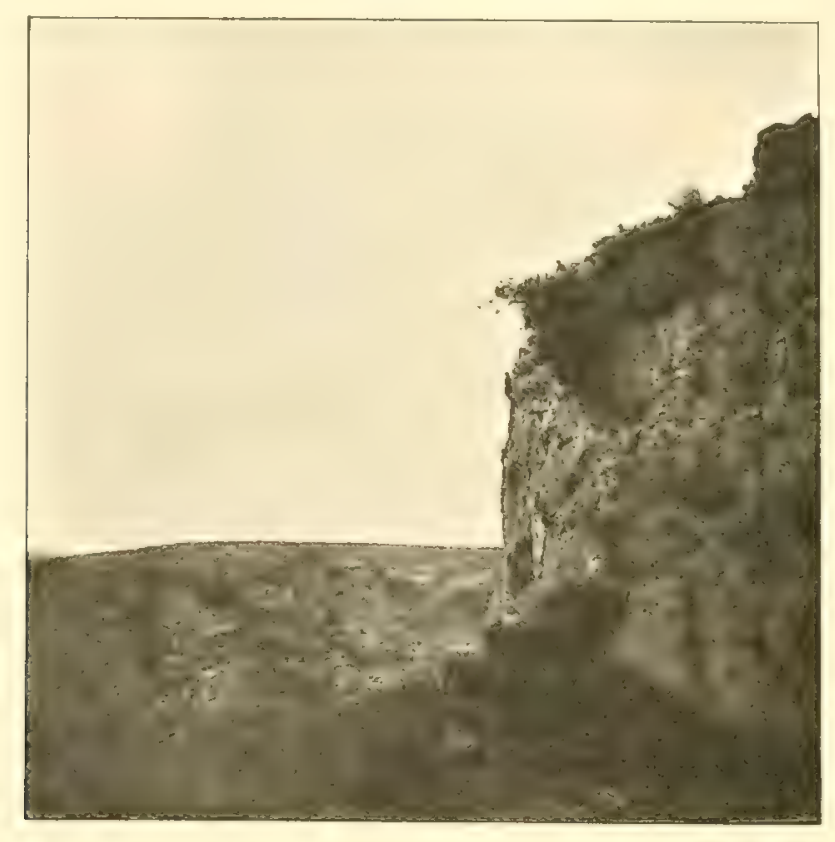

PROFILE OF CRAG WITH CAVERN.

Nesting Place of Eagle Oawl, and formerly of Bonelli's Easle.

needed and no harm befell anyone, but the humour of the situation lay distinstly with the retriever, who tired of being "down-charged" alongside my clothes had whiled away his leisure by thus severing the line of communication between the rock above and his master below. Subsequently I worked round the tank of this little cliff and got a photograph of its profile, 
on a very small scale it is true, but large enough to show one of the party descending to the cavern and those engaged in handling the rope at the summit. To some extent too it may graphically account for my dislike as described earlier in this chapter to going over this cliff without a rope or a friend to gather up the fragments.

In I907 I visited yet another well-known and lons-establinlued nesting place of the Fagle Owl, which has heen regularly expupient by these birds to my knowledge since 1869 , and probably for decades or centuries before that date. My object was to get a photograph of the young in a situation where there would be enough lisht for a snap-shot, since experience had tausht me that it was almost hopeless to get them to remain still for any time. As this nest is placed so that the morning sun shines into it, I felt sure that with good fortune I ought to suceecel. The nest is on a shelf of rock in a cray about $50 \mathrm{ft}$. immediately above a powl of water and can be literally walked into by the most timid of climbers and in consequence is exposed to constint risk lonth of being harried and disturbed. On reaching it I found it empny but next moment I detected the two young (M) which had takin shelter from the heat of the sun's rays, in the midst of a bush of cytisus. They were fully lledged and hat they been permitted to do so, could and would have flapped away and fallen into the water below. To prevent this, I got my companion to sit at the far end of the ledge whilst I herded the two younersters biak into their nest. This they submitted to under protest with many objurgations and violent snaps of their leats together with savage wrabs made with their sharp talons. Finally they resumed their position in the nest, one remaining quiescent for a time whilst the other flung itself betckards and struck out furbusly as I brought the camera to bear at close range, in which eminenty characteristic attitude it appears on the next page. 
The larder is always an interesting feature with the Eagle Owl, and when there are young birds in a nest, it is sometimes large and varied. Five times have I found rabbits, usually with the head and upper portion of the body eaten ; thrice water-voles; whilst in nearly every nest were remains of l'eewits, Kestrels,

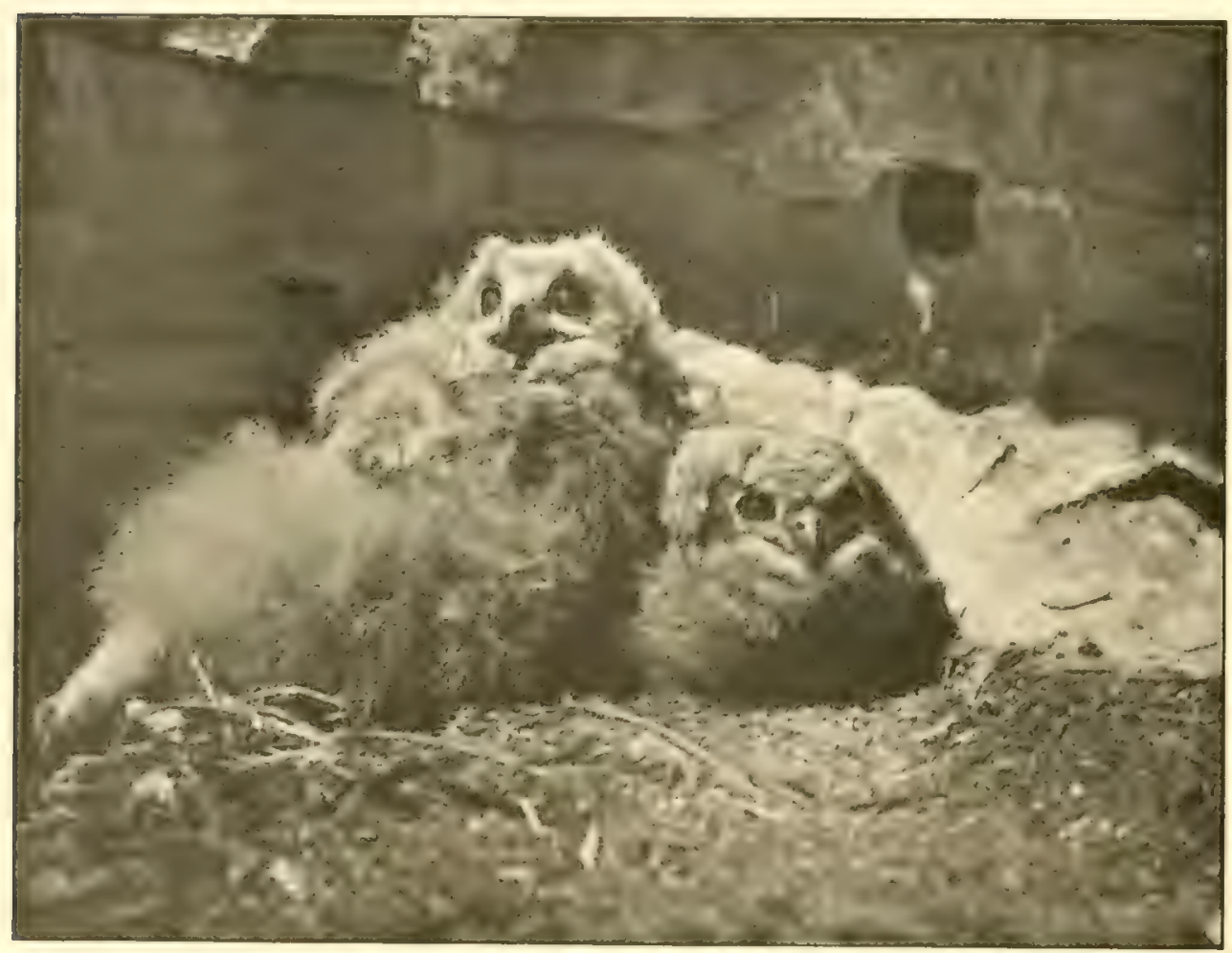

YOUNG EAGLE OWIS IN NEST.

Partridges and various small birds. The Peewits no doubt fall an easy prey to the great Owls, owing to their crepuscular habits. All who have waited for duck at flight-time know how irritating are the Pecwits at that hour of the evening as with querulous cry and loudly humming wings-there is no other word to describe 
the sound they produce as they "shy" at an intruder, which is like that of an electric fan-they cross the view of the expectant shooter and spoil many a fleeting chance of a shot at IVigeon. It was therefore with no small joy and gratification that one evening in March 1907 when crouching in a marsh after sundown for the Wigeon to drop in, and with the Peewits doing their best to annoy and disconcert me, that I beheld in the fading westem light a glorious Eagle ()w skimming straight tomarts me. At the same instant a Peewit passed within a few feet of my face and next moment there was a rush of wings and a cry and a flutter and I knew my friend had replenished his larder up in the sierra and that the two hungry owlets in the heather would not go supperless that night.

As to the Eagle Owls preying upon the Kestrels, I have no ocular proof of how they manage it. But I know of several ()wlo larders which are always full, year after year, of Kestrels primary feathers and other remains. As Kestrels, especially when in colonics, are very much given to fluttering around their nesting stations and making a considerable disturbance about sumetewn, I imagine that the Owls take this opportunity to capture a cortain number of them.

I have for over five years kept the couple of Eagle Owls whose portrait is given on $\mathrm{p} .320$ in an aviary where they have Houriaheal exceedingly and consumed an almost incredible number of rats. Excessively sarvage as already described when tirst talken, they gradually became more amenable and would consent to teke foud

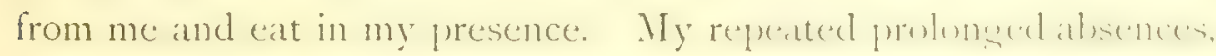
however, during the winter months in Spain hase cumed them w revert to their original uncouth halyits, so much so that mon it in now unusual thing for them to strike viskently at me when I enter the ir dwelling. This is a good-sired cage buile around an iv! tree and with at high pent thatched rouf in the deepr shathw of which in lived 
a barrel. Here when sated they sit side by side, indulging in pistol-like cracks of their beaks when interviewed. But they by no means aroid the light and are often to be seen of a fine day, sitting in the bright sunshine enjoying the warmth of its rays. After various minor engagements with them, during which I received a series of more or less painful stabs from the needle-like hinder talons with which they strike, I procured a fencing mask which to some extent prevents my being taken unawares when engaged in cleaning out or regulating their carge. The courage and pertinacity of these big birds is amazing. One day last summer one of them, after making a violent attack on me which was repulsed with a rake-handle, returned to the assault on eight successive occasions and eventually struck its claws well into my shoulder, after which it retired to its tub and fired volleys of "smaps" at me, evidently much pleased at its success. Despite such minor adventures, feeding Eayle Owls is ever a joy to me, for there is a quaintness and originality about their ways and movements which must be seen to be appreciated.

When food is brought them, they fly to a convenient point such as a log or perch and watch every movement of the feeler intently. Upon a rat or bird being thrown to them they spring up with marvellous agility and "field" it with unerring accuracy, with either left or right foot, even when bowled "wide," dropping back to their perch with their booty. Then if undisturbed, should the foud be of reasonable dimensions, such as a half-grown rat, or a sparrow, it is gravely raised in the talons of one foot and held somewhat as a meditative smoker at times holds his cigar or pipe. Next moment it is seized in the beals head-foremost and swallowed whole. As it disappears the throat is expanded and the beautiful patch of white feathers on it, at other times hardly noticeable, becomes most conspicuous. A pause now generally cunsues, all trace of the meal having departed save an inch or 
two inches of rat's tail which hangs pensively down from one corner of the mouth, or, in the case of a sparrow, occasionally the extremity of the tail feathers. The production of more food at once causes a final gulp to be made and the first course finally disappears, the Owl getting ready for another catch. 'Three young rats or four or five sparrows secom to be thus stowed with but little effort.

The general appearance of the Eagle Owl is known to most people, but few save those who have seen them close at hand realize the marvelinus sise. brilliancy of colour and depth of their wreat yellow eyes, which combined with their so-called "ears, "fine" black tufts on either side of the head, give them a most horritic and impressive appearance. When atarmed or on the alert they compress their plumage and elongate their bodies making at picture of savage determination and strength cither to fight or tlee. To noises, especially those they are unaccustomed to, they are peculiarly sensitive. The rumbling of a cart or waterbarrow for a long time caused them sreat alarm, which they showed by dashing amlessly around their cage. When irritated and angry they assume extraordinary attitudes : every feather on their budies stands erect, nearly tripling their natural size, whilst their wings atre raised an high and arched around so as to form a resular wreath of feathers, in the centre of which appears their heads with their huse yedlow eyes tlashing, their bodies swatyng from side to side as they rest first on one feathered ley and then on the other, all the time siving vent to an appalling series of pistol-shot snaps. This is applatently thedr stock-in-trate for ataming any woukl-be attackers, and is comalnly very effective with cats and many dens, who are clearly at a hou to divine what class of enemy they have to encounter.

For my diminutive Aberdeen terrier "Garry" they have an intense dislike and with small wonder for, whenerer he sere them sitting near the wire, he hurle himself at their catse barking lumbunl: 
and raging up and down in his attempts to get at them. They on their part are no less anxious to close with him and frepuently strike visorously at the wire in the hopes of clamaging him. This warfare has gone on now for five years and both parties are absolutely convinced of their power to obtain a victory and no doubt also in the justice of their cause. Such is Garry's hatred of these birds that he has male repeated efforts when I enter their cage to slip in after me, but as he is equally anxious to have a personal explanation with my captive Bonelli's Eagle, I have no doubt his courage causes him to imagrine himself capable in both cases of defeating them. The bitterness of the quarel has been accentuated by my fiving the big birds live rats to kill, a task he looks upon as one of his especial prerogatives.

When food of larger size, such as a rabbit or full-grown rat, is offered to them, they dash down and seize it and either fly off with it in their talons or, holding it in one foot, limp away on the other dragsing it after them. Arrived at a convenient spot they tuck their prey under them and fluffing out the beautiful vermiculated feathers on and about their thighs until they assume the shape of a pair of big Zouave trousers completely hide their coming meal. On one occasion I threw in a couple of largish halfsrown rabbits, which were promptly seized; one Owl, however, happened to take alarm and dropped its ration, upon which its comrade seized the two, and dispusing them in a convenient heap, quickly expanded his (or her) trousers until both rabbits were completely concealed. The other bird now returned to retrieve its dropped rabbit, and it was a study to observe the anxiety with which it lurched around the cage on the vain quest whilst the other sat erect, puffed out but placid and immovable on top of both rabbits. It was not until the ralie-handle had been vigorously applied that the wearer of the Zouave breeches consented to part with his comrade's rabbit. 
In captivity these birds are somewhat silent; after being fed they usually give a series of weird "boo-oos" of satisfaction;

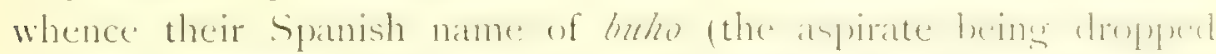
in that language). They also have another cry somewhat resembling a Heron's, which I only hear them utter after night-fall. But in a wild state their cries are peculiarly fascinating and varied, and many a night in the hot summer evenings in Spain have I listened with delight as these grand birds uttered their wilel, melatncholy, hollow calls which echo and re-echo along the rusesed cliffs and gorges in which they spend their joyful existence.

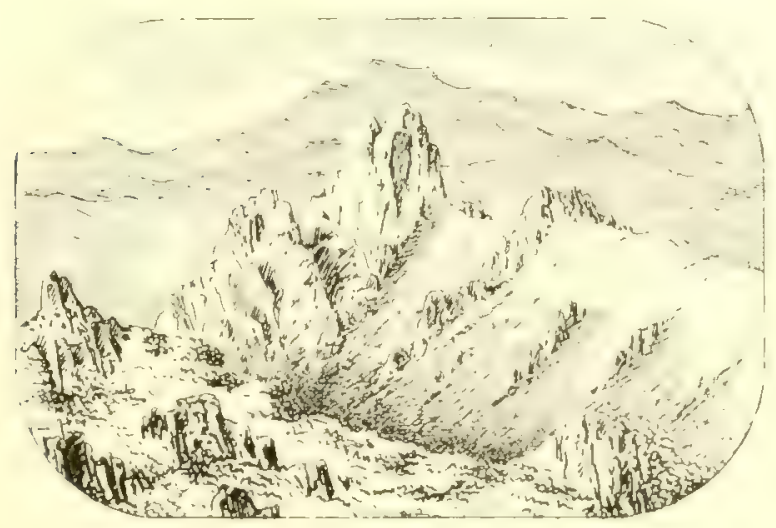




\section{CHAPTER V.}

BONELLI'S EAGLE (Nisaëtus fasciatus).

Used in falconry-Ancient residents at Gibraltar-My first Eagles' nestElaborate preparations - An amateur lowering party--Plumage of Bonellis, adult and young-Great size and power of legs and feet-Records of a Bonelli family-Number of eggs laid-Favourite food-in exchange of eggs, tame Goose's for Eagle's-A ridiculous episode-"Only a photographer" - Rape of the tame Goose's egg-A nasty cliff-A well-drilled lowering party-Admiral Farquhar descends-Perils of old limestone-A nest in I908-An extemporized camera stand - Hanging the operatorYoung Bonelli in nest-Bonelli's Eagle in captivity - Enormous power of feet-Savage nature-Splendid powers of flight.

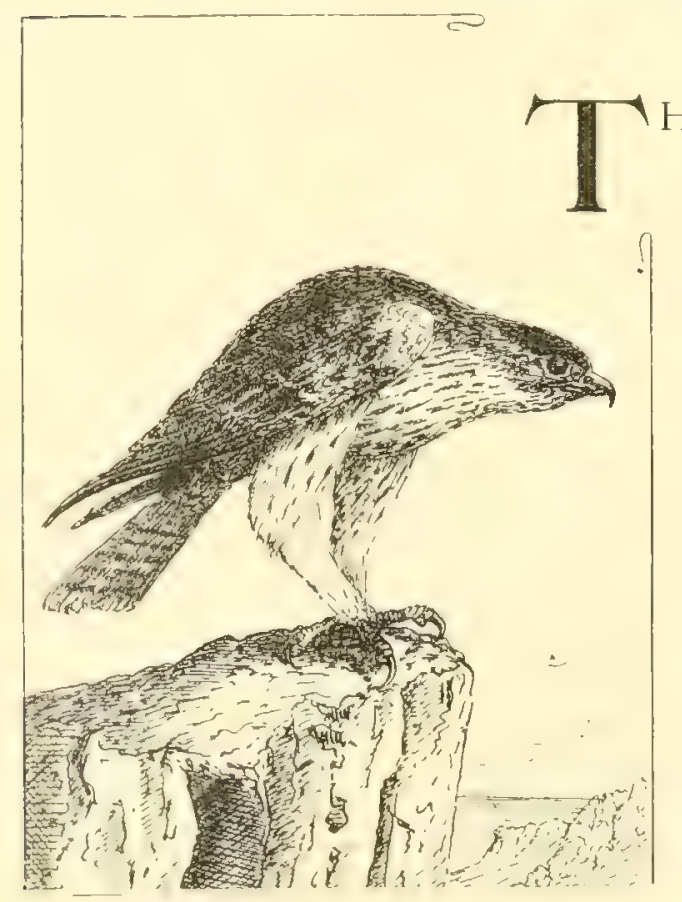

IS comparatively small Eagle appears to have escaped notice until about the year I 822. It is almost inexplicable how the bird should not have attracted attention earlier, for it is so thoroughly aquiline in its build, plumage and habits that it is impossible to confound it with the Buzzards and other lesser raptorial birds. It is essentially a rock-frequenting species and ranges over a considerable portion of the Old World, being found in places suited to its habits from Spain to Central Asia. 


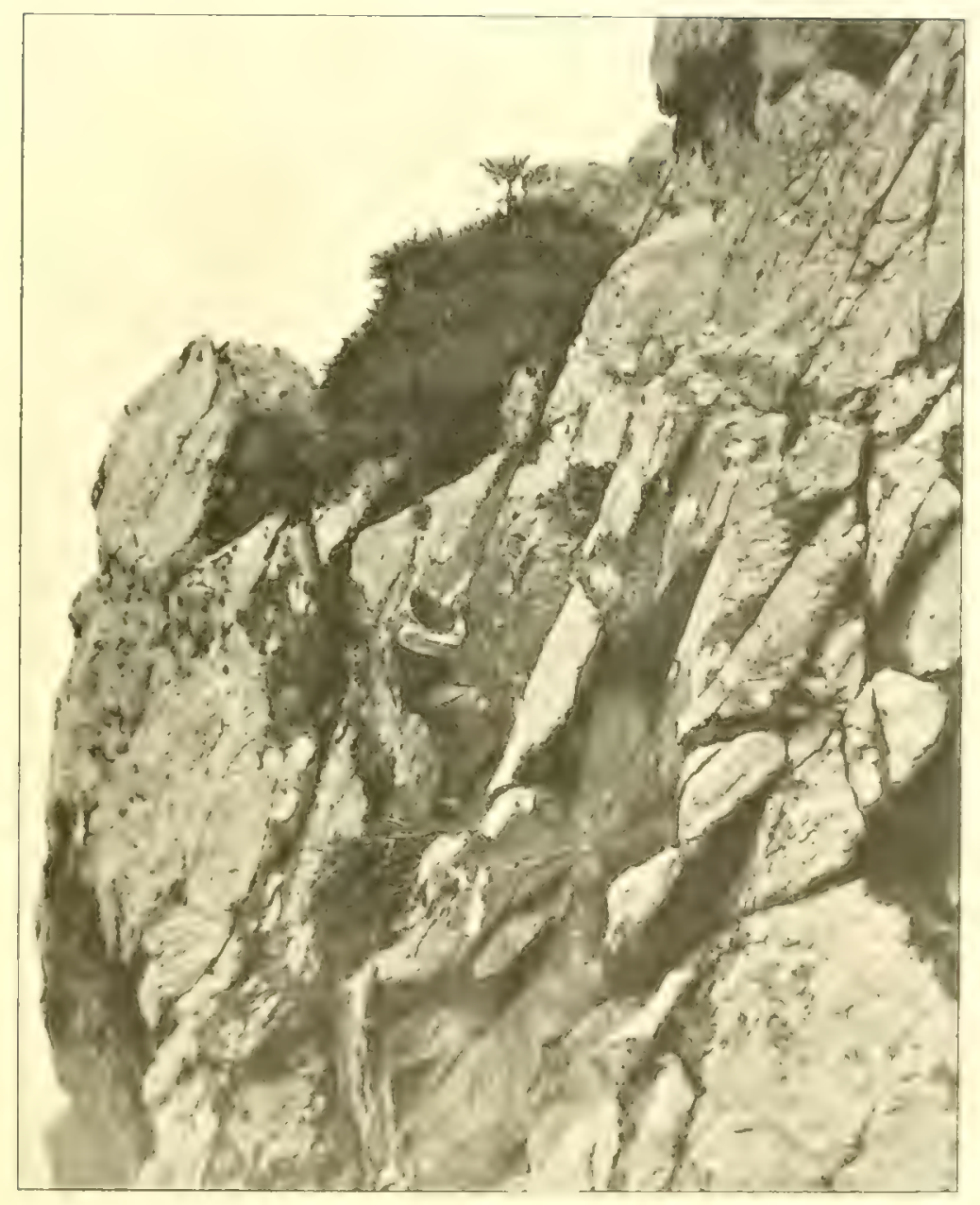

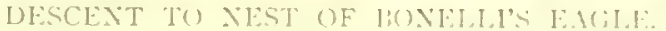



Like many other people whose education in birds had been limited to the so-called British list, I had never even heard of its existence until I first went to Spain in 1874 . But I had

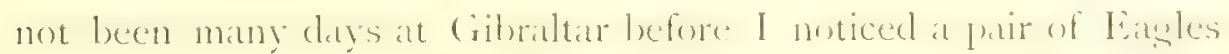
which frequented and. I im halpy to sely, still frerpent, the wreat cliffs on its eastern side, and thus made the acquaintance of a species which hitherts hat been beyond my very limited scope of bird-knowledge. But in ahlition to the natural interest awikened by thus finding myself for the first time in my life in a position to watch and learn something of the habits of Fastes, ats a falconer and the son of a falconer I was intensely attracted by Bonelli's Eagle when I learned that it was the same species which the Afuhans employ for hawking small dect. For varions reasons the larer Eagles have been found to be unsuited for falconry, but there was a report that in Central I sia there was a medium-sized Fayle which was more tractable and this was none other than Bonelli's. According to R. Thompson, linnelli's bagle will talie young decer and full-grown hares; and Allan Hume who quotes this in his book adds "I have myself seen it."

The pair of Eagles which had nested at the back of the Rock from time immemorial (for with Eagles as with a wellestablished dymaty, there is no breati or interlude in the line of autocrats of a definite area), until the advent of Bonelli, had rejoiced in the cuphonions but ambienums name of asuile di lis.s rocas. To the alien English garrison they were likewise known as "Rock Eagles" a term which, as Colonel Irby truly remarks, was all-sufficient for those who would style a burarel a linstaret and vice versê.

It may be readily imagined with what absorbing interest I set myself to watch these birds from in point of vantage at the top of the Rock. In those days the Signal Station was in charge of a Serjeant of the Royal Artillery who had, since he attained 
that elevated position, taken a keen interest in the Eagles and their nesting and kept notes of them. With the aid of one of the powerful telescopes which formed part of his signalman's equipment I was enabled to watch the birds and thus receive my first lessons in the art of studying Eagles in their haunts. I also then first learned, from the Sergeant and Eagles combined, the mysteries of the alternative sites for nesting, adopted by raptorial birds.

This particular pair of Bonelli's Eagles has at least three, if not four, nesting sites on the face of the great precipice south of the Sirnal Station. One of these sites was in full view of the Signal Station Battery of those days. It happened that in the following February the Eagles selected this site for their nestingplace for 1875 , and although I carefully reconnoitred it from both above and below, it was quite beyond my powers, at the time, to reach it. For to do so required a knowledge of cliff-work which I then lacked and further, not only an ample supply of ropes, but of assistants to work them which were, then, so far as I was concened, unobtainable. There was moreover the ancient Garrison Order prohibiting the molestation of the wild birds on the Rock. I however argued to myself that there most assuredly must be other pairs of Bonelli's Eagle nesting in the mountainous country north of Gibraltar and, during the course of an extended expedition later on in the spring, I actually located two pairs. Both were nesting in very big cliffs, over too ft. high and in sites inaccessible without plenty of rope, which we did not possess.

In the following year when riding out from the Rock I saw a pair on the wing but so obsessed was I at this time with the popular belief that Eagles only nested in stupendous cliffs that I dicl not endeavour to track them. Again, a year later when out with the Calpe Hounds I saw one of these Eagles, not far 
from the same crags where I had noted the pair during the preceding year.

Recomizing that there must obrously be some reasm fir this which was worthy of investigation, I took an early opportunity; unobserved, of leaving the hounds. For it is needless to explain that no British officer has any right to abandon the scientific pursuit of a fox in order to follow an Eagle!

I however was rewarded for my pains by seeing the bird, after saling around high abore some rocky ravines, erentually lower its Hight and disappear into a gorge, where I knew there was a small cliff. I did not venture to follow up my observations on that dity for the all-sufficing reasion that the ravine in gutention was a favourite point for foxes to make for. To be found anywhere in the district would bring down upon me the charge of "healing the fox"! Since my own Colonel at this time was Master of the Calpe Hunt, this was, to say the least, undesirable.

Some days later I rode out with a brother subaltern, the present Sir Bartle Frere, and having picketed our horses, we made our way to the top of the suspect cliff. On reaching the edue, I cracked my hunting whip upon which a female linndli dashed out from a point almost exactly below where we stood. At last I had succeeded in my long-protracted quest. It was quite a small place, a nearly vertical cras less than $90 \mathrm{ft}$. in heinht standing abrove a steeply sloping hill-sicle, which wave it the appearance of being much higher. But to examine it a rope was necessary and we returned to the Rock to arrange details.

It was in truth an eventful day in my birdsnesting life when I set out, some days later, to attempt to get this nest. I had no experience of rope work on cliffs but like most perple laul real various accounts of its alleged perils. I accordingly made preparations which, in view of many years subsepuent ayperinces of really dangerous cliffs, now cause me some amuscment. For 
my lowering party I secured no less than three recruits. One, my friend of the previous visit, a second being another Rifleman, Harry Fergusson, and the third, an officer from the garrison.

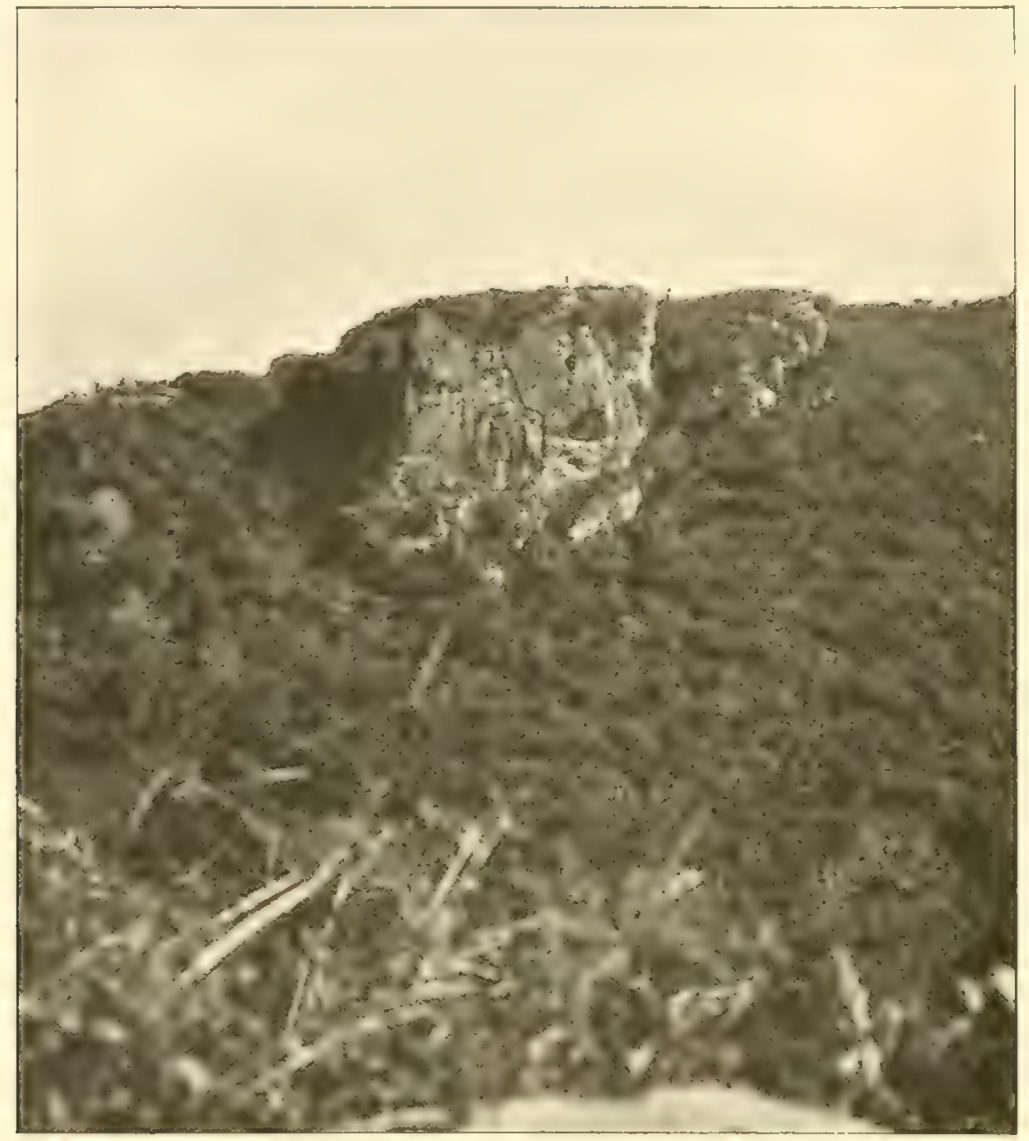

NESTING PLACE OF DONELLI'S EAGLE.

(The nest is in the small car'e, half-zory betacen the firure on the skg'line and the cavern below.)

Arrived at the crag, we once anain sallied the Eagle from her nest, after which I was bound with ropes and lowered over. In order to guard against the entirely imaginary risk of a 2 in. rope cutting 
or fraying during such a short descent a point was selected whence the rope got a clear run and as a result I went through the unnecessary discomfort of swingine clear of the clifi, for which there was no earthly reason. When about $25 \mathrm{ft}$. down I saw the cavern to my left which I eventually reached. As I came oppunite to it, I saw to my intense joy a big nest of sticks and fresh green ilex boughs about $6 \mathrm{ft}$. from the entrance. Haring secureel my footing, I sang out for more rope and scrambled into the carern. There, in front of me, lying in a basin-like depression amid the sreen ilex leaves, were two beatutiful Bonelli's engs! Ithat my feelings were at this moment can only be justly appreciaterl by the unrepentant birdsnester. The carern was but little more than a loole in the face of the crag, measuring about $5 \mathrm{ft}$. in height and some $4 \mathrm{ft}$. in breadth. The floor was of earth and sand and sloped upwards, the cavern yetting moch smaller at its far end.

The eggs were white, very faintly clouded with purplish blotches and with a few rufous makkings, the laregest measuring 2.75 in. by 2.05 in. Having examined my prize thoroughly, I returned to the top of the cliff to set my exs-boxes and other appliances. I was wildly excited at my good fortune, which naturally enough had driven all ideas of any danger of the climb out of my head. Also, the return jumrney hat been so simple: that I had forgotten the blundering descent. Not som commates however, who, one and all as inexperienced ats myself in clift worts and none of them climbers, viewed my conduct as reckless and absurd. Unaware of this opinion and burstins with onthusianm, I described briefly the glories I had seen and turning to the third member of my party said, "Now! I'll lower you down and you shall see an Eagle's nest for yourself." 'The man aypueded w thus suffered from a severe impediment in his speech. Iomkins at me hard and with compressed lips, he ejaculeted, crielenty trom 
the very bottom of his heart, "No! I'm b-b-b-blest if you do!" Fersusson's reply was equally emphatic although somewhat more curt. Baftled in my efforts to share my joy with others, I again descended to the nest and since it was practically impossible to make much of a sketch of the interior of the cavern, I crept in as far as I could and made a water-colour drawing of what the Eagle silw when engaged in her duties of incubation. Indifferent as is this sketch it recalls every incident of that morning's work, now over thirty years ayo. Below the cavern the cliff fell vertically for some $60 \mathrm{ft}$, to a slope covered with dense scrub, at the foot of which ran a stream in a sandy water-course. Across the valley lay a low range of hills at the time brilliant with yellow genistit. Far beyond, the purple masses and jagsed outline of the main sierra completed the picture. A small pen-and-ink copy of this sketch will be found at the end of the chapter on Eagle Owls.

Exactly eighteen years later, in $1 \$ 95$. I once again visited this cliff, this time in quest of Eagle Owls and with my small handcamera photographed the same view that I had previously sketched. A subsequent comparison of sketch and photograph at any rate justified my care with my pencil and recalled to me the cruel criticism once passed on my artistic efforts, namely that at any rate my sketches were very like the places!

The general appearance of the adult Bonelli is dark brown abov: and very white below. Between the shoulders is a conspicuous white patch which makes it easy to identify the species at a considerable distance. The breast is streaked with dark brown but this does not prevent the general white appearance of the bird when viewed from below.

The youns are entirely different, the throat, breast and underparts being of a warm rufous tint, and there is no white patch between the shoulders, at any rate for over a year as I can testify from having reared young Bonellis. The difference between 
the two plumages is consequently most marked. In the second year the breast becomes lighter and large dark streaks appear. The iris also grows paler-a dull umber brown. The adult plumage is certainly not assumed until the third year but I have indisputable ocular prof that the birds sometimes par and brecel when still wearing the immature plumases at any rate the females do so.

As regards their structure, few Eagles, if indeed any, are so powerful for their sise as is Bonelli's. Their massive leass and feet and abnormally large claws are seemingly out of all proportion to the rest of their body. I have a foot of a female Bonelli which might easily be taken as belonging 10 a Golden Eayle, a bird nearly double the size and weight.

When they fly off the nest they make a rapid dive, quickly followed by a sharp upward curve which makes it no easy matter to shoot them. We had practical proof of this more than once in the case of a female belonging to the nest of 1877 , much to the perplexity of those concerned, both excellent shots. Eventually the murder was perpetrated and I have her now stuffed in my collection. She has a very white breast, finely streaked with brown. All the males which I have watched enter or leave a nest have been similar in plumage, but not all the female birde as already mentioned.

I am happy to be able to record that I have the life of only one Bonelli's Eagle on my conscience and this in spite of the many nests I have visited and the innumerable opportunities when I have had them within close range.

The next year the bereaved male found another mate and they nested in a low cliff, not $30 \mathrm{ft}$. high, on a shelf of rock less than $6 \mathrm{ft}$. from the summit, which it was possible to walk into. This nest was in the same ravine as the previous year but on the opplosite

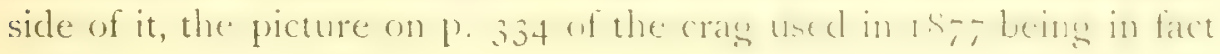




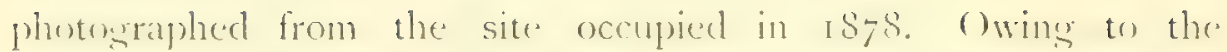
situation of this nest, which had an overhanging rock as well as a gnarled wild olive tree immediately above it, I was able more than once to apporach unseen and to watch the female sitting on her eggs about 8 or $9 \mathrm{ft}$. from me. On such occasions she would soon detect my presence, turning her head round and glancing upwards before dashing off.

In I $\$ 79$ this pair of Eagles moved to a third site in an adjacent valley about 500 yards from the first nest. This nest was placed on a ledge open to the sky only i $5 \mathrm{ft}$. from the top of a crag and about 20 ft. from the base. The ledge sloped downrards and it was a marvel why the nest did not slide off. To reach it was simple enough, since it was pussible to climb to the point where the ledge began, whence it wats necessary to sidle along for some $\mathrm{S}$ or Io ft. A sketch of this nest will be found at the end of the chapter on Cliff climbing on 1. go. There was no handhold and the ledge was smooth and slippery and without herbage, points which no doulit had been duly noted hy the Fingles. Close below the nest was a cavern in which I secreted myself on several occasions in order to watch the old birds. Sometimes I. was given notice of their apprateh hy the shatum cast as one of them satiled round overhead and by cautiously peeping through a crevice I could see the Eargle as it alighted on the edge of the nest and wallecel in. It was an ickeal sport whence on observe the movements and plumage of these beautiful birds.

Seven years later, in I886, on my way out on a birdsnesting expedition to the Levant, I was at Gibraltar for a feu days and rode out to my old haunts. I found the Eagles still in occupation of this site. Lnfortunately they subserpuently dereloped a taste for the fowls belonging to a soatherd who lived hard by and he in revenge climbed to the top of the crag and dropped stones on their ergst a simple matter enough in the circumstances. In consequence. 
they abandoned this site. It speaks for the solid com-truction of the: nests of these Eagles that this same nest is still in existence. I have seen it from time to time during the last twenty years and only recently in 1908 had a look at it, when it was still intact but overgrown with green herbage.

The great majority of the nests of Bonelli's Eagle which I have visited have been placed on an open ledge very near the top of the cliff. So far as I have seen, this seems to be their favourite situation and it is the same whether the cliff is only $50 \mathrm{ft}$. high or $500 \mathrm{ft}$. In most cases there has been some stunted, wind-twisted tree, usually a wild olive, growing immediately above the nest affording a certain amount of sheler both from the weather and from observation. Two eggs is their full complement but it is by no means unusual to find a nest with only one. I have done so myself on five occasions, when there was no question of a possible second egg being laid. As a rule, the eggs are but little marked, some being almost white, but I have twice found single eggs, with fine rufous markings.

The favourite food of Bonelli's Eagle would seem to be rabbits, remains of which I have constantly found in their nests. They are also much akdicted to Partridges and are in conseruence known to the folk in the sierras as perdicera or the "Partridge hunter," to give a rough equivalent. As already mentioned, they have a great liking for the domestic fowl and owing to this and their allener depredations on the very young kids they are much disliked he the peasants. As regards fowls, in nearly every instance where I have heard of sor-called ciolden Earkles taking them it has turned out to be Bonelli's Eagle who was to blame.

Within a few miles of where I pass the winter months in southern Spain there is a fine cliff about 200 feet high on which is a ledge that has served ats a nestims-place for Bumelli's Eagles off and on for many years. ()riginally a comklen Eangles 
site, when these birds were forced to move clsewhere it was taken possession of by a pair of Bonelli's Eagles. In the years when they elected to occupy an alternative site some Ravens used it. In I 894 one of the old birds was shot and its mate forsook the locality. The following year some Griffon V'ultures seized on the old nest. The big female with outspread wings now in the case of Vultures at the British Musenm of Natural History was shot from off this nest. In I905 I once again found myself near the place and from a distance saw a large dark-coloured Eagle leave the nest. It is a good example of the uncertainties attending birdidentification, a task so lightly assumed by many, that in spite of the fact that I have seen many Bonelli's Eayles as well as Golden I made the mistake of imagining the bird I had seen to be a Golden Eagle. I was alone at the time and the nest required ropes to reach it and some days elapsed before I was able to arrange for a party to assist me. The second time I visited the cliff, to my great surprise, in place of the dark Eagle I had seen before a white-breasted bird flew off the nest, without doubt a Bonelli's Eagle. It was evidently a case for investigation, so concealing myself in the scrub at the foot of the cliff I wated and watched. Before long an Eagle, evidently the female, from its size, returned and entered the nest. V'ery soon afterwards I saw a second Eagle flying straight towards me which with my glass I made out to be an adult Bonelli with white underparts. Onward it came and when it was less than 50 yards from the cliff its mate dashed off the nest and flew off in the direction the other had come from. The two birds passed one another like a Hash, in mid-air, at a point less than $100 \mathrm{ft}$. above me and about 30 yands to my front. I thus had an unrivalled chance of comparing them and noted that the outgoing bird was the larger female in inmature plumage. whereas the incoming bird was the smaller male in the white adult dress I have already described. I submit that it would be impossible 
to obtain more conclusive evidence of these birds breeding before they have acquired the well-known adult plumage.

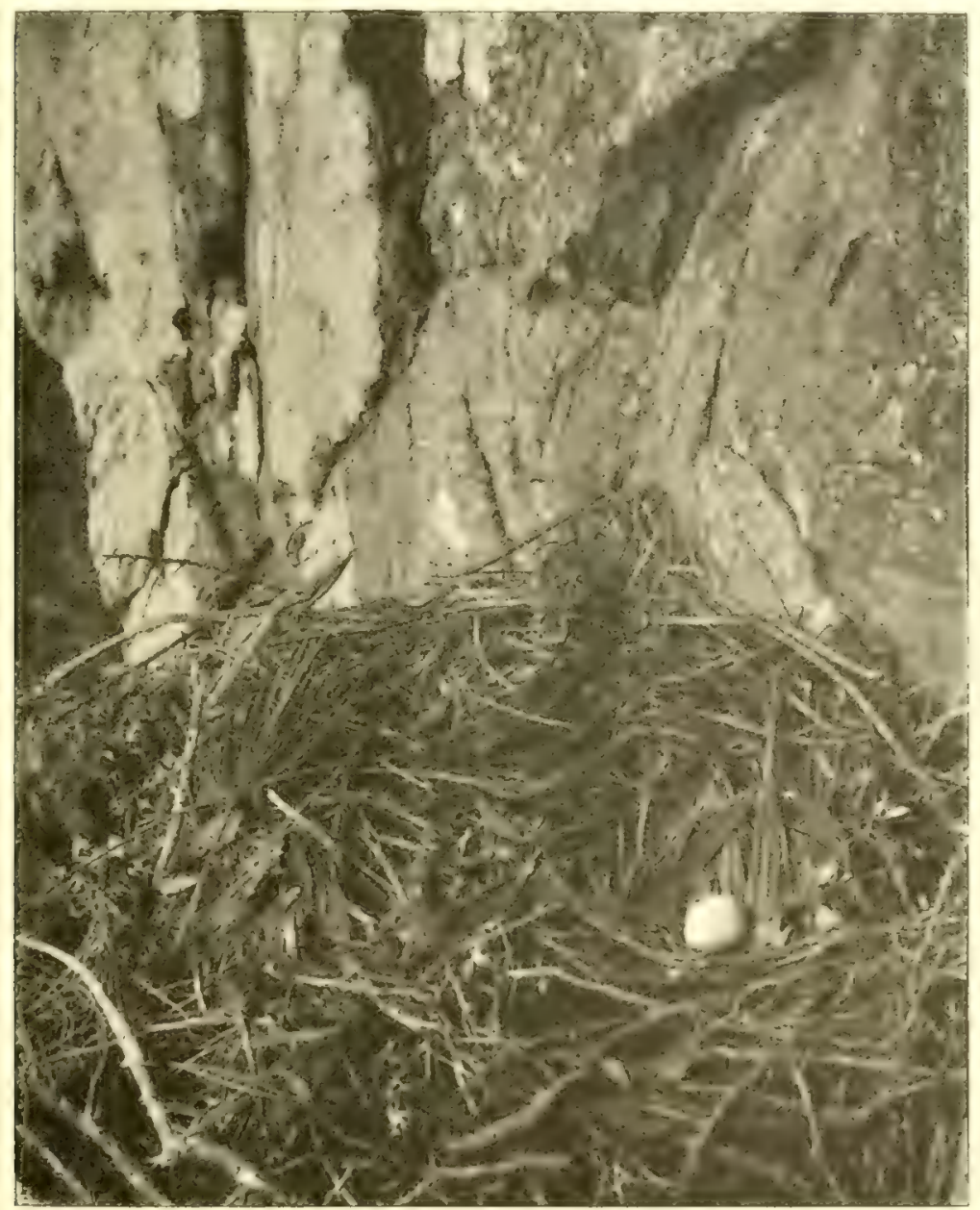

NEST OF BONELLI'S EAGLE.

The male went straight to the nest and took up the duty of incubation without a monentis delay, the femeles winging her way over to the hills to my front and disappearing from riew. Having 
got my party towether we proceeded to the top of the cliff. whence it was but a short drop to the nest, easy enough with a rope. This nest was a big structure of sticks, probably the remains of the Golden Eactes' tenancy supplemented by the Ravens improvements, and was lined with freshly cut branches from the palmetto bushes and some cork-tree boughs.

It contained but a single egg of the usual rounded shape of Eagles exses, well coloured with rufous markings at the larger end. For a moment I hesitated whether I should take the exy or leave it until a second was laid. Eventually, I decided to take it and replaced it with a tame goose's exy which I had with me in view of such emergencies.

I should mention here that it is a good plan always to carry a couple of fowl's egos when on birdsnesting expeclitions so that in the event of it being necessary to revisit a nest, they maly be left in it in place of those abstracted, by which means the old bird may be induced to continue sitting. For such a purpose, I usually carry large fowl's egres but on this accasion chanced to have a goose's, which had been laid by a tame goose which I used as a call-bird when driving IVild Geese during the winter months. It was somewhat larger than bonelli's exg and of course of a totally different shape, since Geese, both wild and domesticated, lay somewhat elongated exgers pointed at both ends, whereas Eagles lay rounded eggs, with one end larger than the other.

Upon blowing the Eargles exy I found it to be considerably incubated, a proof that there was no chance of a second exg being laid. It seemed rather unkind to the Eagles to leave them thus engaged in the fruitless task of endeavouring to hatch off a tame gonse's eng, but as I did not blow the Eagle's until I had returned to our horses, some hundreds of feet below the nest, I was phisically incapable of returning to it to remore the goose's egenIt chanced that some weeks later I rode past the cliff with 


\section{The Photographer and the Tame Goose's Egg i it3}

some friends and we saw the white-breasted female leave it. WC climbed to the summit and looked over. There, sure enough, only $15 \mathrm{ft}$. below us lay the pointed goose's eggr, but, as I had

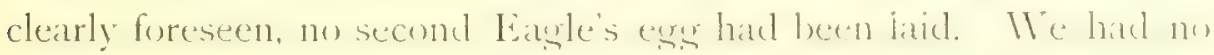
rope with us, else I should have descended and put an end to the deception.

As events turned out, this resulted in an unforeseen but supremely ludicrous episode. A few days after the last visit to Bonelli's crag, on our return from a long expedition one evening, I was informed that two Englishmen had arrived and hard installed themselves in the kitchen of a cottage adjoining my own which I hat temporarily hired since I hat more people staying with me than my small house could hold. On enquiry I found them to be a professional bird photosrapher and his assistant wut on tour in quest of "copy," who by some curious chance had come to stop at the identical spot where I have lived for so many years and which, it should be mentioned, is many hours from the nearest civilization. They assured me they were not collectors, in fact they did not take nests "only photentaphed them." During their stay they made various expeditions in the neighburhoud and then disappeared as suddenly as they had come, as also by the way did sundry Neophrons' and other eggs about the same time.

This occurred in the month of April. In the following March I was as usual staying in the same place and had forgotten all about the incident when one day I received a copy of Country" Life sent me by one of the party who had lowered me to the Bunelli's nest the previone year and had seen me place the sumsers egg in it. In this number, to my intense amusement, as well as to that of all who were concerned in the expedition, there was a most graphic account of the identical nest of Bonelli's Eagle we had robbed, describing how my photegraphing friend hat whaned the egg from it! With the set purpose, apparently, to place on record 
for all time his ignorance of Eagles and their exrys, the unfortunate writer went into the most minute details as to how the egg he had so wallantly obtaned was " white and somewhat pointed at both encls" : in fact an mmistaliable tame goose's esg! How painfully

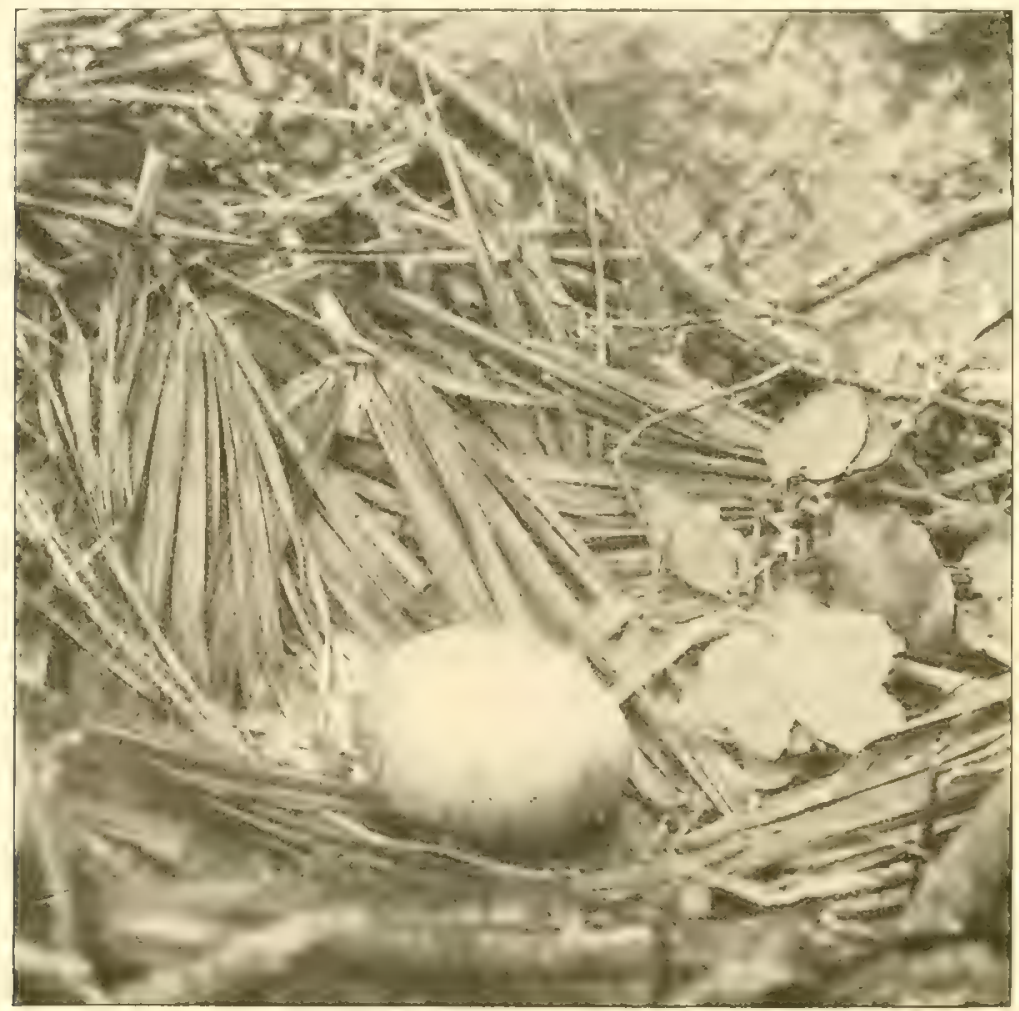

EGG OF BONELLI'S EAGLE. (Size $207 \mathrm{in} . \times 2$ in.)

unlike a Bonelli's egg is this veracious description can be seen by the accompanying photograph which I took of the real exs at about is in. distance when I was lowered to the nest.

Unfortunately, the goose-egger was by his own account not also a cliff-climber, nor was he equipped with a hand-camerat or 
other suitable apparatus for use in what was really a rather awkward situation for camera work. Thus it came about that Country Life lost a unique opportunity of a photograph of an "Eagle's" eggr which, had it appeared, I should have hoped to obtain permission to reproduce here.

Some time after this episode, I met some carboncros (charcual burners), old acquaintances of mine, who lived near the cliff ancl had seen me descend to the nest and photograph it. They had taken a keen interest in the transposition of the goose's for the Eagle's eggr and had, from time to time, looked over the cliff to see if a gosling had hatched out. When therefore "a long Englishman," as they described the photographer, one day appeared on the scene and was at immense trouble to get the much-coveted egg "within his grasp" as he expressed it, they were enormously amused. The sense of humour which happily is so general among these poor fellows, who live cruelly hard lives with nothing to enliven them, found full scope in narrating the story. Nor do I escape altogether, for I am credited with risking my neck in order to put tame goose's eugrgs into Eagles' nests with the express purpose of fooling those who attempt to follow in my footsteps. The final verdict being that El Corond was admittedly loco, mad, but that he at least knew what he wanted, whereas the luckless photogiapher was whiously tomte. imbecile, for he did not know what he was doing. I sometimes wonder in whose collection this most remarliable "prize" now finds a place!

It will be noted that most of the nesting-places of Bonelli's Eangle I have thus described at length were, compratatively spealions. very easy to reach. It is by no means always so, even in the most unfrequented and uninhabited districts. Thus, I know of at nest in the Serrania of Rondit close beneath at iloping terrace on the side of a very precipitous mountain. From this terace there is a sheer 
drop of several hundred feet to a yreat talus below. Above the terrace are a series of other precipices, whence have fallen masses of fractured limestone, framents of which are perched on the terrace or wedged amid the rocks immediately above it.

On the day previous to visiting this spot we had seen a Bonellis Eagle enter the cliff below some wild ulive trees which grew close to the edge. From our position on the talus some $600 \mathrm{ft}$. below it was most difficult to be certain of the precise point. After a wide detour and a long scramble up steep stopes, round rocky bluffs and once right through a big fissure in a clifi, we wained a point above the terrace whence a sort of natural stitircase led down to our cliff. Here we found a rope very useful as a life-line. IV e were now anly $50 \mathrm{ft}$. from the olive trees at the edere of the cliff and it was absolutely necessary to be certain of the precise spot immediately above the nest before attempting to go over the cliff, for it was no place for experimental work. Fortumately I had with me a well-drilled party, so four of us proceeded as close to the edge as possible, separated from one another by $20 \mathrm{ft}$. intervals. We were thus in a position to mark with reasonable accuracy the exact spot the Eagle left when put off her nest. My own billet was in an olive tree which overhums the cliff and to reach it meant a cautious scramble down the sloping talus. To add to un discomfort it was blowing hard and the violent gusts of wind compelled me to hold on as if aloft at sea. Bad as was my situation, I feel sure that some of the others were worse.

When all was ready, some loose rocks were toppled over the edge, which with a pistol-shot caused the Eagle to dash out of the cliff. Thanks to our careful arrangements we were able to locate the point exactly and no time wats lost in making the necessary preparations for lowering. The nest was designated for my companion, Admiral liarpuhar, and I must confess to feeling some (pualms ats I saw him disippearing over the brow. Just at the 


\section{A Dangerous Cliff}

moment some furious rain-squalls were passing and the drifting clouds and vapour halfobscured the view of the rocky valley and winding stream which lay far away, Soo or more feet below us, and made the descent look doubly formidable. The lowering party were perched amid the rocks $30 \mathrm{ft}$. above me and I was in at life-line at the extreme edge, but such was the nature of the cliff that I could see nothing immediately betow me and I remaned crouched down, anxiously feeling the rope as it passed through my hands and waiting for the signal whistle from below. The wind whistled and roured around the edere of the cliff and it seemed impossible to hear anything. I'ery som to my wreat relicf, I heard the whistle, "Haul up," and soon we had our climber back safe among us.

One of those untoward affairs now occurred which illustrate the wide difference between rope-work amome cliffs well-known to the climbers and the reverse. I called attention to this when discussing climbing in general in an earlier part of this book. My comrade having been hanled up to the lowering party, I was in the act of following him up, when a great mass of seemingly solid rock upon which I put my weight sucledenly came awaty in my hand and bounding past me down the shexe, disappeared over the cliff at the point where we had both leen climbing and we heard it crashing and splintering ats it struck the recks hundreds of feet bedow. So much for working amons disintegrated limestone rocks! Nor is it to be wondered at. The excessive rain-fall in this region during the winter months, the dense clouds which so constantly enshroud the mountain tops, the snow and hard frosts of every successive winter and the powerful rays of the Indalucian summer sun, all combine to break up the bartest formations. Some of the huge talus of sharply broken stone which are met with at comparatively low altitudes in this rewion beat docpent testimong to the irresistible forces of Nature. 
In the case in point I was luckily still in my bowline or certainly would not be writing this, but such incidents are most disquieting and do not add to one's sense of security. I mentally rowed to be more careful in future. Oddly enough, others did the same, for two years later when engaged on this book I chanced to ask Almiral Farquhar what, in his opinion, was the nastiest place he had ever been in when eagle-nesting. He at once replied "That Boncli's nest we took toyether," adding that, had he not been so desperately anxious to take a Bonelli's egry with his own hands, he would not have gone over the cliff on that day. Curiously conoug, neither he nor I had ever discussed the affair in the intervening time, possibly the most eloquent proof that we did not altowether enjoy ourselves. But most assuredly it requires a man to be possessed of the true birdsnesting spirit, the spirit that discounts all dangers where a nest must be got, to induce him to go over a cliff as did my okt comrade on this occasion. However he got the egon!

I revisited this district but not this same nesting-place in the spring of Igos, as I was anxious to get a photograph of a Bonellis nest with two exgs in it. The nest I selected for my attempt wats only almut $30 \mathrm{ft}$. from the summit of an orerhanging cliff and was placed on a very small ledue beyond which the big nest protruded consiclerably. Below the nest the cliff inclined inwards so that it was a clear drop to the ground far away below. There was no foothold or support amid the rocks anywhere near the nest, and as soon as I was lowered to it I realized that I had my work cut out for me. fortunately, just above the nest a very sturdy old olive tree was srowing out of a cleft in the rocks, the nest depending for its support upon some of the lower branches of a second tree which curving downwards serred to retain it in its somewhat precarious position on the shelving ledge. I friendly branch of the first olive tree extended above the nest and but $5 \mathrm{ft}$. from it, and I saw that if 
only I could use this branch as a "stand," I might lx able to holk the camera on it steady enough to get a 30 -second exposure. I found however that I needed both hands to keep me from swingin: off the bough and even then my weight cauned it to lend lighty. quite enough anyway to spoil a photograph. To depend on the: rope alone as my support was out of the question, for there is a lot of vibration in $30 \mathrm{ft}$. of $1 \frac{1}{2}$ in. rope.

Looking around, I espied only a couple of feet overhead a still stouter bough and realized that herein laty my opportunity. So, carefully overhauling the end of my rope, I matle it fast 40 this branch so that I remained suspended just below it ly the small of my back. By good luck I was now able to jamb one foot into a cranny and thus to steady myself completely. I now laid the camera on the lower bough in front of me and found to my joy that it was to all intents and purposes stealy.

Determined not to lose such an opportunity, I took a series of photographs with both cameras. One stet, alas! owing to the same defective films which had served me so cruelly in the calse of a Bearded Vulture's nest only the clay before were spoilt. () if the others in three cases the camera slipped and in some the olive branches vibrated in the wind. Owing to my constranded position and the fact that the eggrs were below me I could not look into the finder when photographing and hence lost once or two exposures owing to the exgs being on the alge of the film. Curious to say, my greatest trouble was to find a spot where I could deposit my watch in order to time the exposures. Fventually I managed to suspend it to a twig. I made a vow there and then never again to attempt photography in awkward places unless provided with a wrist watch. It all sounds very trivial, lut there are assuredly troubles enough for the unfortunate climber (n) deavouring at one and the same time to retain his babme and to manipulate a folding-camera without any such extrat ammyances. 
I confess to feeling a sort of sardonic pleasure when in this "precarious and not at all permanent" position, in the words

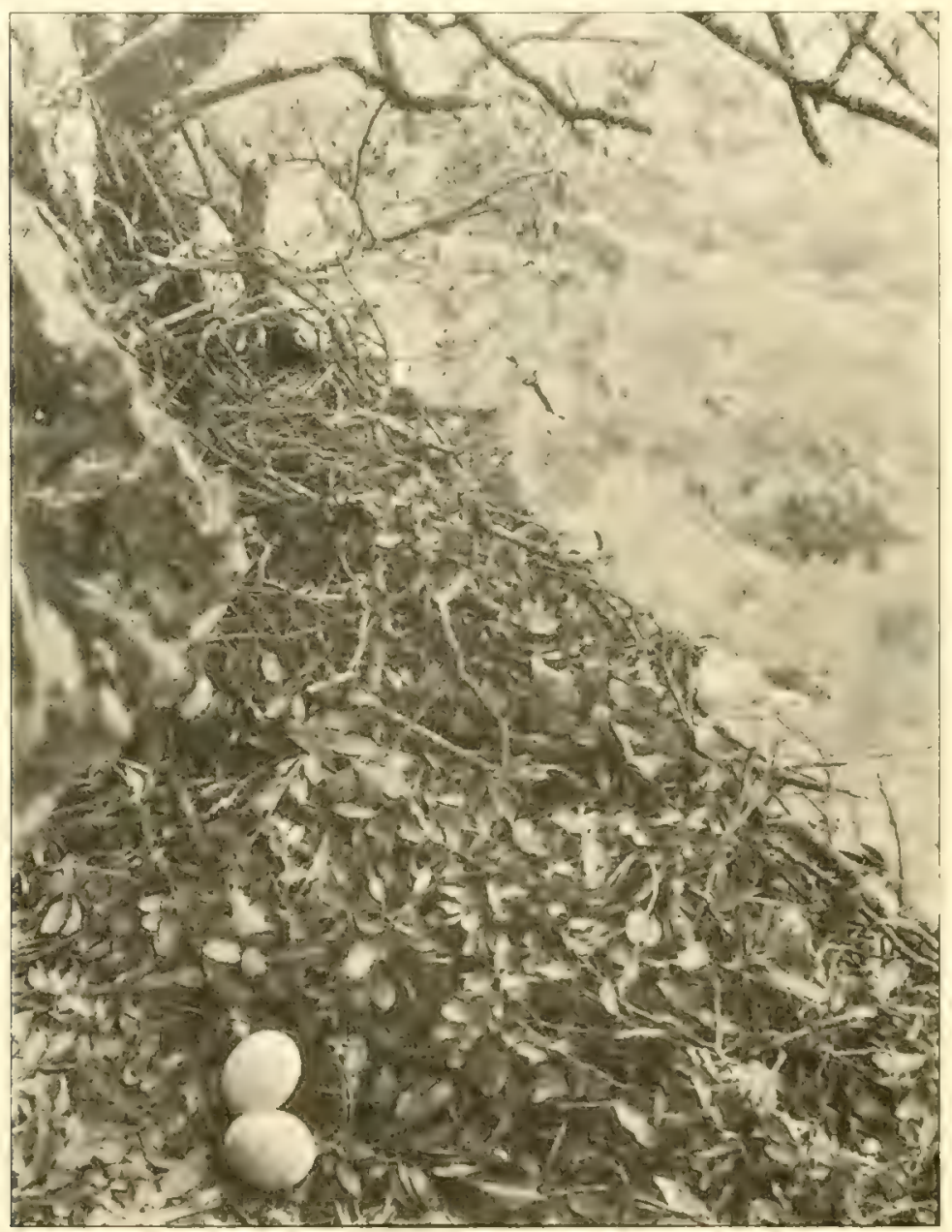

NEST" OF BONFILI'S EAGIE

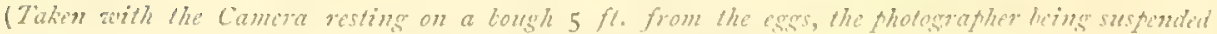
from a branch just aboz'e.)

of Mr. Chucks, at the thought how utterly subversive of all orthodox photography, with its accompanying rigid tripods and 
stands, was my weather-worn olive tree and the light rope wherewith I was lashed thereto.

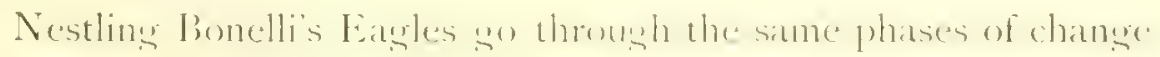
of plumage as do other eagles; from their earliest days the great

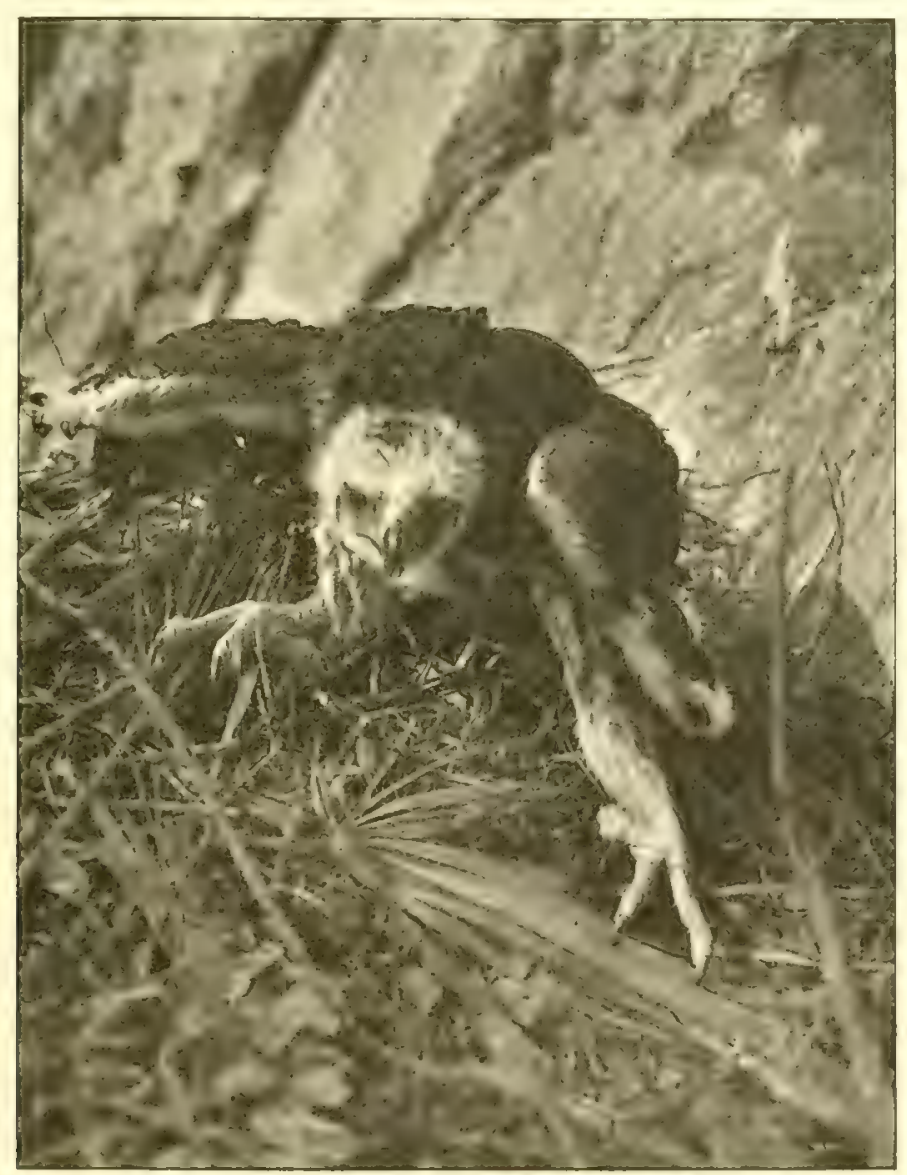

YOUNG RONELLT'S EACLI IN NEST SHOWING FIGHT.

size and power of their feet to which I have already called attention are very noticeable. In I907 I was lowered into a nest containing one young bird, fully fledged. As I landed in the 
nest, it threw itself inter a splendid attitude of definnce and defence as if challenging me to come on.

I had some trouble in photographing this young savage, as when the camera was brought near it, it struck out furiously with its talons and it was wonderful to see what a reach it possessed when it had a mind to inflict an injury. Curiously enough, by its side was the body of a freshly-killed cock Blackbird, plucked almost completely clean of feathers, the bright yellow bill and a few small feathers around the base of it alone serving to indicate what it was. A blackbird would appear to be a very small quarry for such a fine and powerful bird as Bonelli to capture. But the reason was simple enough: the billsides, immediately below the nest and for miles around are densely overgrown with lentiscus, with stunted cork and olive trees scattered at intervals, anid which blackbirds are abundant. No doubt as the Eagles skim over the undulating sround in quest of rabbits or Partridges, innumerable. opportunities occur for grabbing a thoughtless Blackbird, which. after the manner of their kind, ty chattering from one clump to another.

I Iaving decided to take the young Eagke, I attempted to pick it up, but it threw itself on its lack and was so pugnacious that I forwent the pleasure of its company during my ascent. Haring left it to recover its feet, by means of a few feints, I induced it to back towards the edge of the nest, when a push with my foot sent it over into space and it descended with extended wings, parachute fashion, dropping into a big cistus bush a hundred feet below, whence I subsequently retrieved it. This is the bird I have alive at my home in England and a very interesting one it is to study. Its favourite food is rabbits or rats, but judging from its fierce demeanour when cats come near its aviary, I imagine they would have a bad time of it, if they rentured within its grasp. Grasp is indeed the word, for of all the raptorial birds 
I have, from time to time, trained to sit on my fist, none has shown anything like the power of Bonclli, both to strike violently and having struck, to maintain an unyielding clutch of the object held for an indefinite time. The thickest buck-skin falconer's glove is of little protection when this diagle is agsersively inclined. I would much like to enter it to fly at hares, rabbits and P'artridges and feel well-assured I could succeed in tratining it in a very few - weeks, but the certainty that in England it would be shot on the very first occasion it got away from me prevents my doing so. A trait in its character, which argues well for its tractability, is its absence of sulking. Most Eagles possess this defect to a marked degree, some almost incurably so. When it was six months old, I took it in hand and although at first it gave splendid exhibitions of sulks-splendid so far as appearance went, as with drooping wings and every feather expanded and lowered head it endeavoured to shut itself off from me and my importunities; but it realized quickly the inutility of such conduct. In a very short time it would not only sit on my fist but fly to it for food. To a falconer it is easy to see that this fine species is eminently adapted, by structure, habits and temperament for the successful prosecution of the noble art. Now, after eighteen months it will fly to my fist fearlessly. But it resents fiercely any interference with its fooxl and will make a furious dish at me if in any way annoyed. Hence, as a precautionary measure, as with the Eagle Owls, I usually wear a fencing mask when at work in the cage.

As may be easily imatgined, the flight of lionedli's langle is ats buoyant and quick as it is powerful. I have watched them for many years on numerous occasions circling high alone some cliff where they were nesting or hunting over some suitable tract of country, and the ease and grace of their movements at such times are suggestive of the flight of a Falcon. At times they 
will ascend to a great height and remain apparently motionless. literally hanging in the air. In their attack and swoop they are lightning-like. I can recall how in the winter of 1902 I was shooting Partridges on an alluvial plain near the town of El Kasr El Kebir in Morocco. Some birds rose rather wild and I sent away one hard-hit. I had hardly shouted to my companion "Marls that bird 'when a Bunelli's Eagle appeared on the scene with a tremendous swoop and clutching the wounded Partridere, without an instant's check in its speed, swept with it onwards and upwards and ranished out of sight. It was an interesting spectacle for any student of bird-life and one of peculiar fiscination to a falconer.

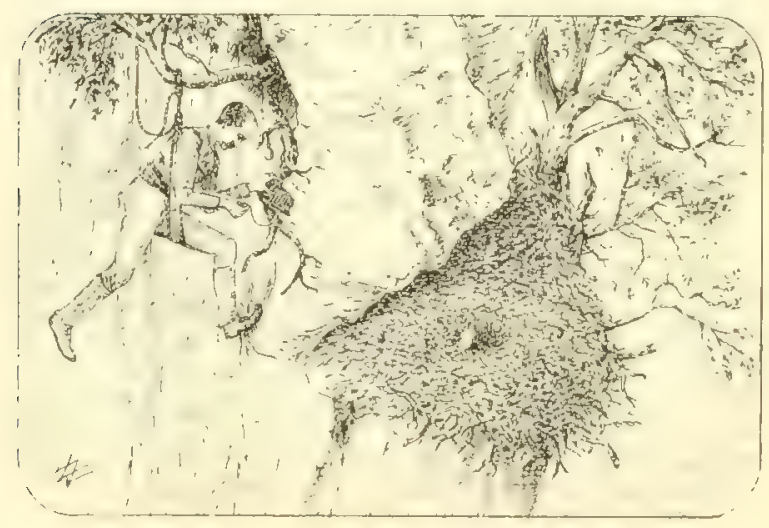





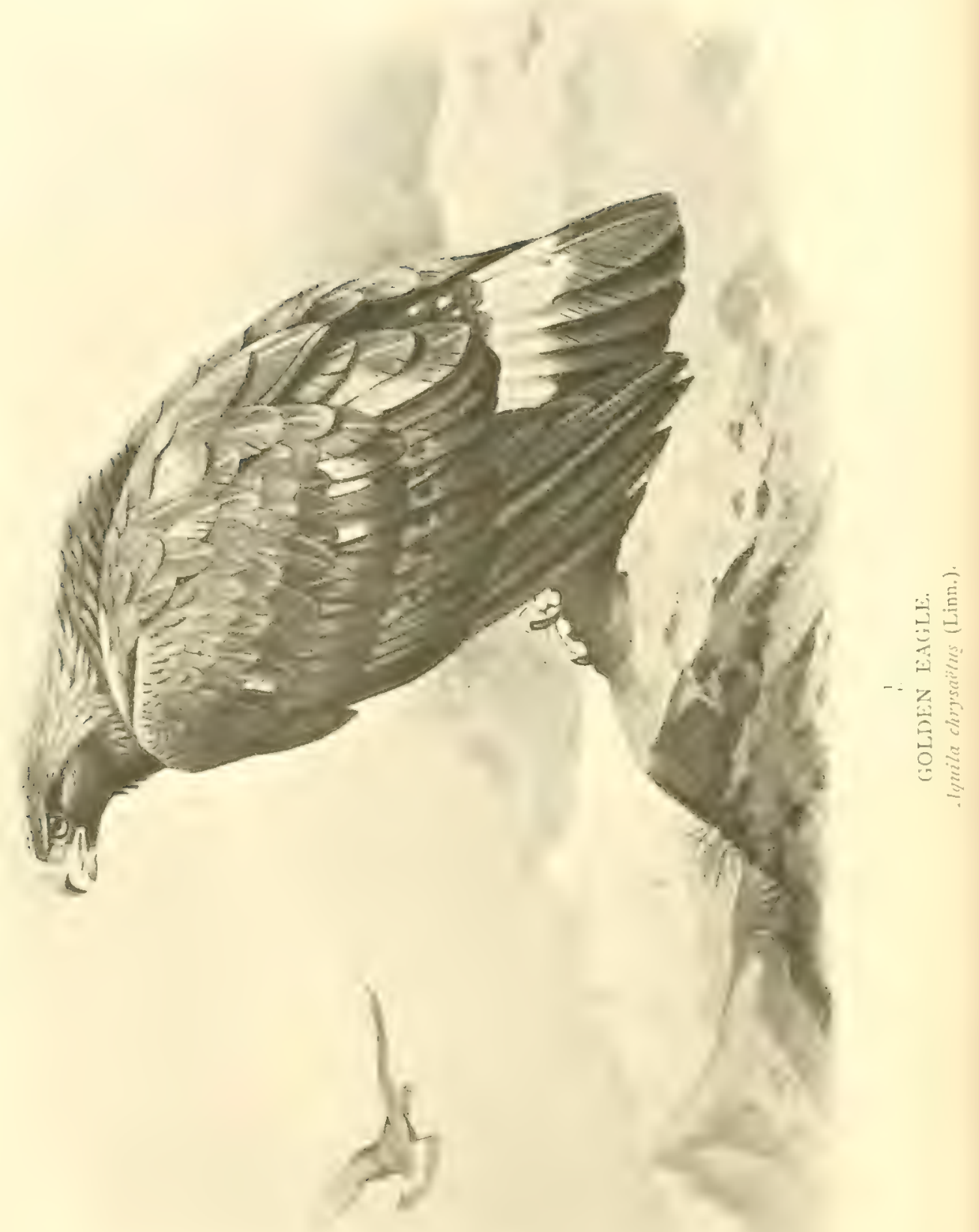




\section{CHAPTER VI. \\ THE GOLDEN EAGLE (Aquila chrysaëtus).}

P'opular ideas of Golden Eagles-Absurd misrepresentations-Preference for limestone country - Repugnance to Griffon Vultures - Alternative nesting sites-Locating nests-The interest of personal observations-The use of paid assistants-A Spanish argument-Partiality to cliffs-But not necessarily big ones-Remote spots their chief safeguard-My first Golden Eagle's nest-An easy descent-A useless camera-A seven years recordAn interesting descent and successful photomraph-Other descents and photographs-Lehaviour of Griffons-The task of locating Golden Eagles' nests - Necessity for careful observation-Results of skilful reconnaissance-A joyful sight for a naturalist-Watching Golden Eagles in their hauntsA glorious spectacle.

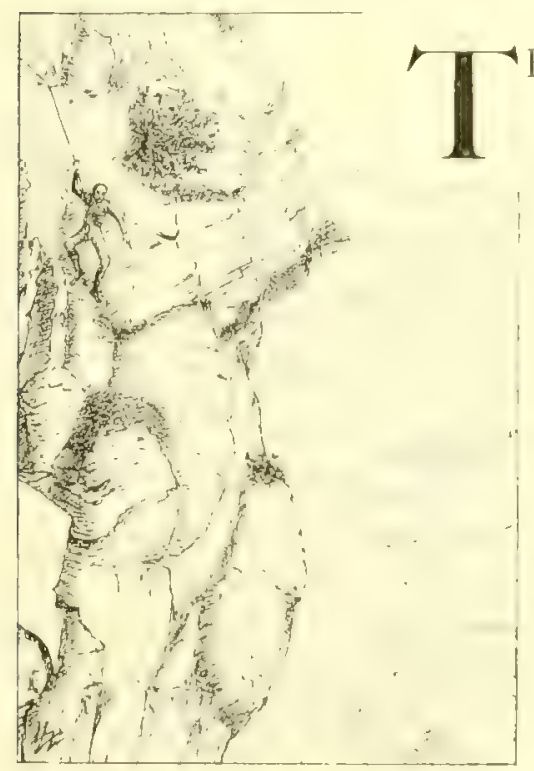

E glamour about the name Eagle, especially Golden Eagle, makes it hard for an ornithologist to avoid offending readers who probably have exaggerated ideas as to Eagles' size, valour, ferocity and general habits. From the earliest days classic writers have idealized the bird and attributed to it so many marvellous qualities that a mere narration of a field-naturalist's everyday experiences among these splendid birds fall far short of the symbolic bird immemoriallyselected by warlike nations as the insignia for their standards. 
Thus the "king of birds," which we have every reason to believe is one of those which pair for life and which is usually seen hunting in company with its mate, (save indeed in the nesting season or on occasions when a single bird may go in quest of food), has been portrayed as combining in larese parties to attack less powerful birds. Landseer's famous picture of "Eagles attacking Swans" is a monumental work of mischiewus misrepresentation, since it not only represents an impossible wathering of Eagles but attributes to them methods of attalck which ne, Eagle ever adopted, since Eargles strilice or pounce on their quarry and do not engage in vulgar brawls either by land or on the water.

Of less importance, but eren more eratuitously misleading are sundry modem journalistic efforts to present the Eanle as a sort of gryphon. I have in my mind's eye a picture of "Attacked by Eagles" in which a man is depicted surrounded by a bevy of gigantic birds as large ats ostriches with a span of wing of 12 feet or more. The veracious account lays the scene in a cocknified health resort in southern France, where Eagles are almost as rare as they are at Brighton.

The Golden Eagles who are my friends, (save indeed on the rare occasions when I take eges from their nests) are quite another bird, averaging about io to $\mathrm{I}_{2}$ 1bs, in weight and with a span of wing of rather over 6 feet. Those who see my skerches and photographs of the various homes of the ciolden Eirgle I have from time to time visited ask me "What do you do when you are attacked?" Please note the formula:-It is not, Do they ever attack you? Here again I must plead to being equally unfortunate, for not only do my Golden Eagles never hunt in bands like wolves or adopt casual babies, hut despite the scores of times I have descended by means of ropes or escalated bige cliffs in quest of Eagles' nests, I have never hatel the honour of being attacked by the infuriated parents. 


\section{Dislike to Griffon Vultures}

I may mention here that although I have climbed to so many nests I have never yet pulled a trigger at a Golden Eagle. Naturally enough I have had them close to me any number of times.

In southern Spain they are curiously local, so much so that writing in 8874 Colonel Irby said that he had never seen one. Some vears later I found them nesting sparsely in the areat sandstone cliffs of western Andalucia and showed Colund Irly two sites, but it was not until I pushed my expeditions into the limestone mountains which form the western and southern spurs of the Sierra Nevada that I made close acquatintance with them. On two occasions only have I seen them in Morocco and I know of a nest on that side of the Straits.

It is difficult to account for the marked preference of the Golden Eagle for the limestone country beyond the fact that they seem to have a supreme dislike for Griffon Vultures and, so far as my personal observations go, never tolerate them near their nests. Since all the larger cliffs in the sandstone country are tenanted by Griffons, this may be one of the reasons. Again, owing to the normal geological formations of the limestone country, there are usually fewer caverns and fissures in any one cliff than amid the sandstone, and hence the (iriffons nesting there are, as a rule, more generally distributed since they hate not the lexal ficilities for living in big colenies which exist in some of the sanchtone credss. For although Gokden Eagles most meloubtedly do drive away any odd pairs of Griffons which may attempt to occupy their own particular cliff, I do not think they would attempt to ount a whole colony. There is however yet another possible reason for the Golden Eagles restricting themselves mainly to the limestone country. The neirly allicel species, the White-shouldered lingle. which frequents the wooded hillsides and valleys of the lower sandstone country, as also do two other tree-nesting Eables, are 
incessantly on the loxk out for foorl and their persistent haryins of these districts mal possilyly not leave sufficient anme to malie it worth while for the Golden Fateles to estaldich hunting quarters in the same region. Rathlits and Partridges are Golden Fateles' favourite food and in the sicera the only serious competitors they meet with for this class of prey is the smaller Bonelli's Lagle and. to a less extent, Eagle Owls, who also dearly love a rabbit.

The Golden Eagles are very partial to young kids and very small lambs and at the period of the year when these are about the herdsmen keep a sharp eye on the movements of the Eagles. When, as occasionally hapenens, a nest is on an open leclge visible from the top of a cliff, the anatherds not seldom drop preces of rock into them so as to smash the eggs and drive the Eagles to some other locality. In this casce the Easles do not entircly leare the district but resort to another site not far off.

This brings me to a very interesting trait in the habits of the Golden Eagle, well known to most liekl naturalists, found in many other Fagles and rapurorial birds, but in nones so marked as in Coulden Eagles.

Every pair of Eagles, whose habits I have had an opportunity of watching over a period of a few years, would seem to have usually at least two alternative sites for their nests, some have three and I know of one with four sites. In fact I only know of one pair out of many; which habitually resort to one place and one only. The reason for this is however apparent for owing to its situation it has never been disturbed. 'This nest is in a small cavern on the face of an absolute wall of limestone rock some 800 ft. high, at about 400 feet from the summit. Above the cliff is a talus of louse stonce at an angle of $45^{\prime \prime}$ or so, aluse which again rise other precipices. In reach the nearest print abore this nest would be a long day's work and to lower a man to the nest would require at least $500 \mathrm{ft}$. of 2 -inch rope and an equal amount of lighter stuff would be most desirable as a life-line. 


\section{The Fascination of Locating Nests}

A most interesting and fascinating occupation, to my mind, is the locating of the nest of all big birds and especially the nest of the Golden Eagle. I am quite aware that in many instances it saves time, trouble and expense to hire local men to mark down the nests of these and other birds, and on emergencies, when time has pressed, I have not scorned to avail myself of such local knowledge, but ahways on the explicit understanding that moldoly site myself was to approach the nest or touch the eggrs or young.

But when all is said and done, some of the happiest days of my life have been those when, possibly after days, weeks or months and in some instances, years of observation, I have without assistance succeeded in solving the riddle of the wild bircls. There is something to me particularly enthralling in having observed an Eagle in a certain district flying on a certain line, or hunting a certain hillside and by denrees, perhaps after repeated feilures and fruitless expeditions, aldong totally distinct watersheds amisl high mountains separated by valleys a day's journey across, reducing the suspected region to one of a few square miles, then, to a single ravine and lastly, to a solitary crag in the same.

Again, the employment of local talent by no means always ensures success. More than once have I been taken to be shown a reputed nest of an Aguila real which has turned out to be nothing more exciting than that of an Egyptian Vulture or of a Kestrel and in one case even of a Rock Dove! The Rock Dove episode, although vexatious, was amusing, as showing the vein of thought of the Spanish herd who conducted me and who, after cross-questioning me as to the reasons why I wanted to get such useless articles as Eagles' eggrs, evidently came to the conclusion that I was a harmless lunatic. I was naturally furious at being let in for a nasty climb up a cliff to a cavern to interview a pigeon and explained my feclings with some decision. He only rejoined:--"You said you wanted to climb a cliff and get a nest 
with two white egrs which were of no use to anybody, there you have the exss, take your gun and shoot the birds, they are capital food, worth more than a —_ Eagle."

But that was many many years aso and before I had learned the lesson, never to be induced to climb to a nest unless I had previously seen the birds and, from watching their movements, had made myself acquainted with their secrets. I dedicate this simple Spanish tale to these "naturalists" who fondly imagine that by paying natives to find them nests and bring them exgs they have mastered the whole art of birdsnesting.

In Spain the Golden Eanle is essentially a rock-nesting bird. Out of a large number of nests I have visited I have never yet come across one in a tree, whereas in Scotland a certain number of the few Eagles which still survive habitually select trees for their nests.

Doubtless one of the reasons why Eagles usually resort to places difficult of access is found in the centuries of persecution they have undergone from mankind, typified in resentful goatherds or peasants whose tlocks or poultry have suffered from Eactes' depredations. But nothing could be wider of the mark than the popular belief that these grand birds invariably nest in the loftiest and most inaccessible cliffs. On the contrary they secm, ats a rule, infinitely to prefer some quict valley where passers-by are few and far between, and where some small crag presents a peculiar difficulty to the would-be climber, to a bold precipice, visible from afitr, known to all the countryside and popularly supposed to be unclimbable. Of course, some Eagle's nests are placed in stupendous cliffs, but, as a rule, provided an adequate supply of ropes can be taken to such a spot, they are much easier and safer to descend than are far smaller crass, possibly only 50 to IoO ft. high, which by reason either of steep and crumbling slopes above or of overhanging rocks are both difficult and dangerous. 
I refrain from the word impossible, and for the good reason that, given sufficient ropes and, above all, skill in their use, and always provided that the toposaphical conditions almit of the requisite gear being transported to the spot, there are very few nests which can be pronounced impossible to reach. Such, at least, are my experiences. Whether successive gencrations of Eargles have learned by bitter experience the fallacy of trusting to height and to height alone as a saferuarel for their nests, it is impossible to say, but every year I live and every fresh nesting place I visit confirms me in the belief that in the selection of sites for their nests wild birds are above all else concerned to escape observation.

The first time I ever had the joy and gratification to see a Golden Eagle's nest containing eggs came to me with but little effort. I was exploring a big limestone hill of the type so frequently seen amid the lower spurs of the Sierra Nevala and sighted a pair of Golden Eayles high werheal, which shorty disappeared round the shoulder of the mountain. Following them up, we came upon a big range of cliffs about $400 \mathrm{ft}$. in height which ran parallel to a steep watercourse.

Above this range was an extensive rocky terrace with a second series of cliffs above, surmemnted ly yet another terrice and a mass of pinnacle crays. After a time we saw one of the Eatgles enter the lower range of cliffs, but from our position it was impossible to be certain of the exact spot. As it was late in the day we returned to our house, and the following morning resumed our search. Commencing operations on the top of the cliff which we reckoned most probably contained the Eargles nest. more by sood luck than by aned manasement I hit off the sput from above, for, on firing a shot, a Golden Eagle clashed out of the cliff almost exactly below the place where I stood. The cliff was perfectly sound limestone, much weithered, and quite 
vertical, a small fissure a few feet deep ran down from the summit hard by where I was, and it was not difficult to guess that the nest was probably placed in this, at some point below, where there was a ledge. I had with me just $50 \mathrm{ft}$. of 2 -inch rope and with this I was lowered some $35 \mathrm{ft}$., enough to see that not far below me: there was a projection which overhung the face of the cliff lower clown. Fortunately, we had also with us $180 \mathrm{ft}$. of I I $\frac{1}{2}$-inch Alpine rope and so, ascending, I doubled this and making a bowline-on-abight went down again. When about 50 ft. down, I passed on one side of the projection and sighted the nest immediately below it, flaced in a small recess, a continuation of the fissure above. Ten feet lower, I got some good handhold which enabled me to work my way upwards from below the projection and reach the nest, which contianed two splendidlycoloured eggs. The nest measured about $3 \mathrm{ft}$. across and was lined with fresh ilex and palmetto leaves. I had with me my small fixed focus camera (it was in the early days of hand-camera work) which could be used, at a pinch, at $7 \mathrm{ft}$. But here I was, only $3 \mathrm{ft}$. from the nest, which lay in dark shadow. I steadied myself ly pressing my fort against the cliff and straghtening my knees but it was no good, for by no possibility could I obtain the necessary focusing distance and, further, a time-exposure was out of the question, owing to the absence of any possible means to improvise a stand on which to rest the camera, and all the time there was the vibration of the rope. Of course I took a "snap" and equally of course it was a failure. I have the picture still, such as it is, with ghostly ill-focused rocks and its interest is that it records the alosolutely sheer nature of the cliff and shows the flutings of water action on the portion of the reck behind the: nest. Having hauled myself into the nest, I packed my eggs and re-ascended. I huring this tine, the olel birds, ats usual, laty off at a distance, rarely coming into view. This nest was in one of 


\section{A Fine Situation}

three alternative sites, all on the face of the same big cliff. The second site was in a very similar position some 200 yards east

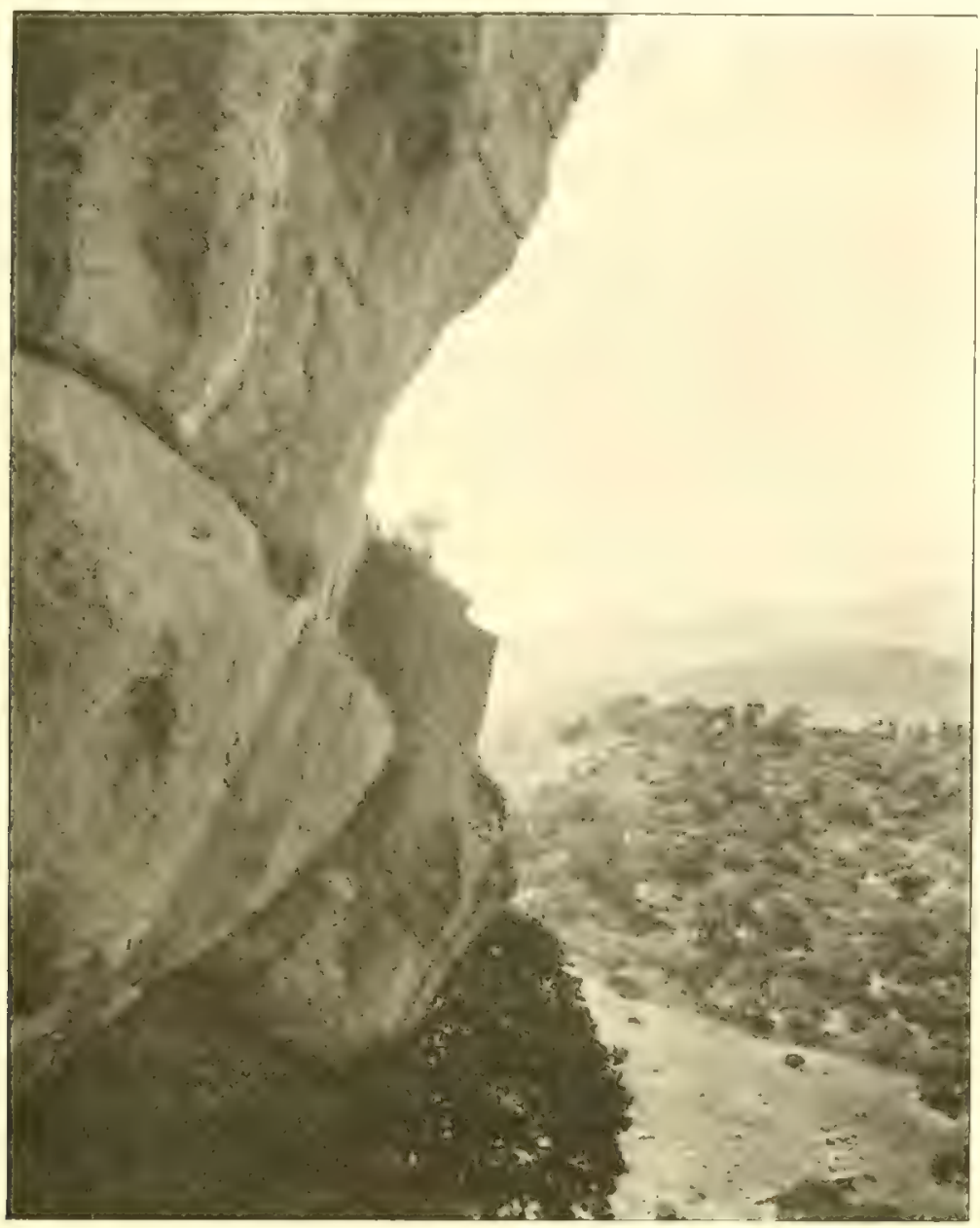

VIEW FRON A GOLDEN EAGLE'S NEST.

of the first, whereas the third was on a buttiess or big terrace, a few hundred yards to the west of it. I have re-visited this cliff several times since and have found the birds sometimes 
occupying one of these sites and at others a fourth site, which I failed to discover, owing to lack of time.

Another pair of Crolden Eargles occupied a hig hill about a day's journey from the nest I have just mentioned. I have had an opportunity to study this pair closely for over seven years and have succeded in funding the various alternative sites they have occupied. The first site, which I will call "A," was on a small terrace about $250 \mathrm{ft}$. from the base of a very precipitous cliff, and perhaps I $50 \mathrm{ft}$. from the top. The view from this nest which is situated many hundreds of feet above the sconeral level of the country below it is very extensive. But, although to the eye the place is most inaccessible, as a matter of fact it can be approached from behind through a small natural embrasure in the rocks which leads right into it. It has for many years been resorted to by Golden Eagles, and although the local goatherds have, as they have told me, often destroyed it, and of late years it has been harried more than once, the hapless old birds still resort to it at intervals.

Two eggs were taken from this nest, not by me, the first year I heard of it. The following year the Eagles nested in a low crag in a small ravine about three miles north of the first nest, which I shall call site "18." Here they happily escapel molestition.

The third year, the old birds removed to a low cliff in a ravine about two and a half mile's distant cast of "I" and thee miles from "B," which I shall call site "C." This nest was on a shelving rock, not i $5 \mathrm{ft}$. from the summit, the ground above was however cxtremely stecp and the soil hose and it was necessary for those who handled the rope to exercise sreatt are before they could obtain

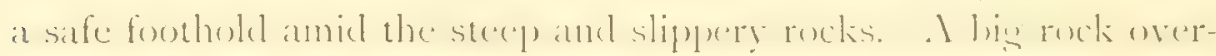

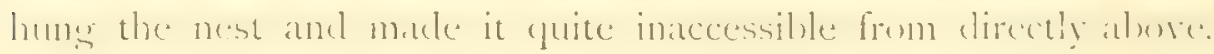
I accordingly went orer to the right of it, but foumel it impressible w work into it from the llank. Finally I went over, some yarels to 
the left, and striking a joint in the rock running at an angle of 45 or so slipued along it with my weight an the ropes liceping myself

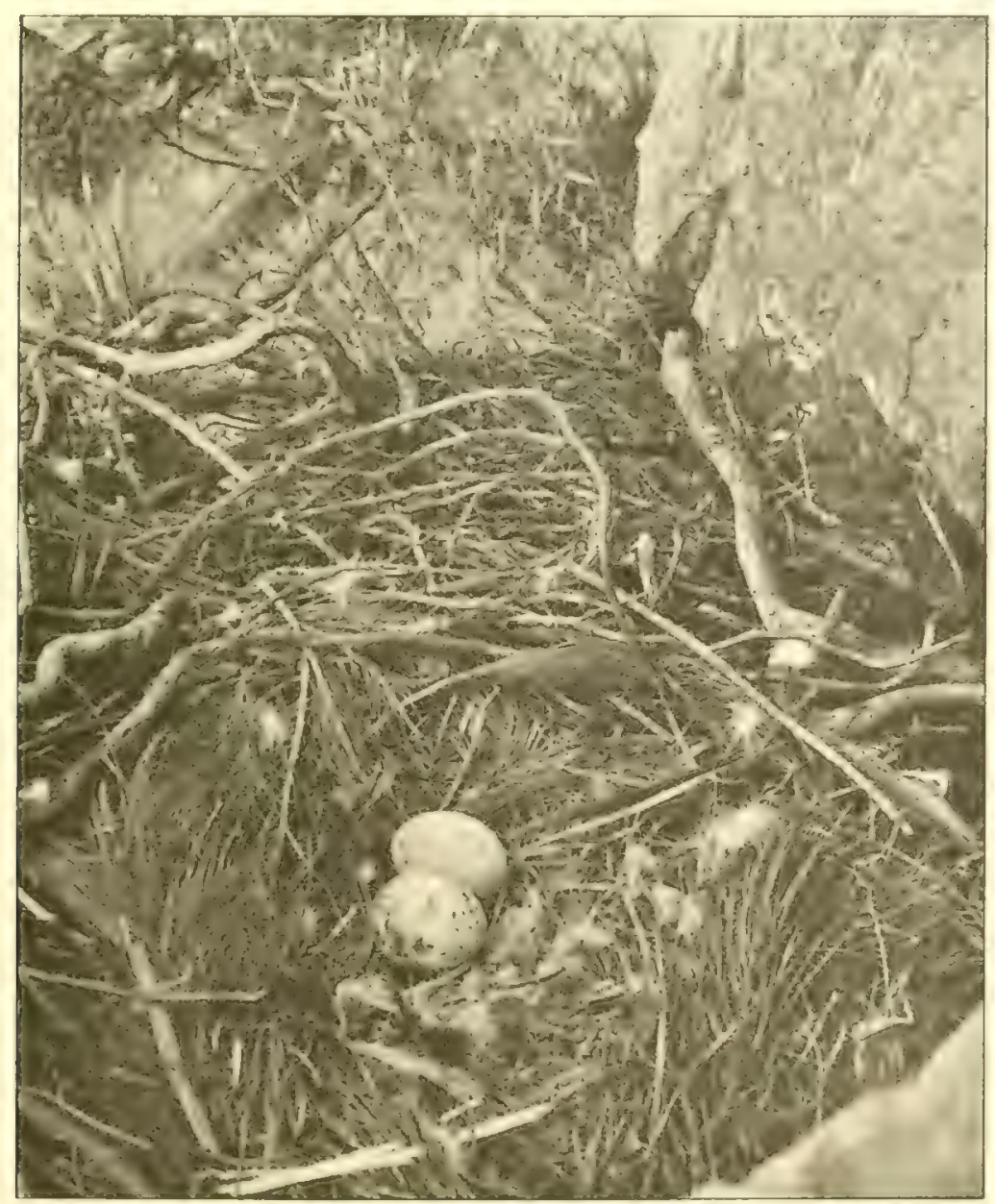

NEST AND EGGS OF GOLTEN F.IGLE.

in to the face of the cliff by handhold. By this means it was easy to gret to the nest, ahays lieeping a strain on the rope, an ensential proviso owing to the absence of any safe forthold. () n this accalsion 
I was equipped with a more suitable camera, the Kodak arranged to focus down from the normal $6 \mathrm{ft}$. to sim. I withered cork tree grew hard by the nest and, by hanging my watch on a twis in front of me and pressing the camera against the fice of the cliff, I was luckily able to take sereral time-exposures of thirty to forty seconds which gave good results. I subsequently revisited site "A "of the previous year and found it to be in the pussession of a Griffon Vulture which had relined the old Eagle's nest with tufts of grass and bents, and had laid its single white egg in it.

In the fourth year neither Eagle nor Vulture occupied site "A," although the cliff was held by sereral pairs of (iriffins. The Eastes this year had returned once again to site "B." This was quite the smallest place I ever saw tenanted by folden Fanles and was almost identical with that at "C," with a steep slope abore and was further actually approachable to within I $2 \mathrm{ft}$. or so from below, along a narrow shelf. Beyond this further progress was impossible and the nest had erentually to be reached from abore.

The fifth year the Eagles returned to site "C," and laid one eng which was unfortumately taken; the female then proceeded to site "A," and laid a second egg, but this nest being easily reached was so disturbed that they forsook it. Unluckily they were weak enough to return once again to the same site "A " in the sixth year, and access being easy the cons were eventually taken. The seventh year they returned to site "C," and laid two exgs. Besides these three sites thus used in rotation as clescribed, I came across a fourth site, where I was told they had at times nested in former years, but, leyond seeing the Fandes around this crag, I have no proof that they did.

This habit of Golden Eagles to select a shelf of rock in comparatively low cliffs is a very curious one. I found the nest of a third pair in almost exactly a similar situation to those already described as "I; " and "C," a diay's march south of them. 
A sketch of this nest appears at the beginning of this chapter. In this case the nest was only a few feet below the crest, the

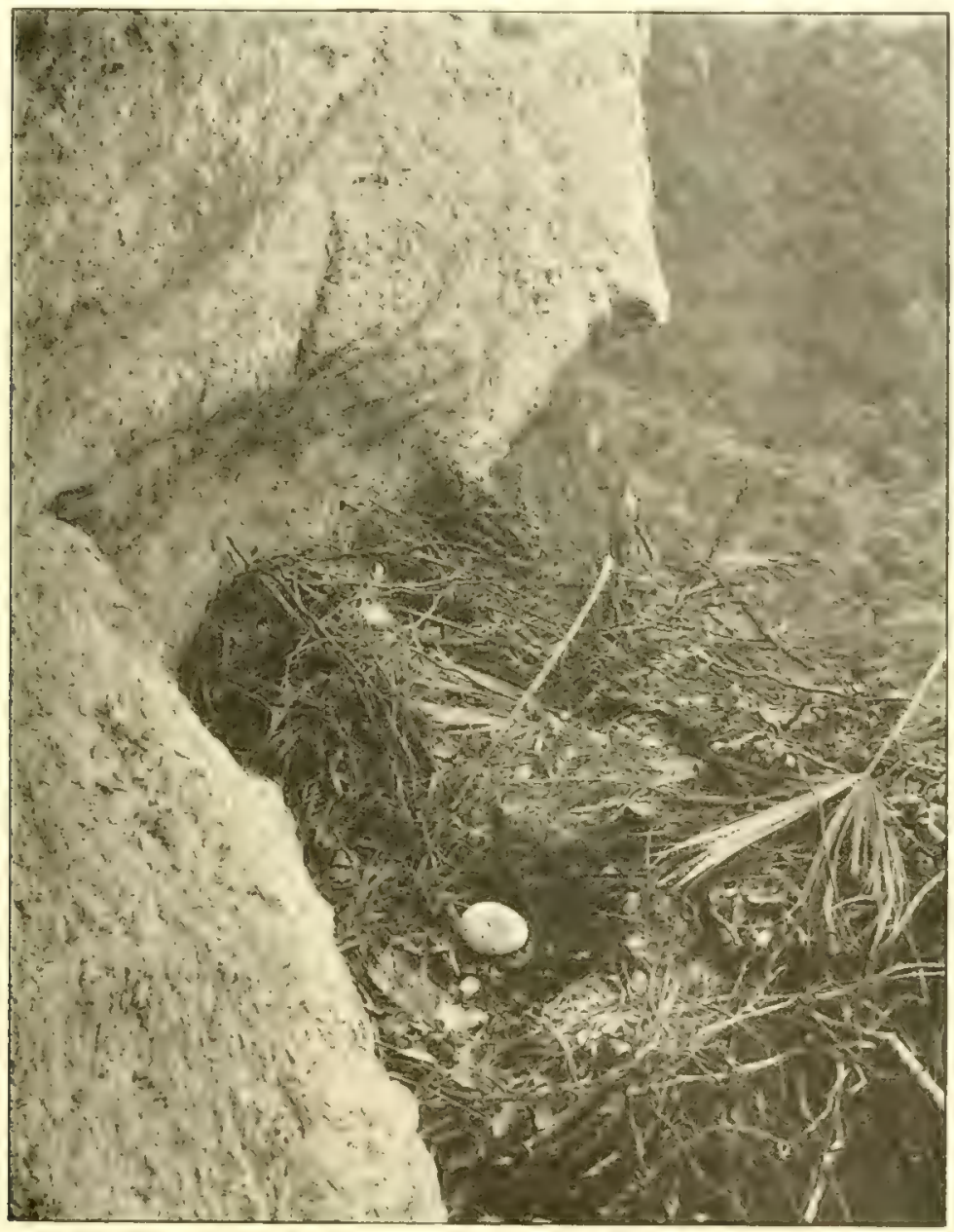

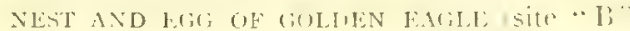

cray itself being about $100 \mathrm{ft}$. in height, whilst atecess to the edge of the cliff was across a dangerous louse tahus of cébris fallen from the immense cliffs above. 
The moral pressure exercised by Golden Eatsles over their despised connections, the huge Griffon Vultures, was very apparent in the case of the nest at site "A." The first year, when the Eagles were in occupation, no Griffons were to be seen about the place, the second year I noticed a pair, the third year one had actually taken possession of the disused Eagre's nest and another pair had established themselves in a biu cavern close by, the fifth year there were four or five nests. The sixth year I first detected the presence of the Eagles by seeing one sudelenly descend from the zenith and buffet a Griffon that came sailing past the great cliff where the Fagle's nest was situated and which made off with great precipitation. As a matter of curiosity I fired subsequently several shots to see if any (iriffons were nesting about the cliffs, but none came out. To make sure, I then climbed up and visited the various nests I knew of and found all alike untenanted and out of repair. A single pair of Neophrons were nesting in the biy cavern which formerly held several Griffons' nests and the female had laid her engs in one of the Griffons' nests of the year before. It would be difficult to produce clearer testimony of the antipathy of Golden Eagles to Griffon Vultures.

Possibly some who read this may imagine that it is a simple matter enough to find the nests of these beautiful birds. Of course, with good luck many things in life are made easy, but in few pursuits that I know of are there more chances of disappointment than in tracking Eagles' nests.

When once a pair of birds are located and their nesting places discorered, it appears to be absurdly simple, and so it may be for the casual visitor who wants to be shown an Earle's nest. and who can by this means get a man to take him straight to the spot. But for the genuine bird watcher, how immense and uncertain is the task and how overwhelming at times are the 


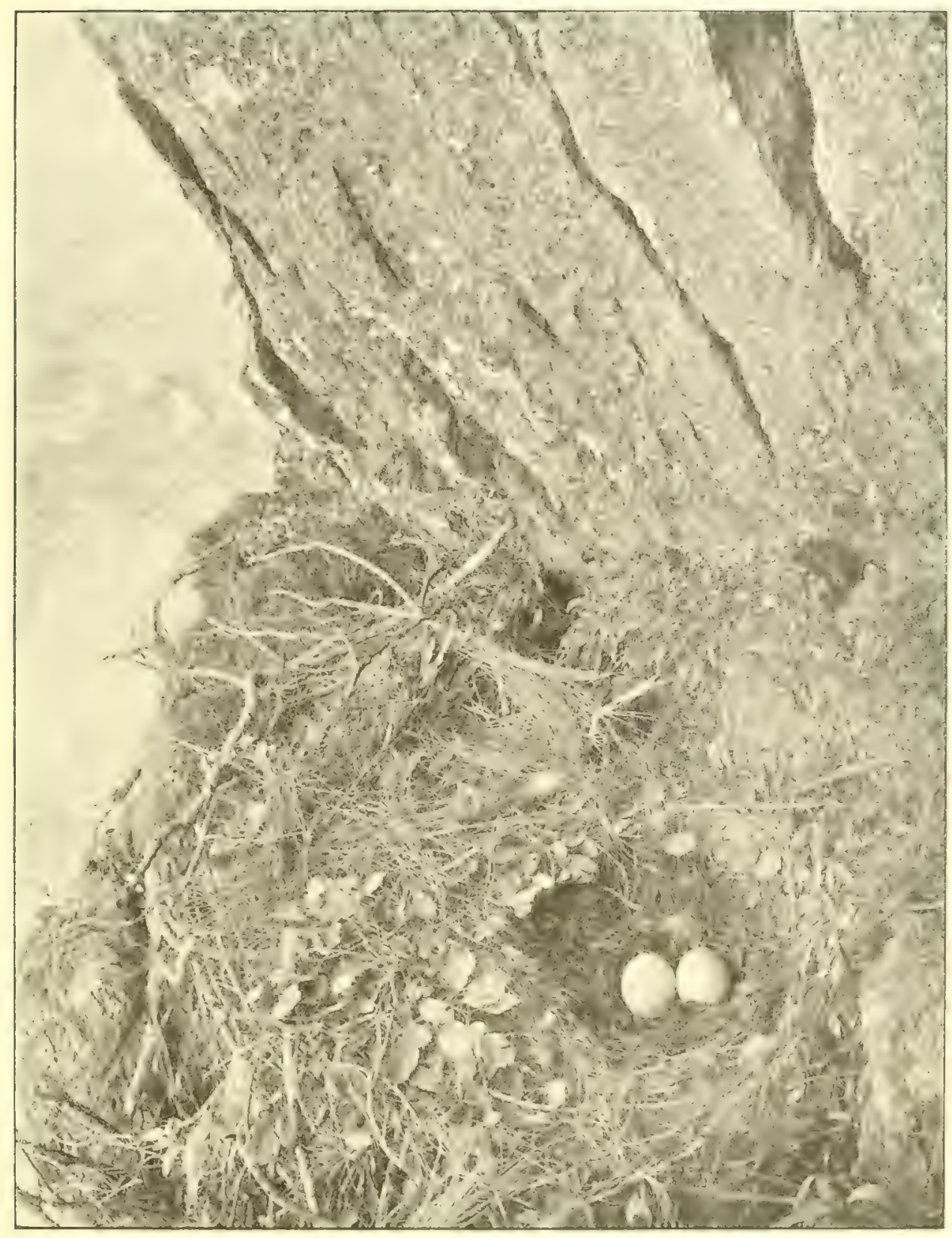

NEST AND EGGS OF GOLDEN EAGLE. 

unexpected diffeulties which present themselves, one after the other, as if to debar him from accomplishing his object!

The mere fact of watching Eagles enter cliffs, either singly or in pairs, is a long way from ultimate success in finding their nests. Owing to their habit of resorting to alternative sites, it not unfrepuently hapens that a par which mat le meditating nesting play around various old nests with aggravating uncertainty. Even after they have come to a decision to repair and re-line one of the nests of former years, they have a way of resorting to some of the other sites and flying in and out of them in a most deceptive manner.

The tyro after seeing the birds thus enter a nest is ever anxious to go to it at once. Such haste is, as a rule, prolific of disappointment. But even when a nest has been undoubtedly fixed and the fact that it contains eggs has been reasonably assured, the final successful approach to it from above is by no means a matter of course. Often it is the work of a whole day to attain the top of the cliff above the Eagle's eyrie and only those who have frequently gone through this scemingly simple operation and have experienced the repeated failures which so often attend it can appreciate the vast difference between seeing a nest from below a cliff and trying to place oneself exactly above it, pussibly many hours later on. As often as not, the configuration of the crestline prevents a near approach to the edge and it may be necessary to make several tentative descents in a bowline to peer over and endeavour to fix the desired spot; and how very unpleasant this process is at times! and how much worse it seems to become, the more you look at it!

But in such a case, as in all wild sport and adventure, the very difficulties add zest to the enterprize and what unspeakible joy it is to the unrepentent birdsnester when after a series of awkwarl adventures he finds himself at last right in to the coreted nest? And to the naturalist how intensely fascinating is such a moment. 
as he looks at the great structure of sticks, perhaps + or even $6 \mathrm{ft}$. across, with its lining of fresh green leaves, in the centre of which lie the two splendid eyss, usually white in ground colour with every shade of rich brown and rufous markings! Such moments repay the true lover of nature for all the labour and risk. Contrast his feelings with those of the "collector" who

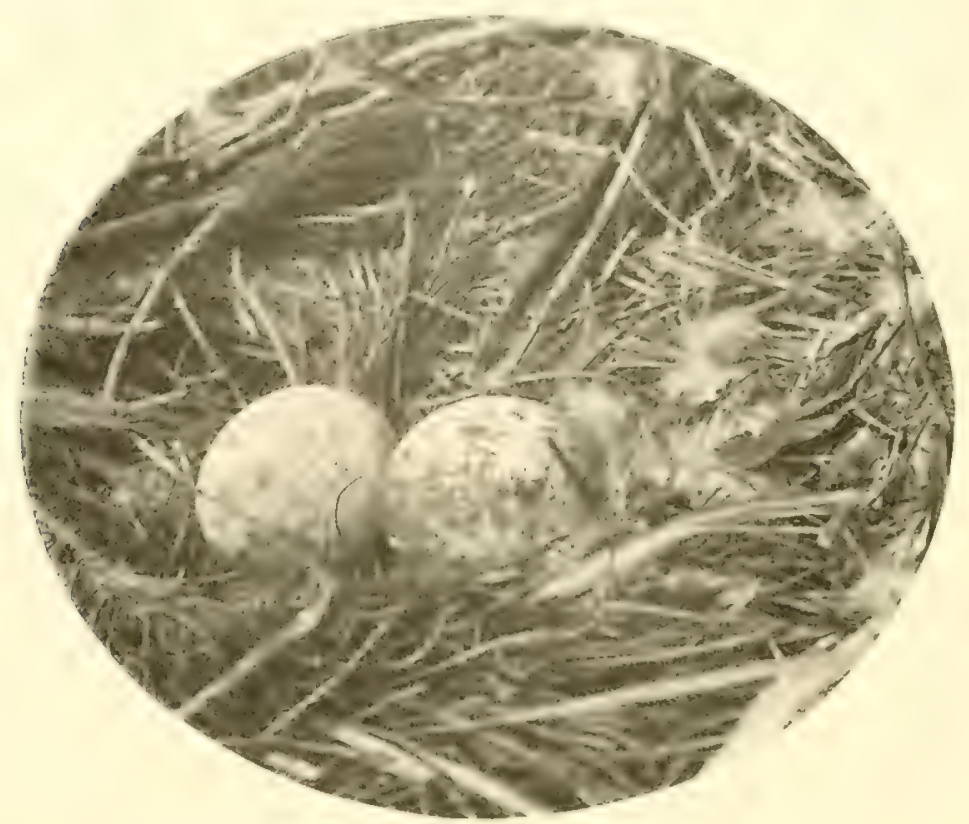

EGGS OF GOLDEN EAGLE. (Size $31 . \mathrm{in} \times 2.35 \mathrm{in}$.).

pays a man to take both the risks and the eggs for him! But whether the object of the quest be to take the eggs, to obtain photographs of the nests or to see the birds in their wild state, it brings a man into touch with one of the most fascinating of studies. The mere watching of these plorisus bires in their haunts is a revelation. The marvellous ease of their thight and the rapid adaptation of their great wings to effect every turn and whece in mid-air is a never failing joy to witness. Seldom is this seen 
with better effect than when a pair of Golden Eagles indulge in a little play around somesreat cliff, which they may possibly be prospecting with a view to nesting. After various beautiful circlings high overhead one will suddenly make a wider curve and swing downwards and inwarls until it enters the shadow cast by the precipice. As it nears the cliff the great feathered legs are dropped and it alights with a lurch on some projection of rock adjacent to the proposed nesting place. For one moment it steadies itself with a few tlaps of its huge wings and then folds them leisurely across its back. Som the other bird will descend rapidly from aloft with a prodigious swoop which carries it on a downward curve far below the point where its mate is resting and before the eye can grasp what it is about, and without any apparent effort, the downward movement is changed into an upward sweep which carries it to the same spot as the other. For a few seconds there is a shrill bickering and mighty thapping of wings, quickly followed by first one and then the other hurlung itself as it were into space, whence, with expanded wings, they rise buoyantly once again into the bright sunlight above the cliff and recommence their aerial evolutions. This have I seen at times, lying prone amid the rocks and sweet-smelling cistus in some wild valley enclosed by the great cliffs above which the Eagles play.

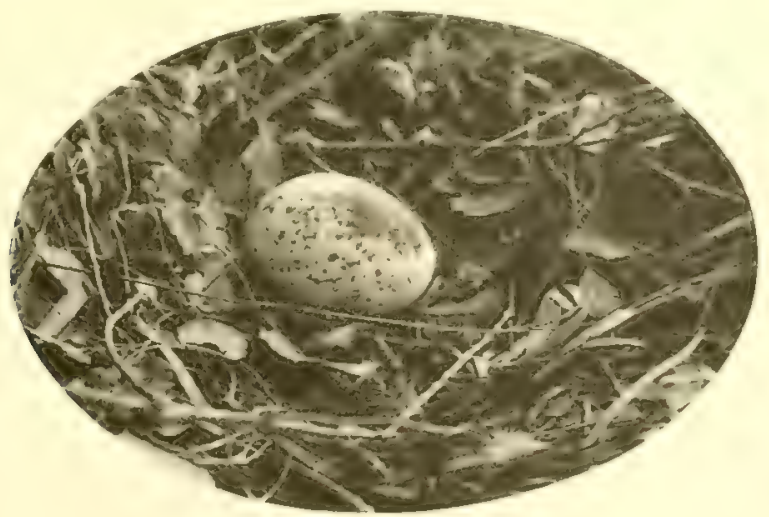




\section{CHAPTER VII. \\ THE EGYPTIAN VULTURE OR NEOPHRON \\ (Neopliron perchoplens).}

A bird of repulsive habits-Yet beautiful on the wing-Handsome eggs-A rock-nesting species in Europe-Gruesome larders-Nest and eggsPlumage-Similarity of young to Bearded Vulture--Regularity in migration-Sites of nests-La cueva del Curvo-An improvised landing net"Laying" a camera-A Marten-cat in possession-A typical Vulture's cavern-A nest amid boulders-A nest in a cork-oak tree-The Calpe Hunt and birdsnesting - An evicted snake Eagle-An undesirable tenantTrapping a Neophron-I'eculiarity of colour pigments on eggs-Neophrons in the Bayuda Desert.

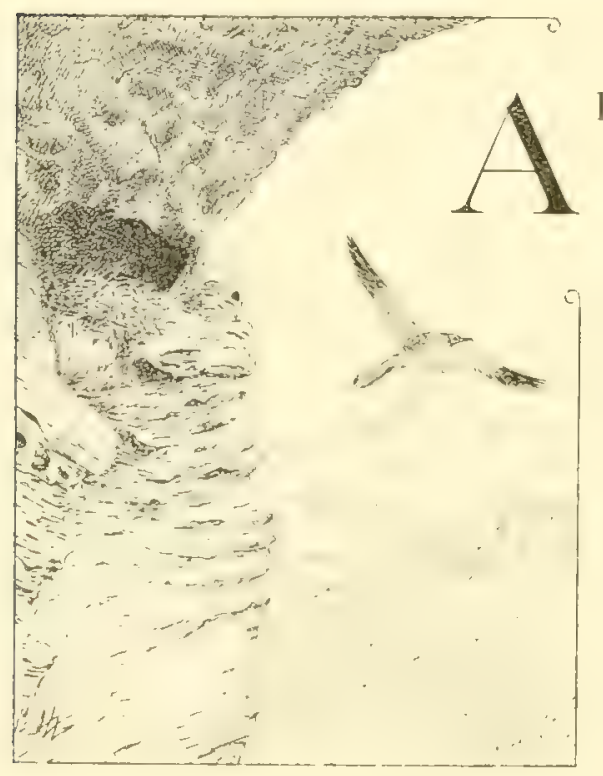

LL that can be said both as regards the evil habits of the big Griffon Vulture and of its splendid appearance on the wing applies with double force to this, the most unsavoury of birds, whose snowy-white plumage and black-tipped wings seen at a distance as it sweeps in wide curves high overhead combined with its light and graceful build, give it a general appearance of cleanliness and delicacy, which its habits so far as regards its feeding and nesting sadly belie. 


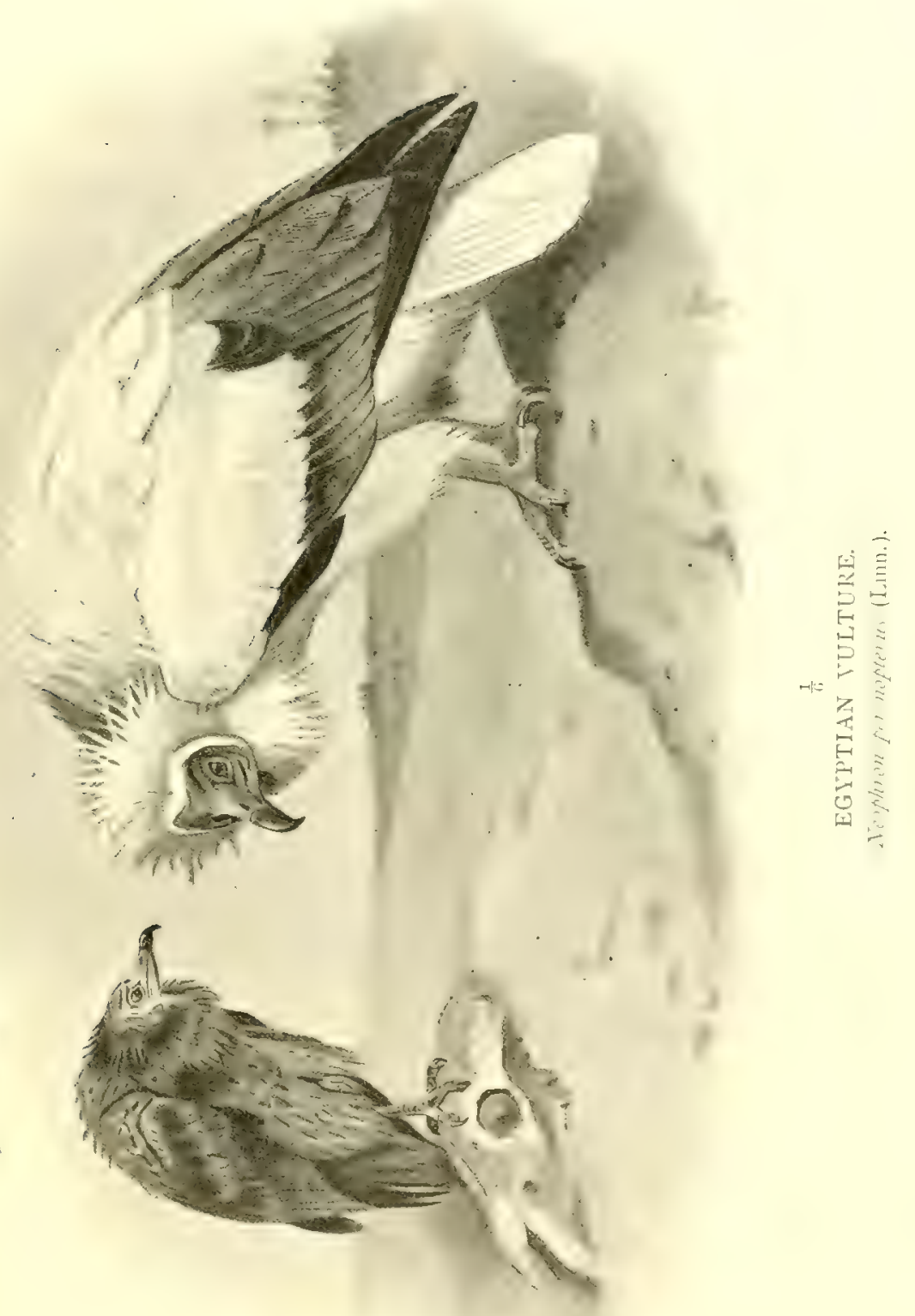



It is when the Egyptian Vulture or Neophron, as it is also styled, is seen close at hand that it is revealed in all its hideousness. The bright yellow shrivelled-up skin of the naked heal is most repulsive, whilst the mere knowledge that the bird is one of the most unclean of feeders on the surface of the earth does not add to its attractiveness. And yet it must be repeated few birds present a finer sight when on the wing and still fewer lay more beautiful engss; some varieties being among the handsomest eggs to be seen. True they differ greatly both in their colour and in the intensity of their shades but I have at times taken eggs which for richness of colouring eclipse even the beautiful esgs of the (Osprey and the P'eregrine. Many birds of prey lay very handsome eggs but very few have such gorgeous combinations of rich brown madelers and purplish markings as have some of the Neophron's eggs in my collection.

The Egyptian Vulture belongs to a sub-family of the Vultures known as the Neophrons and is abundant all along the Mediterranean basin and in Northern Africa. It migrates southward every winter and has been often met with as far south as Rhodesia. Large numbers annually pass northwards through southern Andalucia in February and March, whence they spreat all over Spain. It this time of the year they frequently may be seen collected in considerable numbers in trees. They almost invariably nest in rocks and their nesting in trees in Andalucia is so unusual that when I many years ago found one nesting in a cork tree it was considered a remarkable incident and was duly chronicled as such in the Ibis. The allied species in India ( $N$. gingzimus) habitually nests in trees and I have of late years heard of cases of the Egyptian Vulture doing the same in parts of Spain where rockis are not found, such as the platins of the Guadalquiver. Opinions differ as to whether they ever take living things. Nhthough I have seen them constantly at all seasons for many years, I have 
personally never seen them carrying anything alive. But I believe that they capture both lizards and small snakes, for I have found fresh remains of both of these in their nests.

Again in the majority of Neophron's nests I have visited, and I have visited scores, there have been a number of mummified heads of the big ( )cellated Lizards. True, there is a possibility that other birds kill and eat the lizards, leaving the heads and that the Neophrons pick up these, but as I have said, I believe that they take reptiles. That they are famous collectors of all unconsidered tritles is well-known. A list of atl the articles found in their nests would be simply interminable. Setting aside their main stand-by as scavengers of the lowest type, proofs of which are to be found in almost every nest, I have come across kittens, rats, hedgehogs, tortoises, snaties, lizards, toads, frogs, remains of foxes, of dogs and of fishes and lastly, a defunct young (iriffon Vulture, all either in a putrescent or mummified condition. In addition to animal remains there is usually a miscellaneous collection of pieces of old rope, filthy rags and paper. Among the more unexpected articles I may mention a small bay of flour crawling with mealworms and a playing card - a King of Clubs !

The nest usually has a foundation of sticks and is warmly lined with goatshair and lambswonl, in this respect dorely resembling that of the bearded V'ulture, but of course on a very much smaller scale. Two egrss is the usual number, although sometimes only one is laid. These vary areatly in colour and as a rule each nest contains one egry much more marked than the other. The tirst of the pair laid would seem to be ustally the richest in coleur and for a long time I adopted this theory, until I came across a pair, of which the one with obsolete colouring was well set, whereas the darlier one was quite fresh. From this it will be gathered that sometimes a considerable interval elapses between the dates of litying of the: eggss. Some eggs are richly coloured all oner with dark brown 
and rufous shades, others have a white ground with reddish brown blotehes. Sometimes one e..... will be strongly matsed with brown and the other speckled amel marbled with pale purplimh markings. The young are almost naked when first hatched out, a sparse

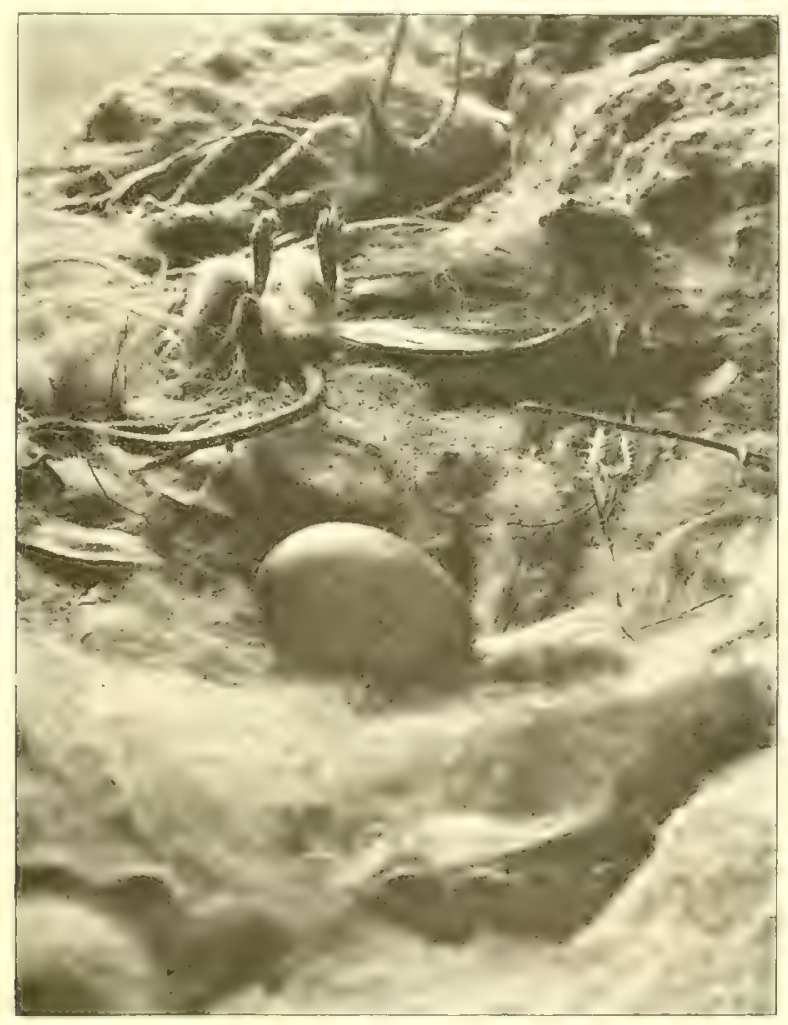

'NEOPHRON'S NEST WITH DEAD RAT IN T.ARDER.

growth of very long white down only partially concealing their skin. Young birds when fully fledged are dark brown all over and at this period of their existence, owing to their wedgeshaped tail have much the appearance of Bearded Vultures on the wing. of course they are only half as large but in the absence of other 
bircts to enable one to form an opinton ats to their size, such a mistake is possible. I confess to having made it twioe myself, at far distant places; nnce amid the rocky hills near Philae, during the Nile Expertition of 1884 , and ance in southern Spain. (On each occasion, the advent on the scene of an adult $N$ (onphron in its black and white plumage quickly disabused me of my mistake, but I mention the circumstance as showing how a person well accustomed to both species can make a mistake.

It is curious that whereas in Egypt and Nubia immature Nenphrons in the brown dress swarm and at times and places greatly exceed those in the white plumase, they are rarely seen in southern Spain save when first they leave the nest. In fact the proportion of achult to immature birds is overwhelming. Thus on 24 March I Sot I noticed twenty white to one dith brown bird roosting in the cork trees. Similarly throughout the whole spring of I907, I saw but one dark brown bird among many scores of adult birds. If, as is probably the case, they do not acquire the adult plumase for three years, it must be concluded that only the adult birds migrate to Europe for the nesting season. Every spring they arrive in hundreds almost invariably in pairs, sometimes ten or fifteen pairs together passing northward. The litroest number pass cluring the last week in March. It is interesting to see how almost to a day a pair will arrive from the African cuast and talic possession of the crags where a nest was in the preceding year. I have seen examples of this on many occasions.

The farourite site for the nest is in a cavern or shelf protected from the rain by an overhanging rock. V'ery ratrely have I seen a nest which was not thus protected. I know of several situations which are used some years by Griffons and in others by Nophrons, also other sites which are used by Rarens and Neophrons. In justice to the Rarens I have never known them return to a place the year after a Nepplaron has defiled it, but I have often seen the converse. 
Like many other birds of prey, Neophrons at times nest in the most difficult and inaccessible places. Thus I know of a nest in a small cavern or rather hole in the face of a cliff over $400 \mathrm{ft}$. high

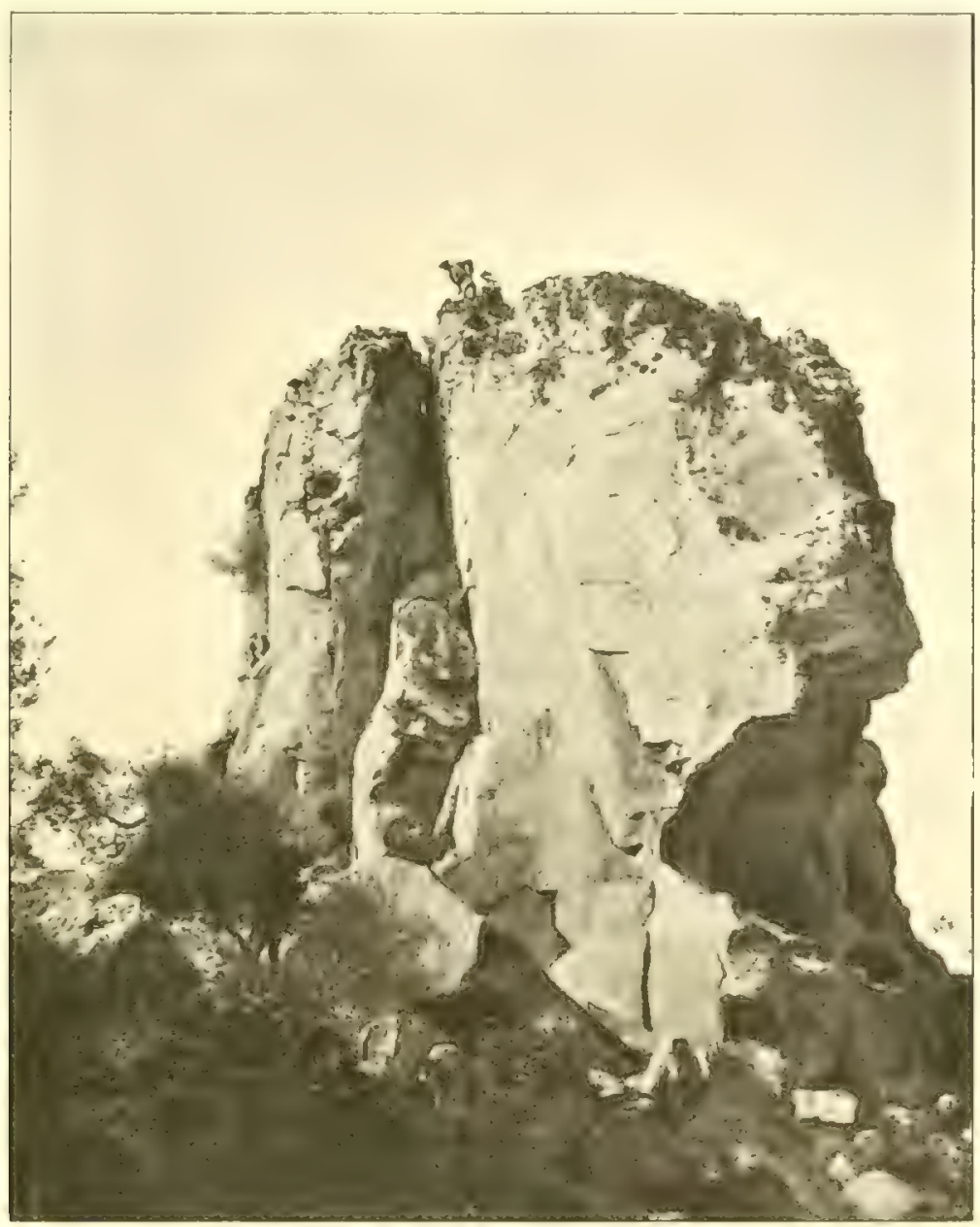

L.A CUEFA DEL CUERIO A NEOPHKON'S CRAG.

and not $40 \mathrm{ft}$. from the bottom. The cliff is known as La Lata "the tin plate," from its smonthness. To get this nest would require several hundred feet of rope. 
Again I know of others in caves on overhanging cliffs which are practically impossible to reach and asuredly are not worth the trouble to attempt. One of the most artfully placed nests I know of is in a pinnacle rock on the side of a low sierra, not more than $30 \mathrm{ft}$. Or $40 \mathrm{ft}$. in height which is unclimbable save at one point.

The crag is riven in two by a deep and narrow "joint" or fissure and the nest is piaced on a ledge in the same, at a point about one-third of the height from the top, and the entrance to it is equally impossible to reach ly escalade from betow or by descent with a rope from above since the rock overhangs as can be seen in the picture on the preceling pase. From time inmemorial a pair of Ravens halel nested in this cray which is known to the country folk as La cuerd del Cueroo, The Raven's Cave, but having been disturbed the Ravens descrted it and for the last fourtecen years it has been usually accupied by a pair of Neophrons.

In 1894 I found the Neophrons in possession and climbed to the top of the crase on the far side, but was apparenty no nearer getting at

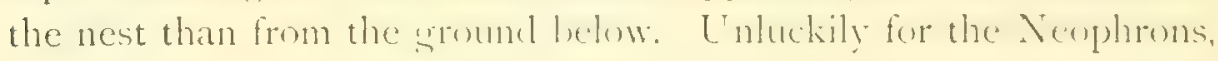
I was able to drop some i $2 \mathrm{ft}$. down the fissure, at the point where the speck of light is to be seen close to the summit and thus get on the same level and within about $6 \mathrm{ft}$. of the nest. From this point I could see the engs lut it was impussible to reach them since between me and the neat the fissure narrowed to only a few inches. I howerer extempriacel a landing net with a cane and a small tin insect-box lashed at the end of it with which I extracted the eggs. In this nest were two wild boar's tusks of some size. Some years later I again visited the same spot and found it tenanted. My object on this accasion was photography and I managed to push my Kedak camera at arm's length into the narrow crevice. It was impossible to look into the fincler, but I propped the camera on bits of rock and lay it as true as I could and gave a long-time exposule. Is will be seen, l got rather more 
of the wall-like side of the fissure into the foreground of the picture than I needed but in the circumstances I was lucky in getting a picture at all.

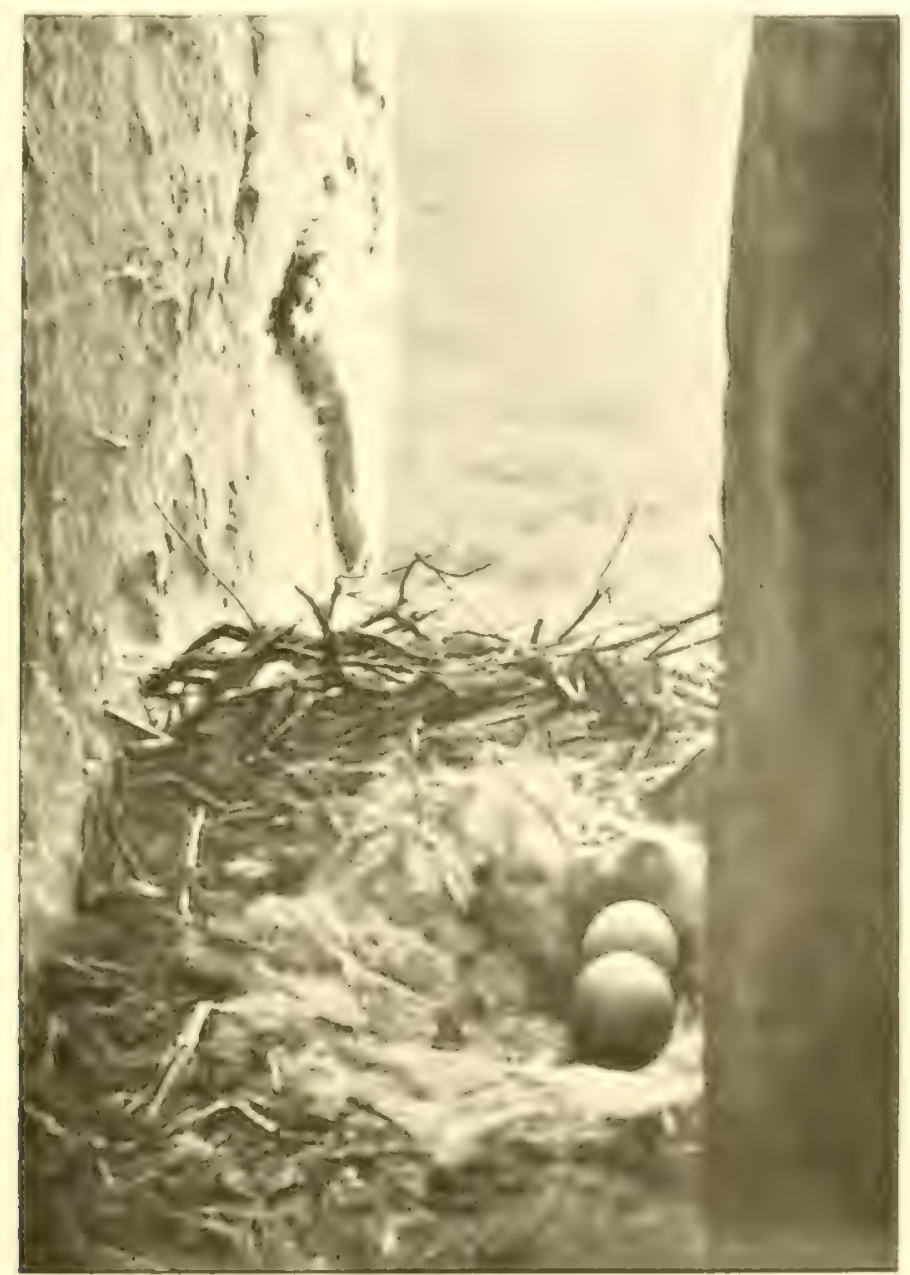

NLST OF NEOPHRON IN XIRKOW EISSURH.

Over the edge of the nest the tops of the cork trees in a wooded valley below the crag can be seen in the picture. The 
ordinary line of approach to this pinnacle ruck is allong this valley in full view of the entrance to the nest. Knowing as I now do of the Raven's cunning habits of making use of a front and back entrance to its nesting place whenerer pussible, I realize how it came about that this cray obtaned its name, for surely never was a place better adapted for a bird to enter or leave without attracting attention.

A few years ago I had a curious meeting in this cave with a beautiful Marten Cat (Mustcla foina). I was squeczing myself down the fissure on my wy to the nest when my daughter, who had climbed to the top of the cras and was watching my descent, called out to me there was an animal in the cavern close to me and looking round I saw on the level of my face throush a rift in the rock a Marten crouching low and showing a fine set of teeth. Quickly drawing my pistol I fired at it at a few inches range? 'The Marten altheugh shot through the hely manaced to spring out of the cave and bounding across the top of the cras disipleared into a deep cleft where it was impossible to extract it. It was a disgraceful let-off but should anybudy deride my non-success, I would sugesest they try for themselves the amusement of putting a hand into a cavern held by a truculent Marten Cat, possibly with kittems not far off.

I know of a big cavern some hundreds of feet up the face of a limestone cliff in the Serrania of Ronta where, in some years, several Griffons nest in close proximity one to another. To reach this cavern it is necessary to sidle along a very narow and somewhat dangerous ledge from one thank of the clift. Several of the Cirifon's nests are either on the floor of the calvern or on comsenient ledges around it and, once the catrern is reatede cin be literally walked into. But there is a sort of natural balcony running along one side of the cavern which can only be wot at ly climbing a fig tree for about 12 or $15 \mathrm{ft}$. (the topmost branches can be 


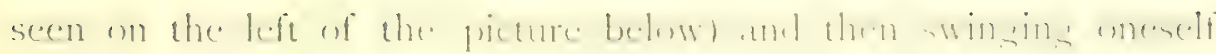
from it on to the balcony. At the far end of this is a considerable

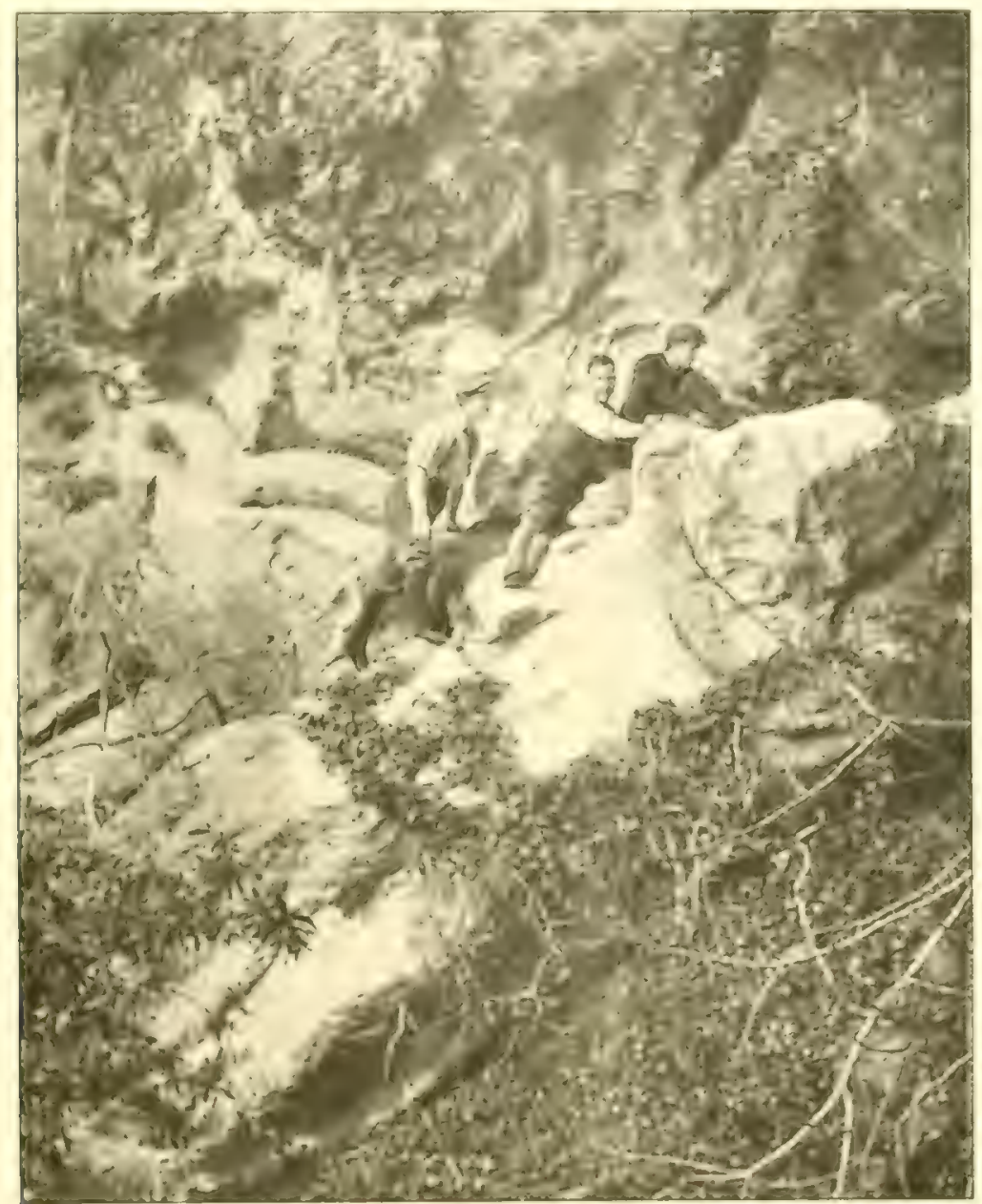

I VUTMURE'S CALPRN.

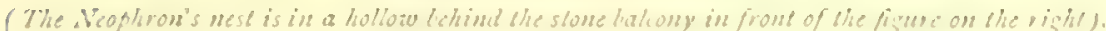

ledge where some years ago I found a Griffon's nest, a picture of which appears att p. t.t.

In 1907 , I visited this cavern with some young naval officers. 
There were no Griffons about, which I accounted for by the fact that a pair of Golden Eagles were nesting in the big cliff just above. A pair of Neophrons had however taken possession and I was fortunate in being able to take a picture of their nest with my Goerz lens. I subsequently sent my party up the tree to inspect the nest and touk a photosuph of them at the moment the leading climber had reached it and was looking into it. I give the picture since it is eminently characteristic of the situations in which both Griffons and Neophrons most delight.

Although I have seen some hundreds of Neophrons nests in all sorts of situations, some most inaccessible and others the reverse, it is only within the last few years that I have found them nesting practically on the mound. Twice, once in 1903 and once in I90\%, have I come across nosts built in a crevice amid big boulders on a hill sicle within a few feet of a mountain path! In each case the birds undoubtedly relied upon the remoteness of the situation and the fact that the path led nowinere save to a tract of yrazing for goats and cattle. As shown in the picture on 1 . $3 S_{3}$ a man standing on the rock in the centre can reach the nest in the small cavern just above it. The photograph is taken from the track. The fact that there are hundreds of similar valleys overgrown with grant heath and cistus and detted with big rey rocks in all directions, all bewikleringly alike, no doubt influenced the birds in their chosce of quarters. But when I recall the long days I have spent and the arduous climbs I have made when in quest of Neophron's nests. such an example of a nesting station is a veritable reductio ad absurdum.

The example of an Egyptian Vulture nesting in a tree which has been alreaty alluded to is a curious one and well illustrative of the danger of erencralizins on the halbits of wild hirels. Prior to finding this the description that this birel "invariably nests in cliffs" was generally accepted. 


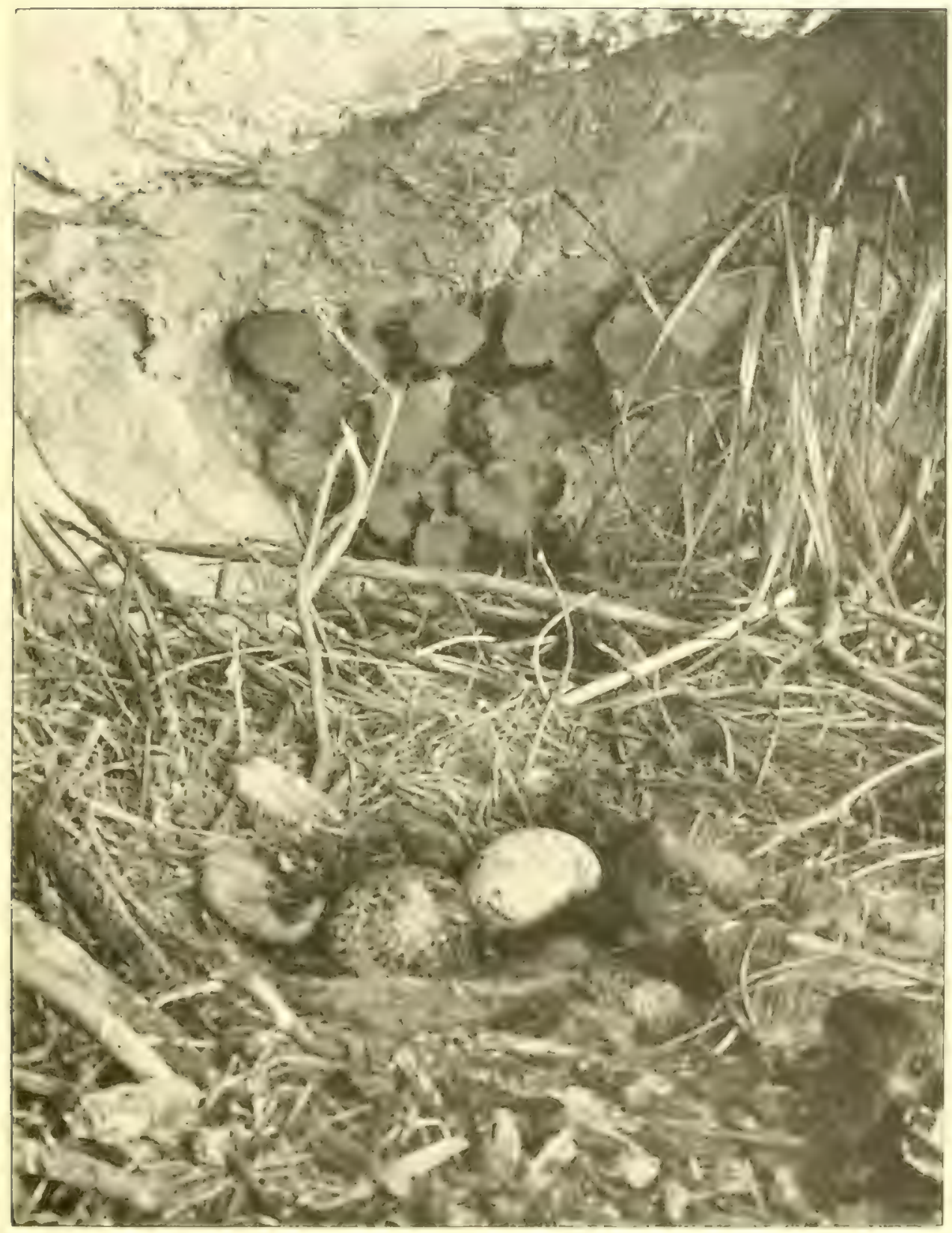





\section{A Nest in a Cork Tree}

It was on 6 April, I879, when riding through the Cork Woods near Gibraltar, on one of my usual tours of inspection of the nesting

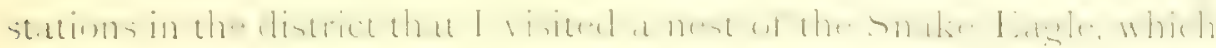
had been occupied by these birds in 1877 . 'This nest was on the horizontal branch of a corli tree about $20 \mathrm{ft}$. from the sround.

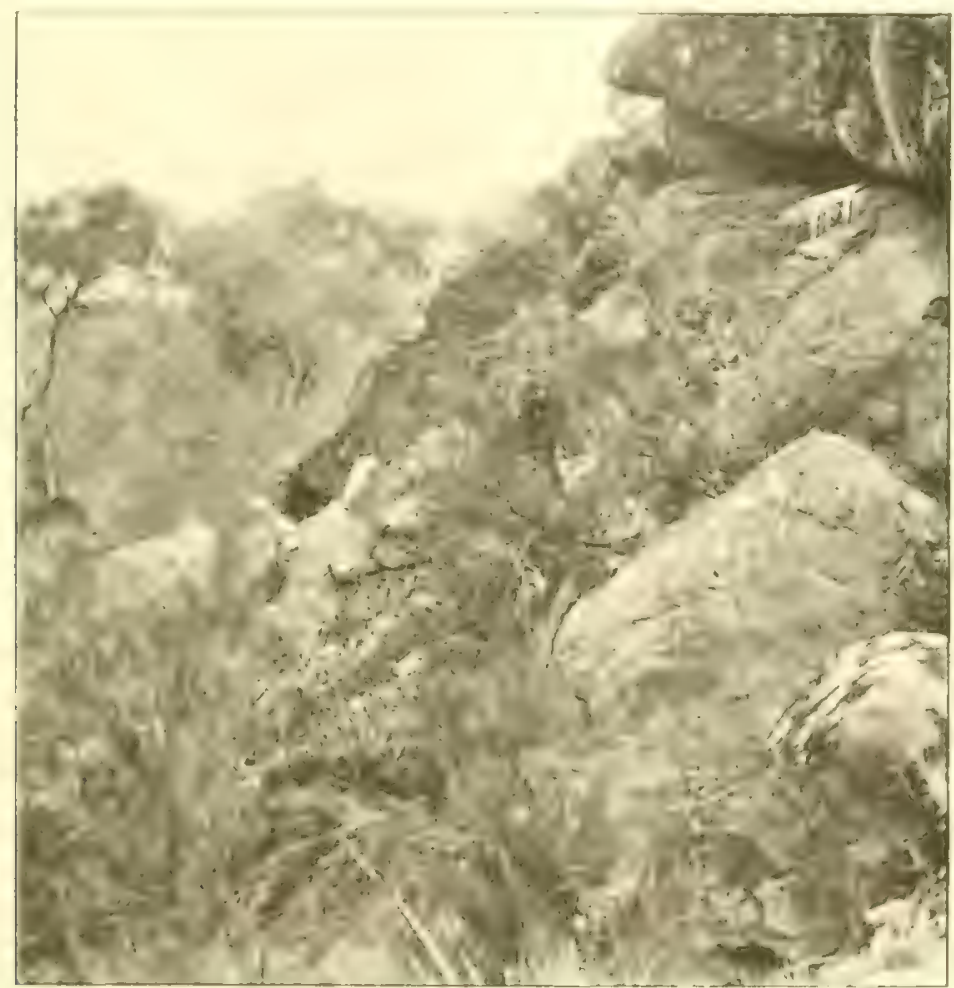

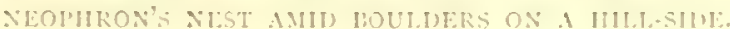

Seeing that it had been recently repared, I climbed up to it and found it freshly lined with goatshair. Since Snake Eacrles invariably use fresh green ilex boughs with leaves on them for lining their nests, this somewhat puzzled me. Still, it was plain that the nest had been recently reparired and, ats if to clinch the matter, at 
Snake Eagle was soaring overhead and making at wreat outcry at my presence. Five days later I was again on my rounds and again climbed to the nest, only to find it empty. But a lot more groats. hair lining had been added since my previnus visit. The old Snake Eagle was again tlying near the spot. Yet again, five days later, on 16 April, I was out with the Calipe hounds and we found a fox near the Duke of Kent's Farm and after some ringing around the briars there he started away for the Soto Gordo and was eventually killed near the Alcadezar Crags. During the run we passed close to the Snake Eagle's tree and for a third time I siw the old bird close to it. Determined to solve the mystery, two days later, on Is April I once again rode out to the nest and approached it warily. When not 20 yads off I saw a big bird sitting in it which on hearing my approach raised its head-the hidenus yellow head of the Egyptian Vulture! At last I had accounted for the seeming departure of the Snake Eagle from its invariable habits. I climbed up and found the nest contained one ego of the deeply marked variety. The Eagle's nest was, to put it plainly, a beastly sight owing to the V'ulture's alterations and additions; I suppose like other new tenants of old dwellings, she woukl have described them as improvements. For the freshly placed goatshair of a week since was now smothered with filthy rags, bits of tarred rope, manure of various sorts and putrid remains of animals and fish. I took the egg and put in a trap; the old bird returned very soon and settled on an adjacent bough whence she walked into the nest. Something however aroused her suspicions, for she suddenly took wing. Exactly a week later, 25 April, I was again on my rounds and being still unable to account for the presence of the Snake Eagle near the Neophron's nest, I visited the cork-tree.

To my great surprise the old Vulture was sitting in the nest and on climbing up I found a second egg, very pale rufous in colouring and smaller than the first. This eger was quite fresh and was, ats far ats I could judge, laid a weeli subsequent to the first one. 
I was determined to trap the old bird as a proof of the unusual circumstances attending her nesting. I had with me a hatrd-boiled egg. It did not take long, with the aid of my" sketching appliances, to colour this ege with a judicious mixture of vandylie brown and light red. Then, climbling up to the tree and noting on which side of the nest the bird entered, I placed my trip near the elge and the hen's eger in the centre of it.

After lying in ambush under a clump of bright cytisus for

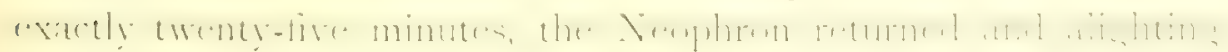
on the bough, as before, walked in and sprang the trap, which held her securcly by one hind-toe, and she fell to the ground. Throwing my jacket over her, she was soon bound captive and conveyed to the Rock. Here I secured her in a "falconer's brace" and she waddled about for some days and feel heartily on anything she could get, but her presence was not appreciated in the Regiment and after a few days interesting study of her pretty ways I removed the brace and let her go, none the worse for her brief confinement.

There is a peculiarity about the exger of the Egyptian Vulture which is seldom met with in the case of other birds' egres. The colouring, especially that of newly-latid egers, is of so superficial a nature as to come off easily. After a severe climb on a hot day I have more than once damaged an egre by taking it up in my warm hand and I have a peculiarly richly marked cogs now in my collection which shows the places where my perspiring fingers gripped it when engaged in blowing it, nigh thirty years ago.

There is something peculiarly unbirdlike and uncanny in the general appearance of these birds and also in their morements on the ground. I have a lively recollection of their habits and customs when in the Soudan in 1885 . About a month after the battle of Abu Klea I was ordered to make a slictch of the place where our square had received the onslaught of the Arabs. The 
bolies of the latter lay about in hundreds, mixed with scores of the swollen carcases of camels and horses. Apparently both the great Marabou Storks (Leptoptilus crmmifens) and the larger Vultures (I molur aurialaris, (jyps rifpelli and others) had given up the task of clearing up the battlefield as one quite beyond their puwers and hal gone to the more convenient scenes of our fighting neat the Nile, where I hat seen many congregated. But the Eugptian Vultures were evidently not so easily claunted and pairs of these evil-lonking birds were to be seen amid the throng of white-coated men, which lay thick in places on the hot sandy hill-side, stalking from one to another as if undecided where to recommence operations.

Some ten days later, during our retreat across the Bayuda I esert, these birds constantly accompanied us, halting when we halted. I have a peculiarly vivid impression of awalsing at grey dawn and perceiving close to me a pair of white birds whose whostly forms in the mysterious early morning light of the Desert seemed more than ever uncanny as they walked about among the recumbent forms of our men still asleep in their bivouacs.

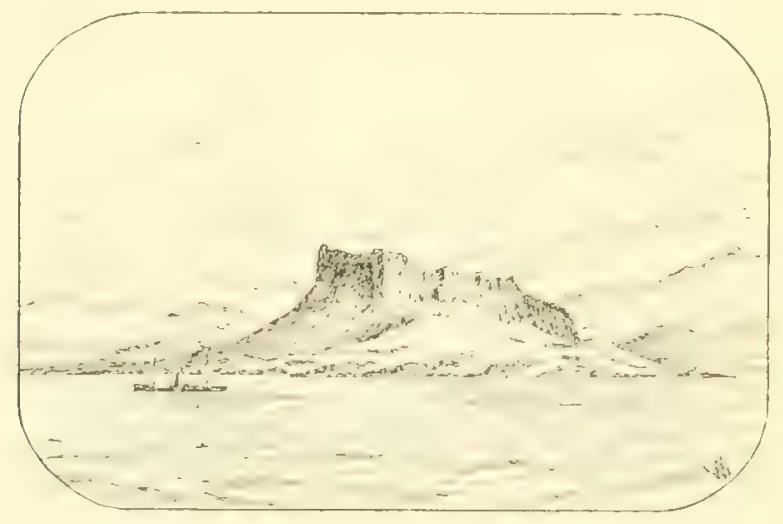





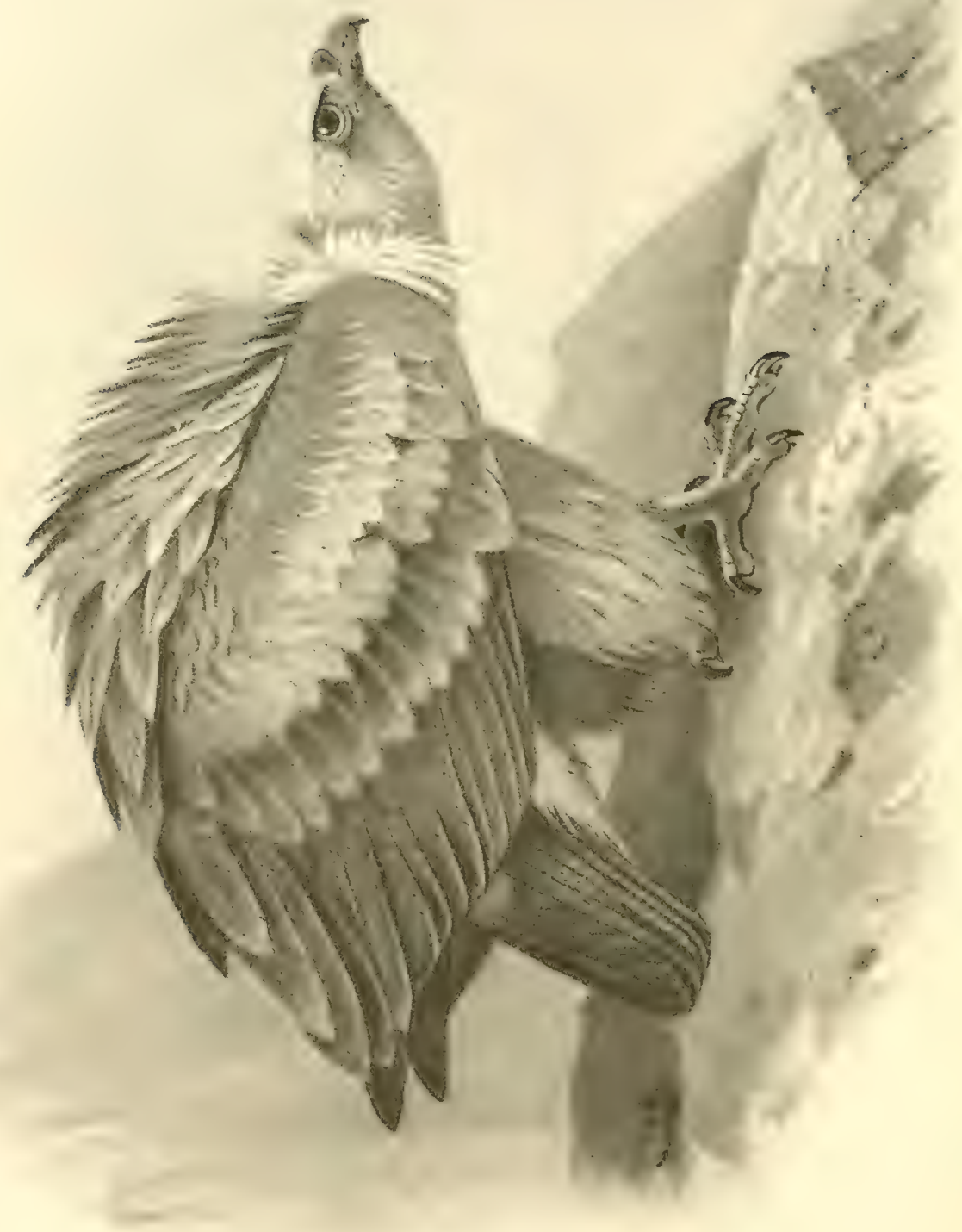




\section{CHAPTFR VII.}

THE GRIFION VULTURE (Gups fillos).

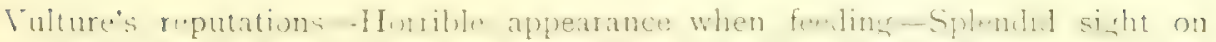
the wing-Personal cleanliness - A tame Griffon-A great bather-The fiscination of latue lirin-My tirst Vukure's clin In um-cirntin climb in I 878 - Nests in caverns - Passages through uptilted strata - Griffons' nestsGreat variety in style- "Marked" Griffon's egors-Dimensions of nests-

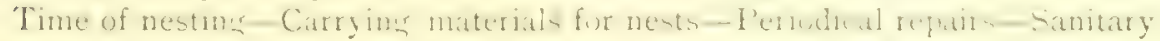
precautions-Carrying powers of loeak and foot-Young Griffons-Habit of simulating death-and extreme sicliness-Closing an interview-The

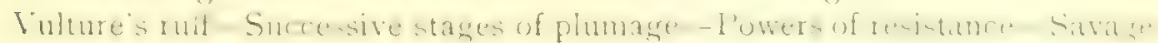
appearance-But harmless and afraid of man-An exception to the rule $-A$ wounded Griffon-Vast numbers of Vultures in Spain-Habit of roosting in trees.

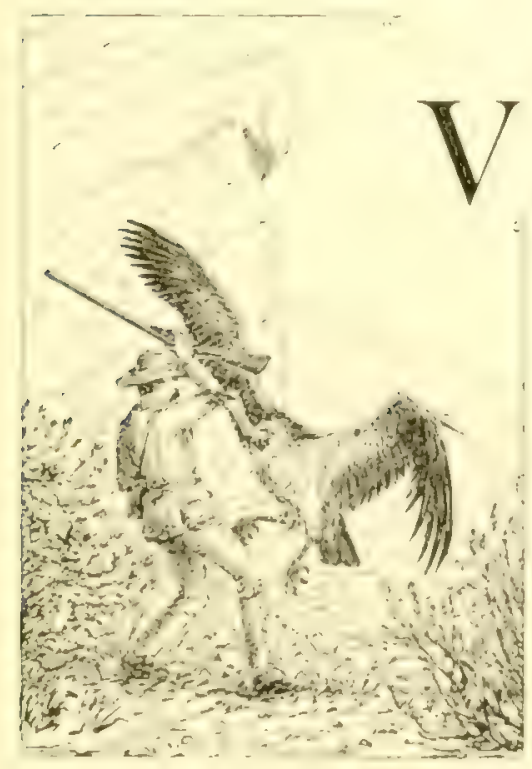

ULTURES have deservedly acquired an unsavoury reputation, and it would be hopeless to expect the average traveller who has seen them intent on their normal occupation of feeding on some carcase, not infrequently putrid, from viewing them with intense disgust and abhorrence. So intent are the bircls as they swarm round a dead animal and rend it to fragments with their powerful beaks, bolting huge lumps, that it is casy enough to approach close enough to watch their every 
movement, and very umpleasant they are. Setting aside their admitted want of discrimination in the matter of food, at any rate according to our tastes, and one or two of their habits and customs immediately connected with it, to which allusion will be made later, they are without question, when on the wing, among the most magnificent of birds. To watch them circling thousands of feet orerhead on the look-out for food or sailing past one of the arand cliffs whither they resort to nest in big colonics is a neverfailing joy. During the many years I have spent among wild birds I have from time to time induced friends to accompany me to some of the nesting-stations of these birds and have as often witnessed the surprise and delight they have betrayed on first secing the Vultures on the wing in these localities. On such occasions one is far removed from the spot where the birds have found their last unsavoury meal, and one only thinks of them and sees them as splendid birds with vast expanse of wing endowed with most marvellous powers of flight.

Those who have only seen a party of Vultures fighting orer a carcase and defiling their plumage with its horrible framents will harlly credit that the Vulture at home, siven reasonable time to perform its toilet after one of its orgies, is one of the most spickand-span of birds. Under its fathers is a mass of snowy white down which is ever kept in the most irreproachable condition. Those who are taken aback by the apparent inconsistency are invited to inspect the case of Vultures at the British MIuscum of Natural History and to judge for themselves of the correctness of my assertion. The big female bird with outspread wings to be seen there was shot from the nest and skinned and preserved by me, and was in exactly the same beautiful clean conclition when first killed as now. Again, a young bird taken from the nest and brought up on fresh food is as little objectionable as is any other bircl lept in captivity. I have put this to a practical test and 


\section{Personal Cleanliness}

kept a young Griffon for over two and a half years; during that time it not only was never in the least offensive but kept its plumage in the finest condition imaginable. A great bather, its chief delight was to be played upon with a garden hose, when it would expand its wings and gyrate slowly so as to let the water strike every part of its body. A favourite position was to throw itself on one side and expand the disengaged wing so that the water could strike its axillaries with force; after some minutes of this treatment it would turn round and similarly expand the other wing for a like course of spraying.

For the purposes of our national and other collections I have from time to time killed and skinned Vultures and Eingles of various sorts, and my experience is that, apart from their food, there is little to chose between the two classes of birds. A Vulture that has not recently had a big meal is in itself, no more unpleasant to handle than is any other big raptorial bird. In fact I have had far more trying times when engaged in preserving

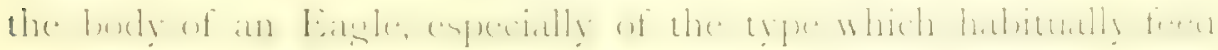
upon snakes and big lizards, than when similarly engaged over a Vulture. All the same, I have no particular desire to repeat the process in either case.

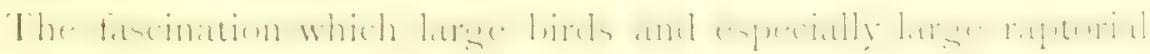
birds have ever had for me would be difficult to explain. From the moment when I first saw Vultures on the wing I became obsessed with the desire to find their nests and see them at home. I had nobody to put me in the waty of this, as I have done for others since, and I had to work on my own lines with no help

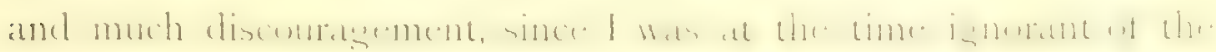
languadre of the country, and my birdsnesting proclivities were

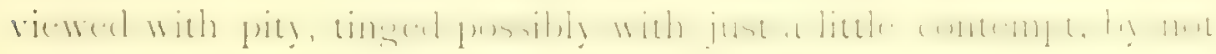
a few of my more enlightened brother officers.

Naturally enough, I directed my quest in the first instance to 
the largest and most inaccessible precipices, which, as we are all told from our childhood, are the home of Fagle and V'ulture. Nor was I disappointed in so far as seeing the bircls went, but they were nesting in situations which were either absolutely impossible to reach without ropes and plenty of them, or by cliff climbing of the most perilous and adventurous type. As I had neither ropes at hand nor any experience of rock-work at the time, I had in the first instance to accept defeat. Threc years elapsed before I was able to make an expedition to the same spot: during that interval I had profited by my former experiences and had become a fairly competent cliff climber. I had, above all, by going aloft at sea obtained the necessary confidence in dealing with heights. Previous to this I was looked upon as an expert tree climber; in fact, there were few trees which I could not climb and none which had defeated me where reaching a coveted nest was concerned. But there is a vast difference between workings up the top of a tall tree, possibly $100 \mathrm{ft}$. high, with a good handhold, and working among crags where the heights are reckoned in hundreds in lieu of in tens of feet and the chances of a sound handhold are most uncertain in places. The cliff where I obtained my first Griffon Vulture's egry has since become well-known owing to an account of my expedition thither, which I wrote to the late Henry Secbohm, having been published in his work on "British Birds' Nests and Eggs," for the Griffon is by courtesy a British Bird owing to a wanderer having been once taken in Ireland. An old friend of mine, however, a famous ornithologist, now dead, who had seen thousands of Griffons in his life, was certain he saw one in the New Forest about twenty-five years ago.

This cliff is a very imposing mass of sandstone which rises over six hundred feet from the stream at its base; a portion of it is much fissured and broken and contains numerous carerns wherein these big birds delight to nest. This part is easily scaled hy any 
good climber. Other portions however to the eye are as smooth as a wall, and decidedly perilous to traverse. The whole surface of the cliff slopes at 60 to 70 degrees, and the stratia at places afford a precarious foot-hold and hand-hold. A distant view of this great cliff as well as one showing a portion of the face of it

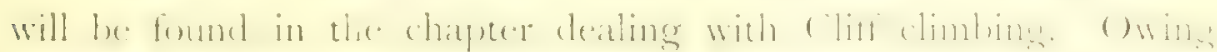
to want of experience I attempted to scale this grand cliff the wrong way and although I was fortunate enough to succeed, I deserved to have broken my neck. I say this with intent, for some sixteen years later I went down this same cliff with the aid

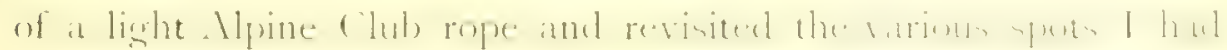

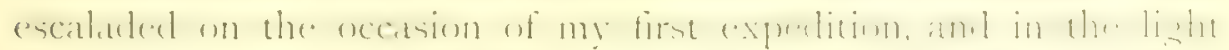

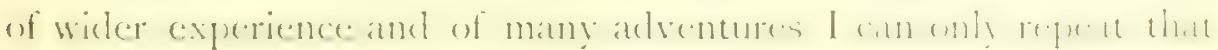
it was sheer good fortune that I came out of that cliff unhurt on the occasion of my first visit. More particularly do I recall two

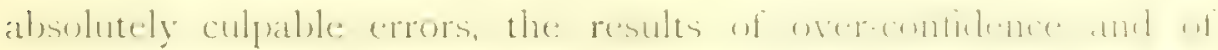
lack of knowledge of the unwritten rules of climbing. Once

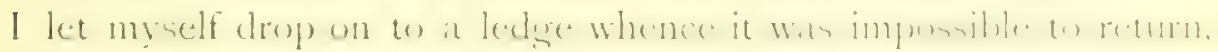
for it is one thing to drop neatly with one's feet on a few square

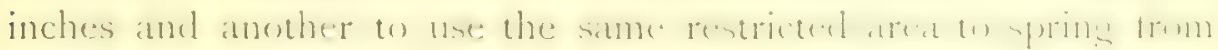
so as to recover one's hand-hold even a foot beyond one's reach overhead; more especially if there is a matter of $300 \mathrm{ft}$. or so between the place where one is standing and the next step below. In this instance I was forced to continue my climb, and it was absolutely a game of chance where I should come to next and whether I should be able to find a way out.

The second mistake was the result of even more unskilful

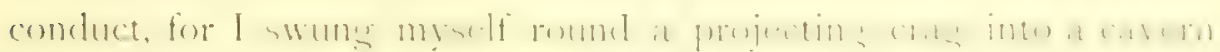
which did not admit of egress by the sime route. A slietch of

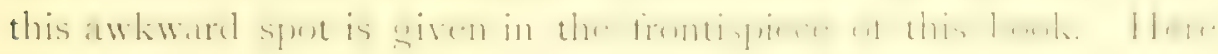
I nearly remained for all time, but fortune once argin favoured

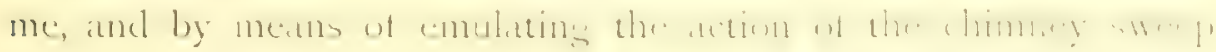


of old I managed to scramble up a fissure for some $50 \mathrm{ft}$. and thus make good my escape. 'To this day I can recall the sensa-

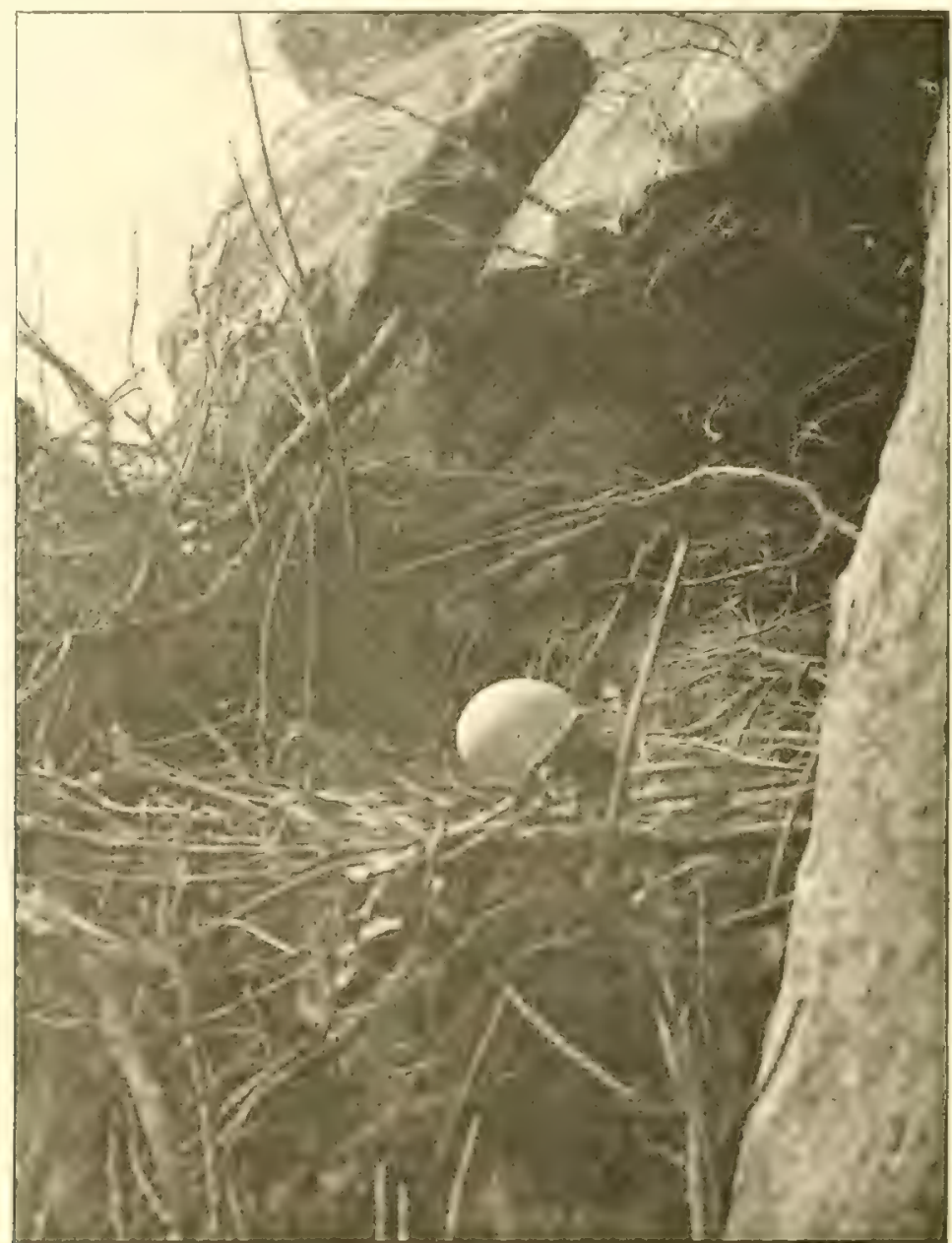

NEST OF GRIFFON VUITURE IN A CAVERN.

tions of the start from that nest at a point where the fissure wats widest and up which I hatel to spread-eagle, back to the cliff, 
and with nothing in front of one except the fresh air and a magnificent view!

Although many, probably the great majority, of Griffons'

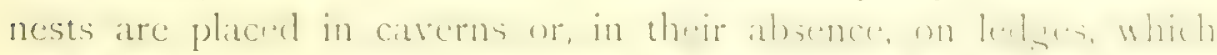

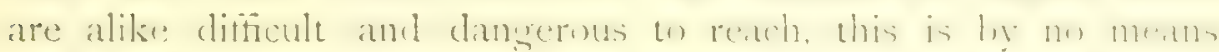

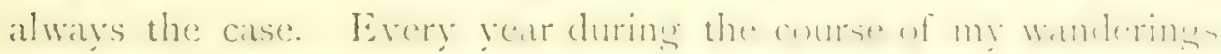

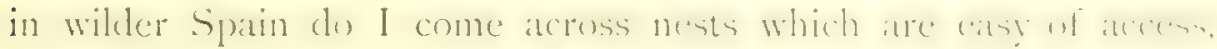

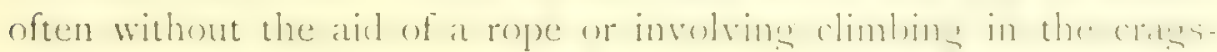
men's sense of the word; espectially in remote dietricts where the birds have not had their nests harried. But even where nests are placed in dancerous and dificult sites. there in sometime a means of avoiding a direct attack in such places. Thus in about half a dozen instances as already described I have taken adrantage of "juints" or other geofoncical formations of the clifts and the existence of deeple chasms and fisumes neatr the summit of the tilted-up crogs to peratrate from the reserese shene throush the heart of the hill and emcrese on a terrace on the fate of the precipice, at times over a hundred feet from the top.

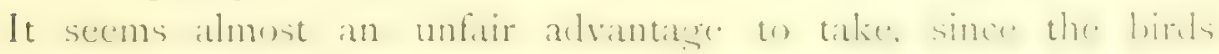
obviously do not reckon upon such tactics. All the same, on several occasions it has proved a most succcessful method of approach, and has been of late years, since I have been

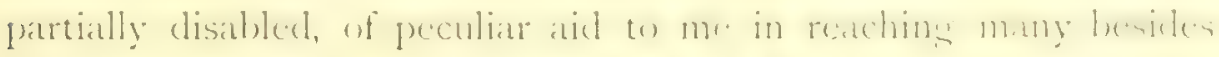

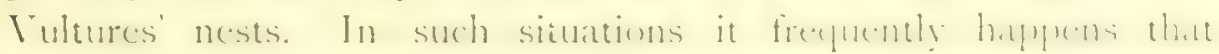

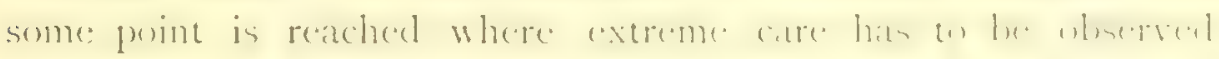
in traversing an awkward place. Once over such a spot and at the first nest it not uncommonly accum that se seret ather nent

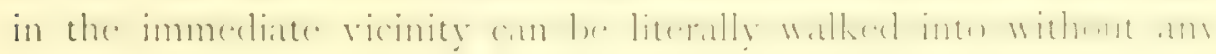
appreciable risk.

Of the nest itself it is difficult to write, for few birds seem to

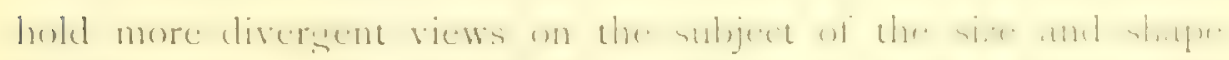

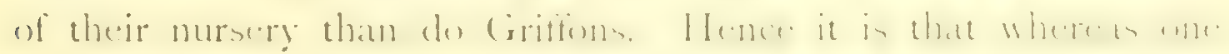


writer styles the nest a great and untidy platform another describes it as a neatly finished and lined bowl. Having had the opportunity of visiting many scores of nests I have come to the conclusion that individual (iriffons vary in their ideas of comfort and cleanliness almost as much ats do human beings, and that in consequence both of the foresoing descriptions are accurate in certain cases.

Some may ask why I thus visit so many nests of the same species of bird. The reply is that although the Griffon usually lays one egs (I have never seen more than one egg in a nest, despite the tale that they sometimes lay two, which I doubt), normally pure white; sometimes their exss are marked with rufous spots and streaks. Such specimens are of course a joy to all who wish for a rare addition to their collections. Hence I never see a Griffon's nest in a situation where it can be reached without undue risk or a sacrifice of valuable time but I pay it a visit, ever sanguine of being rewarded by the sight of a handsomely marked specimen. As a matter of fact I have only come across three egus with any pretensions to marlings in over thirty years, in spite of many scores I have seen. Possibly I have been unlucky, but my estimate is that on the average not more than one in forty are thus marked. Yet one day I had the good fortune to get two marked eggs out of eight nests visited.

The typical Griffon's nest is placed in a cavern, when a cavern is to be found, which, as I have said, partly explains their marked predilection for the sindstone cliffs of southern Spain rather than the limestone, which offer fewer suitable sites. Failing however a cavern or deep fissure, these birds will nest on an open ledge or on the big terraces which are found on some of the great cliffs.

The nests have a foundation of big sticks, dried branches of trees and of heather, the platform varying from $2 \mathrm{ft}$. to $+\mathrm{ft}$. in diameter. Some have a farly neatly formed basin about is in. 


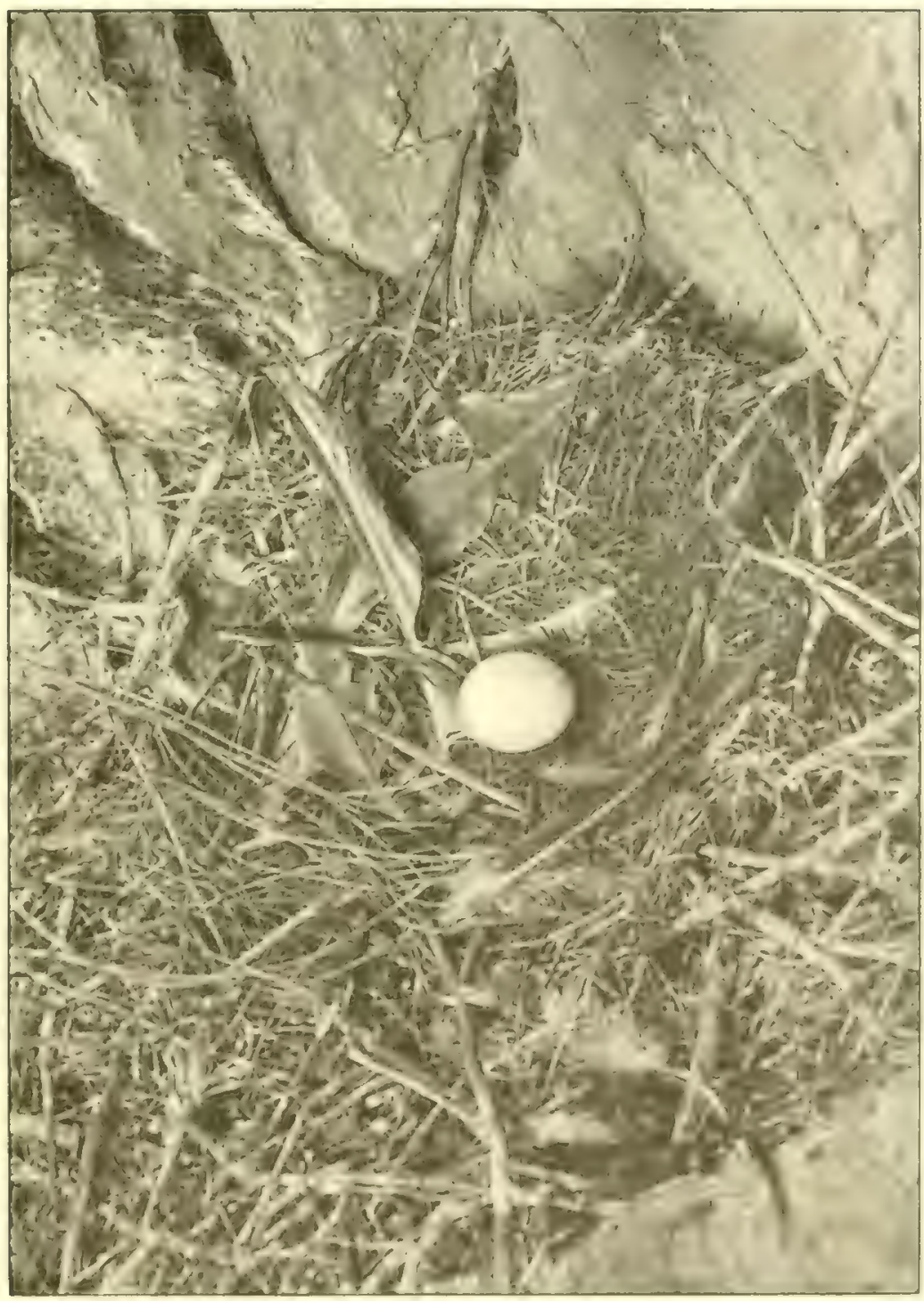

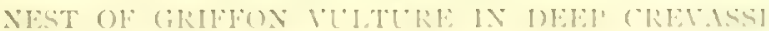





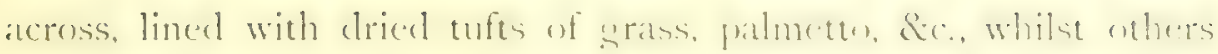

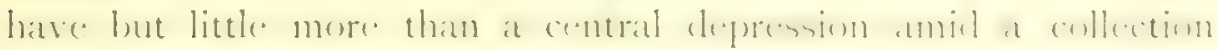

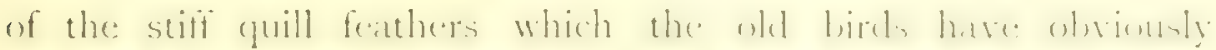

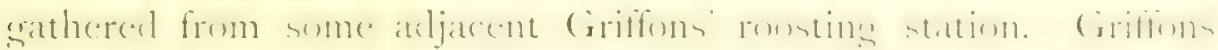
lay as a rule early in February, although I bave seen egges a month eatrice and have taken fresh enses in March and April and still more rarely in May. Most possibly those found in April and later are a second liginge, che: to the firat having heen titken. () one accision I watched no less thate ten patirs of these birds busily condencel in bringing moterials to the ir ne ts ; this wats

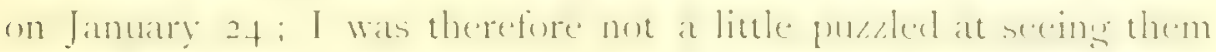
some three monthe later carrying and sized leafy loranches. freshly broken from cork and ilex trees, to the cliffs.

The cirifon often carries its nesting materids in the leak, the

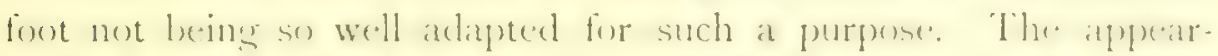
ance of these great hirds stealily winging their waty us sume crats with a leafy branch of cork or ilex or wild olive, a foot or more in length. helel in the beak is alsumblly stencestive of the curious mediateal pictures of the dore returning to the ark with the olive branch. For some vears I imegimed that the birals when thus engaged were buikling a new nest in spite of the batenems

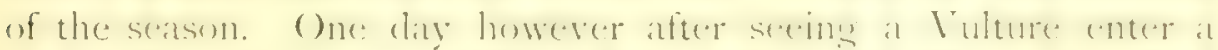
carern, branch in beak, I climber (up) to it and fommel a mewly-lined nest, the infant lulture in it having been provided with an conterely new chamere of beckling in the form of freshly cut branches of s.reen ilex and heath placed on the tope of the dirty and much

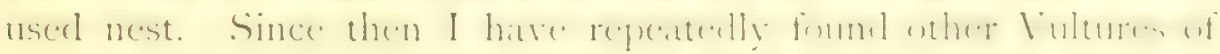

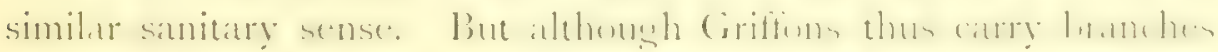

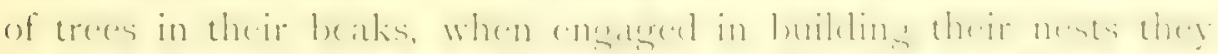

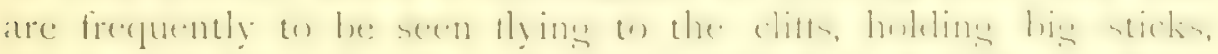

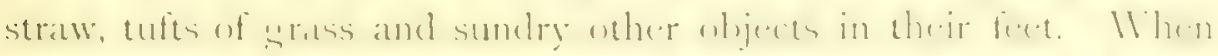

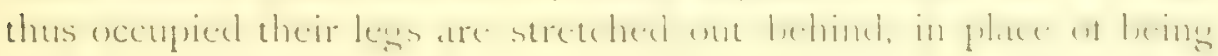


retracted, as is ustal with birds carrying things on the wing. I have often watched Griffons sitting upon the upper l, ranches of a cork-tree

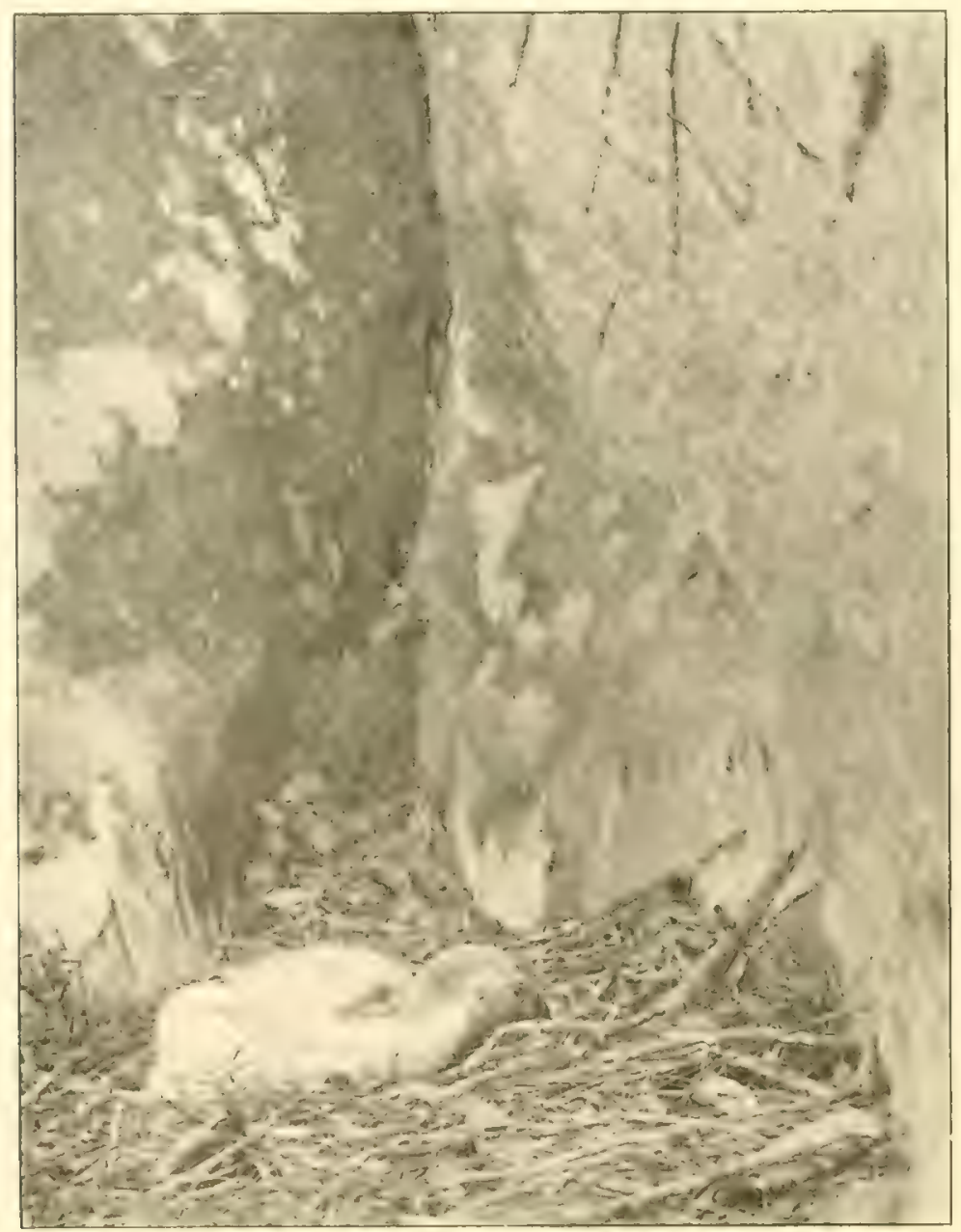

IOUNG GRIFION VULTUKE, AlOUT FOUK DAYS OL.D.

busily engaged in breaking off branches with their powerful beaks to convey to their nests. There can be no doubt that when a Griffon 


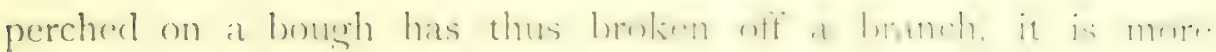
convenient for it to carry it in the beak than in the foot. On

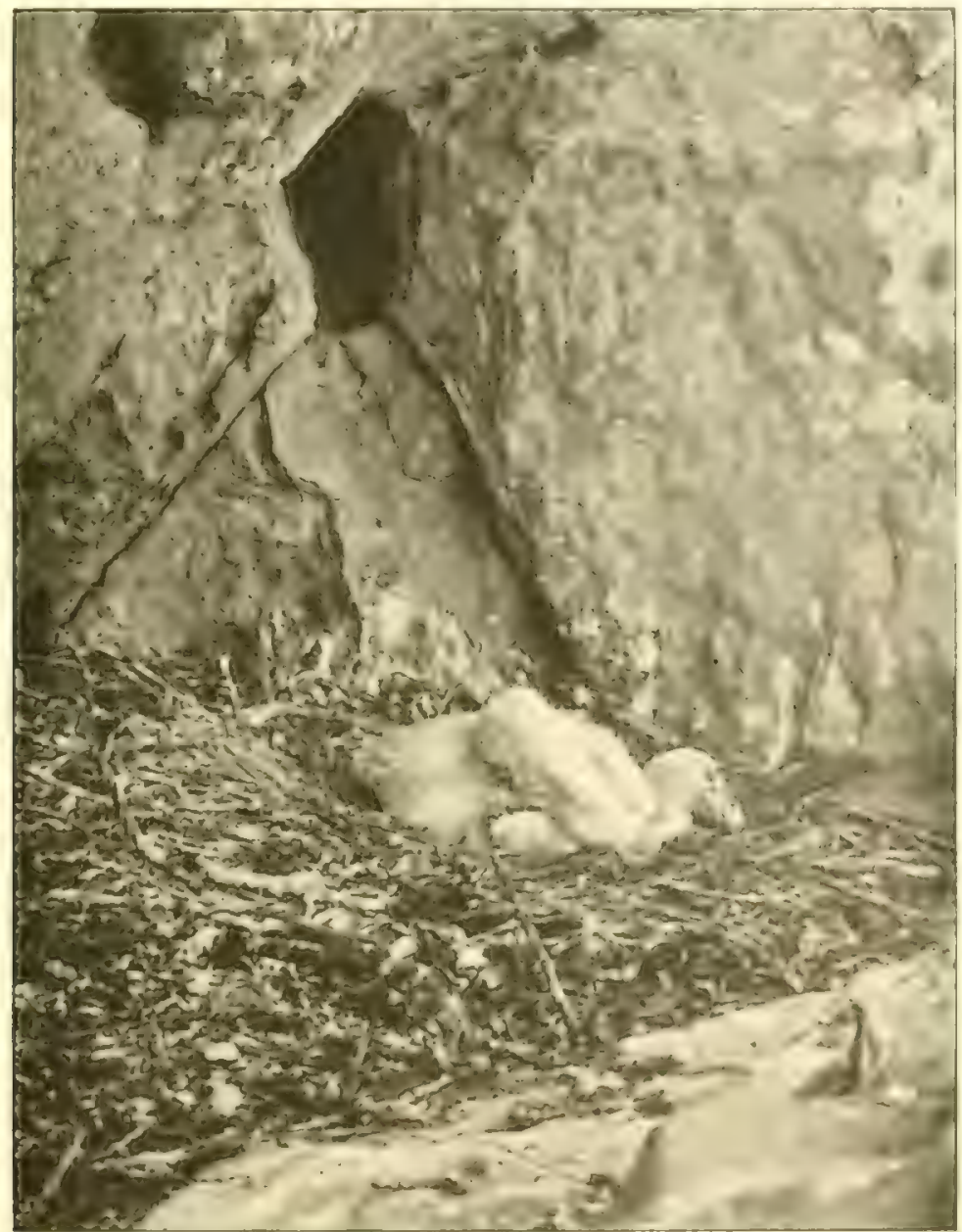

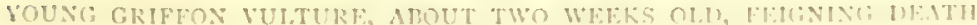

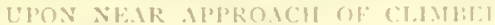

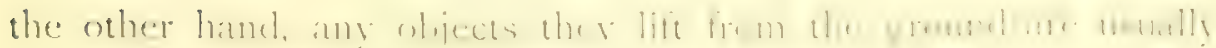
carried in the foot. Cliffs much frequented by Ciriffons as nesting- 
stations are far from being ideal spots, and the pungent smell of death and decay which pervades them is one of the minor trials the enthusiastic naturalist has to bear during the course of his studies.

The egg is of considerable size and very globular in shape measuring about $4 \mathrm{in}$. by $3 . \mathrm{in}$. The young when hatched out are lumps of white down with black bead-like eyes. They rapidly increase in size; when only two weeks old they weigh five pounds and their primary feathers begin to show, whilst the neck feathers which eventually form the ruff are distinctly visible. When the climber suddenly comes across a young Griffon in the nest, no matter what size it may be, (Griffons remain in the nest for some months and until nearly full srown) it instantly simulates death by throwing itself flat with its head lying in at dislocated fashion on one side and remains motionless thus for some time. The illusion thus produced is often heightened by the local conditions. Thus when I came upon the young bird two weeks old figured on the last page, it was a stifling hot day in May. The sun's rays beat fiercely into the gully on the rocks surrounding the nest and there was not a breath of air. The young bird lay with its head on one side and with the nictitating membrane drawn over its eye, as shown in the picture, to all appearance dead. All about the dirty nest were swarms of brilliantly green "blue bottles" which settled on and crawled about the young bird. What between the heat, the sickly effluvia of the place, and the stillness only broken by the buzzing of the carrion flies it was a complete counterfeit presentment of death. It was not until I had got out my camera and taken a couple of pictures of this most accomplished actor that it apparently came to the conclusion that it was about time to come to life again and vary the entertainment.

I have seen young Griffons only a few hours after emerging from the eggr adopt this means to avoid observation, and, as will 


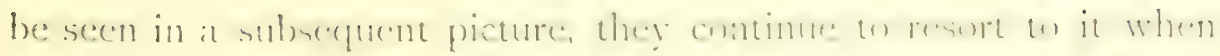

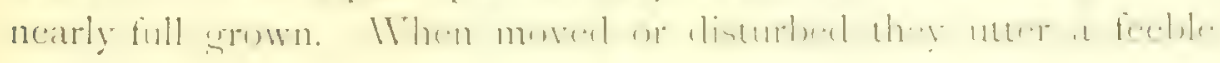
twittering call.

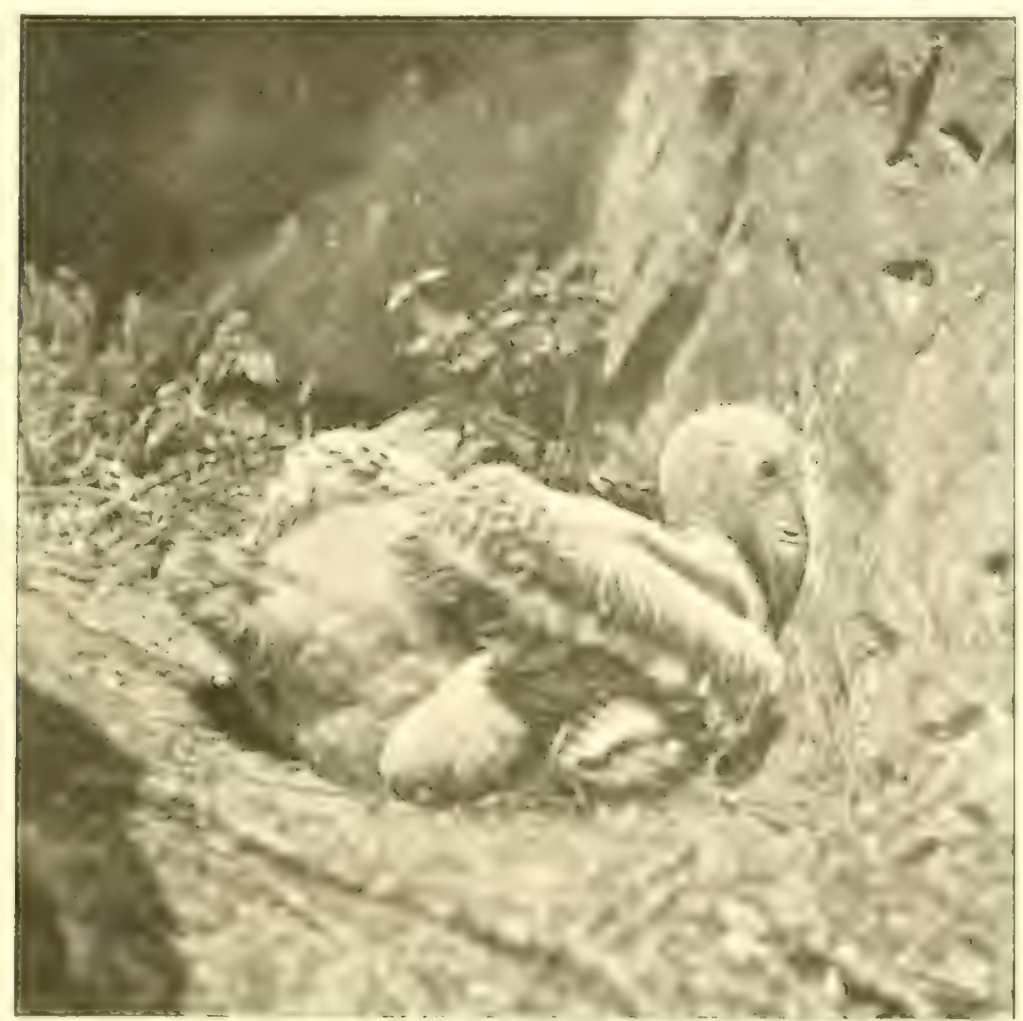

VOUNG (BRIFFON VUITURE, AlBOU'T TIREK WFKKS ()I,I),

When a young Vulture finds that its most earnest attempts at simulating death are ignored and that the intruder persists in remaining in the vicinity, it adopts more active and stringent

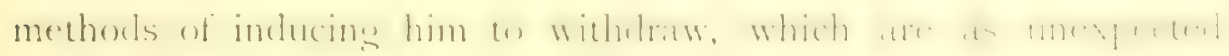
as they are unpleasant. For, after recovering consciousness as

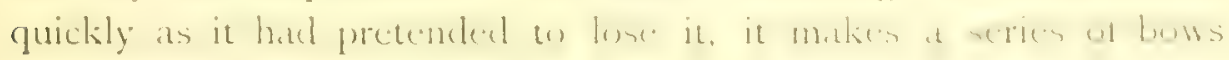


accompanied by a regursitating process which quickly ends in the rejection of the whole of its last meal! Iihen one considers what this must have been, it is best left to the imagrination what it is like when thus presented to the too importunate naturalist.

I made the discovery of this pretty habit in a very simple fashion. It was the first time I had got among the young Vultures and I was naturally much interested in seeing a young bird, which had assuredly never set eyes on a human being before, instantly sham death upon detecting my approach. Having got out my camera and taken a picture of it in this position at a few feet range, I proceeded to wedge the camera on the rock so as to take a time-exposure. The ledge I was on was narrow and behind me was space, the foot of the crag lying some hundreds of feet below. It was at the critical moment when I was deeply engrossed in the usual agonies of hand-camera work that my subject, rising from its simulated trance, made me a present of its last meal! Since then I have seen many young Griffons and have suffered from their manners and customs, but the memory of that first introduction to them and of my hasty departure upwards, for to retire was impossible, lives with me still.

The beautiful white ruff around the saunt neck of a Griffon is a sign of maturity. As a nestling and during the first and second years it has a ruff, but in place of being one of fine white clown it is composed of fulvous lanceolate feathers. The exact period when these give way to the adult plumage is uncertain, but I have proved by the bird I kept in an aviary and which now figures at the British Museum that the change does not come into effect at any rate before the third year. On the other hand I have seen parent Griffons who wore the miniature feather ruff in place of the white down one. From their movements I imagined them to be males; certainly all the females I have put off nests near enough to see the plumage wore the white ruff. 
An adult Griffon weighs about is $1 \mathrm{~b}$. (not 40 lb, as some writers on Spain have asserted), and the expanse of wing varies

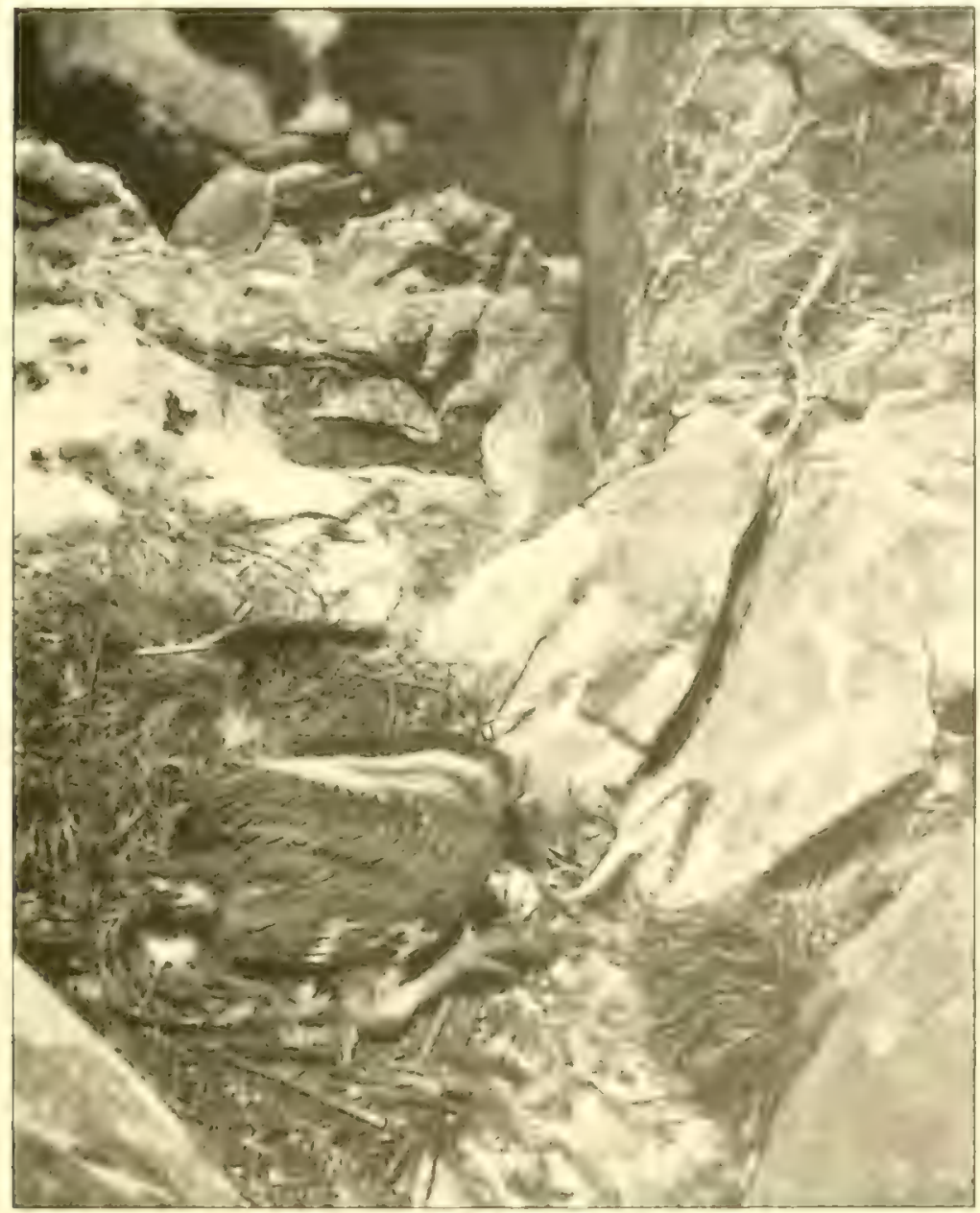

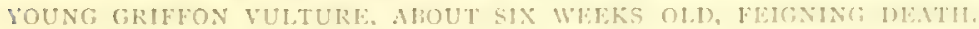

from $8 \mathrm{ft}$. to $9 \mathrm{ft}$; when on the wing the tips of their primaries

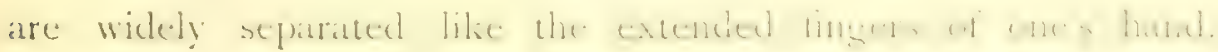
26 
This and the extreme shortness and squareness of the tail are noticeable features, which render it easy to ictentify the bird at at great distance.

I have often been asked whether thesc ureat birds ever show fight when their nests and young are molested. As a matter of fact

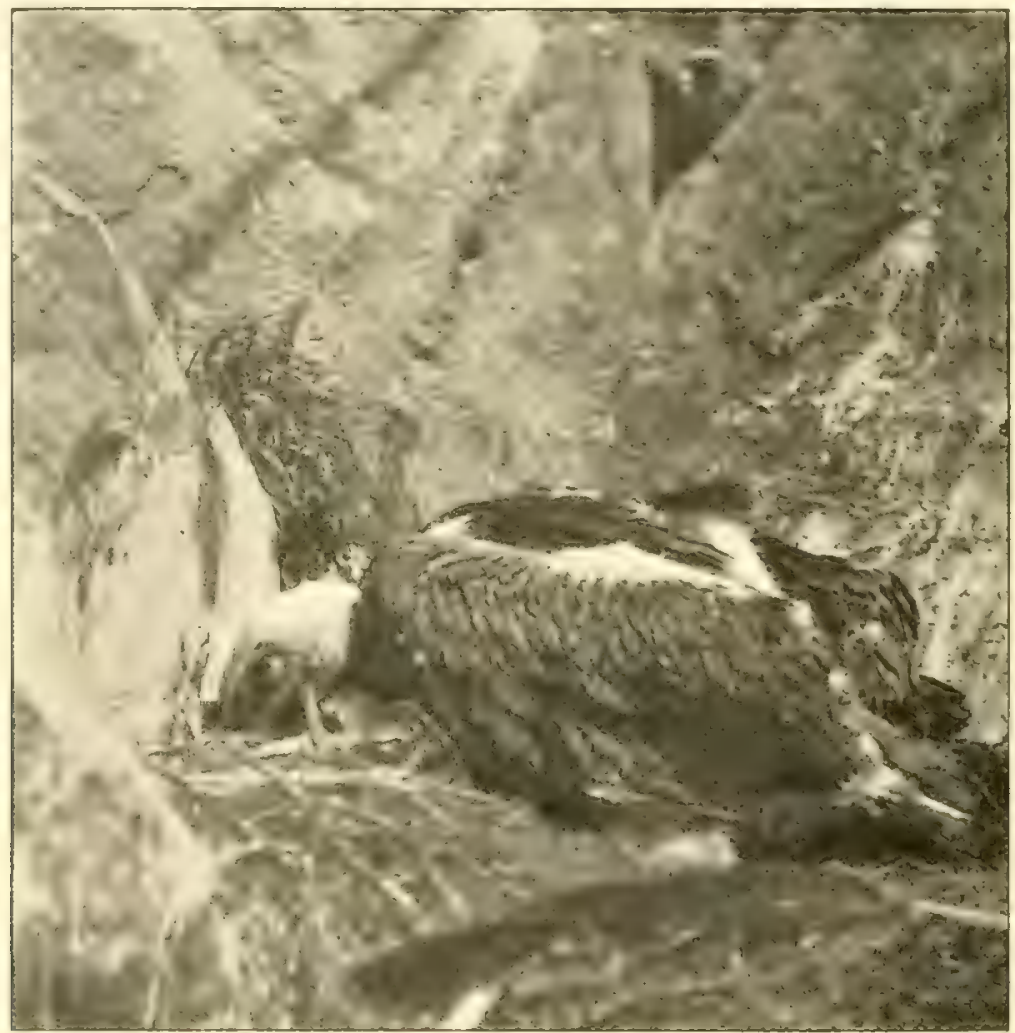

YOUNG GRIFFON VUJTURE, ABOUT EIGHT WEEKS OLD: THE OFFENSIVE-DEFENSIVE.

actually they never do, hut it took me some time hefore I realized that they are far too much alarmed at the presence of man to attempt to attack him. It is of course obvious enough that a bird of such size and weight, and capable of moving with such relocity, could 


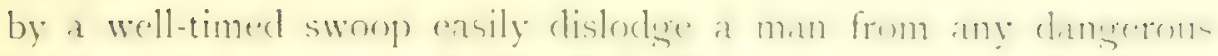
ledge, where both hand-hold and fouthokt are alike uncertain. only the fact remains that they never think of such a thing. Those who hares not penterated inte their haunts an hardly

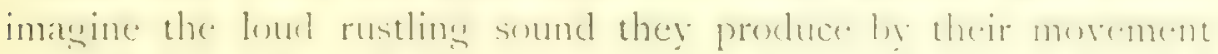
through the air as they approach their nests. At times when ! have feen safely enseonced at the back of some eatern on the

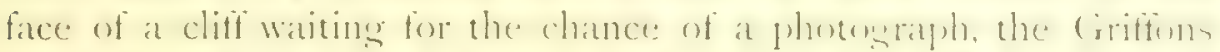
which hat been saling around high above the clist, emboldened

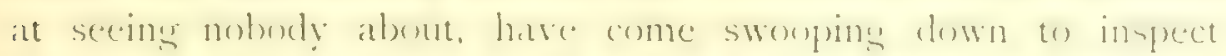
their nests with a noise which an best be likeneel to a pumerful steam-blats ; this, heard for the lirst time, is decidedly statline. Semetimes when I have heen climbing alemes the lace of a rous a cirifom hats sudelenly romended a corner of the clitf elieling within

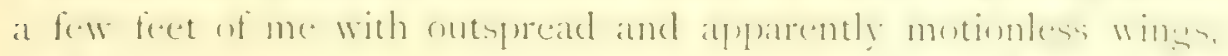

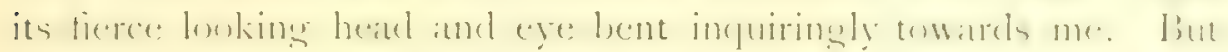

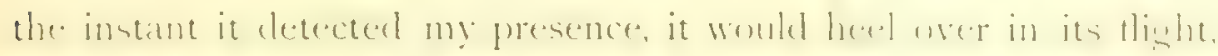

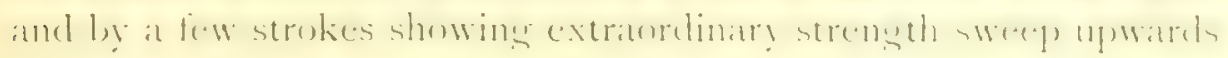
and away.

On one and one only of my many scores of visits to Griffons'

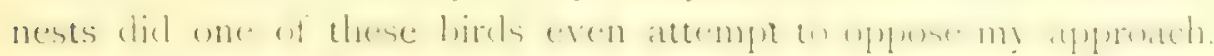
This was in I907; I was working along the ledges of a tall cliff when I heard a hend hissing sound which was reprated atedin and

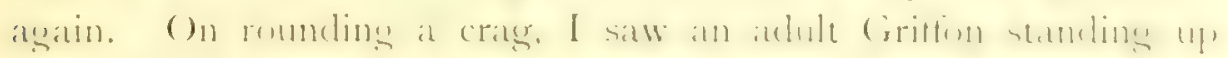
over her nest which contained an egg, not i $5 \mathrm{ft}$. from me. So long as I stood still the great bird continued to strike a series

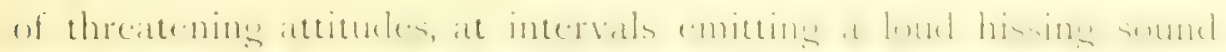

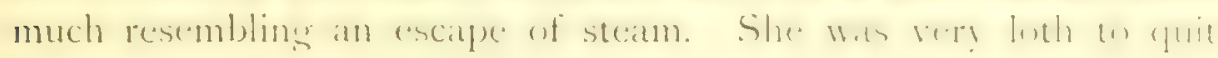
her egg and every time I made as if to depart, she subsided on

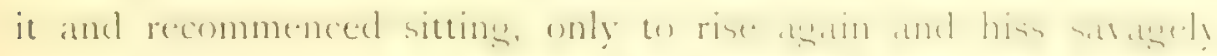
when I returned towards her. I got out my camera and photo-

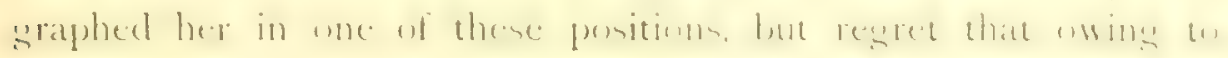


the direction of the sun and the impossibility of my shifting my position on the namew ledge I occupied, the photograph, although of considerable interest, is not sufficintly defined for reproduction here. Eventually the Vulture took wing, hut so lone ats I remained in the vicinity she sailed round the cliff at times passing close to me with a mighty swish of wings in a most threatening manner. It intervals she would alight on some pinnacle cras within 30 yards of me and recommence hissing. Here, owing again to the position of the sun, I utterly fatiled to photograph her although I tried many times.

I tell this story at length because in all my long experiences of Eagles and Vulures I have known no wher bird come so neatr to threatening a man as this.

Ilat this pugnacious Vulture but been aware of her own strength and of the wealiness of my position on the narrow stratum of rock, she could of course easily have dislodged me. But I am well assured nothing would have induced her to approach me any nearer than she did. I can only account for her pugnacity by the fact that her stronghold was in a very remote sierra and in a pusition where she had probably never been approached save by some lad tending goats who would likely enough have been detered by her threatening demeanour. I had not the heart to take that egg and was pleased to see her return to it as I ascended the cliff.

Again, only once have I seen or heard of a Griffon attacking a man and that was in the case of a wounded bird and hence cannot fairly be reckoned as a genuine example. It was at the time I was engaged in obtaining some Vultures for the British Museum. I had shot an old female from the top of a cliff as she left her nest and she fell into the scrub below. Upon woing round to the foot of the clift to pick her up, when forcins my way through the cistus and giant heath, I sucldenly 


\section{Attacked by a Wounded Griffon}

came upon the poor bird lying in an open patch with a broken wing. The instant she saw me, she rose up and made one spring, and before I could parry her advance seized my arm near the shoulder in her powerful beak, tearing a hole in both coat and shirt and inflicting an unpleasant wound, and repeating the attack with great determination before I could despatch her.

It has ever been a marvel to travellers and naturalists how and where the immense numbers of Vultures seen in the countries they

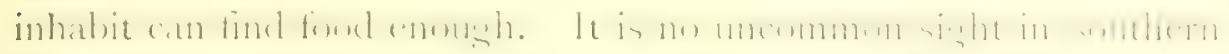
Spain to see eighty or more collected around a single dead beast. Not long since a cow died during the night close to my dwelling, and next morning there were seventy Griffons ready to commence work upon it. Small wonder that, with such a ravenous throng ever ready to perform the funeral obsequies, it takes but a short time for the carcase of horse or cow to disappear. On the other

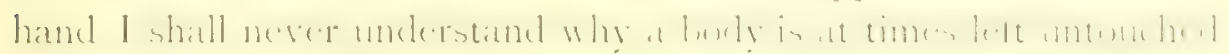
for weeks by the Vultures, though this is so. One of the most curious gatherings of Vultures I have seen was a large party in

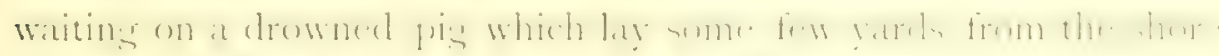

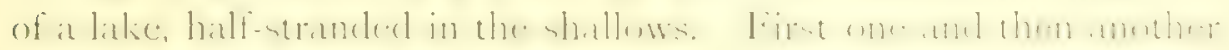

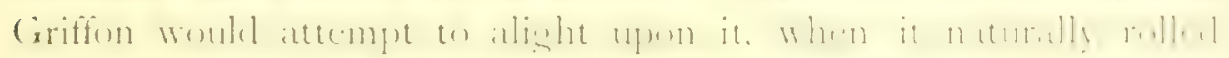

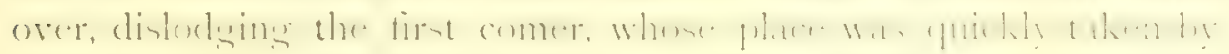
a second. At times the birds engaged in a furious cluel over the carcass, beating the water into foam with their huge wings and

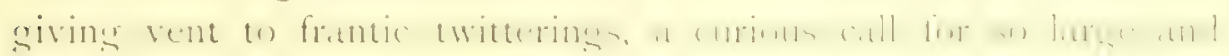
savage a bird.

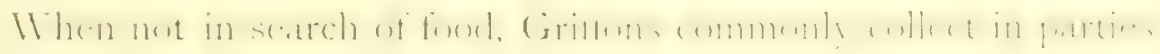
of from ten to thirty and perch on the summit of some crass, whence they can keep a good look out. Should the weather be wet and wild, they are much addicted to roosting in some big cavern among the sierras. In windy weather they collect in the more sheltered valleys and sit on the top of the cork-trees, often only 
20 to $25 \mathrm{ft}$. above the ground. I know of some quiet valleys where, if a strong wind be blowing, I am sure of seeing over thirty Vultures thus at rest, especially after three o'clock of an aftermoon. which seems to be the hour when they usually discontinue their marvellous aerial reconnaissances in quest of carrion.

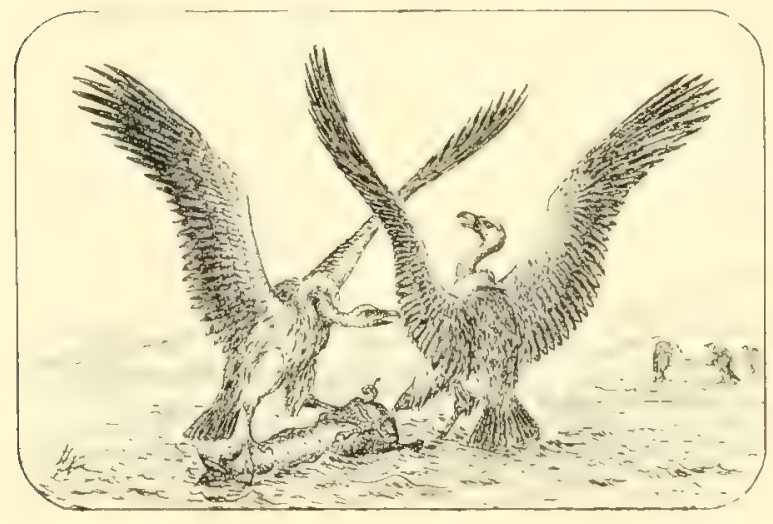





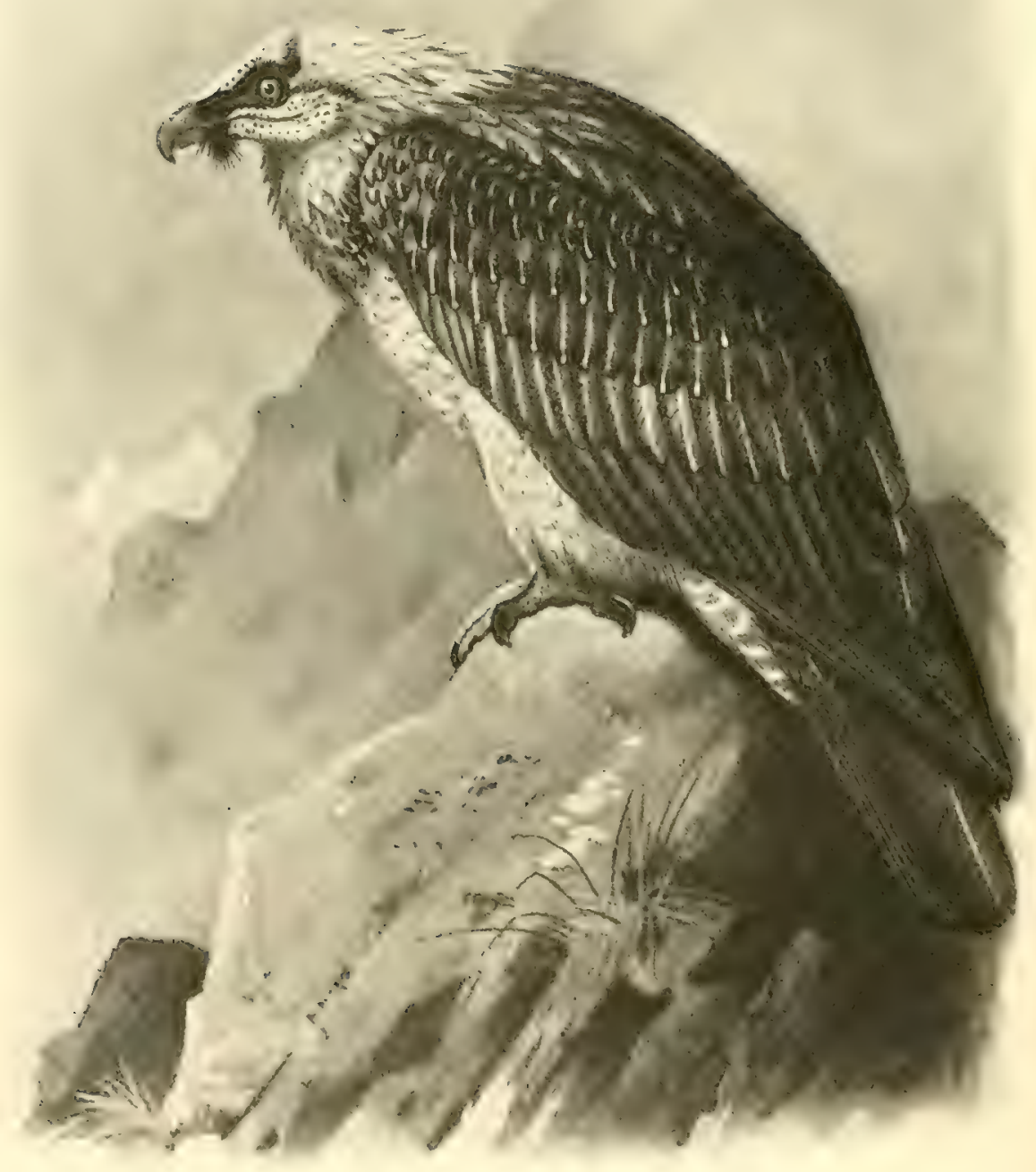

BEARDED VULTURE.

(ijfaiens barbatus (Linn.). 


\section{CH.MTIR IX.}

THE BEARDED VULTURE (Gipaiths bututus).

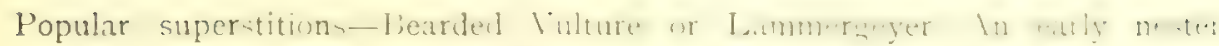
-Repeated unsuccessful efforts to obtain eggs-Splendid powers of flight-A dramatic meeting-Eincounter between liearded V'ulture and Griffon-Locate a nest-Description of cliff and surroundings-Reach terrace below nest-Ice and snow-Baffled-1 forlorn hope-Reach the

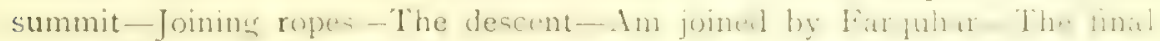
lower-A jambed rope-Reach the nest-Bitter disappointment-Land on

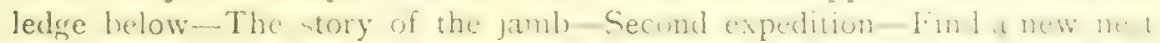
-Description of situation-Reach point Ioo $\mathrm{ft}$. above nest- 1 dangerous cliff-A nasty descent-An overhung nest-Ëmpty again!-An unsolved riddle-Qucbranta-huesos, the Bone-breaker-A reputed habit-Watch Bearded Vulture carry and drop an animal's leg-It descends and feeds off fragments-Re-ascends with leg-Returns to carcass-Conclusive evidence of habit.

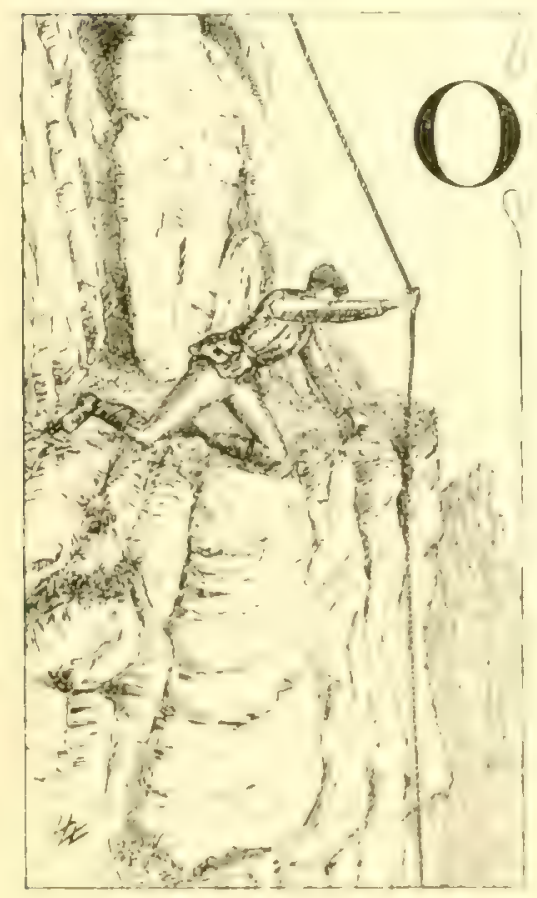

all the great birds of prey there is none which appeals more to the popular inagination than does the Bearded Vulture or, to wive it the imposing title which it still bears in mid-Europe, the Lammerseyer.

There has been sone dispute as to the correct nomenclature of this bird, some advocating the first and others the second of the names siven. Those who yet cling to Limmercreyer do so partly for sentimental reisons: the bird is not British even in the most elastic interpretation and in the recions where it originally became known 
to the world. Switzerland and the Tyrol, it has been since mediceval times invested with almost supernatural powers, from killing adventurous chamois-hunters or boys who sought to rob their nests, by knocking them off cliffs, to carrying off infants and, in its milder moments, preying upon chamois and sheep which it slew and carried off in mid-air to its eyrie in some appalling cliff, many thousands of feet high. Since it was popularly credited with directly causing the death of the sheep, goats, kids and lambs, which undoubtedly form its main food, it earned the title of Lämmergeyer = lamb-vulture, and it is this name which is still applied to it by the majority of people. Those who advocate the other name maintain that the great bird is vulturine in its habits, i.e., never kills the beasts it feeds upon but simply resorts to the carcasses of those which have fallen from the cliffs or which have died of injuries or starvation due to their having been imprisoned in some spot whence escape was impossible. They also declare that the structure of the bird's foot does not lend itself to carrying its prey for any distance, but of this I shall speak later. The late Dr. Stark, who to my knowledge had exceptional opportunities of watching these birds in Europe, boldly asserted that in habits and feeding they were little better than the Emyptian Vulture, a cruel charge against such a noble-looking bird but of which the truth is I fear incontrovertible.

The opponcnts of the name Bearded Vulture pointed out how the biri was not a true Vulture and cited various points such as its well-feathered head and legrs. The other school retorted by callines attention to the distinctly vrulturine beak, and to the foot which approaches much nearer that of the Vulture with its long central toe and blunter claws thai the Eagle's, and further justified the descriptire accuracy of their name in that the bird has a beard consisting of at tuft of black bristly feathers below its beak, ever most conspicuous, and argued that since its general appearance, 


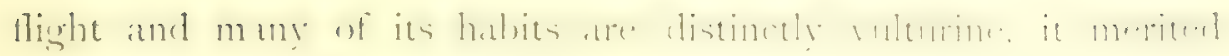
the name of the Bearded Vulture.

In the Himalayas, where it resides, it is well-known to many sportsmen either as the Lämmergeyer or the "Golden Eagle" from its rich rufous colouring. It is probably owing to this that the name of Lämmergeyer has taken such a hold in our language since the vast majority of those among us who have seen it in a wild state are Anglo-Indians.

The late P'rofessor Newton, one of the most learned fand

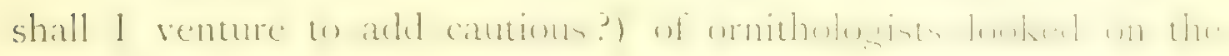
matter as one which could only be solved by an investigation of "characters which are not superficial." Since my own field observations and experiences are mainly in accord with those who style the bird the Bearded Vulture, I have adopted that name and especially so, that all those who in recent years have had opportunities of watching these grand birds in their fastnesses are agreed as to the convenience of the term. Colonel Irby thus styles it in his "Ornithology of the Straits," as did Lord Lilford and Dr. Stark. The latter's experiences were extensive and unique as I have said.

On the other hand, I have not met with any modern maturalist

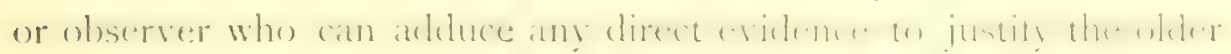

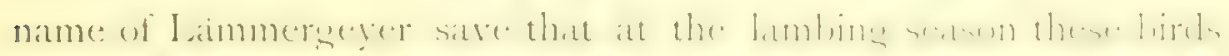

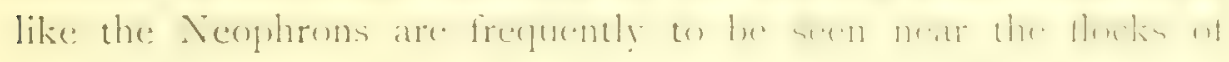
goats and mountain sheep for reasons given by Dr. Stark and quoted by Colonel Irby. After watching these powerful birds

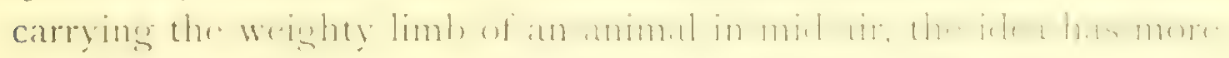
than once struck me that the old tale of Golden Eagles carrying

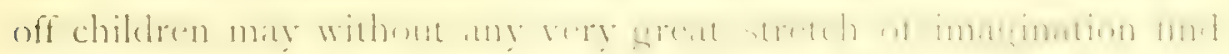

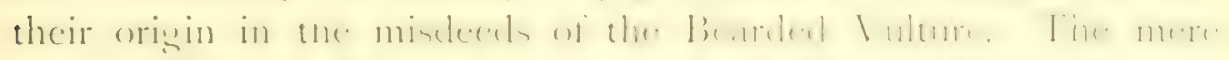

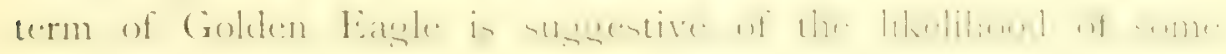
confusion having existed between the two species. Thus, the 
Bearded Vulture is very richly coloured; in brilliant sunlight the bright tawny throat and underparts assume a veritable golden hue, far more so than do the pale tawny feathers on the nape of the Golden Eagle whence the latter derives its somewhat imaginative name. This golden colour of the Bearded Vulture is well-known to all the goatherds and mountain-dwellers in Spain, who invariably describe the birds as colorado, "reddish" in contra-distinction to the Griffon Vulture of fulvous appearance. As already mentioned, many Anglo-English sportsmen style the bird Golden Eagle and the famous traveller James Bruce, who met with it in the highest mountain north of Gondar in Abysinia so far back as I770 and figured it in his hook published in 1790 , did the same. It therefore seems likely enough that the inhabitants of the mountainous districts of mid-Europe mat have likewise described the big bird of prey which was credited with sinister intentions on their infants as a Golden Eagle.

My first introduction to Bearded Vultures was of a very formal nature and led to nothing. A pair frequented some high hills a day's journey from Gibraltar and annually nested in a cavern in a low cliff at the top of a steep acclivity. I was in those days unaware of their very early nesting habits and in consequence never sought for the nest at the proper time of year.

This pair have long since left the locality. Ten years passed before I once again came across them, in a big sierra some ten miles west of the first site. Here they nested undisturbed for some years using two alternative sites, one in a small cavern only a few hundred feet above a goatherd's house and the other in a cavern very nearly the same in shape several hundred feet higher up the cliffs. Photographs of both these sites appear in Colonel Irby's book. It is over twelve years since they in turn abandoned this range of hills and went off without leaving an address.

The Bearded Vulture is, as I have said, at very carly nester. 


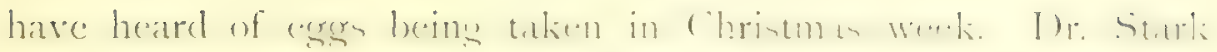

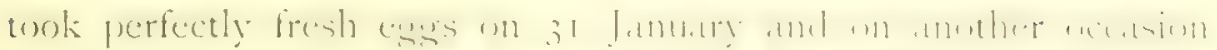
eggs on the point of hatching on 4 February. The mildness or the reverse of the season and the altitude of the nest above the seat

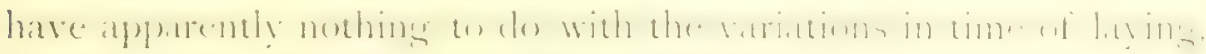
despite the protestations of the goatherds who are ever emphatic on these two points. No better proof of this could be adduced than Dr. Stark's experiences, for, when he took the freshly-laid eggs on 3 I January it was in a very mild season when the snowline was fully 1,000 feet higher up the sierra than when he found the hard-set eggs in the same locality on \& February-in an exceptionally severe spring.

When I was with Crown Prince Rudolf in the d/inames he had with him two young Bearded Vultures, one just cmerging from the down stage and a second three-parts grown, taken from nests in the Sierra Nevada. One of these birds was a full month if not six

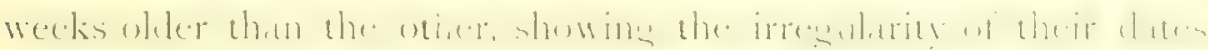
of laying. Firom all I have seen and heard I think from I January to 15 february may be taken as about their usual period for latying eggs.

In all my wanderings after wild birds there was no species which

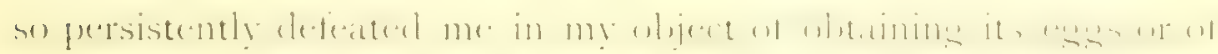

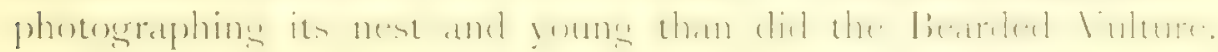

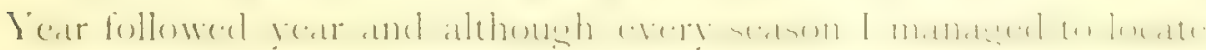

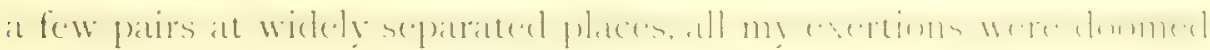
to failure. "Thus, one year I would find myself too early and another year too late. Some years owing to bad weather and the

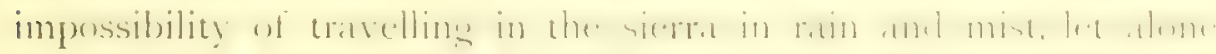

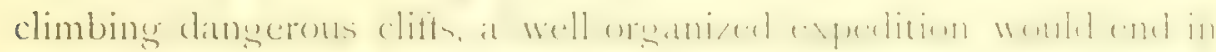
total failure and ignominious retreat.

True, had I on such occasions elected to remain out in my

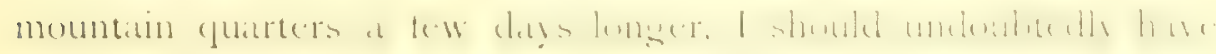


accomplished my object. But here the human factor intervened for my companions were invariably officers of the Navy or Army or Civil officials whose leave of absence was restricted to a few days. As this account will show, the Bearded Vulture's nests which I had marked down for spoliation were situated in places which demander a derree of both skill and nerve on the part of those who handled the ropes, which, with no aspersion on the genuine pluck of my excellent friends among the inhabitants, they lack and with good reason. Fior they do not understand rope-work and they are in consequence unduly apprehensive of the dangers attending it and hence by no means inspire the confidence in the man on the rope which is so essential to avoid disaster.

When on the wing, the Bearded Vulture is easily recognizable from the Griffon Vulture by its long cuneate-shaped tail which is full six inches longer than that of the Griffon and looks even more so when the two birds are flying high overhead.

The Griffon when soaring, habitually keeps its wings widely extended, the carpus and metacarpus forming a slightly re-entrant angle, the sharp pointed head drawn back into the encircling ruff appearing as if set in the apex of a very obtuse $V$ formed by the extended wings. The primaries are all widely separated at the lips and for over a third of their length and can be counted at a wreat distance whilst the short square tail gives to the eye the impression that the wings are set on very far back in the body.

( ) the other hand, the Bearded Vulture when on the wing in quest of food, although at times it emulates the Griffon in its wide circles, when its primaries are similarly separated, has much more the appearance of the Eagle in its Hight. As it ylides along there is often a perceptible salient angle formed by the carpus and metacirpus, which increases greatly as the bird makes one of the wonderful dives which are so charac- 


\section{Means of Identifying on the Wing}

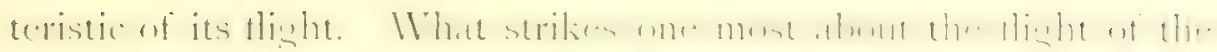

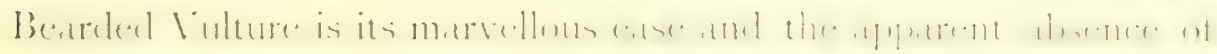

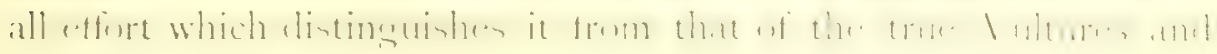
which makes it in my opinion even more graceful than the Golden Eagle's. For it is unusual to see a Bearded Vulture indulge in

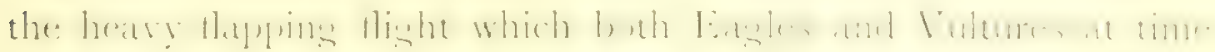
resort to. I am not alone in my views on the subject, for Dr. Stark

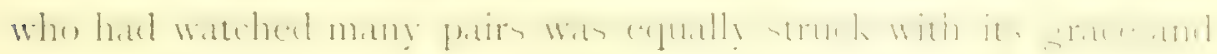
seemingly effortless power.

But although the characteristics of a Bearded Vulture on the

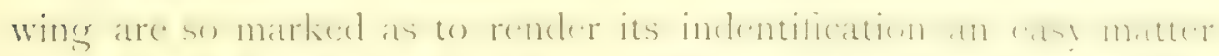

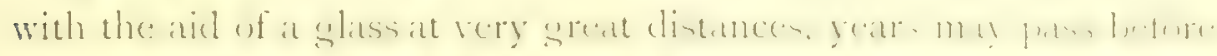

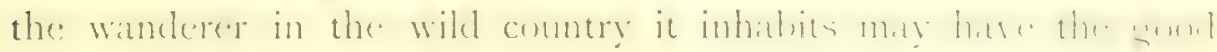

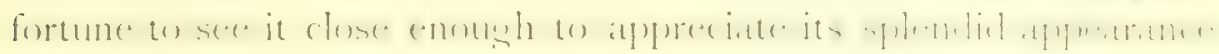
and colouring. Of course where a nest with egers or young can be located, it is a simple matter to conceal oneself near enough to watch the birds at close range. But it is not everybody who has such an opportunity and in my own case it was ten years before I had the good fortune to see this truly magnificent bird at close quarters. The meeting was dramatic in its sudclenness.

I was wandering about a low sierra in quest of nests and carried a gun, according to my usual custom at that time when on a solitary expedition. It was a glorious day in carly spring and when I arrived at the summit, a great piled-up mass of sandstone crags, I set myself to watch and wait on events. The sum was extremely powerful and I was glad to find a shady nook only a few feet below the top of the pinnacle rock forming the highest point of the mountain. A great plain lay at my feet extending for many square miles westward and northward, dotted with comneless herds of brood mares and cattle and droves of piuss. ()ver

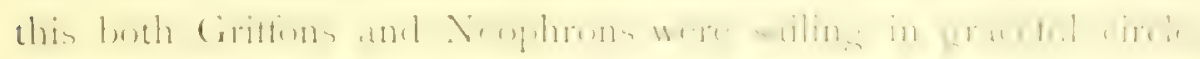
ever on the look out for food. Here I sat, telescope in hand, from 
time to time scamning a sierra beyond the plain which I suspected to be the home of a pair of Black Vultures. How long I sat there I do not remember but as I swept my glass across the distant hills to my front I chanced to pick up a big bird flying towards me. It was still over a mile, possibly two miles distant, but a second stance showed me it was a bearded Vulture winging its way straight at me. Dropping my glass I gripped my gun which lay across my knees and glanced round for some shelter from view. Seeing none near at hand and realizing that any movement on my part might be fatal, I resolved to remain motionless where I was. On came the great bird, obviously unaware of my presence. Doubtless my stained shooting clothes assimilated with the weather-beaten rocks I was leaning ayainst and by bowins my head, my sombrero hicl that greatest foe to all successful sport. especially Bustard-driving, or attempts at concealment in war or peace, the red face of a British soldier.

The Bearded Vulture was now within 50 yards of me, in another instant he would be assuredly mine and at that time, be it remembered, I was most anxious to kill one! Now for the first time in my life dicl I realize what an extraordinarily handsome bircl it is, the fierce-looking head with silvered crown and black "moustaches," as well as the hristly black beard, contrasting with the rich red throat and breast, as with sweeping black pinions it came right at me. It was quite clear it was making for the crag only a few feet above my head as a point of vantage whence to survey the surrounding country. I had by chance already selected the same "look-out" and for similar reasons.

When the great bird was within 20 yards I sprang up and ratised my gun. I shall never forget the savage look of its pale urange eyes, with the encircling blond-red membrane, as it sudclenly checked its flight and, swinging round with a rush of wings rescmbling the noise produced by a steam jet. whirled away. 


\section{A Dramatic Meeting}

I did not fire! Somehow, it secmed to be almost murder to

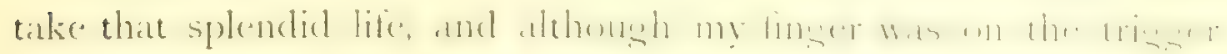
and the bird covered at less than 25 yards, after it had turned, I refrained. I have never regretted my self-control on this nccasion.

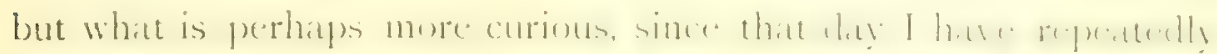
had Bearded Vultures which were nesting within easy shot and I have, so far, never fired at one. I sometimes think that before I

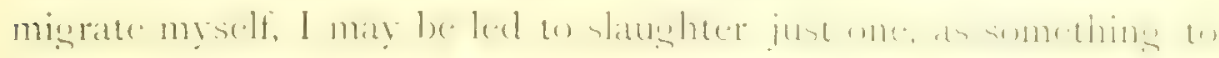
keep me in mind, when I am no longer able to visit their haunts, of these truly glorious birds. But so far I have resisted the temptation.

From time to time in my wanderings I have come across many Bearded Vultures but never have I seen one atgain at such close quarters.

In the spring of 1902 I was living in the mountains between Malaga and Estepona and one day made an expedition to a

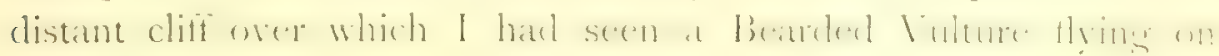
the previous day. I found a very fine cavern tenanted by

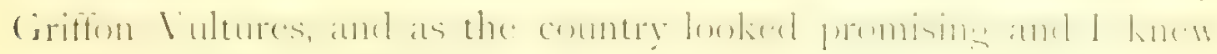
there were Bearded Vultures about, I decided to wait and watch. Some time afterwards a Bearded Vulture came into sight and

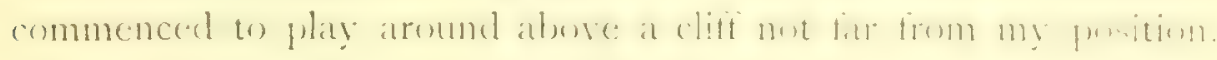
It was evidently not nesting there and from its movements I

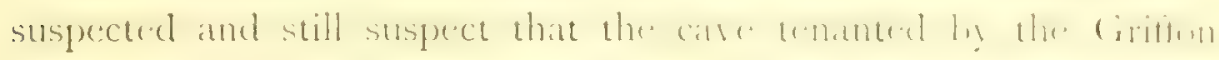
was one of its alternative sites. Subsequent crents gave strength to my views, for presently the old female Griffon, not approving of our prolonged stay on the terrace below her nest, after standing up in her cavern and craning her neck over the brink to take stock of us, dropped off the ledge she was on and flapped away.

As she rounded the cliff above which the liearded Vulture? was soaring, the latter made for her and mobbed her. The 
Griffon was evidently in mortal fear and endeavoured to aroid the meeting with its formidable relative. Next moment the Bearled Vulture, having swooped upwards above the Griffon, turned and struck her vigorously; the two huge birds became interlucked and, losing their equilibrium, fell vertically at least 100 feet.

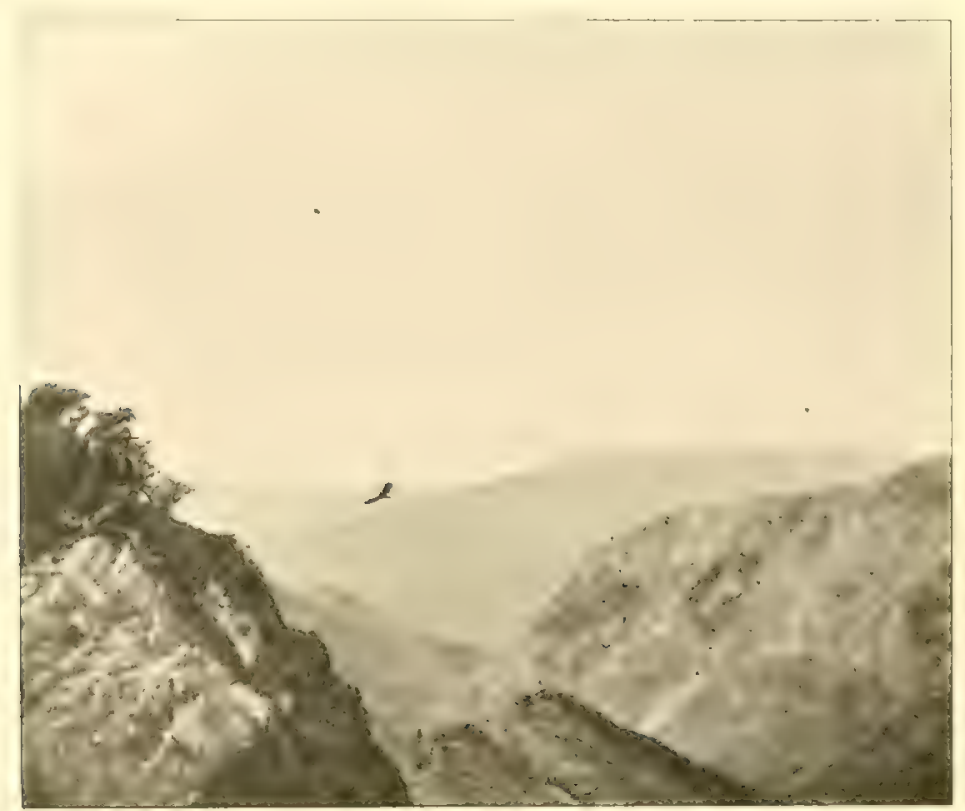

WEARUED VUITURE SOARING AROUND SUMMIT OF CKAG.

It was a marvellous sight for a bird-lover. I had my camera in hand at the moment as I had been trying to take the Griffon standing in her nest and, swinging it round, tried to take a snap at the two great birds before they separated, but failed. The Griffon made off at speed and hardly shows in the photograph but the Bearded Vulture below it is, despite its minute size, recognizable as such owing to its length of tail. 
I subsequently watched it wing its way across a steat valley, over a thousand feet deep, to some crass on the opposite side where I have little doubt it was nesting. I3ut at the time I was too crippled to follow it up and thus lost one of the chances of my life.

My final success after protracted efforts to obtain the exgs and photograph the nest of the Bearded Vulture is one of the most memorable epochs in my life, necessitating as it did five separate expeditions to a remote spot in three successive years and, what is more to the point, very nearly involving me in disaster on three of these.

It was in the spring of 1906 that after four years persistent search and many expeditions, during which I repeatedly located

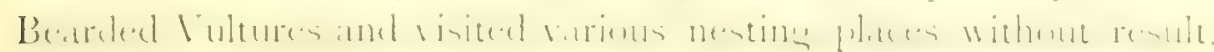
that at last it seemed as if success lay within my grasp. A pair were known to nest in a certain big cliff only two days journey from civilization and accordingly I arranged for a four days trip and enlisted the services of three friends as assistants.

One of the greatest difficulties to be faced in expeditions into the higher ranges of the sierra is the vicissitudes of weather. It may often happen, especially during the winter months, that at the time those living near the sea level or a few hundreds of feet above it are enjoying splendid weather, the sierras may be shrouded in dense cloud-banks, making all bird watching an absolute impossibility. Further, heavy rainstorms may serve to

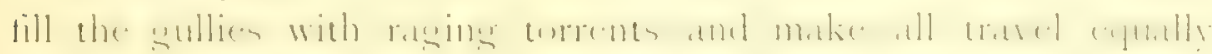
out of the question. Such has been my fate repeatedly.

At the first attempt on the Bearded Vulture's cliff we were favoured by fairly good weather, as regards the absence of fog and rain, but we came in for a desperately cold snap and suffered accordingly. On the second day of our journey we arrived at our

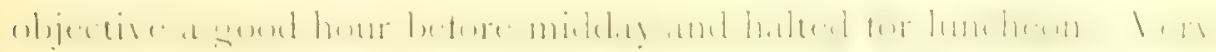


soon we saw first one and then the other of the Bearded Vultures sailing orer the cliffs and shortly marled one of them enter a cavern about 250 feet above our position. I' ith the aid of a glass it was easy to make out the huge nest and, as we watched the old bird moving about in it, we felt sure of our prey.

I, however, determined not to be hurried by my companions and having gained a suitable point immediately below the nest. I made a very careful reconnaissance of the place and with the following results. The hill before us consisted of a series of cliffs divided by steeply sloping terraces. ${ }^{1}$ I may mention that the heights here given were ascertained subsequently by aneroid and the known length of the ropes employed, and, as is almost invariably the case, were found to be greatly in excess of our first estimate. It is one of those curious facts in clealing with heights that whereas those totally unacquainted with them invariably orer-estimate them. men most accustomed to cliff climbing gencrally under-rate them. Thus in the present instance we estimated the cavern to be only $200 \mathrm{ft}$. above us; the mean of four subsequent observations by aneroid proved it to be over $250 \mathrm{ft}$.

Between us and the great cliff lay, at an angle of about 45 degrees, a talus of shattered limestone which had obrinusly fallen from the heights above and issued from a huge rift or chasm some 100 yards on our right. This talus was about 50 ft. in height at the point it emerged. Immediately in front of us was a vertical cliff of the same height, with a very steeply sloping terrace along the top. evidently accessible from the talus. Lpon this terrace were sundry detached crays and then came a second cliff about $150 \mathrm{ft}$. in height. It was in this cliff that the carern containing the nest was situated, less than $60 \mathrm{ft}$. above the terrace. "To reach it seemed absurdly

${ }^{1}$ See General View of Cliff at end of book. 
simple for it was clearly possible to escalade the cliff immediately below it for some way.

My friends, as were our Spanisl attendants, were enthusiastic and wanted to get to work at once. But I, taught by many bitter defeats, before committing myself to attempting to climb from below, reconnoitred with my glass to see if the nest could be

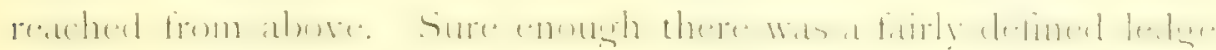
or terrace rather over so ft. above the Vulture's cavern, easily recognizable by an uptilted pinnacle rock about if ft. high which we elected to style the "petrified artichoke," from its smilarity to that vegetable.

If we could only get to this spot, all would be well for us. But here came the rub, for above the "artichoke" were a series

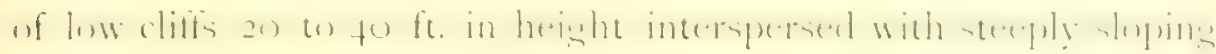
narrow terraces, mounting one upon another like steps and gradually losing themselves in the heights over $500 \mathrm{ft}$. above us amid the drifting clouds which eddied about the crest of the mountain.

It was not an encouraging prospect; for an hour past we had been above the snowline and although the snow was of no depth save in the drifts, the cold was intense. Wherever the sun had thawed the snow on previous days, there was now a coating of ice; hence climbing was peculiarly dangerous.

We however decided to attempt in the first instance to reach the nest from below and, having shouldered our ropes, made our way painfully up the great talus. Arrived at the terrace, we

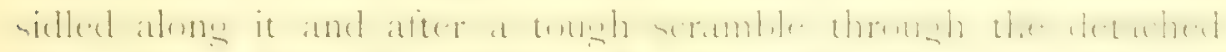

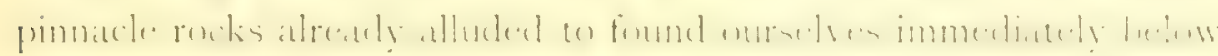
the nest.

And how easy it looked! Various fissures and joints, overgrown with tufts of mosses, saxafrage, heath and scrub made it possible at a point only a few yards to the right of the nest 
to climb some 20 to 25 of the feet of the 50 to 60 which separated us from our much coveted objective.

Among my party I happily numbered my old ally, Admiral Arthur Farquhar, a good climber and, needless to say, with a thorough knowledge of ropes. Two of our Spaniards were exgoatherds and reckoned as good climbers.

It did not require more than a glance to see that the Bearded Vultures had selected this seemingly low-placed cavern, simply because it was totally inaccessible from below and so I at once started off to see if it were possible to work round the left flank of the cliff (facing it) and gain the "artichoke." Meanwhile my companions, more especially the two ex-goatherds, indulged in fruitless gymnastic efforts about twenty feet up the cliff.

At first I made good way and, stopping for breath, was shortly joined by Farquhar who had remained behind to see what the goatherds could do. W'e worked our way amid smooth rocks and across steeply sloping grassy terraces, alike slippery with ice. It was most unpleasant and soon the soles of our alpargatas, which had got wet amid the rank herbage below the cliff, began to freeze! A rope-soled shoe frozen hard is about as nasty a thing to climb rocks with as can well be imagined. It soon becume evident that although we could reach easily the same level as nur "artichoke," we had against us the geological fact that the portion of the hill we were on, by reason of the trend of the strata, made it impossible to cross over to our desired point. For separating us from it was a series of low tiers of rocks and terraces which, whilst enabling us to work upwards, crer led us away from our point. Returning to our party below the nest we found them in the lowest depth of despair and half-frozen. It was not difficult to see that they had come to the conclusion that the nest was unassailable, so leaving them huddled round a fire 
they had kindled, I started off alone on a forlorn hope to try to find a way to the top of the cliff.

Arrived at the point where the talus emerged from the chasm, I commenced a most painful and laborious ascent. At places the loose débris was on the run and it became necessary to escalade the face of the cliff on ene side or the other of it, so as to aroid setting it in motion. I was further most terribly handicapped by my injuries which affected my heart to such an extent that I had constantly to lie down and gasp for breath. At last I found myself on a level grass patch close to the summit and over $500 \mathrm{ft}$ above our starting point. After a rest, I climbed over the brow and looked down towards where the nest lay. But owing to the seneral convexity of the slope of the hill it was impossible to see more than 20 or 30 yards in front.

It was bitterly cold, a piercing wind swept the sierra and the

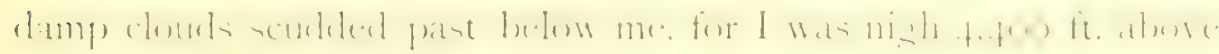
sea-level. The rocks were at places coated in ice whilst half-

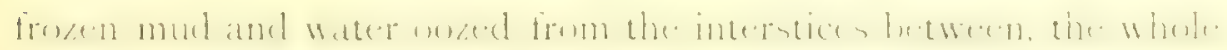
being powdered with snow which lay thick in the gullies. All

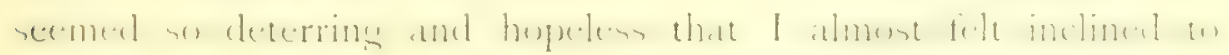

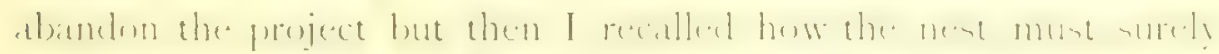
contain eggs and how I longed for some for my collection, not

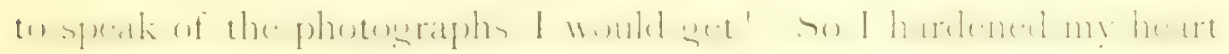

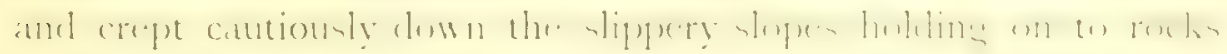
from time to time until I had descended over jo ft. The crags now became much steeper and it was clear that under existing conditions of ice and snow it was foolish to go further without a life-line. Working catiously upwards to my right thank I

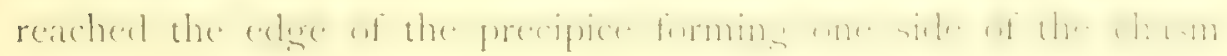
up which I had scrambled and, looking over, saw the rest of my party on the talus $300 \mathrm{ft}$. below me. Hailing them I asked them to come up and bring the ropes, saying that I felt sure we 
could reach the nest from where I was. Half an hour later they joined me bringing with them my three ropes, namely roo ft. each of $2 \mathrm{in}$. and $\mathrm{I} \frac{3}{4}$ in. and $75 \mathrm{ft}$. of $\mathrm{I} \frac{1}{2} \mathrm{in}$. Alpine rope. Time pressed and the cold was so intense that it was useless to think of attempting to join our ropes togrether by long-splicing them and so we decided to join them by knotting. I adjusted my canras sling and, making myself fast to the 1.1 in. rope, started away down the cliff.

The first portion of the descent was simple enough, usually down stcep grass-grown gullies alternating with low cliffs of 20 to $30 \mathrm{ft}$. The general conformation of the mountain was of stratified limestone uptilted almost vertically and presenting the edge of the stratum to the face of the cliff. As a rule, it was easy enough, with the aid of a rope, to drop over these steep places, usually through some narrow sully choked with fractured rocks between the uptilted strata.

After descending about $120 \mathrm{ft}$. in this manner I came to a fairly safe terrace whence some $20 \mathrm{ft}$. below me I could see our land-mark. the "petrified artichoke." In a few minutes I was down alongside of it. Here I had a good look round and was surprised to note the great height I was at, for although now only some $350 \mathrm{ft}$. above our mules below, the valley we had ascended in the morning fell steeply to a small Moorish village nigh 2,000 $\mathrm{ft}$. below and the view to my front was in consequence most extensive, despite the drifting clouds about the higher peaks. I now endeavoured to find a way round the cliff immediately below me and got down some $30 \mathrm{ft}$. or so to my left (facing the cliff) only: to find the ledige I was on merged into the cliff. My climb was not a waste of time for it showed me that there was only one possible way to get at the nest and that was to go over the edge of a rather beetling cras a fell feet to the left of the artichole. So I retraced my way up to the ledge $20 \mathrm{ft}$. above it and there 


\section{A Nasty Descent and a Jambed Rope}

found to my surprise Farquhar. He told me that having seen the last join (at about $160 \mathrm{ft}$.) through the hands of the lowering party, he had come down to bear a hand. I was very glad that he had done so for, in addition to having his moral support, he served as a very necessary connecting link between me and the lowering party and further was able to see how my ropes lay and give them a fair lead when they required it. Leaving him to tend the ropes over the last cliff I descended again to the

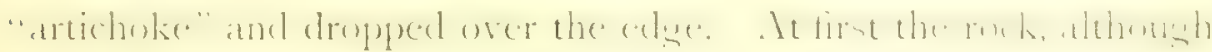
nearly vertical, gave me some handhold, $30 \mathrm{ft}$. below was a very small rocky houf with some herlage on it, upun reaching whith I signalled "Hold hard" and looked over. What I saw was encouraging for about roo ft. below me I espied the outer edge of the terrace whence we had vainly endeavoured to reach the nest

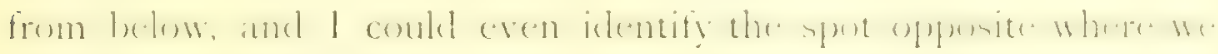
had striven to climb up. The cliff overhung a little and it was quite clear the nest was not more than $50 \mathrm{ft}$. immediately below me.

Lcading my line over a smooth part of the rock and signalling "Lower-away," down I went. As I descended I grabbed at the

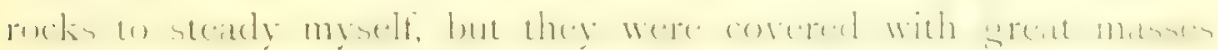

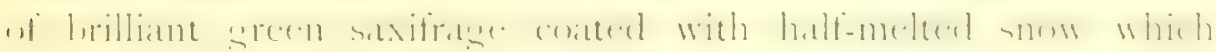

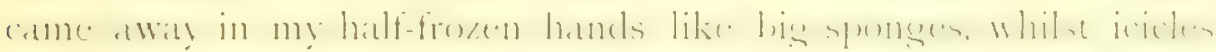
hung from every projecting crag and added to my discomfort.

In all such descents the great art, when once the cragsman has decided on action and the die is cast, is to get over the awkward spots as soon as possible. I had impressed this on my party before starting down. I went down, my rope running out

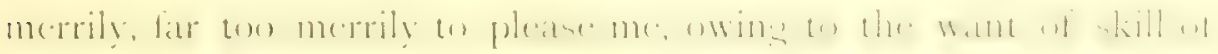
my lowering party, which was of course beyond the control of

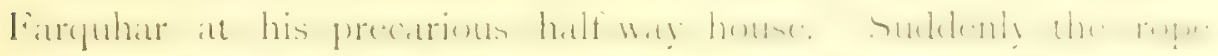

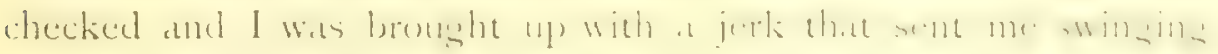


out in a most objectionable manner. It was an awkward moment, as I was in mid-air and with only just enough touch of the cliff to stop myself from revolving. I quickly gave two blasts (n) my whistle; "Lower away" but got no response. Then I tried three blasts, "Haul-up" with as little effect. It was quite clear that something was wrong!

Only those who have gone through similar troublous times can appreciate what this means to a man who has got to look out for himself. The nearest approach I know to the feelings I then experienced is when things go amiss in a balloon and the question arises, what is to be done next?

It did not take long for me to realize that the rope above me had jambir. I looked down and the prospect was mot cheering for I was hanging plumb over a peculiarly hard-looking mass of rock, some jo ft. to $75 \mathrm{ft}$. below. I looked up to see if I could, as in former days, swarm up the rope to the top of the cliff and then remembered that my disabled left shoulder and other injuries effectually barred such a feat of symmastics. So I waited and began to think it out. Suddenly, I felt a sharp jerk and I shot down for a few feet, swinging about helplessly. Whistle in mouth I sounded shrilly "Lower away" and away I went! Less than I $5 \mathrm{ft}$. more lower clown I suddenly found myself opposite the Bearded Vulure's cavern and clutching at the rocks drew myself in and felt my feet strike a soft substance. Next moment I was clinging to the nest. I looked in. It was empty!

What my feelings were, it is perfectly impossible for me to describe, as with difficulty I dragered myself in and took stock of my position. I was in a low cave about $5 \mathrm{ft}$. long, $2 \mathrm{ft}$. to $3 \mathrm{ft}$. high and $t \mathrm{ft}$. in depth. The nest was a huge affair, built of big boughs, filling up the whole cavern, with a cup-shaped depression 24 in. across, lined with great lumps of blatk sheepswoul. brown groatshair and fresh green mosises. Evidently the bird had not 


\section{A Bitter Disappointment}

yet laid and yet it was the last week in March and I knew well that they usually laid early in January! It required little skill to recognize that the nest was perfectly new and unused and that the old birds fully hoped to use it very soon. Also it had most assuredly not been robbed, for there were no traces of a former

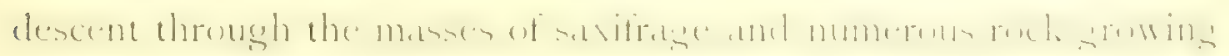
plants and shrubs I had passed on my way down. Anyway, there was nothing now to be done save to get out of the place ats soon as I could, for I felt anxious about my lowering party u! in the snows and bitter cold above me.

And now came a supreme moment. Whas it possible for me to return the way I had come? Obviously the rope had jambed and jambed badly and if this had occurred when being lowered what might not happen when being hauled up? A bad jamb on such occasions matead to a rope parting. It is entirely a question of the strength of those who are hauling on it. Looking down, I sall it was less than $60 \mathrm{ft}$. to the terrace below, and so I decided to go on. After a whistle to warn those above, I gave the two blasts and putting all my weight on the rope slid off the nest. Next moment I felt the rope "rendering" and down I went, now swinging in mid-air. All went well until I was within $\mathrm{I}_{5} \mathrm{ft}$. of the ledge below and then once again I was suddenly checked. In vain did I whistle "Lower away." Could the rope be jambed again? Looking up, I felt it could not be, since the knot next above me was over the cliffedge

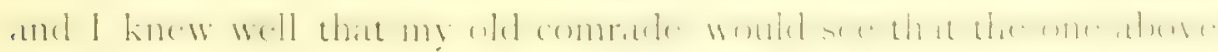
him was all clear. The rope now gave up for a few feet and once

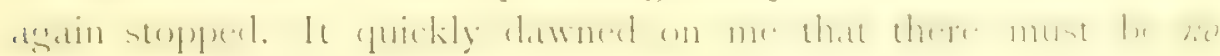
more rope!

It was a time for quick decision, glancing down, I saw that I was within 10 or $12 \mathrm{ft}$. of the rocks below. I knew that there was 5 or $6 \mathrm{ft}$. to spare of the rope securing the sling over my shoulder.

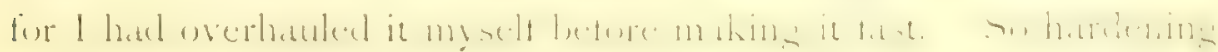


my heart I umbent the portion round ny shoulder and proceeded gingerly to ease up the two half hitches which secured it to the canvas sling in which I was suspended, paying out the line through the thimbles on the sling as I slipped downwards. Arrived at the last few inches, I found my feet were still over $6 \mathrm{ft}$. from the cround, but there was no help for it and I let all go and dropped, landing amid the rocks and scrub shaken and exhausted but unhurt. But all the same it was a very near calculation! I now whistled to "Haul up" and as I saw the free end of my $1 \frac{1}{2}$-in. rope curling about as it went out of view high overhead, I congratulated myself on my escape from a most awkward position.

I subsequently heard that the lowering party who, by the way, had nearly perished of cold in their airy situation, were preatly alarmed at suddenly finding themselves hatiling up a loose rope, since they had no idea of where I had got to and imagined untold horrors.

Before closing this painful story of failure and defeat I must explain when and where my rope jambed and how it came about that I was able to get out of my fix so well. After I left Farquhar on the terrace above the "artichoke" crag he had acted as fugleman, receiving my whistles and signalling on their purport to the lowering party perched high above him. As he paicl out the rope after I disappeared from his view over the "artichole" cliff, the knot joining the $13-i n$ and I $\frac{1}{4}$-in. rope passed him in due course. It was whilst he was "handing" me down the vertical cliff that the rope in rumning over the edge bit in deeply between the uptilted strata neatr the "artichoke" and the miserable knot jambed! At the moment I was rather over $60 \mathrm{ft}$. below this point and Farquhar was over $20 \mathrm{ft}$. above it. Luckily, realizing the grave danger, he at once came down the intervening cliff on the rope, hand-overhatud, and reaching the extreme edge managed somelow to lift the knot clear. This was the jerk I felt! 
I will not say all I think of the episode beyond that I could wish my worst enemy no better diversion than to be in the predicament I was, with no trusty maval officer to get him out of it The person who invented the expression "between the devil and the deep sea" had obviously never been over a bad cliff on a rope that jambed.

From the terrace I made my way down to the mules and found the arriero had lit a huge fire of lentiscus bushes where I was very glad to dry my wet clothes and get into my boots. Half an hour later I was joined by the cliff-party and had io break to them the cloleful news of my utter discomfiture.

Since everything pointed to the Bearded Vulture having the intention to lay in this nest before many days, I decided to revisit it about a fortnight later, by which time I reckoned that the egrss woukl surely be laid. I cane to this conclusion against all my knowledge and experience of the nesting of the Bearded Vulture since it was already two if not three months after their usual time for litying. But I was tempted to set aside all previous records by the fact that the birds were without doubt building a new nest and that probably their first laying had been destroyed by some accident or had been taken from some other site. I had further an excellent precedent in the case of an Osprey's nest in which fresh egers were laid in the month of May, at least two months after the usual time and probably for the same reason.

So it came about that \& April found me once more at the head of a forlorn hope pushing through the mountains for the Vulture's cliff. 'This time we carried with us it coil of 300 it. of 2-in. rope, for I had had enough of joining ropes. As I was

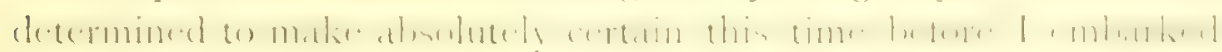

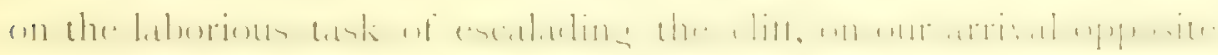
to it, I sent the mules away and lay up with my telescope to watch the old birds. Soon, one and then the other cane into view llying 
high overhead, at times dipping down and flying past the cliff At the end of an hour, one of them suckenly appeared carrying in its beak (not in its feet) a big black mass which looked like a portion of a black lamb and tlew straight into a cliff abust $100 \mathrm{yds}$. from the nest I had descended to. Turning my glass on the spot, I saw to my astonishment a second huge nest which I had not observed on my first visit, doubtless because all my energies were concentrated on the birds and the nest they were then buildins.

I instantly made up my mind that this new nest contained young and that on the occasion of our first risit I had sone to the wrong nest! So thought my companions and yet we had watched the birds tlying in and out of the first nest and they had never shown any inclination to visit the second.

My suspicions were strengthened by watching the great bird standing on the edgre of the nest and judging from her movements and attitude apparently engaged in feeding her young. Presently she entered the nest and disappeared from view. Sitting no doubt on her young, said we. Some minutes later she rose and thrust her head out of the cavern and we could see clearly the fierce eye and the brilliant colouring of head and throat. Then she took wing and sailed away.

Soon the other old bird returned and glided uneasily across the face of the cliff, evidently alarmed at our presence near its sanctuary.

There was no necessity to watch any longer for there was nothing more we could learn of the contents of the nest save by actual inspection.

And now as to the position of the new nest. It was in a small cavern apparently almost identical in size and shape with the first nest and in an almost exactly similar situation but apparently more accessible. From the point where the talus issued from the chasm ran two terraces, the first, the main terrace, was the one we 
had traversed on our former visit, while the second, which was much smaller, in fact, a mere sloping ledge, inclined sharply upwards for about $60 \mathrm{ft}$. to a point about $30 \mathrm{ft}$. below the new nest which for convenience of reference I will call Nest No. 2. The cliff in which was the nest though small was overhung and clearly unscaleable from below.

About i $30 \mathrm{ft}$. above the nest were some serrated tooth-like caps

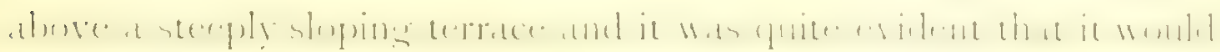

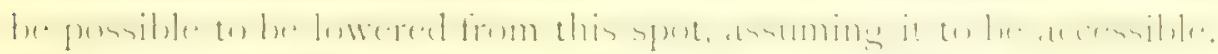
Here lay our difficulty, for above it was a big cliff another hundred feet in height at least and other cliffs again above that. To cffect a descent from such a height would have meant hours of work and it was even doubtful whether the $300 \mathrm{ft}$. of rope we had with us would have been sufficient. Our hopes lay in being able to escalade the sheer cliff forming one side of the chasm and thus gain the tooth-like crags above the nest by a short cut. We therefore started up the big talus and when about igo ft. up it. leaving the bed of the chasm, climbed the cliff on our right (the side farthest from the nest), until we sained a point on a level with the nest which was now not to yards from us.

$I$ found by aneroid that it was about 260 it. above our starting point and in consequence about $10 \mathrm{ft}$. higher than the first nest. Returning to the gloomy chasm, we scrambled up it for another hundred feet and then halted whilst I sent on our two ex-goatherds to reconnoitre up the cliff and try to find a possible route. This they did admirably and soon we were assembled at a point $360 \mathrm{ft}$. up the cliff and (as I know by aneroid) only about $100 \mathrm{ft}$. above the nest.

But we were in a most awkward and danserous position: I

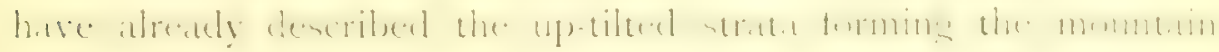
at this point. IVe now found ourselves standing on fractured and worn rocks sloping at an angle of 45 degrees to the edge of 
the Vulture's cliff below us, On one side of us lay about 100 feet of precipitous crags which we had escaladed by using the stratified ledges as steps, whilst on the other a wall of rock barred our further progress.

Between the strata was moist earth and a profusion of herbage, mixed with loose slabs of rock broken from the main stratum by the action of the sun and frost. Amongst these we managed to find a footing and, securing myself in a bowline, I crept cautiously to the edve of the cliff to the music of the clattering of the loose soil and rocks which became detached as I did so. Peering over the edge I saw a small shelf not $40 \mathrm{ft}$. below me with an olive tree srowing on its extreme point. This tree I knew to be exactly over the nest and I also knew that the rock it grew on was an overhanging one. To the left of the tree (facing the cliff) was a convenient grass-grown gully, sloping steeply, with serrated rocks cropping nut in parallel lines. This offered the safest line of descent and a possible means of getting round the over-hanging rock.

Returning to my comrades, I gave out the "special idea." As the place was peculiarly dangerous, I decided to use two ropes. So making fast the centre of our $300 \mathrm{ft}$. coil to a convenient cras and throwing the end of the spare coil over the cliff I aljusted my sling and rope and dropped over the edge. Hardly had I done so, when portions of the surface of the rock above me began to crumble and move! I was prepared for this and with the aid of the life-line was quickly hauled back and proceeded to dislodge the loose rocks. A regular avalanche of rock and rich black earth resulted. When all seemed clear, I was lowered foot by foot, clearing away all loose rocks as I proceeded. To guard in a small way against falling stones, I had filled my sombrero with short heather branches before starting and it was lucky I did so for from time to time the rope detached small fragnents of rocks from above. 


\section{A Scientific Lower}

But I was now met by another trouble, the rope as my weing got on it cut its way deeply into the narrow fissures between the strata and not only loosened more stones but threatened to jamb. At last I reached the edge of my sloping sully, it was only $60 \mathrm{ft}$. from my party above but every foot had been a source of anxiety to all of us.

The cliff now became vertical and I went over and soon found myself on a level with the big nest and some ro ft. to the left of it. It was impossible to get nearer as I was wholly dependent on the rope. Above the nest was the overhanging rock and there seemed just a possibility of my being able to swing in under it, if

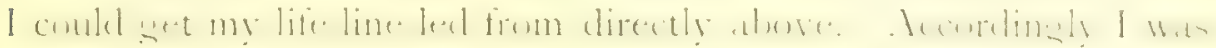
hauled up once again and made my way to the olive tree. Hauling up my life-line I rove it over the bole of the tree and dropped it down the cliff. "Then catching hold of it, I signalled "Lower away" and went down as before with my weight on the rope on my body but keeping a strain on the line over the olive tree. 13y this

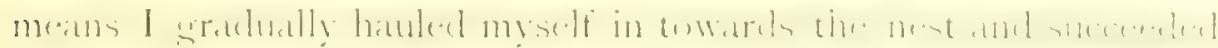
in grabbing a projecting rock at the entrance to the cavern and

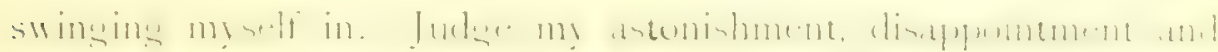
dismay at once again finding the nest cmpty!

It was exactly the same as the first nest, a huge mass of sticks with a deep soft lining of lambswool and goatshair. A big lump of black lambswool lay in the middle of it, the mysterious article which I had seen from afar the Vulture carry to its nest.

Why these birds thus repaired and re-lined a second nest at this season I shall never know, for I could not pay them another visit. One would have imagined that my cup of bitterness and disappointment was about filled but such was not to be. At least 1 would take a photograph of the cavern and the immense nest. To do so, I wanted more rope to enable me to crawl in and set to a favourable point and so signalled up to "Lower away" but 
got no response. Repeated whistles had nu effect and I heard indistinct shouts in reply, so knew that something was wrong and that once again the rope was jambed. Was there to be no end to my ill-luck?

Suddenly I bethought me that probably in hauling myself towards the nest on the life-line I had given the lowering line a "foul lead" through one of the narrow fissures between the vertical strata and had thus jambed it. So it was. Therefore, giving a shrill blast "Hold hard," I eased up the life-line and swung back on the other rope and as it took my full weight I felt it give up and I knew that it had cleared itself. Looking down I saw my life-line was touching the ledge about $30 \mathrm{ft}$. below and so I signalled "lower" and after doing tee-totum for a few yards, due to the overhanging cliff, landed upon the ledge in safety. Thence I made my way down to the talus and on to the mules below, where we all foregathered with as much fortitude as we could command.

Happily our troubles and exertions on this day were to a great extent forgotten owing to other matters of absorbing interest. One of the greatest attractions in the quest of wild birds in their haunts, especially in a wild country such as spain, are the innumerable possible compensations which from time to time may serve to assuage one's wounded feelings and cause one to forget the disappointment of a failure such as I have just described.

It was on the return journey from the scond fruitless expedition to the Bearded Vulture's cliff that I had the great good fortune to witness an exhibition of the ways and habits of that bird which falls to the lot of few.

Most people who have read about birds are well aware that this species is credited with the habit of carrying the larger bones of defunct animals high into the air and dropping them on some rock in order to smash them and thus get at the marrow. Hence 
the bird has acquired the name in Spain of Qucbranta-huesos, "bone-smasher" (from hucsos, a bone, and quebrar, to break). So familiar is this habit to all those who live in the countries where the bird is found that I had not intended to inflict my experiences of the same on the readers of this book, since for years it has been to me a matter of certainty that the Bearded Vulture broke bones by dropping them from a height.

Despite the fact that this curious habit has been accepted by many successive writers, in one of the most recent books on

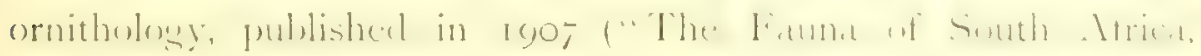
vol. iv., by IV. L. Sclater and A. C. Stark ${ }^{1}$ ) I was surprised to see

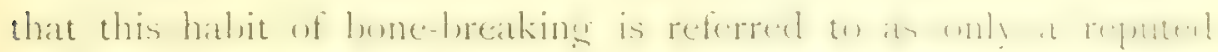
one. But this was not all, in Allan Hume's admirable Notes on

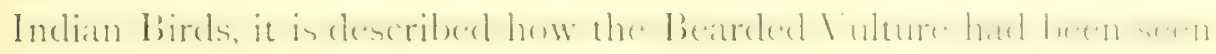

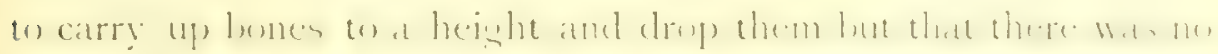
positive proof that this was done of a set purpose, since the reporters of the occurrence had not seen the bird complete the

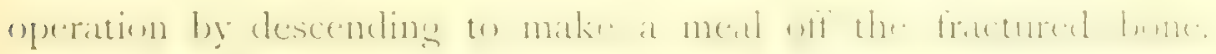
I make not the smallest doubt but this habit of the Bearded

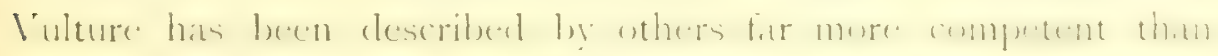

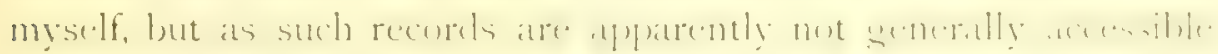
(in fact I can find none in any library), I venture now to describe what I actually saw on this eighth day of April 1906.

I may explain that in southern Spain the name of Quebrankahuesos is known far and wide to all dwellers in the sierras but that

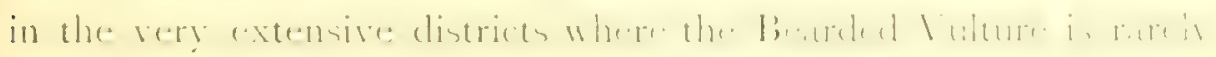
if ever seen, the name is applied to its small relative the Euyptian Vulture or Neophron. The Neophron however has never been

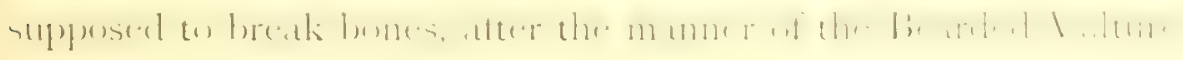

1 Dr. Stark was killed by a Boer shell during the siege of Ladysmith. 
Repeatedly during my wanderings have I had pointed out to me by goatherels and ofhers, situs, places whither the Ouchromterhucsos resorted. to carry out his time-honoured practice of bonesmashing and now and again on visiting such spots have I come across the dried up and putrid limb of a goat or sheep. But hitherto I had never actually witnesserl the methods adopted by the birds.

Now as to our experiences; we had sent our mules towards home down the steep valley which we had followed in our outward royage in the morning and had taken a line along a sreat bluff surmounted by high cliffs on the chance of coming across something of interest. From time to time we sighted Bearded V'ultures high overhead, six times single birds, and twice a pair. probably from the nest we had visited.

Presently we saw a single bird sailing around perhaps 2,000 ft. above, carrying some long object, considerably longer than the long cuncate-tail of the hird. With the telescope I mate this out to be the hind-limb of some large animal. The bird was clutching it with its right foot just below the fetlock and after watching it circling aloft for some minutes, I dropped my glass and mate a pencil slietch of what I saw, from which the drawing here wiven is copied.

Iardiy had I completed this when the bird let the object go. I was accompanied by the late Mr. Edward llunt, the Chief Engineer of the Alseciras-Bubadilla Railway, and we watched the object whirling down, for certainly $1,500 \mathrm{ft}$. until it struck an horizontal terrace of limestone rock below us. The sharp crash it made was distinctly audible from our post, some quarter-mile distant and perhaps $200 \mathrm{ft}$. above the spot where it struck. Almost immediately, the Bearded íulture dived downwards and after one or two descending sweeps alighted close to the object. With my telescope I watched it pull the limb abrut for a few minutes and 


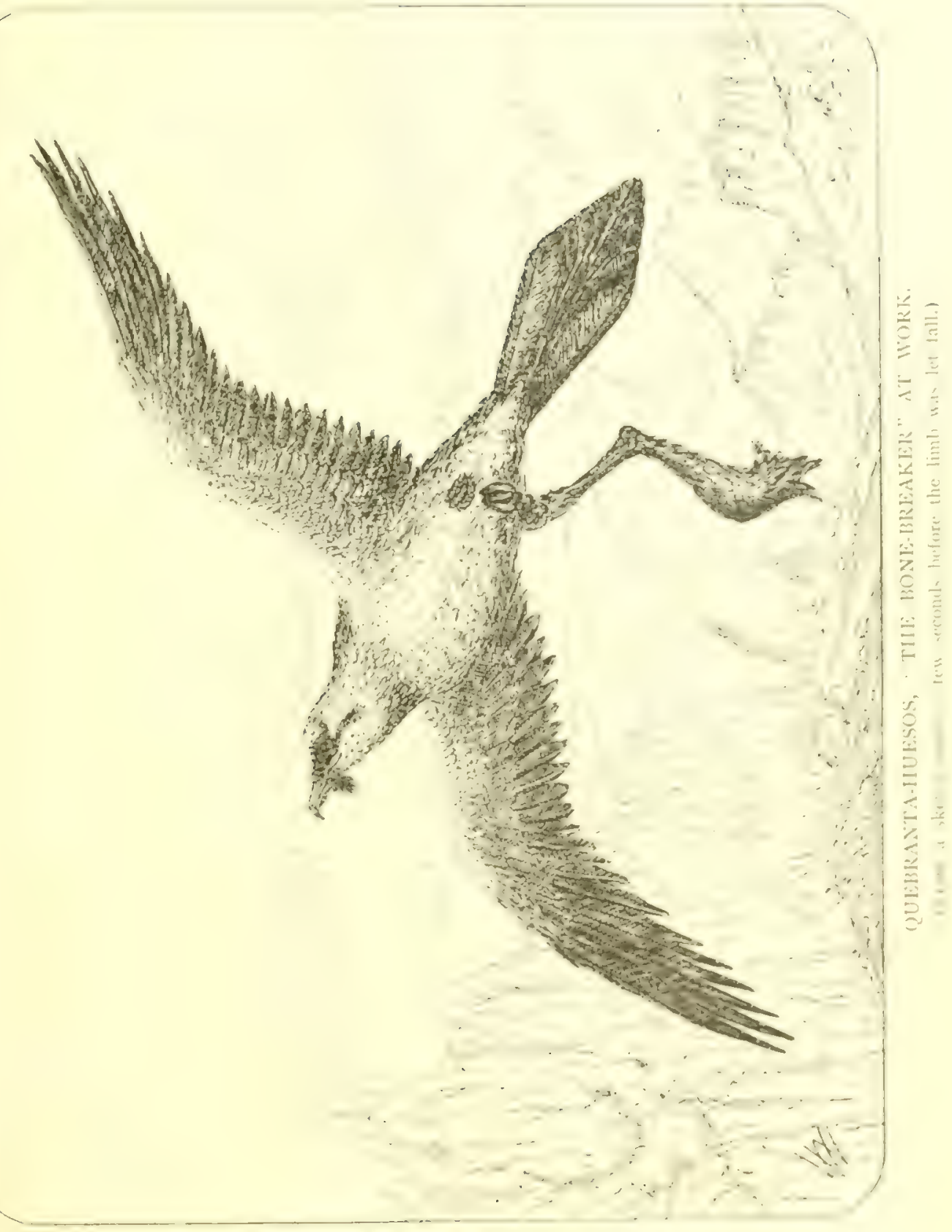



feed off it. Then it seized it, this time with its left foot, angin just below the fetlock and took wing. It was at once noticcable that the limb was much shorter than before, as if the femur had been torn from off it. I made a second sketch of the bird as it soared aloft above us, which appears at the end of this chapter.

Soon it lowered its flight and alighted on a crag a few hundred yards from us where it set to work to pick at the limb. After a time it took wing again this time without the limb but in place of flying upwards it swept down into a valley about $300 \mathrm{ft}$. below the bone-breaking terrace and alighted. With my glass I watched it walk a few yards up to the carcass of a calf and commence to tear at it. Soon it was joined by an adult Neophron, the vast dissimilarity in size between the two birds being most noticcable.

The Neophron did not seem to be alarmed at the presence of its big relative and between times got in a good many tugs and mouthfuls of sorts. After a time the Vulture took wing and sailed off leaving the Neophron in possession. I'rom the terrace we were working along it was a precipitous descent to the bone. breaking plateau and to reach it meant retracing our steps for a mile or more, so I reluctantly left the spot without visiting it. A goatherd with us assured us that it was one of the favourite places for the birds to drop bones and I have no doubt he was right.

The sharp splintering crack made by the impact of the bone on the rock is an unmistakable sound and I can recall instances before the occurrences narrated when I have heard it when climbing in the sierra frequented by Bearded Vultures and the men with me have asserted the cause, which I at the time disbelieved. Since then I have heard it two or three times but never before or since have I thus witnessed the three phases of carying the bone aloft, dropping it and descending to feed on it. 
In nests I have visited I have found fragments of the limbs of sheep, woats, cows, donkeys and other animals with the fractured and splintered bones of the tibia or femur projecting from the dried hide covering the lower portion. By no other means save by a fall could these heavy bones have been thus broken open, for powerful as is the beak of the Bearded Vulture, it is not strong enough to shatter such bones.

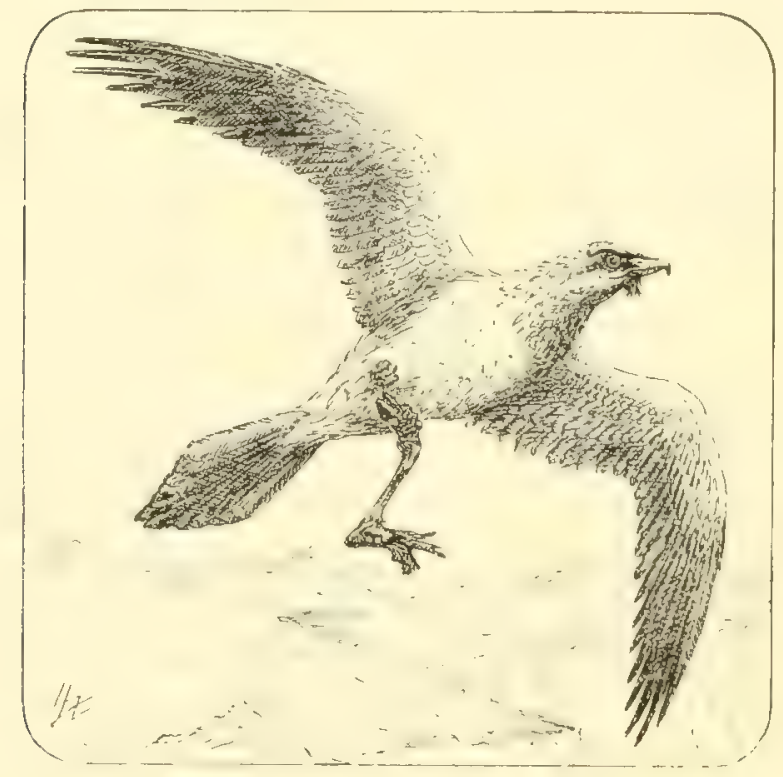




\section{CHAPTIR X. \\ THE BEARDED VUL'TURE (continned).}

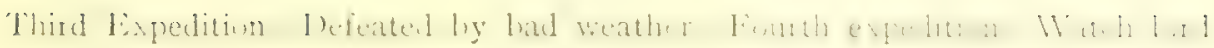
on nest-Fierce appearance-Ascend cliff and an lowered-An asony of hopes and fears-Reach the nest-A young Bearded Vulture-Description of cavern and nest-A Bearded Vulture's larder-l'hotographing young bird - A cramped situation-The attack on the camera-Leave the young bird and descend-Timid behaviour of parent birds-Fifth expedtion--A marvellous panorama $-A$ reduced lowering party $-A$ false lower - Re-ascend$A$ depressing moment- "Now or never"-Am again lowered-Reach the nest-At last! - A horribly nasty cavern-An awkward descent-Defective cartridge-films - A Consolation prize.

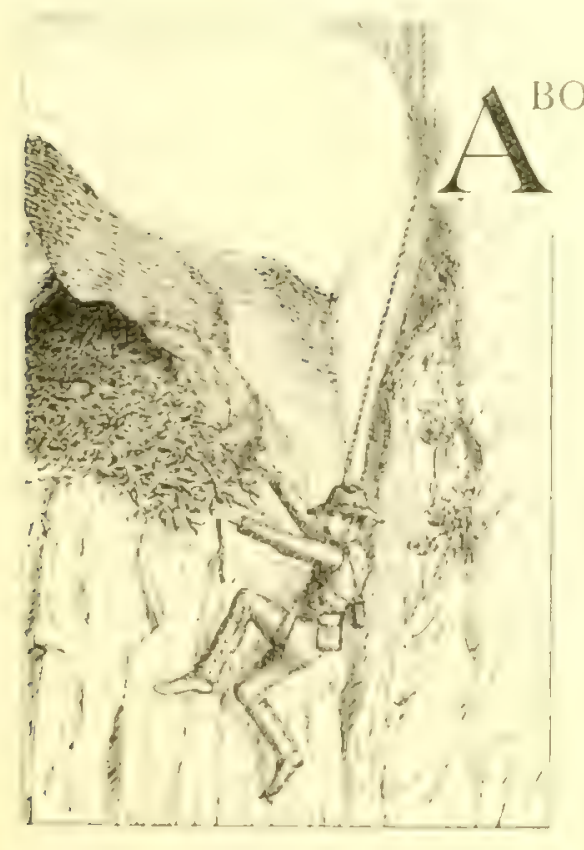

the year following I once again organized an expedition to visit the Bearded Vultures in their home:

The previous dity to our start hat been fine: but bow detached clouds were scudding past the mountain tops and there were other signs of approaching wild weather. At diylight heavy drifting clouds covered all the upper portion of the sicrrat. I tad I been free to do so, I would have put off the expedition 
but my friends, upon whom I depended entircly to handle the ropes, had only limited leave of absence and so, strongly against my better judgment, we set out When less than 1,000 ft. above the sea we entered the clouds and the rain came on and persisted for thres days and three nights. We got within half-a-days ride of our cliff but it was absolutely out of the question to proceed further amid the precipices and we had perforce to retire discomfited. Our return through the mountains was not without adventure since the burns were all in full flood.

Despite this third repulse, I was still sanguine of success, for I reasoned that nobody else would be likely to get at the nest and that if I but vave the birds sufficient time before returning to the attack they would have hatched out their young and I would be rewarded by being able at any rate to photograph the young Bearded Vulture in its nest. It savours somewhat of counting one's chiclens prematurely, but from what I had seen of the Vultures the preceding year and from what I knew of their habits when unmolested, I felt sure that they would again nest in the same cliff this year. I had reckoned on re-visiting the spot in about four weeks but owing to wild weather in the sierras it was close on seven before I once again found myself within striking distance of the great cliff.

It was on a fine but cold morning very early in April that we rokle vut from our halting place of the previous night and proceeded to work our way up the mountain. After some hours we arrived at our old point immediatcly below the nest. The cold was intense and we lit a huge bonfire of scrub and heath to warm ourselves whilst we watched the cliffs. It was whilst thus employed that a Bearled Vulture came sailing over us quite low down anxiously turning its head towards the cliff and on us alternately as it passed. I now felt confident that the nest must be occupied. Nor was I 
mistaken, for shortly afterwards, a Bearded Vulure's head appeared peering at us over the edge of the great nest, which for convenience sake, I have styled "No. 2 " in the preceding chapter. With the telescope it was as easy to see the bird as if close at hand. Surely: no bird ever looked so savare with its cruel pale orange eye encircled with crimson fixed on us. The jet black "eyelorows" and "moustache" (it is sadly unscientific but cxactly expresses the

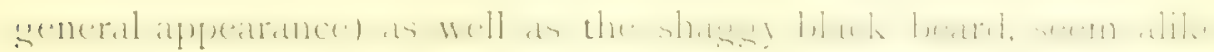
designed to give the bird an aspect of malevolence and ferocity.

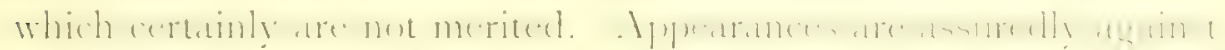
a Bearded Vulure for despite this secmingly ferocious demeanour it exhibits far greater confidence in man than do Griffons, ats is shown by its choice of nesting places at times near human dwellings. On the other hand, notwithstanding all tales to the contrary, the Bearded Vulture is vastly more alarmed than is the

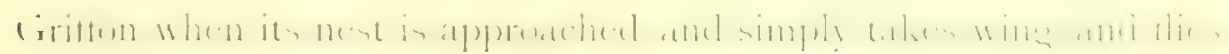
away, regardless of the fate of its offspring, in this trait much resembling its smaller relative the Neophron. The following account of my experiences at the nest, which may be taken ats at typical instance, will, I think afford proof of this.

Having watched us intently for a time, the old bird lowered her head and was lost to view. I was now certain the nest contained young and we made our preparations accordingly. IV e atsecunded the talus as before and on reaching the point whence it emerged from the chasm I escaladed the cliff on the far side of it, until nearly on a level with the nest and took the photograph of the crag which is here reproduced. It was whilst thus engaged that the old bird, hearing the clatter of our feet on the loose stones, once atgain put out her head. This time she wats within shot of us and we all had another opportunity of admiring her splendid colouring. Her baleful look ats she took wing wats it thing in remember. 
In this picture the exact position of this nest is indicated by the arrows. Immediately below it and rather below the centre of the picture is a small terrace on which were some sticks and débris fallen from the big nest above. From this terrace runs the ledge by which I eventually made my escape on the occasion of my risit of the preceding year. As will be noted, it becomes rather awkward to work along as it nears the right edge of the picture and so I dropped down to the ledge below it which joins the talus a few feet beyond the right bottom corner. A close inspection will enable the olive tree to be identified, which forms such an important connecting link in the task of reaching this nest. It lies near the top of the picture just beluw the top arrow. Nest No. I is not visible in this picture, being hidden by the sreat natural bastion or buttress of limestone which occupies the centre of it.

It was exciting work escalading the cliff abutting on the talus: at places the limestone hard become riven and loosened and caused some anxiety for those climbing below us. ITe soon found ourselves on the same steeply shelving terrace as the year before and proceceled to carry out the same plan for the descent. Securing the centre of my 300 feet of rope to a cras. I once again laid one portion down to the olive tree. I'arned by the previous year's experiences I was extra careful in seeing to the "lead" of my own rope and to the dislodging of loose rocks and stones, and fortunate was it that I did so, for we found the whole ledge of the cliff in a state of disinteyration, more so than the year before owing to the recent heavy rains. Finally. I cleared a reasonably safe passage and was lowered down to the olive tree; here I led my life-line as before round it and, easing it, got my weight on the lowering-line and gave the fateful signal. As I dropped over the edge and scraped down along the slippery and wet surface of the cliff, I

1 See also General View of Cliff at end of book. 


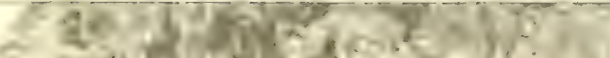

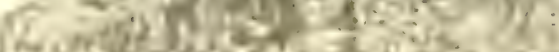

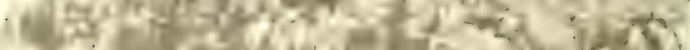

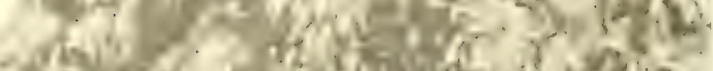

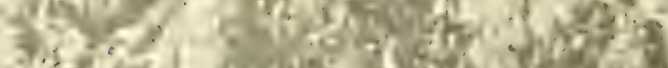

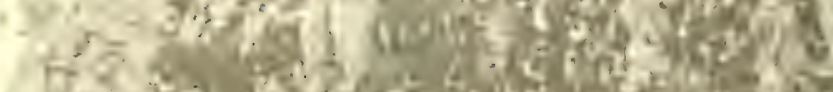

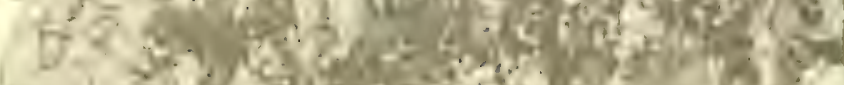

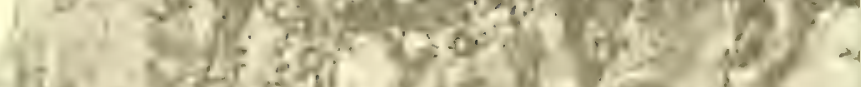

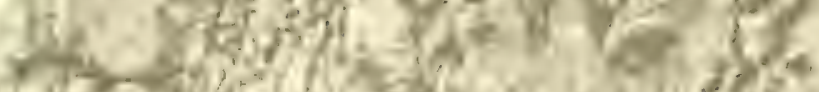

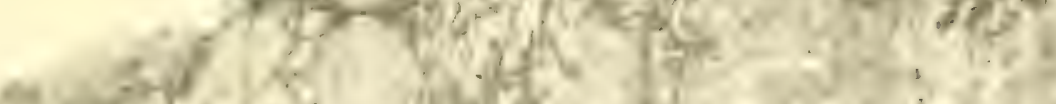

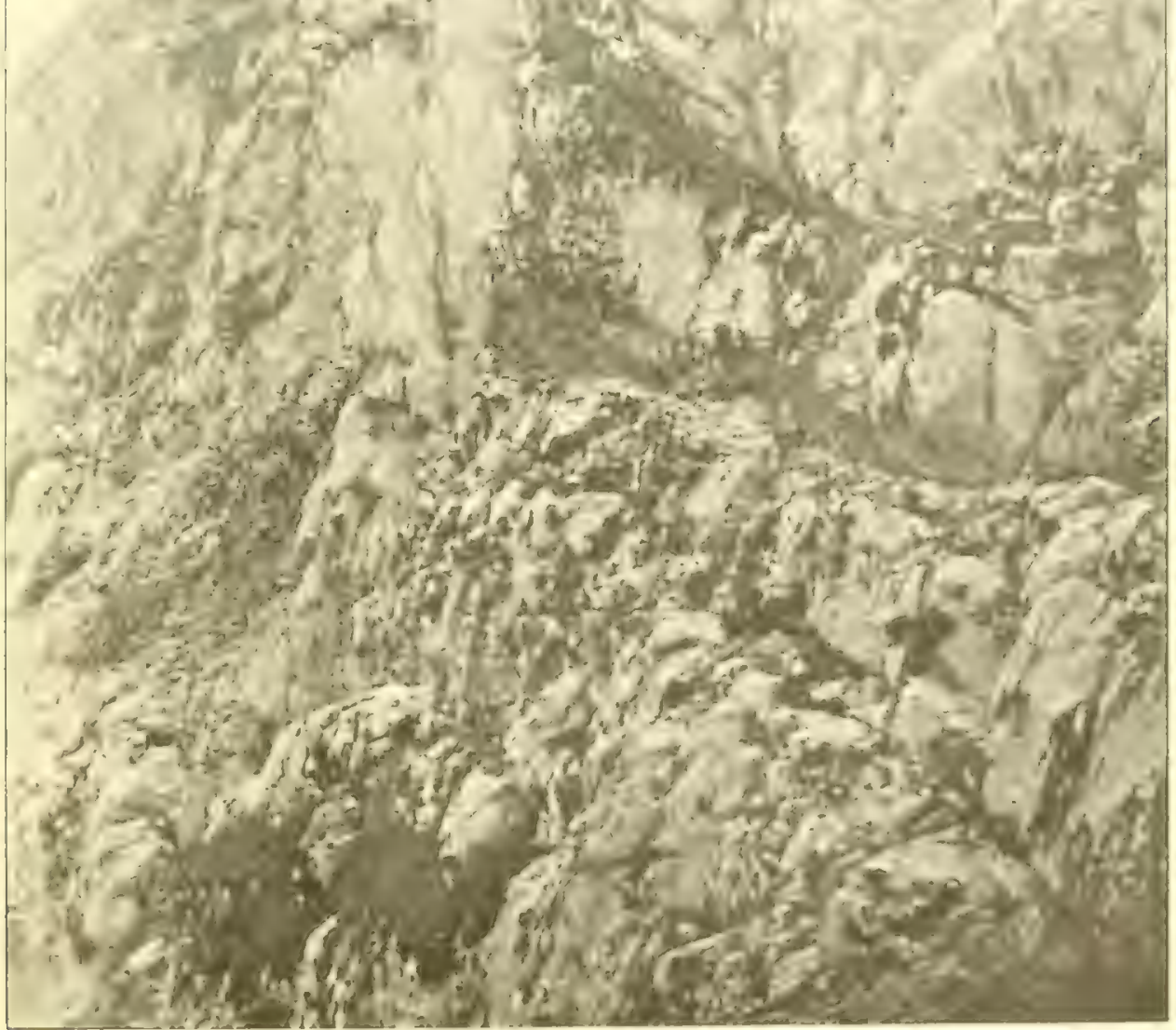

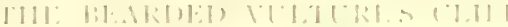





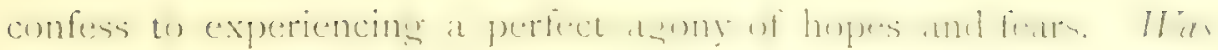
the nest tenanted or not? Arrived at the overhanging cras I

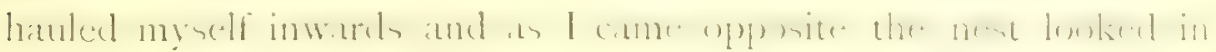
and saw nothing in it!

It was the same huge structure of sticks as of the previous year

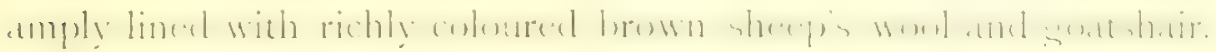
Next instant I detected not four feet from me and flattened down amid the brown wool a big young bird of colour identical with the nest, squatting motionless with head and beak resting on the thick masses of wool in front of it.

The revulsion was indescribable! Swinging myself into the

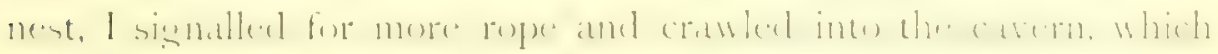
was an awkward cramped place, as will be seen.

Although at the entrance the cavern was six feet high, the roof shelved downwards until at the back it was not two feet above the nest. The total depth of it was about 4 feet and the width 6 feet. Crouching low in the inner corner of the cavern so as to avoid the risk of slipping out, I proceeded to examine the place. The nest measured almost exactly four feet in diameter with a bowl in the inner side, is inches across. The young Vulture was about the size of a tame duck and was covered with a thick close down.

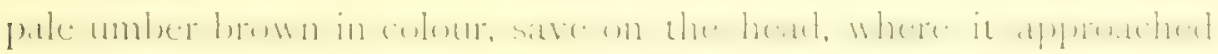
to a vandyke-brown. The primary feathers and tail were just emerging from their quills and were very dark brown and about

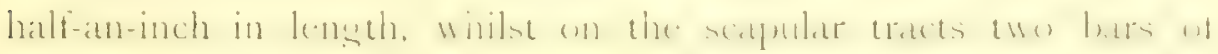
shorter dark feathers were showing. The irides were of a dull

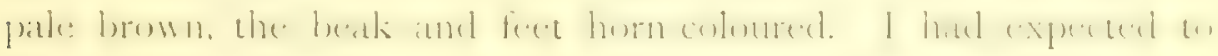
see a bird with a quick eye, but it was exactly the reverse, the

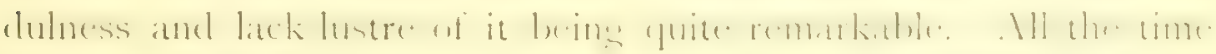

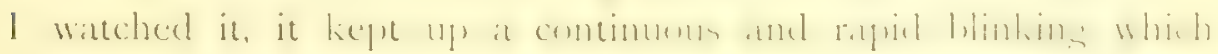
augured ill for photography.

But what impressed me most were the to me entirely novel 
surroundings of the young hirel. Iiesides the mans of sticks, small boushs and branches of dried heath which formed the nest there were several short framents of old rope and a perfect colgotha of remains of animals. Within six inches of the beak of the bird was a calf's foot severed above the fetlock and hard by it a donkey's foot and fetlock joint whilst all around were many portions of the legs of sheep and goats of various lengths. The whole external nest was littered with the horny sheathings of wats and sheeps feet, many of considerable antiquity. ( )ne limb of a big woat mas particularly interesting as showing the manners and customs of these birds. It was a portion of a hind leg with hoof intact and with the femur broken and splintered about half way up. The skin had been neatly turned back below the hock and the bone picked clean. Curiously there was no appreciable smell in the nest, the gruesome remains being either quite fresh, as in the case of the donkey's foot, or dried up.

Having thus satisfied my curiosity to the full and made notes of all I saw, I set to work to photograph the place. Here I was met hy an unexpected difficulty for, setting aside the short distance ariblable, the root was so luw that I cruld with difficulty look into the finder. Also, wherever I crouched, either my feet or knees obtruded themselves into the picture! I soon realized that it was only possible to photonraph the nest and young bird from one side, namely, where I was doubled up. By good fortune in one corner of the cavern there was a small fissure leading into the heart of the rock and by means of squeczing my feet into this and otherwist packing myself into the smallest pessible spatce, I was able to get my camera to work.

I have had many curious experiences in photographing birds' nests but this was one of the most perplexing of the many awkward situations I have ever been in. On my right, between me and the edge of the clitf, Wats at sloping shelf of rock from the rery back of 
which I could get barely $3 \mathrm{ft}$. distance from the bircl. The cancera I had was the old Kodak No. 3 of which the smallest aperture wats equivalent to $\mathrm{F}$. 32. After endless trouble I managed to prop the camera rigilly on the ledge. But every attempt to look into the finder was frustrated by some particulaty hard projecting rocks against which I knocked my head in vain. So I had to content myself with latying my camera on the object by rule of thumb and,

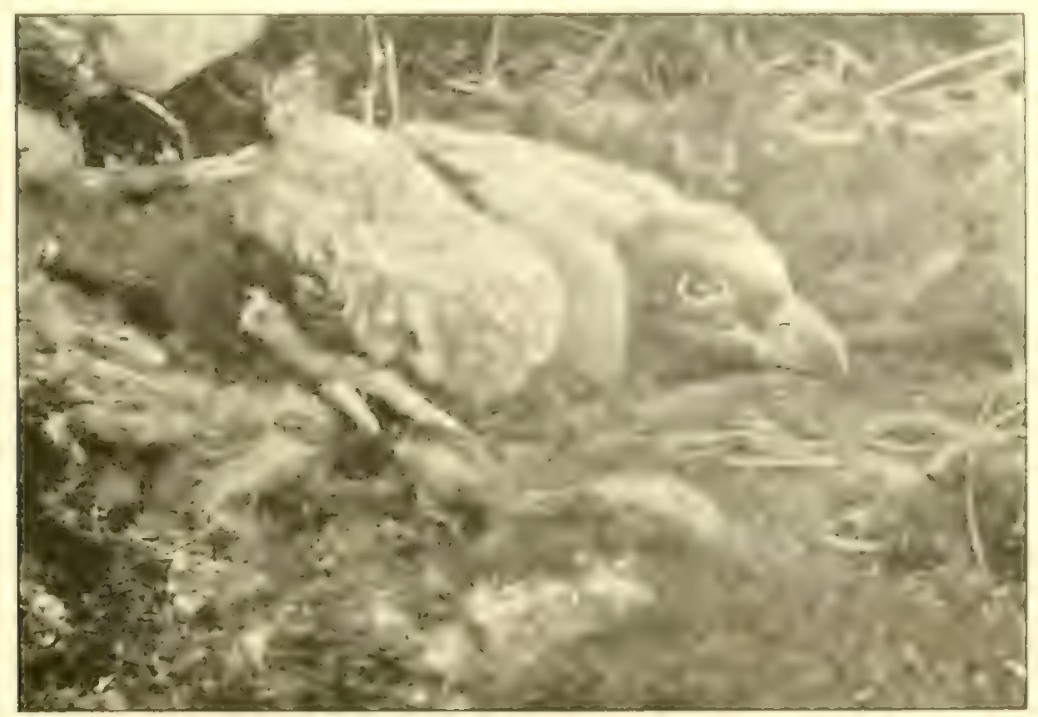

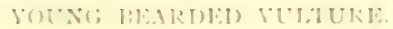

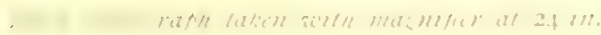

pressing the lever, gave at fo scconds expesure. The whole thing secmed so hopeless and uncertain that I decided not to risk wasting any more films in this mamner.

Before setting to work with the magnifiers I curned the camerat slightly so as to take in the front pare of the nest and the protile of the face of the cliff on the far sicle of the catern. It was well that I did so, for on my return to England I was enabled to juin these 
two photographs with a third (of which hereafter) and re-touch the joins with the result as seen in the full-page illustration given. I may mention here that this is the only made up picture in this book and I trust that the peculiar circumstances may be considered to justify such a proceeding. If the result is somewhat inartistic, I can only plead its absolute reality and that it most faithfully represents what I saw when huddled up in the cavern.

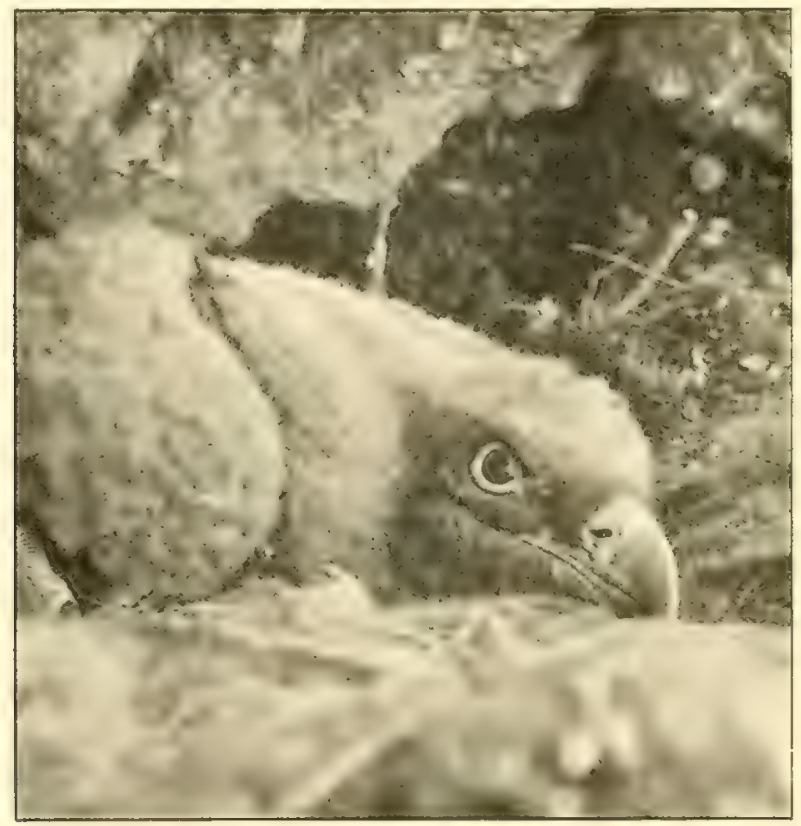

YOUNG BEARIED VLLTURE.

From pholograph taken with magnifier at is in. distance.

I now determined to talic some portraits of the bird itself at more convenient range, so adjusting my 24 in. magnifier, I propped the camera on the rock at that distance from its beak and set to work.

Of the three photographs taken at this distance two were 


\section{Photographing the Young Bird}

fairly successful. In every case I aimed at 35 to 40 seconds exposure. Once the camera slipped off its precarious stand on the sloping ledge and the film was wasted.

I then replaced the 24 -in. magnifier by the IS-in. One and

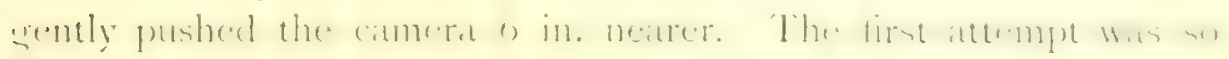

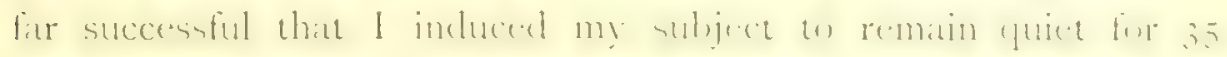
seconds and with the result shown.

A second attemper was mot so happer for after twenty socondes I had equickly to close the shuter ats the hirel sent renthens and, rining up, settled down so as to present me with only a stern view.

I now mate it mistake and endeatoured we turn me recalcitrant sitter round. It at once rose in its wrath and gave vent to a twittering cry very much like an infant (irithn. I was preparing for

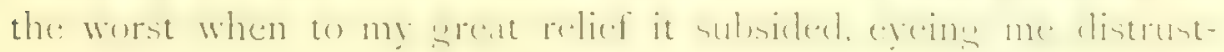
fully: Once again I got the camera to work but as 1 pressed the lever it rose and lurching forward to within a foot of the lens,

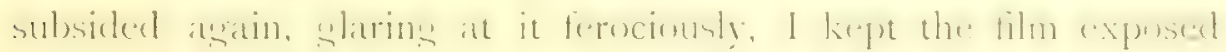

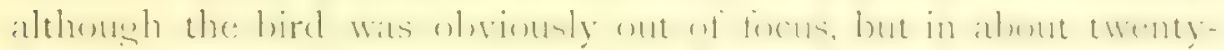

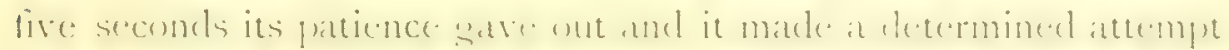

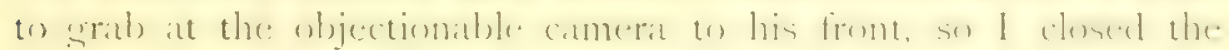
shutter. The result, as may be expected, was not very successful but in the peculiar circumstances it has been given.

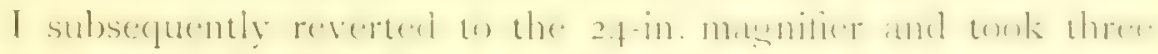

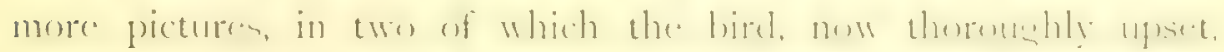

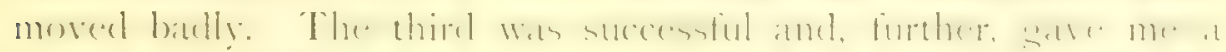

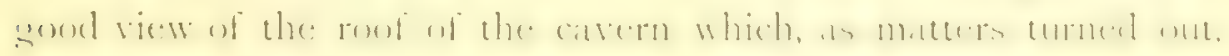
was extremely useful to me when subsequently engaged in compiling the larger picture of the nest.

It was now nearly half-past one o'clock and I had been cramped up in the cavern for over eighty minutes. I had now to decide on the fate of the young bird which I would have much liked to take back to my aviaries in England. It was of the age when 
danger of cramp may be fairly discounted since its quills were sprouting well. But then I remembered hom I still lacked the exgy of the Bearded Vulture for my collection, the only egg of all the sreat raptores which resularly inhahit Siain that I had not taken with mine own hands, and so I decided to leave the young bird unmolested in the hope that by doing so its parents might be induced to nest again in the same cliff next year.

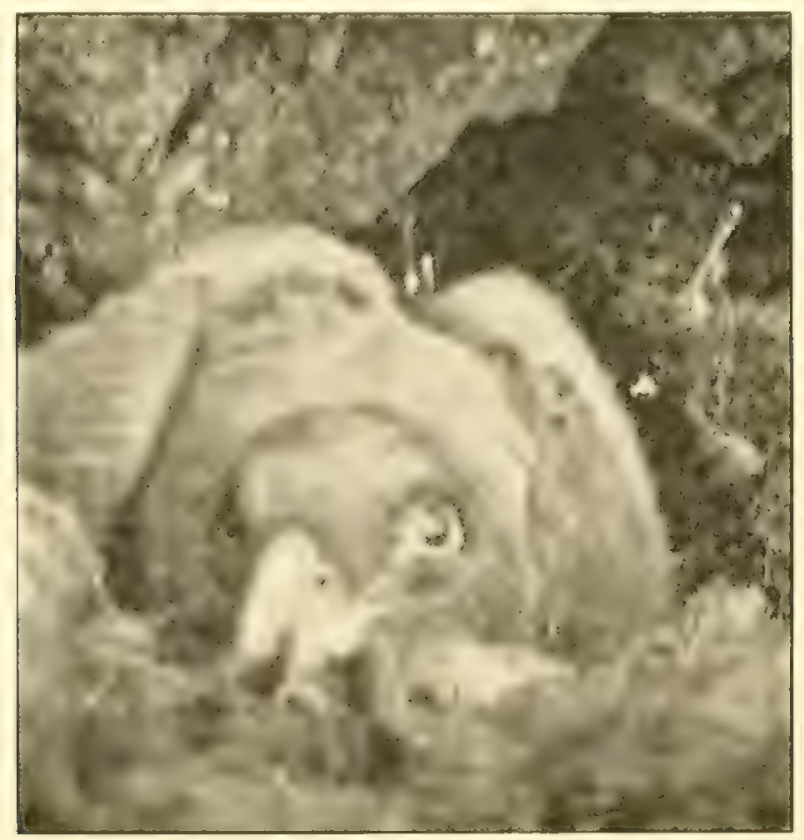

YOUNC| BLARDED VULTURE ATTACKS CAMERA.

From photografh with masnifier at $12 \mathrm{in}$. Histance.

So I packed up my traps and, after signalling to my longsuffering and half-fromen friende aluse, tomk the strain on the rope and dropped on the ledue jo ft. betow, landing on the extreme outside edge of it. Previous to quitting the nest I had thrown out 
a few of the limbs of coats, \&c., to show to my comrades, but most of these had rebounded from the shelf they struck on and gone down I $50 \mathrm{ft}$. or more, a good proof of the vertical and overhanging nature of the cliff, for the ledge under the nest is farly wide.

buring the whole of the time that we were engaged in the climb (some two and a half hours) neither of the old Bearded bultures came near the nest, a marlied diference from the conduct of Griffons in such circumstances. Soon after we rejoined nur mules, one of the ofd birds returned and re-entered the nest. As I was anxious to get a snap-shot of her leaving, I climbed up once arain to the point whence I had photographed the cliff in the moning: As I did so, she quietly slipped off before I could get my camera into action. I then concealed myself for an hour in al cavern hard by, wating for her return, but she was not to be deceived and I eventually rejoined my comrades.

As we made our way down the mountain, both old bircls were seen soaring over the cliff and were later on joined by a third bird. On our homeward road we saw another pair of Bearded Vultures, one of which was carrying the limb of some animal in its left foot. Thus ended our campaign of $190 \%$

During the first week in January 1908 I made all preparations for a renewed attack upon the stronghold of the I3earded Vultures. but was delayed for orel six weeks, hrst by continual bad weather and then by the difficulty of funding safe men to form a lowering party for what I now had good reason to krow was a peculiarly dangerous cliff. At last 1 arranged for one under the suidance of Lieutenant Gerald Hamond R.N. a son of a former commele. the late Commander Robert I amond who had been my companion in many of the birdsnesting expeditions near (ibbaltar thirty years previously, described in the earlier chapeces of this bonk. favoured by splendid weather, we at lengeh found ourseliess on 16 liebruary immediately below the fanous cliff. Sure enough 
the birds were nesting not far off, for soon we saw one of them on the wing and it was tolerably certain that its mate was sitting. A careful inspection of the two nests with a telescope showed that No. I, the first we had visited in 1906, was in occupation whereas No. 2, that of 1907, was obviously in a state of disrepair and untenanted. After firing several pistol shots, in the hope of causing the old bird, if in the nest, to show herself, I sent one of my party up to the terrace $200 \mathrm{ft}$. above us. It was not until he had twice fired my pistol close under the nest and not 20 yards from it that our suspense was relieved by seeing the old bird suddenly raise her head and look out. Eventually she left the nest and grave us a splendid view of her as she swept overhead in the brilliant sunshine. We lost no time in ascending the talus and steep chasm and on reaching the summit $550 \mathrm{ft}$. above the spot where our mules were picketed halted to recover our wind. It was one of those peculiarly lorious days of early spring in southern Spain and the view from our position was magnificent, causing us to pause for some time before setting to work. So clear was the atmosphere that we could distinguish the gleaming waters of the Atlantic near Cape Trafalgar over 50 miles distant whilst northward the great plains of the Guadalete and Guadalquivir, dotted with white towns here and there, extended like another ocean, some 4,000 ft. below us.

IVe now left the summit and worked our way carefully down the steep slippery slopes towards the edge of the big cliff. During this operation one of my party (not a sailor) found the height more trying than he had expected and we left him behind. This was truly unfortunate as it materially weakened the man-power upon which my calculations were based. The old adage that misfortunes never come singly was well borne out in the subsequent operations. Amid the wild desolation of jagged crags and steep slippery slopes which were wreathed in snow when I had visited 


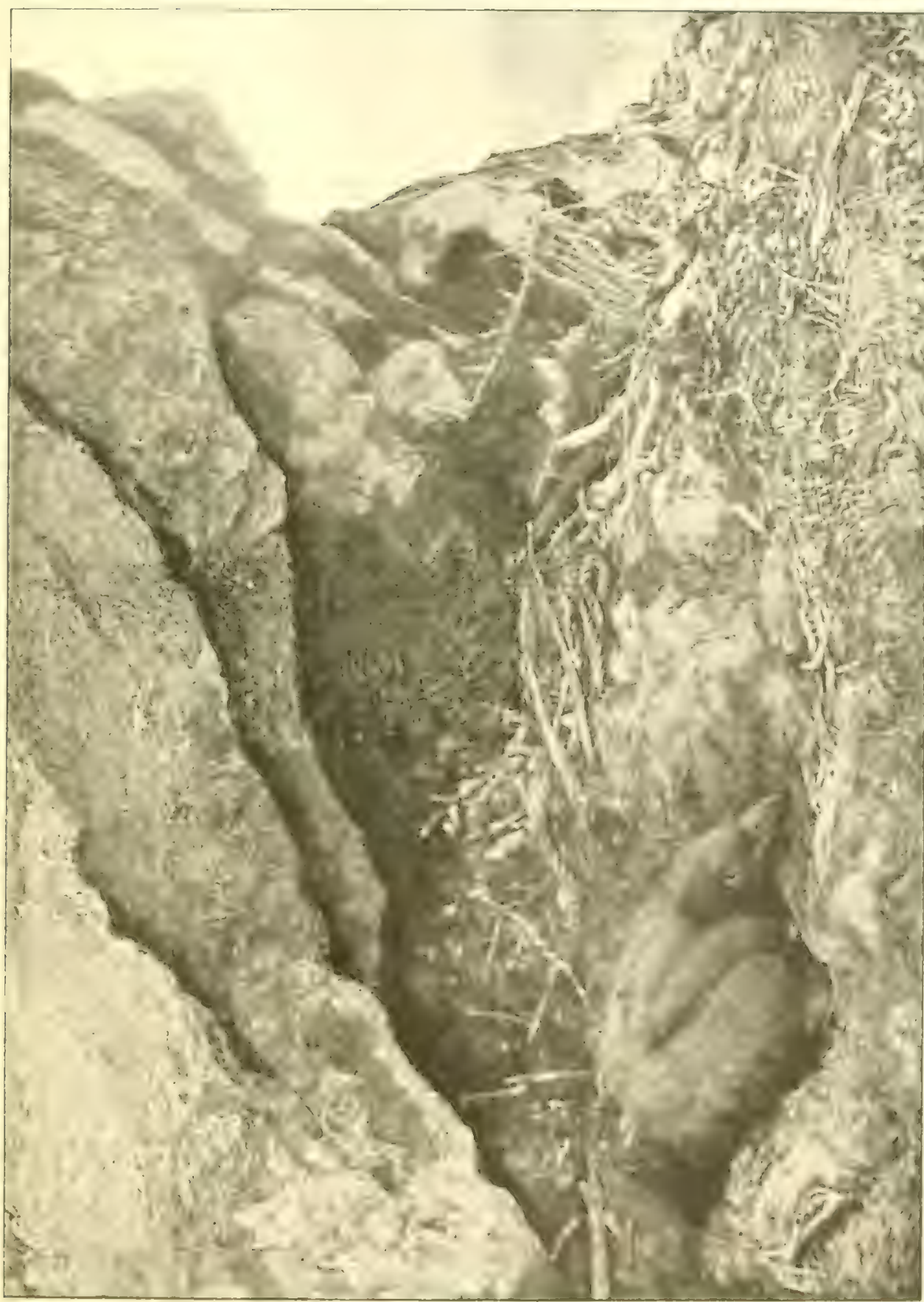





\section{Misfortunes never come singly}

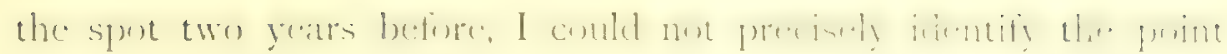
where I had then posted my lowering party. So selecting what seemed to be the lowest suitable spot, I donned my canvas sling and started away down the cliff. Very soon after I had posted my reduced lowering party and dropped down some $50 \mathrm{ft} ., \mathrm{I}$ discosereal I was lusing my direstion and inclinins twe much to the

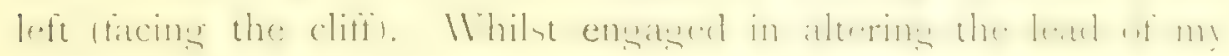
rope to the right so as to recover my proper line, a warning cry from above caused me to look upwards. It was lucky I did so, for

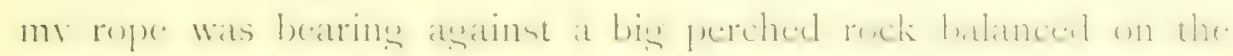

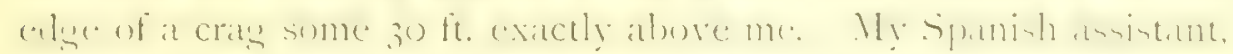

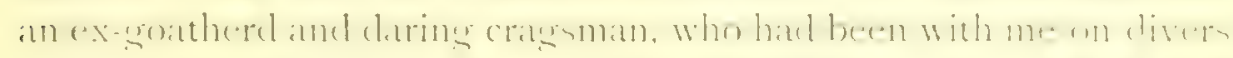

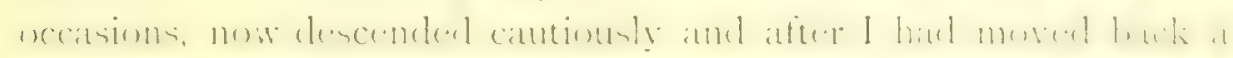

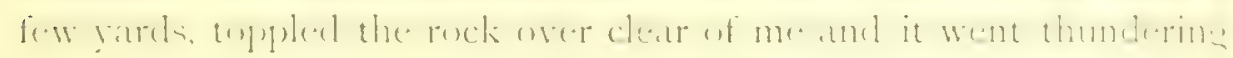

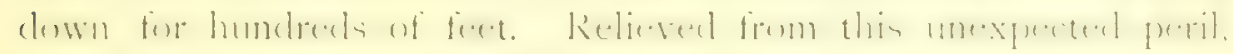
I continued my descent until I reached the grassy ledge imme-

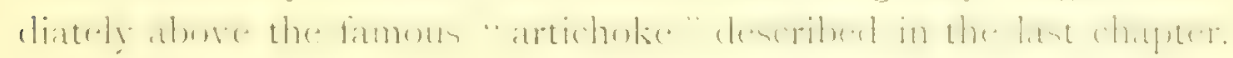

And now I made one of those unfortunate mistakes which, like so many mistakes in life, seem at their inception to be so trivial and yet lead to very awkward results. In the interval which had elapsed since I was last in this part of the cliff I had made many other descents and I was rather uncertain of the exact line I had

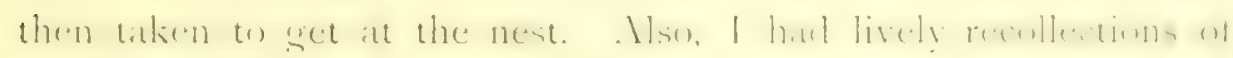
the difficulties and dangers of the descent in 1906 upon the

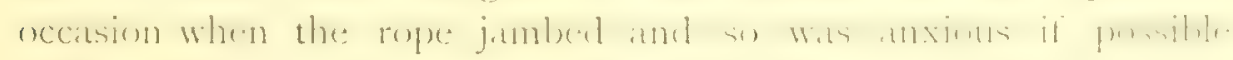
to find a new and easier way down. So I signalled to the muleteer, nigh $400 \mathrm{ft}$. below, to ask the exact position of the nest, and he waved to me to move to the right (facing the cliff) of the "artichoke." This was reassuring, for here I saw a grassy" gully"

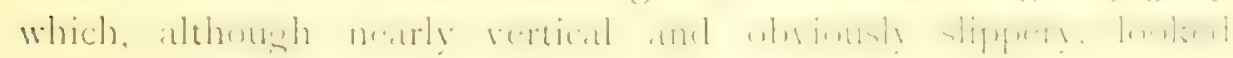

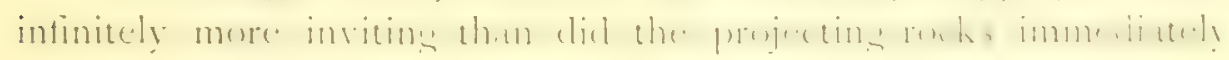
below me of which I had such a disagrecable remembrance. 
So I slipped into the gully and signalled "Lower away" and down I went for over So ft., making futile grabs at loose rocks, masses of saxifrage and plants, all of which came away in my hands together with a shower of stones and soft black soil. Suddenly I found myself scraping past a big projecting mass of rock and I knew I must be close upon the nest. The whistle was in my mouth (as it ever is in critical times) and I sounded on it shrilly "Hold hard" and was brought up with a jerk, swinging clear of the cliff and exactly opposite the extreme right lower corner of the great nest. I was too far down to see into it. A push with my foot caused me to swing outwards and as I swumy back and inwards I grabbed at the cliff and by good fortune secured a fair handhold. All I now required was a little more rope to permit of my hauling myself into the nest. So I whistled for more rope but got no response. Knowing well that it was simply a matter of time for my strength to become exhausted, I now strove to secure myself to the nest by the end of my rope. But no suitable point was to be found and all my attempts at getting a sound handhold amid the big sticks forming the foundations of the nest resulted in my simply pulling them out and causing that part of the structure to slide! A sketch of my unenviable situation at this instant is given at the beginning of the chapter. Meanwhile my vigorous signals for more rope were ignored and I came to the unpleasant conclusion that I must have reached the end of my rope! Looking down I could see the terrace only $50 \mathrm{ft}$. below me. If I could descend to it, I might, by altering the lead of my rope to the left, re-ascend on the proper line and enter the nest at its left side. Anythingwas preferable to attempting to re-ascend that detestable gully with its attendant loose rocks and mud bath. So I whistled again and again but in vain. Without doubt I must be at the end of my tether! Slowly but surely I felt my handhold relaxing and finally I lost my grip and, as I did so, swung outwards with a horrid 


\section{A Critical Moment}

jerk. There was nothing for it, but to try to re-ascend. To my surprise my signal "Haul up" was at once responded to. But, bad as the descent had been the ascent was vastly more unpleasant. Handhold there was none and all efforts on my part to "lighten up" resulted in my detaching a fresh avalanche of stones and débris of all sorts. Up I went, spasmodically and painfully; at times the rope bit deep into soft black soil in the crannies between the vertical strata. When at length I reached the top of the gully, I saw to my surprise my goatherd tending the rope at the exact spot where Admiral Farquhar had joined me two years before. It was some little time before I could

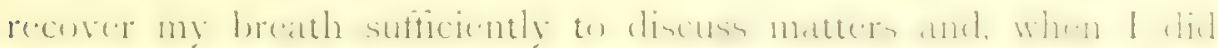

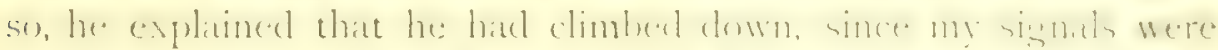

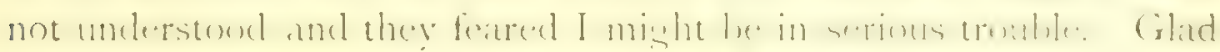
as I was to see him, I felt some misgivings when I recalled how the lowering party was now reduced to Hamond and one other.

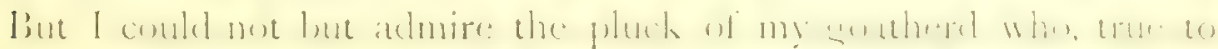

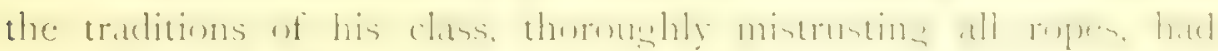

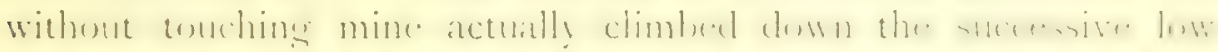

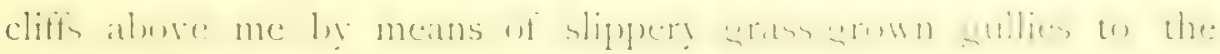
perilous point he now occupied. What this meant can in some degree be imagined from the sketch at the end of the book.

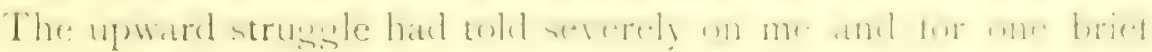

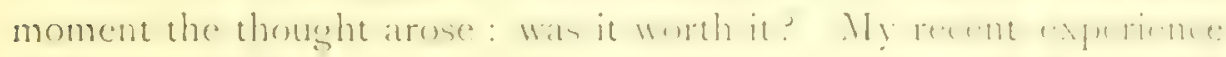

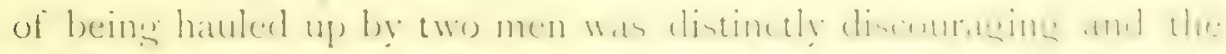

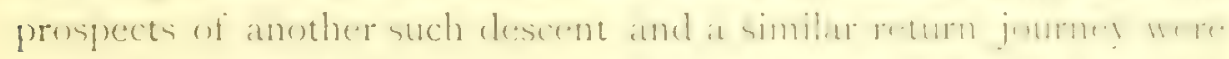

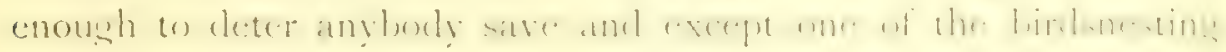
guild inebriated with the exuberance of his calling. My intrepicl

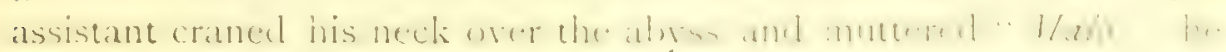
was a man of few words and I knew well what that word con-

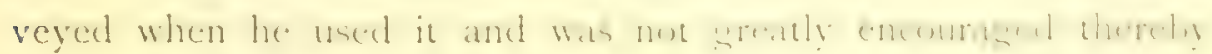
I fancied I detected in his impassive face a lurking contentment 
that he had at last "seen me through," as the expression has it. The idea was intolerable. I asked myself what prevented my going on and the reply came quick. "This: if the rope is not long enough to take you to the terrace below, you probably won't be able to come up again with only two men to haul on you." It must be remembered that at this time I was by no means certain that my lowering party was posted as far down the cliff as in I906, hence my natural anxiety as to the length of my rope. Also, my recent experiences when on a level with the nest pointed to the rope being too short. The situation was maddening for I realized clearly that in all probability it was a case of now or never, so far as my taking the egg of the Bearded V'ulture was concerned. Then came the remembrance of the long series of failures which had attended all my efforts to get this egg, extencling now well over thirty years. And then I recalled how only a quarter of an hour before I had actually had my hand on the coreted nest. My assistant had thoughtfully brought down with him a $\mathrm{I}$ oo $\mathrm{ft}$. coil of light Alpine Club rope, this would at any rate take some of the strain off the lowering party. So making it fast to a convenient cray I heaved the coil into space with a fervent hope that it might prove long enough to aid me in my descent and, if required, in my subsequent ascent. Taking a firm hold of the light rope I was lowered $20 \mathrm{ft}$. to the little green ledge alongside the "artichoke" whence I had a good view of the work before me. Immediately below me the cliff descended sharply for some $30 \mathrm{ft}$. or more to the rounded rocky bluff which marked where it became vertical and in places overhanging. My Alpine rope lay truly down the cliff and disappeared from view over the bluff and I knew the nest was no wreat distance below that point. The sight inspired me with fresh determination and I gave the signal to lower and slithered away at speed. The dic was cast and soon I was scraping over the rocky bluff and 
next moment was hanging just clear of the cliff. Fifty feet or so more brought me opposite to the cavern at the same point as in 1906. Checking my descent by means of the Alpine rope, I whistled "Hold hard" and was thankful when I felt the rope tauten. I brought up with the roof of the cavern about level with my chin. As I lowered my head and peered into the nest, I saw this time that it contained a big exg, richly marked with shades of yellow and brown. At last!

My troubles were not yet over for it was with the greatest

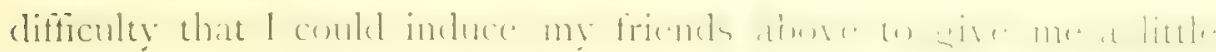
slack rope to enable me to enter the cavern. Also the roof was so low and the floor so shelving that it repuired much contortion to crawl in and, having crawled in, to avoid slipping out. Having made my position secure, I proceeded to cxamine the place. The nest was identical with those of 1906 and 1907 so far as reyards materials, construction and size, but whereas all these had been

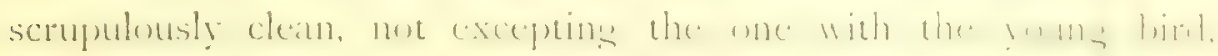
the one I now occupied was in a horribly filthy state. In fact I never saw-or smelt-a nastier one and I was forcibly reminded

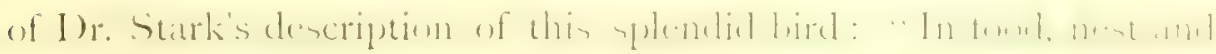
nesting place, it is simply a big Neophron." However, notwith-

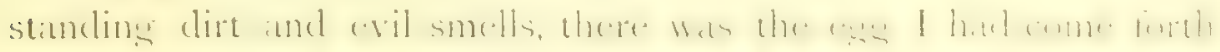

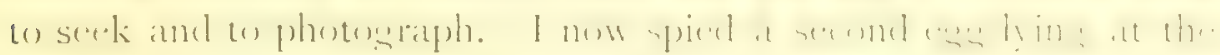
back of the nest against the wall of the cavern, broken into two

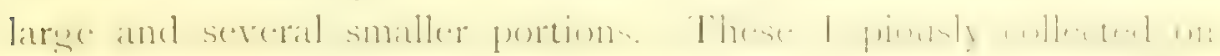
the off-chance of my being able to piece them together.

The work of photographing this nest was peculiarly trying and difficult, for the available space and head room were much less than in the nest of the previous year: $2 !$ ft. Wats the erreatest distance I could work at and then I could not wse the finder of the

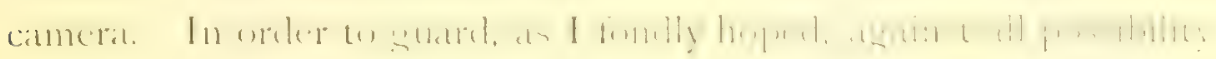
of failure, I had brought with me two cameras and with these I 
proceeded to take an exhaustive series of views of egg and nest at $2 \frac{1}{2}, 2$ and $\mathrm{I} \frac{1}{2} \mathrm{ft}$. distance.

I now had to decide upon my line of retreat. The extreme end of the Alpine rope dangled just level with the nest, showing that I was almost exactly $\mathrm{I}$ oo $\mathrm{ft}$. below my assistant and I reckoned he was about $150 \mathrm{ft}$. below Hamond (as it turned out he was somewhat less). As my 2-inch rope measured $300 \mathrm{ft}$. I calculated I could count on about $50 \mathrm{ft}$. to talie me downward and the friendly terrace below me was certainly not more than $60 \mathrm{ft}$. Anyway it was worth a trial. So I cautiously unbent the rope which encircled me and was secured to the canvas sling and made it fast to the thimbles on the sling at its extreme point so as to utilize all the rope I could. By this means, including the slack I had coiled down in the nest, I gained some Io to $\mathrm{I} 2 \mathrm{ft}$. Grasping the rope firmly, I signalled "Stand-by" and as I felt it tauten I slid out of the nest and in a moment of sheer thoughtlessness, begot of my success, sounded "Lower away." The instant the rope began to run out, I realized I had made a serious error for I was descending at speed with my whole weight on my hands or rather on my one sound arm. There was no time for thought, still less for any signalling and I did the only possible thing. namely quickly lowered myself hand over hand until I felt the sling take the weight of my body, as it should have done in the first instance. 'Thus occupied I was naturally unable to steady myself or minimize the gyration of the rope and I rattled down, now banging one camera now the other and now the box containing the precious egrats well as my linees and elbows against the cliff until I landed with a bump on the rocks below, all well but somewhat shattered. My left arm for a time was quite numb and useless, not having had such a strain put upon it since I was so badly smashed at Graspan in I\$99. A short rest however brought me round and as I disengaged 


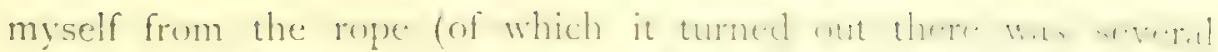

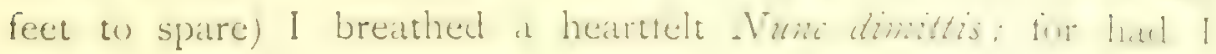

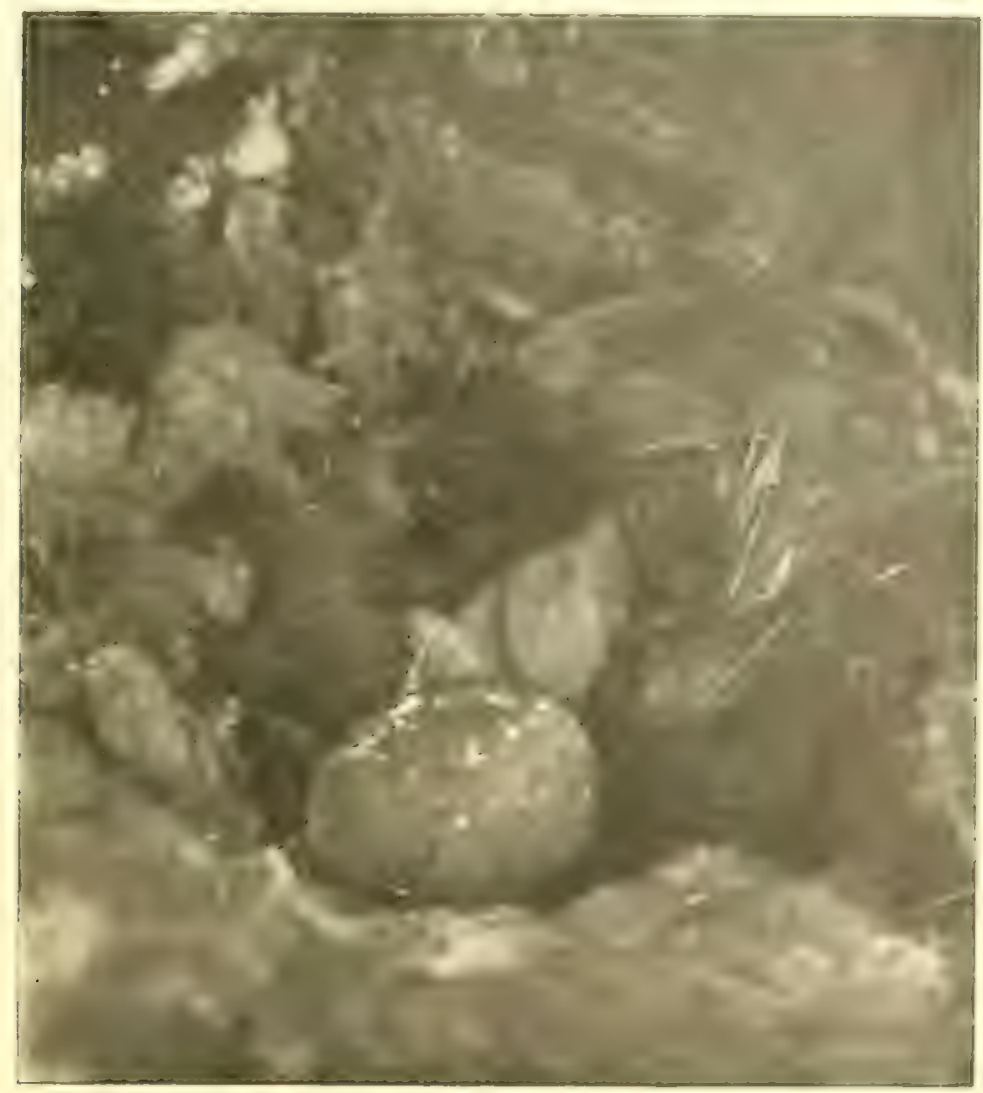

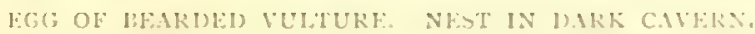

From photografth baten with a machiter at IS ins distance

(size of egg $\left.33^{\circ} \mathrm{in.} \times 2.6 \mathrm{in.}\right)$

not at last succeeded in the one remaining object of my birdnesting life?

The persistent run of ill-luck which accompanied me through

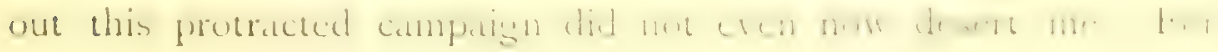


the numerous photographs which I had obtained with such peculiar difficulty turned out to be failures, owing to the films being defective! Since the cartridses were perfectly fresh and had been properly liept in tin-boxes, this was as unexpected as it was rexatious. In the absence of anything better I give the best of a bad lot. Many of them were entirely obliterated by a black fungus-like growth. But if ill-luck attended me in these repeated attempts, I feel I ought to be peculiarly thankful for having come out unhurt from a series of minor accidents.

Soon after regaining the point where our mules stood I was rejoined by my companions from abore. The whole business had taken just three and a half hours, I then learnt from Hamond that the reason he gave me no more rope when I was clinging to the nest in my first descent was that my whistle sinnals were indistinguishable. Probably this was due to my being under a big projecting rock combined with the echoes caused by this and the adjacent caverns behind the great limestone buttress, for as soon as I swung out clear he heard my signal "Haul up " distinctly.

Thus ended my long-drawn-out campainn after the Bearded Vultures, In many respects it was not more risky than other similar expeditions and climbs after Eagles' and V'ultures' nests. Since however it chanced to involve a series of misadventures and incidents, more or less exciting to the actors, but all eminently illustrative of the ups and downs attending the use of ropes on unknown cliffs, I have described it at length and have also reproduced the sketch I made of the cliff on the spot. There is nothing very novel in what I depict, but the sketch sives a fairly accurate view of this fine cliff which is hishly characteristic of the peculiar sites faroured by Bearded Vultures as nesting stations.

A final word as to the behaviour of the old birds. Shortly ifter learing the nest when the pistol shots were fired, the female returned and contered it, and did not leave it again until I was 


\section{Ovum Coronat Opus}

lowered close to it. She then departed and did not return until

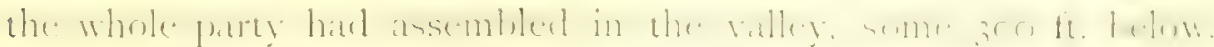
So much for the tales of Bearded Vultures attacking those who molest their egres or young!

As a set-off to my bad fortune in the photonraphic business

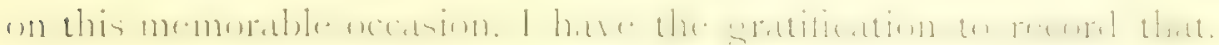
thanks to the skill of one of the staff at the British Muscum of

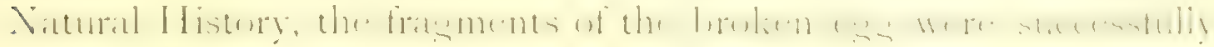

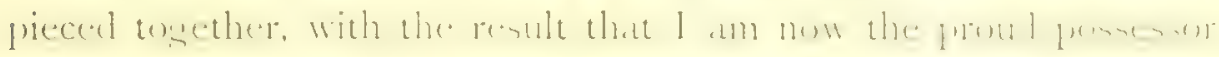
of a pair of beautifully-coloured exress of the Bearded Vulture, which find a fitting resting-place in my collection in the centre

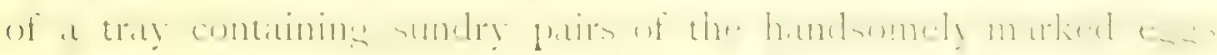
of the Neophron!

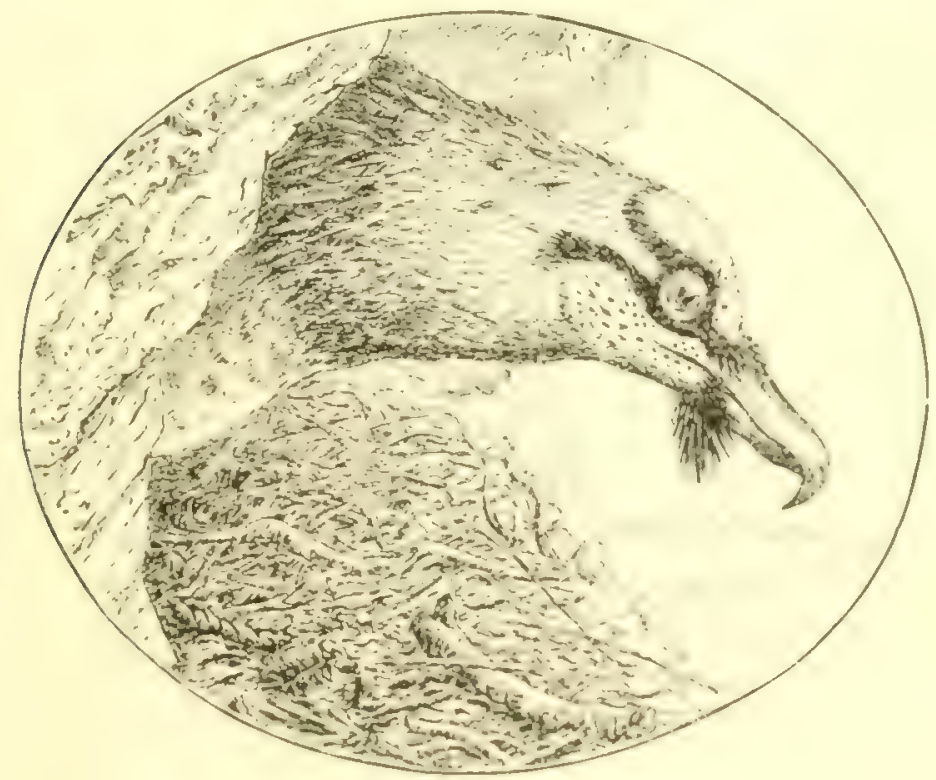

Tin: lixu, 



\section{INDEX.}

ABERDEEN Terrier and Eagle Owls, 327

Accentor collaris, 305

Accipiter nisus, 176

Acrocephalus turdoides, 99

Aëdon galactodes, 158

Aigialitis curonica, 128

A guila imperial, 207

,. negra, 198, 207

"real, 207

Alauda bectica, $\mathrm{I} 29$

"Brachydactyler, 129

" calcundre, 129

Alcala de las Gazules, 268

Alpargitas, 36

Alpine Accentor, 305

" Club ropes, So

Apes' Hill, 239, 310

Aquila adalberti, 196, see White-shouldered Eagle

" chrysiëtus, 355, see Golden Eagle

$"$ mogrilnik, 196

"rapar; 197

Ardec purpured, 95

Ardea ralloides, 112

Ardeolur russalia, 94

Arzila, 239

Astur pulumbarius, 173

13.ETIC.s Short-toed Latk, 129

Barbary, 278

Barrosa, 239

Bayuda Desert, 266

Bearded Vulture, 304, 30f, 375, 407-457; nest of, 374, 424; plumage of, 409, 410, 414; time of nesting, $+10-411$; flight of, +13 ; encounter with (xiffon, 416 ; young, $4+1$

liee-eater, 161; number of eggs, 163; nest of, 163.t; haljits of, I63.t ; St. liee-eater's Day $16_{3}$; eggs of, $16_{3}$

Bee-hives, cork, 163

Belon, ruins of, $233,239,386$

Bird-life, Taking of, 4,6

Birdsnester, true, 7 
Jirdsnestins, 3 ; author's devotion to, $11-12$; on Active Servece, 17-20: preparng for un wild country, camping out and equipment, 21-38; in the Spanish Marshes, 91-93, 104-106, IO9-II 2

Birds, stuffed, 4 ; cage, 9

Blackbird, I5s; eggs, 159 ; in Bonelli's Eagle's nest, 352

Blackcaps, 9

"Black Eagle," 198, 207, 208

Black Kite, 170-173; nesting-place of, $171-2$; nest of, 173

"Wheatear, 289-291; plumage of, 289; nest of, 289-291: eggs of, 291

" winged Stilt, 206

"Vulture, 199, 210-232, 41t; favourite nesting-place of, 210-211; plumage, weight, and size of, 213 ; expanse of wing, 213 ; number of eggs, 217 ; nest and eggs of, 225

Bluejackets climb round Rock, 52, 317

Blue Kock Thrush, 28.4, 287, 289, 291, 317 ; date of nesting, 2S5 ; eggs of, 289

Bonel, the Brothers, 307

Bonelli's Eagle, 50, $313,318,328,330-35 t$; plumage of, $336,337,340$; young, $336-7$; size, 337 ; nesting place, $338,345-6$; nest of, 339,342 ; eggs, 339,342 ; food of, 339 ; kept in confinement, $352-353$; flight of, 353 ; takes Partridge, 354

" IVarbler, 157, 158

Booted Eagle, 172, 177, 178-185; plumage of, 178; nesting-places, 179-180; nest of, 179, 1So; eggs of, 180; young, 182; colour of, 182; taming, 182-184; flying to Falconer's "luse," I 84 ; lost at sea, 185.

Brigandage, 307-309

British Museum of Natural History, 340, 388, 400, 457

Brown-necked Raven, 243

Bruce, James, the Traveller, 410

Bubo ignarus, 3 II, see Eagle Owl

Buff-backed Egret, 94, I 30, see Egret

Bull, in reed beds, 100; young bulls, 126: chased by a, 127 ; dislike for Englishmen, 127-8; hunted up a tree, 200-201; fighting bulls, 202 ; "mild-mannered" bulls, 202

Bunting, Cirl, I2

" Common, 129, 267, 305

" Rock, 305

Bustard, see Great and Little Bustard, 131, 149

Buzzard, Common, 157, I86, 187, 216, 330, $3 \hat{3} 1$

CALANDRA Lark, 129, 267

Camels, "Wild," in Spain, 15

Cameras employed, $42-46$; camera stand, 47

Canvas sling, 8 I

Carabineros, 295 ; fight with, 296

Carime noctur, 161

Carteia, ruins of, 233

Casting-line and weight, 64-68

Cattle, in reed-beds, 100; a "bad cow,"126; "Lagartijo," 127; herdsmen, 126, 20 1

Cetti's Warbler, 157 ; favourite mesting-place of, 157 ; eggs of, 157

Chaffinch, 157,216

Clarles V.'s Wall, 287

Chelidon urbica, $283-4$

Chitf-chatf, 6,157 
Chough, nesting-place of, 305

Ciconia alba, 94

Circaëtus gallicus, 185, see Short-toed Eagle

Circus ceruginosus, 96, see Marsh Harrier

" cincraceus, 104

" cyaneas, 104

" mucrumes, 104

Ciscar, Laja del, 86, 87

Cisticola cursitans, 129

Cliff Climbing, 7I-90; qualifications, 73; Ropes, their dangers and their uses, $73-78$ : travelling naturalist and professional cliff-eggers, 79 ; size and nature of ropes, 79-82 ; whistle signals, $85-86$; author's silk rope, 60, 160 ; Alpine Club rope, 220, 226

Climbing irons, 68

Coccystes glandarius, 237

Colmenares, 163

Common Blackbird, I58 ; number of eggs, I 59 ; in Bonelli's Eagle's nest, 352

. Buzzard, 157, 186, 216, 330, 331

" Chough, 305

. Crane, 107; habits, 107-8; line of migration, 109; favourite nesting-places, 109-10; locating nests, III-117; simulating disablement, 114, 115; nest and eggs, 117-121; young, 122

". Raven, difficult climb to nest, $60.63,157,209,236,241-250$; number of eggs, 242,244 ; puzzling assemblages of, 242 ; identifying the, $243-4$; eggs of, 244 ; dates of nesting, 245 ; cunning habits of concealing nesting-place, $245 \cdot 248$, $378-380$

, Swallow, $157,282,284$

"Wren, 282 ; nesting-places, 282 ; nest of, 282

Contrabandistas, 295-296

Coots' nests, 94, 96, 101

Cork bee-hives, 163

"Woods, in the, $156-165,18 \mathrm{I}, 185,186,383$

Cormorants, 236, 300

Corvus capensis, 19, 20

, corax, 241

" tingitanus, described by Colonel Irby, 243

Coto de Doñana, 15, 171

Cotyle riparia, 282

, rupestris, 282

Crag Martin, 282, 284 ; nest of, 282-3; eggs of, 283,284

Crane, 107, see Common Crane

Crested Lark, I0, 11, I29

Cross-breeding cage birds, II

Crow, South African, 19

Crown Prince Rudolf of Austria, If; "Wild" camels and Flamingoes, 15 ; silk rope, 89 ; young Bearded Vultures, 4I I

Cueva del Cuervo, 248, 377

Cueva del Gato, 300, 301

Culebrera, 185

Curlew. 105 ; Stone-, 128 
D.ARTFORD Warbler, 237

I) oñana, Coto de, I5, 17 I

Doroteo, the woodsman, 217-22:3

Dunalley, Lord, as6

EAGLE, Bonelli's, 330, see Bonelli's Eagle

"Booted, 178, see Booted Eagle

. Snake (or Short-toed), 185, see Snake Eagle

" Golden, 355, see Golden Eagle

"White-shouldered or Imperial, 196, see White-shouldered Eagle

". "Black Eagle," I 98, 207, 208

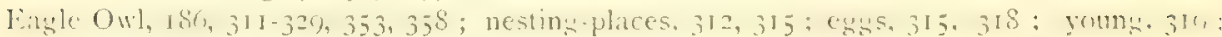
number of egrs, $320-1$; prey of, $324-5,326-7,328$; plumage of, 327 ; cry of, 329

Eggs, collectors of, 5 ; exchangers, 5 ; exchanges, 7, 342; extermination of species, $7 \cdot 8$

Egret, 94, 130

Egyptian Vulture, 75, 248, 372-386, 408; farourite nesting-places, 210, 373, 376-8, 382 ; plumage of, $273,372-3,376$; eggs of, $373,374-5,384,385$; migration of, 373 ; food of, 374 ; nest of, 374 ; young, 375

Emberiac cia, 305

FALCO peregrimus, 305

Falconry, ro ; Bonelli's Eagle used in, 331 ; Booted Eagles, $182-184$

Falcons, IO; Peregrine, 79, 148, 236, 262, 305, 373; and game preserving in Spain, 165

Fantail Warbler, 129

Farquhar, Rear-Admiral Arthur M., 76, 92, 169, 247, 321, 346, 348, 420, 423, 426, 451

"Fauna of South Africa, The," Sclater and Stark's, $43 \hat{3}$

Felis catus, 239

Fergusson, Major Hany James, 61, 127, 142, 148, 198, 286, 304, 312, 336

Flamingo, 15 ; eggs, 15 ; tlight of at Trafalgar, 237

Flowers and l'lants in Spring, I32, 153, 235, 267; Arbutus, 294; Asphodel, 125; Alnond

Blossom, 309 ; Bulrusb, 22, 105; Cistus, 269; Convolvulus, 126, 267; Great Mace-reed, 92 ; Laurestinus, 294; Mediterranean Squill, 125; Oleander, 310 ; I'eonies, 309 ;

l'urple Iris, 126; Reeis, 92, I10-III, II3-I20; Rhododendron, 294; White Heath, 294 Foxes, 304

Frere, Sir liartle, 333

Fringilla serimus, 159 , see Serin Finch

Frogs, 268

GALERITA Cristati, 129

Ciallinule, Purple, 99

Gibraltar, Rock-climbing and cave-exploring, 48-57; Ospreys, sites of nests, 252; 13lue Rock Thrushes, 286-289; Black Wheatears, 289-290; Eagle Owls in 1776 and 1876, 312 ; Ijonelli's Eagle, 331-332

Glarcolu torquata, $112-128$

Golden Eagle, 196, 197, 203, 207, 301, 337, 339, 355-371, 382, 409 ; eggs of, 203, 362, 366 . 370 ; weight of, 356 ; span of wing, 356 ; ncsting-places, 357,358 , 360, 364; food of, 358 ; nest of, 362

Golden Oriole, 159-160; protective colouring, 159; eggs, 160; nest of, 160-1 
Golden Plover, 149

Goldfinch, II, I 57

Goose, Wild, I04, I.47; Grey-lag, I04; call bird, 342; tame goose's egrgs, 342-34t

Goshawk, $10,173 \cdot 176$; retiring habits, $173-174$; eggs of, 174 , 176 ; identifying bird, $175-6$

Grass Snakes, 95, 128

Great Bustard, 90, 95, 105, I28, I3I-I48; habitat, $132-4$; question of migration, 134 ; in its glory, 135-136; mating habits, 136-7; antics of, $136-8$; favourite nesting-place, 138 -1 40 ; number of eggs, $1.40-3$; hatching out, 142-4; weights of, I.4.-5; flight of, $145-7$; encounter with Eagle, $147-8$

Great Reed Warbler, 99

"Spotted Cuckoo, 237

" , Woodpecker, 157, 161

" Titmouse, 157, 216

Grebe, Great Crested, 99

Green Cormorants, 236

Greenfinches, II

Green Plover, Peewit or Lapwing, 206

Griffon Vulture, 387-406; nest and eggs, 87 ; favourite nesting-place of, 210; number of eggs, 217 ; a Griffons' cliff, 273-277; a famous colony, 299, 340 ; cleanliness of, 388-9; nesting-places, 390, 393, 394; dates of laying, 395 ; nest-building, 395-6; young, 277, 398; feigning death, 398-400; plumage of, 400 ; weight of, 401 ; span of wing, 401 ; identifying the bird, 402; Golden Eagles and Griffons, 357, 366; "marked" eggs, 394 ; size of, 398; defending nest, 403 ; wounded bird attacking, 404 ; marvellous numbers, 405 ; habits when resting, 405-426; encounter with Bearded Vulture, 416

Grus communis, 107, see Common Crane

Guadalquivir, marismas of, I4-I 5

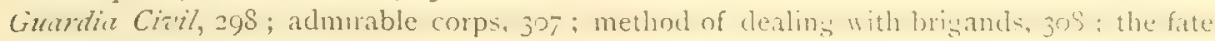
of "Monte Cristo," 309

Gulls, 105, 243, 256

Gypaëtus barbatus, 407, see Bearded Vulture

Gyps fulvus, 387, see Grifion Vulture

HAMOND, Lieut. R. Gerald, R.N., 447, 451, 456; Commander Robert N., R. N., 447

Hancock, John, of Newcastle, 4

Hand Cameras employed, 42-46

Harriers, 102, 103, 130, 169, 187, 311 ; Hen, 104; Pale-chested, 104; nest of young, 10; ; their spirited defiance, 105.6 ; and game preserving in Spain, 165

Hawking, 10, I82-4, 33 I

Hawks, 190, and game preserving in Spain, 165

Herdsmen, I26, 20I

Herons, Purple, 95, 96, 98, Ior, 102 ; nests, 96 ; Common, misnamed Crane, 108

Hirundo rustica, 157

Hoopoe, 16I, 237

House Martin, $28_{3}, 284$, 3 O I

Hume, Allan, "Notes on Indian Birds," 190, 21 3, 331, 433

Hunt, Edward, 434

Hydrochelidon hybrida, 99, I 12, see Whiskered Tern

Hypolais polyglotta, 158 
ILEX, 304

Ibis, 243,373

Imperial Eagle, 196 ; Spanish, 196

Irby, Colonel L. H., I4-15, 21, 87, 104, 109, 134, 141, 158, 161, 162, 173, 174, 189, 192, 197 , $199,213,214,234,243,245,292,313,331,357,409,410$

Irvine, Captain J. D'Arcy, R.N., 220,

Ivy and tree-climbing, 177

JACKDAW, I2, 305

Jay, 157

KESTRELS, 130, 236, 306, 324, 325

Kites, 169, 190, 216; and game preserving in Spain, 165, see Biack Kite, Red Kite

Knox's, Rev. A. E., "Ornithological Rambles in Sussex," If

LACERTA occllata, 128

Laishley, Richard, "British Birds' Eggs," I2

Laja del Ciscar, 86

Lämmergeyer, see Bearded Vulture, 407

Landseer's "Eagles attacking Swans," 35 '

Lnmizes rufus, 159

Lapwing, Peewit, or Green I'lover, 3if, 324,325

Larks, 9, 129

La viuda Varéla, 201

Leptoptilus crumeniferus, 386

Lesser Black-backed Gulls, 236, $2+3$

Lilford, Lord, 4 ; visits Captain V'erner's Falcons, 10, I4, I 5, 21, 68, I 40, 168, 173, 21 4, 287, 409

Limestone cliffs, dangers of old, 303,347

Linnet, II, I2

Little Bustard, I05, 149-155; beatitiful plumage of, 150 ; flight of, 150 ; methods of approach. ing, I 50-I; difficulty of finding nests, 152 ; nesting habits, 153 ; number of egs5, 153-4

Little Owl, I6I

" Ringed Plover, I $2 \delta$

Lizards, 169,182,186,187, 193; and game preserving in Spain, 165

Locustclla luscinioides, igs

Magnifiers, use of, 45

Mallard, 95

Marabou Stork, 386

Marismas of the Guadalquivir, 14, 15

Marsh Harrier, 96, 98, 99, 101, 102, 104; young, 106

Marten cat, 380

Martins, 282-284

Meade- WValdo, Edmund G. B., 133

Melodious Willow Warbler, 158

Merlin and Crested Larks, Io

Merops apiaster, $16 \mathrm{I}-164$

Milvns ictimus, 166, see Red Kite

" migrans, 170, see Black Kite 
Mistle Thrush, I2

Montagu's Harrier, 104

"Monte Cristo," the latest brigand, 307; his fate, 308

Moorish remains, 28I, 297

Moorish villages, 296-8

Mustelu foina, 380

NAPIER, Major Hon. Robert, 285 ; Lord, of Magdala, I 4 I; 285

Natural History, British IIuseum of, 340, $388,400,457$

Neophron, 387, see Egyptian Vulture

Neopliron percnopteries, 372, see Egyptian Vulture

Nests, stone-built, $292 \cdot 3$

Newton, 'rofessor Alfred, I.4, 254, 409

Nightingales, 9 ; in Andalucia, 158

Niscëtus fasciatus, 330, see Bonelli's Eagle

"pennatus, 178 , see Booted Eagle

"Notes on Indian Birds" (Allan Hume), I go, 2I 3, 33 I, 433

OCellated Lizards, I28, 130, 169, 186, 187, 374

(Edicnemus scolopar, $\times 28$

Oriole, 159

Oriolus galbula, 159, see Golden Oriole

"Ornithology of the Straits of Gibraltar," Irby"s, I t, 313, 409

"Ornithological Rambles in Sussex," Knox's, If

Orphean Warbler, Western, $15 \delta^{\circ}$

Ospreys, 236, 251-264, 373, 427; nest, Gibraltar, 51-52; favourite nesting-places of, 253 ; foot of, $253-4$; fishing, 255 ; eggs of, 256,263 ; nest of, 263

Otis tarda, $13 \mathrm{t}$, see Great Bustard

"tetrax, I49, see Little Bustard

Owl, Scops, 161; Little, 161; Eagle, 311

PANDIO.V halicëtus, 251

Parent birds, slaughter of, 6,8

Partridges, 206, 324, 339, 352, 354, 358; and game preserving in Spain, 165

Pedrero, 290

Peewit, Lapwing, or Green Plover, in White-shouldered Eagle's larder, 206 ; in Eagle Ow/s' larders, 314, 324; caught by Eagle Ow1, 325

Peregrine Falcon, 10, 79, 236, 305, 373

Petrocossyphus cyanus, 284 , see Blue Rock Thrush

Photography in Birdsnesting, 40-47; the advantages of the hand camera, 42-46

l'hotography, 90, I76, 190.I, I94, 226.8, 248.250, 263-4, 318, 32I, 349, 362, 366, 378-9, 400, $403-4,443-5,453-4,+55-6$

Purga bueyes, 94,130

Phylloscopus bonellii, 157

Pillars of Hercules, 310

Pipits, 130

Plover, Lesser Ringed, 128; Golden, 149; Green, 314, 324, 325

Porphyrio caruleus, 99

Powys, Hon. 'Tliomas, 287 
P'atincoles, 112, 128

I'rehistoric remains, 233, 270, 281

I'rittie, Hon. Henry $\mathrm{O}^{\prime} \mathrm{C}, 286$

P'uerto de Guadarrama, 231

P'urple Gallinule, 99

I'urple Heron, 95-98, 102

P'whocorax graculus, 305

DIFRRANTA-RIESOS, 433-434, see Bearded Vulturc

RAIPITS, I82, 206, 238, 239, 339, 352, 358, and gane preserving in Spain

kaven, 24I, see Common Raven

Red Kite, 166-170; flight of, 166-168; nest of, I68; trapping old bird, 168

Reptiles, 169, 181, 186

Retriever, in Crane's Nest, I 19-120; severs rope on Easle Owls' cliff, 321-322

Riff Coast, 310

Rock Bunting, 305

Rock Sepulchres, 270-1

Roe deer, 163,216

Rock Doves, 282, 300, 306, 359

"Rock Eagles," 331

Ronda, 295, 298, 303, 309

Rope-soled shoes (or Alpargatas), 36

Ropes, weights and sizes, 80-82; a jambed rope, 42.4, 426-427; silk rope, 3I, 76, 87, 89-90 Rosia Bay 285

Rudolf, Crown Prince, of Austria, I.4-15, 89, 171, 195, 204. 41 I

Rufous Warbler, Western, 158

ST. IBEE-EATER'S Day, 163

St. Joln, Charles, "The Wild Sports of the Highlands," 13

Salvin, Francis Henry, Io

Sand Martin, 282

Saunders, Howard, 21

Savi's Warbler, 198, 204

Sicuicola leucura, 289 , see Black Wheatear

Sclater, IV. L., 432

Scops 0 wl, r6I ; seeking nest of, 151

Sea Eagle, 234, 236

Secuestrudores, 307

Seebohm, Henry, 203, "British Birds' Nests and Eggs," 390

Selous, F. C., 9

Serin Finch, 157, 159

Serrania de Ronda, 239, 295, 305, 380

Short-eared Owl, 313

Short-toed Eagle, 185

$$
\text { , Larks, } 129
$$

Shrike, Woodchat, 159

Sierra Bermeja, 239 
Sierra Blanca, 239

" de Guadarrama, 215, 223, 228

$"$ de Libar, 306,308

"Nevada, 295, 357, 361, 411

Silk Rope, 3I; as a "traveller," 76 ; on an emergency, 87; Crown Prince Rudolf's, 89; manifold uses, go

Sison, I 49

Sketch book and water-colours, to

Sketching, I4, 39-4I, 47, 318, 336, 338, \&c.

Smugglers, 295-96

Snakes, 95, 169, 182, 186, 187, 193; and game preserving in Spain, 165

Snake Eagle, 172, 173, 180, $185-195,186,383,384$; size of, IS6; weight of; 186 ; prey of, 186,187 ; nest of, $187,189,383$; eggs of, number and variety, 190; young, 193; trapping a, $194^{-5}$

Snipe, 102, 132, 207

Solitario, 284

Snto Gordo, 384

Spanish Imperial Eagle, 196

Spanish Oak, 63, 159

Sparrowhawk, 10, I I, 176-177

Squacco Heron, 112

Stark, Arthur C., 109, 198, 206, 211, 214, 408, 409, 411, 413, 433, 453

Stork, 94, 109, 128

Stone-Curlew, i 28

Subterranean passage through cliff, $275-276$

Swallow, $2 S_{4}$ Stream, 300-302

Syle'ia orphea, I 58

TANGIER Raven, 243,244

Tawny Eagle, 197

Teal, 206

Tern, Whiskered, 99, II2

Thompson, R., and Bonelli's Eagle, 331

Titmouse, Great, 157

Tobacco growing, 296

Trafalgar, 237 ; Sierra above, 233-4; cliffs of, 235-240; Cape, 234 ; Bay of, 268

Traps, 35 ; a merciful plan, $35-36$

Trapping; 35-36; Red Kite, 168; Booted Eagle, 182; Snake Eagle, 194-195; Common Raven, 224; Egyptian Vulture, 384-385

Tree Climbing, art of, 58-60; Tom Brown's advice, 59; use of ropes, 63-68; risks of climbing irons, 68; ropes and trons in combination, 60 ; dress and eyupment, $(x),-0$ : ivy risks, 177

Tropidonotus natrix, 128

$" \quad$ viperinus 95

UPUPA epops, 161, 237

VARÉLA, la viuda, 201 
Vegus or Plains, 123-12S, 130, 132

Vemer, Colonel William J., cage birds, Nightingales and Blackcaps, 9; a keen Falconer, I0; Hawks and Falcons, IO; Merlins and Crested Larks, 10-1I ; breeder of hybrids, II; early lessons in birdsnesting, I I- 13

Vertigo, author's remedy, 49-50

Vipera latasti, 95, see Snakes

Viper, 95

Viperine Grass Snake, 95

Vision of birds, relative quickness of, 105

Vultur monachus, 210 , see Black Vulture

Vulture, Bearded, fo7, sec liearded Vulture

. Black, 2Io, see Black Vulture

. Egyptian (or Neophron), 372, see Egyptian Vulture

" Griffon, 387 , see Griffon Vulture

WAGTAILS, I 30

Warblers, $157^{-1} 5^{\circ}$

Water-colour sketching and birdsnesting, $14,39-41,47,318,336,33 \mathrm{~S}$

IVater-tortoise, 268

Weaver-bird, Black-and-red, is

Western Orphean Warbler, i58

Western Rutous Warbler, 158

W'lseatear, Black, 289, see Black Wheatear

Whiskered Tern, 99, I I 2

Whistle signals, $85-86$

White, Rev. Gilbert, of Selborne, 252, 312

White, Rev, John, 252, 312

White-slouldered Eagle, 147, 185, 196-209, 216, 257 ; plumage of, 197-8, 199; nest of, 199; length of, 199 ; weight of, 199 ; eggs of, 203 ; favourite food of, 206

White storks, 94, 128, 109

IVigeon, 102, 206, 325

Wilczek, Count Hans, 89

"Wild" Camels in Spain, 15

Wild Duck, 95

3irds, study of, 2.3

, Cat, 239

"Goose, 104, 147, 187

"Wild Spain," 2 I

Willow Warbler, I 57

Wolley, John, on Cranes, I17, 122

Wolves, 304

Woodchat Shrike, 159; egrgs of, 159

Woodpecker, Great Spotted, 157, I61

Wood Warbler, 157

Woods, Cork, 156-165, 181, 185, 186, 383

YARRELL, William, on Osprey's foot, 254

ZOological. Gardens, 286

Printed by Jons BAle, Sons \& DAxifisson, Ltd, Great Titchfield Strect, London, W: 


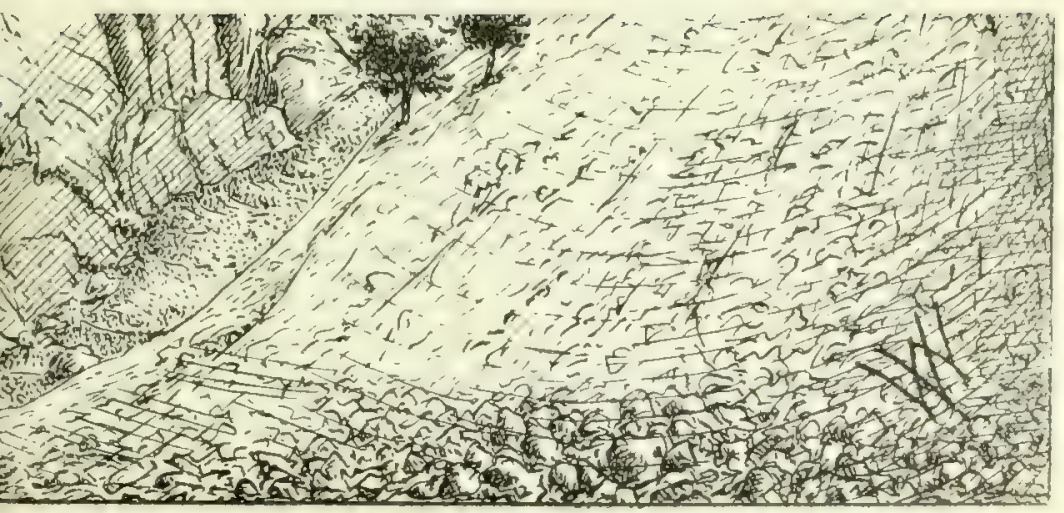

The general "lead" of the ropes used in the various descents are shown by lines drawn from the Lowering Parties to the Nests and Landing places below.

IVILIOUGHRY VERNER. 

General View of limestone Cliff, a Nesting Station of the Bearded Vulture.

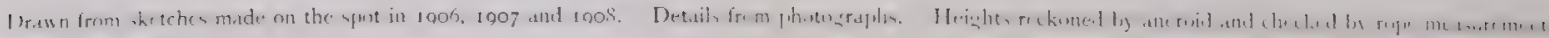

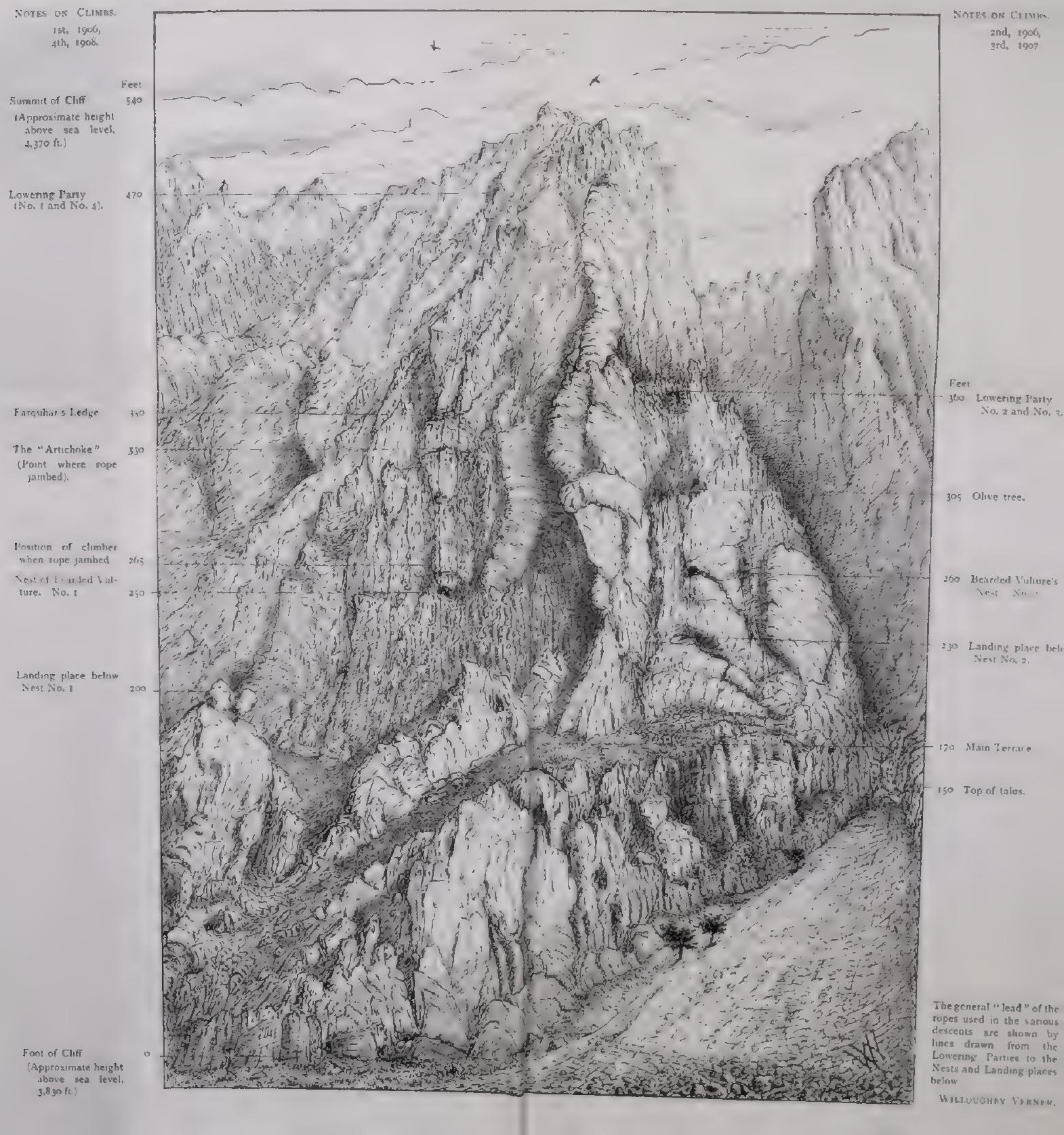










